\title{
Microfungi associated with Clematis (Ranunculaceae) with an integrated approach to delimiting species boundaries
}

\author{
Chayanard Phukhamsakda ${ }^{1,2,3}$ - Eric H. C. McKenzie ${ }^{4}$ - Alan J. L. Phillips ${ }^{5}$ - E. B. Gareth Jones ${ }^{9,10}$ • D. Jayarama Bhat ${ }^{14}$. \\ Stadler Marc ${ }^{16}$. Chitrabhanu S. Bhunjun ${ }^{3}$. Dhanushka N. Wanasinghe ${ }^{2,3,8,15} \cdot$ Benjarong Thongbai ${ }^{16}$. \\ Erio Camporesi ${ }^{11,12,13}$. Damien Ertz ${ }^{17,20} \cdot$ Ruvishika S. Jayawardena ${ }^{3} \cdot$ Rekhani Hansika Perera $^{3,18}$. \\ Anusha H. Ekanayake ${ }^{3}$. Saowaluck Tibpromma ${ }^{2,8,19} \cdot$ Mingkwan Doilom $^{2,8,19} \cdot$ Jianchu Xu ${ }^{2,19,8} \cdot$ Kevin D. Hyde $^{1,2,3,6,7,8}$
}

Received: 5 March 2020 / Accepted: 6 May 2020 / Published online: 7 July 2020

(c) The Author(s) 2020

\begin{abstract}
The cosmopolitan plant genus Clematis contains many climbing species that can be found worldwide. The genus occurs in the wild and is grown commercially for horticulture. Microfungi on Clematis were collected from Belgium, China, Italy, Thailand and the UK. They are characterized by morphology and analyses of gene sequence data using an integrated species concept to validate identifications. The study revealed two new families, 12 new genera, 50 new species, 26 new host records with one dimorphic character report, and ten species are transferred to other genera. The new families revealed by multigene phylogeny are Longiostiolaceae and Pseudomassarinaceae in Pleosporales (Dothideomycetes). New genera are Anthodidymella (Didymellaceae), Anthosulcatispora and Parasulcatispora (Sulcatisporaceae), Fusiformispora (Amniculicolaceae), Longispora (Phaeosphaeriaceae), Neobyssosphaeria (Melanommataceae), Neoleptosporella (Chaetosphaeriales, genera incertae sedis), Neostictis (Stictidaceae), Pseudohelminthosporium (Neomassarinaceae), Pseudomassarina (Pseudomassarinaceae), Sclerenchymomyces (Leptosphaeriaceae) and Xenoplectosphaerella (Plectosphaerellaceae). The newly described species are Alloleptosphaeria clematidis, Anthodidymella ranunculacearum, Anthosulcatispora subglobosa, Aquadictyospora clematidis, Brunneofusispora clematidis, Chaetosphaeronema clematidicola, C. clematidis, Chromolaenicola clematidis, Diaporthe clematidina, Dictyocheirospora clematidis, Distoseptispora clematidis, Floricola clematidis, Fusiformispora clematidis, Hermatomyces clematidis, Leptospora clematidis, Longispora clematidis, Massariosphaeria clematidis, Melomastia clematidis, M. fulvicomae, Neobyssosphaeria clematidis, Neoleptosporella clematidis, Neoroussoella clematidis, N. fulvicomae, Neostictis nigricans, Neovaginatispora clematidis, Parasulcatispora clematidis, Parathyridaria clematidis, P. serratifoliae, P. virginianae, Periconia verrucose, Phomatospora uniseriata, Pleopunctum clematidis, Pseudocapulatispora clematidis, Pseudocoleophoma clematidis, Pseudohelminthosporium clematidis, Pseudolophiostoma chiangraiense, $P$. clematidis, Pseudomassarina clematidis, Ramusculicola clematidis, Sarocladium clematidis, Sclerenchymomyces clematidis, Sigarispora clematidicola, S. clematidis, S. montanae, Sordaria clematidis, Stemphylium clematidis, Wojnowiciella clematidis, Xenodidymella clematidis, Xenomassariosphaeria clematidis and Xenoplectosphaerella clematidis. The following fungi are recorded on Clematis species for the first time: Angustimassarina rosarum, Dendryphion europaeum, Dermatiopleospora mariae, Diaporthe ravennica, D. rudis, Dichotomopilus ramosissimum, Dictyocheirospora xishuangbannaensis, Didymosphaeria rubi-ulmifolii, Fitzroyomyces cyperacearum, Fusarium celtidicola, Leptospora thailandica, Memnoniella oblongispora, Neodidymelliopsis longicolla, Neoeutypella baoshanensis, Neoroussoella heveae, Nigrograna chromolaenae, N. obliqua, Pestalotiopsis verruculosa, Pseudoberkleasmium chiangmaiense, Pseudoophiobolus rosae, Pseudoroussoella chromolaenae, P. elaeicola, Ramusculicola thailandica, Stemphylium vesicarium and Torula chromolaenae. The new combinations are Anthodidymella clematidis (三Didymella clematidis), A. vitalbina (三Didymella vitalbina), Anthosulcatispora brunnea (三Neobambusicola brunnea), Fuscohypha kunmingensis (三Plectosphaerella kunmingensis), Magnibotryascoma rubriostiolata ( $\equiv$ Teichospora rubriostiolata), Pararoussoella mangrovei ( $\equiv$ Roussoella mangrovei), Pseudoneoconiothyrium euonymi (三Roussoella euonymi), Sclerenchymomyces jonesii (三Neoleptosphaeria jonesii), Stemphylium rosae (三Pleospora rosae), and S. rosae-caninae (三Pleospora rosae-caninae). The microfungi on Clematis is distributed in several classes of
\end{abstract}

Extended author information available on the last page of the article 
Ascomycota. The analyses are based on morphological examination of specimens, coupled with phylogenetic sequence data. To the best of our knowledge, the consolidated species concept approach is recommended in validating species.

Keywords 73 new taxa $\cdot$ Ascomycota $\cdot$ Belgium $\cdot$ China $\cdot$ Dothideomycetes $\cdot$ Incertae sedis $\cdot$ Italy $\cdot$ Lecanoromycetes . Phylogeny $\cdot$ Sordariomycetes $\cdot$ Taxonomy $\cdot$ Thailand $\cdot$ UK

Table of Contents

Phylum Ascomycota R.H. Whittaker

Subphylum Pezizomycotina Erikss. \& K. Winka

Class Dothideomycetes Erikss. \& K. Winka

Subclass Pleosporomycetidae Schoch et al.

Pleosporales Luttr. ex M.E. Barr

Amniculicolaceae Zhang et al.

1. Fusiformispora Phukhams. \& K.D. Hyde, gen. nov.

2. Fusiformispora clematidis Phukhams., M.V. de Bult \& K.D. Hyde, sp. nov.

Amorosiaceae Thambug. \& K.D. Hyde

3. Angustimassarina rosarum Tibpromma, Camporesi \& K.D. Hyde, new host record

Cyclothyriellaceae Jaklitsch \& H. Voglmayr

4. Massariosphaeria clematidis Phukhams., Wanas., Camporesi \& K.D. Hyde, sp. nov.

Dictyosporiaceae Boonmee \& K.D. Hyde

5. Aquadictyospora clematidis Phukhams., Bhat \& K.D. Hyde, sp. nov.

6. Dictyocheirospora clematidis Phukhams., Bhat \& K.D. Hyde, sp. nov.

7. Dictyocheirospora xishuangbannaensis Tibpromma \& K.D. Hyde, new host record

8. Pseudocoleophoma clematidis Phukhams. \& K.D. Hyde, sp. nov.

Didymellaceae Gruyter, Aveskamp \& Verkley

9. Anthodidymella Phukhams., Camporesi \& K.D. Hyde, gen. nov.

10. Anthodidymella clematidis (Woudenb., Spiers \& Gruyter) Phukhams. \& K.D. Hyde, comb. nov.

11. Anthodidymella ranunculacearum Phukhams., Camporesi \& K.D. Hyde, sp. nov.

12. Anthodidymella vitalbina (Petr.) Phukhams. \& K.D. Hyde, comb. nov.

13. Neodidymelliopsis longicolla Hou, Crous \& L. Cai, new host record

14. Xenodidymella clematidis Phukhams., Camporesi \& K.D. Hyde, sp. nov.
Didymosphaeriaceae Munk

15. Chromolaenicola clematidis Phukhams. \& K.D. Hyde, sp. nov.

16. Didymosphaeria rubi-ulmifolii Ariyaw., Camporesi \& K.D. Hyde, new host record

Hermatomycetaceae Locq. ex A. Hashim. \& K. Tanaka

17. Hermatomyces clematidis Phukhams., Bhat \& K.D. Hyde, sp. nov.

Leptosphaeriaceae Barr

18. Alloleptosphaeria clematidis Phukhams. \& K.D. Hyde, sp. nov.

19. Sclerenchymomyces Phukhams. \& K.D. Hyde, gen. nov.

20. Sclerenchymomyces clematidis Phukhams. \& K.D. Hyde, sp. nov.

21. Sclerenchymomyces jonesii (Wanasinghe, Camporesi \& K.D. Hyde) Phukhams. \& K.D. Hyde, comb. nov.

Longiostiolaceae Phukhams., Doilom \& K.D. Hyde

22. Longiostiolaceae Phukhams., Doilom \& K.D. Hyde, fam. nov.

Lophiostomataceae Luerss.

23. Neovaginatispora clematidis Phukhams., Ertz, Gerstmans \& K.D. Hyde, sp. nov.

24. Pseudocapulatispora clematidis Phukhams. \& K.D. Hyde, sp. nov.

25. Pseudolophiostoma chiangraiense Phukhams. \& K.D. Hyde, sp. nov.

26. Pseudolophiostoma clematidis Phukhams. \& K.D. Hyde, sp. nov.

27. Sigarispora clematidis Phukhams. \& K.D. Hyde, sp. nov.

28. Sigarispora clematidicola Phukhams., Camporesi \& K.D. Hyde, sp. nov.

29. Sigarispora montanae Phukhams., Sue \& K.D. Hyde, sp. nov.

Melanommataceae Winter

30. Neobyssosphaeria Wanas., Jones \& K.D. Hyde, gen. nov.

31. Neobyssosphaeria clematidis Wanas., Phukhams., Jones \& K.D. Hyde, sp. nov. 
Neomassarinaceae Mapook \& K.D. Hyde

32. Pseudohelminthosporium Phukhams. \& K.D. Hyde, gen. nov.

33. Pseudohelminthosporium clematidis Phukhams. \& K.D. Hyde, sp. nov.

Nigrogranaceae Jaklitsch \& H. Voglmayr

34. Nigrograna chromolaenae Mapook \& K.D. Hyde, new host record

35. Nigrograna obliqua Jaklitsch \& H. Voglmayr, new host record

Occultibambusaceae Dai \& K.D. Hyde

36. Brunneofusispora clematidis Phukhams. \& K.D. Hyde, sp. nov.

Paradictyoarthriniaceae Doilom, Liu \& K.D. Hyde

37. Xenomassariosphaeria clematidis Wanas., Phukhams., Camporesi \& K.D. Hyde, sp. nov.

Periconiaceae Nann.

38. Periconia verrucosa Phukhams, Ertz, Gerstmans \& K.D. Hyde, sp. nov.

Phaeoseptaceae Boonmee, Thambug. \& K.D. Hyde

39. Pleopunctum clematidis Phukhams., Bhat \& K.D. Hyde, sp. nov.

Phaeosphaeriaceae Barr

40. Chaetosphaeronema clematidicola Phukhams, Ertz, Gerstmans \& K.D. Hyde, sp. nov.

41. Chaetosphaeronema clematidis Phukhams, Ertz, Gerstmans \& K.D. Hyde, sp. nov.

42. Dermatiopleospora mariae Wanas., Camporesi, Jones \& K.D. Hyde, new host record

43. Leptospora clematidis Phukhams., Ertz, Gerstmans, \& K.D. Hyde, sp. nov.

44. Leptospora thailandica Phukhams. \& K.D. Hyde, new host record

45. Longispora Phukhams. \& K.D. Hyde, gen. nov.

46. Longispora clematidis Phukhams. \& K.D. Hyde, sp. nov.

47. Pseudoophiobolus rosae Phookamsak, Wanas., Phukhams., Camporesi \& K.D. Hyde, new host record

48. Wojnowiciella clematidis Phukhams., Ertz, Gerstmans \& K.D. Hyde, sp. nov.

Pleosporaceae Nitschke

49. Stemphylium clematidis Wanas., Camporesi \& K.D. Hyde, sp. nov.
50. Stemphylium rosae (Wanas. et al.) Phukhams. \& K.D. Hyde, comb. nov.

51. Stemphylium rosae-caninae (Wanas. et al.) Phukhams. \& K.D. Hyde, comb. nov.

52. Stemphylium vesicarium (Wallr.) E.G. Simmons, new host record

Pseudoberkleasmiaceae Phukhams. \& K.D. Hyde

53. Pseudoberkleasmium chiangmaiense Lu \& K.D. Hyde, new host record

Pseudomassarinaceae Phukhams. \& K.D. Hyde

54. Pseudomassarinaceae Phukhams. \& K.D. Hyde, fam. nov.

55. Pseudomassarina Phukhams. \& K.D. Hyde, gen. nov.

56. Pseudomassarina clematidis Phukhams, Camporesi \& K.D. Hyde, sp. nov.

Pseudolophiotremataceae Hyde \& S. Hongsanan

57. Clematidis italica Tibpromma, Camporesi \& K.D. Hyde

Roussoellaceae Liu, Phookamsak, Dai \& K.D. Hyde

58. Neoroussoella clematidis Phukhams. \& K.D. Hyde, sp. nov.

59. Neoroussoella fulvicomae Phukhams. \& K.D. Hyde, sp. nov.

60. Neoroussoella heveae Senwanna, Phookamsak \& K.D. Hyde, new host record

61. Pararoussoella mangrovei (Phukhams. \& K.D. Hyde) Phukhams. \& K.D. Hyde, comb. nov.

62. Pseudoneoconiothyrium euonymi (Crous \& Akulov) Phukhams. \& K.D. Hyde, comb. nov.

63. Pseudoroussoella chromolaenae Mapook \& K.D. Hyde, new host record

64. Pseudoroussoella elaeicola (Konta \& K.D. Hyde) Mapook \& K.D. Hyde, new host record

Sulcatisporaceae Tanaka \& K. Hirayama

65. Anthosulcatispora Phukhams. \& K.D. Hyde, gen. nov.

66. Anthosulcatispora brunnea (Chen \& C. Norphanphoun) Phukhams. \& K.D. Hyde, comb. nov.

67. Anthosulcatispora subglobosa Phukhams. \& K.D. Hyde, sp. nov.

68. Parasulcatispora Phukhams. \& K.D. Hyde, gen. nov.

69. Parasulcatispora clematidis Phukhams. \& K.D. Hyde, sp. nov. 
Teichosporaceae Barr

70. Floricola clematidis Phukhams., Camporesi \& K.D. Hyde, sp. nov.

71. Magnibotryascoma rubriostiolata (Jaklitsch \& Voglmayr) Phukhams., Jones \& K.D. Hyde, comb. nov. and new host record

72. Ramusculicola clematidis Phukhams. \& K.D. Hyde, sp. nov.

73. Ramusculicola thailandica Thambug. \& K.D. Hyde, new host record

Thyridariaceae Tian \& K.D. Hyde

74. Parathyridaria clematidis Phukhams., Camporesi \& K.D. Hyde, sp. nov.

75. Parathyridaria serratifoliae Phukhams., Ertz, Gerstmans \& K.D. Hyde, sp. nov.

76. Parathyridaria virginianae Phukhams., Ertz, Gerstmans \& K.D. Hyde, sp. nov.

Torulaceae Corda

77. Dendryphion europaeum Crous \& R.K. Schumacher, new host record

78. Torula chromolaenae Li, Phookamsak, Mapook \& K.D. Hyde, new host record

Dothideomycetes, family incertae sedis

Dyfrolomycetales Pang, Hyde \& E.B.G. Jones

Pleurotremataceae Watson

79. Melomastia clematidis Phukhams., \& K.D. Hyde, sp. nov.

80. Melomastia fulvicomae Phukhams., \& K.D. Hyde, sp. nov.

Class Lecanoromycetes Erikss. \& K. Winka

Subclass Ostropomycetidae Reeb, Lutzoni \& Cl. Roux

Ostropales Nannf.

Stictidaceae Fr.

81. Fitzroyomyces cyperacearum Crous, new host record

82. Neostictis Ekanayaka, Camporesi \& K.D. Hyde, gen. nov.

83. Neostictis nigricans Ekanayaka, Phukhams., Camporesi \& K.D. Hyde, sp. nov.

Class Sordariomycetes Erikss. \& K. Winka Subclass: Sordariomycetidae Erikss. \& K. Winka
Chaetosphaeriales Huhndorf, Mill. \& F.A. Fernández

Chaetosphaeriales, genera incertae sedis

84. Neoleptosporella Phukhams. \& K.D. Hyde, gen. nov.

85. Neoleptosporella clematidis Phukhams., Konta \& K.D. Hyde, sp. nov.

Sordariales Chadef. ex Hawksw. \& O.E. Erikss.

Chaetomiaceae G. Winter

86. Dichotomopilus ramosissimum (X. Wei Wang \& L. Cai) X. Wei Wang \& Samson, new host record

Sordariaceae Winter

87. Sordaria clematidis Phukhams. \& K.D. Hyde, sp. nov.

Subclass Diaporthomycetidae Senan., Maharachch. \& K.D. Hyde

Diaporthales Nannf.

Diaporthaceae Hohn. ex Wehm.

88. Diaporthe clematidina Phukhams., M.V. de Bult $\&$ K.D. Hyde, sp. nov.

89. Diaporthe ravennica Thambug., Camporesi \& K.D. Hyde, new host record

90. Diaporthe rudis (Fr.) Nitschke, new host record

Phomatosporales Senan., Maharachch. \& K.D. Hyde Phomatosporaceae Senan. \& K.D. Hyde

91. Phomatospora uniseriata Phukhams., M.V. de Bult \& K.D. Hyde, sp. nov.

Diaporthomycetidae, family incertae sedis Distoseptisporaceae Hyde \& E. McKenzie

92. Distoseptispora clematidis Phukhams., M.V. de Bult \& K.D. Hyde, sp. nov.

Subclass Xylariomycetidae Erikss. \& W. Winka

Amphisphaeriales Hawksw. \& O.E. Erikss

Sporocadaceae Corda

93. Pestalotiopsis verruculosa Maharachch. \& K.D. Hyde, new host record

Xylariales Nannf.

Diatrypaceae Nitschke

94. Neoeutypella baoshanensis Raza, Shang, Phookamsak \& L. Cai, new host record

Subclass Hypocreomycetidae Erikss. \& K. Winka Glomerellales Chadef. ex Re'blova' et al. 
Plectosphaerellaceae Gams, Summerb. \& R. Zare

95. Fuscohypha kunmingensis (Phookamsak, J.F. Li \& K.D. Hyde) Jayaward., Phukhams. \& K.D. Hyde, comb. nov.

96. Xenoplectosphaerella Jayaward., Phukhams. \& K.D. Hyde, gen. nov.

97. Xenoplectosphaerella clematidis Jayaward., Phukhams. \& K.D. Hyde, sp. nov.

\section{Hypocreales Lindau}

Nectriaceae Tul \& C. Tul

98. Fusarium celtidicola Shang, Camporesi \& K.D. Hyde, new host record

Sarocladiaceae Lombard

99. Sarocladium clematidis Phukhams., Ertz, Gerstmans \& K.D. Hyde, sp. nov.

Stachybotryaceae Lombard \& P. Crous

100. Memnoniella oblongispora Lin, McKenzie, Wang $\&$ K.D. Hyde, new host record

\section{Introduction}

Clematis (Ranunculaceae) is a flowering climber which has become a popular plant in horticulture (Linnaeus 1753; Yuan et al. 2010). The genus contains between 250 and 350 species and hybrids (Grey-Wilson 2000; Lehtonen et al. 2016; He et al. 2019). Clematis is widespread in warm-temperate or montane ecosystems and is native to most areas of China, Europe, Korea, and Russia (Tamura 1956; Ziman and Keener 1989; Yuan and Yang 2020). Clematis vitalba (old man's beard), the type species of Clematis is an invasive weed broadly distributed in Europe, and also expanding to New Zealand and South America (Ogle et al. 2000; Leuschner and Ellenberg 2017; Redmond and Stout 2018). Clematis vitalba can influence the biodiversity dynamics of native plants (Ogle et al. 2000; Ashton and Lerdau 2008). In Thailand, Clematis species are mostly found in the northern provinces of Chiang Mai, Chiang Rai and Nan, which are mountainous areas with a tropical savanna climate (Tamura 1997, 2000). Many Clematis species are grown as ornamental plants. Clematis species are also used in Traditional Chinese Medicine and some secondary metabolites isolated from Clematis have been tested in vitro, but there are no reports of successful clinical tests or if it is safe to consume the plant parts (Ding et al. 2009; Fu et al. 2010; Feng et al. 2011; Hawaze et al. 2012; Lu et al. 2014; Zhao et al. 2016). Clematis species are herbaceous vines, with opposite compound, bipinnate to tripinnate leaves, and leather-like flowers with feather achenes (Johnson 2001) (Fig. 1). Section-level phylogenetic classification of Clematis by Lehtonen et al. (2016) includes specific characteristics and geographic distribution for each section. The estimated divergence time of the available sequences for Clematis have shown that the stem age was in the Oligocene (25.99 million years ago; Lehtonen et al. 2016).

Fungal species associated with Clematis have been documented since the late eighteenth century (Lamarck 1805; Saccardo 1892; Farr and Rossman 2020; Index Fungorum 2020). Index Fungorum and the U.S. National Fungus Collections Fungal Database lists over 500 records, mainly as saprobes, or pathogens that can cause leaf lesions and wilt in Clematis species (Baylis 1954; Braun 1992; Ahn and Shearer 1998; Wanasinghe et al. 2014; Chen et al. 2015; Crous et al. 2019).

In this study, Clematis samples were collected in Belgium, China, Italy, Thailand, and the UK to establish the microfungi associated with this host and to analyze their host-specificity. In addition, fungal isolates were evaluated for their antagonistic activity against selected microorganism (Phukhamsakda et al. 2018; Hyde et al. 2019b; Macabeo et al. 2020). The delineation of new species introduced in this study relies on a polyphasic approach based on morphological traits (MSC), molecular data (PSC), and application of Genealogical Concordance Phylogenetic Species Recognition (GCPSR) (Taylor et al. 2000). GCPSR model relies on performing a pairwise homoplasy index coupled with phylogenetic relatedness in a multi-locus dataset and the interpretation of nucleotide differences (Turner et al. 2013; Quaedvlieg et al. 2014; Jeewon and Hyde 2016). We also compared the morphology of our new collections with documented fungal taxa recorded in public databases and discuss their ecological species concepts.

\section{Materials and methods}

\section{Sample collection, morphological study and isolation}

Fresh Clematis specimens were collected or received from Belgium, China, Italy, Thailand and England (the UK). Some specimens have single collection because this study mainly focused on the diversity of fungi associated with Clematis. One collection is defined as a sample of fungus that can be identified with a single collecting trip which was used to cast the number of species. Thus, the plant materials were mainly collected and received from a single trip of the aforementioned countries. The specimens were maintained 


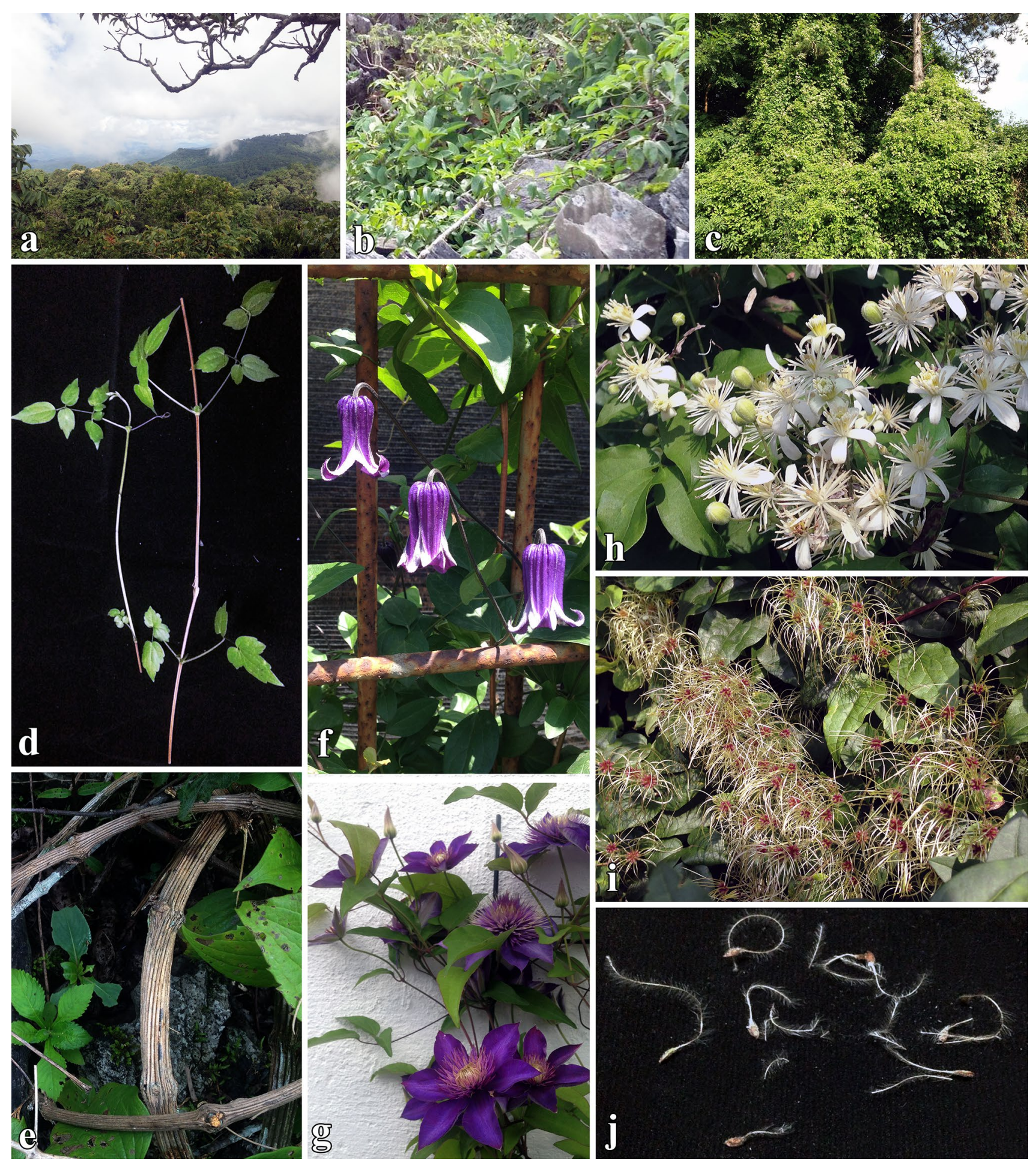

Fig. 1 a-c Habitats of Clematis species. d Opposite compound with bi-pinnate to tri-pinnate leaves. e Woody climbing stem. f Inflorescence of $C$. pitcheri. g Inflorescence of $C$. "Crystal Fountain". h Inflorescence of $C$. vitalba. i Achenes of $C$. vitalba. $\mathbf{j}$ Enlarged achenes of C. subumbellata with plumose style 
in paper bags for transport to the laboratory. The specimens were examined using a Motic SMZ 168 Series stereo-microscope. Thereafter, vertical free-hand sections were made by a razor blade and placed on a droplet of sterilized water on a glass slide. A Nikon ECLIPSE 80i compound microscope was used to examine the samples and a Canon 600D digital camera fitted to the microscope was used to photograph the samples. Tarosoft $(\mathrm{R})$ Image Frame Work program was used for measurements and photo-plate were made by using Adobe Photoshop CS6 Extended version 10.0 software (Adobe Systems, United States).

Pure cultures were obtained from single ascospores isolation on malt extract agar (MEA: $33.6 \mathrm{~g} / \mathrm{L}$, malt extract Dif $^{\mathrm{TM}}$ ) or potato dextrose agar (PDA: $39 \mathrm{~g} / \mathrm{L}$, potato dextrose media Difco ${ }^{\mathrm{TM}}$ ) as described by Chomnunti et al. (2014) which were incubated at $16-25^{\circ} \mathrm{C}$ with the standard light cycles, $12 \mathrm{~h}$ in the light followed by $12 \mathrm{~h}$ in the dark for about four up to eight weeks. Asexual reproduction was induced by placing agar squares with mycelia on water agar or MEA placed with additional substances such as sterile pine needles or rice straws. Authentic type specimens are deposited in Mae Fah Luang University (MFLU) herbarium and ex-type living cultures are deposited at the Mae Fah Luang Culture Collection (MFLUCC). Faces of fungi numbers (Jayasiri et al. 2015) and Index Fungorum numbers (2020) are provided.

\section{DNA extraction, amplification and sequencing}

The Biospin Fungus Genomic DNA Extraction Kit (BioFlux ${ }^{\circledR}$ ) (Hangzhou, P. R. China) and gene extraction kit (Bio Basic Inc., Canada) were used for DNA extraction from mycelium. The fruiting bodies DNA was extracted by using Forensic DNA Kit-D3591-01 (OMEGA bio-tek) following the manufacturer's instructions. Polymerase chain reaction (PCR) was used to amplify partial gene regions with primer pairs as described in Tibpromma et al. (2018). The PCR amplifications were performed in a total volume of $25 \mu \mathrm{L}$ solution containing 10-20 ng of DNA template, Easy Taq PCR Super Mix (mixture of Easy Taq TM DNA Polymerase, dNTPs, and optimized buffer) and 10 picomolar forward and reverse primers. Amplification reactions were performed following Phukhamsakda et al. (2016) and Tibpromma et al. (2018). Genomic DNA and PCR amplification products were checked on $1 \%$ agarose gel. PCR products were purified as described in the manufacturer's instructions (EZ-10 PCR Products Purification Kit, Bio basic Canada INC.). Sequences were generated by Shanghai Sangon Biological Engineering Technology \& Services Co. (Shanghai, P.R. China) and the sequencing service at Helmholtz Centre For Infection Research (HZI, Braunschweig, Germany).

\section{Sequence alignment and phylogenetic analysis}

Consensus sequences were assembled using SeqMan v. 7.0.0 (DNASTAR, Madison, WI). Sequences of closely related strains were retrieved using BLAST searches against GenBank (http://www.ncbi.nlm.nih.gov). Sequences were aligned with MAFTT version 7 (Katoh et al. 2019) (http:// mafft.cbrc.jp/alignment/server), with minimal adjustment of the ambiguous nucleotides by visual examination and manually corrected in AliView program (Larsson 2014). Leading or trailing gaps exceeding the primer binding site were trimmed from the alignments prior to tree building and alignment gaps were treated as missing data. The concatenation of the multigene datasets was created in Sequence Matrix (Vaidya et al. 2011).

Phylogenetic analyses of the single gene and combined gene were based on maximum parsimony (MP), maximum likelihood (ML) and Bayesian inference posterior probabilities (BYPP). PAUP program was used for MP bootstrap analyses, with 1000 bootstrap replicates using 10 rounds of the heuristic search replicates to estimate the homoplasy yield. The random addition of sequences and subsequent TBR branch swapping during each bootstrap replicate, with each replicate was limited to 1000 rearrangements. Gaps were treated as missing data; all characters were unordered and given equal weight. The statistics for parsimony were described under the phylogenetic legend with the values of Tree Length (TL), Consistency Index (CI), Retention Index (RI), Relative Consistency Index (RC) and Homoplasy Index (HI) calculated for trees generated under different optimality criteria. The best fitting substitution model for each single gene partition and the concatenated data set was determined in MrModeltest 2.3 (Nylander 2004) for Bayesian inference posterior probabilities and ML. Maximum likelihood analyses, including 1000 bootstrap replicates, were performed using the RAxML-HPC2 on XSEDE (8.2.12) in the CIPRES Science Gateway (Stamatakis 2014; Miller et al. 2017). The general time reversible (GTR) model was used for nucleotide substitution with a discrete gamma distribution plus invariant site $(\mathrm{GTR}+\mathrm{I}+\mathrm{G})$. The bootstrap replicates were summarized onto the best scoring tree (Miller et al. 2017). The Bayesian inference posterior probabilities (PP) distribution (Zhaxybayeva and Gogarten 2002) was estimated by Markov Chain Monte Carlo sampling (MCMC) in MrBayes 3.2.2 on XSEDE (Ronquist and Huelsenbeck 2003). Six simultaneous Markov chains were run for $1,000,000$ to $10,000,000$ generations, depending on individual settings for the fungal group. The resulted trees were sampled at one tree every 100th or 1000th generation. The first $10-25 \%$ of burn-in phase of the analyses were discarded based on suitable burnin phases determined by using Tracer version 1.7 (Rambaut et al. 2018). The remaining trees were used to calculate 
posterior probabilities in the majority-rule consensus (MRC) trees $(50 \%)$ with critical value for the topological convergence diagnostic set to 0.01 .

FigTree v. 1.4 (Rambaut 2014) was used to visualize phylogenetic trees and data files and the phylogram was edited using Adobe Illustrator CS v. 6 (Adobe Systems, USA). All sequences generated in this study were submitted to GenBank. All entries are represented using phylogenetic tree and relevant description.

\section{Genealogical concordance phylogenetic species recognition analysis}

The closely related strains that resulted from morphology and phylogeny evidence of recombination were prospectively analyzed using the genetic distances by performing a pairwise homoplasy index test $(\Phi \mathrm{w})$ (Taylor et al. 2000; Bruen et al. 2006). A pairwise homoplasy index (PHI) test was performed in SplitsTree (version 4.1.4.4) using the Kimura's two parameter (K2P) models for low genetic distance datasets. $\operatorname{LogDet}$ transformation were applied for the average of nucleotide frequencies and splits decomposition graph options (Gu and Li 1996a, b; Taylor et al. 2000; Bruen et al. 2006; Huson and Bryant 2006; Gioan and Paul 2012; Nishimaki and Sato 2019). The standard deviation of split frequencies PHI test results $\left(\Phi_{\mathrm{w}}\right)<0.05$ indicate significant recombination within the dataset.

\section{Taxonomy}

Phylum Ascomycota R.H. Whittaker

The taxa are arranged as in the Outline of Fungi and fungus-like organisms (Wijayawardene et al. 2016, 2020).

\section{Subphylum Pezizomycotina Erikss. \& K. Winka}

\section{Class Dothideomycetes sensu O.E. Erikss \& Winka}

For the classification of Dothideomycetes we follow Hyde et al. (2013), Liu et al. (2017) and Hongsanan et al. (2020).

\section{Subclass Pleosporomycetidae C.L. Schoch et al.}

\section{Pleosporales Luttrell ex M.E. Barr}

Pleosporales is the largest and most diverse order in Dothideomycetes with over 75 families (Hongsanan et al. 2020).

\section{Amniculicolaceae Y. Zhang, C.L. Schoch, J. Fourn., Crous \& K.D. Hyde}

Amniculicolaceae was introduced for freshwater-associated ascomycetes. This family is characterized by solitary ascomata with a rough black surface. The members usually stain the surface of the substrate purple and have short pedicellate asci, with hyaline or pale brown or brown, 1- to multi-septate or muriform ascospores (Hyde et al. 2013). The family comprises Amniculicola, Murispora, Neomassariosphaeria, Pseudomassariosphaeria and Vargamyces (Zhang et al. 2009; Hyde et al. 2013; Ariyawansa et al. 2015a; Hernández-Restrepo et al. 2017). We introduce a novel saprobic genus, Fusiformispora from Clematis collections in Thailand. Maximum likelihood and Bayesian analyses of the combined dataset (LSU, SSU, ITS, tefl and $r p b 2)$ is shown in Fig. 2.

Fusiformispora Phukhams. \& K.D. Hyde, gen. nov. Index Fungorum number: IF557106; Facesoffungi number: FoF 07242, Fig. 3.

Etymology: Genus name reflects the fusiform shape of its ascospores.

Saprobic on decaying wood or herbaceous plant material in terrestrial habitats. Sexual morph: Ascomata on surface of the host, covered by a pseudoclypeus, visible as black spots, solitary, scattered, uniloculate, obpyriform to compressed globose, coriaceous, brown to dark brown, ostiolate. Ostioles central, brown to dark brown, papillate. Peridium multilayered, cells of textura angularis, inner layers comprising thin, hyaline cells. Hamathecium composed of dense, filiform, branched, transverly septate, trabecular pseudoparaphyses anastomosing above asci. Asci 8 -spored, bitunicate, fissitunicate, thick-walled, cylindric-clavate, apically rounded, short, with a furcate pedicel, with ocular chamber. Ascospores biseriate, partially overlapping, broad fusiform, tapering towards the acute ends, hyaline, with guttules in each cell, constricted at the septa, smooth-walled, with a thin mucilaginous sheath. Asexual morph: Undetermined.

Type species: Fusiformispora clematidis Phukhams., M.V. de Bult \& K.D. Hyde

Fig. 2 The Bayesian 50\% majority-rule consensus phylogram based on combined LSU, SSU, ITS, tef1 and $r p b 2$ sequence data of related families in Pleosporales. The topology and clade stability of the combined gene analyses was compared to the single gene analyses. The tree is rooted with species of Hysteriales. One hundred and fiftythree strains were included in the DNA analyses which comprised 4394 characters (848 characters for LSU, 1044 characters for SSU, 556 characters for ITS, 910 characters for tefl, and 1036 characters for $r p b 2$, including gap regions). The tree from the maximum likelihood analysis had similar topology to the Bayesian analyses. The best scoring RAxML tree had a final likelihood value of -73089.933914 . The matrix had 2676 distinct alignment patterns, with $40.81 \%$ undetermined characters and gaps. Estimated base frequencies were as follows; $\mathrm{A}=0.246412, \mathrm{C}=0.245743, \mathrm{G}=0.272077, \mathrm{~T}=0.235768$; substitution rates $\mathrm{AC}=1.617324, \mathrm{AG}=3.695355, \mathrm{AT}=1.662826$, $\mathrm{CG}=1.183453, \mathrm{CT}=8.283938, \mathrm{GT}=1.000000$; gamma distribution shape parameter $\alpha=0.635095$. The GTR $+\mathrm{I}+\mathrm{G}$ model was selected for every partition in Bayesian analysis. Bootstrap values (BS) greater than 50\% BS (ML, left) and Bayesian posterior probabilities (BYPP, right) greater than 0.90 are given at the nodes. Hyphens (-) represent support values less than 50\% BS/0.90 BYPP. The type sequences are in bold and the species determined in this study are indicated in blue 


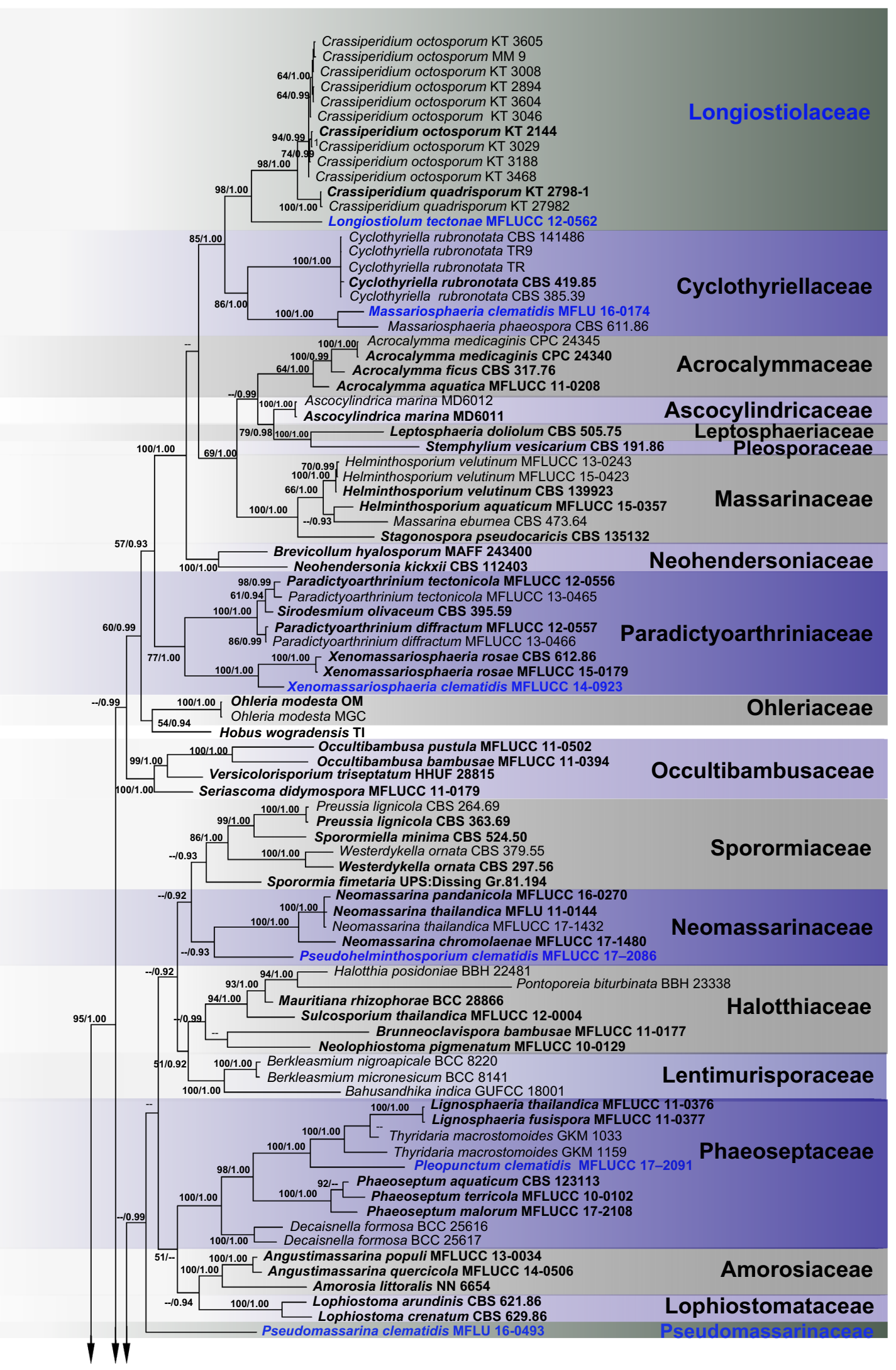




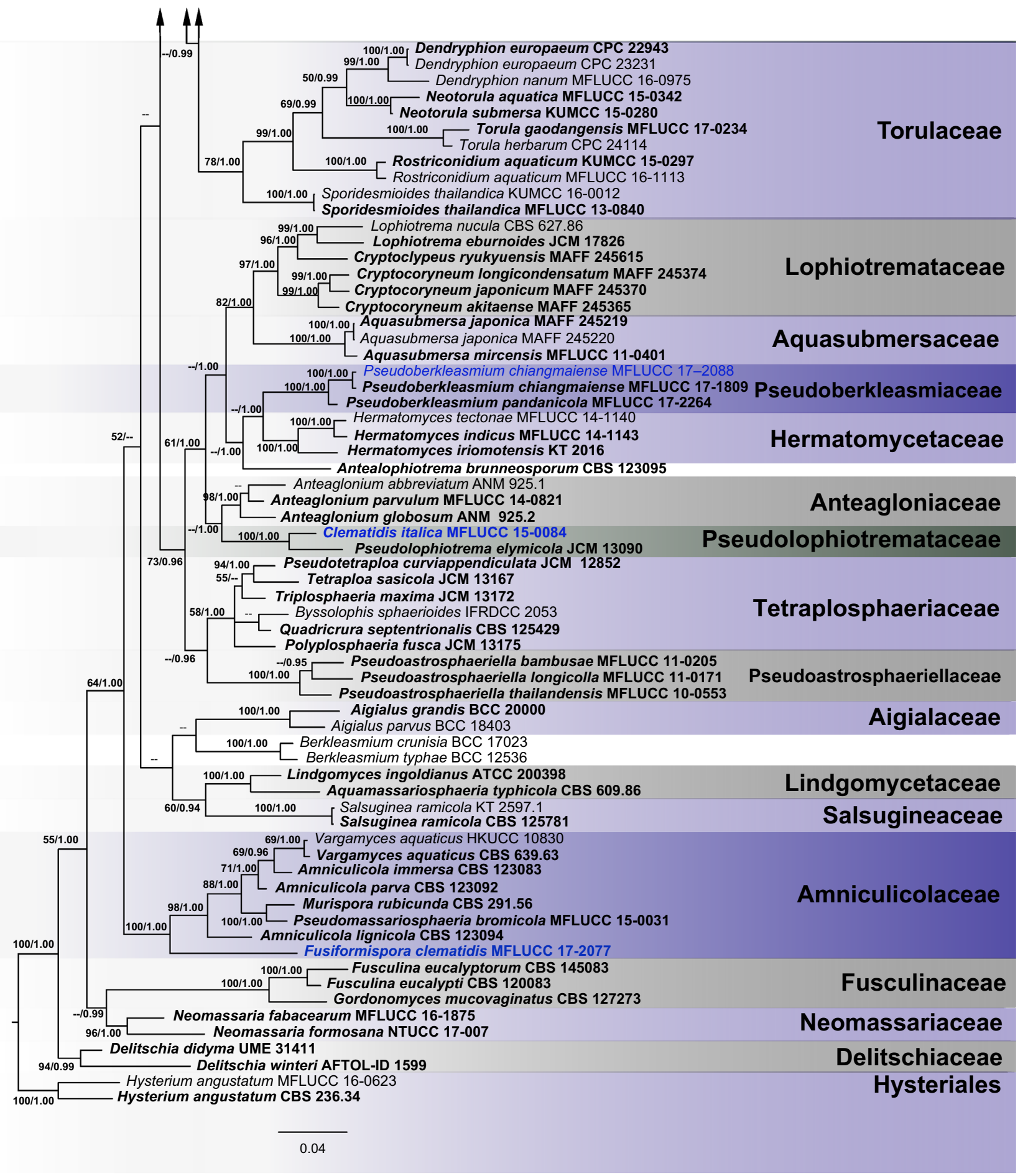

Fig. 2 (continued)

Notes: Fusiformispora is established as a monotypic genus. In the multi-gene phylogenetic analyses, the isolate MFLUCC 17-2077 formed a basal lineage with other genera in Amniculicolaceae (Fig. 2) with strong support (100\% ML/1.00 BYPP). The genus is compatible with the concept of Amniculicolaceae in having compressed globose, coriaceous, brown to dark brown ascomata, ostiolate, with trabeculate, anastomosed pseudoparaphyses (sensu Liew et al. 2000), and fusiform ascospores that are hyaline and septate with mucilaginous appendages (Zhang et al. 2009). 

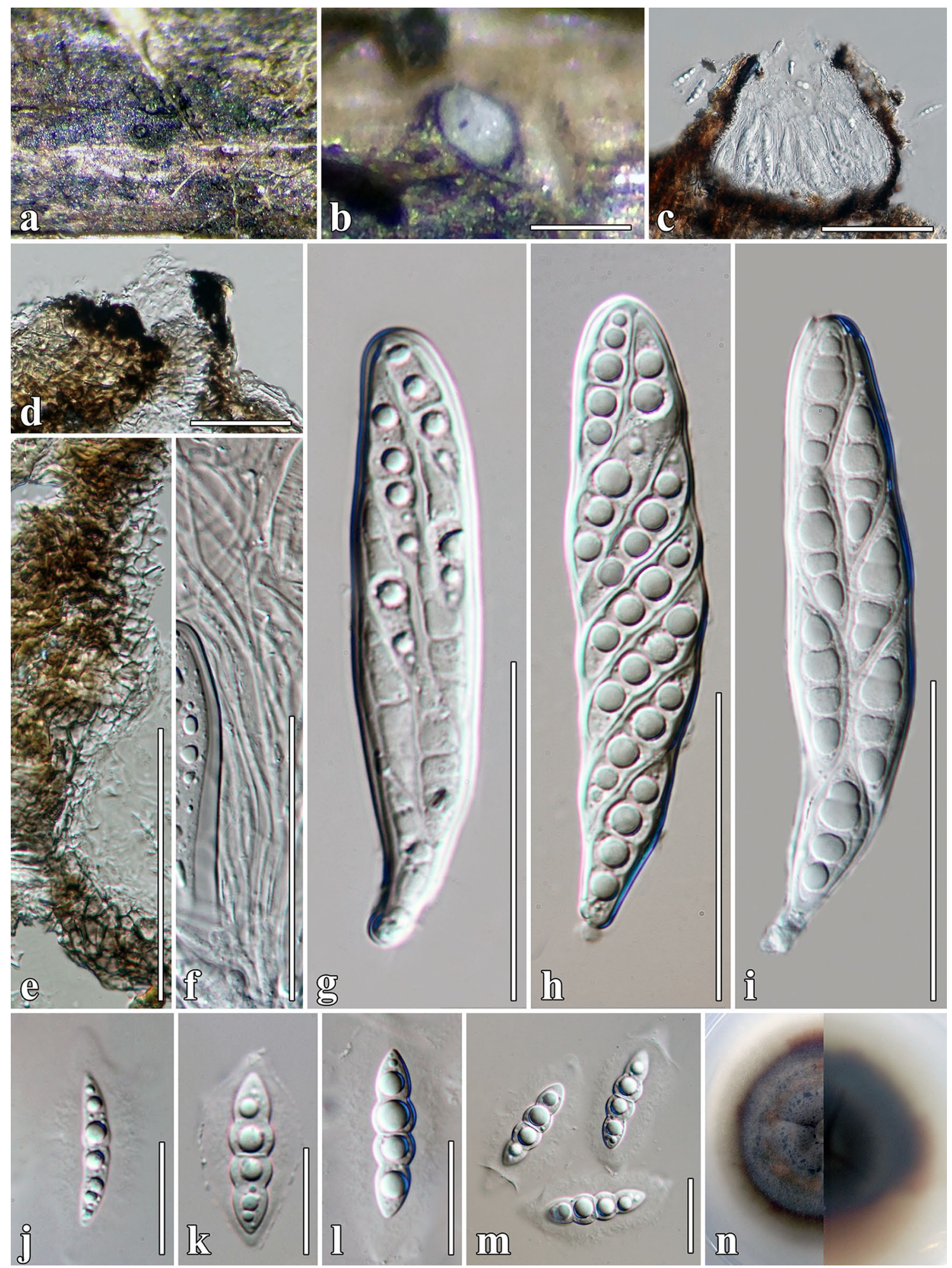

Fig. 3 Fusiformispora clematidis (MFLU 17-1485, holotype). a Appearance of ascoma on host surface. b Close up of ascoma on host substrate. c Vertical section of ascoma. d Ostiolar canal. e Section of peridium. f Pseudoparaphyses. g-i Asci. j-m Ascospores. $\mathbf{n}$ Culture characteristics on MEA. Scale bars: $\mathbf{b}=200 \mu \mathrm{m}, \mathbf{c}=100 \mu \mathrm{m}, \mathbf{d}$, $\mathbf{j}-\mathbf{m}=20 \mu \mathrm{m}, \mathbf{e}-\mathbf{i}=50 \mu \mathrm{m}$ 
Fusiformispora is similar to Amniculicola Zhang \& K.D. Hyde, however, the genus differs by having thinner peridium walls with sub-carbonaceous ascomatal type. Amniculicola is an aquatic genus and its species have cylindrical asci and uniseriate arrangement of ascospores, while Fusiformispora has cylindric-clavate asci and biseriate arrangement of ascospores and is from a terrestrial habitat. We therefore, introduce a new genus based on morphological and phylogenetic evidence for a fungal collection on Clematis fulvicoma.

Fusiformispora clematidis Phukhams., M.V. de Bult \& K.D. Hyde, sp. nov.

Index Fungorum number: IF557107; Facesoffungi number: FoF 07243, Fig. 3.

Etymology: Epithet reflects the host Clematis.

Holotype: MFLU 17-1485.

Saprobic on dead stems of Clematis fulvicoma. Sexual morph: Ascomata $165-190 \times 200-275 \mu \mathrm{m}(\bar{x}=175 \times 225 \mu \mathrm{m}$, $\mathrm{n}=5$ ), on surface of host, covered by a pseudoclypeus, visible as black spots, immersed to superficial, solitary, scattered, uniloculate, obpyriform to compressed globose, base flattened, brown to dark brown, partially carbonaceous, roughwalled, with apical ostioles. Ostioles central, $55 \times 35 \mu \mathrm{m}$, brown to dark brown, papillate, with easily opening by a pore, filled with periphyses. Peridium 10-18 $\mu \mathrm{m}$ wide, multilayered, comprising 4-5 layers of brown to dark brown cells of textura angularis, inner layers comprising thin, hyaline cells. Hamathecium composed of dense, 0.5-1.5 $\mu \mathrm{m}$ wide ( $\bar{x}=1.3 \mu \mathrm{m}, \mathrm{n}=50$ ), filiform, branched, trabeculate pseudoparaphyses, anastomosing above the asci, reaching the ostiole, transversely septate. Asci $86-127 \times 18-24 \mu \mathrm{m}$ $(\bar{x}=100 \times 25 \mu \mathrm{m}, \mathrm{n}=40), 8$-spored, bitunicate, fissitunicate, thick-walled, cylindric-clavate, apically rounded, short, with furcate pedicel, ocular chamber clearly visible when immature. Ascospores $24-36 \times 5-10 \mu \mathrm{m}(\bar{x}=30 \times 8 \mu \mathrm{m}, \mathrm{n}=50)$, biseriate, partially overlapping, broad fusiform, tapering towards the ends, acute at both ends, hyaline, with (1-)3-4 transverse septa, with large guttules in each cell, constricted at the septa, deeply constricted at the median septum, cell above median septum slightly wider than below, smoothwalled, with 4-12 $\mu \mathrm{m}$ wide mucilaginous sheath. Asexual morph: Undetermined.

Culture characters: Colonies on MEA reaching $50 \mathrm{~mm}$ diam. after 4 weeks at $25{ }^{\circ} \mathrm{C}$. Cultures from above, greybrown, with reddish brown mixed in the mycelium, dense, colonies circular, flat, umbonate, raised from the agar in the centre, dull, covered with aerial mycelium, white mycelium at the edge; reverse dark brown, dense, circular, with irregular, fimbriate margin, pinkish mycelium radiating outwardly.

Material examined: Thailand, Chiang Rai Province, on dead stems of Clematis fulvicoma Rehder \& E.H. Wilson, 20 March 2017, C. Phukhamsakda, CMTH22 (MFLU 17-1485, holotype); ex-type living culture, MFLUCC 17-2077.
Host: Clematis fulvicoma-(This study).

Distribution: Thailand-(This study).

GenBank accession numbers: LSU: MT214542; SSU: MT226661; ITS: MT310589; tef1: MT394725; rpb2: MT394677.

Notes: In a BLASTn search of GenBank, the LSU sequence of Fusiformispora clematidis MFLUCC 17-2077 showed $96 \%$ similarity to Lindgomyces pseudomadisonensis KT 2742 (LC149916), while the ITS sequence had 91\% similarity to Vargamyces aquaticus CBS 636.91 (NR_154471). Fusiformispora clematidis is phylogenetically distinct, therefore we introduce the collection as a new species.

Amorosiaceae Thambug. \& K.D. Hyde

Amorosiaceae was introduced for Amorosia Mantle \& D. Hawksw. and Angustimassarina Thambugala, Tanaka \& K.D. Hyde (Thambugala et al. 2015). Amorosiaceae is characterized by immersed or semi-immersed ascomata with a short crest-like papilla, and hyaline ascospores with a mucilaginous sheath. Asexual morphs of this family were described as sporodochia (Mantle et al. 2006; Thambugala et al. 2015). Jayasiri et al. (2019) reported Amorocoelophoma from a decaying pod of Cassia species. Phylogeny combined with morphological observations confirm the placement of Amorocoelophoma as the first coelomycetous species in Amorosiaceae (Fig. 4).

Angustimassarina Thambug., Kaz. Tanaka \& K.D. Hyde

Angustimassarina was described for fungal species that have ascospores resembling Massarina while being narrowly fusiform in shape. The genus has immersed to semi-immersed ascomata, coriaceous, dark brown to black, globose to subglobose, ostiolate, cylindrical to cylindric-clavate asci and fusiform to cylindrical or ellipsoidal-fusiform ascospores surrounded by a mucilaginous sheath. The asexual morph of this genus is hyphomycetous. Twelve species are listed in Index Fungorum for Angustimassarina (Thambugala et al. 2015; Wanasinghe et al. 2018; Hyde et al. 2019a). In this study, Angustimassarina rosarum was isolated from Clematis viticella and identification was based on multigene phylogenetic analysis of LSU, SSU, ITS, and tefl sequence data (Fig. 4) and its compatible morphology (Fig. 5).

Angustimassarina rosarum Tibpromma, Camporesi \& K.D. Hyde, Fungal Diversity 89: [21] (2018), new host record.

Index Fungorum number: IF553939; Facesoffungi number: FoF 03964, Fig. 5.

Saprobic on dead stems of Clematis viticella. Sexual morph: Ascomata $221-306 \times 267-400 \mu \mathrm{m}(\bar{x}=265 \times 340 \mu \mathrm{m}$, $\mathrm{n}=5$ ), scattered, gregarious, immersed, coriaceous, dark globose to subglobose, brown to black, ostiolate. Ostioles $57 \times 134 \mu \mathrm{m}$, central, rounded, papillate, with opening by a pore. Peridium $14-40(-60) \mu \mathrm{m}(\bar{x}=20 \mu \mathrm{m}, \mathrm{n}=10)$, thick at 
Fig. 4 The best scoring RAxML tree with a final likelihood value of - 10209.184183 based on combined LSU, SSU, ITS and tefl 1 sequence data for Amorosiaceae. The topology and clade stability of the combined gene analyses was compared to the single gene analyses. The tree is rooted with species of Sporormiaceae. The tree from the maximum likelihood analysis had similar topology to the Bayesian 50\% majority-rule consensus phylogram. The matrix had 809 distinct alignment patterns with $21.55 \%$ undetermined characters and gaps. Estimated base frequencies were as follows; $\mathrm{A}=0.246053$, $\mathrm{C}=0.243449, \mathrm{G}=0.269921$, $\mathrm{T}=0.240577$; substitution rates $\mathrm{AC}=1.221779, \mathrm{AG}=2.152972$, $\mathrm{AT}=1.558241, \mathrm{CG}=0.998233$, $\mathrm{CT}=7.007203, \mathrm{GT}=1.000000$; gamma distribution shape parameter $\alpha=2.180328$. The species determined in this study is indicated in blue. Bootstrap values (BS) greater than $50 \%$ BS (ML, left) and Bayesian posterior probabilities (BYPP, right) greater than 0.90 are given at the nodes. Hyphens (-) represent support values less than $(\mathrm{BS} \geq 50 \% / \mathrm{BYPP} \geq 0.90)$

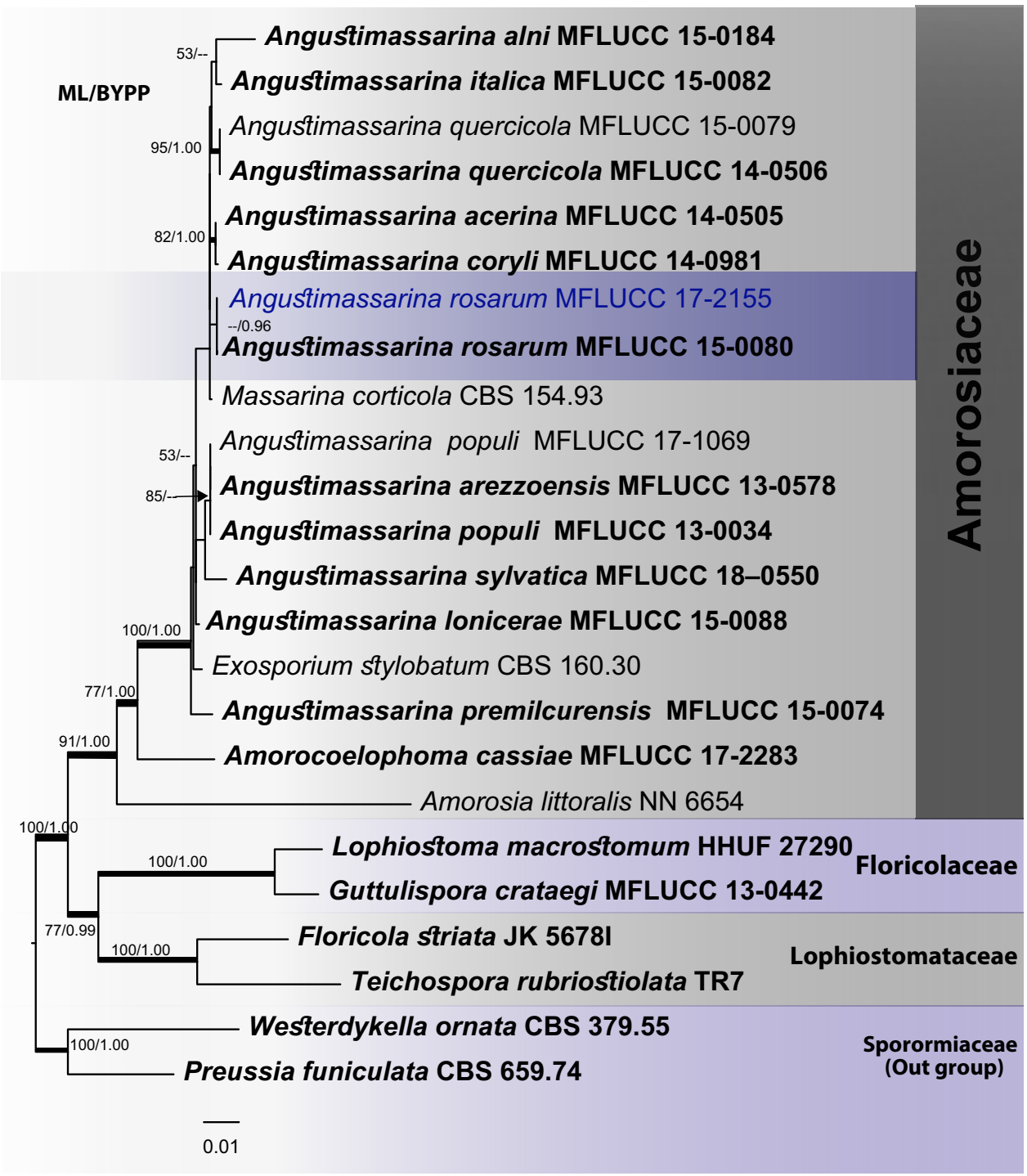

the sides, broad at the apex and thinner at the base, comprising brown to dark brown cells of textura angularis, fusing at the outside with the host tissues. Hamathecium composed of dense, 1.5-2.5 $\mu$ m wide, septate, long, cellular pseudoparaphyses, embedded in a gelatinous matrix. Asci $77-85 \times 10-16 \mu \mathrm{m}(\bar{x}=78 \times 15 \mu \mathrm{m}, \mathrm{n}=30), 8$-spored, bitunicate, fissitunicate, broad cylindrical to cylindrical-clavate, with bulbous pedicel, rounded at the apex, with a minute ocular chamber. Ascospores $17-23 \times 4-4.5 \mu \mathrm{m}(\bar{x}=20 \times 4 \mu \mathrm{m}$, $\mathrm{n}=15$ ), biseriate, partially overlapping, broad fusiform, hyaline, 1(-3) septate, deeply constricted at the primary septum, widest at the centre and tapering towards the ends, straight, smooth-walled, 1(-3)-guttulate, surrounded by a 5-10 $\mu \mathrm{m}$ wide mucilaginous sheath. Asexual morph: Undetermined.

Culture characters: Colonies on MEA reaching $30 \mathrm{~mm}$ diam. after 4 weeks at $25^{\circ} \mathrm{C}$. Culture black in the middle, radiating white, dense, circular, umbonate, entries edge, shiny, dull, undulate, radially furrowed, reverse black, radiating outwardly, white.

Material examined: Belgium, Flemish Brabant, Meise Botanic Garden, Bouchout Domain, dead stems of Clematis viticella L., 13 June 2017, D. Ertz \& C. Gerstmans, BRCV1 (MFLU 17-1513); living culture, MFLUCC 17-2155.

Hosts: Clematis viticella, Rosa canina-(Wanasinghe et al. 2018; this study).

Distribution: Belgium, Italy-(Wanasinghe et al. 2018, this study).

GenBank accession numbers: LSU: MT214543; SSU: MT226662; ITS: MT310590; tef1: MT394726; rpb2: MT394678.

Notes: Angustimassarina rosarum (MFLUCC 15-0080) was described from Rosa canina in Italy (Wanasinghe et al. 2018). We compared our collection with A. rosarum and both have similar morphology in terms of ascomata, asci, and ascospores. Angustimassarina rosarum (MFLUCC 

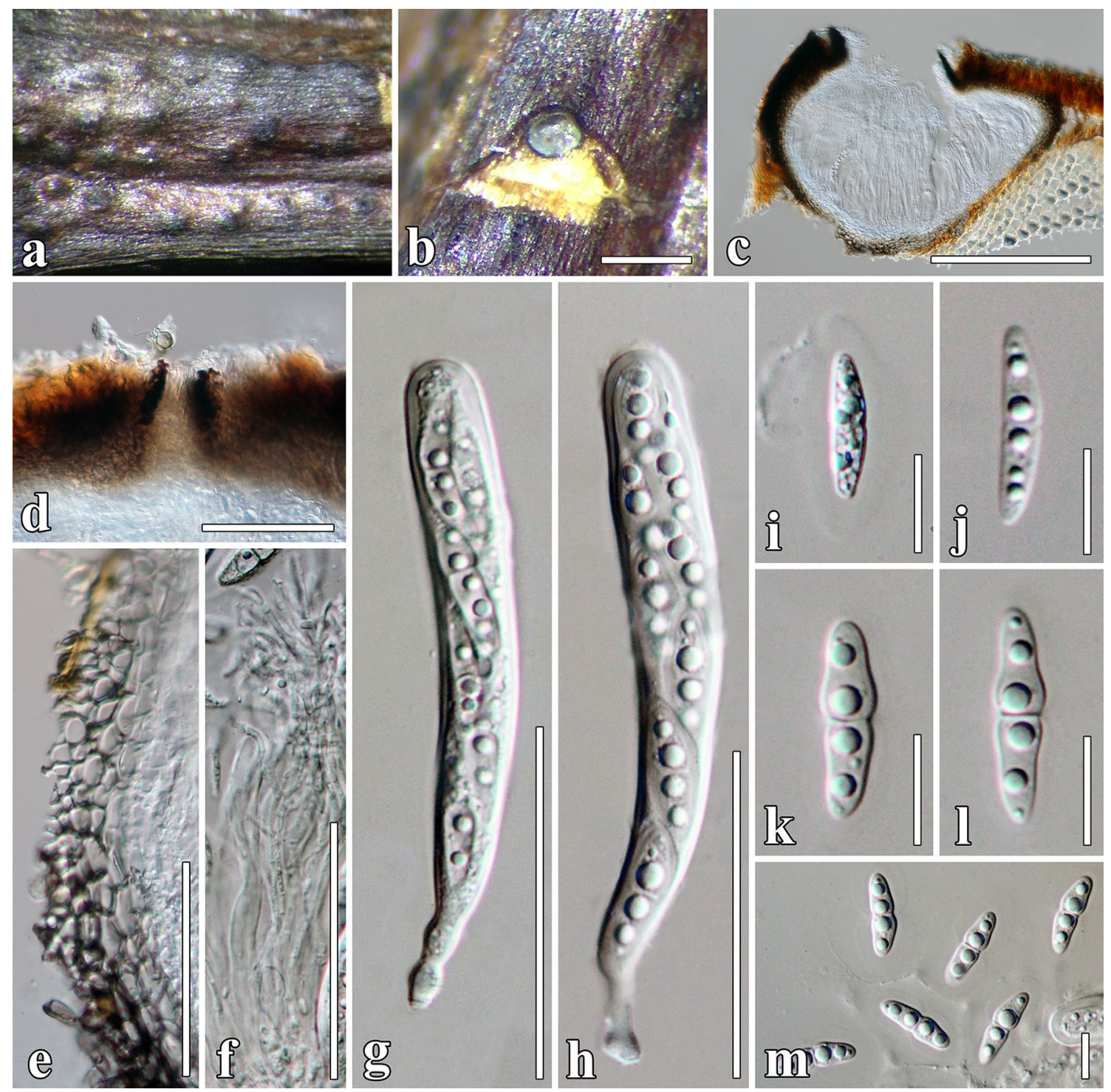

Fig. 5 Angustimassarina rosarum (MFLU 17-1513). a Appearance of ascomata on host surface. b Close up of ascoma on host substrate. c Vertical section through ascoma. d Ostiolar canal. e Section of

peridium. f Pseudoparaphyses. $\mathbf{g}-\mathbf{h}$ Asci. i-m Ascospores. Scale bars: $\mathbf{b}=500 \mu \mathrm{m}, \mathbf{c}=200 \mu \mathrm{m}, \mathbf{d}-\mathbf{f}=50 \mu \mathrm{m}, \mathbf{g}, \mathbf{h}=20 \mu \mathrm{m}, \mathbf{i}-\mathbf{m}=10 \mu \mathrm{m}$

15-0080) has globose to subglobose, cylindric-clavate asci $(124 \times 143 \mu \mathrm{m})$, and club-shaped pedicel $(70 \times 10 \mu \mathrm{m})$. It has a minute ocular chamber, with fusiform to ellipsoidal ascospores $(19 \times 5 \mu \mathrm{m})$ and a hyaline, 1 septate at the centre, with two large guttules in each cell. Our collection has larger ascomata $(265 \times 340 \mu \mathrm{m})$, but is similar in overall morphology (Fig. 5). In molecular analysis, the new strain forms a close relationship with A. rosarum (MFLUCC 15-0080). Comparison of the ITS sequence data reveals no significant difference (one base pair difference) between our new collection and A. rosarum (MFLUCC 15-0080). However, the tefl sequence is not available for A. rosarum (MFLUCC 15-0080) for comparison. Therefore, we introduce a new host record of A. rosarum on Clematis species herein.

Cyclothyriellaceae Jaklitsch \& Voglmayr

Cyclothyriellaceae was introduced for Cyclothyriella rubronotata (= Thyridaria rubronotata) and Massariosphaeria phaeospora as revealed by molecular phylogeny (Jaklitsch and Voglmayer 2016). Cyclothyriellaceae is characterized by scattered, immersed-erumpent ascomata, with occasional purple stain on plant tissue, and narrow, anastomosing, trabeculate pseudoparaphyses (sensu Liew et al. 2000). Asci are cylindrical to clavate, bitunicate and 8-spored. Ascospores are brown, ellipsoid to fusoid, with several eusepta. The asexual morph is pycnidial with hyaline to brown conidia (Zhang et al. 2012; Jaklitsch and Voglmayer 2016). We describe a novel species of Massariosphaeria recorded on Clematis vitalba from Italy (Fig. 2). 
Massariosphaeria (E. Müll.) Crivelli

Massariosphaeria was introduced for species with reddish brown to brown, multi-septate, phragmosporous to dictyosporous and usually with colouration on the surface of the substrate (Crivelli 1983; Leuchtmann 1984; Zhang et al. 2012). Several studies have proved the polyphyletic placement of Massariosphaeria, classifying them into distinct genera (Zhang et al. 2012; Ariyawansa et al. 2015a; Phukhamsakda et al. 2016). Massariosphaeria has comparable peridium and phragmosporous characters with Chaetomastia (Teichosporaceae) (Barr 1989). However, the characteristic of ascomata position and the ascospores characters of Chaetomastia and Massariosphaeria are distinct. The type species Massariosphaeria phaeospora (CBS 611.86) is currently placed in Cyclothyriellaceae (Fig. 2). Twenty-one epithets are listed under Massariosphaeria in Index Fungorum (2020). Based on phylogenetic analysis including Cyclothyriellaceae, our collection (MFLU 16-0174) clustered with M. phaeospora (CBS 611.86) with strong support (100\% MLBS/1.00 BYPP). A new Massariosphaeria species on Clematis vitalba is introduced herein (Fig. 6).

Massariosphaeria clematidis Phukhams., Wanas., Camporesi \& K.D. Hyde, sp. nov.

Index Fungorum number: IF557108; Facesoffungi number: FoF 07248, Fig. 6.

Etymology: Epithet reflects the host Clematis.

Holotype: MFLU 16-0174.

Saprobic on dead stems of Clematis vitalba. Sexual morph: Ascomata 340-430 $215-300 \mu \mathrm{m}$ $(\bar{x}=280 \times 255 \mu \mathrm{m}, \mathrm{n}=5)$, with only black shiny ostioles present on the surface of host, solitary, scattered, immersed, globose to compressed globose, sub-carbonaceous to coriaceous, dark brown to black, rough-walled, with short hyphae projecting from peridium, ostiolate. Ostioles centrally located, $125-175 \times 110-130 \mu \mathrm{m}(\bar{x}=140 \times 120 \mu \mathrm{m}, \mathrm{n}=10)$, carbonaceous, papillate, periphysoids. Peridium $22-33 \mu \mathrm{m}$ wide, composed of 6-8(-12 at apex) layers of dark brown to black cells of textura angularis, inner layer composed of hyaline gelatinous cells. Hamathecium composed of numerous, dense, long, $1.6-3.5 \mu \mathrm{m}$ wide $(\bar{x}=2.5 \mu \mathrm{m}$, $\mathrm{n}=50$ ), filiform, transversely septate, branched, anastomosing, cellular pseudoparaphyses. Asci 150-225 $\times 20-30 \mu \mathrm{m}$ $(\bar{x}=180 \times 25 \mu \mathrm{m}, \mathrm{n}=20), 8$-spored, bitunicate, fissitunicate, cylindric-clavate to broad cylindrical, with furcate pedicel, with ocular chamber visible when immature. Ascospores $35-45 \times 10-15 \mu \mathrm{m}(\bar{x}=40 \times 12 \mu \mathrm{m}, \mathrm{n}=50)$, biseriate or overlapping, broad fusiform, narrow towards the apex, initially hyaline, becoming yellowish to brown at maturity, 6-8-transversely euseptate, constricted at the septa, third cell from apex usually enlarged, smooth-walled, guttulate and indentations present, surrounded by a $8-20 \mu \mathrm{m}$ wide, mucilaginous sheath. Asexual morph: Undetermined.
Culture characters: Colonies on MEA reaching $20 \mathrm{~mm}$ diam. after 4 weeks at $18{ }^{\circ} \mathrm{C}$. Culture from above brown, yellowish towards the edge, dense, circular, flat, dull, fimbriate, radially furrowed, and slightly covered with white aerial mycelium; reverse black with radiating cream mycelium.

Material examined: Italy, Forlì-Cesena Province, Strada San Zeno-Galeata, dead aerial stems of Clematis vitalba L., 7 November 2013, E. Camporesi, IT1509 (MFLU 16-0174, holotype).

Host: Clematis vitalba-(This study).

Distribution: Italy—(This study).

GenBank accession numbers: LSU: MT214544; SSU: MT226663; ITS: MT310591.

Notes: Our new collection MFLU 16-0174 from Italy formed a close relationship with the type species of Massariosphaeria, M. phaeospora (CBS 611.86) with strong support (100\% ML/1.00 BYPP). The strain is compatible with the concept of Massariosphaeria in having scattered, immersed, papillate ascomata with thick ostiolar wall, dense pseudoparaphyses, cylindro-clavate asci and broad fusiform, reddish brown to brown, multi-septate ascospores with a mucilaginous sheath (Müller 1950; Zhang et al. 2012). MFLU 16-0174 is distinguishable from M. phaeospora by its partial carbonaceous ostioles, narrower, 6-8-transversely euseptate ascospores which are swollen at the third cell. Massariosphaeria vitalbae (三Leptosphaeria vitalbae) was described from Clematis vitalba in Switzerland (Ahn and Shearer 1998). Characters of MFLU 16-0174 include a long neck $(\bar{x}=140 \times 120 \mu \mathrm{m})$, with sub-carbonaceous to coriaceous peridium types and ascospores enlarged at the third cell. Massariosphaeria vitalbae has sub-parenchymatous cells type with short ostiolar necks and 9-10-septate and ascospores enlarged at the third cell (Müller 1950). Massariosphaeria vitalbae closely resembles Paramassariosphaeria clematidicola, however, fresh collections are required to clarify its taxonomic placement (Wanasinghe et al. 2016b).

In a BLASTn search of GenBank, the LSU sequence of Massariosphaeria clematidis (MFLU 16-0174) was found to be $96 \%$ similar to M. phaeospora strain CBS 611.86 (FJ795503). We introduce a novel species of Massariosphaeria, M. clematidis based on the morphological (Fig. 6) and phylogenetic evidence (Fig. 2).

\section{Dictyosporiaceae Boonmee \& K.D. Hyde}

Dictyosporiaceae was introduced with Dictyosporium as the type genus in Dothideomycetes (Boonmee et al. 2016). The sexual morph of Dictyosporiaceae has immersed to erumpent or superficial, globose to subglobose and dark brown to black ascomata including bitunicate, cylindricclavate asci with septate and hyaline ascospores with a thick mucilaginous sheath (Tanaka et al. 2015; Boonmee et al. 2016). Most members of Dictyosporiaceae have a hyphomycetous asexual morph with cheirosporous or dictyosporous 

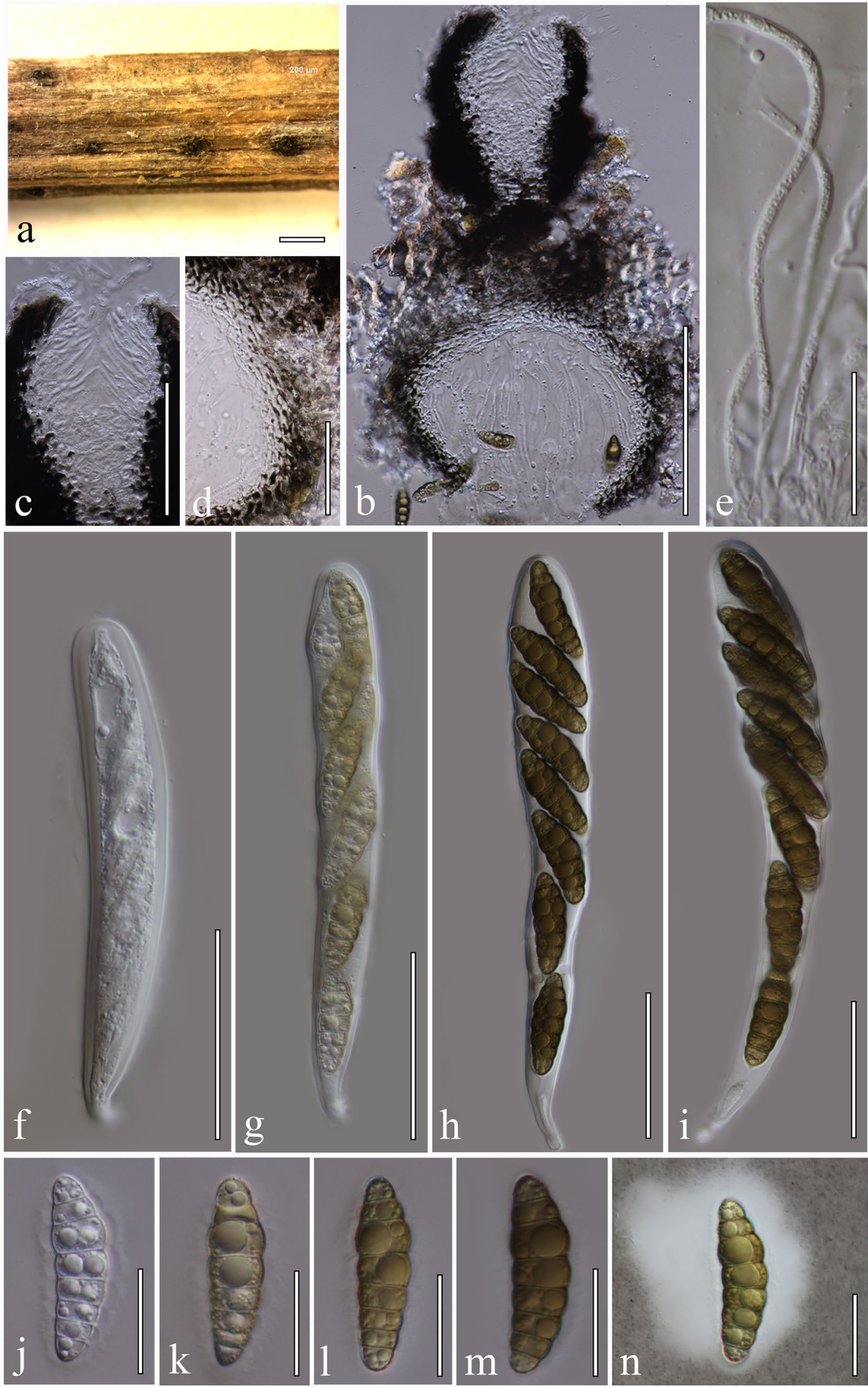
\Fig. 6 Massariosphaeria clematidis (MFLU 16-0174, holotype). a Appearance of ascomata on host surface. b Vertical section of ascoma. c Ostiolar canal. d Section of peridium. e Pseudoparaphyses. $\mathbf{f}-\mathbf{i}$ Asci. $\mathbf{j}-\mathbf{m}$ Ascospores. $\mathbf{n}$ Ascospore in $10 \%$ Indian ink. Scale bars: $\mathbf{a}=500 \mu \mathrm{m}, \mathbf{b}=200 \mu \mathrm{m}, \mathbf{c}=100 \mu \mathrm{m}, \mathbf{d}-\mathbf{i}=50 \mu \mathrm{m}, \mathbf{j}-\mathbf{n}=20 \mu \mathrm{m}$

conidia, pycnidia with coleophoma-like characters and phialidic conidiogenesis cells. Fourteen genera are listed under Dictyosporiaceae (Iturrieta-González et al. 2018; Wijayawardene et al. 2018; Crous et al. 2019). We provide an updated phylogenetic tree of Dictyosporiaceae and propose a new species and a new host record of Aquadictyospora, Dictyocheirospora and Pseudocoleophoma on Clematis (Fig. 7).

\section{Aquadictyospora Luo, Hyde \& H.Y. Su}

Aquadictyospora was introduced to accommodate a dictyosporous taxon on submersed decaying wood, and typified with A. lignicola Z.L. Luo et al. The genus is characterized by sporodochia, superficial, circular or subglobose conidiomata, micronematous conidiophores with monoblastic conidiogenesis cells, and uniformly medium brown dictyosporous conidia with a subglobose, hyaline cell at the basal end (Li et al. 2016). We introduce a second species of Aquadictyospora based on morphology (Fig. 8) and phylogenetic analyses (Fig. 7).

Aquadictyospora clematidis Phukhams., Bhat \& K.D. Hyde, sp. nov.

Index Fungorum number: IF557125; Facesoffungi number: FoF 07250, Fig. 8.

Etymology: Name refers to the host plant, Clematis.

Holotype: MFLU 17-1488.

Saprobic on dead stems of Clematis sikkimensis. Sexual morph: Undetermined. Asexual morph: Hyphomycetous. Colonies 53-97 ×121-213 $\mu \mathrm{m}(\bar{x}=72 \times 153 \mu \mathrm{m}, \mathrm{n}=10)$, on natural substrate forming sporodochial conidiomata, superficial, compact, scattered, subglobose to oval, dark brown to reddish brown, velvety. Mycelium 2-3 $\mu \mathrm{m}$ wide, immersed, consisting of branched septate hyphae. Conidiophores 6-11 $\times 2-4 \mu \mathrm{m}(\bar{x}=8 \times 3 \mu \mathrm{m}, \mathrm{n}=10)$, micronematous, hyaline to pale brown, smooth. Conidiogenous cells 5-8 $\times 3-5 \mu \mathrm{m}$, holoblastic, monoblastic, solitary, discrete, determinate. Conidia 17-38 × 15-24 $\mu \mathrm{m}(\bar{x}=32 \times 20 \mu \mathrm{m}$, $\mathrm{n}=50$ ), dictyosporous, compactly depressed, obovoid, appearing broadly rounded in upper half, heavily pigmented at the upper half, smooth, entirely reddish brown, with hyaline mammiform basal cell, smooth basal cell, 5-11 $\times 4-11 \mu \mathrm{m}(\bar{x}=8 \times 8 \mu \mathrm{m}, \mathrm{n}=40)$, not complanate, secession involves splitting of the basal, without appendages.

Culture characters: Colonies on MEA reaching $50 \mathrm{~mm}$ diam. after 4 weeks at $25^{\circ} \mathrm{C}$. Cultures from above brownish beige at the centre, grey radiating outwardly, dense, raised with concave edge, circular, entire edge, umbonate, papillate with fairly fluffy, wrinkled folded, covered with white aerial mycelium; reverse dark brown at the centre, faintly zonate, white mycelium at the edge.

Material examined: Thailand, Nan Province, on dead stem of Clematis sikkimensis (Hook. f. \& Thomson) Drumm. ex Burkill, 2 May 2017, C. Phukhamsakda, CMTH26 (MFLU 17-1488, holotype); ex-type living culture, MFLUCC 17-2080.

Host: Clematis sikkimensis-(This study).

Distribution: Thailand-(This study).

GenBank accession numbers: LSU: MT214545; SSU: MT226664; ITS: MT310592; tef1: MT394727, rpb2: MT394679.

Notes: The species is assigned to Aquadictyospora based on its compatible morphological features such as superficial sporodochia with subglobose to oval conidiomata, micronematous conidiophores with monoblastic conidiogenous cell, and dictyosporous conidia with hyaline, mammiform basal cells (Li et al. 2016). Aquadictyospora clematidis has smaller non-cheiroid conidia $(32 \times 20 \mu \mathrm{m})$ than $A$. lignicola which has larger cheiroid conidia $(50 \times 24 \mu \mathrm{m})$. Aquadictyospora clematidis was found in a terrestrial habitat while A. lignicola was from submerged substrates (Fig. 8). In a BLASTn search of GenBank, the ITS sequence had 95\% similarity while the tefl sequence had $95 \%$ similarity to the type species, A. lignicola. The new strain is introduced as a new species of Aquadictyospora based on polyphasic evidence.

Dictyocheirospora D'souza, Boonmee \& K.D. Hyde

Boonmee et al. (2016) introduced Dictyocheirospora (typified by $D$. rotunda) for an aero-aquatic sporodochial fungus with cheiroid dictyospores. Nineteen species are listed in Index Fungorum (2020) and interestingly, no sexual morph has been described for this genus (Wang et al. 2016; Tibpromma et al. 2018; Hyde et al. 2017, 2019a). We introduce Dictyocheirospora clematidis as a novel species and D. xishuangbannaensis as a new host record from Clematis based on compatible morphological and phylogenetic analysis (Fig. 9).

Dictyocheirospora clematidis Phukhams., D.J. Bhat \& K.D. Hyde, sp. nov.

Index Fungorum number: IF557126; Facesoffungi number: FoF 07251, Fig. 9.

Etymology: Name refers to the host plant, Clematis.

Holotype: MFLU 17-1497.

Saprobic on dead stem of Clematis sikkimensis. Sexual morph: Undetermined. Asexual morph: Hyphomycetous. Colonies 200-340 $\mu \mathrm{m}$ wide $(\bar{x}=265 \mu \mathrm{m}, \mathrm{n}=20)$, on natural substrate forming sporodochial conidiomata, superficial, gregarious, scattered, punctiform, blackish brown, velvety, glistening, orbicular, with abundant sporulation, conidia 


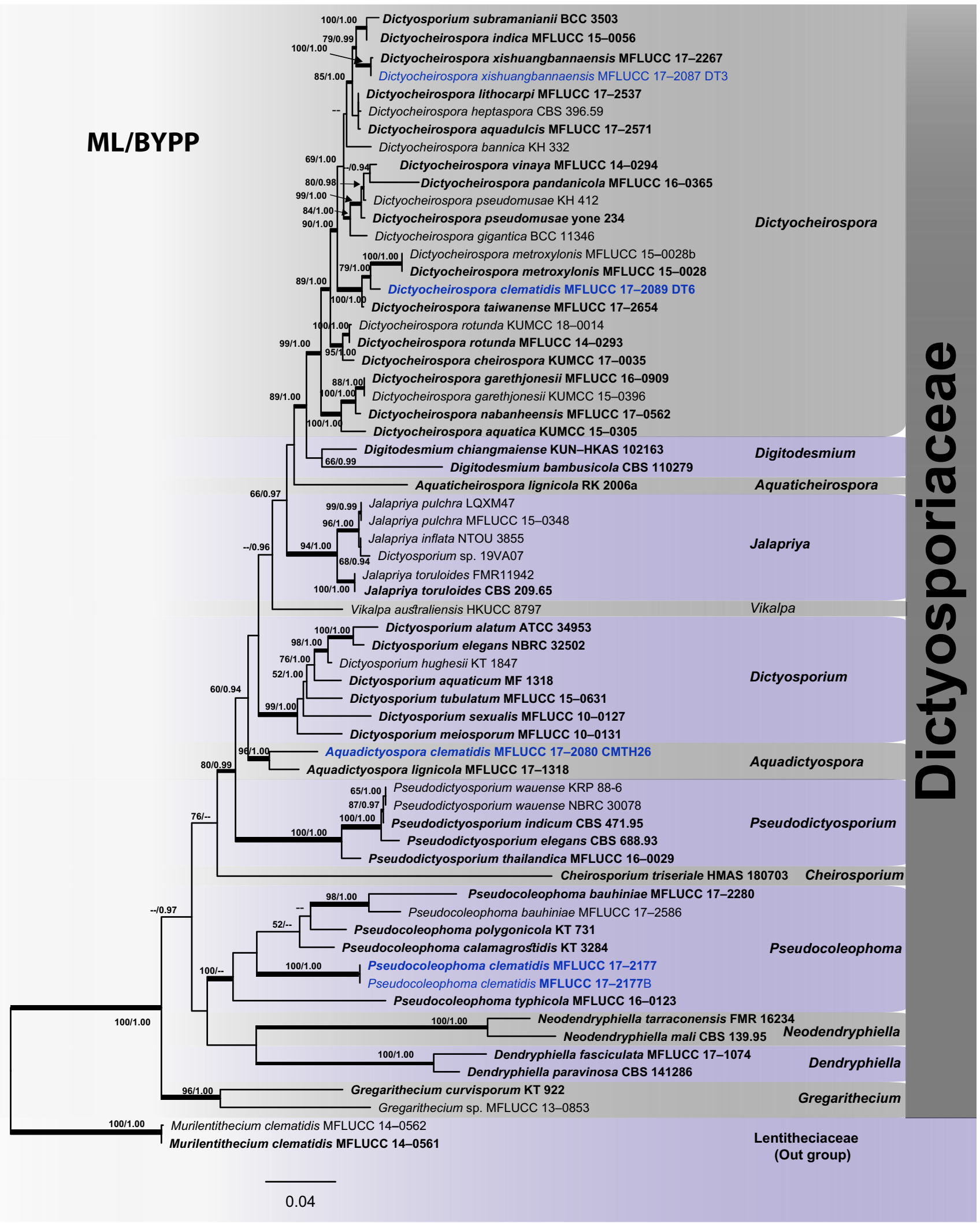


4Fig. 7 The best scoring RAxML tree with a final likelihood value of -15336.133569 based on LSU, ITS and tef1 sequence data for Dictyosporiaceae species. The topology and clade stability of the combined DNA analyses was compared to the single gene analyses. The tree is rooted with sequences of Murilentithecium clematidis (MFLUCC 14-0561, MFLUCC 14-0562) in Lentitheciaceae. The tree from the maximum likelihood analysis had similar topology to the Bayesian analyses. The matrix had 1009 distinct alignment patterns, with $37.31 \%$ undetermined characters and gaps. Estimated base frequencies were as follows; $\mathrm{A}=0.234307, \mathrm{C}=0.254705$, $\mathrm{G}=0.271061, \mathrm{~T}=0.239927$; substitution rates $\mathrm{AC}=1.414609$, $\mathrm{AG}=2.411925, \quad \mathrm{AT}=2.055489, \quad \mathrm{CG}=0.612591, \quad \mathrm{CT}=6.466528$, $\mathrm{GT}=1.000000$; gamma distribution shape parameter $\alpha=0.761212$. The species determined in this study are indicated in blue. Bootstrap values (BS) greater than 50\% BS (ML, left) and Bayesian posterior probabilities (BYPP, right) greater than 0.90 are given at the nodes. Hyphens (-) represent support values less than 50\% BS/0.90 BYPP. Thick branches represent significant support values from all analyses (BS $\geq 70 \% / B Y P P \geq 0.95$ )

readily liberated when agitated. Mycelium immersed, composed of brown, smooth, thin-walled, septate hyphae. Conidiophores $15 \times 3 \mu \mathrm{m}$, micronematous, pale brown, smooth, thin-walled. Conidiogenous cells 5-6×3-4 $\mu \mathrm{m}$, holoblastic, monoblastic, integrated, terminal, determinate, hyaline, smooth-walled. Conidia 42-60× 15-30 $\mu \mathrm{m}(\bar{x}=50 \times 23 \mu \mathrm{m}$, $\mathrm{n}=40$ ), solitary, acrogenous, cheiroid, with a basal connecting cell, discharges after mounted in water, cognac brown, consisting of 6-7 rows of cells, individual rows discoid. Conidial arm 34-60×7-10 $\mu \mathrm{m}(\bar{x}=52 \times 9 \mu \mathrm{m}, \mathrm{n}=30)$, digitate, cylindrical, inwardly curved at the tip, arising from a basal cell, 10-12 distosepta, slightly constricted at the septa, with large guttule in each cell.

Culture characters: Colonies on MEA reaching $40 \mathrm{~mm}$ diam. after 4 weeks at $25^{\circ} \mathrm{C}$. Cultures from above, black, dense, circular, entire edge, umbonate, papillate with aerial mycelium, wrinkled and folded, narrow fringe of submerged mycelium, covered with grey aerial mycelium; reverse black, white mycelium present at the edge.

Material examined: Thailand, Chiang Rai Province, Doi Tung, on dead stem of Clematis sikkimensis, 2 May 2017, C. Phukhamsakda \& M.V. de Bult, CMTHDT06 (MFLU 17-1497, holotype); ex-type living culture, MFLUCC 17-2089.

Host: Clematis sikkimensis-(This study).

Distribution: Thailand-(This study).

GenBank accession numbers: LSU: MT214546; SSU: MT226665; ITS: MT310593; tef1: MT394728, rpb2: MT394680.

Notes: Dictyocheirospora species are highly diverse especially in tropical regions (Boonmee et al. 2016; Tibpromma et al. 2018; Yang et al. 2018a; Hyde et al. 2019a). Dictyocheirospora clematidis is similar to D. metroxylonis based on characters (Table 1), but the ITS sequence shows $97 \%$ similarity ( $2.8 \%$ nucleotide differences) while the tefl sequence has $96 \%$ similarity (4.6\% nucleotide differences). Dictyocheirospora clematidis clustered in the same clade as D. taiwanense but it has distinct characters. Dictyocheirospora taiwanense usually has 5 rows of cells in the conidia and they are longer than those of $D$. clematidis $(78 \times 18$ vs $50 \times 23 \mu \mathrm{m})$. In the phylogenetic analysis, $D$. clematidis (MFLUCC 17-2089) clustered with D. metroxylonis (MFLUCC 15-0282) and D. taiwanense (MFLUCC 17-2654) but formed a well-separated clade with good support of $79 \%$ in ML and 1.00 in BYPP (Fig. 7).

Dictyocheirospora xishuangbannaensis Tibpromma \& K.D. Hyde, Fungal Divers 93:14 (2018), new host record

Index Fungorum number: IF554476; Facesoffungi number: FoF 04485, Fig. 10

Saprobic on dead stem of Clematis sikkimensis. Sexual morph: Undetermined. Asexual morph: Hyphomycetous. Colonies $235-423 \mu \mathrm{m}$ wide $(\bar{x}=326 \mu \mathrm{m}, \mathrm{n}=20)$, on natural substrate forming sporodochial conidiomata, superficial, gregarious, scattered, punctiform, blackish brown, velvety, glistening, orbicular, with abundant sporulation, conidia readily liberated when agitated. Mycelium $2 \mu \mathrm{m}$ wide, immersed, composed of hyaline to pale brown, smooth, thin-walled, septate hyphae. Conidiophores $10-20 \times 3-6 \mu \mathrm{m}(\bar{x}=12 \times 4 \mu \mathrm{m}, \mathrm{n}=10)$, micronematous, hyaline to light brown, smooth, thin-walled. Conidiogenous cells $3-7 \times 2-6 \mu \mathrm{m}(\bar{x}=5 \times 4 \mu \mathrm{m}, \mathrm{n}=10)$, holoblastic, integrated, terminal, determinate, hyaline, smooth-walled. Conidia $32-53 \times 16-27 \mu \mathrm{m}(\bar{x}=46 \times 20 \mu \mathrm{m}, \mathrm{n}=50)$, solitary, acrogenous, cheiroid, oblong or subglobose, with a basal connecting cell, discharges after mounted in water, cognac brown, heavily pigmented upper part, consisting of 6-7 rows of cells, rows digitate. Conidial arm 40-55 $\times 6-9 \mu \mathrm{m}$ ( $\bar{x}=46 \times 6 \mu \mathrm{m}, \mathrm{n}=30$ ), cylindrical, curved at both ends, arising from a basal cell, reddish brown, heavily pigmented at the upper part, 7-11 distoseptate, slightly constricted at the septa, with large guttule in each cell.

Culture characters: Colonies on MEA reaching $40 \mathrm{~mm}$ diam. after 4 weeks at $25{ }^{\circ} \mathrm{C}$. Cultures from above, dark brown, dense, circular, edge entire, umbonate, papillate with white aerial mycelium, wrinkled and folded, narrow fringe of submerged mycelium; reverse dark brown, erose.

Material examined: Thailand, Chiang Rai Province, on dead stem of Clematis sikkimensis, 2 May 2017, C. Phukhamsakda \& M.V. de Bult, CMTHDT03 (MFLU 17-1495); living culture, MFLUCC 17-2087.

Hosts: Clematis sikkimensis, Pandanus sp.-(Tibpromma et al. 2018; this study).

Distribution: China, Thailand-(Tibpromma et al. 2018; this study).

GenBank accession numbers: LSU: MT214547; SSU: MT226666; ITS: MT310594; tef1: MT394729.

Notes: Dictyocheirospora xishuangbannaensis was recorded from Pandanus by Tibpromma et al. (2018) and our 

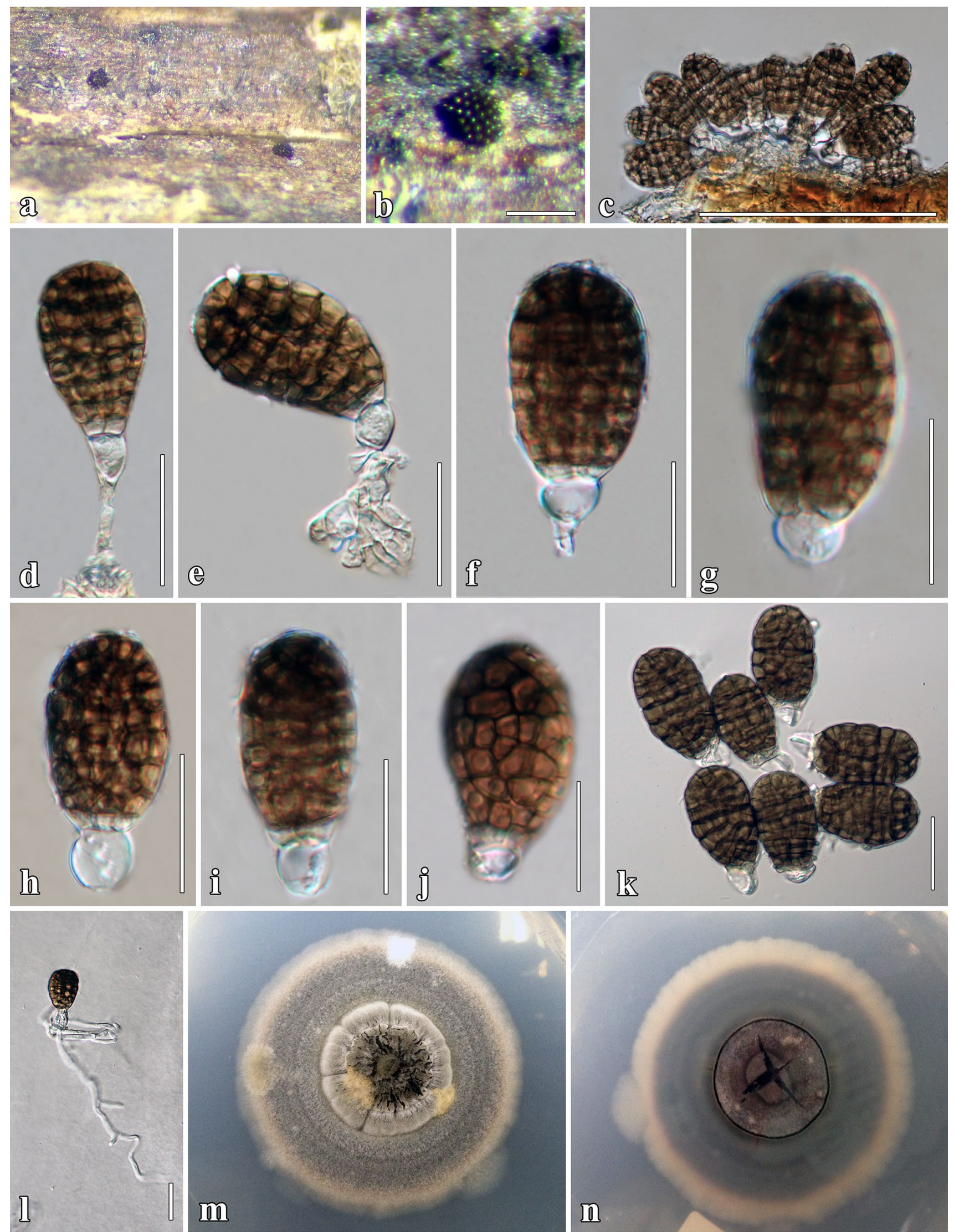
४Fig. 8 Aquadictyospora clematidis (MFLU 17-1488, holotype). a, b Sporodochia on natural substrate. c Vertical section through sporodochium. d-e Conidia attached to conidiophores. $\mathbf{f}-\mathbf{k}$ Mature conidia. $\mathbf{l}$ Germinated conidia. $\mathbf{m}, \mathbf{n}$ Culture characteristics on MEA. Scale bars: $\mathbf{b}=100 \mu \mathrm{m}, \mathbf{c}=100 \mu \mathrm{m}, \mathbf{d}-\mathbf{l}=20 \mu \mathrm{m}$

collection resembles this species morphologically (Fig. 10). The first record of D. xishuangbannaensis was from southern China (Xishuangbanna, Yunnan Province), while our collection was found in the northern part of Thailand (Chiang Rai Province). Northern Thailand and Xishuangbanna both have a tropical climate and share similar weather in both the wet and dry seasons (Cao et al. 2006). It can be hypothesized that $D$. xishuangbannaensis generally occurs in tropical climates (Boonmee et al. 2016; Tibpromma et al. 2018; Yang et al. 2018a). This is the first record of $D$. xishuangbannaensis on Clematis species. We also provide sequence data and phylogenetic analyses in Fig. 7.

\section{Pseudocoleophoma Tanaka \& K. Hiray.}

Pseudocoleophoma is characterized by its immersed to erumpent, ostiolate ascomata, cylindrical to clavate and short pedicellate asci and fusiform, 1-septate, sheathed ascospores. The genus produces coleophoma-like asexual morph with phialidic, doliiform to lageniform conidiogenous cells and cylindrical, hyaline conidia. We introduce a new species in Pseudocoleophoma based on molecular and morphology (Figs. 7, 11).

Pseudocoleophoma clematidis Phukhams. \& K.D. Hyde, sp. nov.

Index Fungorum number: IF557127; Facesoffungi number: FoF 07252, Fig. 11.

Etymology: Name refers to the host plant, Clematis from which the fungus was isolated.

Holotype: MFLU 16-0280.

Saprobic on dead stems of Clematis vitalba. Sexual morph: Undetermined. Asexual morph: Conidiomata $130-150 \times 100-130 \mu \mathrm{m}(\bar{x}=140 \times 110 \mu \mathrm{m}, \mathrm{n}=5)$, pycnidial, solitary, aggregated, uniloculate, immersed, with black shiny ostioles visible, globose to subglobose, coriaceous, subcoriaceous at the outer layers, thick-walled, black to dark brown, ostioles. Ostioles $30 \times 50 \mu \mathrm{m}$, central, papillate, ovoid. Conidiomatal wall 20-30 $\mu \mathrm{m}$ wide, of equal thickness, multilayered, outer layer composed of 8-10 layers of light brown to brown cells of textura angularis, lined with a thick hyaline layer bearing conidiogenous cells. Conidiophores reduced to conidiogenous cells. Conidiogenous cells $2-4 \times 1.5-4 \mu \mathrm{m}(\bar{x}=2.5 \times 3 \mu \mathrm{m}, \mathrm{n}=30)$, holoblastic, phialidic, determinate, discrete, cylindrical to subcylindrical, smooth-walled, hyaline, arising from inner layers of conidioma. Conidia $5-8 \times 2-4 \mu \mathrm{m}(\bar{x}=6 \times 4 \mu \mathrm{m}, \mathrm{n}=50)$, oval, slightly curved towards the ends, aseptate, with 1(-2) guttules in each cell, hyaline when immature, yellowish brown at maturity, smooth-walled.

Culture characters: Colonies on MEA reaching $20 \mathrm{~mm}$ diam. after 2 weeks at $16{ }^{\circ} \mathrm{C}$. Cultures from above, cream, dense, circular, umbonate, papillate with fluffy, covered with white aerial mycelium; reverse dark brown at the centre, cream radiating outwardly.

Material examined: Italy, Arezzo Province, Badia TegaOrtignano Raggiolo, on dead aerial branch of Clematis vitalba, 9 March 2013, E. Camporesi, IT 1110 (MFLU 16-0280, holotype); ex-type living culture, MFLUCC 17-2177.

Host: Clematis vitalba-(This study).

Distribution: Italy-(This study).

GenBank accession numbers: LSU: MT214548, MT214549; SSU: MT226667; ITS: MT310595, MT310596; tef1: MT394730.

Notes: Based on the multi-gene phylogenetic analyses (Fig. 7), Pseudocoleophoma clematidis strain MFLUCC 17-2177 (Fig. 11) clusters between P. calamagrostidis (KT 3284) and P. typhicola (MFLUCC 16-0123). Pseudocoleophoma clematidis is different from other Pseudocoleophoma species by having pycnidial walls which are flat at the base and yellowish brown conidia (Tanaka et al. 2015; Hyde et al. 2016; Jayasiri et al. 2019, Fig. 11). This study confirmed its placement in Pseudocoleophoma. In a BLASTn search of GenBank, the closest match of the LSU sequence of MFLUCC 17-2177 is P. calamagrostidis (HHUF 30450) with 97\% similarity, while the closest match of the ITS sequence is $P$. polygonicola (HHUF 27558) with $92 \%$ similarity.

Didymellaceae Gruyter, Aveskamp \& Verkley

Valenzuela-Lopez et al. (2018) accepted 26 genera in Didymellaceae. Didymellaceous taxa frequently occur as plant pathogens, causing drooping and wilting of plant leaves or gummy stem blight leading to death of the plant (Sudisha et al. 2004; Vaghefi et al. 2012; Ahmadpour et al. 2017; Wijayawardene et al. 2017). The combined dataset of LSU, ITS and $r p b 2$ sequences for a multilocus analysis tree revealed distinct lineages in Didymellaceae (Fig. 12). In the present study, a cluster of fungi associated with Clematis species formed a distinct lineage, Anthodidymella, a novel genus in Didymellaceae, a novel species in Xenodidymella, and a new host record in Neodidymelliopsis.

Anthodidymella Phukhams., Camporesi \& K.D. Hyde, gen. nov.

Index Fungorum number: IF557128; Facesoffungi number: FoF 07255, Fig. 13 

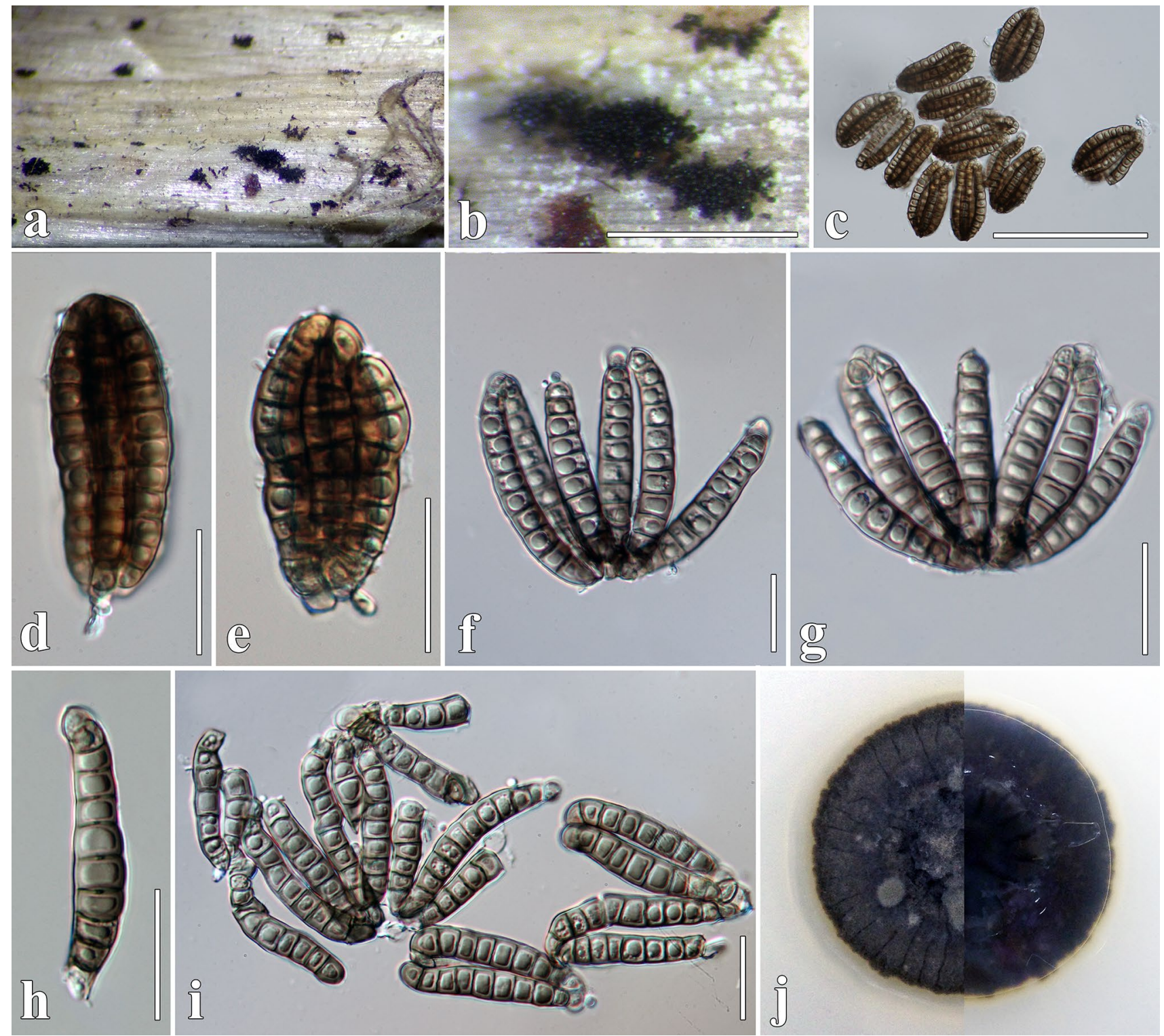

Fig. 9 Dictyocheirospora clematidis (MFLU 17-1497, holotype). a, b Sporodochia on natural substrate. c Sporodochium mounted in water. d-i Mature conidia. $\mathbf{j}$ Culture characteristics on MEA. Scale bars: $\mathbf{b}=500 \mu \mathrm{m}, \mathbf{c}=100 \mu \mathrm{m}, \mathbf{d}-\mathbf{g}=20 \mu \mathrm{m}, \mathbf{h}, \mathbf{i}=10 \mu \mathrm{m}$

Table 1 Synopsis of related Dictyocheirospora species and the new species from this study

\begin{tabular}{|c|c|c|c|}
\hline \multirow[t]{2}{*}{ Species } & \multicolumn{2}{|l|}{ Conidia } & \multirow[t]{2}{*}{ References } \\
\hline & Average size $(\mu \mathrm{m})$ & Shape & \\
\hline D. clematidis & $50 \times 23$ & $\begin{array}{l}\text { Cheiroid, acrogenous, cylindrical, cognac brown, consisting of } 6-7 \text { rows of } \\
\text { cells }\end{array}$ & This study \\
\hline D. metroxylonis & $60 \times 20$ & Cheiroid dictyospores, cylindrical, pale brown, consisting of 4-6 rows of cells & Phookamsak et al. (2019) \\
\hline D. taiwanense & $78 \times 18$ & $\begin{array}{l}\text { Cheiroid dictyospores, brown, ellipsoid to cylindrical, consisting of } 5 \text { rows of } \\
\text { cells }\end{array}$ & Hyde et al. (2019a) \\
\hline
\end{tabular}



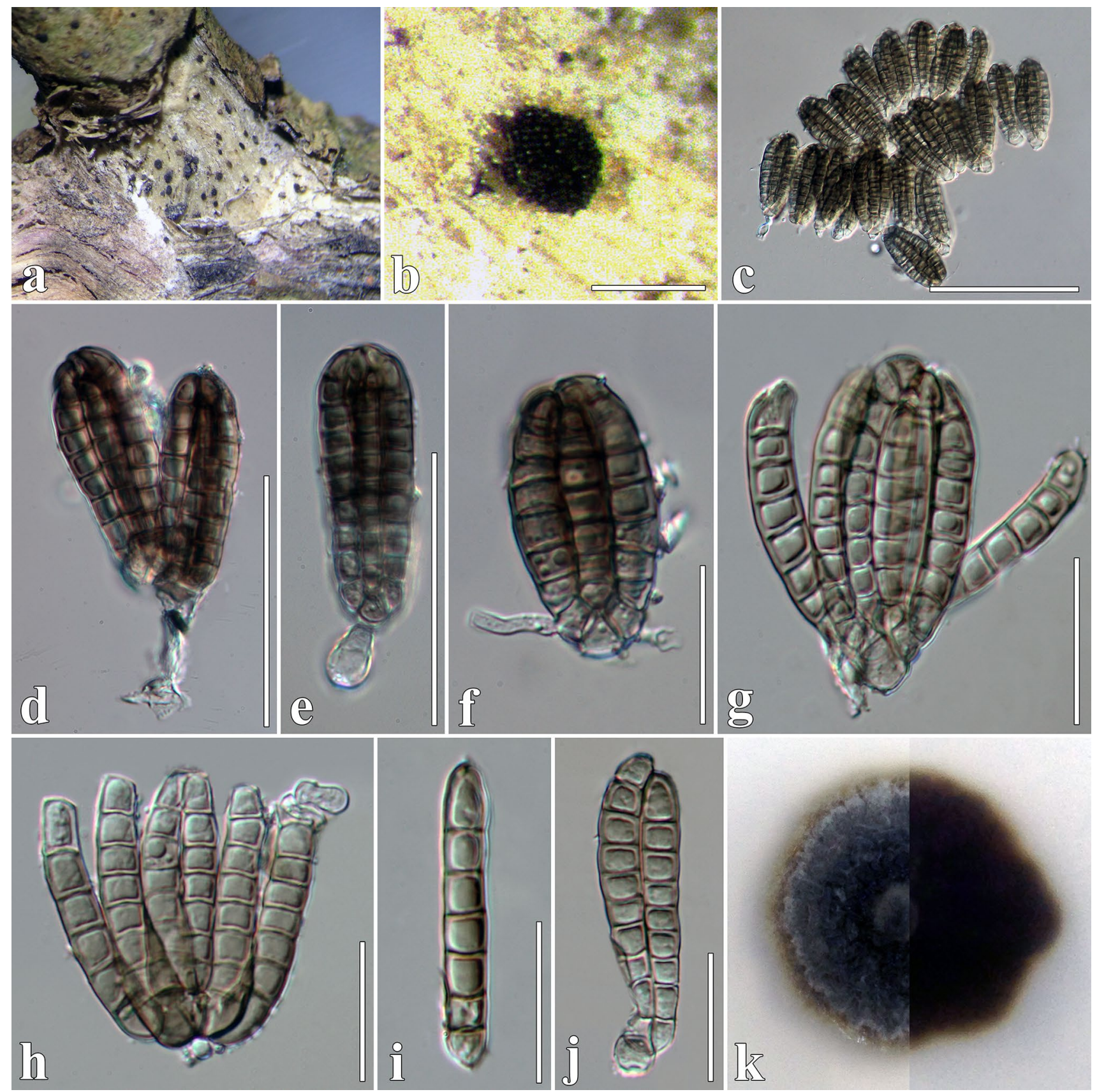

Fig. 10 Dictyocheirospora xishuangbannaensis (MFLU 17-1495). a, b Sporodochia on natural substrate. c Sporodochium mounted in water. $\mathbf{d}-\mathbf{h}$ Mature conidia. $\mathbf{i}-\mathbf{j}$ Separated rows of conidium. $\mathbf{k}$ Cul-

Etymology: Anthos-meaning flower, Anthodidymella refer to species of Didymella that frequently occur on flowering plants. ture characteristics on MEA. Scale bars: $\mathbf{b}=200 \mu \mathrm{m}, \mathbf{c}=100 \mu \mathrm{m}$, $\mathbf{d}-\mathbf{e}=50 \mu \mathrm{m}, \mathbf{f}-\mathbf{g}=20 \mu \mathrm{m} . \mathbf{h}-\mathbf{j}=10 \mu \mathrm{m}$

Saprobic or necrotic on leaf and dead stems of herbaceous plants Sexual morph: Ascomata superficial, solitary or clustered, globose or subglobose to pyriform, with elongated ostioles. Perithecial wall consisting of textura globulosa. 

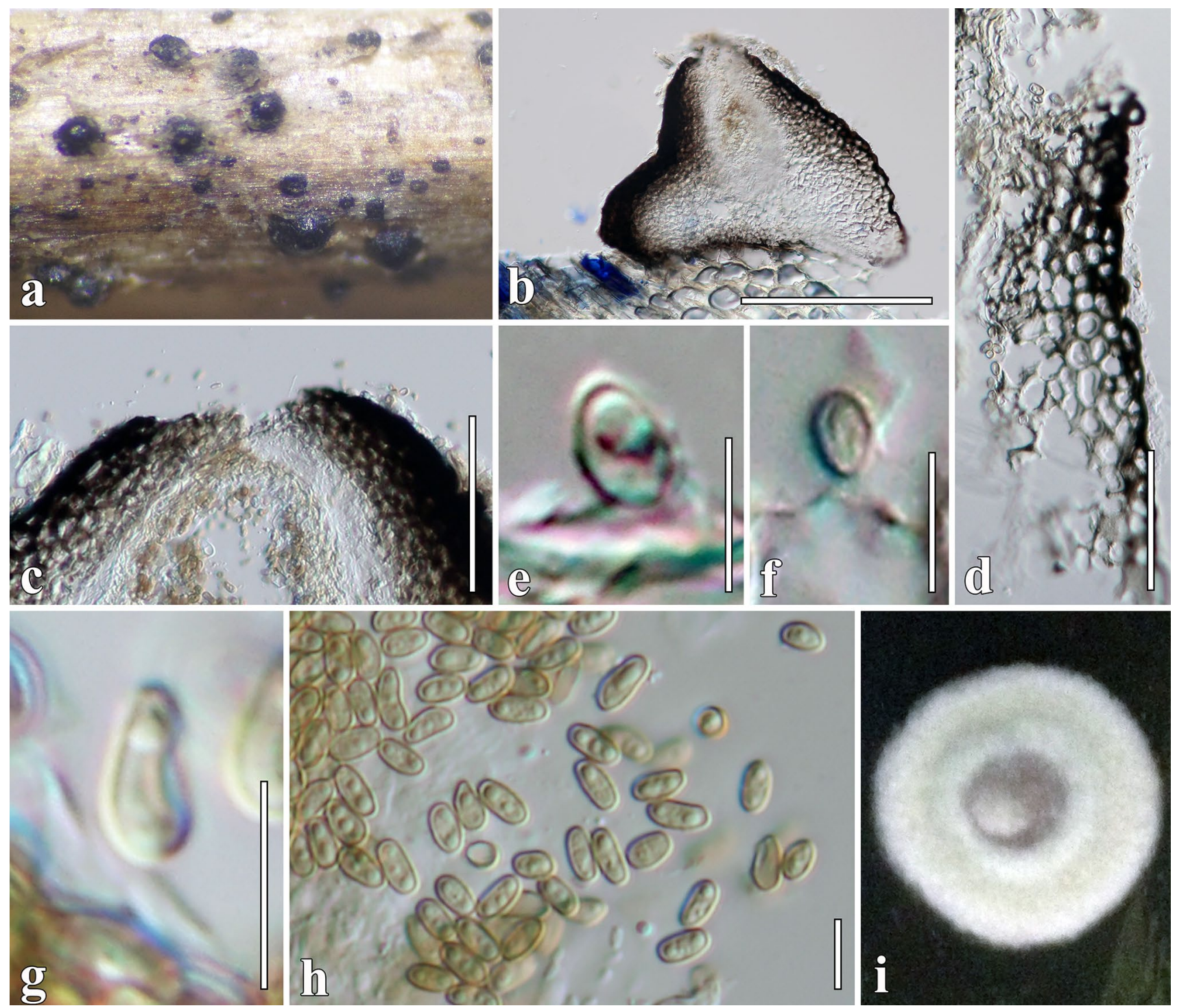

Fig. 11 Pseudocoleophoma clematidis (MFLU 16-0280, holotype). a Appearance of conidiomata on Clematis vitalba. $\mathbf{b}$ Vertical section through conidioma. c Ostiolar canal. d Section of conidioma wall.

Hamathecium composed of numerous, dense, pseudoparaphyses. Asci 8-spored, bitunicate, cylindrical club-shaped pedicel. Ascospores uniseriate or partially overlapping, ovate to obpyriform, 1-septate, hyaline (Woudenberg et al. 2009). Asexual morph: Conidiomata pycnidial, uniloculate, immersed under host epidermis, subglobose to depressed, coriaceous, thin-walled, dark brown to brown, with papillate ostioles. Conidiomatal wall thin layers, pseudoparenchymatous, with brown cells of textura globulosa, lined with a hyaline cell-layer bearing conidiogenous cells. Conidiophores reduced to conidiogenous cells. Conidiogenous cells phialidic, determinate, discrete, ampulliform, cylindrical to subcylindrical, hyaline. Conidia oblong or oval, rounded ends, e-g Conidiogenous cells and conidia. h Conidia. i Culture characteristics on MEA. Scale bars: $\mathbf{b}=200 \mu \mathrm{m}, \mathbf{c}=50 \mu \mathrm{m}, \mathbf{d}=20 \mu \mathrm{m}, \mathbf{e}-$ $\mathbf{h}=5 \mu \mathrm{m}$

hyaline, aseptate or septate, smooth-walled. Chlamydospores absent.

Type species: Anthodidymella ranunculacearum Phukhams., Camporesi \& K.D. Hyde

Notes: Anthodidymella is introduced for a strongly supported clade (93\% ML/1.00 BYPP, Fig. 12) of Didymella species unit that is associated with Clematis (Aveskamp et al. 2010). Anthodidymella clematidis was described as Phoma clematidina as it clustered with other Phoma clematidina isolates (Woudenberg et al. 2009; Golzar et al. 2011). Phoma clematidina not only causes symptoms on Clematis species, but also is a saprobe on other hosts. It has been used as a control agent of Clematis vitalba in New Zealand (Gourlay et al. 2000). An updated study classified Phoma 


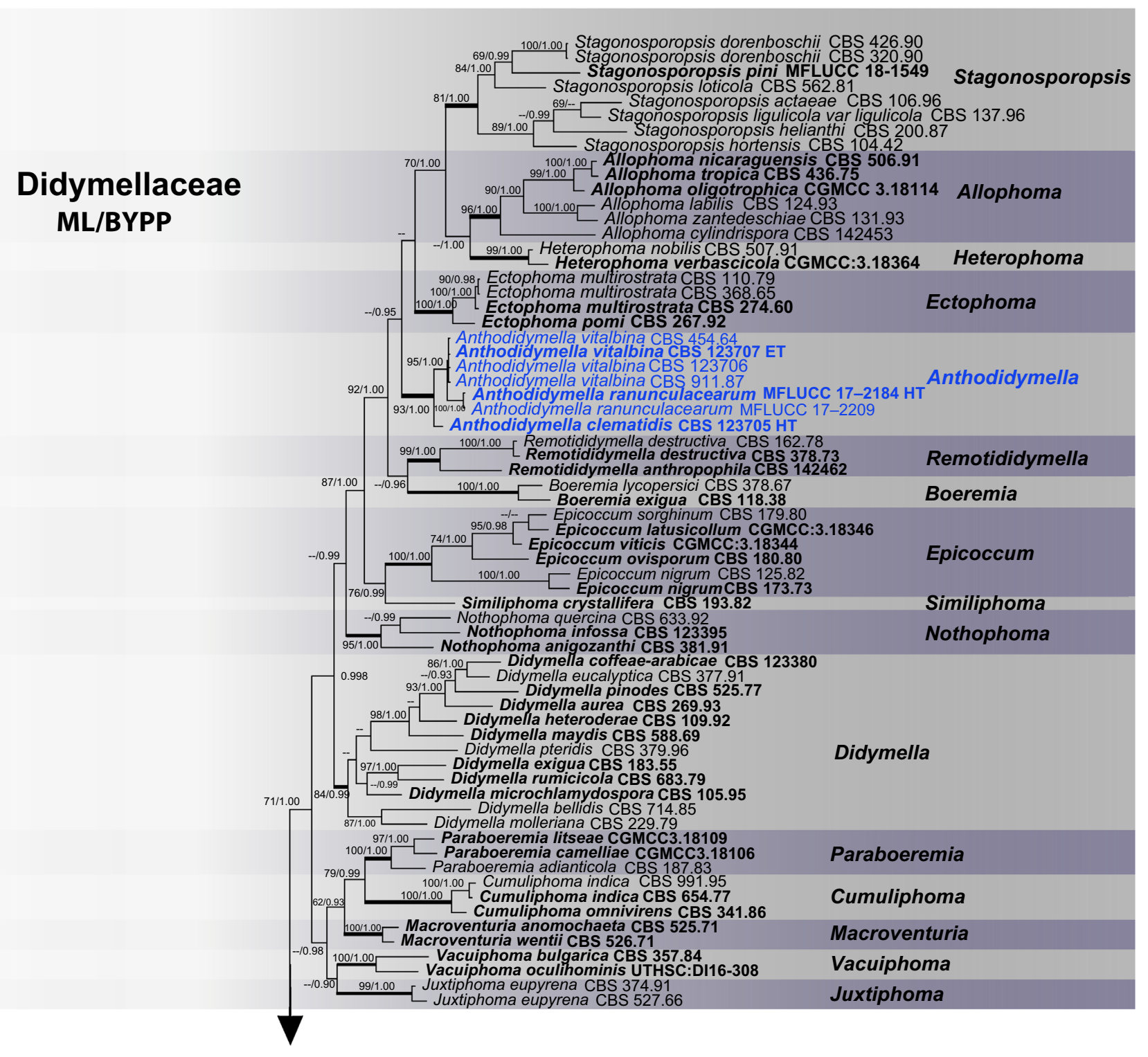

Fig. 12 Phylogram generated from maximum likelihood analysis based on combined LSU, ITS, and $r p b 2$ sequence data representing Didymellaceae species. Related sequences were taken from Chen et al. (2017) and Valenzuela-Lopez et al. (2018). One hundred and nine strains were included in the combined DNA analyses which comprised 2094 characters (964 characters for LSU, 531 characters for ITS, 599 characters for RPB2, including gap regions). Leptosphaeria conoidea (CBS 616.75) and L. doliolum (CBS 505.75) in Leptosphaeriaceae (Pleosporales) were used as out-group taxa. The topology and clade stability of the combined gene analyses was compared to the single gene analyses. The tree from the maximum likelihood analysis had similar topology to the Bayesian analyses. The best sorting RaxML tree with a final likelihood value of -18910.278845 is presented. The matrix had 602 distinct alignment patterns with $6.40 \%$ undetermined characters or gaps proportions. Estimated base frequencies were as follows: $\mathrm{A}=0.247270, \mathrm{C}=0.227052, \mathrm{G}=0.279182$, $\mathrm{T}=0.246495 ;$ substitution rates $\mathrm{AC}=2.142238, \mathrm{AG}=8.227445$, $\mathrm{AT}=2.335028, \quad \mathrm{CG}=1.021789, \quad \mathrm{CT}=16.735281, \quad \mathrm{GT}=1.000000$; gamma distribution shape parameter $\alpha=0.490873$. The GTR $+\mathrm{I}+\mathrm{G}$ model was used for each partition in Bayesian analysis. The species determined in this study are indicated in blue. Bootstrap values (BS) greater than 50\% BS (ML, left) and Bayesian posterior probabilities (BYPP, right) greater than 0.90 are given at the nodes. Hyphens (-) represent support values less than 50\% BS/0.90 BYPP. Thick branches represent significant support values from all analyses (BS $\geq 70 \% / B Y P P \geq 0.95)$ 


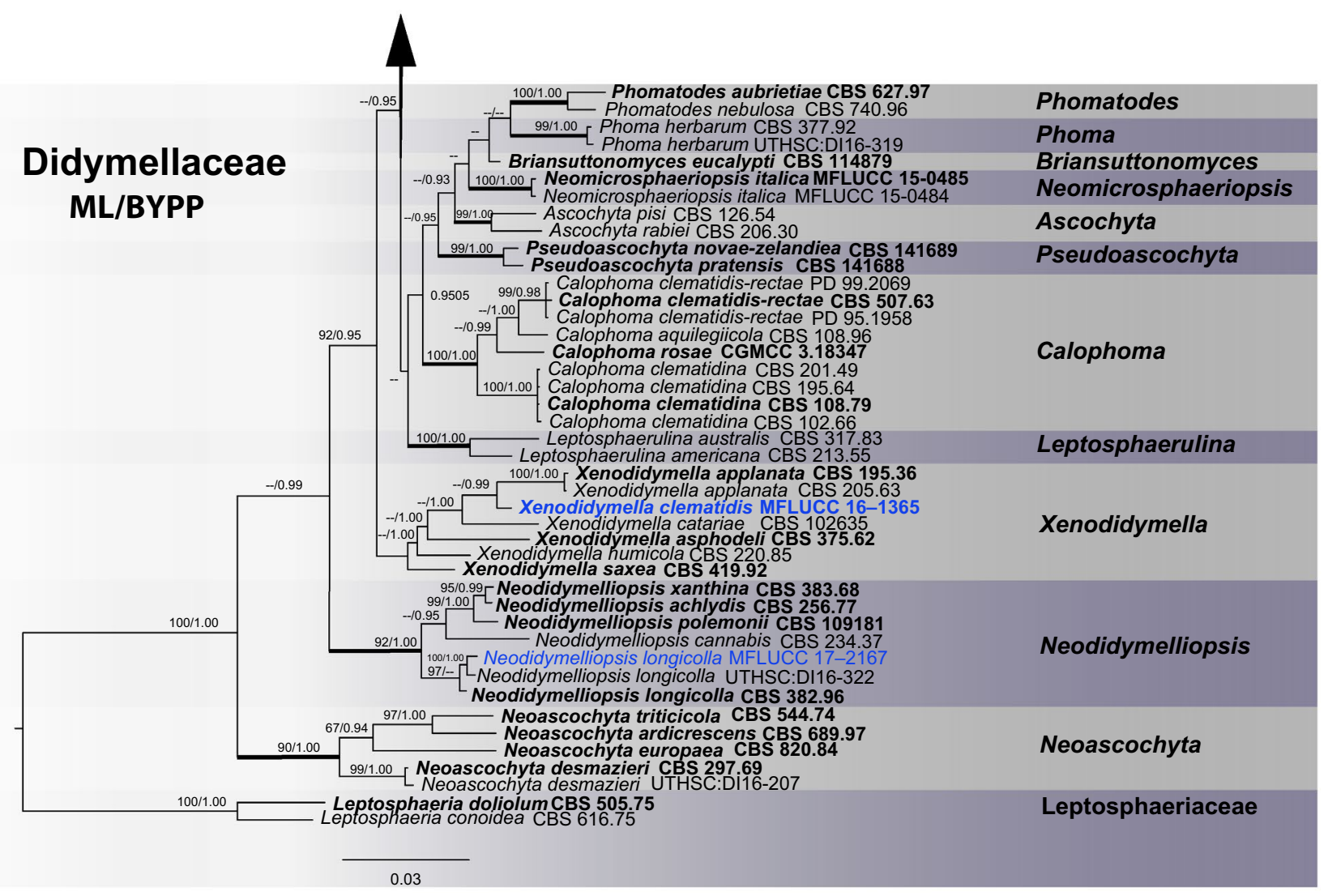

Fig. 12 (continued)

collections isolated from necrotic leaf tissues of Clematis species into Anthodidymella, Calophoma, and Phoma (Woudenberg et al. 2009; Valenzuela-Lopez et al. 2018, this study, Fig. 12).

Anthodidymella has similar morphology to Didymella in its solitary or clustered, globose ascomata, thin-walled cells of textura globulosa, with ovate to obpyriform, 1 septum, hyaline ascospores without a mucilaginous sheath. The asexual morph is pycnidial with phialidic, determinate, and discrete conidiogenous cells (Chen et al. 2017). However, Anthodidymella have broad-cylindrical asci, obpyriform ascospores while Didymella has oblong asci and broadfusiform ascospores (Woudenberg et al. 2009; Aveskamp et al. 2010). The asexual morph of Anthodidymella has globose or flask-shaped, phialidic conidiogenous cells with oblong or elongated-oval conidia. The combined dataset of the LSU, ITS, and rpb2 sequences for Didymellaceae revealed a lineage including Anthodidymella clematidis, $A$. ranunculacearum (type species) and $A$. vitalbina (Fig. 12).

Anthodidymella clematidis (Woudenb., Spiers \& Gruyter) Phukhams. \& K.D. Hyde, comb. nov.

Index Fungorum number: IF557129; Facesoffungi number: FoF 07256

Basionym: Didymella clematidis Woudenb., Spiers \& Gruyter in Woudenberg et al., Persoonia 22:60 (2009)

Synonym: Phoma clematidina (Thüm.) Boerema, Versl. Medsd. Plziektenk. Dienst Wageningen 153:17 (1979)

Notes: Since the fungus has been introduced before one fungus $=$ one name $($ Taylor 2011), the isolate CBS 123705 bears two names for its pleomorphic life-cycles The strain was originally described as Phoma clematidina from a 

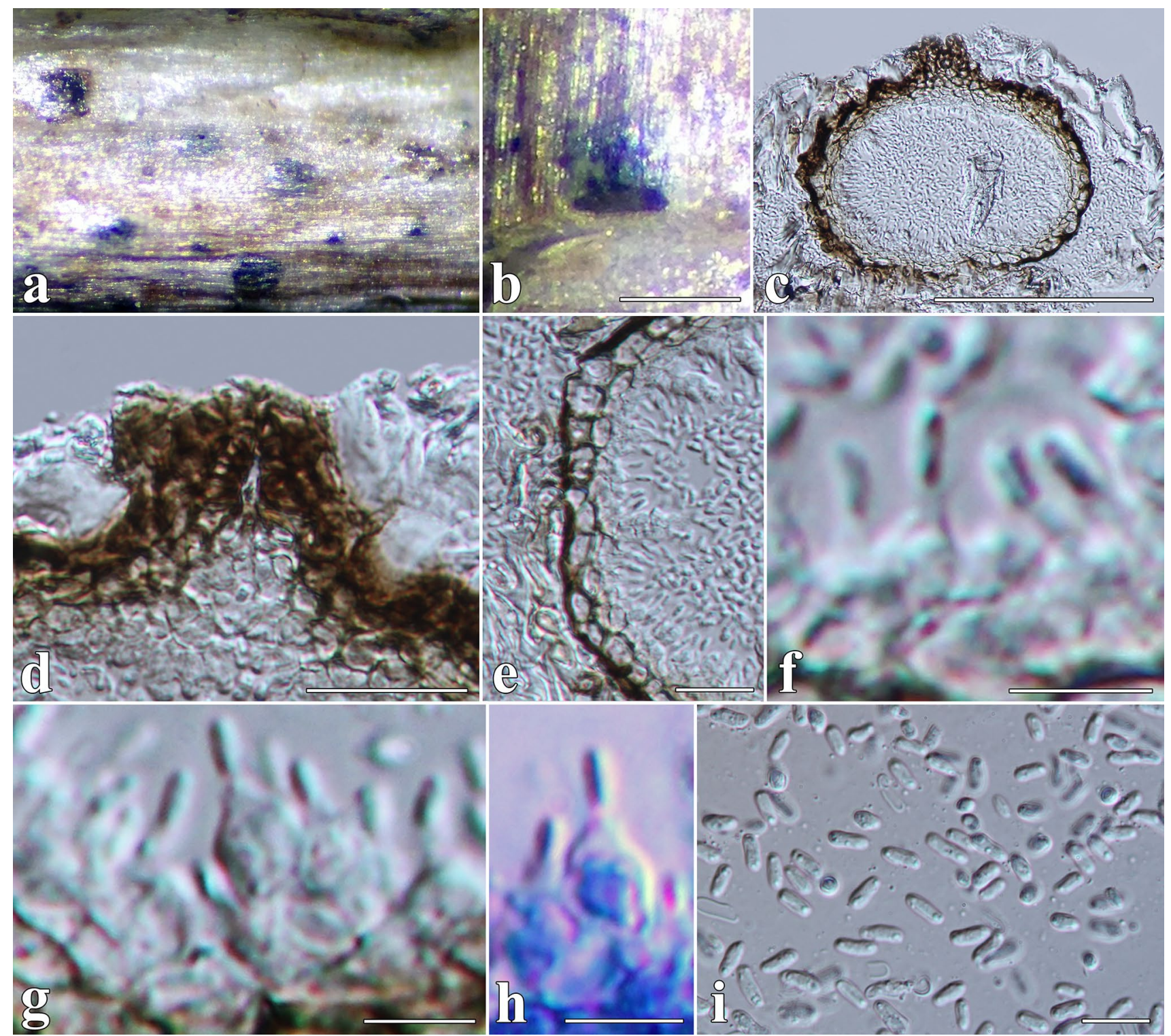

Fig. 13 Anthodidymella ranunculacearum (MFLU 17-1468, holotype). a Appearance of conidiomata on Clematis vitalba. b Close up of conidioma on host substrate. $\mathbf{c}$ Vertical section through conidioma. d Ostiolar canal. e Section of partial conidioma wall. $\mathbf{f}-\mathbf{h}$ Con-

necrotic leaf spot of Clematis ligusticifolia and developed both sexual morph and asexual morph characters in pure culture (Woudenberg et al. 2009). Anthodidymella clematidis was initially described as Didymella clematidis for its sexual morph epithet (=Phoma clematidina as asexual name) as it clustered with other Phoma clematidina isolates (Woudenberg et al. 2009; Golzar et al. 2011). The new combination, Anthodidymella clematidis is proposed for Didymella clematidis (CBS 123705).

Host: Clematis ligusticifolia-(Woudenberg et al. 2009).

Distribution: USA-(Woudenberg et al. 2009). idiogenous cells and conidia (h conidiogenous cells in cotton blue). $\mathbf{i}$ Conidia. Scale bars: $\mathbf{b}=200 \mu \mathrm{m}, \mathbf{c}=100 \mu \mathrm{m}, \mathbf{d}=20 \mu \mathrm{m}, \mathbf{e}=10 \mu \mathrm{m}$, $\mathbf{f}-\mathbf{i}=5 \mu \mathrm{m}$

Anthodidymella ranunculacearum Phukhams., Camporesi \& K.D. Hyde, sp. nov.

Index Fungorum number: IF557130; Facesoffungi number: FoF 07257, Fig. 13.

Etymology: The specific epithet reflects the host family, Ranunculaceae.

Holotype: MFLU 17-1468.

Saprobic on dead stems of Clematis vitalba. Sexual morph: Undetermined. Asexual morph: Conidiomata 99-214×130-246 $\mu \mathrm{m}(\bar{x}=142 \times 169 \mu \mathrm{m}, \mathrm{n}=5)$, pycnidial, solitary, sometimes aggregated, uniloculate, immersed under epidermal layer, subglobose to depressed, coriaceous, 
thin-walled, brown to dark brown, with ostiolate. Ostioles $25 \times 42 \mu \mathrm{m}$, central, papillate, with pore. Conidiomatal wall 10-28(-36) $\mu \mathrm{m}$ wide, of 2-5 layers, each cell-layer $10 \mu \mathrm{m}$ wide, light brown to brown cells of textura globulosa, heavily pigmented in the outer layers, lined with a hyaline innermost layer bearing conidiogenous cells. Conidiophores reduced to conidiogenous cells. Conidiogenous cells $2.5-5 \times 1.5-3.5 \mu \mathrm{m}(\bar{x}=3.5 \times 2 \mu \mathrm{m}, \mathrm{n}=30)$, phialidic, determinate, discrete, ampulliform, cylindrical to sub-cylindrical, smooth-walled, hyaline, arising from the inner layer of conidioma. Conidia $6-10 \times 2-5 \mu \mathrm{m}(\bar{x}=6 \times 4 \mu \mathrm{m}, \mathrm{n}=50)$, oblong or oval, slightly curved toward the ends, rounded ends, with 1(-2) guttules in each cell, hyaline, aseptate, smooth-walled.

Culture characters: Colonies on MEA reaching $20 \mathrm{~mm}$ diam. after 2 weeks at $25{ }^{\circ} \mathrm{C}$. Cultures; above: greyish brown or dark green, dense, circular, umbonate, papillate, fluffy, covered with aerial mycelium, reverse dark brown.

Material examined: Italy, Forlì-Cesena Province, Valdinoce-Meldola, on dead aerial branch of Clematis vitalba, 3 February 2015, E. Camporesi, IT 2364 (MFLU 17-1536, holotype); ex-type living culture, MFLUCC 17-2184= MFLUCC 17-2209.

Host: Clematis vitalba-(This study).

Distribution: Italy—(This study).

GenBank accession numbers: MFLUCC 17-2184; LSU: MT214550; SSU: MT226668; ITS: MT310597; tef1: MT394731; rpb2: MT394681; act: MT394620. MFLUCC 17-2209; LSU: MT214551; SSU: MT226669; ITS: MT310598; tef1: MT394732; act: MT394621.

Notes: Anthodidymella ranunculacearum (MFLUCC 17-2184) is similar to A. vitalbina (CBS 123707, ex-epitype), a strain recorded from the same host (Woudenberg et al. 2009). However, A. ranunculacearum differs from A. vitalbina in its thicker conidiomatal wall (10-36 vs 5.5-9.5 $\mu \mathrm{m}$, Fig. 13). In a BLASTn search of GenBank, the ITS sequence had $99.5 \%$ similarity $(2.25 \%$ nucleotide differences), while the act sequence had $91 \%$ similarity (77 nucleotide differences in 297 nucleotides). Thus, the new strain is introduced as a new species of Anthodidymella based on guidelines of Jeewon and Hyde (2016). Additionally, A. ranunculacearum is designated as the type species of Anthodidymella based on available material and an ex-type culture.

Anthodidymella vitalbina (Petr.) Phukhams. \& K.D. Hyde, comb. nov.

Index Fungorum number: IF557131; Facesoffungi number: FoF 07258.

Basionym: Ascochyta vitalbae Briard \& Har. apud Briard, Rev. Mycol. (Toulouse) 13: 17. (1891).

三Diplodina vitalbae (Briard \& Har.) Allesch., Rabenh. Krypt.-Fl., ed. 2. Pilze 6 (Lief. 69): 683. 1900 (1901).
Synonym: Diplodina clematidina Fautrey \& Roum. apud Roum., Rev. Mycol. (Toulouse) 14: 105 (1892).

= Didymella vitalbina Petr, Annls mycol. 38(2/4): 348 (1940).

= Phoma clematidina (Thüm.) Boerema, Versl. Medsd. Plziektenk. Dienst Wageningen, 1978 153: 17 (1979).

Notes: Anthodidymella vitalbina was introduced for Didymella vitalbina (= Phoma clematidina as asexual name) which was reported from a necrotic leaf spot of Clematis species (Woudenberg et al. 2009). Phoma clematidina (strain CBS 123707) was isolated from Clematis vitalba and developed sexual and asexual morphs in culture. The sexual morph is named as Didymella vitalbina Petr. and was chosen as an epitype of $D$. vitalbina by Woudenberg et al. (2009). In the analyses of combined LSU, ITS, and $r p b 2$ sequence data of Didymellaceae, the ex-epitype strain (CBS 123707) and the related strains clustered with Anthodidymella clematidis. Therefore, we transfer Didymella vitalbina (= Phoma clematidina) to Anthodidymella vitalbina based on phylogenetic relationship of compatible morphology of both morphs. The nomenclature changes are also based on one fungus $=$ one name protocol.

Host: Clematis vitalba-(Woudenberg et al. 2009).

Distribution: Austria, France, Switzerland-(Woudenberg et al. 2009).

\section{Neodidymelliopsis Qian \& L. Cai}

Neodidymelliopsis was introduced for one section of phoma-like species that reside within Didymellaceae and is typified by N. cannabis (Chen et al. 2017). The genus is characterized by immersed or erumpent subglobose to pyriform, ostiolate ascomata, cylindrical to clavate asci and subovoid to ellipsoidal, hyaline, septate ascospores. The asexual morph is phoma-like with pycnidial conidiomata, a 2-7-layered pseudoparenchymatous pycnidial wall, phialidic conidiogenous cells, and aseptate or occasionally 1-septate conidia (Chen et al. 2015, 2017). We introduce a new host record of $N$. longicolla from Clematis vitalba in Italy (Fig. 14).

Neodidymelliopsis longicolla Hou, Crous \& L. Cai, Stud. Mycol. 87: 153 (2017), new host record

Index Fungorum number: IF820006; Facesoffungi number: FoF 07259, Fig. 14.

Saprobic on dead stems of Clematis vitalba. Sexual morph: Undetermined. Asexual morph: Conidiomata 70-95 $\times 124-134 \mu \mathrm{m}(\bar{x}=84 \times 130 \mu \mathrm{m}, \mathrm{n}=5)$, pycnidial, aggregated, uniloculate, superficial or covered by host epidermal layer, subglobose to depressed, cupulate when dried coriaceous, thick-walled, light brown to brown, with papillate ostioles. Ostioles $80 \times 38 \mu \mathrm{m}$, central, papillate, opening by a pore. Conidiomatal wall 10-17(-27) $\mu \mathrm{m}$ wide, composed of 5-7 layers of light brown to brown cells of 
textura angularis, heavily pigmented at the outer layers, lined with a hyaline layer bearing conidiogenous cells. Conidiophores reduced to conidiogenous cells. Conidiogenous cells $2.5-7 \times 2-4.5 \mu \mathrm{m}(\bar{x}=4.5 \times 3.5 \mu \mathrm{m}, \mathrm{n}=30)$, phialidic, annellidic, determinate, discrete, ampulliform, cylindrical to sub-cylindrical, smooth-walled, hyaline, arising from the inner layers of conidiomata. Conidia $6.5-10 \times 2-4.5 \mu \mathrm{m}$ $(\bar{x}=8 \times 4 \mu \mathrm{m}, \mathrm{n}=50)$, oblong-elliptical, oval, slightly curved towards the ends, rounded ends, with 1(-2) guttules in each cell, initially aseptate and hyaline, becoming pale brown and 1-septate at maturity, constricted at the septum, wall verrucose.

Culture characters: Colonies on MEA reaching $20 \mathrm{~mm}$ diam. after 2 weeks at $25{ }^{\circ} \mathrm{C}$. Cultures from above, cream with white at the centre, medium dense, circular, umbonate, papillate, fluffy, covered with white aerial mycelium; reverse brown white cream at the edge.

Material examined: Italy, Forlì-Cesena Province, Castrocaro Terme, on dead aerial branch of Clematis vitalba, 19
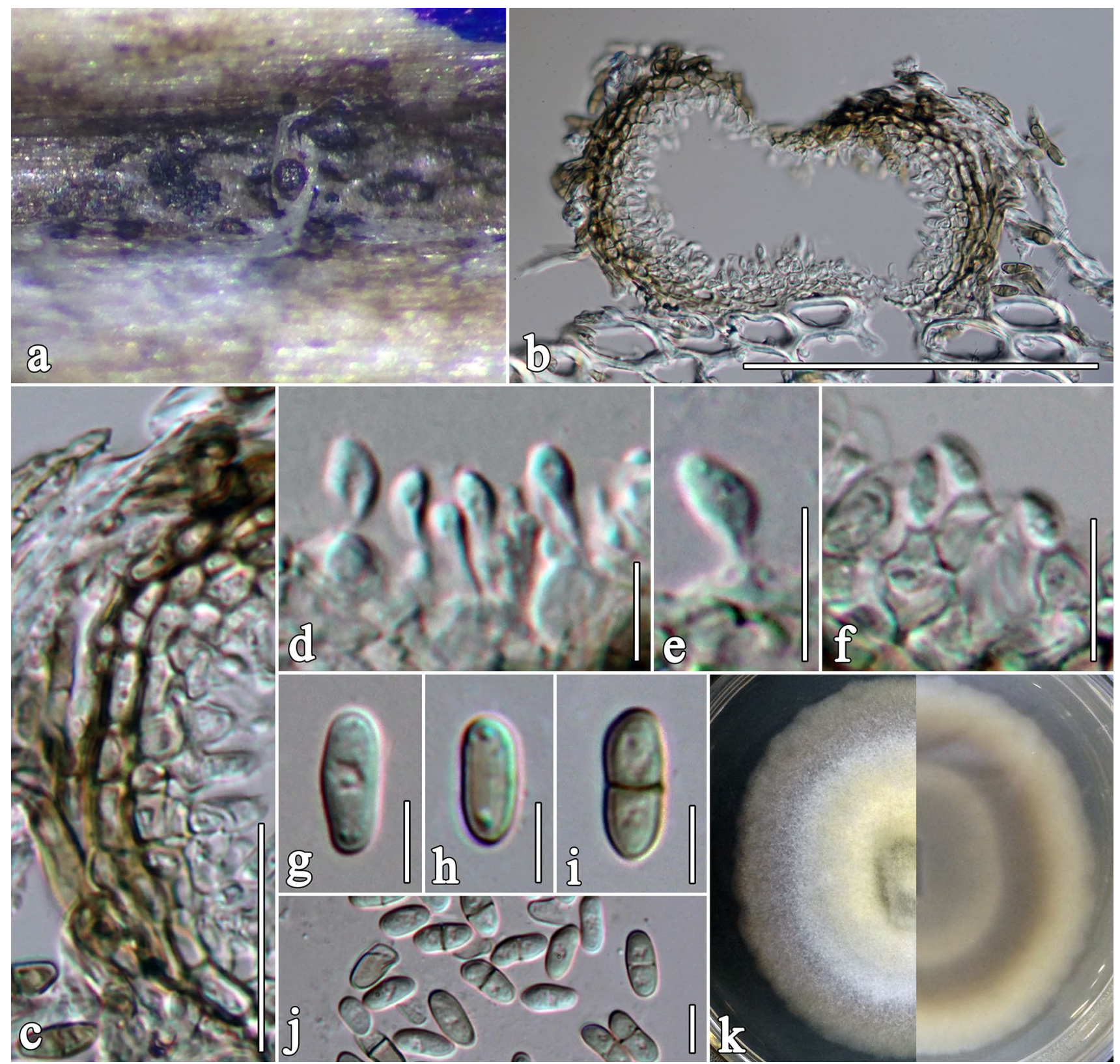

Fig. 14 Neodidymelliopsis longicolla (MFLU 20-0421). a Appearance of conidiomata on Clematis vitalba. b Vertical section through conidioma. $\mathbf{c}$ Section of conidioma wall. $\mathbf{d}-\mathbf{f}$ Conidiogenous cells and conidia. g-j Conidia. $\mathbf{k}$ Culture characteristics on MEA. Scale bars: $\mathbf{b}=100 \mu \mathrm{m}, \mathbf{c}=20 \mu \mathrm{m}, \mathbf{d}-\mathbf{f}=10 \mu \mathrm{m}, \mathbf{g}-\mathbf{j}=10 \mu \mathrm{m}$ 
September 2012, E. Camporesi, IT739 (MFLU 20-0421); living culture, MFLUCC 17-2167.

Hosts: Soil in desert, Clematis vitalba-(Chen et al. 2017; this study).

Distribution: Israel, Italy_(Chen et al. 2017; this study).

GenBank accession numbers: LSU: MT214552; SSU: MT226670; ITS: MT310599; tef1: MT394733; rpb2: MT394682.

Notes: A new isolate of Neodidymelliopsis longicolla (MFLUCC 17-2167) was collected from Clematis vitalba in Italy. The new isolate formed a close relationship with the type (100\% ML/1.00 BYPP). Neodidymelliopsis longicolla (CBS 382.96) was originally reported from a soil sample in Israel. The characters of the type strain were obtained from a culture on OA medium. The new collection differs slightly from the type material in having a shorter ostioles (Fig. 14).

\section{Xenodidymella Chen \& L. Cai}

Xenodidymella typified by X. applanata ( $\equiv$ Didymosphaeria applanata) has Phoma argillacea as the asexual morph (Corlett 1981; Gruyter et al. 2013; Chen et al. 2015). Xenodidymella is distinct from other genera in Didymellaceae in having a thick peridium and ellipsoidal, allantoid or subcylindrical, unicellular conidia. Xenodidymella is reported from Europe and USA and consists of five species (Farr and Rossman 2020; Index Fungorum 2020). We introduce a novel species of Xenodidymella clematidis from Clematis vitalba in Italy and provide phylogenetic and morphological comparisons (Figs. 12, 15).

Xenodidymella clematidis Phukhams., Camporesi \& K.D. Hyde, sp. nov.

Index Fungorum number: IF557132; Facesoffungi number: FoF 07260, Fig. 15.

Etymology: Refers to the host genus Clematis.

Holotype: MFLU 16-2288.

Saprobic on dead stems of Clematis vitalba. Sexual morph: Undetermined. Asexual morph: Conidiomata 220-375 $\times 180-290 \mu \mathrm{m}(\bar{x}=280 \times 230 \mu \mathrm{m}, \mathrm{n}=5)$, pycnidial, aggregated, uniloculate, superficial or semi-immersed, subglobose to depressed globose, cupulate, when dried coriaceous, thick-walled, brown to light brown, with ostioles. Ostioles central, papillate, opened-like pore. Conidiomatal wall $10-15(-25 \mu \mathrm{m}$ at apex) wide, composed of 7-9 layers of light brown to brown cells of textura angularis, heavily pigmented at the outer layers, lined with a hyaline layer bearing conidiogenous cells. Conidiophores reduced to conidiogenous cells. Conidiogenous cells $2-6(-12) \times 2.3-3.3 \mu \mathrm{m}$ $(\bar{x}=5 \times 3 \mu \mathrm{m}, \mathrm{n}=20)$, enteroblastic, phialidic, determinate, discrete, ampulliform, smooth-walled, hyaline, arising from the inner layers of conidiomata. Conidia $4-8 \times 2-5 \mu \mathrm{m}$ $(\bar{x}=6 \times 3.5 \mu \mathrm{m}, \mathrm{n}=50)$, oblong-elliptical, oval, slightly curved towards the ends, rounded ends, hyaline, with 1(-2) guttules in each cell, aseptate, verrucose.

Culture characters: Colonies on MEA reaching $20 \mathrm{~mm}$ diam. after 2 weeks at $16^{\circ} \mathrm{C}$. Cultures from above, grey with white aerial mycelium, dense, circular, umbonate, papillate, fluffy, reverse brownish white, cream at the edge.

Material examined: Italy, Forlì-Cesena Province, Monte Fumaiolo, dead aerial branch of Clematis vitalba, 6 August 2016, E. Camporesi, IT3054 (MFLU 16-2288, holotype); ex-type living culture, MFLUCC 16-1365.

Host: Clematis vitalba-(This study).

Distribution: Italy-(This study).

GenBank accession numbers: LSU: MT214553; ITS: MT310600; act: МT394622.

Notes: In the phylogenetic analysis, Xenodidymella clematidis clustered with $X$. applanata with strong support (1.00 in BYPP). Xenodidymella clematidis has a long ostiole, with oblong-elliptical or oval conidia, while $X$. applanata has a short ostiole and ellipsoidal conidia (Gruyter et al. 2002; Chen et al. 2015). Xenodidymella applanata is commonly a pathogen of raspberry (Rubus sp.). Xenodidymella clematidis was a saprobe on Clematis vitalba (Fig. 15). In a BLASTn search of GenBank, the ITS sequence had 98\% similarity (11 nucleotides differences out of 488 nucleotides). The new strain is introduced as a new species of Xenodidymella herein.

\section{Didymosphaeriaceae Munk}

The latest treatment of Didymosphaeriaceae was by Ariyawansa et al. (2014a). The family is typified with Didymosphaeria. Several genera have been introduced to the family based on morphological and phylogenetic evidence (Tibpromma et al. 2018; Wanasinghe et al. 2018; Wijayawardene et al. 2018). Mapook et al. (2020) introduced Chromolaenicola Mapook \& K.D. Hyde into Didymosphaeriaceae. Phylogeny and morphological comparisons revealed a novel species of Chromolaenicola and a new host record of Didymosphaeria rubi-ulmifolii from Clematis (Fig. 16).

\section{Chromolaenicola Mapook \& K.D. Hyde}

Mapook et al. (2020) introduced Chromolaenicola (typified with $C$. nanensis) for a monophyletic clade of fungi described on Chromolaena odorata. Chromolaenicola is characterized by immersed to semi-immersed and coriaceous ascomata, cylindrical asci, and uniseriate, ellipsoid, muriform ascospores (Mapook et al. 2020). The asexual morph is pycnidial, with enteroblastic, phialidic conidiogenous cells, and oblong or oval to ellipsoid, globose to subglobose conidia (Jayasiri et al. 2019; Mapook et al. 2020). We introduce a new species Chromolaenicola clematidis based on morphological comparison (Fig. 17) and phylogenetic analyses (Fig. 16). 


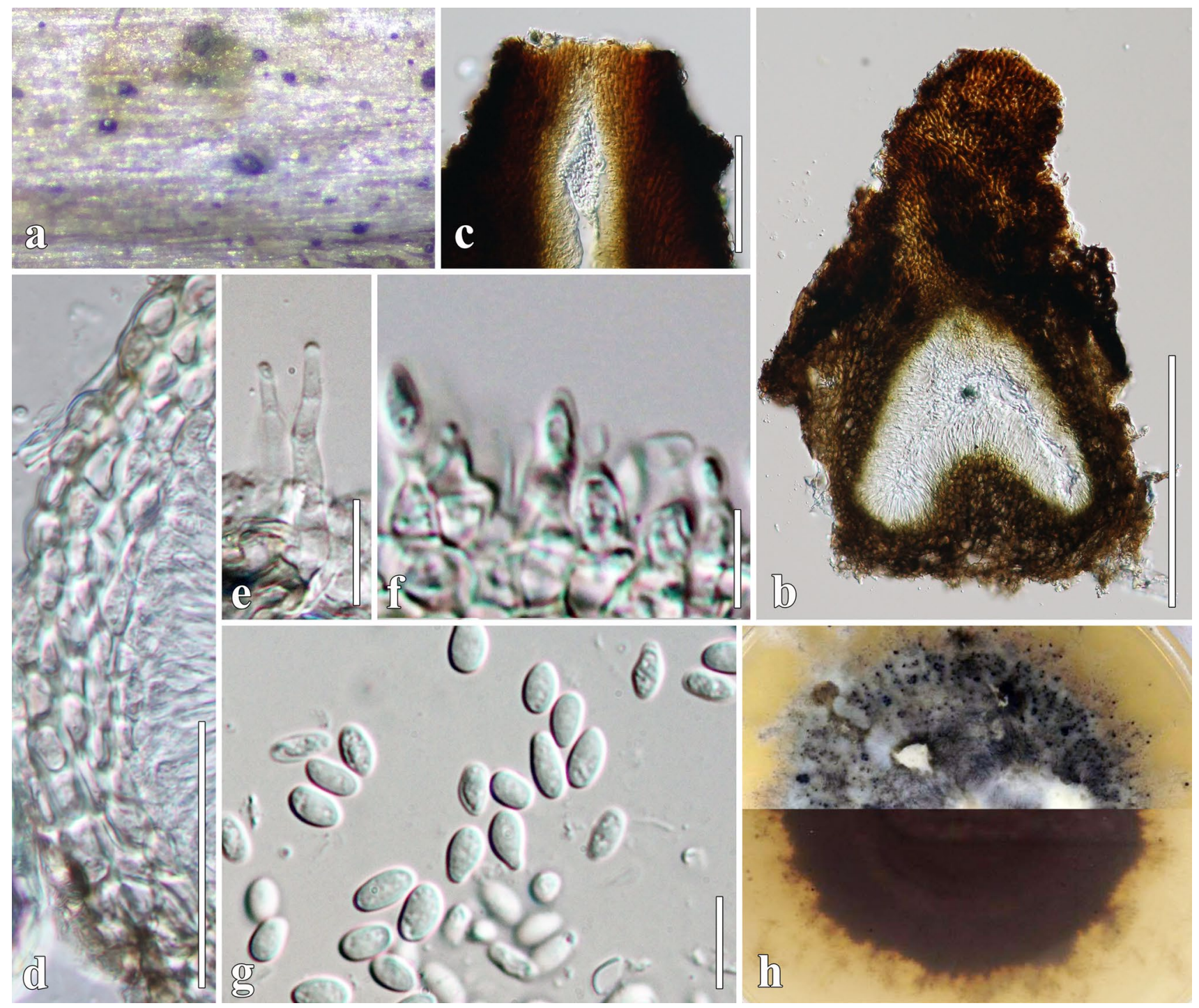

Fig. 15 Xenodidymella clematidis (MFLU 16-2288, holotype). a Appearance of conidiomata on Clematis vitalba. b Vertical section through conidioma. c Ostiolar canal. d Section of conidioma wall. e,

Chromolaenicola clematidis Phukhams. \& K.D. Hyde, sp. nov.

Index Fungorum number: IF557133; Facesoffungi number: FoF 07253, Fig. 17.

Etymology: Named after the host genus, Clematis.

Holotype: MFLU 17-1483.

Saprobic on dead stem of Clematis subumbellata. Sexual morph: Undetermined. Asexual morph: Conidiomata 76-145 ×107-128 $\mu \mathrm{m}(\bar{x}=121 \times 117 \mu \mathrm{m}, \mathrm{n}=10)$, pycnidial, solitary, uniloculate, immersed, globose, coriaceous, thin, brown to light brown, ostiolate. Conidiomatal wall 5-10 $\mu \mathrm{m}$ wide, uniform, wider at apex, composed of 3-5 layers of pale brown to bronze cells of textura angularis, lined with a thin, hyaline layer bearing conidiogenous cells. Conidiophores reduced to conidiogenous cells. Conidiogenous cells f Conidiogenous cells and conidia. $\mathbf{g}$ Conidia. $\mathbf{h}$ Culture characters on MEA. Scale bars: $\mathbf{b}=200 \mu \mathrm{m}, \mathbf{c}, \mathbf{d}=50 \mu \mathrm{m}, \mathbf{e}-\mathbf{g}=10 \mu \mathrm{m}$

2.6-4.5 $\times 4-7 \mu \mathrm{m}(\bar{x}=3.5 \times 5 \mu \mathrm{m}, \mathrm{n}=20)$, enteroblastic, phialidic, determinate, discrete, truncate, hyaline, smooth, arising from the inner layer of pycnidial wall. Conidia $7-10 \times 4.5-7 \mu \mathrm{m}(\bar{x}=8.5 \times 6 \mu \mathrm{m}, \mathrm{n}=50)$, broad oblong or oval, rounded ends, hyaline when immature, reddish brown at maturity, 1-septate, with guttule in each cell, roughwalled, verrucose.

Cultural characters: Colonies on MEA reaching $30 \mathrm{~mm}$ diam. after 4 weeks at $25^{\circ} \mathrm{C}$. Cultures from above, dark brown, radiating outwardly, dense, umbonate, undulate edge, umbonate, papillate, fluffy, covered with white aerial mycelium; reverse dark brown, undulate.

Material examined: Thailand, Chiang Rai Province, Mae Sai District, dead stems of Clematis subumbellata, 20 March 


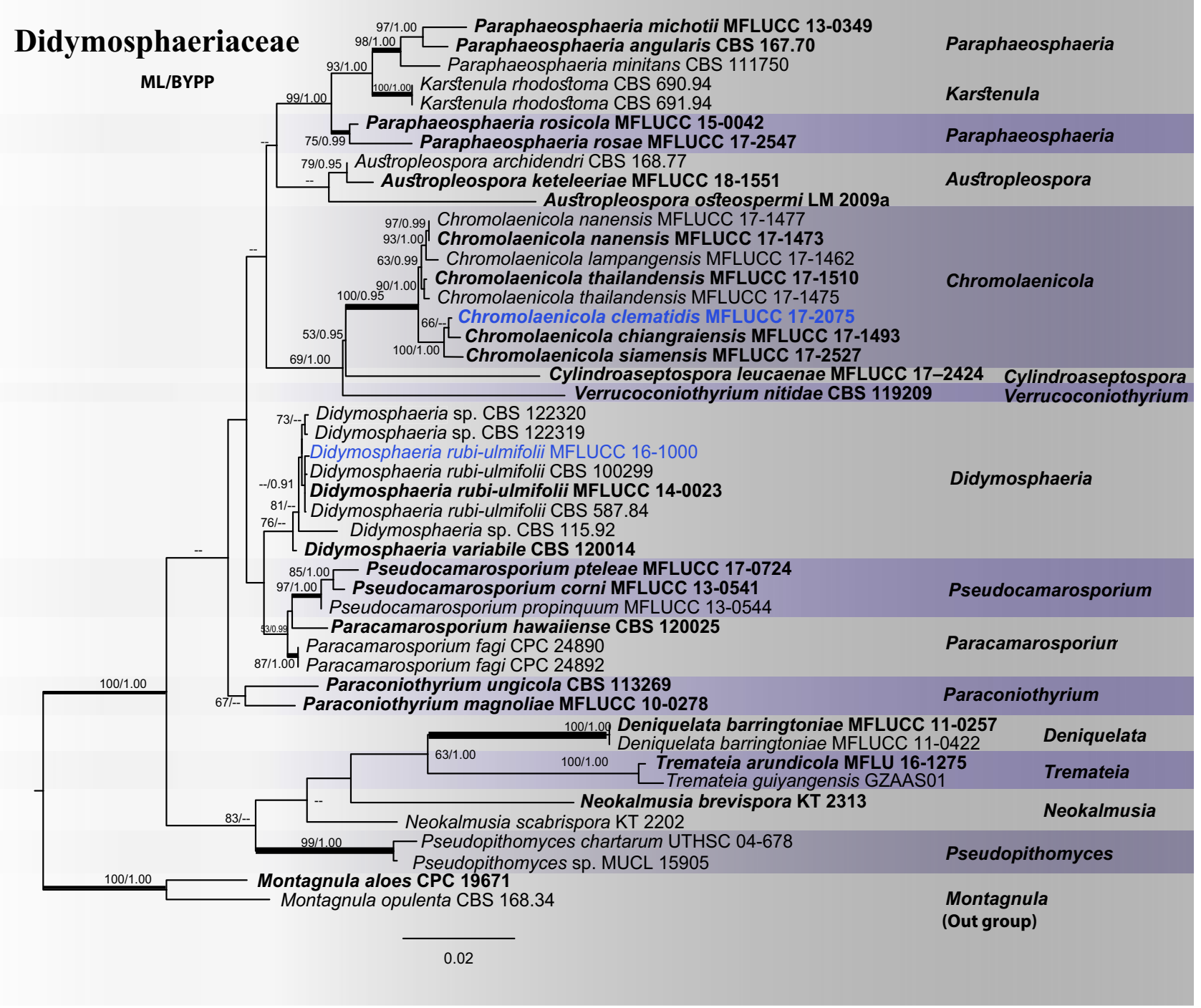

Fig. 16 The best scoring RAxML tree with a final likelihood value of - 12878.030199 based on combined LSU, ITS, SSU, rpb2 and tub sequence data of Didymosphaeriaceae. The tree is rooted with sequences of Montagnula species. Forty-six strains were included in the combined DNA sequence analyses which comprised 3681 characters (860 characters for LSU, 516 characters for ITS, 913 characters for SSU, 935 characters for $r p b 2,457$ characters for $t u b$, including gap regions). The topology and clade stability of the combined gene analyses was compared to the single gene analyses. The tree from the maximum likelihood analysis had similar topology to the Bayesian analyses. The matrix had 764 distinct alignment patterns, with $9.02 \%$ undetermined characters or gaps propotions. Estimated base frequen-

2017, C. Phukhamsakda, CMTH19 (MFLU 17-1483, holotype); ex-type living culture, MFLUCC 17-2075.

Host: Clematis subumbellata-(This study).

Distribution: Thailand-(This study).

GenBank accession numbers: LSU: MT214554; SSU: MT226671; ITS: MT310601; rpb2: MT394683. cies were as follows: $\mathrm{A}=0.239562, \mathrm{C}=0.247759, \mathrm{G}=0.271470$, $\mathrm{T}=0.241209 ;$ substitution rates $\mathrm{AC}=1.719408, \mathrm{AG}=2.576378$, $\mathrm{AT}=1.444379, \quad \mathrm{CG}=0.958169, \quad \mathrm{CT}=9.083623, \quad \mathrm{GT}=1.000000$; gamma distribution shape parameter $\alpha=0.621443$. In our analysis, GTR + I + G model was used for each partition in Bayesian posterior analysis. The species determined in this study are indicated in blue. Bootstrap values (BS) greater than 50\% BS (ML, left) and Bayesian posterior probabilities (BYPP, right) greater than 0.90 are given at the nodes. Hyphens (-) represent support values less than 50\% BS/0.90 BYPP. Thick branches represent significant support values from all analyses at the genus level (BS $\geq 70 \% / B Y P P \geq 0.95$ )

Notes: In our phylogenetic analysis (Fig. 16), Chromolaenicola clematidis (MFLUCC 17-2075) clustered with $C$. chiangraiensis Mapook \& K.D. Hyde with moderate statistical support (66\% ML/0.82 BYPP). A comparison of the ITS sequences showed three nucleotide differences in 516 nucleotides, while the $r p b 2$ showed five nucleotide differences in 935 nucleotides. Chromolaenicola clematidis has smaller 

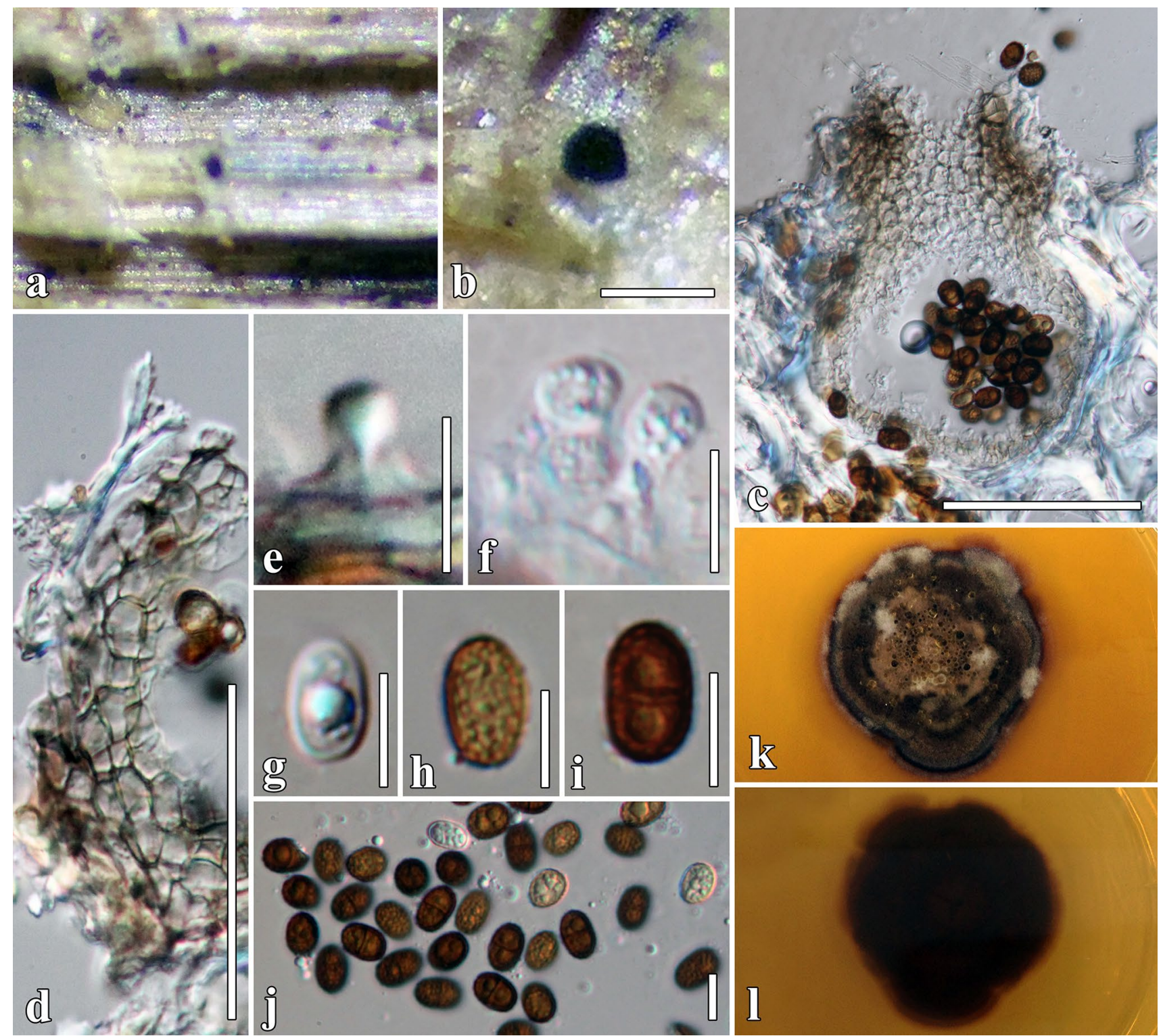

Fig. 17 Chromolaenicola clematidis (MFLU 17-1483, holotype). a b Appearance of conidiomata on Clematis subumbellata. c Vertical section through conidioma. d Section of conidioma wall. e-f Con-

idiogenous cells and conidia. $\mathbf{g}-\mathbf{j}$ Conidia. $\mathbf{k}-\mathbf{l}$ Culture characters on MEA. Scale bars: $\mathbf{b}=200 \mu \mathrm{m}, \mathbf{c}, \mathbf{d}=50 \mu \mathrm{m}, \mathbf{e}-\mathbf{j}=5 \mu \mathrm{m}$

conidia than $C$. chiangraiensis (mean $8.5 \times 6$ vs $11 \times 7.5 \mu \mathrm{m}$ ) with guttules in each cell (Fig. 17, Table 2). The new strain is introduced as a new species of Chromolaenicola based on the guidelines proposed by Jeewon and Hyde (2016).

\section{Didymosphaeria Fuckel}

Didymosphaeria is characterized by trabeculate pseudoparaphyses (sensu Liew et al. 2000), which anastomose above the cylindrical asci, and uniseriate, 1-septate ascospores (Aptroot 1995; Ariyawansa et al. 2014b). The asexual morph of Didymosphaeria has been suggested to be Ascochyta, fusicladiella-like, Periconia, and phoma-like species but a holomorphic connection has not been proven (Sivanesan 1984; Kirk et al. 2008; Ariyawansa et al. 2014b). Didymosphaeria is typified by $D$. futilis, however, fresh collections are needed to confirm its phylogenetic placement (Ariyawansa et al. 2014a; Wijayawardene et al. 2018). More than 500 epithets are listed under Didymosphaeria (Index Fungorum 2020), but only seven species were accepted by Aptroot (1995). Only three species of Didymosphaeria have phylogenetic evidence (D. rubi-ulmifolii, D. variabile, and Didymosphaeria sp. (as Paraconiothyrium brasiliense CBS 115.92, CBS 587.84, CBS 122319 and CBS 122320)) (Verkley et al. 2004). In this study, phylogenetic analyses based 
Table 2 A comparison of Chromolaenicola species discussed in this study

\begin{tabular}{lllll}
\hline Species & Conidiomata $(\mu \mathrm{m})$ & Conidiogenous cells $(\mu \mathrm{m})$ & Conidia $(\mu \mathrm{m})$ & Host \\
\hline Chromolaenicola clematidis & $76-145 \times 107-128$ & $2.6-4.5 \times 4-7$ & $7-10 \times 4-7$ & Clematis subumbellata \\
Ch. chiangraiensis (MFLUCC 17-1493) & - & $3.5-6.5 \times 1-2$ & $9-14 \times 6-9$ & Chromolaena odorata (Asteraceae) \\
Ch. siamensis & $110-165 \times 140-190$ & $6.5-7.4 \times 3.2-4.7$ & $7-9 \times 5-6$ & Leucaena sp. (Fabaceae) \\
(MFLUCC 17-2527) & & & & \\
\hline
\end{tabular}

on a combined dataset of the LSU, ITS, SSU, rpb2, and tub sequences revealed a new host record for D. rubi-ulmifolii on Clematis heracleifolia from China (Fig. 18).

Didymosphaeria rubi-ulmifolii Ariyaw., Camporesi \& K.D. Hyde, Phytotaxa 176:111 (2014), new host record

Index Fungorum number: IF808165; Facesoffungi number: FoF 07254, Fig. 18.

Saprobic on dead stem of Clematis heracleifolia. Sexual morph: Ariyawansa et al. (2014a). Asexual morph: Conidiomata 78-160×75-244 $\mu \mathrm{m}(\bar{x}=110 \times 120 \mu \mathrm{m}$, $\mathrm{n}=5$ ), pycnidial, solitary, unilocular or multilocular, scattered, immersed or erumpent, under host epidermis, globose to compressed, brown to dark brown, without ostioles. Pycnidial wall 12-20(-30 $\mu \mathrm{m}$ at apex $)$ wide, composed of 4-5 brown cell layers of textura angularis, inner layer subhyaline, lining bearing conidiogenous cells. Conidiophores reduced to conidiogenous cells. Conidiogenous cells $1.8-5 \times 2-4 \mu \mathrm{m}(\bar{x}=3 \times 3 \mu \mathrm{m}, \mathrm{n}=20)$, enteroblastic, phialidic, determinate, smooth-walled, hyaline. Conidia 6-11 $\times 2.5-4.5 \mu \mathrm{m}(\bar{x}=9 \times 4 \mu \mathrm{m}, \mathrm{n}=50)$, ellipsoid, 1 septum, constricted at septum, rounded ends, initially hyaline, pale brown at maturity, with 1-2 guttules, smooth-walled.

Cultural characters: Colonies on MEA reaching $30 \mathrm{~mm}$ diam. after 4 weeks at $16{ }^{\circ} \mathrm{C}$. Cultures from above, olive brown at the centre, radiating outwardly, medium dense, circular, entire edge, umbonate, papillate, fairly fluffy, covered with white aerial mycelium; reverse dark brown at the centre, faintly zonate slightly present, white mycelium at the edge.

Material examined: China, Dali, on dead terrestrial stem of Clematis heracleifolia DC., 8 May 2016, C. Phukhamsakda, CMCN03 (MFLU 17-1460); living culture, MFLUCC 16-1000.

Hosts: Coffea arabica, Rubus ulmifolius, Clematis heracleifolia-(Verkley et al. 2004; Ariyawansa et al. 2014a; this study).

Distribution: Brazil, China, Italy-(Verkley et al. 2004; Ariyawansa et al. 2014a; this study).

GenBank accession numbers: LSU: MT214555; SSU: MT226672; ITS: MT310602; tef1: MT394734.

Notes: Ariyawansa et al. (2014a) introduced Didymosphaeria rubi-ulmifolii from a collection of Rubus ulmifolius in Italy. The ex-type strain (MFLUCC 14-0023) formed a distinct clade with the type strain of Paraconiothyrium brasiliense (CBS 100299). Based on the multilocus phylogenetic analyses, our strain (MFLUCC 16-1000) formed a close relationship with the other $D$. rubi-ulmifolii strains with moderate support (Fig. 16), with no significant pairwise differences. Morphological comparison of D. rubi-ulmifolii (MFLUCC 16-1000) with the asexual morph report in $D$. rubi-ulmifolii (strain CBS 100299) show that they are different in the conidial characters (Fig. 18). Strain MFLUCC 16-1000 is saprobic and has 2-celled conidia while, CBS 100299 has single celled conidia in culture (Verkley et al. 2004). This study is the first record of D. rubi-ulmifolii on Clematis species.

Hermatomycetaceae Locq. ex A. Hashim. \& Kaz. Tanaka

Hermatomycetaceae is typified by Hermatomyces and currently only known from asexual morph characters (Tibpromma et al. 2016, 2018; Koukol et al. 2018; Hyde et al. 2019a). We introduce a novel Hermatomyces species based on its distinct morphology with phylogenetic support (Figs. 19, 20).

\section{Hermatomyces Speg.}

Hermatomyces tucumanensis is the type species. The genus has sporodochial conidiomata, and muriform, lenticular, hyaline or dematiaceous conidia of one or two types (Spegazzini 1911; Chang 1995; Tibpromma et al. 2016; Hashimoto et al. 2017; Hyde et al. 2019a). Examination of a Clematis collection revealed a novel species Hermatomyces clematidis based on its distinct morphological and phylogenetic relationship from other Hermatomyces. This is the first record of a Hermatomyces species on Clematis (Fig. 21).

Hermatomyces clematidis Phukhams., D.J. Bhat \& K.D. Hyde, sp. nov.

Index Fungorum number: IF557134; Facesoffungi number: FoF 07244, Fig. 21.

Etymology: Name refers to the host plant, Clematis.

Holotype: MFLU 17-1493.

Saprobic on dead stem of Clematis sikkimensis. Sexual morph: Undetermined. Asexual morph: Hyphomycetous. Colonies on natural substrate forming sporodochial conidiomata, subiculate, superficial, scattered, circular or oval, blackish brown, velvety, glistening, orbicular, with 

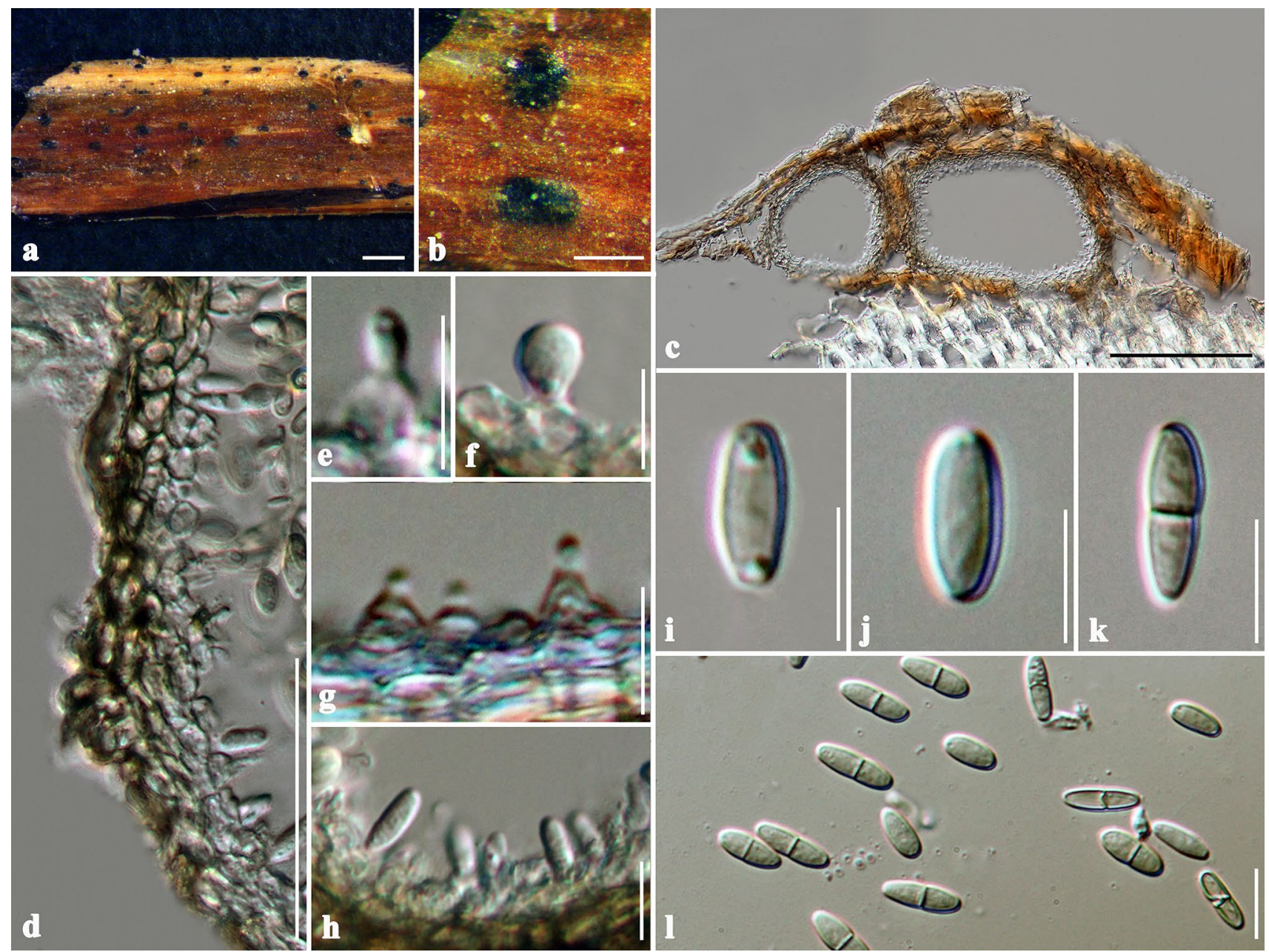

Fig. 18 Didymosphaeria rubi-ulmifolii (MFLU 17-1535). a, b Appearance of conidiomata on Clematis heracleifolia. c Vertical section through conidioma. d Section of conidioma wall. $\mathbf{e}-\mathbf{h}$ Con-

abundant sporulation, conidia readily liberated when agitated, $410-565 \mu \mathrm{m}$ wide $(\bar{x}=490 \mu \mathrm{m}, \mathrm{n}=20)$. Mycelium 2-4 $\mu \mathrm{m}$ wide, mostly superficial, composed of a loose or compact network of repent, branched, septate, roughwalled, thick-walled, reddish brown to brown hyphae; subicular hyphae short, densely packed. Conidiophores $22-38 \times 2-5 \mu \mathrm{m}$, micronematous or semi-macronematous, mononematous, cylindrical, erect, verruculose, aseptate, branched, often corresponding to conidiogenous cells, reddish brown to brown. Conidiogenous cells $7-13 \times 4-7 \mu \mathrm{m}$, holoblastic, monoblastic, solitary, integrated, terminal, determinate, cylindrical or slightly subulate, subsphaerical or ampulliform, reddish brown to brown, sometimes hyaline. Conidia dimorphic solitary, smooth-walled; lenticular conidia: $30-45 \times 24-31 \mu \mathrm{m}(\bar{x}=40 \times 28 \mu \mathrm{m}, \mathrm{n}=30)$, muriform, smooth, disc-shaped, circular to oval in front view, central cells brown to reddish brown, peripheral cells hyaline to subhyaline, forming a wide and distinct ring, slightly idiogenous cells and conidia. i-l Conidia. Scale bars: $\mathbf{a}=500 \mu \mathrm{m}$, $\mathbf{b}=200 \mu \mathrm{m}, \mathbf{c}=100 \mu \mathrm{m}, \mathbf{d}=20 \mu \mathrm{m}, \mathbf{e}-\mathbf{k}=5 \mu \mathrm{m}, \mathbf{l}=10 \mu \mathrm{m}$

constricted at the septa, inside view composed of one column of 5-6 cells, end cells subhyaline to pale brown, often carrying remnant of conidiogenous cell at base; cylindrical conidia: $29-35 \times 12-14 \mu \mathrm{m}(\bar{x}=32 \times 13 \mu \mathrm{m}, \mathrm{n}=20)$, straight or flexuous, septate, constricted at the septa, consisting of one or two columns, usually separate at apex, each column with 4-5 transverse septa, obclavate, apical cell acute, basal cells rounded, smooth, hyaline.

Culture characters: Colonies on MEA reaching $50 \mathrm{~mm}$ diam. after 4 weeks at $25^{\circ} \mathrm{C}$. Cultures from above, white, dense, circular, margin erose, umbonate, papillate with fairly fluffy, wrinkled, folded, pale orange, covered with cream aerial mycelium; reverse dark brown at the centre, faintly zonate at the edge, greyish orange radiating outwardly.

Material examined: Thailand, Chiang Rai Province, on dead stem of Clematis sikkimensis, 2 May 2017, C. Phukhamsakda \& M.V. de Bult, CMTHDT01 (MFLU 


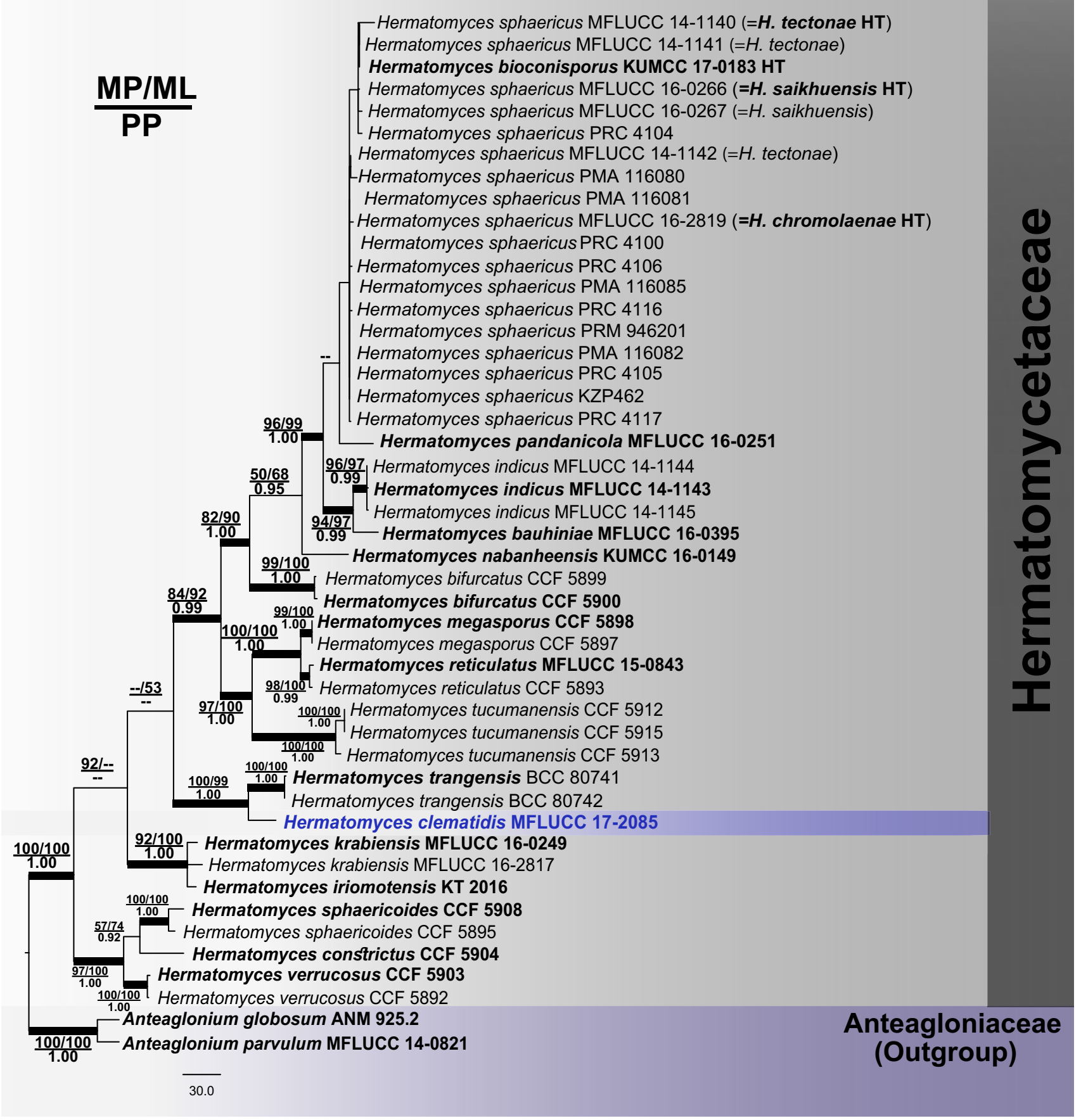


4Fig. 19 Phylogram generated from maximum parsimony analysis based on combined LSU, ITS, tef1 and $r p b 2$ sequence data. Related sequences are taken from Nuankaew et al. (2019) and retrieved from GenBank. Forty-nine strains were included in the analysis of the combined DNA loci and comprise 3309 characters (826 characters for LSU, 514 characters for ITS, 948 characters for tefl, 1021 characters for $r p b 2$, including gaps). The tree is rooted with Anteaglonium globosum (ANM 925.2) and A. parvulum (MFLUCC 14-0821) in Anteagloniaceae. Maximum parsimony analysis of 471 parsimony informative characters resulted in a most parsimonious tree $(\mathrm{CI}=0.674$, $\mathrm{RI}=0.879, \mathrm{RC}=0.593, \mathrm{HI}=0.326$ ). The best scoring $\mathrm{RAxML}$ tree had a final likelihood value of -10433.015131 . The matrix had 802 distinct alignment patterns with $28.12 \%$ undetermined characters and gaps. Estimated base frequencies were: $\mathrm{A}=0.244372, \mathrm{C}=0.264291$, $\mathrm{G}=0.261114, \mathrm{~T}=0.230223 ;$ substitution rates $\mathrm{AC}=0.858179$, $\mathrm{AG}=3.949480, \quad \mathrm{AT}=1.122065, \quad \mathrm{CG}=0.761732, \quad \mathrm{CT}=11.028490$, $\mathrm{GT}=1.000000$; gamma distribution shape parameter $\alpha=0.151089$. In our analysis, GTR $+\mathrm{I}+\mathrm{G}$ model was used for each partition in Bayesian posterior analysis. Bootstrap values (BS) greater than $50 \%$ BS (ML, left) and Bayesian posterior probabilities (BYPP, right) greater than 0.90 are given at the nodes. Hyphens (-) represent support values less than 50\% BS/0.90 BYPP. Thick branches represent significant support values from all analyses (BS $\geq 70 \% / B Y P P \geq 0.95)$. The ex-type strains are in bold and black. The newly generated sequence is in bold and blue

17-1493, holotype); ex-type living culture, MFLUCC 17-2085.

Host: Clematis sikkimensis-(This study).

Distribution: Thailand-(This study).
GenBank accession numbers: LSU: MT214556; SSU: MT226673; ITS: MT310603; tef1: MT394735; rpb2: MT394684.

Notes: Hermatomyces clematidis is introduced as a new species based on its distinct morphology and phylogenetic results of a combined LSU, ITS, tefl, and rpb2 dataset (Fig. 19). Hermatomyces clematidis matches the generic concept in having sporodochial conidiomata, with both lenticular and cylindrical conidia (Doilom et al. 2017; Hashimoto et al. 2017, Fig. 21). Morphological comparison with known Hermatomyces species shows it is similar to $H$. tucumanensis, however, the conidiophore of $H$. clematidis are straighter with larger conidia ((22-)27-35×18-25 vs 30-45 ×24-31 $\mu \mathrm{m})$ (Koukol et al. 2018). In the phylogenetic analysis, $H$. clematidis formed a close relationship with $H$. trangensis with strong support (100\% MP/99\% ML/1.00 BYPP). Hermatomyces trangensis is associated with sugar palm in southern Thailand (Nuankaew et al. 2019). Hermatomyces trangensis differs from $H$. clematidis because it lacks cylindrical conidia. In a BLASTn search of GenBank, the closest match of the LSU sequence of MFLUCC 17-2085 is H. subiculosa (MFLUCC 15-0843) with 97\% similarity, while the closest match of the ITS sequence was $H$. tectonae (MFLUCC 14-1140) (NR_154079) with 97\% similarity.

Based on current evidence, phylogenetic results from the concatenated gene loci does not delineate Hermatomyces
Fig. 20 The splits graph from the pairwise homoplasy index (PHI) test generated from the concatenated gene set of LSU, ITS, tefl and $r p b 2$ sequence data of closely related species using both LogDet transformation and splits decomposition. PHI test results $\left(\Phi_{\mathrm{w}}\right)<0.05$ indicates significant recombination within the dataset

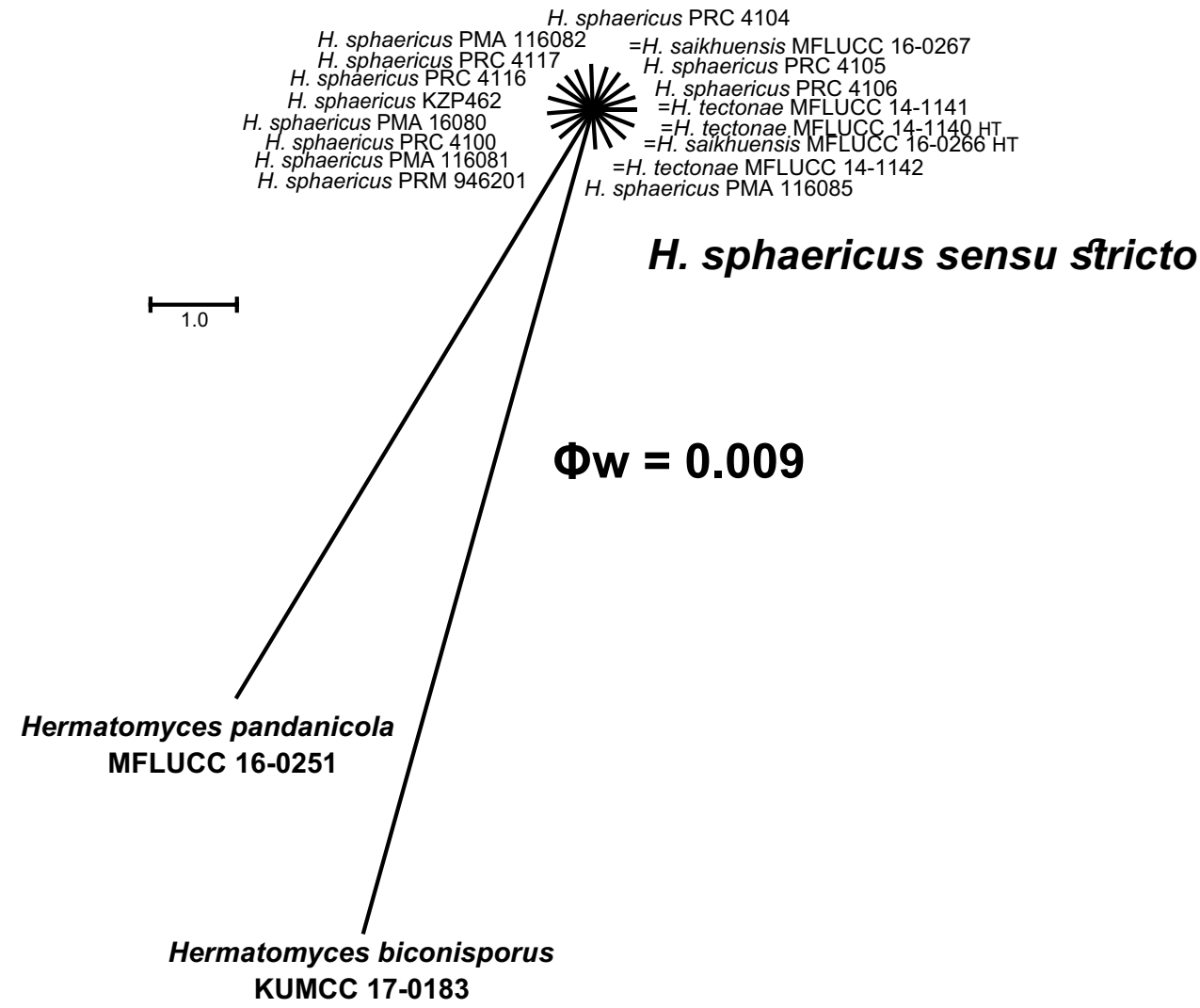


species, especially the H. sphaericus clade (Fig. 19). Therefore, we applied the GCPSR concept with the H. sphaericus clade. Seventeen isolates of $H$. sphaericus formed an isolated clade with two species (H. biconisporus and $H$. pandanicola) forming distant relationship lineage with low statistic support. However, the pairwise homoplasy index showed $\Phi w=0.009$ when the degree of genealogical correlation model was applied between neighbouring strains of the clade (Fig. 20). These results are not congruent with the phylogenetic lineages shown in Fig. 19, which rather indicate that $H$. biconisporus, $H$. pandanicola and $H$. sphaericus should currently be treated as the same species.

\section{Leptosphaeriaceae Barr}

Leptosphaeriaceae is typified by Leptosphaeria. Ariyawansa et al. (2015b) illustrated the members of Leptosphaeriaceae and included ten genera. Quaedvlieg et al. (2013) introduced an asexual morph genus, Acicuseptoria Quaedvl., Verkley \& Crous to the family, however, a multilocus phylogenetic analysis (Fig. 22) reveals that Acicuseptoria clusters with Paraleptosphaeria. Crous and Groenewald (2017a) introduced Querciphoma isolated from stems and leaves of woody plants in a terrestrial environment. Members of this family usually have a single, papillate, immersed or erumpent, perithecial ascomata, with thick, scleroplectenchymatous or plectenchymatous cells and cylindrical asci with hyaline to brown, transversely septate ascospores (Hyde et al. 2013; Ariyawansa et al. 2015b). The asexual morphs in Leptosphaeriaceae can be coelomycetous or hyphomycetous (Gruyter et al. 2013; Hyde et al. 2013; Crous and Groenewald 2017). We introduce a novel Alloleptosphaeria species and describe a novel genus Sclerenchymomyces based on distinct morphology and phylogenetic support (Fig. 22).

\section{Alloleptosphaeria Ariyaw., Wanas. \& K.D. Hyde}

Alloleptosphaeria was introduced as a monotypic genus to accommodate A. italica from Clematis vitalba in Italy (Ariyawansa et al. 2015b). It has immersed ascomata and a thin-walled peridium of reddish brown to dark brown pseudoparenchymatous cells (Ariyawansa et al. 2015b). In our phylogenetic analysis (Fig. 22), Alloleptosphaeria formed a distinct clade basal to Leptosphaeria sensu stricto. We introduce the second species of Alloleptosphaeria from Clematis subumbellata collected in Thailand (Fig. 23).

Alloleptosphaeria clematidis Phukhams. \& K.D. Hyde, sp. nov.

Index Fungorum number: IF557109; Facesoffungi number: FoF 07286, Fig. 23.

Etymology: Epithet reflect the host genus Clematis.
Holotype: MFLU 17-1479.

Saprobic on dead stems of Clematis subumbellata. Sexual morph: Ascomata $210-260 \times 125-190 \mu \mathrm{m}(\bar{x}$ $=237 \times 160 \mu \mathrm{m}, \mathrm{n}=5$ ), on surface of the host, covered by a pseudoclypeus, visible as black spots, immersed, solitary, scattered, uniloculate, obpyriform, coriaceous, black to dark brown, rough-walled, with apical ostioles. Ostioles $70-85 \times 50-70 \mu \mathrm{m}(\bar{x}=80 \times 60 \mu \mathrm{m}, \mathrm{n}=5)$, central, pale brown to dark brown, papillate, opening by a pore, ostioles with periphyses. Peridium $9-17(-25 \mu \mathrm{m}$ at apex $)$ wide, thin, multilayered, pseudoparenchymatous cell type, comprising 4-5 layers of brown to dark brown cells of textura angularis, inner layers comprising thin, hyaline cells. Hamathecium composed of numerous, $5-3.5 \mu \mathrm{m}$ wide $(\bar{x}=2.5 \mu \mathrm{m}, \mathrm{n}=50)$, dense, filiform branched, anastomosing above asci, reaching the ostioles, transversely septate, cellular pseudoparaphyses. Asci $75-125 \times 8-15 \mu \mathrm{m}(\bar{x}=105 \times 10 \mu \mathrm{m}, \mathrm{n}=40), 8$-spored, bitunicate, fissitunicate, cylindrical, apically rounded, short, bulbous pedicel, ocular chamber clearly visible when immature. Ascospores $15-25 \times 6-9 \mu \mathrm{m}(\bar{x}=18 \times 7 \mu \mathrm{m}, \mathrm{n}=50)$, uniseriate, partially overlapping, broad fusiform, tapering towards the ends, round at both ends, with (1-)4-5 transverse septa, 1-longitudinal septum in each ascospore, initially hyaline, yellowish at maturity, slightly constricted at the septa, deeply constricted at the median septum, cell above median septum slightly wider than that below, verruculose, with guttule in each cell, with thin mucilaginous sheath. Asexual morph: Undetermined.

Culture characters: Colonies on MEA reaching $20 \mathrm{~mm}$ diam. after 4 weeks at $25^{\circ} \mathrm{C}$. Culture from above dark brown radiating outwardly, wrinkled folded in the middle, dense, circulate, flattened, umbonate, edge irregular, fairly fluffy; reverse black in the middle and dark brown at the edge, orange pigment slightly diffusing into the agar.

Material examined: Thailand, Chiang Rai Province, on dead stems of Clematis subumbellata, 20 March 2017, C. Phukhamsakda, CMTH15 (MFLU 17-1479, holotype); extype living culture, MFLUCC 17-2071.

Host: Clematis subumbellata-(This study).

Distribution: Thailand-(This study).

GenBank accession numbers: LSU: MT214557; SSU: MT226674; ITS: MT310604; tef1: MT394736; rpb2: MT394685.

Notes: Alloleptosphaeria clematidis is the first report of Alloleptosphaeria from Thailand and the second Alloleptosphaeria species known on Clematis. Alloleptosphaeria clematidis formed a robust clade with $A$. italica with strong support (97\% ML/1.00 BYPP, Fig. 22). Alloleptosphaeria clematidis is compatible with the generic concept of Alloleptosphaeria in having immersed ascomata with a 

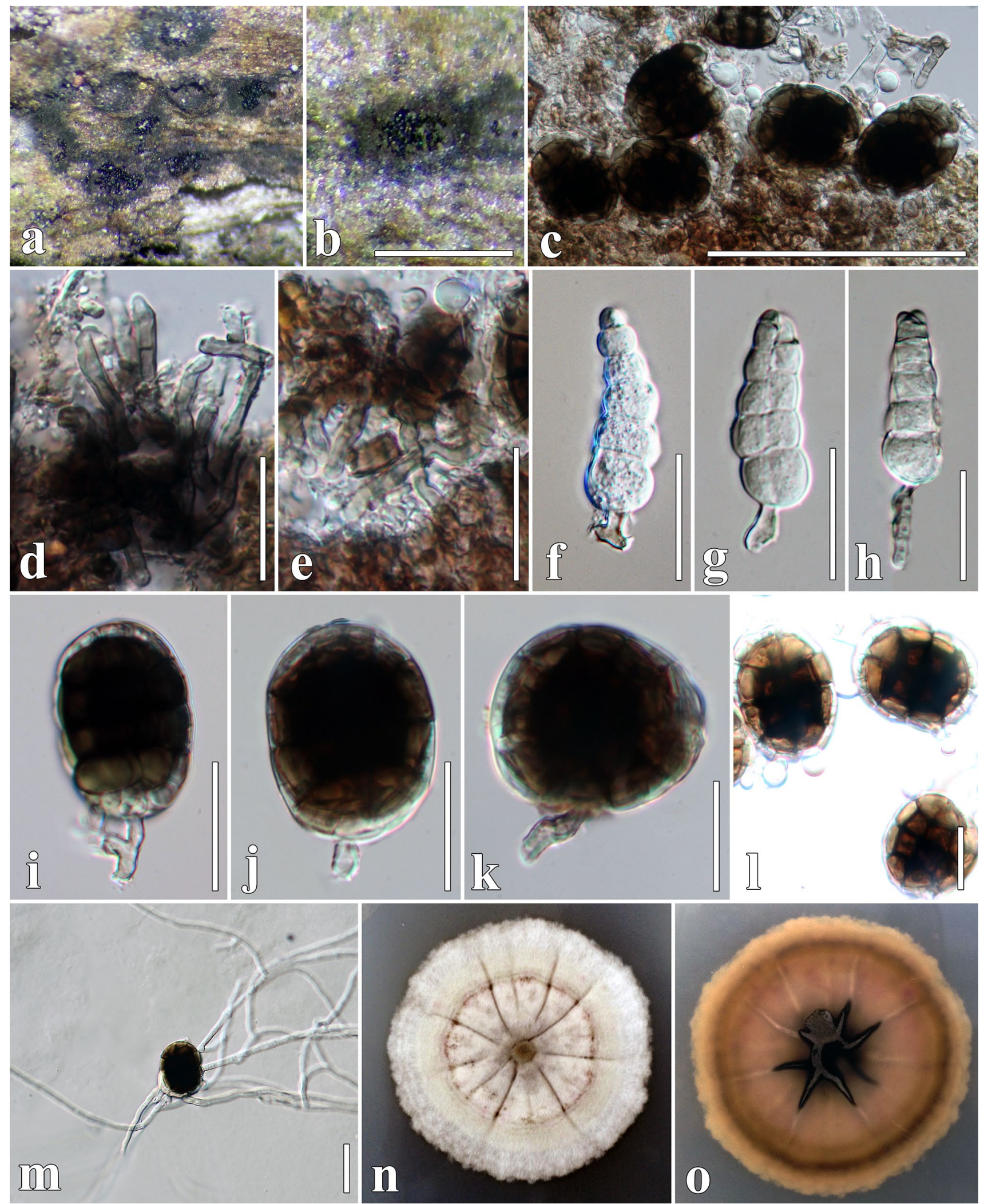

Fig. 21 Hermatomyces clematidis (MFLU 17-1493, holotype). a, b Sporodochia on natural substrate. c Vertical section of sporodochia. d, e Subicular hyphae. f-h Cylindrical conidia. i-l Mature lenticular conidia. $\mathbf{m}$ Germinated conidium. $\mathbf{n}$, o Culture characters on MEA. Scale bars: $\mathbf{b}=500 \mu \mathrm{m}, \mathbf{c}=100 \mu \mathrm{m}, \mathbf{d}-\mathbf{m}=20 \mu \mathrm{m}$ 


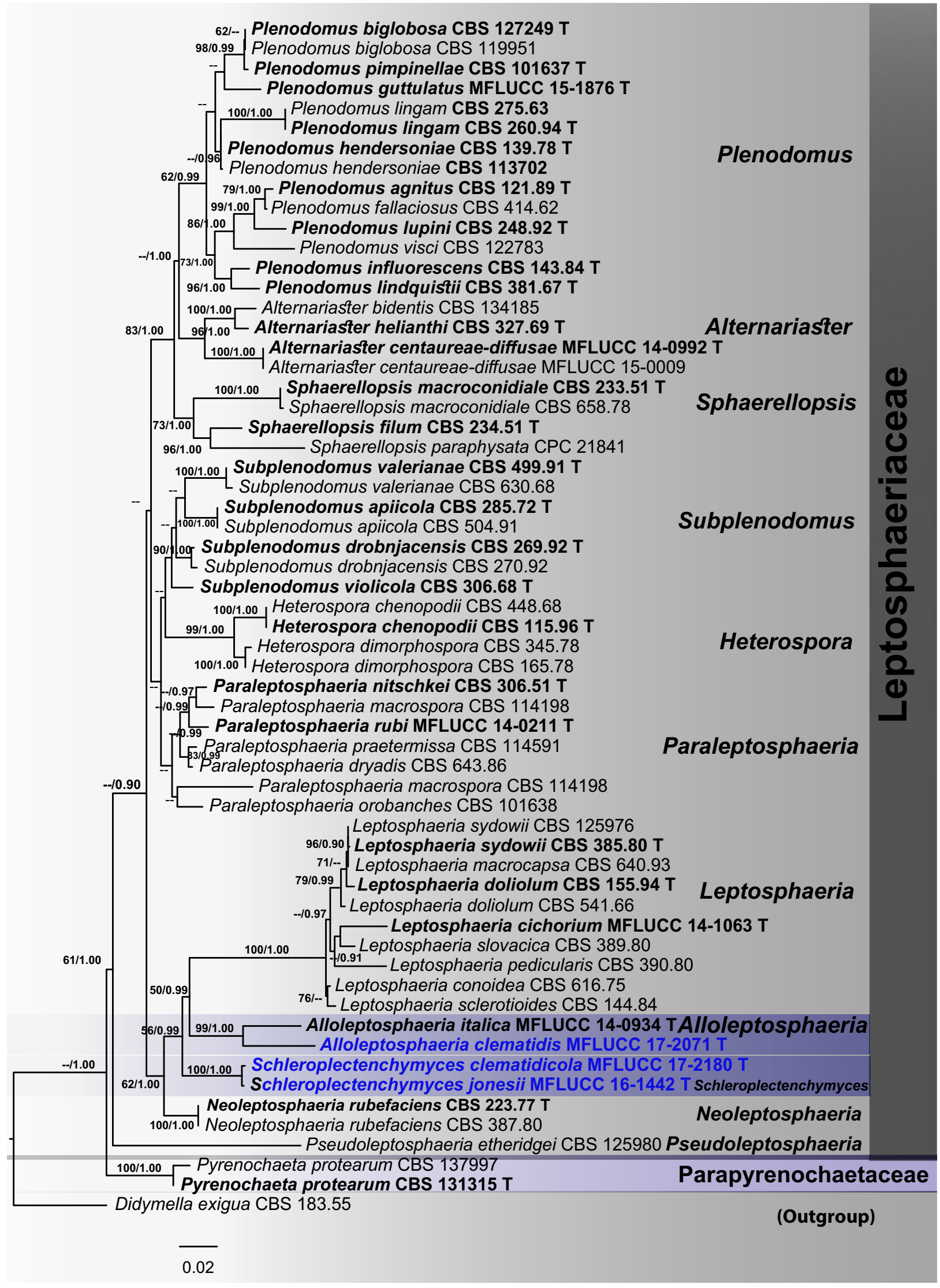


4Fig. 22 The best scoring RAxML tree with a final likelihood value of - 13918.604336 based on combined LSU, SSU, ITS and tef1 sequence data for Leptosphaeriaceae. The tree is rooted with a member of the Didymellaceae. Seventy strains were included in the combined gene sequence analyses, which comprise 3257 characters (831 characters for LSU, 951 characters for SSU, 566 characters for ITS, and 909 characters for tefl, including gap regions). The topology and clade stability of the combined gene analyses was compared to the single gene analyses. The matrix had 649 distinct alignment patterns, with $45.29 \%$ of undetermined characters and gaps. Estimated base frequencies were as follows; $\mathrm{A}=0.244507, \mathrm{C}=0.225295$, $\mathrm{G}=0.271500, \quad \mathrm{~T}=0.258698 ;$ substitution rates $\mathrm{AC}=1.503087$, $\mathrm{AG}=2.814632, \quad \mathrm{AT}=2.230882, \quad \mathrm{CG}=0.467105, \quad \mathrm{CT}=7.217503$, $\mathrm{GT}=1.000000$; gamma distribution shape parameter $\alpha=0.541381$. In our analysis, GTR + I + G model was used for every partition in Bayesian analysis. The species determined in this study are indicated in blue. Bootstrap values (BS) greater than 50\% BS (ML, left) and Bayesian posterior probabilities (PP, right) greater than 0.90 are given at the nodes. Hyphens (-) represent support values less than $50 \%$ BS/0.90 BYPP. The supported values from all analyses are BS $\geq 70 \% /$ $\mathrm{BYPP} \geq 0.95$

thin-walled peridium of brown to dark brown or reddish brown, pseudoparenchymatous cells (Ariyawansa et al. 2015b). Based on morphology, A. clematidis is distinguished by its cylindrical asci and the presence of 1 longitudinal septum in its yellowish ascospore (Fig. 23). In a BLASTn search of GenBank, the closest match of the ITS region of MFLUCC 17-2071 is $92.5 \%$ similarity to Subplenodomus iridicola strain CBS 143395 (NR_159068). Pairwise comparison of the ITS region of MFLUCC 17-2071 with $A$. italica (MFLUCC 14-0934) shows 97 nucleotide differences from 566 base pairs $(17.13 \%)$.

Sclerenchymomyces Phukhams. \& K.D. Hyde, gen. nov. Index Fungorum number: IF557110; Facesoffungi number: FoF 07287, Fig. 24

Etymology: Genus name reflects the characteristic of scleroplectenchyma tissue type.

Saprobic on dead or dead branch of herbaceous or woody plants in terrestrial habitats. Sexual morph: Ascomata covered by plant epidermis, located on the surface of host substrate, black, shiny, superficial to semi-immersed, solitary, globose, black, ostiolate. Ostioles central, short, filled with hyaline cells. Peridium composed of blackish to dark brown cells of textura angularis, thick, multilayered, scleroplectenchymatous cells, cells towards the inside lighter. Hamathecium composed of numerous, branched, septate, pseudoparaphyses. Asci 8-spored, bitunicate, fissitunicate, cylindrical, short-pedicellate. Ascospores uniseriate, partial overlapping, muriform, broad ellipsoidal, narrowed towards the ends, initially hyaline, becoming brown at maturity, constricted at median septum, guttulate, surrounded by a mucilaginous sheath (Wanasinghe et al. 2016). Asexual morph: Conidiomata pycnidial, solitary, sometimes aggregated, uniloculate or multiloculate, erumpent or superficial on host substrate, with black shiny ostioles, globose to subglobose, coriaceous, dark brown to brown. Ostioles central, papillate, oblong. Conidiomatal wall thick-walled, multilayered, scleroplectenchymatous or pseudoparenchymatous cells, flat at base, composed of textura angularis, lined with a thick hyaline layer bearing conidiogenous cells. Conidiophores reduced to conidiogenous cells. Conidiogenous cells enteroblastic, phialidic, determinate, discrete, sub-cylindrical to truncate, smooth-walled, hyaline, arising from the inner layers of conidiomata. Conidia ellipsoid or cylindrical to oblong, rounded at both ends, slightly curved, hyaline when immature, yellowish at maturity, aseptate or septate, guttulate, smooth-walled.

Type species: Sclerenchymomyces clematidis Phukhams. \& K.D. Hyde

Notes: Sclerenchymomyces is introduced for a lineage comprising Sclerenchymomyces clematidis and S. jonesii (三Neoleptosphaeria jonesii) which received strong support (99\% ML/1.00 BYPP, Fig. 22). Based on the multigene phylogenetic analyses, Sclerenchymomyces formed a separate lineage to Alloleptosphaeria, Leptosphaeria sensu stricto and Neoleptosphaeria (62\% ML/1.00 BYPP). The members of Leptosphaeriaceae are remarkable by their characteristic scleroplectenchymatous or pseudoparenchymatous tissue types (Ariyawansa et al. 2015b). Two isolates of Sclerenchymomyces share similar characters in having black, shiny, superficial to semi-immersed ascomata with a multilayer of scleroplectenchymatous tissue type (Wanasinghe et al. 2016a, Fig. 24). Sclerenchymomyces shares similar pycnidial characters with Leptosphaeria sensu stricto and Neoleptosphaeria in the scleroplectenchymatous or plectenchymatous cell type in the peridium (Ariyawansa et al. 2015b). However, Leptosphaeria species only have transverse septa while Sclerenchymomyces has longitudinal septa in the ascospores (Fig. 24). Sclerenchymomyces has oblong, brown phragmoconidia in nature and phoma-like characters in culture (Gruyter et al. 2013; Wanasinghe et al. 2016). The combined dataset of the LSU, SSU, ITS and tefl sequences for Leptosphaeriaceae revealed a lineage of Sclerenchymomyces as a new genus from Clematis (Fig. 22).

Sclerenchymomyces clematidis Phukhams. \& K.D. Hyde, sp. nov.

Index Fungorum number: IF557111; Facesoffungi number: FoF 07288, Fig. 24.

Etymology: Name refers to the host plant, Clematis.

Holotype: MFLU 16-2492.

Saprobic on dead stems of Clematis vitalba. Sexual morph: Undetermined. Asexual morph: Conidiomata 187-225 ×85-217 $\mu \mathrm{m}(\bar{x}=210 \times 130 \mu \mathrm{m}, \mathrm{n}=10)$, pycnidial, solitary, sometimes aggregated, uniloculate or multiloculate, erumpent or superficial on host substrate, with black shiny ostioles visible, globose to subglobose, 

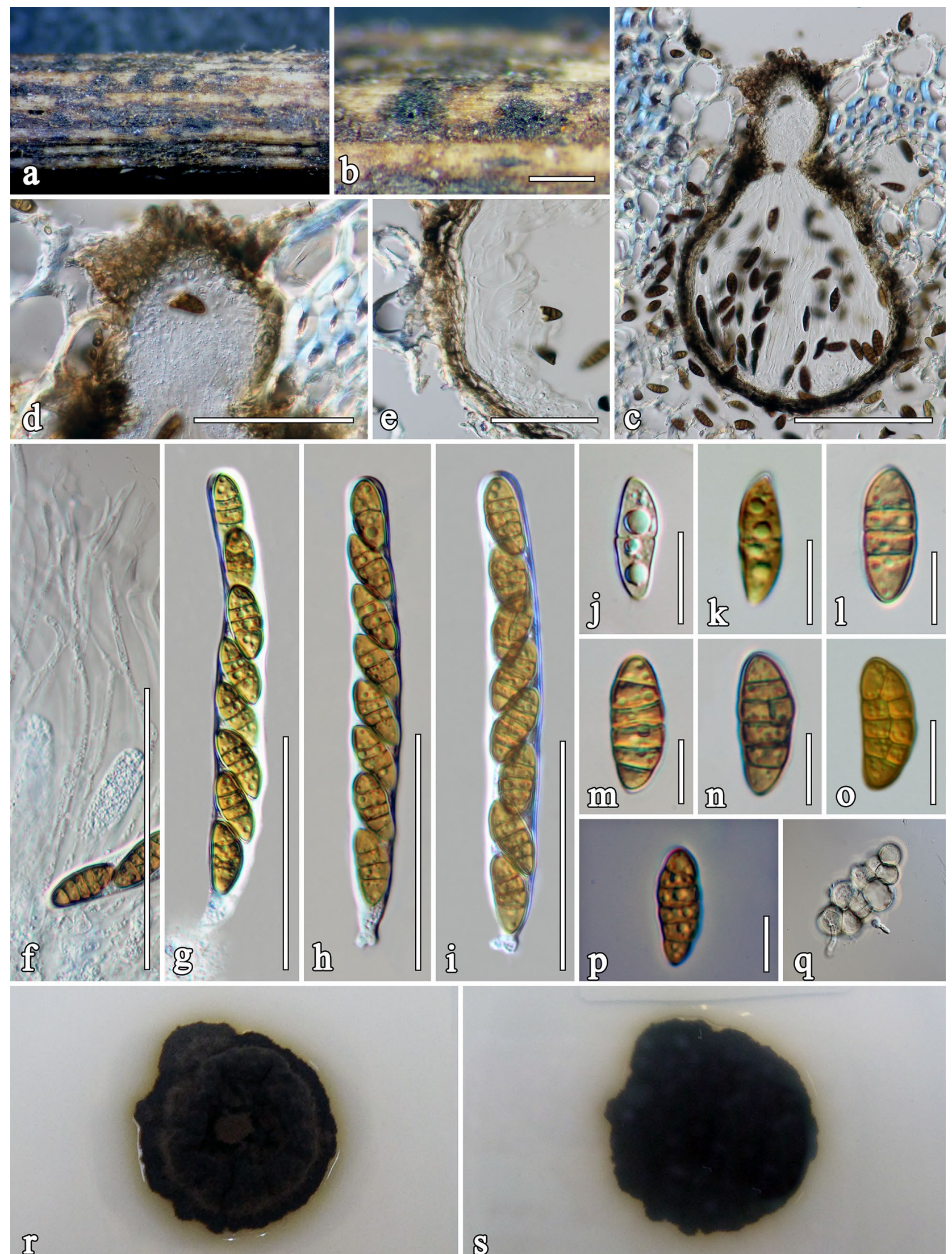

\$

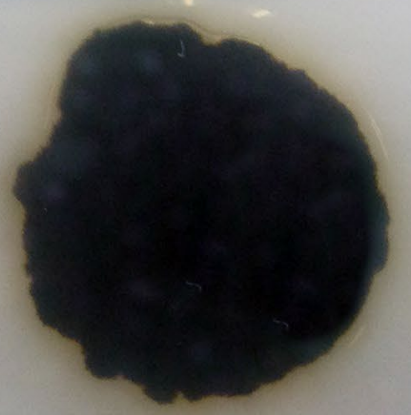


४Fig. 23 Alloleptosphaeria clematidis (MFLU 17-1479, holotype). a Appearance of ascomata on Clematis subumbellata. b Close up of ascoma on host substrate. c Vertical section through ascoma. d Ostiolar canal. e Section of peridium. f Pseudoparaphyses. g-i Asci. j-p Ascospores (p Ascospore in 10\% Indian ink). q Germinated ascospore. $\mathbf{r}$, s Culture characteristics on MEA. Scale bars: $\mathbf{b}=200 \mu \mathrm{m}, \mathbf{c}=100 \mu \mathrm{m}, \mathbf{d}, \mathbf{f}-\mathbf{i}=50 \mu \mathrm{m}, \mathbf{e}=20 \mu \mathrm{m}, \mathbf{j}-\mathbf{p}=10 \mu \mathrm{m}$

coriaceous, dark brown to brown, ostiolate. Ostioles central, papillate, oblong. Conidiomatal wall 14-30(-35) $\mu \mathrm{m}$ wide, multilayered, scleroplectenchymatous cells, flat at base, outer layer composed of 5-9 layers of light brown to brown cells of textura angularis, lined with a thick hyaline layer bearing conidiogenous cells. Conidiophores reduced to conidiogenous cells. Conidiogenous cells 3-8 $\times 1.5-4 \mu \mathrm{m}$ $(\bar{x}=5 \times 3 \mu \mathrm{m}, \mathrm{n}=30)$, enteroblastic, phialidic, determinate, discrete, sub-cylindrical to truncate, smooth-walled, hyaline, arising from the inner layers of conidiomata. Conidia $11-18 \times 2.5-5 \mu \mathrm{m}(\bar{x}=14 \times 4 \mu \mathrm{m}, \mathrm{n}=50)$, broad cylindrical to oblong, rounded at both ends, hyaline when immature, yellowish at maturity, slightly curved, 3-septate, with 1(-2) guttules in each cell, smooth-walled.

Culture characters: Colonies on MEA reaching $40 \mathrm{~mm}$ diam. after 4 weeks at $25^{\circ} \mathrm{C}$. Cultures from above, creambrown, spare mycelia, circular, umbonate, papillate with fluffy, covered with white aerial mycelium; reverse dark brown at the centre, cream radiating outwardly.

Material examined: Italy, Forlì-Cesena Province, near Meldola, on dead aerial branch of Clematis vitalba, 15 November 2013, E. Camporesi, 1518C (MFLU 16-2492, holotype); ex-type living culture, MFLUCC 17-2180.

Host: Clematis vitalba-(This study).

Distribution: Italy-(This study).

GenBank accession numbers: LSU: MT214558; SSU: MT226675; ITS: MT310605; tef1: MT394737; rpb2: MT394686.

Notes: Sclerenchymomyces clematidis is distinct from $S$. jonesii in conidial characters (Fig. 24). Sclerenchymomyces clematidis has broad cylindrical to oblong, yellowish conidia with 3 septa and 1(-2) guttules, while $S$. jonesii has hyaline, aseptate conidia (Wanasinghe et al. 2016a). In a BLASTn search of GenBank, the LSU sequence of S. clematidis (strain MFLUCC 17-2180) was $98.7 \%$ similar to $S$. jonesii (三Neoleptosphaeria jonesii), while the ITS sequence showed $97.28 \%$ similarity to NR_152375. Pairwise comparison of the ITS sequence reveals nine bases pair differences $(1.59 \%)$ between S. clematidis and S. jonesii (MFLUCC 16-1442). The tefl region shows seven bases pair difference between $S$. clematidis and S. jonesii.

Sclerenchymomyces jonesii (Wanasinghe, Camporesi \& K.D. Hyde) Phukhams. \& K.D. Hyde, comb. nov.
Basionym: Neoleptosphaeria jonesii Wanasinghe, Camporesi \& K.D. Hyde, in Wanasinghe, Camporesi \& Hu, Mycosphere 7(9): 1373 (2016)

Index Fungorum number: IF552569; Facesoffungi number: FoF 02716

Notes: Wanasinghe et al. (2016a) introduced Neoleptosphaeria jonesii for a fungus whose morphology and phylogeny are related to Neoleptosphaeria rubefaciens (Gruyter et al. 2013; Wanasinghe et al. 2016a). The analyses of combined LSU, SSU, ITS and tefl sequence data for Leptosphaeriaceae showed that the ex-type strain of Neoleptosphaeria jonesii (MFLUCC 16-1442) clustered with Sclerenchymomyces clematidis (MFLUCC 17-2180), a fungal strain reported from the same host. Pairwise comparison of the ITS sequence data reveals 85 bases pair difference from 566 (15.9\%, including gap region) between $N$. jonesii (MFLUCC 16-1442) and N. rubefaciens (CBS 223.77 and CBS 387.80). According to phylogeny (Fig. 22) coupled with morphology, we transfer $N$. jonesii to Sclerenchymomyces.

Host: Clematis vitalba-(Wanasinghe et al. 2016a).

Distribution: Italy_(Wanasinghe et al. 2016a).

Longiostiolaceae Phukhams., Doilom \& K.D. Hyde, fam. nov.

Index Fungorum number: IF557086; Facesoffungi number: FoF 07215, Fig. 25.

Saprobic on dead bark. Sexual morph: Ascomata immersed to semi-immersed, uniloculate, solitary, globose to subglobose, coriaceous, base flattened, ostiolate. Ostioles long, obtuse or dolabriform, central. Peridium thick, comprising several layers of scleroplectenchymatous or pseudoparenchymatous cell types, dark brown to black cells arranged in a textura angularis or textura globosa. Hamathecium composed of numerous, filiform, septate, branched, cellular pseudoparaphyses. Asci 4-8-spored, bitunicate, cylindrical to clavate, pedicellate, with ocular chamber. Ascospores biseriate, partial overlapping, broad fusiform, hyaline, brownish at the mature state, multi-septate, with or without mucilaginous sheath. Asexual morph: coelomycetous-like or hyphomycetous-like structures produced in culture. Conidiomata scattered, globose to subglobose, ostiolate. Conidiomatal wall thick, comprising of multilayered textura angularis, pale brown to brown cells. Conidiophores reduced to conidiogenous cells. Conidiogenous cells annellidic, doliiform to ampulliform. Conidia cylindrical, hyaline, bud scars disjunctors at base, multi-septate, smooth, without sheath (Matsumura et al. 2018). Colonies on MEA produce conidia structures on aerial mycelium, subglobose to ellipsoidal, initially hyaline, becoming black, aseptate, smooth-walled.

Type genus: Longiostiolum Doilom, Ariyaw. \& K.D. Hyde, in Li et al., Fungal Diversity 78: 55 (2016) 


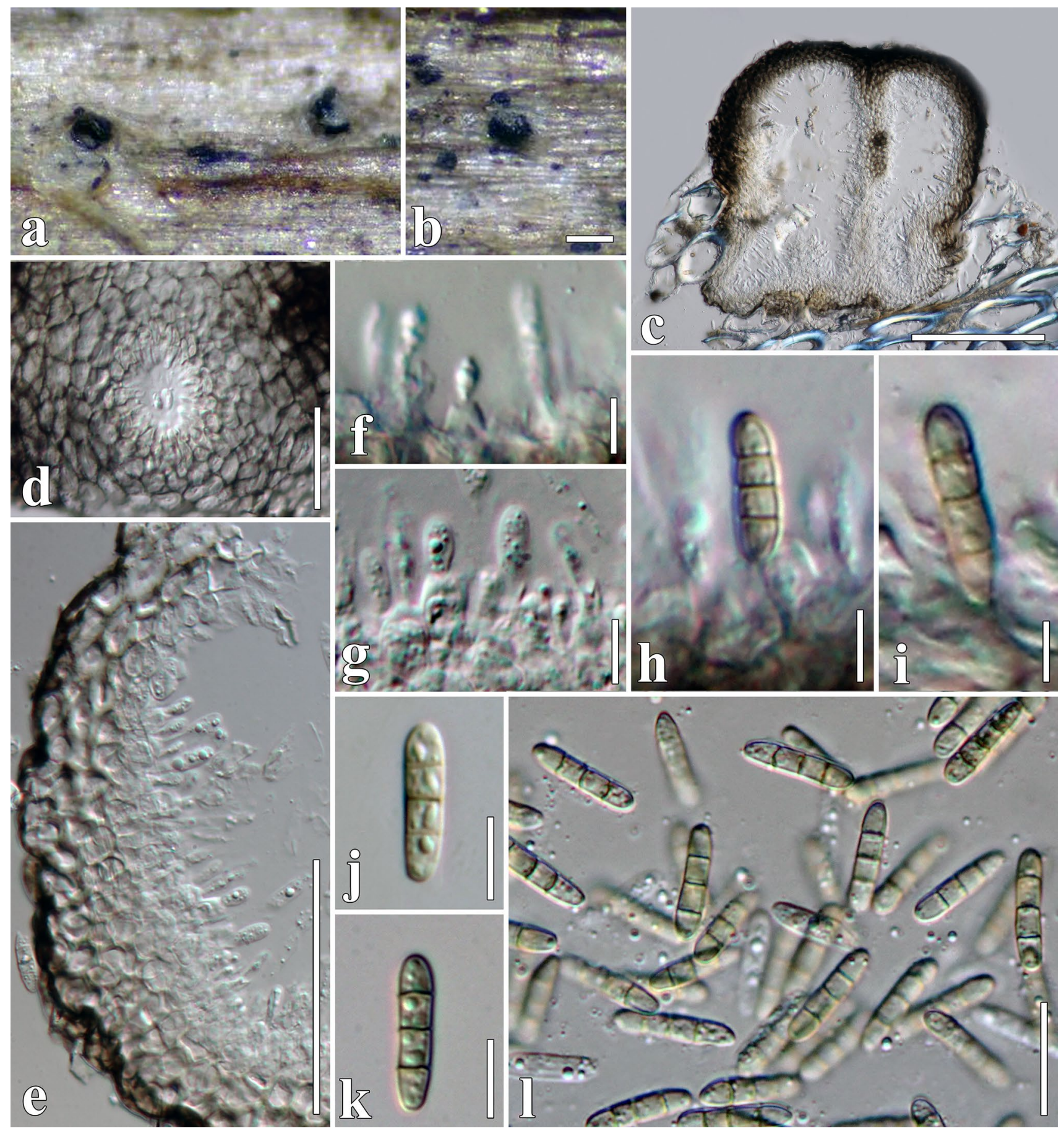

Fig. 24 Sclerenchymomyces clematidis (MFLU 16-2492, holotype). a Appearance of conidiomata on Clematis vitalba. b Close up of conidioma on host substrate. $\mathbf{c}$ Vertical section through conidiomata. d
Ostiole from above. e Section of conidioma wall. $\mathbf{f}-\mathbf{i}$ Conidiogenous cells and conidia. $\mathbf{j}-\mathbf{l}$ Conidia. Scale bars: $\mathbf{b}=200 \mu \mathrm{m}, \mathbf{c}=100 \mu \mathrm{m}$, $\mathbf{d}=20 \mu \mathrm{m}, \mathbf{e}=50 \mu \mathrm{m}, \mathbf{f}-\mathbf{l}=5 \mu \mathrm{m}$ 
Notes: Longiostiolaceae is introduced to accommodate two ascomycetous genera, Crassiperidium and Longiostiolum. Longiostiolum was introduced by Li et al. (2016) for a fungus associated with Tectona grandis from northern Thailand. Matsumura et al. (2018) reported Crassiperidium from twigs of Fagus crenata in Japan. Crassiperidium and Longiostiolum were associated with wood and share characters in having immersed to semi-immersed, uniloculate ascomata, thick-walled scleroplectenchymatous or pseudoparenchymatous cell, with hyaline ascospores turning brownish at maturity ( $\mathrm{Li}$ et al. 2016; Matsumura et al. 2018). The asexual morphs of these two genera are different, with Crassiperidium forming pycnidial conidiomata with hyaline conidia, and Longiostiolum forming a hyphomycetous-like structure with globose, black conidia in culture (Fig. 25).

Matsumura et al. (2018) found that Crassiperidium was related to Cyclothyriellaceae (Pleosporales) based on phylogeny of an SSU, LSU and $r p b 2$ sequence dataset. Longiostiolum was assigned as an incertae sedis taxon in Pleosporales based on combined LSU, SSU, rpb2 and tefl sequence data (Li et al. 2016). Phylogenetic analysis based on the LSU regions of Crassiperidium and Longiostiolum formed a clade together with moderate support (57\% ML, data not shown) and sister to Cyclothyriellaceae. The concatenated dataset of LSU, SSU, ITS, tef1 and rpb2 showed Crassiperidium species (C. octosporum and C. quadrisporum) and Longiostiolum tectonae (MFLUCC 12-0562) forming a close relationship with strong support (98\% ML/1.00 BYPP) and related to Cyclothyriellaceae (Fig. 2). Therefore, we introduce a new family to accommodate this distinct lineage.

Type genus: Longiostiolum Doilom, Ariyaw. \& K.D. Hyde, in Li et al., Fungal Diversity 78: 55 (2016).

Type species: Longiostiolum tectonae Doilom, Bhat \& K.D. Hyde, in Li et al., Fungal Diversity 78: 55 (2016).

Genera included: Crassiperidium Matsum. \& Kaz. Tanaka (Matsumura et al. 2018); Longiostiolum Doilom, Ariyaw. \& K.D. Hyde (Li et al. 2016).

Hosts: Fagus crenata, Tectona grandis-(Li et al. 2016; Matsumura et al. 2018).

Distribution: Japan, Thailand-(Li et al. 2016; Matsumura et al. 2018).

Longiostiolum tectonae Doilom, Bhat \& K.D. Hyde, in Li et al., Fungal Diversity 78: 55 (2016)

Index Fungorum number: IF 551900, Facesoffungi number: FoF 01882, Fig. 25.

Notes: Based on the phylogenetic analysis of the combined LSU, SSU, $r p b 2$ and tef1 sequence data, the genus Longiostiolum tectonae (MFLUCC 12-0562) formed a distinct lineage in Pleosporales with no statistical support $(\mathrm{Li}$ et al. 2016). In a BLASTn search of GenBank, the closest match of the LSU sequence of MFLUCC 12-0562 is
Crassiperidium octosporum (strain MAFF 242971) with 97\% similarity, while the ITS sequence showed $86.5 \%$ similarity.

Host: Tectona grandis-(Li et al. 2016).

Distribution: Thailand-(Li et al. 2016).

\section{Lophiostomataceae Sacc. [as 'Lophiostomaceae']}

Lophiostomataceae was accepted by Mugambi and Huhndorf (2009). Members of this family are saprobes in terrestrial and aquatic habitats (Saccardo 1883; Tanaka and Harada 2003; Thambugala et al. 2015; Hashimoto et al. 2018). The family is characterized by carbonaceous ascomata with a slit-like ostiolar neck or opening (Zhang et al. 2009). A revision of Lophiostomataceae by Thambugala et al. (2015) based on multi-locus phylogeny along with the re-examination of holotype specimens revealed the boundaries of the family. Hashimoto et al. (2018) revised the classification based mainly on ascospore appendages and introduced several new genera. Mapook et al. (2020) introduced Pseudocapulatispora Mapook \& K.D. Hyde and currently, there are 25 genera in the family (Wijayawardene et al. 2020). A phylogenetic analysis based on a combined LSU, ITS, SSU, tef1 and rpb2 sequence dataset (Figs. 26, 27) of lophiostomataceous taxa on Clematis from Europe and Asia revealed novel species of Neovaginatispora, Pseudocapulatispora, Pseudolophiostoma and Sigarispora, which are introduced with morphological support.

\section{Neovaginatispora Hashim., K. Hiray. \& Kaz. Tanaka}

Hashimoto et al. (2018) reanalysed Lophiostomataceae and segregated Neovaginatispora fuckelii (Sacc.) Hashim., K. Hiray. \& Kaz. Tanaka from the type species of Vaginatispora based on phylogenetic analyses. Neovaginatispora is distinct in its thin, sub-carbonaceous peridium of uniform thickness (Thambugala et al. 2015). We introduce a second species of Neovaginatispora from Clematis viticella (Fig. 28).

Neovaginatispora clematidis Phukhams., D. Ertz \& C. Gerstmans \& K.D. Hyde, sp. nov.

Index Fungorum number: IF557117; Facesoffungi number: FoF 07289, Fig. 28.

Etymology: Name refers to the host plant, Clematis.

Holotype: MFLU 17-1514.

Saprobic on dead stems of Clematis viticella. Sexual morph: Ascomata $145-250 \times 108-160 \mu \mathrm{m}$ $(\bar{x}=172 \times 134 \mu \mathrm{m}, \mathrm{n}=10)$, solitary, gregarious, semiimmersed to erumpent, globose to compressed, coriaceous, dark brown to black, ostiolate. Ostioles $50-65 \times 76-83 \mu \mathrm{m}$ $(\bar{x}=58 \times 80 \mu \mathrm{m}, \mathrm{n}=5)$, with a crest-like apex, central, filled with hyaline periphyses. Peridium $13-28 \mu \mathrm{m}$ wide $(\bar{x}=19 \mu \mathrm{m}, \mathrm{n}=20)$, uniform, wider and heavily pigmented at the apex, composed of 5(-6) layers of somewhat 


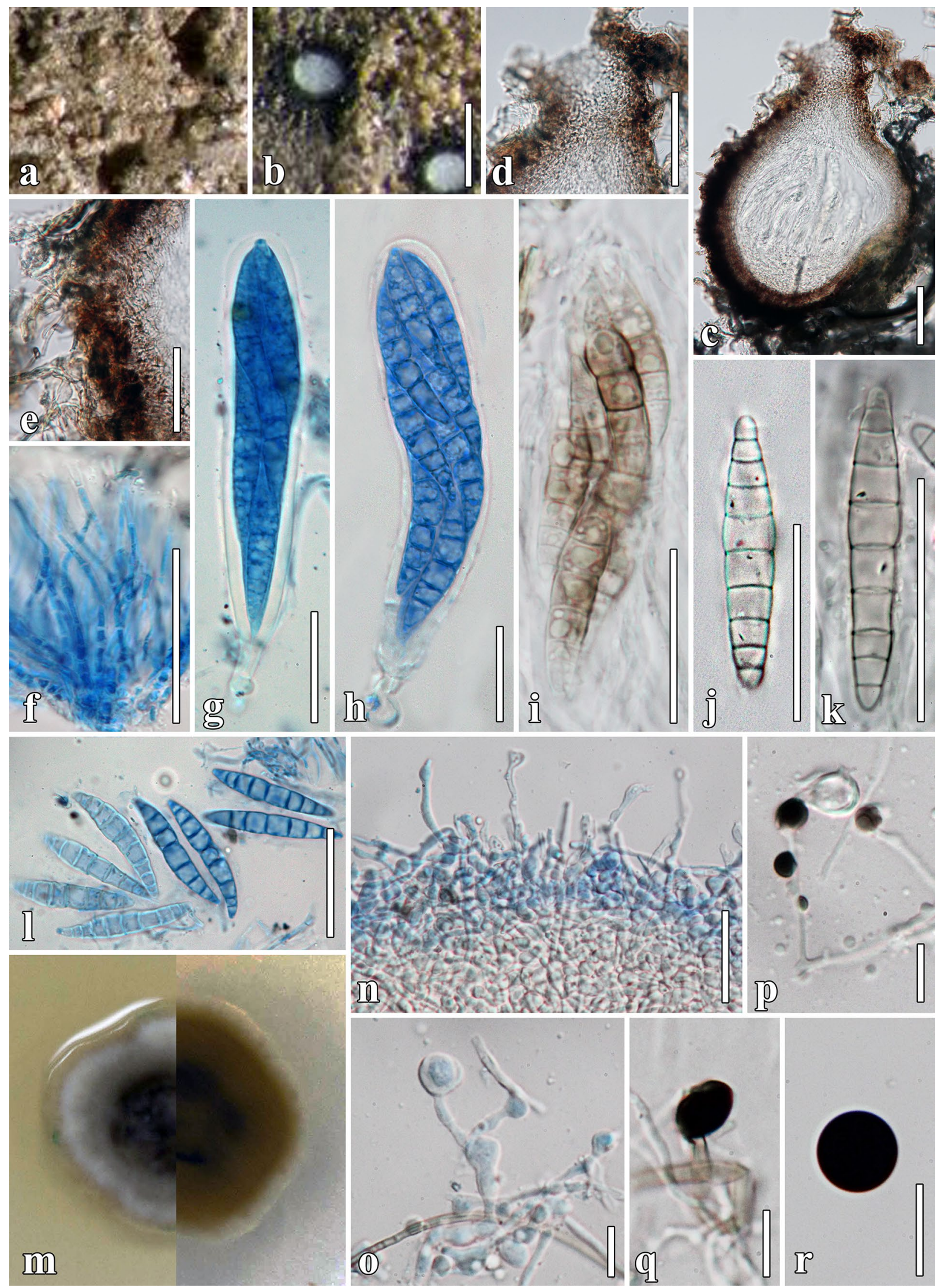


४Fig. 25 Longiostiolum tectonae (MFLU 15-3532, holotype). a, b Appearance of ascomata on host substrate. c Vertical section through ascoma. d Ostiolar canal. e Section of peridium. f Cellular pseudoparaphyses. g-i Asci. $\mathbf{j}-\mathbf{l}$ Ascospores. m Culture characters on MEA. n-q Conidiogenous cell. $\mathbf{r}$ Conidia. Scale bars: $\mathbf{b}=200 \mu \mathrm{m}, \mathbf{c}$, $\mathbf{d}=100 \mu \mathrm{m}, \mathbf{e}-\mathbf{l}=50 \mu \mathrm{m}, \mathbf{n}=10 \mu \mathrm{m}, \mathbf{o}-\mathbf{r}=5 \mu \mathrm{m}$

flattened, thin-walled cells of textura angularis, cells towards the inside lighter, inner layer composed of thin hyaline gelatinous layer. Hamathecium composed of numerous, dense, 2-3 $\mu \mathrm{m}$ wide, filamentous, branched, septate, pseudoparaphyses, embedded in a gelatinous matrix. Asci 53-105 $\times 9-12 \mu \mathrm{m}(\bar{x}=78 \times 11 \mu \mathrm{m}, \mathrm{n}=40), 8$-spored, bitunicate, fissitunicate, cylindrical-clavate to clavate, with short, bulbous pedicel, apically rounded, with an ocular chamber. Ascospores $16-19 \times 5-7 \mu \mathrm{m}(\bar{x}=16 \times 6 \mu \mathrm{m}, \mathrm{n}=40)$, biseriate or partially overlapping, hyaline, broad fusiform with acute ends, tapering towards the ends, 1-euseptate, strongly constricted at the septum, upper cell broader than lower cell, smooth-walled, with two guttules in each cell, with $2 \mu \mathrm{m}$ wide globose appendages at both ends. Asexual morph: Undetermined.

Culture characters: Colonies on MEA reaching $30 \mathrm{~mm}$ diam. after 4 weeks at $25{ }^{\circ} \mathrm{C}$. Cultures from above, dark brown, dense, circular, umbonate, rough surface, dull, undulate, radially furrowed, covered with grey aerial mycelium, oil droplets formed in the middle of cultures; reverse black radiating outwardly.

Material examined: Belgium, Flemish Brabant, Meise Botanic Garden, Bouchout Domain, dead stems of Clematis viticella, 13 June 2017, D. Ertz \& C. Gerstmans, BRCV2 (MFLU 17-1514, holotype); ex-type living culture, MFLUCC 17-2156.

Host: Clematis viticella-(This study).

Distribution: Belgium-(This study).

GenBank accession numbers: LSU: MT214559; SSU: MT226676; ITS: MT310606; tef1: MT394738.

Notes: Neovaginatispora clematidis is compatible with the concept of Neovaginatispora in having thin, uniform peridium layers with short and globose appendages at both ends (Thambugala et al. 2015). Neovaginatispora clematidis was found on Clematis viticella in Belgium whereas Neovaginatispora fuckelii has mainly been isolated from herbaceous plant in Japan except the strain MFLUCC 17-2652 that was isolated from Mangifera indica in Taiwan. Neovaginatispora clematidis is somewhat similar to the type specimen of $N$. fuckelii (CBS 101952), but being distinguishable in its broad fusiform ascospores with a single eusepta (Fig. 28). Neovaginatispora fuckelii and $N$. clematidis are reported from different continents and closely related by morphology but distinct over the five gene loci phylogeny.

In the multigene phylogenetic analyses, the strain formed a strongly supported clade with $N$. fuckelii (98\% ML/1.00
BYPP, Fig. 26). This clade contains four isolates of $N$. fuckelii and a single isolate of $N$. clematidis (Fig. 26). The ITS sequence shows six nucleotide differences while the tefl sequence has 10 nucleotide differences. In a BLASTn search of the GenBank, the ITS sequence has $98 \%$ similarity to Vaginatispora aquatica (MFLUCC 11-0083), while the tefl sequence has $93.49 \%$ similarity to V. scabrispora (LC312583). The GCPSR concept was applied to clade (a) for testing significant recombination between these isolates (Laurence et al. 2014). A pairwise homoplasy index of $\Phi \mathrm{W}=1.0$ showed that there is no significant recombination of the gene flow in $N$. clematidis and $N$. fuckelii isolates (Fig. 27a). The new species of Neovaginatispora is therefore introduced based on morphological support and phylogenetic analysis.

Pseudocapulatispora Mapook \& K.D. Hyde

Pseudocapulatispora was introduced by Mapook et al. (2020) with Pseudocapulatispora longiappendiculata as the type species. The genus is characterized by slit-like ostioles, a peridium of textura prismatica and ascospores with relatively long appendages at the end of capped sheaths. We introduce a second species of Pseudocapulatispora from Clematis subumbellata based on morphology (Fig. 29) and phylogenetic analysis (Fig. 26).

Pseudocapulatispora clematidis Phukhams. \& K.D. Hyde, sp. nov.

Index Fungorum number: IF557118; Facesoffungi number: FoF 07290, Fig. 29.

Etymology: The epithet reflects the host, Clematis.

Holotype: MFLU 17-1469.

Saprobic on dead stem of Clematis subumbellata. Sexual morph: Ascomata 197-386 × 160-252 $\mu \mathrm{m}$ $(\bar{x}=300 \times 209 \mu \mathrm{m}, \mathrm{n}=10)$, solitary, scattered, immersed, with only black shiny ostioles visible, subglobose to compressed, base flattened, coriaceous to carbonaceous at the apex, brown to black, with a developed pseudoclypeus, ostiolate. Ostioles $84-148 \times 56-86 \mu \mathrm{m}(\bar{x}=107 \times 66 \mu \mathrm{m}$, $\mathrm{n}=5$ ), with a crest-like apex, central, long, elongated and laterally compressed, surrounded by a small blackened pseudoclypeus, with irregular wall, filled with hyaline periphyses. Peridium $10-23(-38 \mu \mathrm{m}$ at apex $)$ wide $(\bar{x}=23 \mu \mathrm{m}$, $\mathrm{n}=20$ ), uniform, wider at the apex, heavily pigmented at the apex, composed of 4(-5) layers of textura prismatica, cells towards the inside lighter, inner layer composed of thin, hyaline gelatinous layer, at the apex fusing and indistinguishable from the host tissues. Hamathecium composed of numerous, dense, 1.5-3 $\mu \mathrm{m}$ wide, filamentous, branched, septate, pseudoparaphyses, situated between and above the asci, embedded in a gelatinous matrix. Asci $68-117 \times 12-22 \mu \mathrm{m}$ $(\bar{x}=99 \times 18 \mu \mathrm{m}, \mathrm{n}=40), 8$-spored, bitunicate, fissitunicate, oblong to cylindrical-clavate, with short, furcate pedicel, 


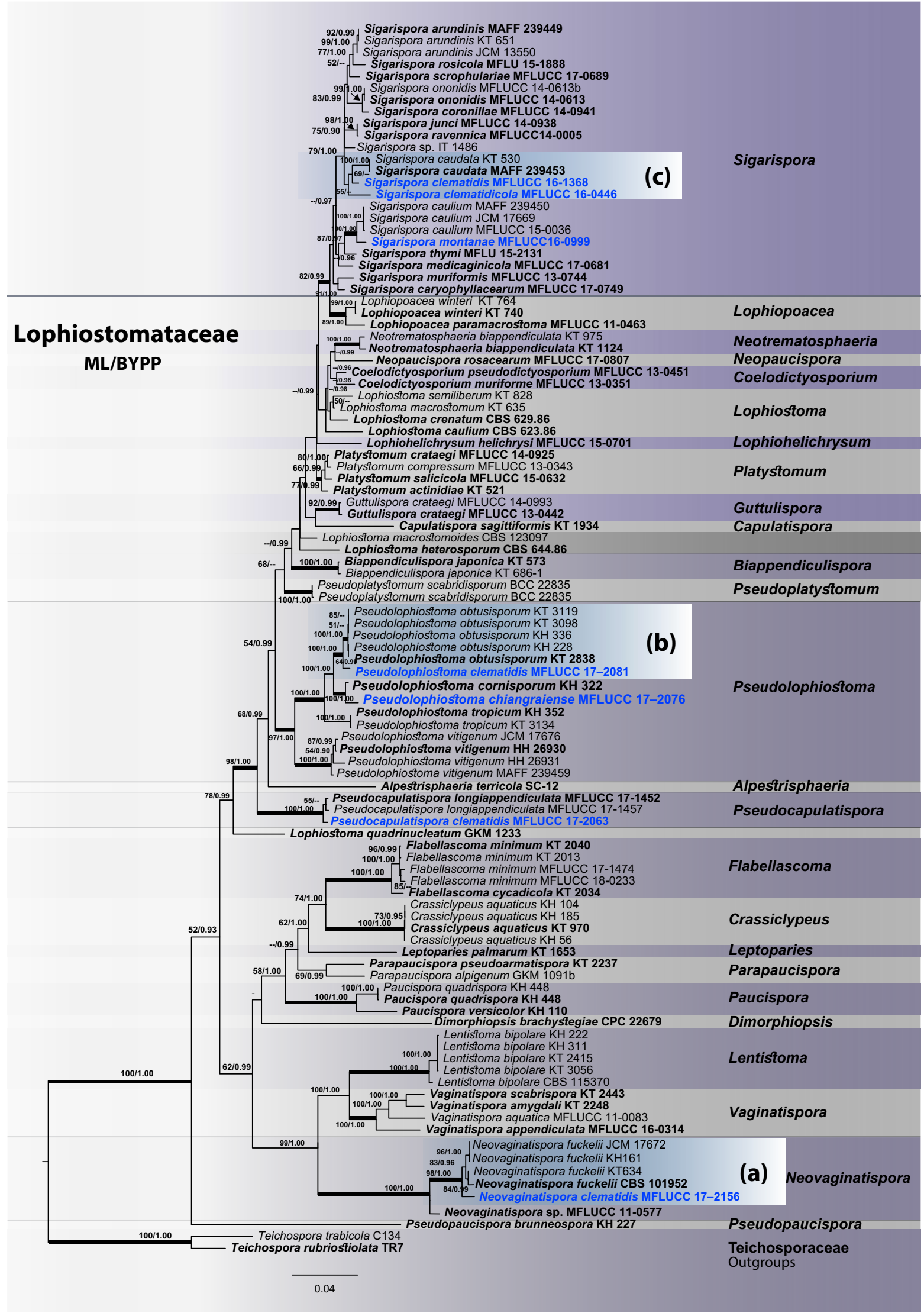


4Fig. 26 The best scoring RAxML tree with a final likelihood value of - 33003.460353 based on combined LSU, ITS, SSU, tef1 and rpb2 sequence data. The tree is rooted with Teichospora rubriostiolata (TR7) and T. trabicola (C134) in Teichosporaceae. One hundred and two strains were included in the combined sequence analyses which comprise 5255 characters (1300 characters for LSU, 921 characters for ITS, 1004 characters for SSU, 992 characters for tefl and 1038 characters for $r p b 2$, including gaps). The topology and clade stability of the combined gene analyses was compared to the single gene analyses. The tree from the maximum likelihood analysis had similar topology to the Bayesian analyses. The matrix had 1938 distinct alignment patterns with $36.36 \%$ undetermined characters or gaps proportions. Estimated base frequencies were as follows: $\mathrm{A}=0.248970$, $\mathrm{C}=0.248285, \quad \mathrm{G}=0.267331, \mathrm{~T}=0.235414 ; \quad$ substitution rates $\mathrm{AC}=1.347247, \quad \mathrm{AG}=3.679551, \quad \mathrm{AT}=1.191656, \quad \mathrm{CG}=1.272401$, $\mathrm{CT}=7.723696$, GT $=1.000000$; gamma distribution shape parameter $\alpha=0.579807$. In our analysis, GTR $+\mathrm{I}+\mathrm{G}$ model was used for each partition in Bayesian posterior analysis. The species determined in this study are indicated in blue. Bootstrap values (BS) greater than 50\% BS (ML, left) and Bayesian posterior probabilities (BYPP, right) greater than 0.90 are given at the nodes. Hyphens (-) represent support values less than 50\% BS/0.90 BYPP. Thick branches represent significant support values from all analyses at the genus level $(\mathrm{BS} \geq 70 \% / \mathrm{BYPP} \geq 0.95)$

apically rounded, with an ocular chamber. Ascospores $22-28 \times 7-12 \mu \mathrm{m}(\bar{x}=25 \times 9 \mu \mathrm{m}, \mathrm{n}=50)$, biseriate or partially overlapping, ellipsoid, tapering towards the ends, acute ends, hyaline, 1-euseptate, strongly constricted at the septum, with guttule in each cell, slightly swollen near median septum, sheath drawn out from both ends to form polar appendages, $14-25 \times 3-5 \mu \mathrm{m}(\bar{x}=19 \times 4 \mu \mathrm{m}, \mathrm{n}=50)$, end caps visible at the ends of the appendages, with a lateral pad-like structure, up to $4 \mu \mathrm{m}$ wide at side. Asexual morph: Undetermined.

Culture characters: Colonies on MEA reaching $30 \mathrm{~mm}$ diam. after 4 weeks at $25{ }^{\circ} \mathrm{C}$. Cultures from above, pale green to yellow brown in the middle, dense, circular, umbonate, surface rough, dull, fimbriate, radially furrowed, covered with yellow aerial mycelia, oil droplets formed in the middle of the culture; reverse cream radiating outwardly, yellow pigment diffusing in the agar.

Material examined: Thailand, Phayao Province, Phu Sang District, dead stems of Clematis subumbellata, 20 March 2017, C. Phukhamsakda, CMTH05 (MFLU 17-1469, holotype); ex-type living culture, MFLUCC 17-2063.

Hosts: Clematis subumbellata-(This study).

Distribution: Thailand-(This study).

GenBank accession numbers: LSU; MT214560; SSU: MT226677; ITS: MT310607; tef1: MT394739; rpb2: MT394687.

Notes: In the phylogeny (Fig. 26), this species clustered with the type species, Pseudocapulatispora longiappendiculata (Mapook et al. 2020). Morphological comparison of $P$. clematidis and $P$. longiappendiculata revealed that $P$. clematidis (Fig. 29) has larger ascomata $(300 \times 209$ vs $240 \times 135 \mu \mathrm{m})$, with shorter polar appendages $(19 \times 4 \mathrm{vs}$
$25 \times 4.5 \mu \mathrm{m})$. The tefl sequence of Pseudocapulatispora clematidis (MFLU 17-1469) had 95\% similarity to P. longiappendiculata (5\% nucleotide differences in the tefl region). Therefore, the new strain is introduced as a new species based on morphology and phylogenetic evidence.

Pseudolophiostoma Thambug., Kaz. Tanaka \& K.D. Hyde Pseudolophiostoma vitigenum is the type species. The genus was introduced for a lophiostomataceous taxon that formed a distinct clade from the type species of Lophiostoma (Hirayama and Tanaka 2011; Thambugala et al. 2015). Five species are listed in Index Fungorum (Index Fungorum 2020). We introduce two new species namely; $P$. chiangraiensis and $P$. clematidis, to accommodate species from Thailand which occurred on Clematis species (Figs. 30, 31).

Pseudolophiostoma chiangraiense Phukhams. \& K.D. Hyde, sp. nov.

Index Fungorum number: IF557119; Facesoffungi number: FoF 07291, Fig. 30.

Etymology: The epithet reflects the location where the fungus was collected.

Holotype: MFLU 17-1484.

Saprobic on dead stem of Clematis fulvicoma. Sexual morph: Ascomata 276-293×94-294 $\mu \mathrm{m}(\bar{x}=286 \times 239 \mu \mathrm{m}$, $\mathrm{n}=10$ ), solitary, scattered, sometimes gregarious, immersed, with only black shiny ostioles visible, subglobose or compressed, flattened base, coriaceous, carbonaceous at the apex, dark brown to black, with a well-developed clypeus, indistinguishable from substrate, ostiolate. Ostioles $74-127 \times 88-129 \mu \mathrm{m}(\bar{x}=94 \times 103 \mu \mathrm{m}, \mathrm{n}=5)$, with opening by a pore, central, elongated and laterally compressed, irregular wall, carbonaceous, black, filled with hyaline periphyses. Peridium $14-32 \mu \mathrm{m}$ wide $(\bar{x}=23 \mu \mathrm{m}, \mathrm{n}=20)$, uniform, wider at the apex, heavily pigmented at the apex, composed of 3(-4) layers of textura angularis and textura prismatica, thin-walled cells, cells towards inside lighter than outside, somewhat flattened, inner layer composed of thin, hyaline gelatinous layer, at the apex fusing and indistinguishable from the host tissues. Hamathecium composed of numerous, dense, 2-3 $\mu \mathrm{m}$ wide, filamentous, branched, septate, cellular pseudoparaphyses, embedded in a gelatinous matrix. Asci 78-119×11-16 $\mu \mathrm{m}(\bar{x}=96 \times 13 \mu \mathrm{m}, \mathrm{n}=40), 8$-spored, bitunicate, fissitunicate, broad cylindrical to cylindrical-clavate, with furcate pedicel, apically rounded, with an ocular chamber. Ascospores $20-32 \times 4-7 \mu \mathrm{m}(\bar{x}=26 \times 6 \mu \mathrm{m}, \mathrm{n}=50)$, uniseriate, overlapping, hyaline, becoming pale brown at senescence, broad-fusiform, tapering towards the ends, acute ends, 1-euseptate, strongly constricted at the septum, with 1(-2) guttules in each cell, slightly swollen near median septum, with 6-10 $\mu$ m wide sheath drawn-out to form polar appendages, sheath drawn out, with a pad-like structure, up to $4 \mu \mathrm{m}$ wide at side. Asexual morph: Undetermined. 
Fig. 27 The splits graph from the pairwise homoplasy index (PHI) test generated from the concatenated gene set of LSU, ITS, SSU, tef1 and $r p b 2$ sequence data of closely related species of Neovaginatispora (a), Pseudolophiostoma (b) and Sigarispora (c) using both LogDet transformation and splits decomposition. PHI test results $\left(\Phi_{\mathrm{W}}\right)<0.05$ indicates significant recombination within the dataset. The strains determined in this study are in bold and blue

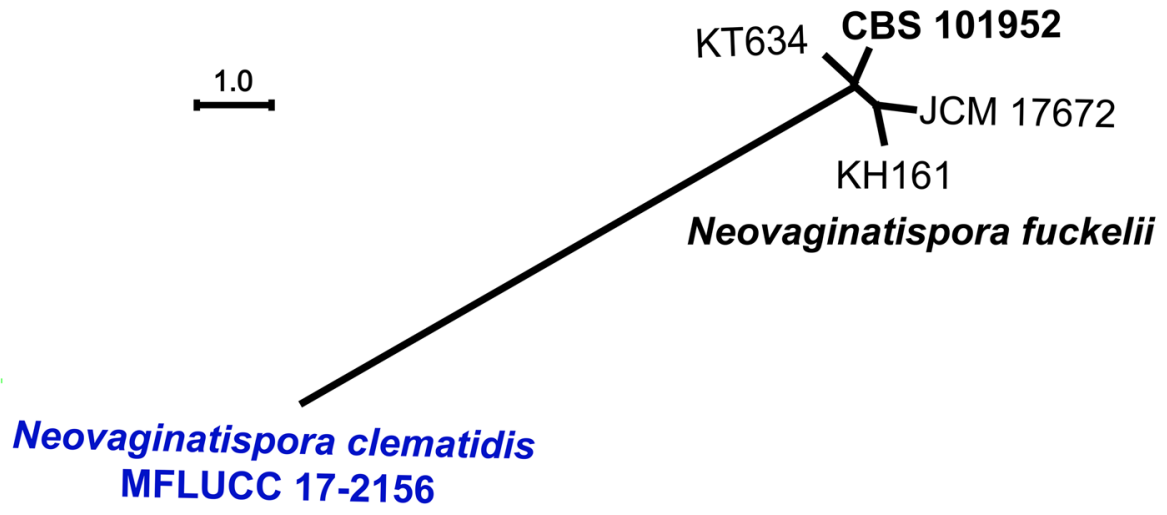

(a) $\Phi_{w}=1.0$

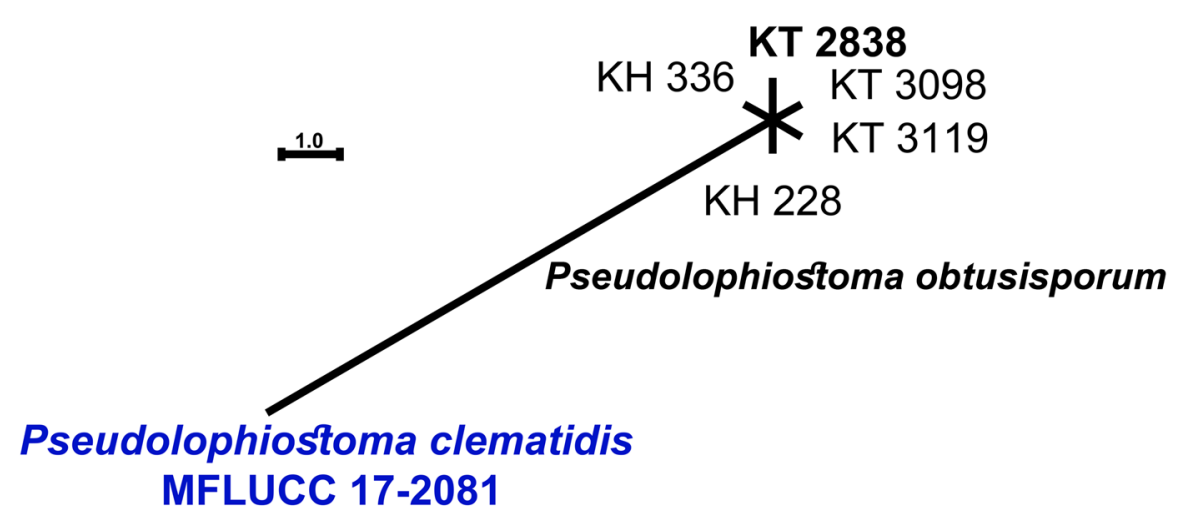

(b) $\Phi w=1.0$

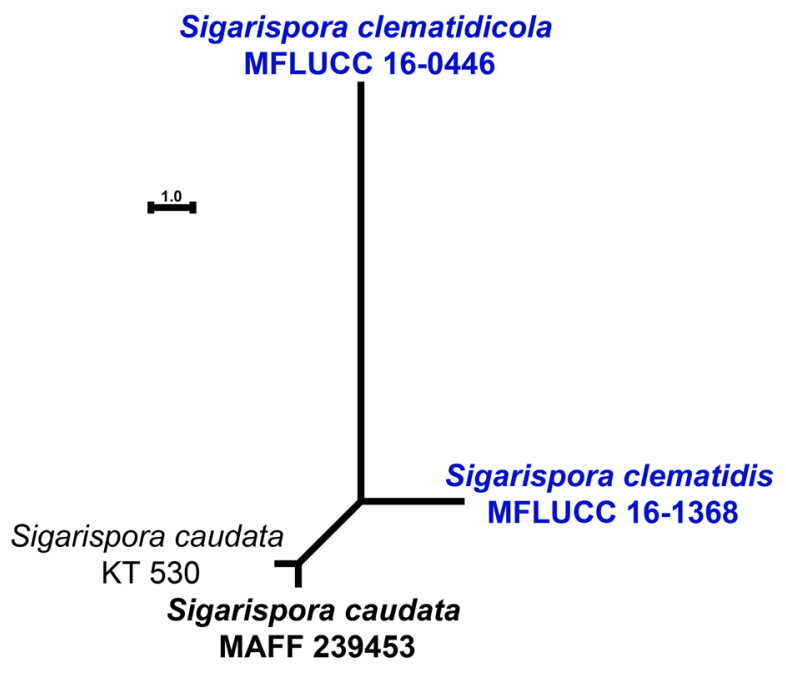

(c) $\Phi w=1.0$ 
Culture characters: Colonies on MEA reaching $30 \mathrm{~mm}$ diam. after 4 weeks at $25{ }^{\circ} \mathrm{C}$. Cultures from above, olivebrown to dark brown in the middle, dense, circular, convex with papillate surface, fluffy, rough surface, radially furrowed, covered with grey aerial mycelium, oil droplets formed in the middle of culture; reverse dark brown, radiating outwardly.

Material examined: Thailand, Chiang Rai Province, Mae Sai District, dead stems of Clematis fulvicoma, 20 March 2017, C. Phukhamsakda \& M. van de Bult, CMTH21 (MFLU 17-1484, holotype); ex-type living culture, MFLUCC 17-2076.

Host: Clematis fulvicoma-(This study).

Distribution: Thailand-(This study).

GenBank accession numbers: LSU: MT214561; SSU: MT226678; ITS: MT310608; tef1: MT394740; rpb2: MT394688.

Notes: In the phylogenetic analysis, Pseudolophiostoma chiangraiensis (MFLUCC 17-2076) formed a close relationship with $P$. cornisporum KH 322 (100\% ML/1.00 BYPP, Fig. 30). We compared P. chiangraiensis (MFLUCC 17-2076) with P. cornisporum (KH 322) and both have similar characters in being immersed, with only black shiny ostioles visible on the host, and broad-fusiform, 1-euseptate ascospores, with acute ends (Fig. 30). Ascomata of P. chiangraiensis are smaller than $P$. cornisporum $(286 \times 239$ vs 650-700 $\times 580-650 \mu \mathrm{m})$. In a BLASTn search of GenBank, the ITS sequence had $99 \%$ similarity to $P$. cornisporum $\mathrm{KH}$ 322 (NR_158930), while the $r p b 2$ gene was $98 \%$ similar to LC312602.

Pseudolophiostoma clematidis Phukhams. \& K.D. Hyde, sp. nov.

Index Fungorum number: IF557120; Facesoffungi number: FoF 07292, Fig. 31.

Etymology: The epithet reflects the host, Clematis.

Holotype: MFLU 17-1489.

Saprobic on dead stem of Clematis fulvicoma. Sexual morph: Ascomata $352-370 \times 139-243 \mu \mathrm{m}$ $(\bar{x}=358 \times 220 \mu \mathrm{m}, \mathrm{n}=10)$, solitary, scattered, immersed, with only black shiny ostioles visible, with globose to compressed, flattened base, coriaceous to carbonaceous at the apex, dark brown to black, with a developed pseudoclypeus, ostiolate. Ostiole $140-159 \times 60-80 \mu \mathrm{m}(\bar{x}=150 \times 70 \mu \mathrm{m}$, $\mathrm{n}=5$ ), with a crest-like apex and with opening by a pore, central, elongated and laterally compressed, surrounded by a small blackened pseudoclypeus, irregular wall, filled with hyaline periphyses. Peridium 9-28 $\mu \mathrm{m}$ wide $(\bar{x}=14 \mu \mathrm{m}$, $\mathrm{n}=20$ ), uniform, wider at the apex, heavily pigmented at the apex, composed of 4(-5) layers of textura prismatica, cells towards the inside lighter, somewhat flattened, inner layer composed of thin, hyaline gelatinous layer, at the apex fusing and indistinguishable from the host tissues. Hamathecium composed of numerous, dense, 2-3 $\mu$ m wide, filamentous, branched, septate, pseudoparaphyses, situated between and above the asci, embedded in a gelatinous matrix. Asci 67-106 $\times 10-14 \mu \mathrm{m}(\bar{x}=88 \times 12 \mu \mathrm{m}, \mathrm{n}=40), 8$-spored, bitunicate, fissitunicate, oblong to cylindrical-clavate, with short, furcate pedicel, apically rounded, with an ocular chamber. Ascospores $23-31 \times 5-9 \mu \mathrm{m}(\bar{x}=26 \times 7 \mu \mathrm{m}, \mathrm{n}=50)$, biseriate or partially overlapping, hyaline, broad-fusiform, tapering towards the ends, round at the end, 1-euseptate, strongly constricted at the septum, with 2(-3) guttules in each cell, slightly swollen near median septum, with $6-10 \mu \mathrm{m}$ sheath drawn out to form polar appendages, with a lateral pad-like structure, up to $3 \mu \mathrm{m}$ wide. Asexual morph: Undetermined.

Culture characters: Colonies on MEA reaching $50 \mathrm{~mm}$ diam. after 4 weeks at $25{ }^{\circ} \mathrm{C}$. Cultures from above, olive gray to dark brown in the middle, dense, circular, umbonate, surface rough, dull, fimbriate, radially furrowed, covered with grey aerial mycelium, oil droplets formed in the middle of culture; reverse: dark brown radiating outwardly.

Material examined: Thailand, Chiang Rai Province, Mae Sai District, dead stems of Clematis fulvicoma, 20 March 2017, C. Phukhamsakda \& M. van de Bult, CMTH27 (MFLU 17-1489, holotype); ex-type living culture, MFLUCC 17-2081.

Host: Clematis fulvicoma-(This study).

Distribution: Thailand-(This study).

GenBank accession numbers: LSU: MT214562; SSU: MT226679; ITS: MN393004; tef1: MT394741; rpb2: MT394689.

Notes: Pseudolophiostoma clematidis (MFLUCC 17-2081) formed a sister clade to P. obtusisporum strains (100\% ML/1.00 BYPP, Fig. 26). Pseudolophiostoma obtusisporum is commonly reported on herbaceous plants or palms in Japan (Hashimoto et al. 2018). The morphology of $P$. clematidis resembles $P$. obtusisporum except for the larger ascomata with thinner peridium (Fig. 31). A comparison of sequence data revealed that the two species differ in all studied loci (2 bp differences in ITS, $15 \mathrm{bp}$ in tefl and $13 \mathrm{bp}$ in $r b p 2$ ). In a BLASTn search of GenBank, the ITS sequence had 99\% similarity to the type specimen of Pseudolophiostoma obtusisporum (HHUF 30583), while rpb2 sequence had $98 \%$ similarity to LC 312605 , derived from the same voucher specimen.

This strain was further evaluated for secondary metabolites and biological activities. Pseudolophiostoma clematidis (MFLUCC 17-2081) showed moderate growth of microbes and cytotoxicity in vitro (Macabeo et al. 2020).

Sigarispora Thambug. \& K.D. Hyde

Sigarispora was introduced by Thambugala et al. (2015) to accommodate Lophiostoma ravennicum and some lophiostomataceous taxa that formed a separate clade from the type species of Lophiostoma. Sigarispora is characterized 

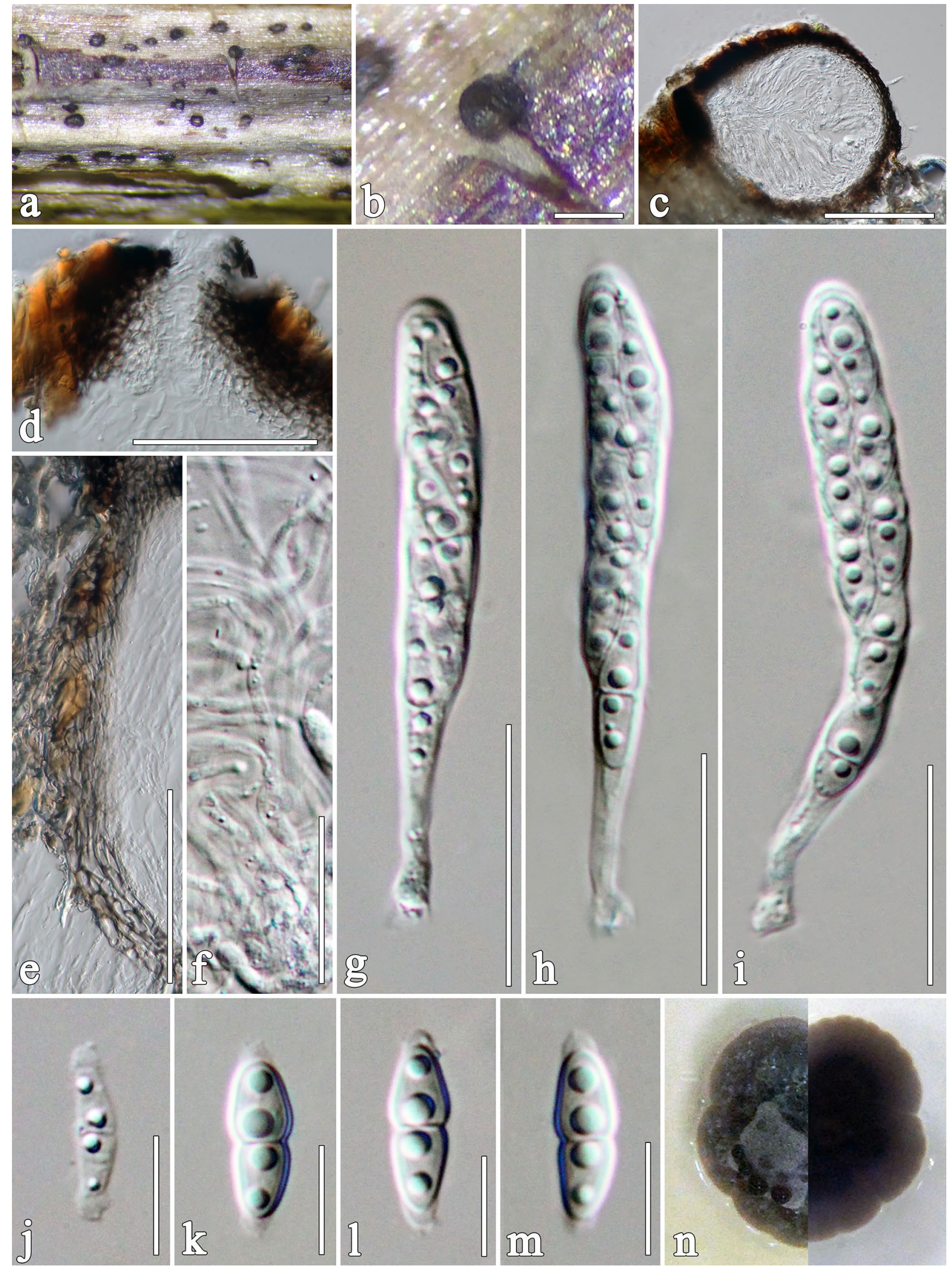
4Fig. 28 Neovaginatispora clematidis (MFLU 17-1514, holotype). a Appearance of ascomata on host surface. b Close up of ascoma on host substrate. c Vertical section through ascoma. d Ostiolar canal. e Section of peridium. f Pseudoparaphyses. $\mathbf{g}-\mathbf{i}$ Asci. $\mathbf{j}-\mathbf{m}$ Ascospores. n Culture characteristic on MEA. Scale bars: $\mathbf{b}=200 \mu \mathrm{m}, \mathbf{c}=100 \mu \mathrm{m}$, $\mathbf{d}=50 \mu \mathrm{m}, \mathbf{e}-\mathbf{i}=20 \mu \mathrm{m}, \mathbf{j}-\mathbf{n}=10 \mu \mathrm{m}$

by its immersed to semi-immersed ascomata, with a small crest-like ostioles, and brown cigar-shaped, multi-septate ascospores (Thambugala et al. 2015; Wanasinghe et al. 2018). Fourteen species are listed in Index Fungorum (Jayasiri et al. 2015; Index Fungorum 2020). We introduce three new species of Sigarispora from Clematis species, S. clematidicola, S. clematidis and S. montana (Figs. 32, 33, 34).

Sigarispora clematidicola Phukhams., Camporesi \& K.D. Hyde, sp. nov.

Index Fungorum number: IF557121; Facesoffungi number: FoF 07293, Fig. 32.

Etymology: The epithet reflects the host Clematis.

Holotype: MFLU 20-0419.

Saprobic on dead stems of Clematis vitalba. Sexual morph: Ascomata 255-288 $\times 217-254 \mu \mathrm{m}$ $(\bar{x}=276 \times 238 \mu \mathrm{m}, \mathrm{n}=10)$, solitary, scattered immersed, with only black shiny ostioles present, dark brown to black, globose to compressed, coriaceous, rough-walled, sometimes with dark brown hyphae projecting from the peridium, pseudoclypeus, ostiolate. Ostioles $60-135 \times 67-156 \mu \mathrm{m}(\bar{x}$ $=97 \times 102 \mu \mathrm{m}, \mathrm{n}=5$ ), with a crest-like apex, central, elongated and laterally compressed, irregular wall, filled with hyaline periphyses. Peridium $13-48 \mu \mathrm{m}$ wide $(\bar{x}=29 \mu \mathrm{m}$, $\mathrm{n}=20$ ), wider at the apex, thinner at the base, with 6-7 layers of lightly pigmented light brown to brown, thick-walled cells of textura angularis, lighter pigmented cells towards inside, somewhat flattened, inner layer composed of hyaline gelatinous layer, fusing and indistinguishable from the host tissues. Hamathecium numerous, dense, 2-3 $\mu \mathrm{m}$ wide, filamentous, branched, septate, pseudoparaphyses, embedded in a gelatinous matrix. Asci 101-125 $\times 12-19 \mu \mathrm{m}$ $(\bar{x}=115 \times 16 \mu \mathrm{m}, \mathrm{n}=40), 8$-spored, bitunicate, fissitunicate, broad cylindrical to clavate, with furcate pedicel, rounded at the apex, with an ocular chamber. Ascospores $22-29 \times 7-9 \mu \mathrm{m}(\bar{x}=26 \times 8 \mu \mathrm{m}, \mathrm{n}=50)$, biseriate or partially overlapping, initially hyaline, becoming yellowish brown at maturity, broad fusiform, tapering towards the end, mostly curved (3-)5-transversely euseptate, constricted at the septa, cells above central septum swollen, guttulate, indentations present, without or with 2-4 $\mu$ m sheath drawn out to form polar appendages. Asexual morph: Undetermined.

Culture characters: Colonies on MEA, slow-growing, reaching $20 \mathrm{~mm}$ diam. after 4 weeks at $25^{\circ} \mathrm{C}$. Culture centrally black dense, circular, flat, umbonate, surface rough; reverse: mycelium strongly radiating into agar, black.
Material examined: Italy, Forlì-Cesena Province, Viale Salinatore-Forlì, dead aerial branch of Clematis vitalba, 23 February 2015, E. Camporesi, IT2389-A (MFLU 20-0419, holotype); ex-type living culture, MFLUCC 16-0446.

Host: Clematis vitalba-(This study).

Distribution: Italy-(This study).

GenBank accession numbers: LSU: MT214563; SSU: MT226680; ITS: MT310609; tefl: MT394742.

Notes: Based on phylogenetic evidence, the isolates of Sigarispora caudata (KT 530, MAFF 239453), S. clematidicola (MFLUCC 16-0446) and S. clematidis (MFLUCC 16-1368) formed a moderately supported clade (Fig. 26). Sigarispora clematidicola (Fig. 32) and S. clematidis (Fig. 33) share morphological similarity such as brown ascospores with polar appendages, while $S$. caudata lacks polar appendages (Table 3). Sigarispora clematidicola, differs from $S$. clematidis in having smaller ascomata, asci and ascospores (Table 3). A pairwise comparison of tef1 sequences of S. clematidis and S. caudata showed $98 \%$ similarity with 11 nucleotide differences. The tefl sequences of $S$. clematidicola and $S$. clematidis showed 30 nucleotide differences. A pairwise homoplasy index showed $\Phi_{\mathrm{w}}=1.0$ when genealogical correlation model was applied between neighboring strains of clade (c) (Fig. 27c). The result is congruent with the phylogenetic lineages shown in Fig. 26. Thus, $S$. caudata (KT 530, MAFF 239453), S. clematidicola (MFLUCC 16-0446) and S. clematidis (MFLUCC 16-1368) are significantly different from each other based on molecular as well as morphological data.

Sigarispora clematidis Phukhams., \& K.D. Hyde, sp. nov. Index Fungorum number: IF557122; Facesoffungi number: FoF 07294, Fig. 33

Etymology: The epithet reflects the host Clematis.

Holotype: MFLU 20-0417

Saprobic on dead stem of Clematis vitalba. Sexual morph: Ascomata 416-493 ×337-386 $\mu \mathrm{m}$ ( $\bar{x}=444 \times 369 \mu \mathrm{m}, \mathrm{n}=10)$, solitary, scattered, immersed, with only black shiny ostioles visible, globose to compressed, coriaceous, dark brown to black, rough-walled, ostiolate. Ostioles $151-187 \times 107-170 \mu \mathrm{m}(\bar{x}=167 \times 129 \mu \mathrm{m}$, $\mathrm{n}=5$ ), with a crest-like apex and with opening by a pore, central, elongated and laterally compressed, irregular wall, filled with hyaline periphyses, pseudoparenchymatous cells. Peridium $6-46(-76 \mu \mathrm{m}$ at apex) wide $(\bar{x}=32 \mu \mathrm{m}$, $\mathrm{n}=20$ ), wider at the apex, thinner at the base, with lightly pigmented, thick-walled cells of textura angularis, cell towards the inside lighter, somewhat flattened, inner layer composed of thick, hyaline gelatinous layer. Hamathecium composed of numerous, dense, 1.5-2.5 $\mu \mathrm{m}$ wide, filamentous, branched, septate, pseudoparaphyses, situated between and above the asci embedded in a gelatinous matrix. Asci 96-145 × 10-18 $\mu \mathrm{m}(\bar{x}=118 \times 14 \mu \mathrm{m}, \mathrm{n}=40), 8$-spored, 

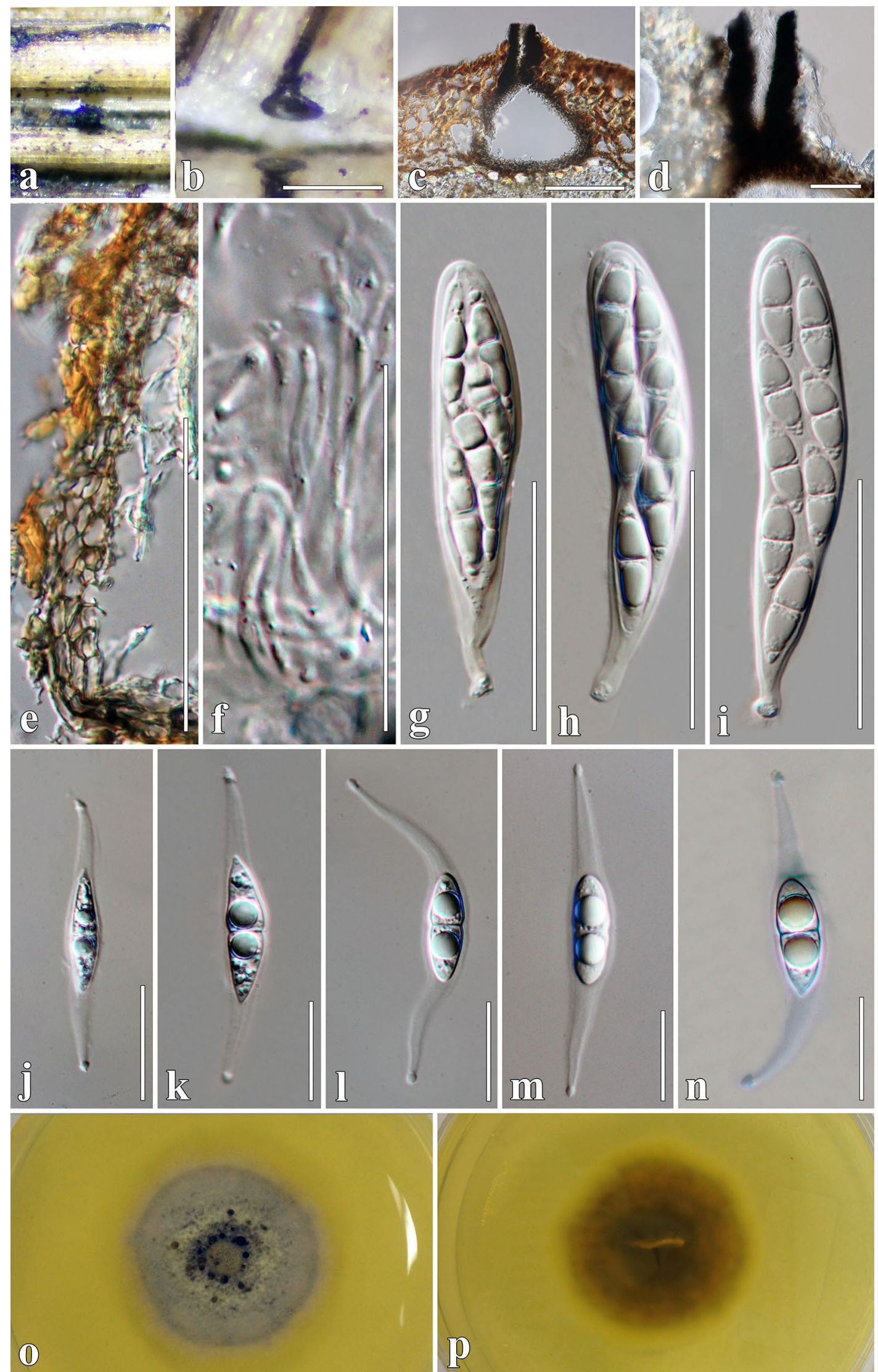
4Fig. 29 Pseudocapulatispora clematidis (MFLU 17-1469, holotype). a Appearance of ascoma on host surface. b Close up of ascoma on host substrate. c Vertical section through ascoma. d Ostiolar canal. e Section of peridium. f Pseudoparaphyses. g-i Asci. j-m Ascospores. $\mathbf{n}$ Ascospore in cotton blue showing the end chambers. $\mathbf{o}$, p Culture characteristic on MEA. Scale bars: $\mathbf{b}=500 \mu \mathrm{m}, \mathbf{c}=200 \mu \mathrm{m}$, $\mathbf{d}-\mathbf{i}=50 \mu \mathrm{m}, \mathbf{j}-\mathbf{n}=20 \mu \mathrm{m}$

bitunicate, fissitunicate, clavate, with furcate pedicel, rounded at the apex, with an ocular chamber. Ascospores 22-30 $\times 6-9 \mu \mathrm{m}(\bar{x}=24 \times 7 \mu \mathrm{m}, \mathrm{n}=60)$, biseriate or partially overlapping, broad fusiform, tapering towards the ends, initially hyaline, becoming yellowish brown at maturity, acute ends, mostly curved, 5-6 transversely eusepta, slightly constricted at the septa, cells above central septum swollen, guttulate, indentations present, with 5-10 $\mu \mathrm{m}$ long sheath drawn out to form polar appendages. Asexual morph: Undetermined.

Culture characters: Colonies on MEA reaching $50 \mathrm{~mm}$ diam. after 4 weeks at $25^{\circ} \mathrm{C}$. Cultures from above, centrally black, dense, circular, flat, umbonate, surface rough, dull, fimbriate, radially furrowed, slightly covered with white aerial mycelium; reverse: mycelium strongly radiating into the agar, black with radiating brown outwardly.

Material examined: UK, Hampshire, Swanick Lake, dead stems of Clematis vitalba, 9 July 2016, E.B.G. Jones, GJ307 (MFLU 20-0417, holotype); ex-type living culture, MFLUCC 16-1368.

Host: Clematis vitalba—(This study).

Distribution: UK-(This study).

GenBank accession numbers: LSU: MT214564; SSU: MT226681; ITS: MT310610; tef1: MT394743.

Notes: See note under Sigarispora clematidicola.

Sigarispora montanae Phukhams., Sue, K.D. Hyde, sp. nov. Index Fungorum number: IF557124; Facesoffungi number: FoF 07295, Fig. 34.

Etymology: The epithet reflects the host species, Clematis montana.

Holotype: MFLU 20-0418.

Saprobic on dead stems of Clematis montana. Sexual morph: Ascomata $180-230 \times 140-200 \mu \mathrm{m}$ $(\bar{x}=200 \times 160 \mu \mathrm{m}, \mathrm{n}=5)$, solitary, scattered, semiimmersed, with black shiny ostioles, globose, coriaceous, partial carbonaceous at the apex, dark brown to black, rough-walled, forming a clypeus like character, ostiolate. Ostioles (40-)70-100 $\times 30-60 \mu \mathrm{m}(\bar{x}=80 \times 50 \mu \mathrm{m}, \mathrm{n}=5)$, with a crest-like apex, central, elongated and laterally compressed, irregular wall, filled with hyaline periphyses. Peridium $13-30 \mu \mathrm{m}$ wide $(\bar{x}=20 \mu \mathrm{m}, \mathrm{n}=30)$, wider at the apex, thinner at the base, with 6-7 layers of lightly pigmented light brown to dark brown, thick-walled cells of textura angularis, cells towards the inside lighter, at the outside darker, inner layer composed of thick hyaline gelatinous layer, fusing and indistinguishable from the host tissues. Hamathecium composed of numerous, dense, $1.2-1.5 \mu \mathrm{m}(\bar{x}=1.3 \mu \mathrm{m}$, $\mathrm{n}=30$ ), filamentous, branched, septate, anastomosing, pseudoparaphyses, embedded in a gelatinous matrix. Asci $105-130 \times 10-14 \mu \mathrm{m}(\bar{x}=120 \times 15 \mu \mathrm{m}, \mathrm{n}=20), 8$-spored, bitunicate, fissitunicate, broad cylindrical to clavate, with a long, with furcate pedicel, rounded at the apex, with an ocular chamber. Ascospores $20-26 \times 5-7 \mu \mathrm{m}(\bar{x}=22 \times 5 \mu \mathrm{m}$, $\mathrm{n}=50$ ), biseriate or partially overlapping, broad fusiform, tapering towards the ends, initially hyaline, becoming yellowish brown at maturity, mostly curved, $3(-5)$ transversely eusepta, constricted at the septa, cells above central septum swollen, indentations present, with 3-5 $\mu \mathrm{m}$ sheath drawn out to form polar appendages. Asexual morph: Undetermined.

Culture characters: Colonies on MEA, reaching $25 \mathrm{~mm}$ diam. after 4 weeks at $16{ }^{\circ} \mathrm{C}$. Cultures from above, centrally grey, bearing cream outwardly, dense, circular, flat, umbonate, surface rough; reverse cream with dark brown.

Material examined: China, Yunnan Province, Dali District, on dead stems of Clematis montana, 20 May 2016, C. Phukhamsakda, CMCR1 (MFLU 20-0418, holotype); ex-type living culture, MFLUCC 16-0999.

Host: Clematis montana-(This study).

Distribution: China-(This study).

GenBank accession numbers: LSU: MT214565; SSU: MT226682; ITS: MT310611; tef1: MT394744.

Notes: In the phylogenetic analysis, Sigarispora montanae (Fig. 34) clustered basal to Sigarispora caulium with strong support (100\% ML/1.00 BYPP, Fig. 26). Sigarispora montanae has relatively small ascomata and longer pedicels when compared with $S$. caulium (Thambugala et al. 2015, Table 3). In a BLASTn search of GenBank, the closest matches of tefl sequence of MFLUCC 16-0999 is 96.5\% similar to S. thymi strain MFLU 15-2131 (MG829241). The tefl sequences of $S$. montanae had $98 \%$ similarity to Sigarispora caulium (MFLUCC 15-0036) with 15 nucleotide differences in the tefl region (Thambugala et al. 2015; Wanasinghe et al. 2018).

Melanommataceae Winter (=Pseudodidymellaceae)

Melanomma Nitschke ex Fuckel is the generic type (Winter 1885). Members of this family can occur on twigs or bark of various woody plants in terrestrial, marine or freshwater habitats. Melanommataceae is characterized by carbonaceous or coriaceous, gregarious, immersed to erumpent, globose to subglobose, papillate or epapillate, thick-walled, pseudoparenchymatous cells, trabeculate pseudoparaphyses, ascospores uniseriate or biseriate, fusoid to ellipsoidal, or muriform, hyaline or brown, 1 to multi-septate, with or without a mucilaginous sheath. Their asexual morphs can be hyphomycetes or coelomycetes (Sivanesan 1984; Huhndorf 1993; Liew et al. 2000; Tian et al. 2015; Wanasinghe et al. 2018). Wijayawardene et al. (2018) accepted 24 genera, 


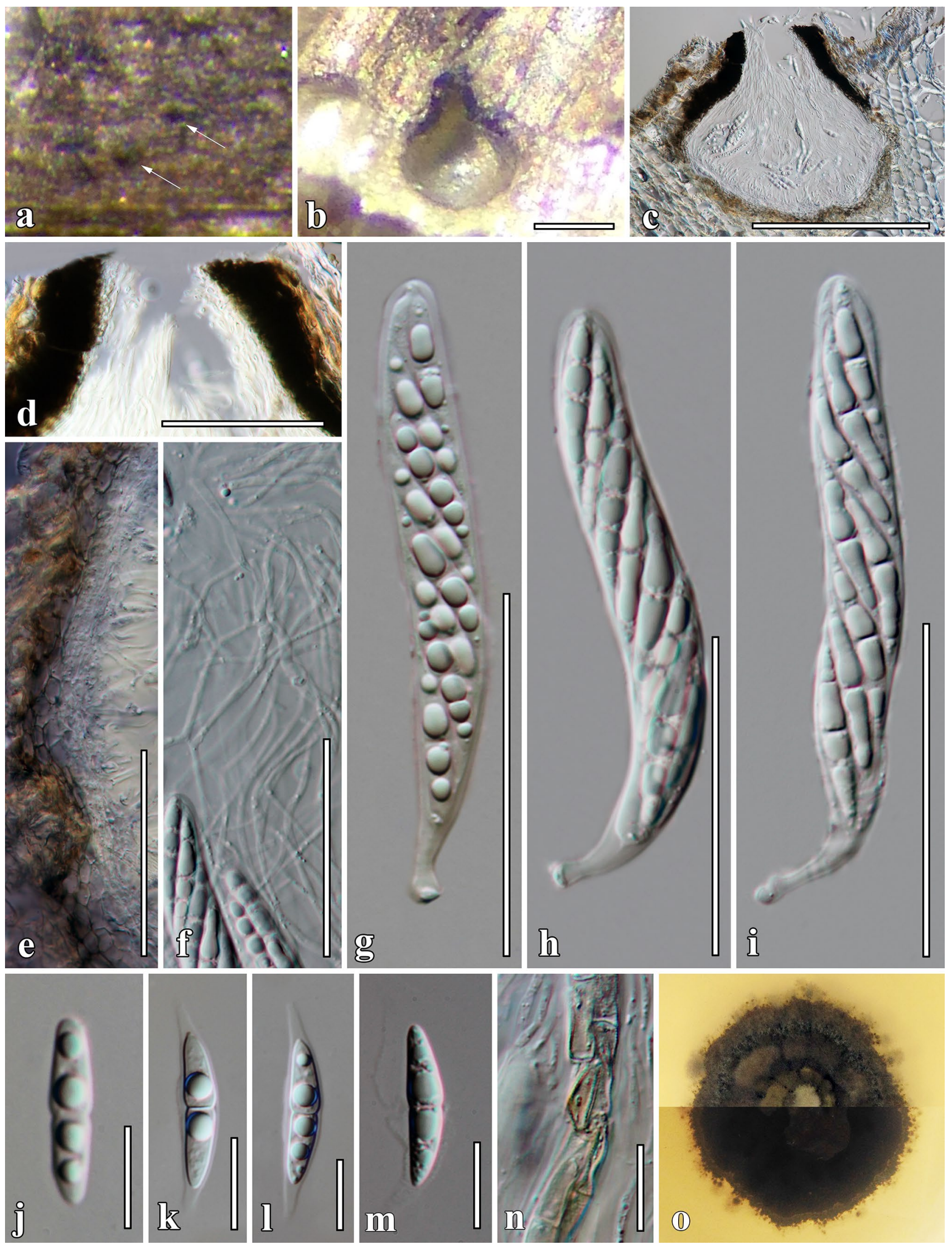


४Fig. 30 Pseudolophiostoma chiangraiense (MFLU 17-1484, holotype). a Appearance of ascoma on host surface. b Close up of ascoma on host substrate. c Vertical section of ascoma. d Ostiolar canal. e Section of peridium. f Pseudoparaphyses. g-i Asci. j-m Ascospores. n Senescent spores. o Culture characteristics on MEA. Scale bars: b, $\mathbf{c}=200 \mu \mathrm{m}, \mathbf{d}-\mathbf{i}=50 \mu \mathrm{m}, \mathbf{j}-\mathbf{n}=10 \mu \mathrm{m}$

thereafter Wanasinghe et al. (2018) introduced five more genera to Melanommataceae. An analysis of fungal collections on Clematis vitalba revealed a novel genus, Neobyssosphaeria based on a multi-gene phylogeny of LSU, SSU and ITS sequence data for Melanommataceae (Fig. 35).

Neobyssosphaeria Wanas., E.B.G. Jones \& K.D. Hyde, gen. nov.

Index Fungorum number: IF557189; Facesoffungi number: FoF 07281, Fig. 36.

Etymology: Name refers to the similarity of its morphology to Byssosphaeria.

Saprobic on decaying wood or herbaceous plants in terrestrial habitats. Sexual morph: Ascomata immersed, ostioles orange, solitary or gregarious, globose to depressedglobose, coriaceous, ostiolate. Ostioles central, papillate, opening by a pore, filled with periphyses with orange pigment around the pore. Peridium thick, multilayered, outer layer composed of reddish brown cells of textura angularis, inner layer composed of thin and hyaline cells of textura angularis. Hamathecium composed of numerous, dense, filiform, branched, anastomosing, transversely septate, trabeculate pseudoparaphyses. Asci 8 -spored, bitunicate, fissitunicate, cylindrical-clavate, pedicelate with an occular chamber. Ascospores biseriate, broadly fusiform, hyaline, constricted at the septa, guttulate in each cell, with or without a mucilaginous sheath. Asexual morph: Undetermined.

Type species: Neobyssosphaeria clematidis Wanas., Phukhams., E.B.G. Jones \& K.D. Hyde

Notes: Neobyssosphaeria is established as a monotypic genus with $N$. clematidis as the type species. Based on multigene analyses, isolate MFLUCC 17-0794 formed a basal lineage to Byssosphaeria, but this placement is not supported by the statistical analyses. Byssosphaeria is characterized by superficial ascomata with bright yellow, orange or red colouration around the ostioles, hairy hypha protruding from the outside of peridium, long pedicellate asci, and hyaline or pale brown ascospores (Barr 1990; Tian et al. 2015). Neobyssosphaeria is similar to Byssosphaeria in its orange apex (Zhang et al. 2012; Hyde et al. 2013). However, Neobyssosphaeria is distinguished by its immersed ascomata with central papilla filled with periphyses, cellular pseudoparaphyses and broad fusiform and hyaline ascospores (Fig. 36). Our taxon failed to produce an asexual morph in culture and therefore it is not possible to compare the asexual characteristics with species of Byssosphaeria. In the BLASTn search of GenBank, the closest match of the LSU region of MFLUCC 17-0794 is Uzbekistanica yakutkhanika (strain MFLUCC 17-0842) with $94.48 \%$ similarity (accession number MG829090). Uzbekistanica is however phylogenetically not closely related to our new collection (Fig. 35). Therefore, we believe it is taxonomically prudent to name our collection in a new genus until further studies are carried out with further taxonomic sampling and DNA based sequence analyses.

Neobyssosphaeria clematidis Wanas., Phukhams., E.B.G. Jones \& K.D. Hyde, sp. nov.

Index Fungorum number: IF557190; Facesoffungi number: FoF 07282, Fig. 36.

Etymology: Named after the host genus, Clematis.

Holotype: MFLU 17-0614.

Saprobic on dead stems of Clematis vitalba. Sexual morph: Ascomata 525-550 $\times 500-520 \mu \mathrm{m}$ $(\bar{x}=535 \times 510 \mu \mathrm{m}, \mathrm{n}=5)$, immersed, ostiole part orange, solitary or gregarious, globose to depressd-globose, coriaceous, indistinguishable from host tissue, brown to pale brown, rough-walled, ostiolate. Ostioles $235-270 \times 190-230 \mu \mathrm{m}$ $(\bar{x}=250 \times 200 \mu \mathrm{m}, \mathrm{n}=5)$, central, papillate, opening by a pore, filled with periphyses, with orange pigment around pore. Peridium $30-50(-70 \mu \mathrm{m}$ at apex $)$ wide, thick, multilayered, outer layer composed of heavily pigmented, reddish brown cells of textura angularis, inner layer composed of thin and hyaline cells of textura angularis. Hamathecium composed of numerous, $1.6-3 \mu \mathrm{m}(\bar{x}=2.3 \mu \mathrm{m}$, $\mathrm{n}=50$ ), dense, filiform, branched, anastomosing, septate, cellular pseudoparaphyses. Asci $160-210 \times 20-30 \mu \mathrm{m}$ $(\bar{x}=185 \times 25 \mu \mathrm{m}, \mathrm{n}=20), 8$-spored, bitunicate, fissitunicate, cylindrical, long pedicellate with a furcated base, clavate, apically rounded, with ocular chamber. Ascospores 55-75 $\times 8-14 \mu \mathrm{m}(\bar{x}=60 \times 11 \mu \mathrm{m}, \mathrm{n}=30)$, biseriate, partially overlapping, broad fusiform, sometimes inequilateral, with acute ends, hyaline, 7-euseptate, constricted at the septa, cell above median septum enlarged, with guttules in each cell, rough-walled, without mucilaginous sheath. Asexual morph: Undetermined.

Culture characters: Colonies on MEA reaching $20 \mathrm{~mm}$ diam. after 4 weeks at $16{ }^{\circ} \mathrm{C}$. Above cream with orange in the middle, with white edge, medium dense, flattened, umbonate, floccose; reverse: cream, thin, flat, circular.

Material examined: UK, Hampshire, Botley wood, on dead stems of Clematis vitalba, 25 May 2016, E.B.G. Jones, GJ 298 (MFLU 17-0614, holotype); ex-type living culture, MFLUCC 17-0794.

Host: Clematis vitalba-(This study).

Distribution: UK-(This study).

GenBank accession numbers: LSU: MT214566; SSU: MT408594. 


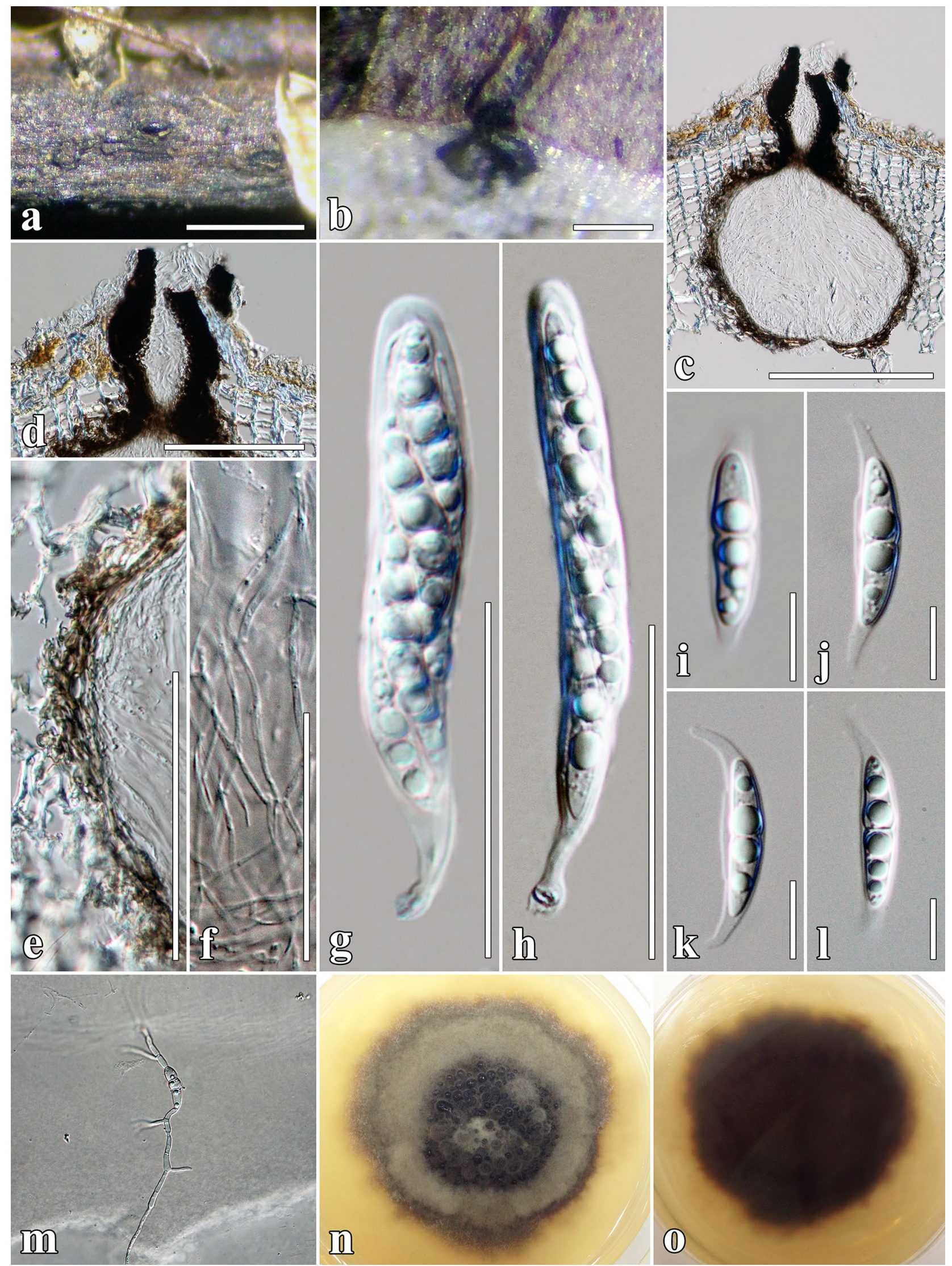


4Fig. 31 Pseudolophiostoma clematidis (MFLU 17-1489, holotype). a Appearance of ascoma on host surface. b Close-up of ascoma on host substrate. c Vertical section of ascoma. d Ostiolar canal. e Section of peridium. f Pseudoparaphyses. g-h Asci. i-l Ascospores. m Germinated ascospore n, o Culture characteristics on MEA. Scale bars: $\mathbf{a}=500 \mu \mathrm{m}, \mathbf{b}, \mathbf{c}=200 \mu \mathrm{m}, \mathbf{d}, \mathbf{e}=100 \mu \mathrm{m}, \mathbf{f}-\mathbf{h}=50 \mu \mathrm{m}, \mathbf{i}-$ $\mathbf{l}=10 \mu \mathrm{m}$

Notes: The new fungus morphologically resembles many genera in Pleosporales (e.g. Angustimassarina, Aquastroma, Aquilomyces, Carinispora, Falciformispora, Keissleriella, Lophiopoacea, Lophiostoma, Parabambusicola, Quintaria) in its cylindrical-clavate asci and hyaline, fusiform ascospores with large guttule in each cell (Zhang et al. 2012; Tanaka et al. 2015; Thambugala et al. 2015). However, these taxa are phylogenetically not closely related to Neobyssosphaeria clematidis (see Notes Neobyssosphaeria for further details). Neobyssosphaeria clematidis differs from Byssosphaeria species by its immersed ascomata, lacking hairy hypha protruding from the outside of the peridium (Tian et al. 2015).

\section{Neomassarinaceae Mapook \& K.D. Hyde}

The type genus of Neomassarinaceae is Neomassarina. The family is phylogenetically related to Sporormiaceae but the characters of the sexual morphs are different. Neomassarinaceae can be characterized by its crest-like ostiolar necks, with a carbonaceous texture, cylindrical to cylindricclavate asci and broad fusiform ascospores surrounded by a mucilaginous sheath (Thambugala et al. 2015; Tibpromma et al. 2017; Mapook et al. 2020). In this study, a dataset of LSU, SSU, ITS, tefl and rpb2 were used for phylogenetic analyses (Fig. 2). A collection associated with Clematis formed a clade related to Neomassarinaceae. Thus, we introduce a new genus Pseudohelminthosporium and a first report of the asexual morph in Neomassarinaceae (Fig. 37).

Pseudohelminthosporium Phukhams. \& K.D. Hyde, gen. nov.

Index Fungorum number: IF557191; Facesoffungi number: FoF 07283, Fig. 37.

Etymology: Referring to its similarity to Helminthosporium.

Saprobic on decaying wood or herbaceous plant material in terrestrial habitats. Sexual morph: Undetermined. Asexual morph: Colonies on host substrates, effuse, black, hairy, scattered, dark brown. Mycelium immersed from the substrate forming dark brown stroma-like aggregations. Conidiophores macronematous, simple, solitary, branched at the apex, stripes straight or flexuous, cylindrical, dark brown to reddish brown, multi-septate, with well-defined small pores at the apex, smooth or verruculose. Conidiogenous cells monotretic or polytretic, integrated, terminal on conidiophores, doliiform to oblong, pale brown. Conidia phragmosporous, acrogenous, broad fusiform or obclavate, dark brown to reddish brown, distoseptate when young, becoming euseptate at maturity, verrucose, dark brown bud scars disjunctions present at the basal position, hyaline, elongate cells at the upper end of conidia, with guttules in each cell.

Type species: Pseudohelminthosporium clematidis Phukhams. \& K.D. Hyde

Notes: Pseudohelminthosporium is established as a monotypic genus. Based on the multi-gene analysis (Fig. 2), the isolate MFLUCC 17-2086 formed a basal lineage with Neomassarina species with moderate support (0.93 BYPP). Pseudohelminthosporium is morphologically similar to $\mathrm{Hel}$ minthosporium (Massarinaceae) in having brown to dark brown phragmosporous conidia (Voglmayr and Jaklitsch 2017). Helminthosporium species have obclavate to rostrate, pale golden brown to brown conidia, with distoseptate and angular lumina. Pseudohelminthosporium is distinguishable by its solitary stipes with monotretic or polytretic conidiogenous cells, phragmosporous, broad fusiform or obclavate conidia, distoseptate when young, becoming euseptate at maturity, with hyaline, elongate cells at the upper end of the conidia and with large guttule in each cell (Fig. 37).

Pseudohelminthosporium clematidis Phukhams. \& K.D. Hyde, sp. nov.

Index Fungorum number: FoF 07284; Facesoffungi number: FoF 07284, Fig. 37.

Etymology: The epithet "clematidis" refers to the host substrate.

Holotype: MFLU 17-1494.

Saprobic on decaying wood or herbaceous plant material in terrestrial habitats. Sexual morph: Undetermined. Asexual morph: Colonies on Clematis sikkimensis effuse, black, hairy, scattered, dark brown. Mycelium immersed, on the substrate surface forming stroma-like aggregations of dark brown sheet. Conidiophores 125-435 $\times 9-20 \mu \mathrm{m}$ $(\bar{x}=230 \times 12 \mu \mathrm{m}, \mathrm{n}=20)$, macronematous, simple, solitary, branched at the apex, stipes straight or flexuous, cylindrical, erect, septate, smooth, dark brown to reddish brown, 8-14 septa, brown, well-defined small pores with dark scar at the apex, smooth or verruculose. Conidiogenous cells $17-60 \times 9-12 \mu \mathrm{m}(\bar{x}=40 \times 12 \mu \mathrm{m}, \mathrm{n}=10)$, monotretic or polytretic, integrated, terminal, becoming intercalary, doliiform to oblong, pale brown. Conidia 63-142 $\times 16-26 \mu \mathrm{m}$ $(\bar{x}=87 \times 20 \mu \mathrm{m}, \mathrm{n}=20)$, phragmosporous, acrogenous, broad fusiform or obclavate, distoseptate at the early state, 3-5-euseptate at maturity, slightly constricted at septa, dark brown to reddish brown, verrucose, gradually tapering to $13 \mu \mathrm{m}$ at the distal end, with a dark brown to black scar present at the base, subhyaline, elongate cells at the upper end of conidia, with (1-)2 guttules in each cell. 

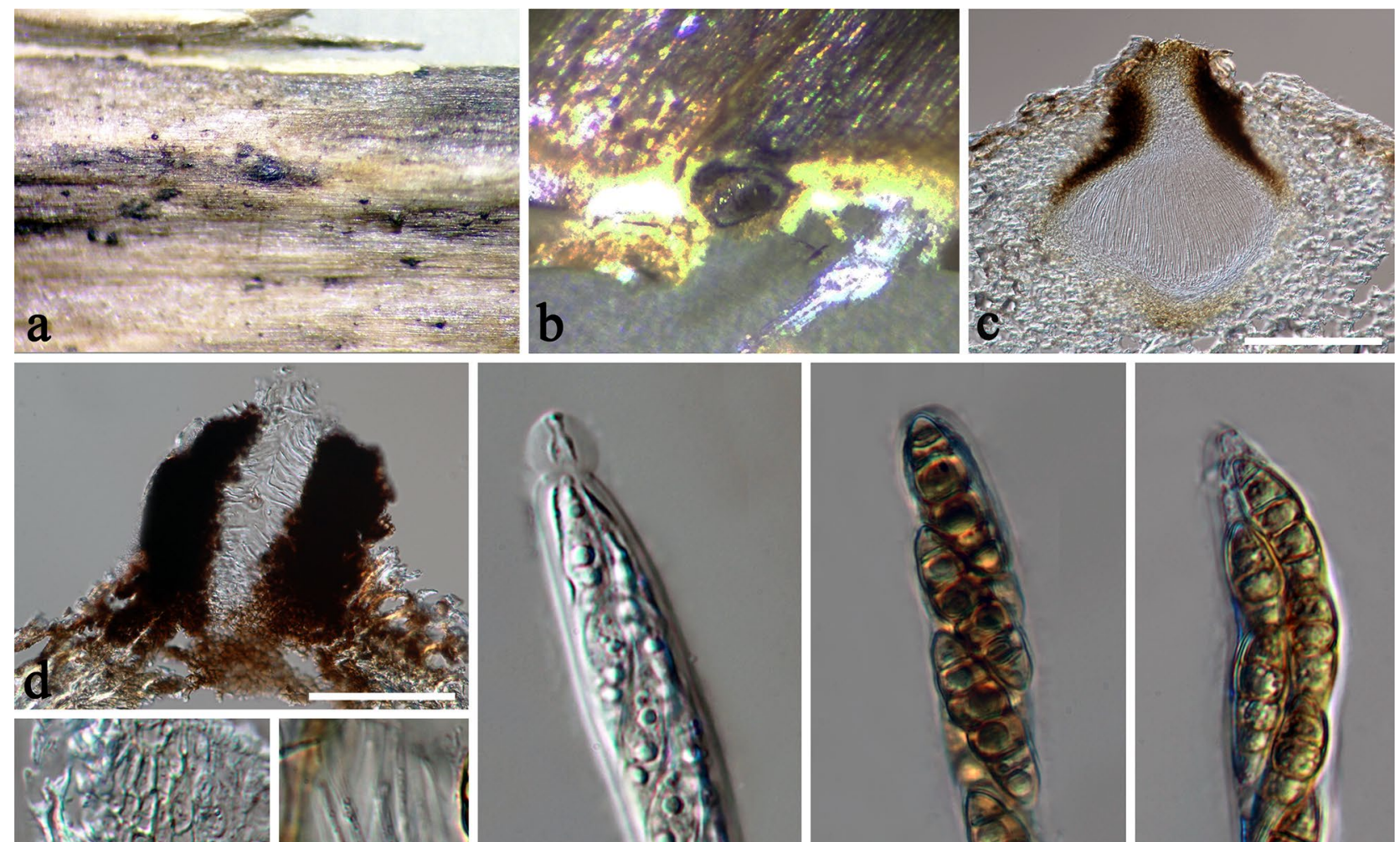

and

angers:

a) 1

(1) 20.1012.

inforis

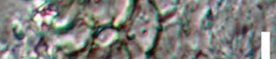

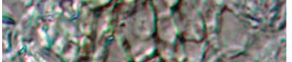

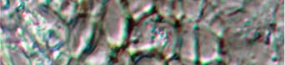

$x$ r on bu

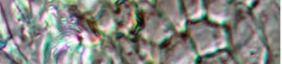

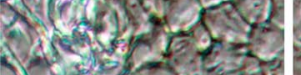
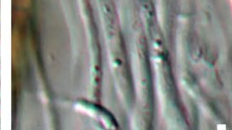

(3)
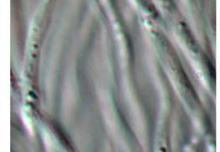

1e. 020

e nos.5.

1)

(1) $1:$

toptoral
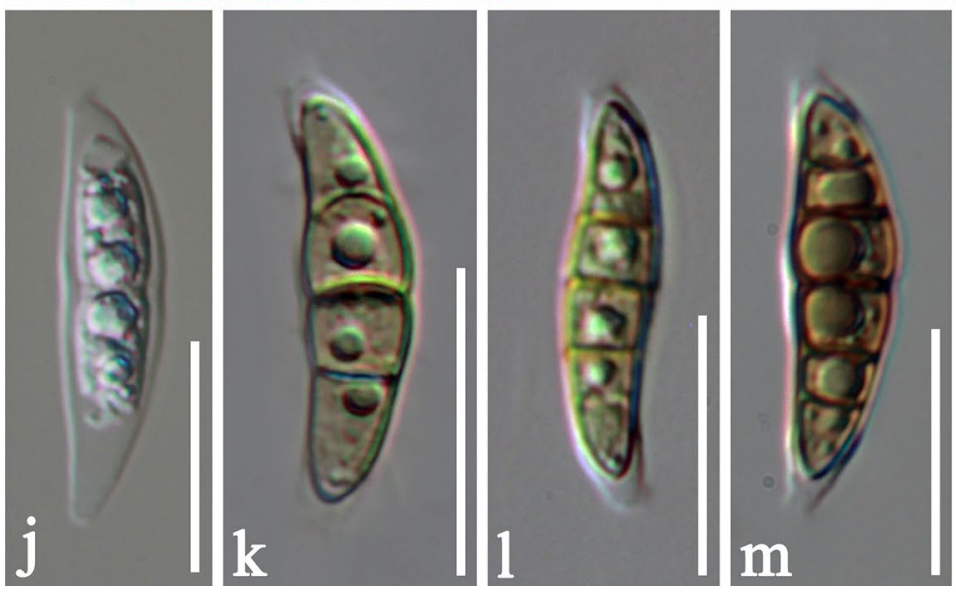

h
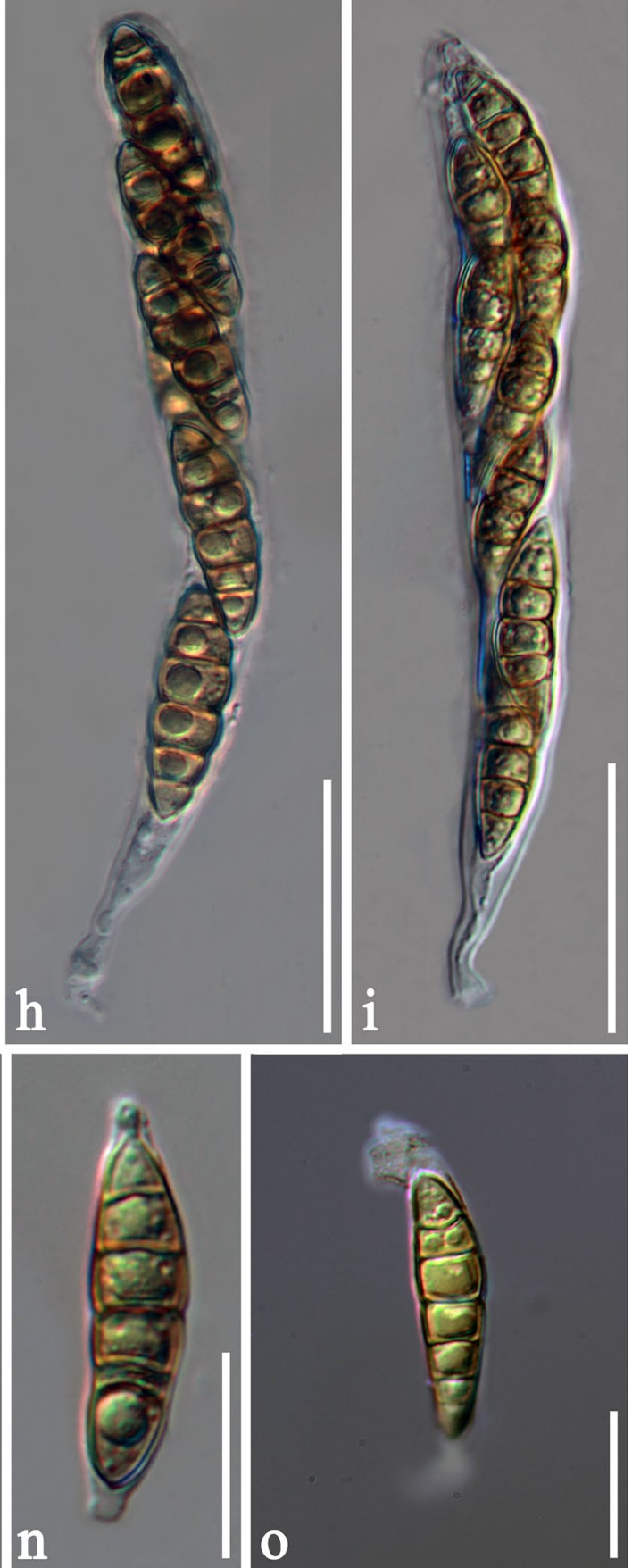
४Fig. 32 Sigarispora clematidicola (MFLU 20-0419, holotype). a Appearance of ascoma on host surface. b Close up of ascoma. c Vertical section of ascoma. d Ostiolar canal. e Peridium. f Pseudoparaphyses. g-i Asci. j-o Ascospores (o Ascospore in 10\% Indian ink; note the boundary of polar appendages). Scale bars: $\mathbf{c}, \mathbf{d}=100 \mu \mathrm{m}, \mathbf{e}$, $\mathbf{f}=50 \mu \mathrm{m}, \mathbf{g}-\mathbf{i}=20 \mu \mathrm{m}, \mathbf{j}-\mathbf{o}=10 \mu \mathrm{m}$

Culture characters: Colonies on MEA reaching $40 \mathrm{~mm}$ diam. after 4 weeks at $25^{\circ} \mathrm{C}$. Culture from above, brownish grey, dark green, white in the center, forming cream fluffy mycelium at the edge, dense, umbonate, raised with concave edge, rough, dull, lobate, radially furrowed, with brown pigment slightly diffusing into the agar; reverse dark brown.

Material examined: Thailand, Chiang Rai Province, Mae Sai District, dead stems of Clematis sikkimensis, 24 June 2017, C. Phukhamsakda \& M. van de Bult, CMTHDT02 (MFLU 17-1494, holotype); ex-type living culture, MFLUCC 17-2086.

Host: Clematis sikkimensis-(This study).

Distribution: Thailand-(This study).

GenBank accession numbers: LSU: MT214567; SSU: MT226683; ITS: MT310612; tef1: MT394627; rpb2: MT394690.

Notes: In a BLASTn search of GenBank, the closest match for the LSU sequence of MFLUCC 17-2086 was Preussia terricola strain CBS 317.65 (GQ203725) with $96.77 \%$ similarity. The closest match for the ITS region was Forliomyces uniseptata strain MFLUCC 15-0765 (NR_154006). Based on the multi-locus phylogenetic support (Fig. 2), Pseudohelminthosporium formed a separate lineage related to Neomassarina species but lacked backbone support. Therefore, Pseudohelminthosporium is treated as a distinct genus in Neomassarinaceae.

\section{Nigrogranaceae Jaklitsch \& H. Voglmayr}

Nigrogranaceae was erected to accommodate a wellsupported clade of Nigrograna in Pleosporales, with Nigrograna as the generic type (Jaklitsch and Voglmayer 2016). Nigrogranaceae was isolated from the bark of wood and is characterized by its immersed to erumpent ascomata, surrounded by a subiculum with only papillate ostioles seen on the host substrate. The remarkable characteristics of Nigrogranaceae include broad-fusiform to narrowly ellipsoid ascospores with 1-3-euseptate, and pale to chocolate brown ascospores. The asexual morph has pseudoparenchymatous pycnidia and rod-like to ellipsoid, 1-celled, hyaline or subhyaline conidia (Gruyter et al. 2013). Only Nigrograna is accepted in Nigrogranaceae (Wijayawardene et al. 2017, 2018, Fig. 38).

Nigrograna Gruyter, Verkley \& P.W. Crous

Gruyter et al. (2013) introduced Nigrograna for isolates reported as infectious human pathogen (Serrano et al. 1998;
Ahmed et al. 2018). The genus is typified by Nigrograna mackinnonii (Gruyter et al. 2013), and includes 13 species (Index Fungorum 2020) based on phylogenetic analyses of a concatenated dataset of LSU, SSU, ITS and tefl data (Fig. 38) coupled with morphology. Nigrograna chromolaenae and $N$. oblique, on Clematis species, are new host records (Figs. 39, 40).

Nigrograna chromolaenae Mapook \& K.D. Hyde, Fungal Divers (2020), new host record

Facesoffungi number: FoF 07297, Fig. 39.

Saprobic on dead stems of Clematis fulvicoma. Sexual morph: Ascomata $135-251 \times 87-238 \mu \mathrm{m}(\bar{x}=178 \times 141 \mu \mathrm{m}$, $\mathrm{n}=10$ ), on the surface of the host, solitary, gregarious, immersed, the surface of host slightly swollen, subglobose to depressed, coriaceous, dark brown to brown, smooth-walled, papillate. Ostioles $119 \times 95 \mu \mathrm{m}$, central, dark brown, filled with periphyses. Peridium 9-15 $\mu \mathrm{m}$ wide, multilayered, composed of 5-7 layers of dark brown cells of textura angularis, heavily pigmented at the outer layer, the inner layer composed of hyaline and thin layer. Hamathecium composed of numerous, $0.8-1.5 \mu \mathrm{m}$ wide $(\bar{x}=0.8 \mu \mathrm{m}, \mathrm{n}=50)$, dense, filiform, branched, septate, pseudoparaphyses, anastomosing above asci. Asci 45-60 ×7-9 $\mu \mathrm{m}(\bar{x}=46 \times 7 \mu \mathrm{m}, \mathrm{n}=30)$, 8 -spored, bitunicate, fissitunicate, cylindrical-clavate to clavate, with furcate pedicel, apically rounded, ocular chamber visible when immature. Ascospores 11-13 $\times 3-5 \mu \mathrm{m}$ $(\bar{x}=12 \times 4 \mu \mathrm{m}, \mathrm{n}=50$ ), biseriate, ellipsoid to broad fusiform, sometimes inequilateral, with rounded ends, cognac brown, (1-)3-septate, constricted at septum, cell above median septum enlarged, with guttule in each cell, smooth-walled, without mucilaginous sheath. Asexual morph: Undetermined.

Culture characters: Colonies on MEA reaching $30 \mathrm{~mm}$ diam. after 4 weeks at $25{ }^{\circ} \mathrm{C}$. Cultures from above, dark brown, covered with white mycelia in the center, dense, irregular, umbonate, lobate, velvety, with flat parchmentlike stromatic sheets; reverse dark brown, lobate.

Material examined: Thailand, Chiang Rai Province, on dead branches of Clematis fulvicoma, 20 April 2017, C. Phukhamsakda, CMTH25 (MFLU 17-1487); living culture, MFLUCC 17-2079.

Hosts: Chromolaena odorata, Clematis fulvicoma(Mapook et al. 2020; this study).

Distribution: Thailand-(Mapook et al. 2020; this study).

GenBank accession numbers: LSU: MT214568; SSU: MT226684; ITS: MT310613; tef1: MT394628; rpb2: MT394691.

Notes: Based on phylogenetic analyses (Fig. 38), MFLUCC 17-2079 clustered with Nigrograna chromolaenae (MFLUCC 17-1437). Mapook et al. (2020) introduced N. chromolaenae from a stem of Chromolaena odorata collected in Thailand. Characters of the ex-type strain such as ascomata, asci and ascospores were reported in Mapook 


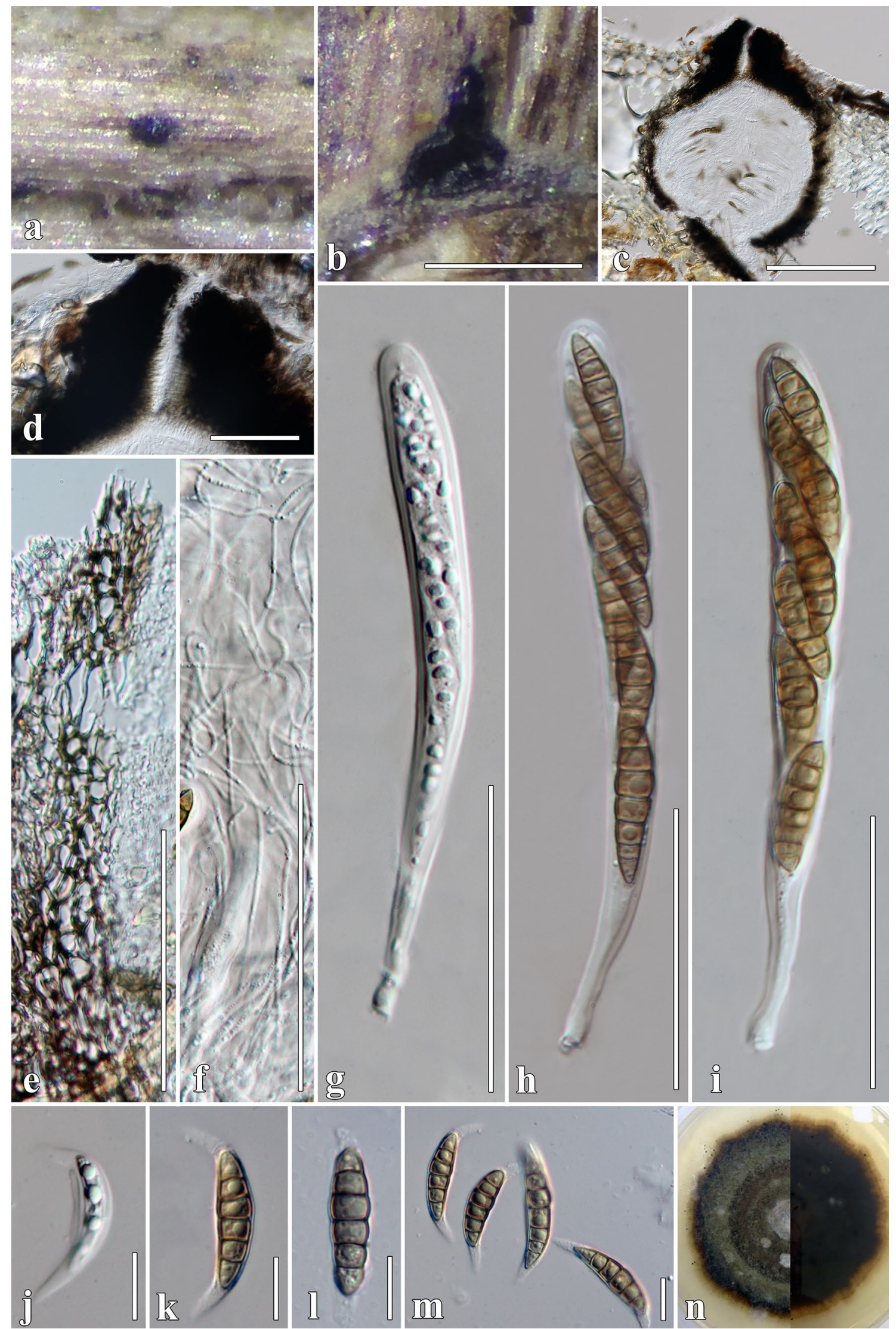


४Fig. 33 Sigarispora clematidis (MFLU 20-0417, holotype). a Appearance of ascoma on host surface. b Close up of ascoma. c Section of ascoma. d Ostiolar canal. e Section of peridium. f Pseudoparaphyses. g-i Asci. $\mathbf{j}-\mathbf{m}$ Ascospores. $\mathbf{n}$ Culture characteristics on MEA. Scale bars: $\mathbf{b}=500 \mu \mathrm{m}, \mathbf{c}=200 \mu \mathrm{m}, \mathbf{d}-\mathbf{i}=50 \mu \mathrm{m}, \mathbf{j}-\mathbf{m}=10 \mu \mathrm{m}$

et al. (2020) and were similar to our collection (Fig. 39). A comparison of the ITS and tefl sequence data revealed no significant difference between our new collection and the ex-type strain. Therefore, we introduce Nigrograna chromolaenae on Clematis as a new host record.

Nigrograna obliqua Jaklitsch \& H. Voglmayr, Studies in Mycology 85: 59 (2016), new host record

Index Fungorum number: IF817783; Facesoffungi number: FoF 07298, Fig. 40.

Saprobic on dead stems of Clematis vitalba. Sexual morph: Ascomata 193-450 × 188-294 $\mu \mathrm{m}$ $(\bar{x}=266 \times 258 \mu \mathrm{m}, \mathrm{n}=5)$, on the surface of the host, solitary, sometimes gregarious, immersed, only black shiny ostioles visible, subglobose to depressed, coriaceous, brown to reddish brown, smooth-walled, papillate. Ostioles 80-165 ×74-96 $\mu \mathrm{m}$, central, dark brown, filled with periphyses. Peridium 11-27 $\mu \mathrm{m}$ wide, with brown hyphae projecting from the outer layer, composed of 8-10 layers of dark brown cells of textura angularis, heavily pigmented at outer layer, the inner layer hyaline and thin. Hamathecium composed of numerous, $1-1.3 \mu \mathrm{m}(\bar{x}=1.2 \mu \mathrm{m}, \mathrm{n}=50)$, dense, filiform, branched, transverse septate, pseudoparaphyses. Asci $60-101 \times 10-16 \mu \mathrm{m}(\bar{x}=86 \times 12 \mu \mathrm{m}, \mathrm{n}=20), 8$-spored, bitunicate, fissitunicate, clavate to broad cylindrical, with furcate pedicel, apically rounded, ocular chamber visible when immature. Ascospores $16-20 \times 5-8 \mu \mathrm{m}(\bar{x}=18 \times 6 \mu \mathrm{m}$, $\mathrm{n}=50$ ), biseriate, overlapping, ellipsoid to broad fusiform, sometimes inequilateral, with rounded ends, initially hyaline, pale brownish to brown at the maturity, (1-)3-eusepta, constricted at septa, cell above median septum enlarged, the second cell slightly wider than others, with guttule in each cell, smooth-walled, without mucilaginous sheath. Asexual morph: Undetermined.

Culture characters: Colonies on MEA reaching $30 \mathrm{~mm}$ diam. after 4 weeks at $16{ }^{\circ} \mathrm{C}$. Cultures from above, dark brown, covered with greyish orange mycelia on the surface, dense, irregular, umbonate, lobate, velvety, flat parchment-like stromatic sheets developed, reverse dark brown, fimbriae.

Material examined: Italy, Forlì-Cesena Province, Corniolo-Santa Sofia, dead aerial branch of Clematis vitalba, 17 February 2014, E. Camporesi, IT 1726 (MFLU 16-0190); living culture, MFLUCC 14-0945.

Hosts: Clematis vitalba, Ribes uva-crispa, Salix caprea, Sambucus nigra, S. racemosa-(Jaklitsch et al. 2016; this study).
Distribution: Austria, France, Italy, UK-(Jaklitsch et al. 2016; this study).

GenBank accession numbers: LSU: MT214569; ITS: MT310614.

Notes: Our new collection is morphologically similar and phylogenetically related to the type species of Nigrograna obliqua (strain MF2). MFLUCC 14-0945 is not very different from that of the type species (Fig. 40). Jaklitsch and Voglmayr (2016) introduced four strains of $N$. obliqua from various shrubs and trees. In the phylogenetic analyses MFLUCC 14-0945 formed a close relationship with the ex-type strain reported from Salix caprea (84\% ML/0.99 BYPP). Interestingly, three strains of $N$. obliqua (BW4, KE and MRP) formed a separate clade from the type strain. However, the morphological data of $N$. obliqua strains BW4, KE and MRP were not available for comparison. We report $N$. obliqua on Clematis vitalba as a new host record (Fig. 40).

Occultibambusaceae Dai \& K.D. Hyde

Occultibambusaceae is typified by Occultibambusa D.Q. Dai \& K.D. Hyde. The species in this family are generally associated with monocotyledon such as Occultibambusa, Seriascoma, and Versicolorisporium. Doilom et al. (2017) reported Neooccultibambusa, another species from Tectona grandis and Brunneofusispora from dead wood in China. Occultibambusaceae is characterized by immersed, solitary to gregarious ascomata with ostioles, broadly cylindrical to clavate asci with broad-fusiform, hyaline to dark brown usually septate ascospores. Pycnidia are reported in the asexual morph of this family (Hatakeyama et al. 2008; Dai et al. 2017).

\section{Brunneofusispora Huang \& K.D. Hyde}

Brunneofusispora sinensis is the type species. The genus was recorded from dead wood near a river and is characterized by immersed, uniloculate ascomata, cylindrical to clavate and short pedicellate asci, and hyaline to brown, broadly fusiform ascospores (Phookamsak et al. 2019). Brunneofusispora clematidis is reported as a second species of Brunneofusispora on Clematis and is illustrated. An updated phylogenetic analysis of a concatenated dataset of LSU, tefl, ITS and SSU sequence data is presented in Fig. 41.

Brunneofusispora clematidis Phukhams. \& K.D. Hyde, sp. nov.

Index Fungorum number: IF557194; Facesoffungi number: FoF 07299, Fig. 42.

Etymology: Name refers to the host Clematis.

Holotype: MFLU 17-1478.

Saprobic on dead stems of Clematis subumbellata. Sexual morph: Ascomata 160-210 × 165-186 $\mu \mathrm{m}(\bar{x}$ 


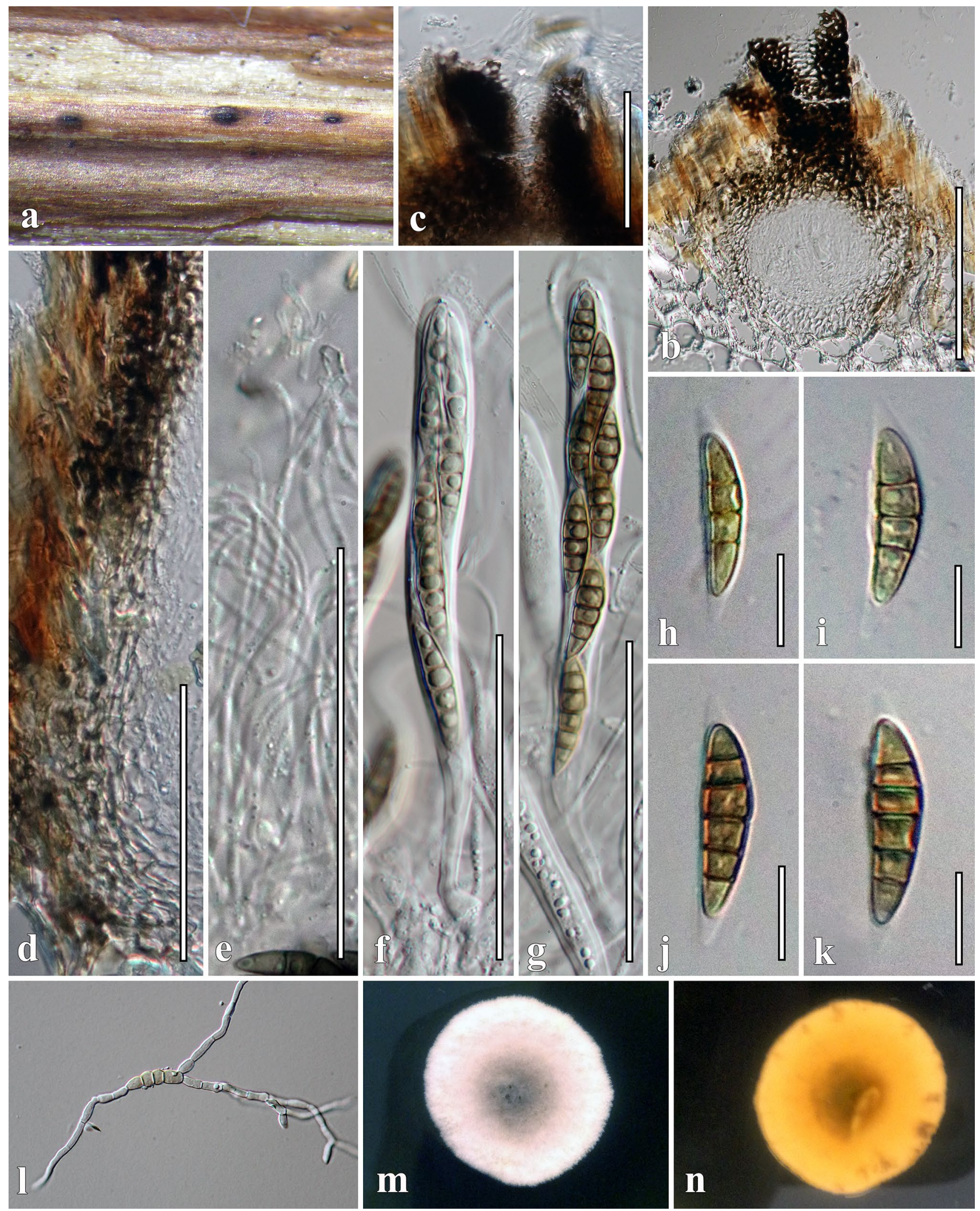

Fig. 34 Sigarispora montanae (MFLU 20-0418, holotype). a Appearance of ascomata on host surface. b Vertical section of ascoma. c Ostiolar canal. d Section of peridium. e Pseudoparaphy- ses. f, g Asci. h-k Ascospores. $\mathbf{l}$ Germinated ascospore. m, $\mathbf{n}$ Culture characteristics on MEA. Scale bars: $\mathbf{b}=100 \mu \mathrm{m}, \mathbf{c}-\mathbf{g}=50 \mu \mathrm{m}$, $\mathbf{h}-\mathbf{k}=10 \mu \mathrm{m}$ 
Table 3 Morphological comparison of known Sigarispora species

\begin{tabular}{|c|c|c|c|c|c|c|c|}
\hline \multirow[t]{2}{*}{ Species } & \multirow[t]{2}{*}{ Ascomata $(\mu \mathrm{m})$} & \multirow[t]{2}{*}{ Asci $(\mu \mathrm{m})$} & \multicolumn{3}{|l|}{ Ascospores } & \multirow[t]{2}{*}{ Host } & \multirow[t]{2}{*}{ References } \\
\hline & & & Size $(\mu \mathrm{m})$ & Septa & $\begin{array}{l}\text { Appendages } \\
(\mu \mathrm{m})\end{array}$ & & \\
\hline $\begin{array}{c}\text { Sigarispora } \\
\text { arundinis }\end{array}$ & $\begin{array}{l}320-416 \times 250- \\
310\end{array}$ & $\begin{array}{l}94- \\
112.5 \times 12.5- \\
14.5\end{array}$ & $\begin{array}{l}22-32.5 \times 6.3- \\
7.9\end{array}$ & 5 & Both ends & $\begin{array}{c}\text { Phragmites } \\
\text { australis }\end{array}$ & $\begin{array}{l}\text { Thambugala et al. } \\
\text { (2015) }\end{array}$ \\
\hline $\begin{array}{l}\text { S. caryophylla- } \\
\text { cearum }\end{array}$ & $\begin{array}{l}420-500 \times 400- \\
500\end{array}$ & $80-120 \times 10-12$ & $30-40 \times 7-8.5$ & $5-9$ & Not present & $\begin{array}{l}\text { Caryophy- } \\
\text { llaceae }\end{array}$ & $\begin{array}{l}\text { Wanasinghe et al. } \\
\text { (2018) }\end{array}$ \\
\hline S. caudata & $\begin{array}{l}145-210 \times 210- \\
305\end{array}$ & $\begin{array}{l}86- \\
112.5 \times 10.5- \\
13\end{array}$ & $\begin{array}{l}23.5- \\
34.5 \times 5.5-7\end{array}$ & $(4)-5-(6)$ & Not present & $\begin{array}{l}\text { Dactylis glom- } \\
\quad \text { erata }\end{array}$ & $\begin{array}{l}\text { Thambugala et al. } \\
\text { (2015) }\end{array}$ \\
\hline S. caulium & $\begin{array}{l}180-340 \times 200- \\
280\end{array}$ & $75-100 \times 12-14$ & $18-25 \times 5-8$ & 5 & Both ends & $\begin{array}{l}\text { Herbaceous } \\
\quad \text { Rosa canina }\end{array}$ & $\begin{array}{l}\text { Thambugala et al. } \\
\text { (2015) }\end{array}$ \\
\hline S. clematidicola & $\begin{array}{l}255-288 \times 217- \\
254\end{array}$ & $\begin{array}{l}101- \\
125 \times 12-19\end{array}$ & $22-29 \times 7-9$ & $(3-) 5$ & $2-4$ & $\begin{array}{l}\text { Clematis } \\
\text { vitalba }\end{array}$ & This study \\
\hline S. clematidis & $\begin{array}{l}416-493 \times 337- \\
386\end{array}$ & $96-145 \times 10-18$ & $22-30 \times 6-9$ & $5-6$ & $5-10$ & $\begin{array}{l}\text { Clematis } \\
\text { vitalba }\end{array}$ & This study \\
\hline S. coronillae & $\begin{array}{l}350-400 \times 390- \\
\quad 450\end{array}$ & $\begin{array}{l}120- \\
140 \times 14-17\end{array}$ & $20-26 \times 8-10$ & $\begin{array}{l}\text { 4-5 trans- } \\
\text { versely } \\
\text { eusepta, 2-4 } \\
\text { vertical septa }\end{array}$ & Not present & $\begin{array}{c}\text { Coronilla } \\
\text { emerus }\end{array}$ & $\begin{array}{l}\text { Thambugala et al. } \\
\text { (2015) }\end{array}$ \\
\hline S. junci & $\begin{array}{l}200-300 \times 200- \\
250\end{array}$ & $\begin{array}{l}120- \\
140 \times 14-18\end{array}$ & $26-33 \times 6.5-8$ & $5-7$ & $\begin{array}{l}\text { 5-8 } \mu \mathrm{m} \text { of } \\
\text { mucilaginous } \\
\text { sheath }\end{array}$ & Juncus sp. & $\begin{array}{l}\text { Wanasinghe et al. } \\
\text { (2018) }\end{array}$ \\
\hline $\begin{array}{l}\text { S. medicag- } \\
\text { inicola }\end{array}$ & $\begin{array}{l}400-500 \times 300- \\
350\end{array}$ & $80-120 \times 10-15$ & $24-28 \times 6.5-7$ & $5-6$ & $8-10$ & $\begin{array}{l}\text { Medicago } \\
\text { falcata }\end{array}$ & $\begin{array}{l}\text { Wanasinghe et al. } \\
\text { (2018) }\end{array}$ \\
\hline S. montanae & $\begin{array}{l}180-230 \times 140- \\
200\end{array}$ & $\begin{array}{l}105- \\
130 \times 10-14\end{array}$ & $20-26 \times 5-7$ & $3(-5)$ & $3-5$ & $\begin{array}{l}\text { Clematis mon- } \\
\text { tana }\end{array}$ & This study \\
\hline S. muriformis & $\begin{array}{l}425-660 \times 335- \\
560\end{array}$ & $84-130 \times 12-18$ & $18-28 \times 7-12$ & $\begin{array}{l}\text { 5-8 trans- } \\
\text { versely } \\
\text { eusepta, 2-3 } \\
\text { longitudinal } \\
\text { septa }\end{array}$ & Not present & $\begin{array}{l}\text { Helichrysum } \\
\text { italicum }\end{array}$ & $\begin{array}{l}\text { Tibpromma et al. } \\
\text { (2017) }\end{array}$ \\
\hline S. ononidis & $240 \times 311$ & $96-169 \times 17-19$ & $27-34 \times 11-12$ & $3-5$ & Not present & Ononis spinosa & Li et al. (2016) \\
\hline S. ravennica & $\begin{array}{l}211-282 \times 121- \\
187\end{array}$ & $55-70 \times 9-11$ & $18-21 \times 4-6$ & 6 & $\begin{array}{l}\text { Not present, } \\
\text { sometimes } \\
\text { with terminal } \\
\text { appendages }\end{array}$ & Poaceae & $\begin{array}{l}\text { Thambugala et al. } \\
\text { (2015) }\end{array}$ \\
\hline S. rosicola & $\begin{array}{l}400-500 \times 300- \\
350\end{array}$ & $80-120 \times 10-15$ & $17-23 \times 5-6$ & 5 & $2-5$ & Rosa sp. & $\begin{array}{l}\text { Wanasinghe et al. } \\
\text { (2018) }\end{array}$ \\
\hline S. scrophulariae & $\begin{array}{l}280-350 \times 250- \\
300\end{array}$ & $70-90 \times 10-12$ & $18-22 \times 5-6$ & $4-5$ & $2-4$ & $\begin{array}{c}\text { Scrophularia } \\
\text { donetzica }\end{array}$ & $\begin{array}{l}\text { Wanasinghe et al. } \\
\text { (2018) }\end{array}$ \\
\hline S. thymi & $\begin{array}{l}600-700 \times 450- \\
550\end{array}$ & $80-120 \times 12-16$ & $23-33 \times 6-7$ & $4-6$ & Not present & $\begin{array}{l}\text { Thymus mar- } \\
\text { shallianus }\end{array}$ & $\begin{array}{l}\text { Wanasinghe et al. } \\
\text { (2018) }\end{array}$ \\
\hline
\end{tabular}

$=185 \times 176 \mu \mathrm{m}, \mathrm{n}=5$ ), on the surface of the host, solitary, gregarious, uniloculate, semi-immersed, shiny, globose to depressed, coriaceous, dark brown to black, rough-walled, papillate, ostiolate. Ostioles $96-105 \times 86-110 \mu \mathrm{m}$, central, dark brown, filled with short periphyses. Peridium 8-17(-28) $\mu \mathrm{m}$ wide, multilayered, composed of 4-5 layers of dark brown cells of textura prismatica, heavily pigmented at outer layer, the inner layer hyaline and thin. Hamathecium composed of medium dense, $1.7-4.5 \mu \mathrm{m}$ wide $(\bar{x}=2.7 \mu \mathrm{m}$, $\mathrm{n}=50$ ), filiform, branched, septate, cellular pseudoparaphyses. Asci $45-117 \times 12-24 \mu \mathrm{m}(\bar{x}=73 \times 17 \mu \mathrm{m}, \mathrm{n}=20)$, 8 -spored, bitunicate, fissitunicate, clavate, with furcate pedicelate, apically rounded, ocular chamber visible when immature. Ascospores $17-35 \times 5-10 \mu \mathrm{m}(\bar{x}=27 \times 9 \mu \mathrm{m}$, 


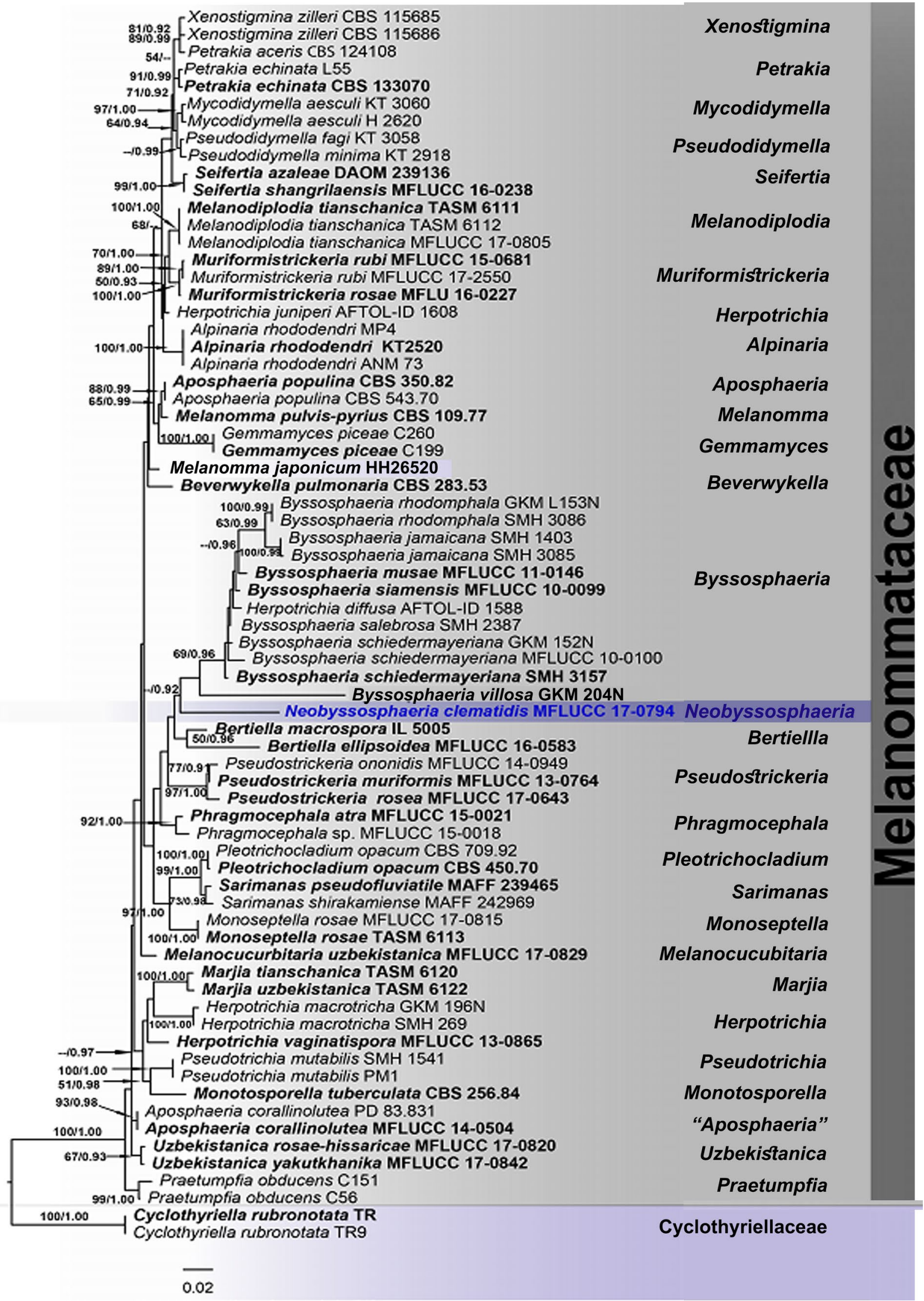


4Fig. 35 The best scoring RAxML tree with a final likelihood value of - 9510.121854 based on combined LSU, SSU and ITS sequence data for Melanommataceae. The tree is rooted with members of the Cyclothyriellaceae. Seventy-one strains were included in the combined sequence analyses which comprised 2564 characters (921 characters for LSU, 1061 characters for SSU, 582 characters for ITS, including gap regions). The matrix had 602 distinct alignment patterns, with $31.43 \%$ of undetermined characters and gaps. Estimated base frequencies were as follows; $\mathrm{A}=0.254800, \mathrm{C}=0.214111, \mathrm{G}=0.278600$, $\mathrm{T}=0.252489 ;$ substitution rates $\mathrm{AC}=2.132797, \mathrm{AG}=2.875535$, $\mathrm{AT}=1.394124, \quad \mathrm{CG}=0.797579, \quad \mathrm{CT}=9.867341, \quad \mathrm{GT}=1.000000$; gamma distribution shape parameter $\alpha=0.481484$. In our analysis, $\mathrm{GTR}+\mathrm{I}+\mathrm{G}$ model was used for each partition in Bayesian posterior analysis. The species determined in this study, is indicated in blue. Bootstrap values (BS) greater than 50\% BS (ML, left) and Bayesian posterior probabilities (BYPP, right) greater than 0.90 are given at the nodes. Hyphens (-) represent support values less than $50 \%$ BS/0.90 BYPP. The supported values from all analyses are BS $\geq 70 \%$ / $B Y P P \geq 0.95$

$\mathrm{n}=50$ ), biseriate, broad fusiform to ellipsoid, sometimes inequilateral, ends acute, initially hyaline, pale brown at maturity, 1-euseptate, constricted at septum, with guttule in each cell, smooth-walled with mucilaginous sheath. Asexual morph: Undetermined.

Culture characters: Colonies on MEA reaching $30 \mathrm{~mm}$ diam. after 4 weeks at $25{ }^{\circ} \mathrm{C}$. Cultures from above, black, with greyish orange aerial mycelia on the surface, dense, irregular, umbonate, lobate, velvety, flat, parchment-like; reverse black, fimbriae.

Material examined: Thailand, Chiang Rai Province, on dead branches of Clematis subumbellata, 20 April 2017, C. Phukhamsakda, CMTH 14 (MFLU 17-1478, holotype); ex-type living culture, MFLUCC 17-2070.

Host: Clematis subumbellata-(This study).

Distribution: Thailand-(This study).

GenBank accession numbers: LSU: MT214570; SSU: MT226685; ITS: MT310615; tef1: MT394629; rpb2: MT394692.

Notes: In the phylogenetic analysis, Brunneofusispora clematidis clustered with the type species $B$. sinensis with strong support (100\% ML/1.00 BYPP, Fig. 41). Brunneofusispora clematidis can be distinguished from B. sinensis by its thinner peridium layer (8-17(-28) vs 20-45 $\mu \mathrm{m})$ and longer ascospores (Phookamsak et al. 2019). Comparison of 607 nucleotides across the ITS region reveals 74 bp (12.2\%) differences between $B$. clematidis and B. sinensis. Therefore, B. clematidis is introduced as a new species (Fig. 42).

\section{Paradictyoarthriniaceae Doilom, Liu \& K.D. Hyde}

Paradictyoarthriniaceae was established to accommodate a hyphomycetes genus Paradictyoarthrinium (P. diffractum, type species) in aquatic and terrestrial habitats (Matsushima 1996; Liu et al. 2015, 2018). Multilocus phylogenetic analyses revealed a rock-inhibiting hyphomycete, Coniosporium olivaceum Link (三Sirodesmium olivaceum CBS 395.59) that is related to Paradictyoarthriniaceae (Ruibal et al. 2009). Wanasinghe et al. (2018) introduced the first sexual morph, Xenomassariosphaeria to Paradictyoarthriniaceae. We introduce an additional species of Xenomassariosphaeria on Clematis vitalba in Italy (Figs. 2, 43).

Xenomassariosphaeria Jayasiri, Wanas. \& K.D. Hyde

Xenomassariosphaeria was introduced for massariosphaeria-like species that formed a close relationship within Paradictyoarthriniaceae (Tanaka and Harada 2004; Wanasinghe et al. 2018). The genus is characterized by semiimmersed to erumpent, short papillate ascomata, unequal peridium of thick pseudoparenchymatous cells, cylindrical to cylindric-clavate, subsessile to short pedicellate asci, with broad fusiform, hyaline to brown, asymmetric, multiseptate ascospores (Wanasinghe et al. 2018). Based on a multigene analysis of LSU, SSU, ITS, tef1 and rpb2 sequence data (Fig. 2), Xenomassariosphaeria clematidis formed a clade with the type species $X$. rosae with strong support $(100 \%$ ML/1.00 BYPP, Fig. 2).

Xenomassariosphaeria clematidis Wanas., Phukhams., Camporesi \& K.D. Hyde, sp. nov.

Index Fungorum number: IF557112; Facesoffungi number: FoF 07350, Fig. 43.

Etymology: Epithet reflects the host Clematis.

Holotype: MFLU 16-0119.

Saprobic on dead stems of Clematis vitalba. Sexual morph: Ascomata 273-283 × 184-208 $\mu \mathrm{m}$ $(\bar{x}=275 \times 190 \mu \mathrm{m}, \mathrm{n}=5)$, solitary, scattered, immersed, with only black spot visible on the host surface, globose, coriaceous, dark brown to black, rough-walled, ostiolate. Ostioles centrally located, short papillate, with periphysoids. Peridium 12-37 $\mu \mathrm{m}$ wide, composed of 5(-7 at apex) layers of dark brown outer layers of textura angularis, inner layer composed of hyaline gelatinous cells. Hamathecium composed of numerous, $2.3-3.5 \mu \mathrm{m}$ wide $(\bar{x}=2.7 \mu \mathrm{m}$, $\mathrm{n}=50$ ), dense, filiform, septate, branched, cellular pseudoparaphyses. Asci $91-120 \times 20-28 \mu \mathrm{m}(\bar{x}=107 \times 25 \mu \mathrm{m}$, $\mathrm{n}=20$ ), 8-spored, bitunicate, fissitunicate, clavate to cylindric-clavate, with furcate pedicel, with ocular chamber visible when immature. Ascospores $27-33 \times 7-11 \mu \mathrm{m}$ $(\bar{x}=30 \times 9 \mu \mathrm{m}, \mathrm{n}=50)$, biseriate, naviculate, narrow towards the lower ends, initially hyaline, becoming yellowish to brown at maturity, 7-8 transversely eusepta, slightly constricted at the septa, third cells from apex usually enlarged, smooth-walled, guttulate and indentations present, without mucilaginous sheath. Asexual morph: Undetermined.

Culture characters: Colonies on MEA reaching $20 \mathrm{~mm}$ diam. after 4 weeks at $18{ }^{\circ} \mathrm{C}$. Cultures from above, brown radiating yellowish towards the edge, dense, circular, flat, dull, fimbriate, radially furrowed, and slightly covered with 

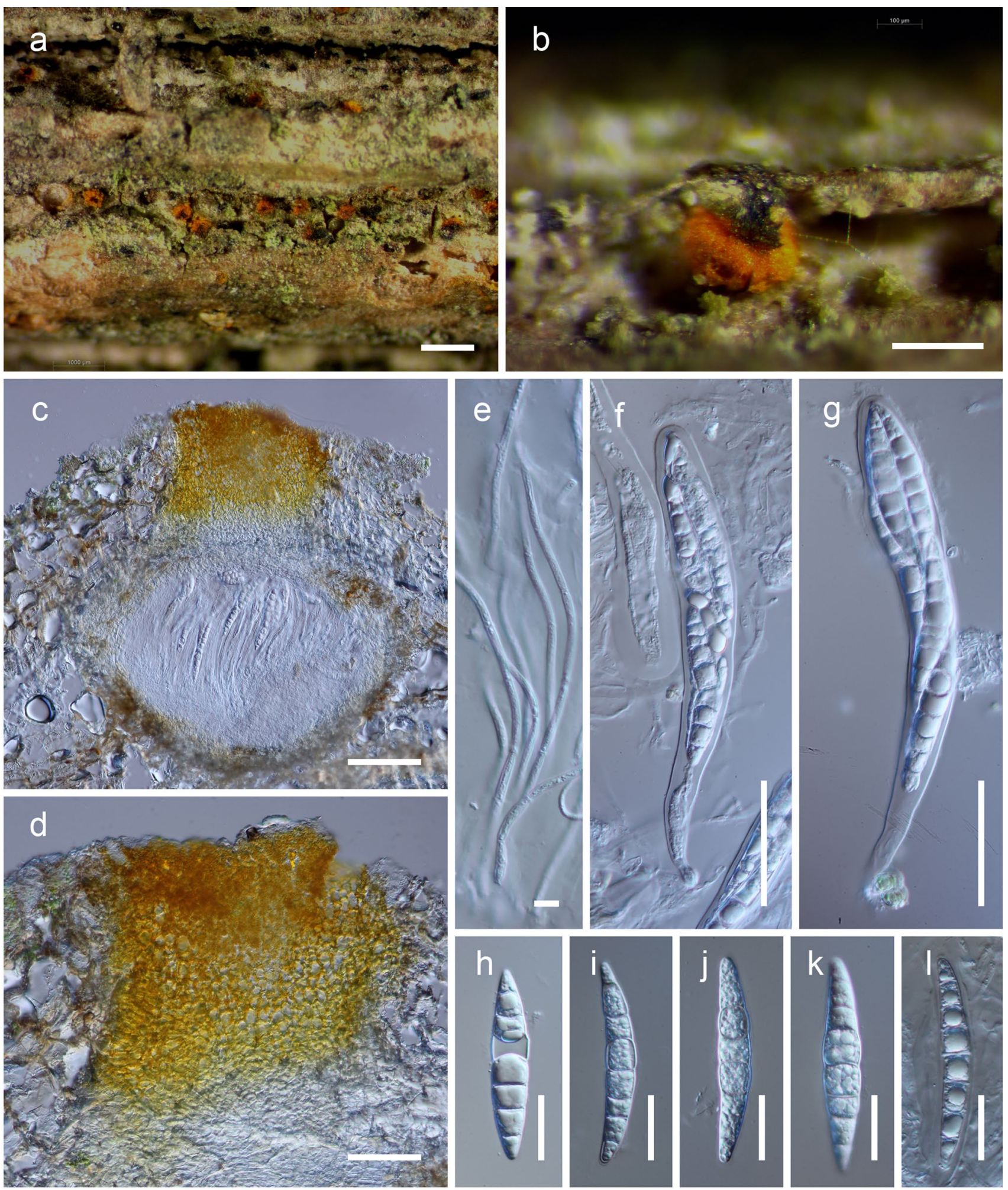

Fig. 36 Neobyssosphaeria clematidis (MFLU 17-0614, holotype). a, b Appearance of ascomata on Clematis vitalba. c Vertical section through ascoma. d Close up of ostiolar canal. e Cellular pseudopara- physes. f, $\mathbf{g}$ Asci. h-l Ascospores. Scale bars: $\mathbf{a}=1 \mathrm{~cm}, \mathbf{b}=200 \mu \mathrm{m}$, $\mathbf{c}=100 \mu \mathrm{m}, \mathbf{d}, \mathbf{f}-\mathbf{g}=50 \mu \mathrm{m}, \mathbf{e}=5 \mu \mathrm{m}, \mathbf{h}-\mathbf{l}=20 \mu \mathrm{m}$ 

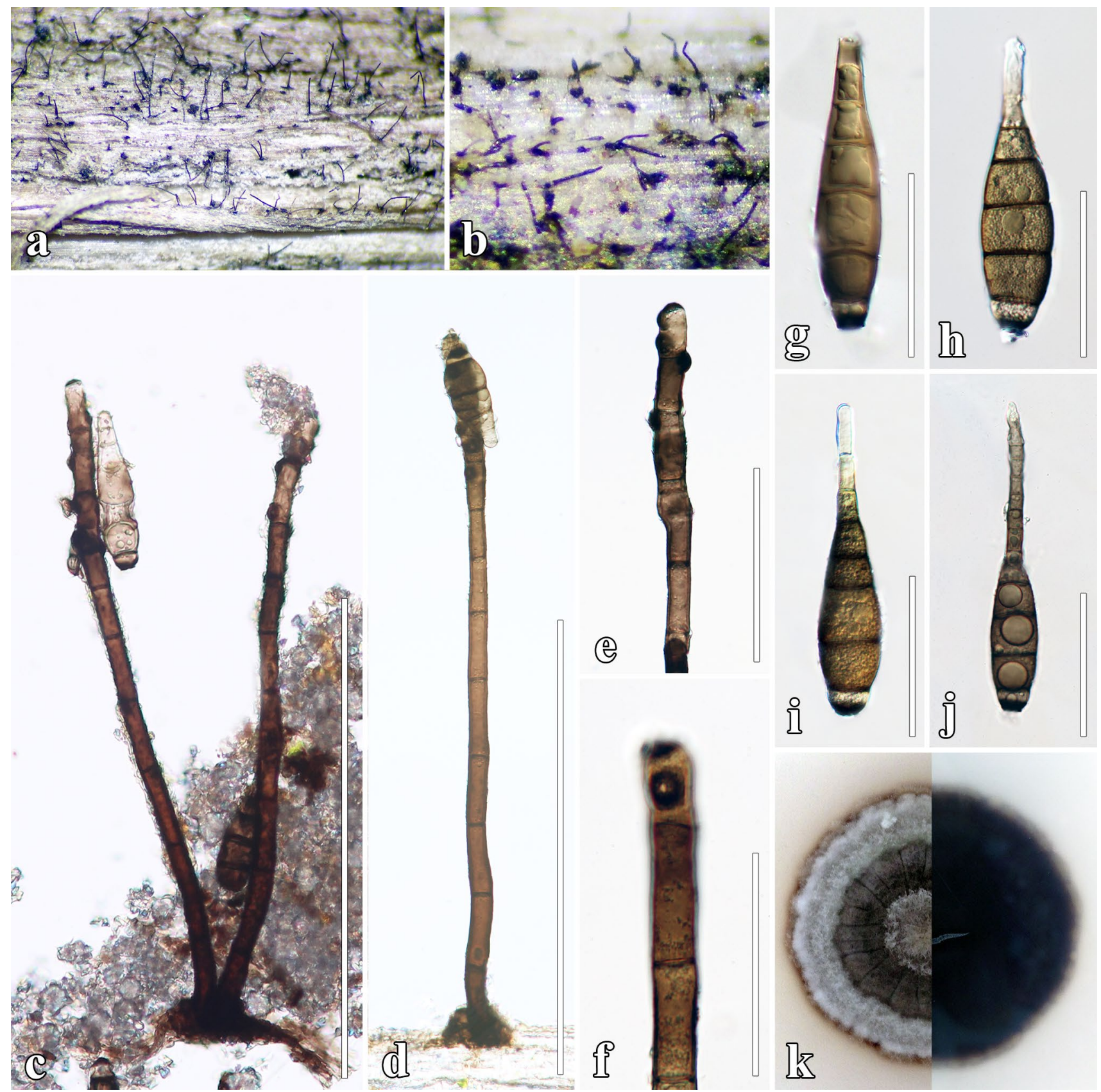

Fig. 37 Pseudohelminthosporium clematidis (MFLU 17-1494, holotype). a, b Conidiophores on natural substrate (Clematis sikkimensis). c, d Mononematous conidiophores. e, f Conidiogenous cells and

white aerial mycelium; reverse black with radiating brown mycelium.

Material examined: Italy, Forlì-Cesena Province, Poggio alla Lastra-Bagno di Romagna, dead aerial stems of Clematis vitalba, 19 January 2013, E. Camporesi, IT1019 (MFLU 16-0119, holotype); ex-type living culture, MFLUCC 14-0923.

Hosts: Clematis vitalba-(This study).

Distribution: Italy—(This study). conidia. g-j Conidia (Black basal conidia). k Culture characteristics on MEA. Scale bars: $\mathbf{c}, \mathbf{d}=500 \mu \mathrm{m}, \mathbf{e}=100 \mu \mathrm{m}, \mathbf{f}-\mathbf{j}=50 \mu \mathrm{m}$

GenBank accession numbers: LSU: MT214571; ITS: MT310616; tef1: MT394630.

Notes: In the phylogenetic analyses (Fig. 2), strain MFLUCC 14-0923 formed a close relationship with the type species Xenomassariosphaeria rosae (MFLUCC 15-0179) with strong support (100\% ML/1.00 BYPP). Xenomassariosphaeria clematidis shares common features with Xenomassariosphaeria in having immersed ascomata with thick papilla, cylindrical or clavate asci, and brown, multiseptate 


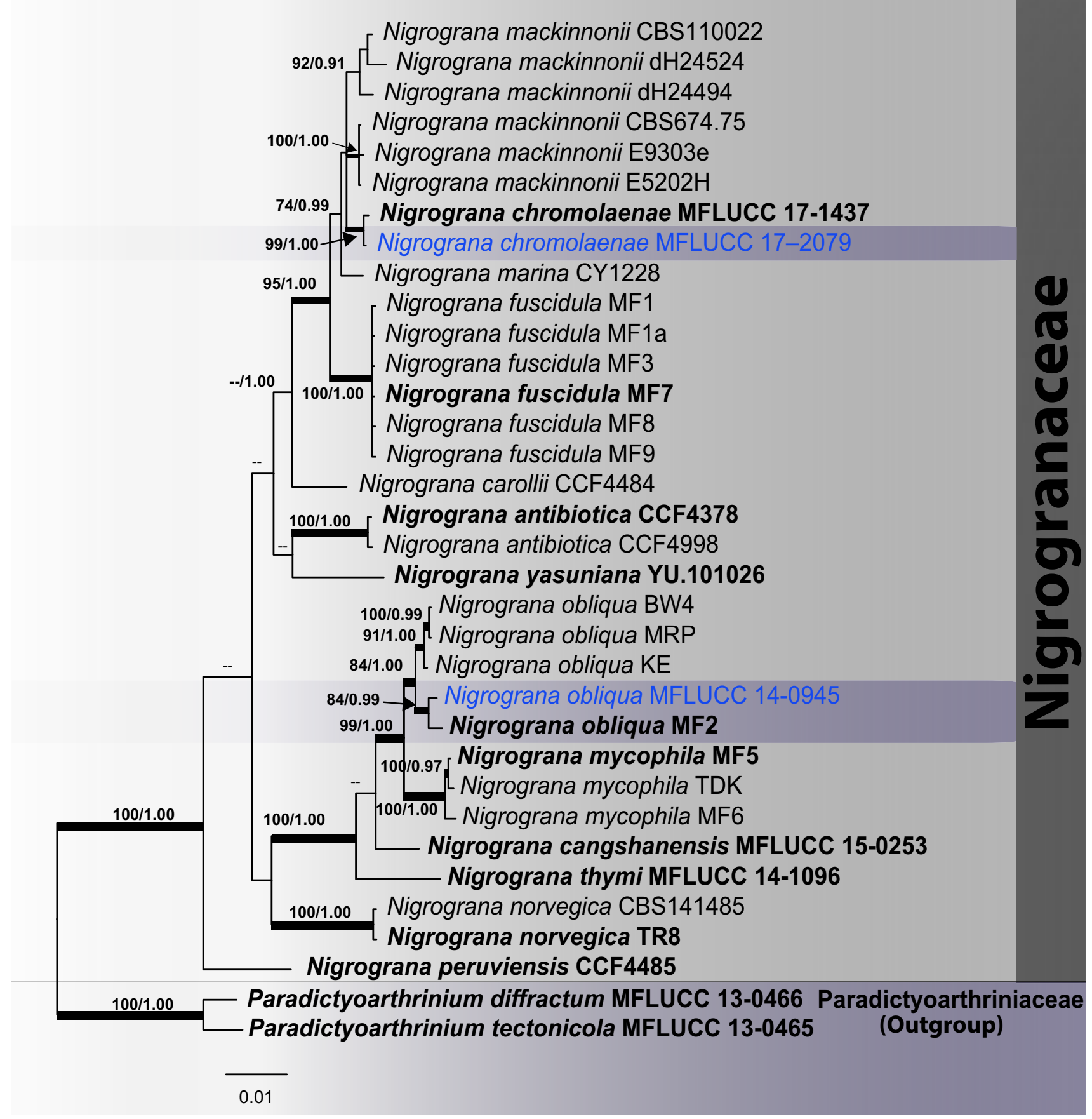

Fig. 38 The Bayesian 50\% majority-rule consensus phylogram based on combined LSU, ITS, SSU and tefl sequence data for Nigrogranaceae. The topology and clade stability of the combined gene analyses was compared to the single gene analyses. The tree is rooted with members of Paradictyoarthriniaceae. Thirty-four strains were included in the combined gene sequence analyses which comprised 3202 characters $(851$ characters for LSU, 474 characters for ITS, 1027 characters for SSU, 850 characters for tef1, including gap regions). The tree from the maximum likelihood analysis had similar topology to the Bayesian analyses. The best scoring RAxML tree had a final likelihood value of -8012.999545 . The matrix had 487 distinct alignment patterns with $20.65 \%$ of undetermined characters and gaps. Estimated base frequencies were as follows; $\mathrm{A}=0.244997$, $\mathrm{C}=0.242630, \quad \mathrm{G}=0.268950, \quad \mathrm{~T}=0.243423 ; \quad$ substitution rates $\mathrm{AC}=1.469986, \quad \mathrm{AG}=2.972149, \quad \mathrm{AT}=1.574187, \quad \mathrm{CG}=0.656303$, $\mathrm{CT}=11.538665, \mathrm{GT}=1.000000$; gamma distribution shape parameter $\alpha=0.62491$. In our analysis, GTR $+\mathrm{I}+\mathrm{G}$ model was used for each partition in Bayesian posterior analysis. The species determined in this study are indicated in blue. Bootstrap values (BS) greater than 70\% BS (ML, left) and Bayesian posterior probabilities (BYPP, right) greater than 0.90 are given at the nodes. Hyphens (-) represent support values less than $70 \% \mathrm{BS} / 0.90$ BYPP. Thick branches represent significant support values from all analyses (BS $\geq 70 \% / B Y P P \geq 0.95$ ) 
ascospores (Tanaka and Harada 2004; Wanasinghe et al. 2018). Xenomassariosphaeria clematidis is distinguished by its unique obovoid ascospores that are narrow towards the lower end, brown and multi-septate (Fig. 43).

In a BLASTn search of GenBank, the LSU sequence of $X$. clematidis (strain MFLUCC 14-0923) is $97.5 \%$ similar to $X$. roumeguerei (strain CBS 612.86, MH873692). The ITS region of $X$. clematidis (strain MFLUCC 14-0923) had 91.5\% similarity with $X$. roumeguerei (strain CBS 612.86, MH862004). Thus, we introduce a novel species, X. clematidis based on morphological and phylogenetic evidence.

\section{Periconiaceae Nann.}

Tanaka et al. (2015) verified Periconiaceae belonged in Pleosporales based on modern fungal systematics. Although sequence data is not available for the type species of Periconia (P. lichenoides), the morphological characters of extant Periconia species correspond to $P$. lichenoides (Mason and Ellis 1953; Tanaka et al. 2015). Periconiaceae is characterized by scattered, immersed to erumpent ascomata, pseudoparaphyses, oblong to cylindrical asci, and broadly fusiform, 1-septate, hyaline ascospores. Asexual characters include synnemata or noosia-like, macronematous, mononematous conidiomata, monoblastic to polyblastic, discrete and branched conidiogenous cells, and globose to ellipsoidal, aseptate, catenate, brown conidia (Tanaka et al. 2015).

\section{Periconia Tode}

Over 190 species are listed under Periconia (Index Fungorum 2020). Based on phylogenetic analyses of a concatenated dataset of LSU, ITS, and tefl sequence data coupled with morphological characters, $P$. verrucosa is described as a new species from Clematis viticella (Figs. 44, 45).

Periconia verrucosa Phukhams, Ertz, Gerstmans \& K.D. Hyde, sp. nov.

Index Fungorum number: IF557143; Facesoffungi number: FoF 07296, Fig. 45.

Etymology: The epithet "verrucosa" refers to the surface of conidia being verrucose.

Holotype: MFLU 17-1516.

Saprobic on dead stems of Clematis viticella. Sexual morph: Undetermined. Asexual morph: Colonies effuse on the natural substrate, scattered, hairy, dark brown. Mycelium partly superficial, semi-immersed, branched, composed of pale brown, septate hyphae. Conidiophores $170-296 \times 10-12 \mu \mathrm{m}(\bar{x}=225 \times 11 \mu \mathrm{m}, \mathrm{n}=20)$, macronematous, mononematous, solitary, gregarious, scattered, erect, stipes straight or slightly flexuous, with 3-4 short branches at the apex, cylindrical, smooth, dark brown, 2-4-septate, smooth or verruculose. Conidiogenous cells $11-26 \times 6-14 \mu \mathrm{m}(\bar{x}=16 \times 7 \mu \mathrm{m}, \mathrm{n}=20)$, monoblastic or polyblastic, acropetally proliferating, integrated, terminal, oblong, retrogressive, pale brown. Conidia $7-15 \mu \mathrm{m}(\bar{x}$ $=12 \mu \mathrm{m}, \mathrm{n}=50$ ), in branched chains, acrogenous, globose, aseptate, thick-walled, hyaline when immature, dark brown to reddish brown at maturity, verrucose, bud scars or disjunctors present at the site of attachment, easily separating.

Culture characters: Colonies on MEA reaching $30 \mathrm{~mm}$ diam. after 2 weeks at $25^{\circ} \mathrm{C}$. Cultures from above, cream or white, mycelia medium dense, circular, umbonate, papillate, fluffy, slightly radiating outwardly; reverse: cream at the centre, radiating outwardly.

Material examined: Belgium, Flemish Brabant, Meise Botanic Garden, Bouchout Domain, on dead stems of Clematis viticella, 13 June 2017, D. Ertz \& C. Gerstmans, BRCV4 (MFLU 17-1516, holotype); ex-type living culture, MFLUCC 17-2158.

Hosts: Artemisia sp., Sasa kurilensis, Clematis viticella(Tanaka et al. 2015; this study).

Distribution: Belgium, Japan-(Tanaka et al. 2015; this study).

GenBank accession numbers: LSU: MT214572; SSU: MT226686; ITS: MT310617; tef1: MT394631.

Notes: Phylogenetic analysis included LSU, ITS and tefl sequence data with related sequences retrieved from GenBank (Fig. 44). Periconia verrucosa (MFLUCC 17-2158) formed a strongly supported clade (96\% ML/0.99 BYPP) with three unnamed Periconia strains (KT 1820A, KT 1825 and S-900, Tanaka et al. 2015). These strains do not have morphological characters for comparison. A comparison of the ITS nucleotide bases shows that $P$. verrucosa (MFLUCC 17-2158) has one nucleotide difference with strain S-900 and one nucleotide difference with KT 1820A and KT 1825 in tefl region. This is regarded as not significant (Jeewon and Hyde 2016). We introduce $P$. verrucosa as a new species to accommodate this clade of Periconia (Fig. 45).

\section{Phaeoseptaceae Boonmee, Thambug. \& K.D. Hyde}

Phaeoseptaceae was established for lignicolous fungal lineages on wood. Five genera are included in the family: Decaisnella, Lignosphaeria, Phaeoseptum (generic type), Pleopunctum and putative strains of Thyridaria macrostomoides (Abdel-Wahab and Jones 2003; Zhang et al. 2012; Ariyawansa et al. 2015a; Thambugala et al. 2015; Hyde et al. 2018a; Liu et al. 2019; Phukhamsakda et al. 2019). Phaeoseptaceae members have ascomata immersed in host tissues, short papillate, anastomosed pseudoparaphyses, cylindrical-clavate, long pedicellate asci and broadly fusoid, single or multi-transverse septa, and hyaline to brown ascospores (Hyde et al. 2018a). Phaeoseptaceae had pycnidial or sporodochial characters as asexual morph (Liu et al. 2019). We describe a novel species of Pleopunctum recorded from Clematis in Thailand, based on a multi-gene analysis (Fig. 46) coupled with comparable morphology (Fig. 47). 


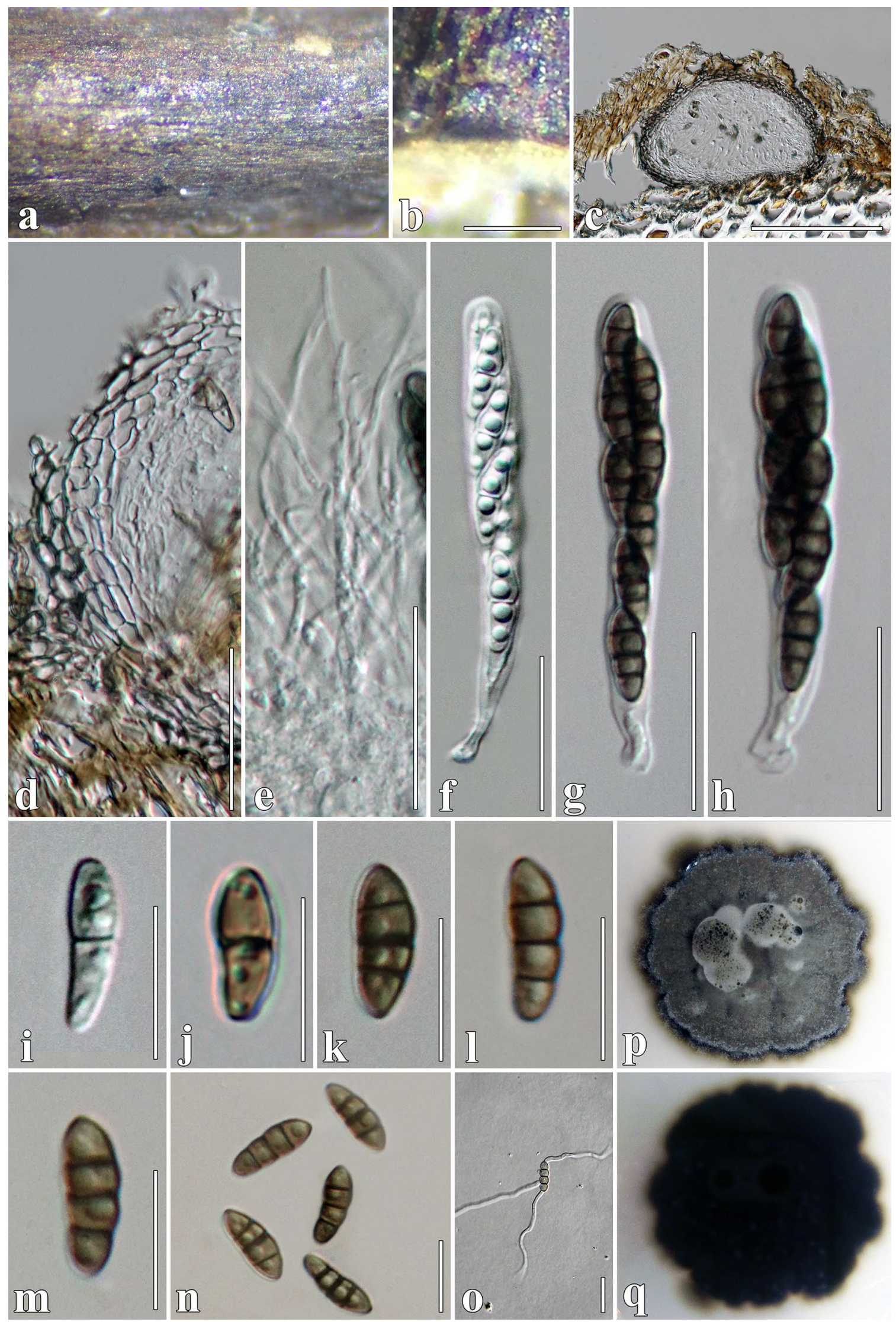


४Fig. 39 Nigrograna chromolaenae (MFLU 17-1487). a, b Appearance of ascomata on Clematis fulvicoma. c Vertical section through ascoma. d Section of peridium. e Pseudoparaphyses. f-h Asci. i-n Ascospores. o Germinated ascospore. $\mathbf{p}$, q Culture characteristics on MEA. Scale bars: $\mathbf{b}=200 \mu \mathrm{m}, \mathbf{c}=100 \mu \mathrm{m}, \mathbf{d}-\mathbf{h}=20 \mu \mathrm{m}, \mathbf{i}-\mathbf{0}=10 \mu \mathrm{m}$

\section{Pleopunctum Liu, K.D. Hyde \& J.K. Liu}

Liu et al. (2019) introduced the first asexual morph of Pleopunctum (typified by P. ellipsoideum) in Phaeoseptaceae from decaying wood collected in China. The genus is characterized by sporodochial conidiomata, macronematous, mononematous conidiophores, monoblastic conidiogenous cells and muriform conidia that have a globose basal cell. The multilocus phylogeny (LSU, SSU, ITS, tefl and rpb2) revealed a new species of Pleopunctum from Clematis based on the morphology and well supported values from multigene phylogeny (Fig. 46).

Pleopunctum clematidis Phukhams., Bhat \& K.D. Hyde, sp. nov.

Index Fungorum number: IF557139; Facesoffungi number: FoF 07301, Fig. 47.

Etymology: The epithet "clematidis" refers to the host plant, Clematis.

Holotype: MFLU 17-1499.

Saprobic on dead branch of Clematis sikkimensis Sexual morph: Undetermined. Asexual morph: Colonies on natural substrate forming sporodochial conidiomata, 168-278 $\mu \mathrm{m}$ wide, superficial, scattered, gregarious, oval, brown, velvety, glistening, orbicular, conidia readily liberated when agitated. Mycelium immersed, septate, smoothwalled, thin-walled, yellowish brown to brown hyphae, 3.5-4.5 $\mu \mathrm{m}$ wide, subicular hyphae short, medium packed. Conidiophores 6.5-15.5 ×2-5 $\mathrm{m}$, micronematous, mononematous, cylindrical or truncate, erect, smooth or finely verruculose, aseptate, unbranched, often reduced to conidiogenous cells, initially hyaline, brown at maturity. Conidiogenous cells 3-8 $\times 4-9 \mu \mathrm{m}$, holoblastic, monoblastic, integrated, terminal, determinate, cylindrical or slightly truncate, subspherical or ampulliform, hyaline. Conidia dimorphic, solitary, smooth-walled; lenticular conidia $16-33 \times 15-23 \mu \mathrm{m}(\bar{x}=25 \times 20 \mu \mathrm{m}, \mathrm{n}=50)$, muriform, smooth, broadly ellipsoidal to oval in front view, yellowish brown to brown, slightly constricted at the median septa, inner view composed of one column of 5-7 cells, end cells subhyaline to pale brown, often carrying remnant of conidiogenous cell at base; cylindrical conidia $15-35 \times 6-11 \mu \mathrm{m}$ $(\bar{x}=20 \times 8 \mu \mathrm{m}, \mathrm{n}=30)$, straight or flexuous, septate, constricted at the septa, consisting of one column, 2-3-septate, doliiform, broad clavate, narrow towards apex, apex rounded, basal cells globose or subglobose, smooth, hyaline.

Culture characters: Colonies on MEA at room temperature $\left(25^{\circ} \mathrm{C}\right)$ reaching $7 \mathrm{~cm}$ after 2 weeks. Cultures from above, circular with lobate margin, olive mycelium, white at the margin, white aerial mycelium, smooth at the surface and raised; reverse beige, not sporulating.

Material examined: Thailand, Chiang Rai Province, Doi Tung, on dried stem of Clematis sikkimensis, 2 May 2017, C. Phukhamsakda \& M.V. de Bult, CMTHDT08 (MFLU 17-1499, holotype); ex-type living culture, MFLUCC 17-2091.

Host: Clematis sikkimensis-(This study).

Distribution: Thailand-(This study).

GenBank accession numbers: LSU: MT214573; ITS: MT310618; tef1: MT394632; rpb2: MT394693.

Notes: Pleopunctum clematidis (MFLUCC 17-2091) is similar to extant species of Pleopunctum in having sporodochial conidiomata, holoblastic, monoblastic conidiogenous cells and muriform lenticular conidia (Liu et al. 2019). The strain is distinguishable from other Pleopunctum species by its yellowish brown and smaller lenticular conidia. Additionally, $P$. clematidis has dimorphic conidia on the natural substrate. The dimorphic conidia type have been documented in Hermatomycetaceae, however, P. clematidis was without subicular hyphae (Tibpromma et al. 2018; Hyde et al. 2019a, Fig. 47). The multi-gene phylogeny of LSU, SSU, ITS, tefl and $r p b 2$ sequence data revealed that $P$. clematidis formed a sister lineage to $P$. ellipsoideum (MFLUCC 19-0390) and P. pseudoellipsoideum (MFLUCC 19-0391) with strong support (100\% MP/100\% ML/1.00 BYPP, Fig. 46). In a BLASTn search of GenBank, the closest match to MFLUCC 17-2091 is Lignosphaeria fusispora (strain MFLUCC 11-0377, KP888646) with 97.78\% similarity in the LSU locus, while the closest match with the ITS sequence is $85.42 \%$ similar to KP899140.

\section{Phaeosphaeriaceae Barr}

In this family, the taxa are mostly endophytes, pathogens or saprobes in various habitats (Quaedvlieg et al. 2013; Phookamsak et al. 2014). We follow the treatment of Hyde et al. (2020a) and report a novel genus and four new species based on molecular data coupled with morphological evidence.

\section{Chaetosphaeronema Moesz}

Chaetosphaeronema hispidulum is the type species (Moesz 1915; Clements and Shear 1931). Chaetosphaeronema is characterized by immersed pycnidia with minute ostioles, enteroblastic, phialidic, determinate, discrete conidiogenous cells and cylindrical, hyaline, 1-septate conidia (Sutton 1980; Hyde et al. 2016). Ophiobolus cirsii (MFLUCC13-0218) is closely related to Chaetosphaeronema as suggested by Zhang et al. (2012). Five species are accepted under Chaetosphaeronema with two strains having sequence data (Phookamsak et al. 2019). Our phylogenetic analysis (Fig. 48) revealed two new species of 

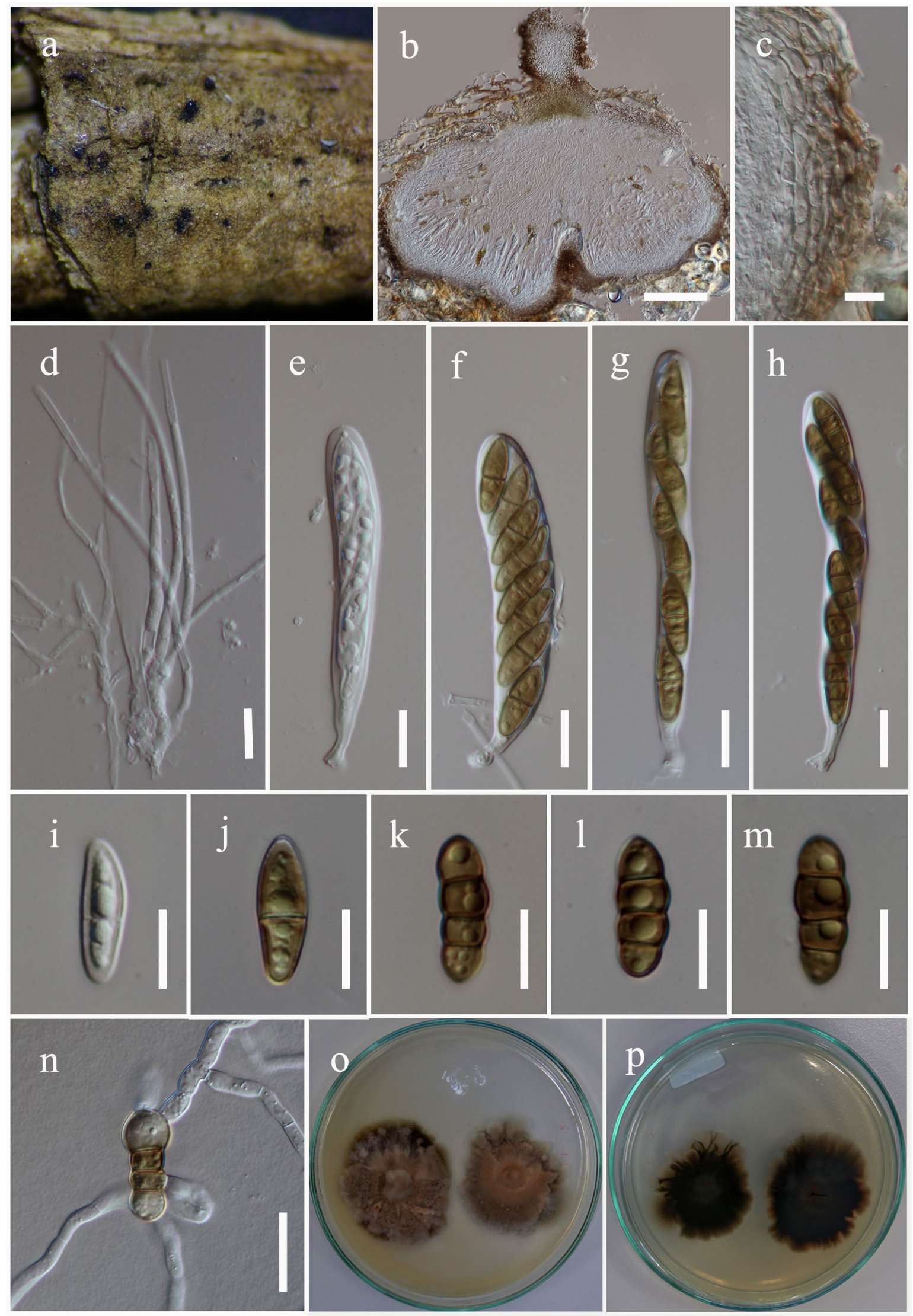
४Fig. 40 Nigrograna obliqua (MFLU 16-0190). a Appearance of ascomata on Clematis vitalba. b Vertical section through ascoma. c Section of peridium. d Pseudoparaphyses. e-h Asci. i-m Ascospores. $\mathbf{n}$ Germinated ascospore. $\mathbf{o}$, $\mathbf{p}$ Culture characteristics on MEA. Scale bars: $\mathbf{b}=100 \mu \mathrm{m}, \mathbf{c}-\mathbf{h}=20 \mu \mathrm{m}, \mathbf{i}-\mathbf{n}=10 \mu \mathrm{m}$

Chaetosphaeronema from Clematis species, with the sexual morph reported for the genus (Figs. 49, 50).

Chaetosphaeronema clematidicola Phukhams., Ertz, Gerstmans \& \& K.D. Hyde, sp. nov.

Index Fungorum number: IF557196; Facesoffungi number: FoF 07303, Fig. 49.

Etymology: The epithet reflects the host Clematis.

Holotype: MFLU 17-1508.

Saprobic on Clematis patens. Sexual morph: Ascomata $275-480 \times 260-405 \mu \mathrm{m}(\bar{x}=394 \times 330 \mu \mathrm{m}, \mathrm{n}=5)$, scattered or sometimes clustered, gregarious, semi-immersed, erumpent through host tissue, visible as raised, with only black shiny ostioles visible on the host surface, uniloculate, subglobose to compressed, dark brown to black, ostiolate, papillate. Ostioles $132-248 \times 97-120 \mu \mathrm{m}(\bar{x}=174 \times 110 \mu \mathrm{m}$, $\mathrm{n}=10$ ), central, campanulate, composed of dark brown to black walled cells, rounded at the apex, with periphyses, ostioles filled with orange pigment at the pore. Peridium 13-35 $\mu \mathrm{m}$ wide $(\bar{x}=23 \mu \mathrm{m}, \mathrm{n}=20)$, thicker at apex, composed of several layers of pale brown to dark brown cells of a textura angularis, inner layer lined with subhyaline cells of textura prismatica. Hamathecium of numerous, 2-3.5 $\mu \mathrm{m}$ wide $(\bar{x}=2.6 \mu \mathrm{m}, \mathrm{n}=50)$, filamentous, cellular pseudoparaphyses, with distinct septa, embedded in mucilaginous matrix, anastomosing at the apex. Asci 139-208×6-7 $\mu \mathrm{m}$ $(\bar{x}=176 \times 6 \mu \mathrm{m}, \mathrm{n}=20), 8$-spored, bitunicate, broadly filiform to cylindrical, short, with furcate pedicel, apically rounded, ocular chamber visible when young. Ascospores $134-188 \times 1.5-7 \mu \mathrm{m}(\bar{x}=162 \times 2.5 \mu \mathrm{m}, \mathrm{n}=30)$, fasciculate, in parallel or spiral, scolecosporous, sometimes breaking at the septa, hyaline to yellowish brown, (18-)20(-23)-septate, not constricted at the septa, smooth-walled, with minute guttules in each cell. Asexual morph: Undetermined

Culture characters: Colonies growing on MEA reaching $40 \mathrm{~mm}$ after 4 weeks at $25^{\circ} \mathrm{C}$. Cultures from above, sparse, irregular, filamentous, flattened, smooth surface, with fimbriae edge, cream at the margin, white with pale yellowish at the centre; reverse colony cream at the margin and dark brown at the centre.

Material examined: Belgium, Flemish Brabant, Meise Botanic Garden, Bouchout Domain, dead stems of Clematis patens C. Morren \& Decne., 13 June 2017, D. Ertz \& C. Gerstmans, BRCP4 (MFLU 17-1508, holotype); ex-type living culture, MFLUCC 17-2151.

Host: Clematis patens-(This study).

Distribution: Belgium-(This study).
GenBank accession numbers: LSU: MT214574; SSU: MT226687; ITS: MT310619; tef1: MT394633; rpb2: MT394694.

Notes: Chaetosphaeronema clematidicola grouped with Chaetosphaeronema species (Fig. 48) with strong support (100\% ML/1.00 BYPP). Chaetosphaeronema clematidicola (MFLUCC 17-2151) is similar to Leptospora (L. rubella) and Pseudoophiobolus based on their ascospore morphology, but MFLUCC 17-2151 differs in having orange colouration at the ostioles (Shoemaker 1976; Phookamsak et al. 2017). A morphological comparison of Chaetosphaeronema clematidicola with Ophiobolus cirsii (MFLUCC 13-0218) showed that it is similar in having fasciculate, cylindrical ascospores (Fig. 49). However, Ophiobolus cirsii has erumpent ascomata without pigment at the ostioles. Petrak (1944) mentioned that the ophiobolus-like characteristic is usually associated with Chaetosphaeronema species. Zhang et al. (2012) showed that Chaetosphaeronema is genetically related to Phaeosphaeriaceae. Phookamsak et al. (2014) subsequently confirmed the taxonomy placement and mentioned that ophiobolus-like species could be the sexual morph of Chaetosphaeronema. The asexual morph of C. clematidicola could not be obtained for morphological comparison.

In the phylogenetic analysis, C. clematidicola (MFLUCC 17-2151) grouped with C. clematidis (MFLUCC 17-2147), another species also on Clematis. A comparison of the ITS region (including of the $5.8 \mathrm{~S}$ region) showed three nucleotide differences (588/599-98\% with no gaps). A comparison of the tefl region revealed 12 base pair differences (842/874—96\% with no gaps). Thus, we keep these isolates as distinct species.

Chaetosphaeronema clematidis Phukhams., Ertz, Gerstmans \& K.D. Hyde, sp. nov.

Index Fungorum number: IF557195; Facesoffungi number: FoF 07302, Fig. 50

Etymology: The epithet name "clematidis" refers to the host substrate.

Holotype: MFLU 17-1504

Saprobic on dead branches of Clematis orientalis. Sexual morph: Undetermined. Asexual morph: Conidiomata $175-348 \times 115-234 \mu \mathrm{m}(\bar{x}=234 \times 159 \mu \mathrm{m}, \mathrm{n}=5)$, pycnidial, solitary, sometimes aggregated, uniloculate, immersed, with only black shiny ostioles visible, globose to compressed, brown to dark brown, coriaceous, thick-walled, ostiolate, with minute papilla. Ostioles $41-139 \times 66-85 \mu \mathrm{m}$ $(\bar{x}=105 \times 73 \mu \mathrm{m}, \mathrm{n}=5)$, central, oblong, lined with periphyses. Conidiomatal wall $12-32 \mu \mathrm{m}$ wide $(\bar{x}=20 \mu \mathrm{m}$, $\mathrm{n}=20$ ), comprises dark brown to light brown cells of textura angularis, lined with a hyaline layer bearing conidiogenous cells. Conidiophores reduced to conidiogenous cells. Conidiogenous cells $6-14 \times 1.5-3 \mu \mathrm{m}(\bar{x}=10 \times 2.5 \mu \mathrm{m}, \mathrm{n}=70)$, enteroblastic, phialidic, determinate, discrete, cylindrical to 


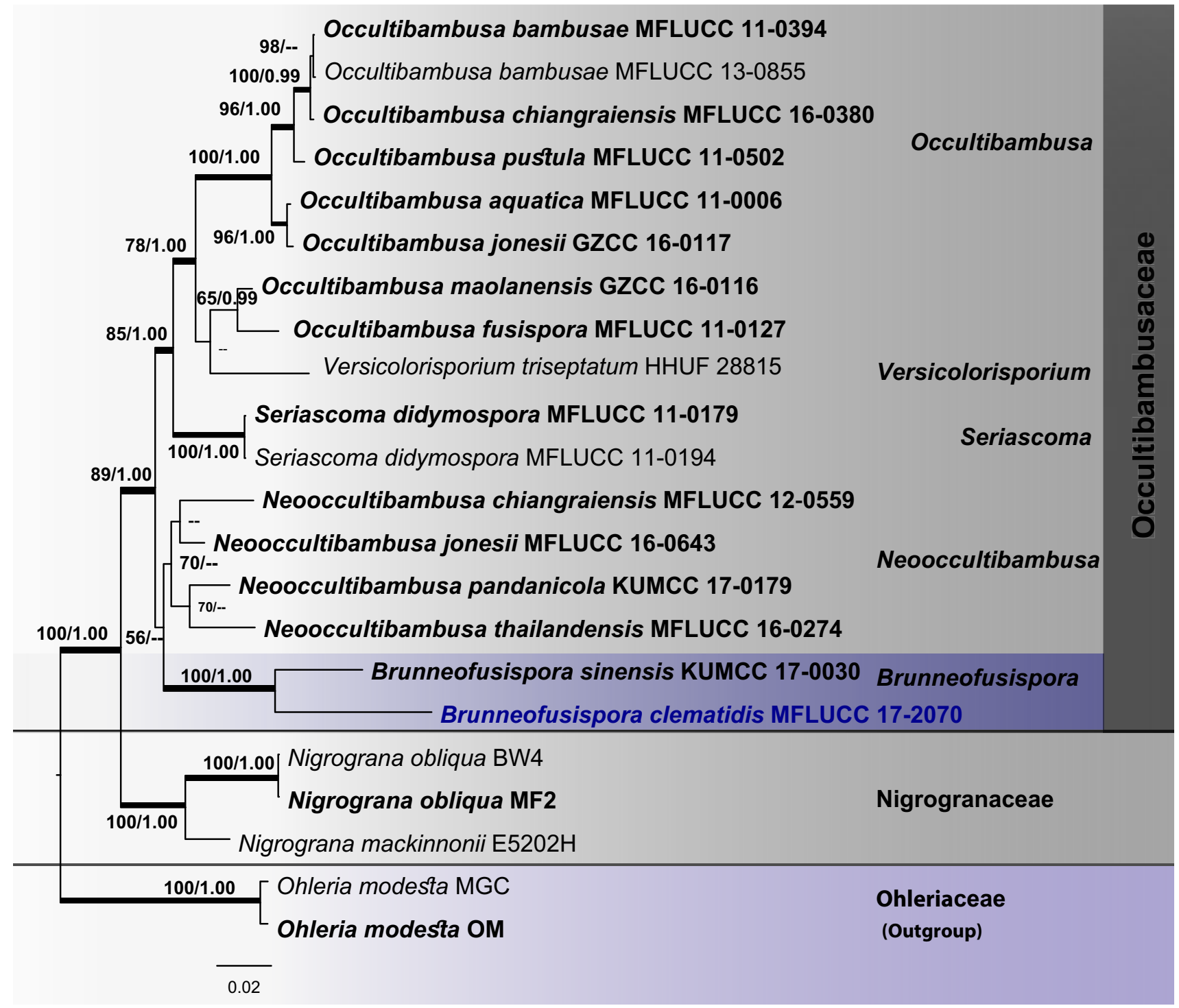

Fig. 41 Bayesian 50\% majority-rule consensus phylogram based on combined LSU, tef1, ITS and SSU sequence data for Occultibambusaceae. The topology and clade stability of the combined gene analyses was compared to the single gene analyses. The tree is rooted with members of Ohleriaceae. Twenty-two strains were included in the combined sequence analyses which comprised 3213 characters (851 characters for LSU, 730 characters for tefl, 607 characters for ITS, 1025 characters for SSU, including gap regions). The tree from the maximum likelihood analysis had a similar topology to the Bayesian analyses. The best scoring RAxML tree had a final likelihood value of -8012.999545 . The matrix had 763 distinct alignment patterns with $26.03 \%$ undetermined characters and gaps. Esti-

subcylindrical, hyaline, canal and collarette minute, smoothwalled, arising from the inner layers of conidioma. Conidia $10-15 \times 4-7 \mu \mathrm{m}(\bar{x}=12 \times 5 \mu \mathrm{m}, \mathrm{n}=100)$, cylindrical, hyaline, slightly curved, with $1(-2)$ guttules in each cell, aseptate to 1 septum, smooth-walled.

Culture characters: Colonies on MEA reaching $20 \mathrm{~mm}$ diam. after 3 weeks at $25^{\circ} \mathrm{C}$. Cultures from above, cream mated base frequencies were as follows; $\mathrm{A}=0.244085, \mathrm{C}=0.246189$, $\mathrm{G}=0.275394, \quad \mathrm{~T}=0.234331 ;$ substitution rates $\mathrm{AC}=1.902831$, $\mathrm{AG}=2.660713, \quad \mathrm{AT}=1.395112, \quad \mathrm{CG}=1.125830, \quad \mathrm{CT}=7.375307$, $\mathrm{GT}=1.000000$; gamma distribution shape parameter $\alpha=0.601072$. In our analysis, GTR + I + G model was used for each partition in Bayesian posterior analysis. The species determined in this study is indicated in blue. Bootstrap values (BS) greater than 50\% BS (ML, left) and Bayesian posterior probabilities (BYPP, right) greater than 0.90 are given at the nodes. Hyphens (-) represent support values less than $50 \%$ BS/0.90 BYPP. Thick branches represent significant support values from all analyses $(\mathrm{BS} \geq 70 \% / \mathrm{BYPP} \geq 0.95$ )

to pale yellow in the middle, with medium sparse mycelia, circular, umbonate, papillate fairly fluffy, covered with grey aerial mycelium, radially furrowed, dark brown pigment diffusing in the agar; reverse: dark brown at the centre, cream radiating outwardly.

Material examined: Belgium, Flemish Brabant, Meise Botanic Garden, Bouchout Domain, dead stems of 
Clematis orientalis L., 13 June 2017, D. Ertz \& C. Gerstmans, BRCO1 (MFLU 17-1504, holotype); ex-type living culture, MFLUCC 17-2147.

Host: Clematis orientalis - (This study).

Distribution: Belgium-(This study).

GenBank accession numbers: LSU: MT214575; SSU: MT226688; ITS: MT310620; tef1: MT394634; rpb2: MT394695.

Notes: Chaetosphaeronema clematidis is similar to other Chaetosphaeronema species in having immersed pycnidia, unilocular, with enteroblastic, phialidic, cylindrical, a channel and collarette, minute conidiogenous cells and cylindrical, hyaline conidia (Sutton 1980; Hyde et al. 2016, Fig. 50). It is phylogenetically close to $C$. achilleae Huang \& K.D. Hyde and C. hispidulum (Corda) Moesz, but differs by the lack of setae on top of the ostioles and by larger conidia. In the phylogenetic analysis, the strain formed a close relationship with C. clematidicola (see under C. clematidicola notes for more details).

Dematiopleospora Wanas., Camporesi, E.B.G. Jones \& K.D. Hyde

Dematiopleospora is typified by D. mariae Wanas., Camporesi, E.B.G. Jones \& K.D. Hyde. The genus is characterized by brown setae filling the ostiolar canal, superficial ascomata and muriform ascospores with pale end cells. There are seven species in the genus (Wanasinghe et al. 2018, Fig. 51).

Dermatiopleospora mariae Wanas., Camporesi, E.B.G. Jones \& K.D. Hyde, in Wanasinghe, et al., Cryptog. Mycol. 35(2): 110 (2014), new host record

Index Fungorum number: IF550536; Facesoffungi number: FoF 07304, Fig. 52.

Saprobic on dead stems of Clematis vitalba. Sexual morph: Ascomata 131-210×156-300 $\mu \mathrm{m}$ $(\bar{x}=195 \times 240 \mu \mathrm{m}, \mathrm{n}=5)$, superficial, solitary, scattered, subglobose, flattened at base, dark brown to black, coriaceous, cupulate when dry, ostiolate. Ostioles $35-42 \times 50-66 \mu \mathrm{m}$, papillate, brown, smooth, comprising short, light brown setae. Peridium $11-24 \mu \mathrm{m}$ wide $(\bar{x}=19 \mu \mathrm{m}, \mathrm{n}=20)$, thick, with 7-9 layers, outer layer heavily pigmented, comprising reddish to dark brown cells of textura angularis, inner layer composed of hyaline thin-walled cells of textura angularis. Hamathecium composed of numerous, 2-4 $\mu \mathrm{m}$ wide, filamentous, branched, septate, cellular pseudoparaphyses. Asci 100-125×13-19 $\mu \mathrm{m}(\bar{x}=111 \times 16 \mu \mathrm{m}, \mathrm{n}=40), 8$-spored, bitunicate, fissitunicate, cylindrical to cylindric-clavate, pedicellate, thick-walled at the apex, with minute ocular chamber. Ascospores 20-26×7-10 $\mu \mathrm{m}(\bar{x}=23 \times 9 \mu \mathrm{m}$, $\mathrm{n}=40$ ), partially overlapping, $1-2$-seriate, muriform, ellipsoidal to broad fusiform, slightly curved, ends acute, upper part wider than the lower part, 5-6-transversely septate, with 1-3 vertical septa, deeply constricted at the central septum, initially hyaline, becoming yellowish brown at maturity, ends remaining lighter and without a mucilaginous sheath. Asexual morph: Undetermined.

Culture characters: Colonies on MEA reaching $20 \mathrm{~mm}$ diam. after 4 weeks at $18{ }^{\circ} \mathrm{C}$. Culture from above, medium dense, circular, margin smooth, white, flat, surface rough; reverse cream radiating outwardly, dark brown in the middle.

Material examined: Italy, Forlì-Cesena Province, Fiumana di Predappio dead and hanging branches of Clematis vitalba, 31 January 2013, E. Camporesi, IT 1037 (MFLU 16-0121).

Hosts: Clematis vitalba, Ononis spinosa-(Wanasinghe et al. 2014; this study).

Distribution: Italy-(Wanasinghe et al. 2014; this study).

GenBank accession numbers: LSU: MT214576; SSU: MT226689; ITS: MT310621; tef1: MT394635.

Notes: Dermatiopleospora mariae MFLU 16-0121 (Fig. 52) grouped with the type strain of D. mariae (MFLUCC 13-0612) with moderate statistical support of 60\% ML (Fig. 51). Dermatiopleospora mariae (MFLUCC 13-0612) was originally described from Ononis spinosa in Italy. Morphological characters of our collection are similar to the type strain (Wanasinghe et al. 2014). The ITS sequence of our collection shows five base pair differences, however, the tefl data is identical to D. mariae (MFLUCC 13-0612).

\section{Leptospora Rabenh.}

Leptospora is typified by L. rubella and clustered in Phaeosphaeriaceae (Hyde et al. 2016). Morphological characters of the holotype of Leptospora mentioned that the fungus stains host tissue red to purple and is red at the apical part of ostiolar canal (Rabenhorst 1857; Shoemaker 1976; Crous et al. 2006). Phylogenetic analyses of a combined LSU, SSU, ITS and tefl dataset revealed one new species and a new host record of Leptospora from Clematis species (Figs. 53, 54).

Leptospora clematidis Phukhams., Ertz, Gerstmans \& K.D. Hyde, sp. nov.

Index Fungorum number: IF557197; Facesoffungi number: FoF 02441, Fig. 53.

Etymology: The specific name "clematidis" refers to the host.

Holotype: MFLU 17-1505.

Saprobic on Clematis patens. Sexual morph: Ascomata $95-245 \times 127-247 \mu \mathrm{m}(\bar{x}=159 \times 202 \mu \mathrm{m}, \mathrm{n}=5)$, dark brown to black, scattered, sometimes semi-immersed, erumpent through host epidermis, only black shiny dots are visible on the host surface, uniloculate, subglobose, compressed, dark brown to black, coriaceous, ostiolate. Ostioles $28-40 \times 38-87 \mu \mathrm{m}$, central, pseudoclypeus, with periphyses filling the ostiolar canal, pale brown to brown, with light orange pigment at the pore. Peridium 10-32 $\mu \mathrm{m}$ wide, uniform, composed of $4(-5)$ layers of cells arranged in textura 


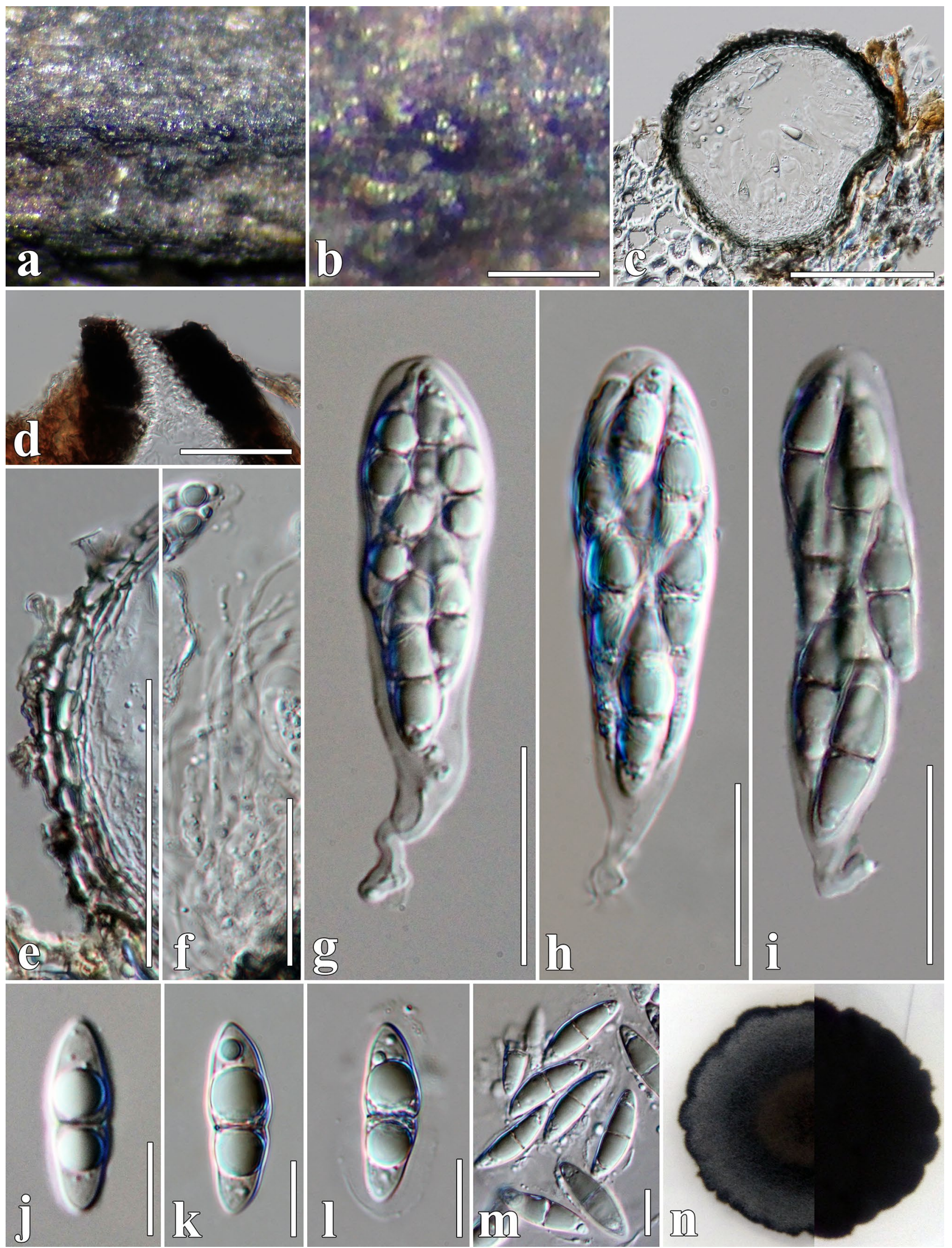


४Fig. 42 Brunneofusispora clematidis (MFLU 17-1478, holotype). a, b Appearance of ascomata on Clematis subumbellata. c Vertical section through ascoma. d Ostiolar canal. e Section of peridium. $\mathbf{f}$ Pseudoparaphyses. g-i Asci. $\mathbf{j}-\mathbf{m}$ Ascospores. n Culture characteristics on MEA. Scale bars: $\mathbf{b}=200 \mu \mathrm{m}, \mathbf{c}=100 \mu \mathrm{m}, \mathbf{d}, \mathbf{e}=50 \mu \mathrm{m}, \mathbf{f}$, $\mathbf{g}-\mathbf{i}=20 \mu \mathrm{m}, \mathbf{j}-\mathbf{m}=10 \mu \mathrm{m}$

angularis, brown to dark brown, inner layer lined with subhyaline cells of textura angularis. Hamathecium composed of numerous, 2-4 $\mu \mathrm{m}$ wide, filamentous, cellular pseudoparaphyses, with distinct septa, embedded in mucilaginous matrix, anastomosing at the apex. Asci 67-96 $\times 7-11 \mu \mathrm{m}$ $(\bar{x}=78 \times 10 \mu \mathrm{m}, \mathrm{n}=30), 8$-spored, bitunicate, clavate, with short, furcate pedicel, apically rounded, ocular chamber present when young. Ascospores $17-33 \times 3-6 \mu \mathrm{m}$ $(\bar{x}=26 \times 5 \mu \mathrm{m}, \mathrm{n}=30)$, narrowly turbinate, rounded at apex, acute at the bottom, hyaline to yellowish brown, 3-septate, cell above median septa slightly enlarged, slightly constricted at the septa, smooth-walled, with minute guttule in each cell, polar appendages visible when immature. Asexual morph: Undetermined.

Culture characters: Colonies on MEA reaching $30 \mathrm{~mm}$ diam. after 4 weeks at $25{ }^{\circ} \mathrm{C}$, from above: sparse, circulate, flattened, surface smooth, with fimbriate edge, cream at the margin, white with pale yellowish at the centre; colony below brown at the margin and centre.

Material examined: Belgium, Flemish Brabant, Meise Botanic Garden, Bouchout Domain, dead stems of Clematis patens, 13 June 2017, D. Ertz \& C. Gerstmans, BRCP1 (MFLU 17-1505, holotype); ex-type living culture, MFLUCC 17-2148, ibid. (MFLU 17-1509, paratypes); exparatype living culture, MFLUCC 17-2152.

Host: Clematis patens-(This study).

Distribution: Belgium-(This study).

GenBank accession numbers: MFLUCC 17-2148: LSU: MT214577; SSU: MT226690; ITS: MT310622; tef1: MT394636; rpb2: MT394696. MFLUCC 17-2152: LSU: MT214578; SSU: MT226691; ITS: MT310623; tef1: MT394637; rpb2: MT394697.

Notes: Leptospora clematidis shares common characters with Leptospora in having uniloculate ascomata, ostioles with light orange pigment, a peridium of thinwalled cells arranged in textura angularis, and light yellow ascospores (Hyde et al. 2016). Leptospora clematidis has similar morphology to L. galii (KUMCC 15-0521), the strain recorded from Galium sp. in Italy. However, our new species differs from L. galii in having larger ascomata that are subglobose with clavate, furcate asci (Hyde et al. 2016, Fig. 53).

Phylogeny (Fig. 48) reveals that L. clematidis forms a close relationship with L. galii (KUMCC 15-0521) with strong support (100\% ML/1.00 BYPP, Fig. 48). A comparison of the ITS region (including $5.8 \mathrm{~S}$ region) showed 10 nucleotide differences (585/594-98\%, with a single gap). A comparison of the tefl region revealed 15 base pair differences (822/837-98\%, with no gaps). Thus, we describe L. clematidis as a distinct species.

Leptospora thailandica Phukhams. \& K.D. Hyde, in Hyde et al. Fungal Diversity 80: 100 (2016), new host record

Index Fungorum number: IF552239; Facesoffungi number: FoF 02381, Fig. 54.

Saprobic on dead branches of Clematis subumbellata. Sexual morph: Ascomata 188-229 ×159-179 $\mu \mathrm{m}$, immersed to erumpent through host tissue, only black shiny dots are visible on the host surface, solitary, scattered, globose to compressed, smooth, brown to dark brown. Ostioles $120-132 \times 91-95 \mu \mathrm{m}(\bar{x}=125 \times 92 \mu \mathrm{m}, \mathrm{n}=5)$, papillate, oblong, dark brown to light brown, heavily pigmented outer layer, smooth, filled with periphyses, reddish to orange pigment around pore. Peridium $12-18 \mu \mathrm{m}$ wide, up to $30 \mu \mathrm{m}$ at the apex, thin-walled, brown to dark brown, pseudoparenchymatous cells, composed of 5-7 layers of textura angularis, inner layers composed of hyaline gelatinous cells. Hamathecium composed of numerous, 2.8-5.5 $\mu \mathrm{m}$ wide $(\mathrm{n}=30)$, broad, branched, filamentous, septate, cellular pseudoparaphyses. Asci $63-107 \times 8-13 \mu \mathrm{m}$ $(\bar{x}=77 \times 10 \mu \mathrm{m}, \mathrm{n}=30), 8$-spored, bitunicate, cylindrical to cylindrical-clavate, with short furcate pedicel, apically rounded, ocular chamber visible when immature. Ascospores $40-77 \times 2-5 \mu \mathrm{m}(\bar{x}=58 \times 4 \mu \mathrm{m}, \mathrm{n}=40)$, fasciculate, scolecosporous, tapering towards the ends, hyaline when immature, pale brown at maturity, with minute guttule in each cell, with (7-)8-17-septate, slightly constricted at the septa, with 3-5 $\mu \mathrm{m}$ sheath drawn out to form bipolar appendages, with a pad-like structure at the apices. Asexual morph: Undetermined.

Culture characters: Colonies on MEA reaching $30 \mathrm{~mm}$ diam. after 4 weeks at $25{ }^{\circ} \mathrm{C}$. Culture from above brown, sparse, circular, faintly zonate, convex with moderate aerial mycelium, downy, with slightly irregular at margins; reverse brown at the edge, light brown at the centre, dense, margin rough, not pigmented.

Material examined: Thailand, Phayao Province, on dead branches of Clematis subumbellata, 20 March 2017, C. Phukhamsakda, CMTH10 (MFLU 17-1474); living culture, MFLUCC 17-2066.

Hosts: Chromolaena odoratain, Clematis patens, Duranta sp.-(Hyde et al. 2016; Mapook et al. 2020; this study).

Distribution: Thailand-(Hyde et al. 2016; Mapook et al. 2020; this study).

GenBank accession numbers: LSU: MT214579; SSU: MT226692; ITS: MT310624; tef1: MT394638.

Notes: Our new collection of Leptospora thailandica (MFLUCC 17-2066) is morphologically similar to the type species (MFLUCC 16-0385) which was reported from 

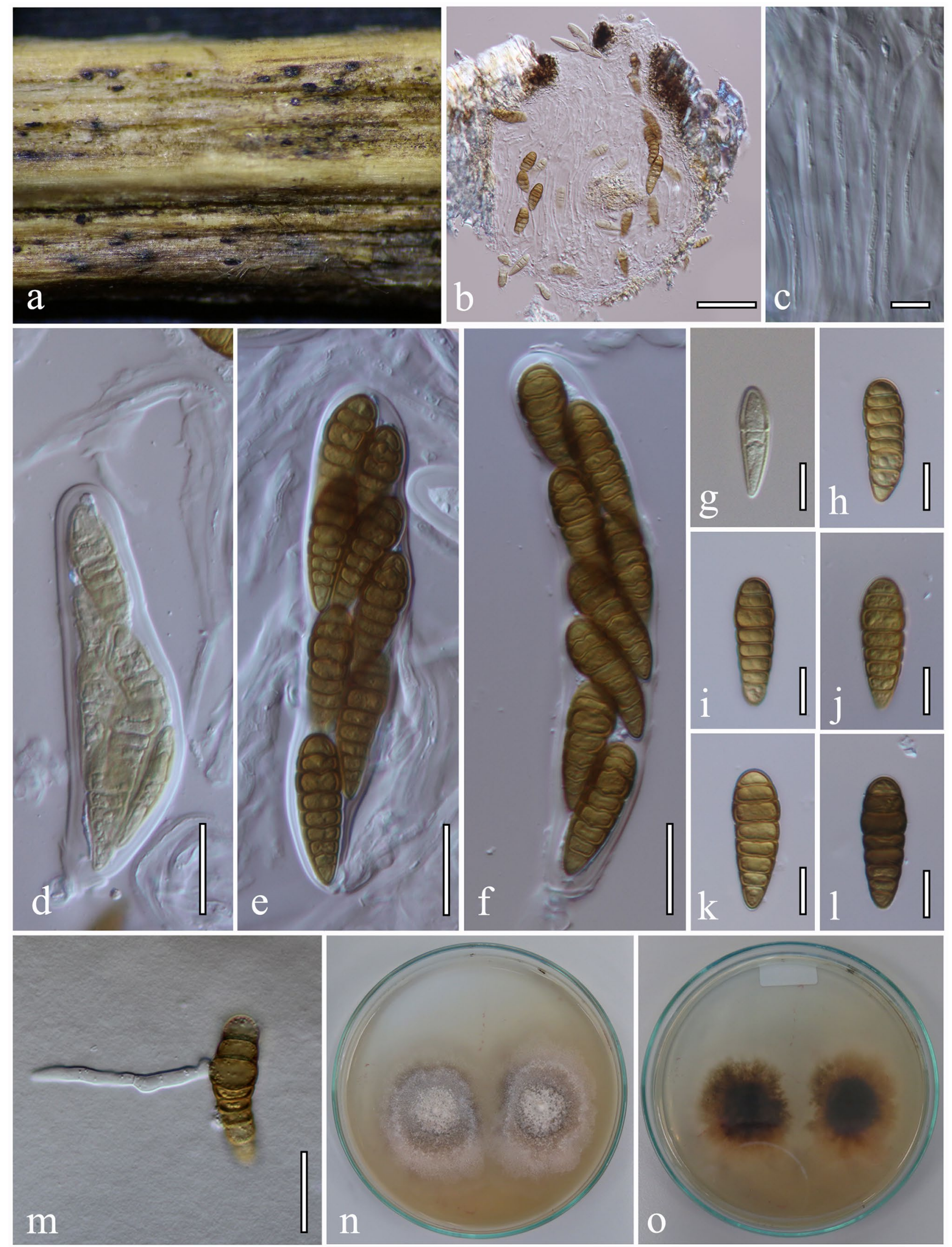
4Fig. 43 Xenomassariosphaeria clematidis (MFLU 16-0119, holotype). a Appearance of ascomata on host surface. b Vertical section of ascoma. c Pseudoparaphyses. d-f Asci. g-l Ascospores. m Germinated ascospore. $\mathbf{n}, \mathbf{o}$ Cultures characteristics on MEA. Scale bars: $\mathbf{b}=100 \mu \mathrm{m}, \mathbf{c}-\mathbf{f}=20 \mu \mathrm{m}, \mathbf{g}-\mathbf{m}=10 \mu \mathrm{m}$

Duranta sp. (Hyde et al. 2016). The collection MFLUCC 17-2066 stains the host substrate pinkish red (Fig. 54). Phylogenetic analysis of combined sequence data indicated that L. thailandica (MFLUCC 17-2066) clusters together with the type strain and the strain reported from Chromolaena odorata with strong support (100\% ML/1.00 BYPP, Fig. 48). The ITS sequence of our collection shows two base pair differences from the type strain (from 577 characters, including gap regions), while the tefl region is $100 \%$ identical.

Longispora Phukhams. \& K.D. Hyde, gen. nov.

Index Fungorum number: IF557198; Facesoffungi number: FoF 07305, Fig. 55.

Etymology: The generic epithet referring to the long ascospores.

Saprobic on herbaceous plant in terrestrial habitats. Sexual morph: Ascomata solitary, immersed to erumpent, subglobose to compressed, cupulate when dry, brown to dark brown, with brown hyphae projecting from the peridium, ostiolate. Ostioles papillate, oblong, brown to light brown, heavily pigmented at outer layer, smooth, filled with periphyses, with a reddish to orange pigment around the pore. Peridium thick-walled, wider at the apex, comprising brownwalled cells of textura angularis. Hamathecium composed of numerous, branched, filamentous, transversely septate, cellular pseudoparaphyses. Asci 8-spored, bitunicate, cylindricalclavate, with short pedicel, with a visible ocular chamber. Ascospores fasciculate, scolecosporous, ends rounded, hyaline when immature, pale brown at maturity, multi-septate, deeply constricted at the swollen cell, slightly constricted at the other septa, not separating into part spores. Asexual morph: Undetermined. Hyde

Type species: Longispora clematidis Phukhams. \& K.D.

Notes: Longispora is established as a monotypic genus with $L$. clematidis as the type species. The genus is typical of Phaeosphaeriaceae in having compressed globose, coriaceous, brown to dark brown ascomata, with a reddish to orange pigments around the ostiolar pore, cellular pseudoparaphyses and fasciculate, scolecosporous, pale brown and multi-septate ascospores (Rabenhorst 1857; Crous et al. 2006; Phookamsak et al. 2014). Longispora has morphological characters similar to Leptospora and the sexual morph character of Chaetosphaeronema and Neosetophoma ( $N$. camporesii) in having pigmentation in the ostiolar canal (Hyde et al. 2016, 2020; this study). Moreover, the fasciculate, scolecosporous, ascospores are common in
Phaeosphaeriaceae such as in Ophiobolus, Ophiosphaerella or Pseudoophiobolus (Phookamsak et al. 2017). Longispora is distinguishable from other genera having scolecospores in Phaeosphaeriaceae in its cupulate ascomata with colouration around the ostiolar pore, and asci that are cylindrical-clavate, short with a bulbose pedicel, and ascospores that are deeply constricted at the swollen cell.

Based on the multi-gene phylogenetic analysis (Fig. 48), MFLU 20-0420 formed a basal lineage to Leptospora and Populocrescentia with strong support (96\% ML/1.00 BYPP, Fig. 48). A BLAST result of the nucleotide sequences showed $98.84 \%$ similarity to Phaeosphaeria oryzae (CBS 110110 ) in the LSU region, while the ITS region showed 89.24\% similarity to Populocrescentia forlicesenensis (MFLUCC 14-0651).

Longispora clematidis Phukhams. \& K.D. Hyde, sp. nov. Index Fungorum number: IF557199; Facesoffungi number: FoF 07306, Fig. 55.

Etymology: The epithet reflects the host Clematis.

Holotype: MFLU 20-0420.

Saprobic on dead stems of Clematis vitalba. Sexual morph: Ascomata $324-340 \times 362-368 \mu \mathrm{m}(\bar{x}$ $=332 \times 365 \mu \mathrm{m}, \mathrm{n}=5$ ), solitary, scattered, immersed to erumpent through host tissue, only black shiny dots are visible on the host surface, subglobose to compressed, cupulate when dry, brown to dark brown, with brown hyphae projecting from the peridium, ostiolate. Ostioles $79-105 \times 75-85 \mu \mathrm{m}(\bar{x}=94 \times 80 \mu \mathrm{m}, \mathrm{n}=5)$, papillate, oblong, brown to light brown, heavily pigmented at outer layer, smooth, filled with periphyses, with a reddish to orange colouration around the pore. Peridium 15-30(-35) $\mu \mathrm{m}$ wide, up to $50 \mu \mathrm{m}$ at apex, wider at the apex, comprising 6(-8)-layers of brown-walled cells of textura angularis, outer layer heavily pigmented, with inner region comprising hyaline cells of textura angularis. Hamathecium composed of numerous, $2-4 \mu \mathrm{m}$ wide $(\mathrm{n}=50)$, branched, filamentous, septate, cellular pseudoparaphyses. Asci $97-157 \times 9-15 \mu \mathrm{m}$ $(\bar{x}=128 \times 12 \mu \mathrm{m}, \mathrm{n}=35), 8$-spored, bitunicate, cylindricalclavate, with short bulbose pedicel, apically rounded, with visible ocular chamber. Ascospores $93-124 \times 2-5 \mu \mathrm{m}(\bar{x}$ $=110 \times 4 \mu \mathrm{m}, \mathrm{n}=40$ ), fasciculate, scolecosporous, ends rounded, hyaline when immature, pale brown at maturity, with minute guttule in each cell, (17-)19-23-septate, swollen near the septa between the 11th or 13th or 14th cell, deeply constricted at the swollen cell, slightly contricted at the other septa, not separating into part spores, indentations present. Asexual morph: Undetermined.

Culture characters: Colonies on MEA reaching $20 \mathrm{~mm}$ diam. after 4 weeks at $16^{\circ} \mathrm{C}$. Culture slow growing, black, dense, rhizoid, raised with concave edge, rough, irregular at the margins; reverse: black, dense, not pigmented. 


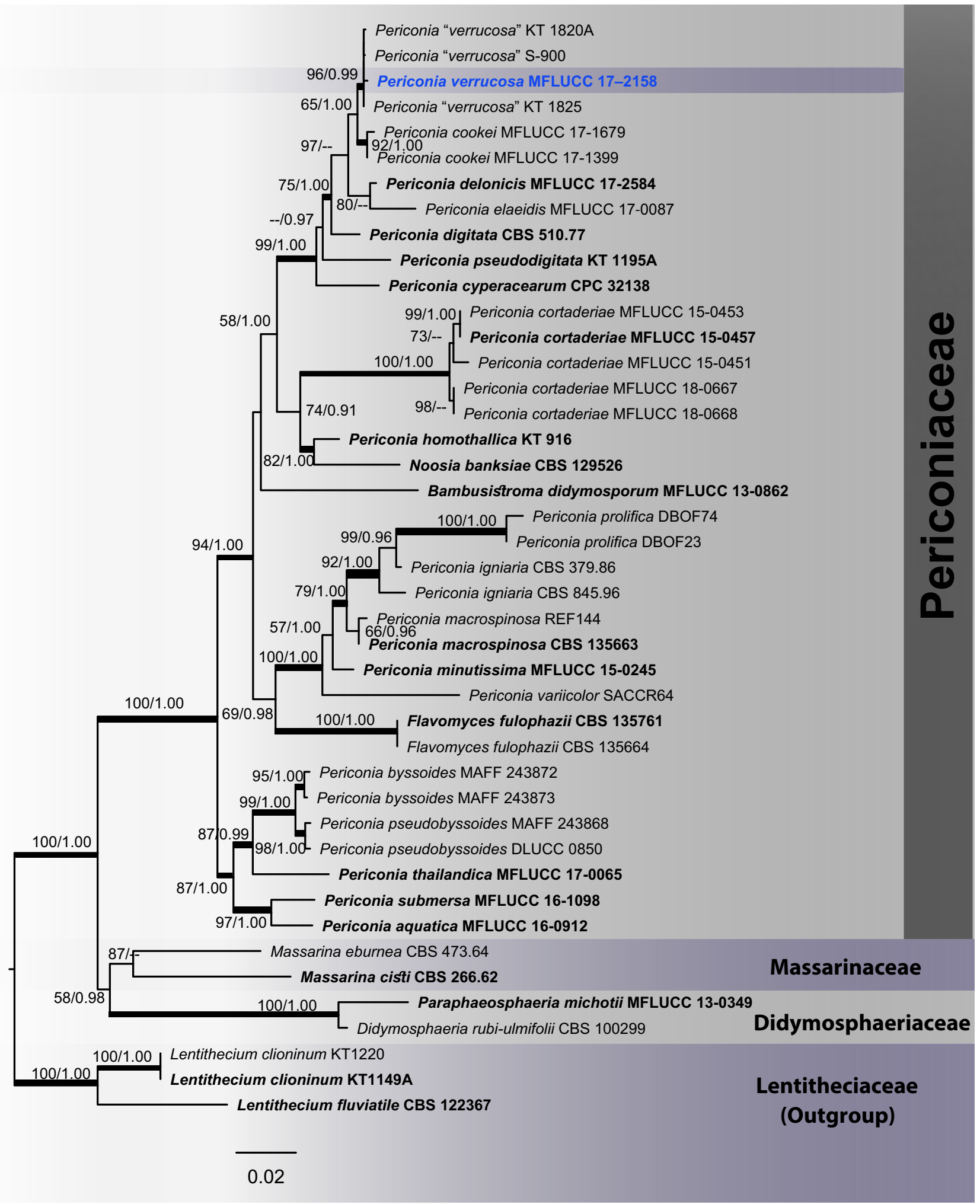

Material examined: Italy, Forlì-Cesena Province, Viale Salinatore-Forlì City, on dead aerial branch of Clematis vitalba, 23 February 2015, E. Camporesi, IT2389B (MFLU 20-0420, holotype).
Hosts: Clematis vitalba-(This study).

Distribution: Italy-(This study).

GenBank accession numbers: LSU: MT214580; SSU: MT226693; ITS: MT310625; tefl: MT394639. 
4Fig. 44 The best scoring RAxML tree with a likelihood value of - 10209.184183 based on combined LSU, ITS and tef1 sequence data for Periconiaceae. The tree is rooted with species of Lentitheciaceae. Forty-seven strains were included in the combined gene sequence analyses which comprised 2974 characters (1320 characters for LSU, 620 characters for ITS, 1034 characters for tef1, including gap regions). The topology and clade stability of the combined gene analyses was compared to the single gene analyses. The tree from the maximum likelihood analysis had similar topology to Bayesian $50 \%$ majority-rule consensus phylogram. The matrix had 865 distinct alignment patterns with $33.43 \%$ undetermined characters and gaps. Estimated base frequencies were as follows; $A=0.229606$, $\mathrm{C}=0.269654, \quad \mathrm{G}=0.273255, \mathrm{~T}=0.227485 ; \quad$ substitution rates $\mathrm{AC}=1.424251, \quad \mathrm{AG}=2.110026, \quad \mathrm{AT}=1.548277, \quad \mathrm{CG}=1.179391$, $\mathrm{CT}=7.719698, \mathrm{GT}=1.000000$; gamma distribution shape parameter $\alpha=0.673748$. In our analysis, a GTR $+\mathrm{I}+\mathrm{G}$ model was used for each partition in the Bayesian posterior analysis. The species determined in this study is indicated in blue. Bootstrap values (BS) greater than $50 \%$ BS (ML, left) and Bayesian posterior probabilities (BYPP, right) greater than 0.90 are given at the nodes. Hyphens (-) represent support values less than 50\% ML/0.90 BYPP. Thick branches represent significant support values from all analyses (ML $\geq 70 \% / B Y P P \geq 0.95)$

Notes: Longispora clematidis is characterized by having sessile, cupulate ascomata, reddish orange ostioles, cellular pseudoparaphyses, cylindric-clavate asci with a bulbose pedicel and filiform ascospores, which are multi-septate and swollen between the 11th-14th cells (Fig. 55). We introduce L. clematidis based on morphological and phylogenetic analyses.

Pseudoophiobolus Phookamsak, Wanas., S.K. Huang, Camporesi \& K.D. Hyde

Pseudoophiobolus is typified by P. mathieui (Westend.) Phookamsak, Wanas., S.K Huang, Camporesi \& K.D. Hyde. The genus was introduced to accommodate an ophioboluslike taxon that is phylogenetically distant from Ophiobolus sensu stricto (Phookamsak et al. 2017). Pseudoophiobolus is distinguishable from other ophiobolus-like species in having semi-immersed to erumpent, papillate ascomata with pseudoparenchymatous cells, arranged in a textura angularis to textura prismatica, cellular pseudoparaphyses, and fasciculate, scolecosporous multi-septate ascospores with a swollen cell, that do not split into part spores. A new host record of $P$. rosae on Clematis is presented (Fig. 56).

Pseudoophiobolus rosae Phookamsak, Wanas., Phukhams., Camporesi \& K.D. Hyde in Phookamsak et al. Fungal Diversity 87: 330 (2017), new host record

Index Fungorum number: IF553928; Facesoffungi number: FoF 03805, Fig. 56.

Saprobic on dried stems of Clematis vitalba. Sexual morph: Ascomata 290-345 ×240-305 $\mu \mathrm{m}(\bar{x}=317 \times 274 \mu \mathrm{m}$, $\mathrm{n}=5$ ), uniloculate, scattered, solitary, semi-immersed to superficial, ampulliform, globose, cupulate when dried, dark brown to black, with dark brown, septate mycelium at the base, ostiolate. Ostioles $117-135 \times 100-117 \mu \mathrm{m}$, oblong, apex rounded, short papillate, composed of several layers of dark pseudoparenchymatous cells, with opening by a pore, filled with hyaline periphyses. Peridium 12-30(-36) $\mu \mathrm{m}$ wide, slightly thickened, composed of 6(-9) layers of dark brown cells arranged in textura angularis, pseudoparenchymatous cells, inner layers comprising 2 layers of hyaline cells, arranged in textura angularis. Hamathecium composed of dense, $2-4 \mu \mathrm{m}$ wide $(\bar{x}=2.5, \mathrm{n}=50)$, wide, broad, branched, filamentous, septate, cellular pseudoparaphyses, anastomosing at the apex, embedded in a hyaline gelatinous matrix. Asci $64-153 \times 9-14 \mu \mathrm{m}(\bar{x}=116 \times 12 \mu \mathrm{m}, \mathrm{n}=30), 8$-spored, bitunicate, fissitunicate, cylindric-clavate, with short bulbose pedicel, apically rounded, with well-developed ocular chamber. Ascospores (40-)75-110 $\times 3-5 \mu \mathrm{m}(\bar{x}=88 \times 4 \mu \mathrm{m}$, $\mathrm{n}=40$ ), fasciculate, scolecosporous, curved, pale yellowish to yellowish, with rounded ends, tapered towards the lower cells, swollen at the 8th or 10th cell, 17(-22)-septate, not constricted at the septa, smooth-walled. Asexual morph: Undetermined.

Culture characters: Colonies on MEA reaching $40 \mathrm{~mm}$ diam. after 4 weeks at $16^{\circ} \mathrm{C}$. Culture medium dense, circular, umbonate, surface smooth, edge erose, thinly hairy, green at the edge, yellowish to cream at the centre; reverse: cream at the margin, brown at the centre, not producing pigmentation in agar.

Material examined: Italy, Arezzo Province, QuotaPoppi City, dead aerial branch of Clematis vitalba, 5 June 2016, E. Camporesi, IT 2983A (MFLU 15-1014); living culture, MFLUCC 16-1364.

Hosts: Clematis vitalba, Rosa canina-(Phookamsak et al. 2017; This study).

Distribution: Italy-(Phookamsak et al. 2017; This study).

GenBank accession numbers: LSU: MT214581; SSU: MT226694; ITS: MT310626; tef1: MT394640.

Notes: Our collection, MFLUCC 16-1364 formed a clade with the type strain of Pseudoophiobolus rosae (MFLUCC 17-1786) with strong support (100\% ML/0.99 BYPP, Fig. 48). Our strain is morphologically similar to the type strain of $P$. rosae which was reported on Rosa canina (Phookamsak et al. 2017, Fig. 56). A nucleotide comparison of the ITS and tefl regions of MFLUCC 16-1364 and the type strain are $100 \%$ identical. Thus, we report a new host record of Pseudoophiobolus rosae on Clematis.

Wojnowiciella Crous, Hern.-Restr. \& M.J. Wingf.

Wojnowiciella eucalypti is the type species. The genus is characterized by a papillate, ostiolate conidiomata, ampulliform, phialidic conidiogenous cells, hyaline, aseptate microconidia and brown, multi-septate macroconidia (Wijayawardene et al. 2013; Crous et al. 2015a). The genus has morphological resemblance to Wojnowicia which was introduced by Saccardo (1892). However, Crous et al. (2015a) 

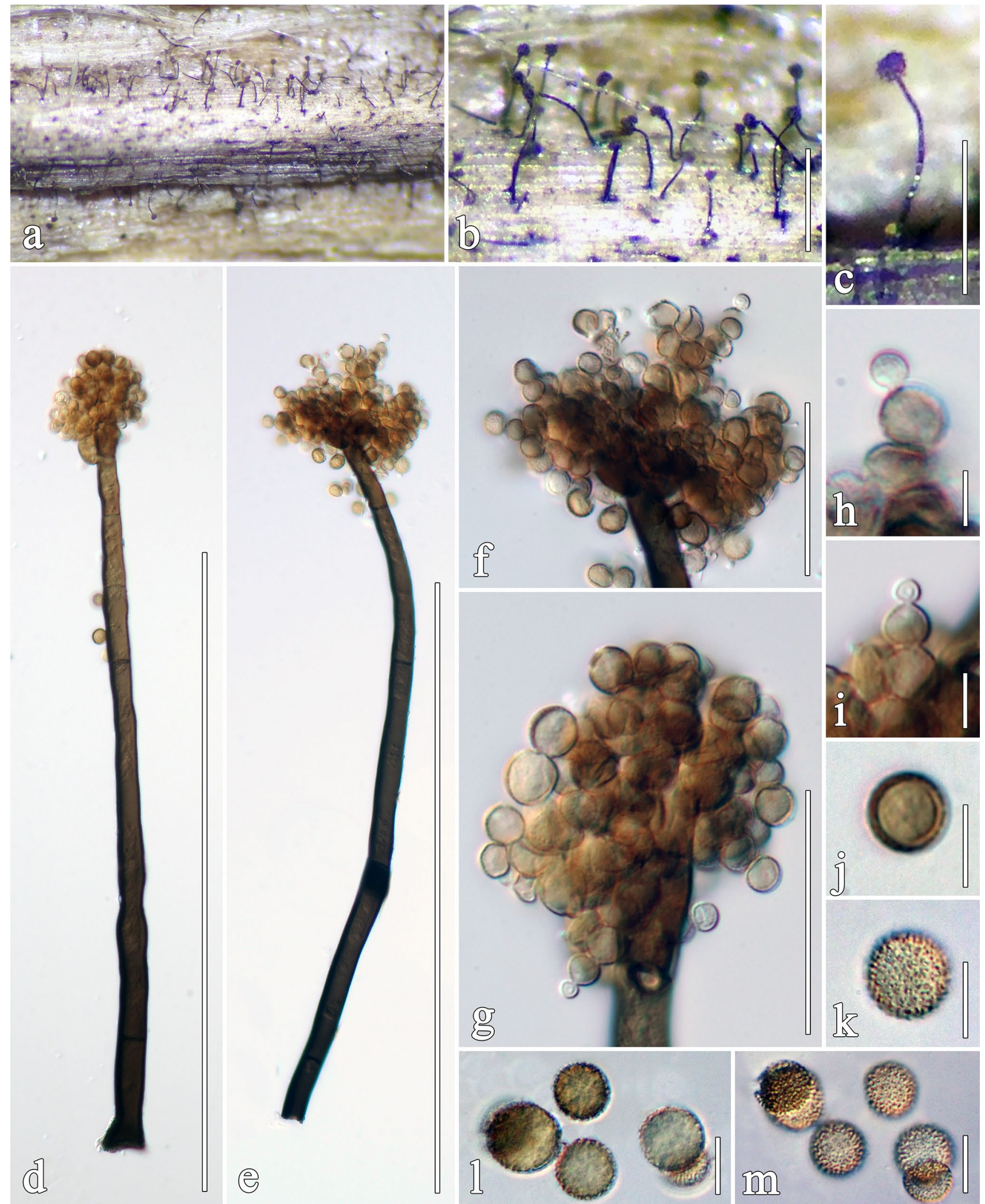

Fig. 45 Periconia verrucosa (MFLU 17-1516, holotype). a, b Sporodochia on natural substrate. c Close up of sporodochia. d, e Conidiophores. $\mathbf{f}-\mathbf{i}$ Conidiogenous cells. $\mathbf{j}-\mathbf{m}$ Conidia. Scale bars: $\mathbf{b}=500 \mu \mathrm{m}, \mathbf{c}-\mathbf{e}=250 \mu \mathrm{m}, \mathbf{f}, \mathbf{g}=50 \mu \mathrm{m}, \mathbf{h}, \mathbf{i}=10 \mu \mathrm{m}, \mathbf{j}-\mathbf{m}=5 \mu \mathrm{m}$ 


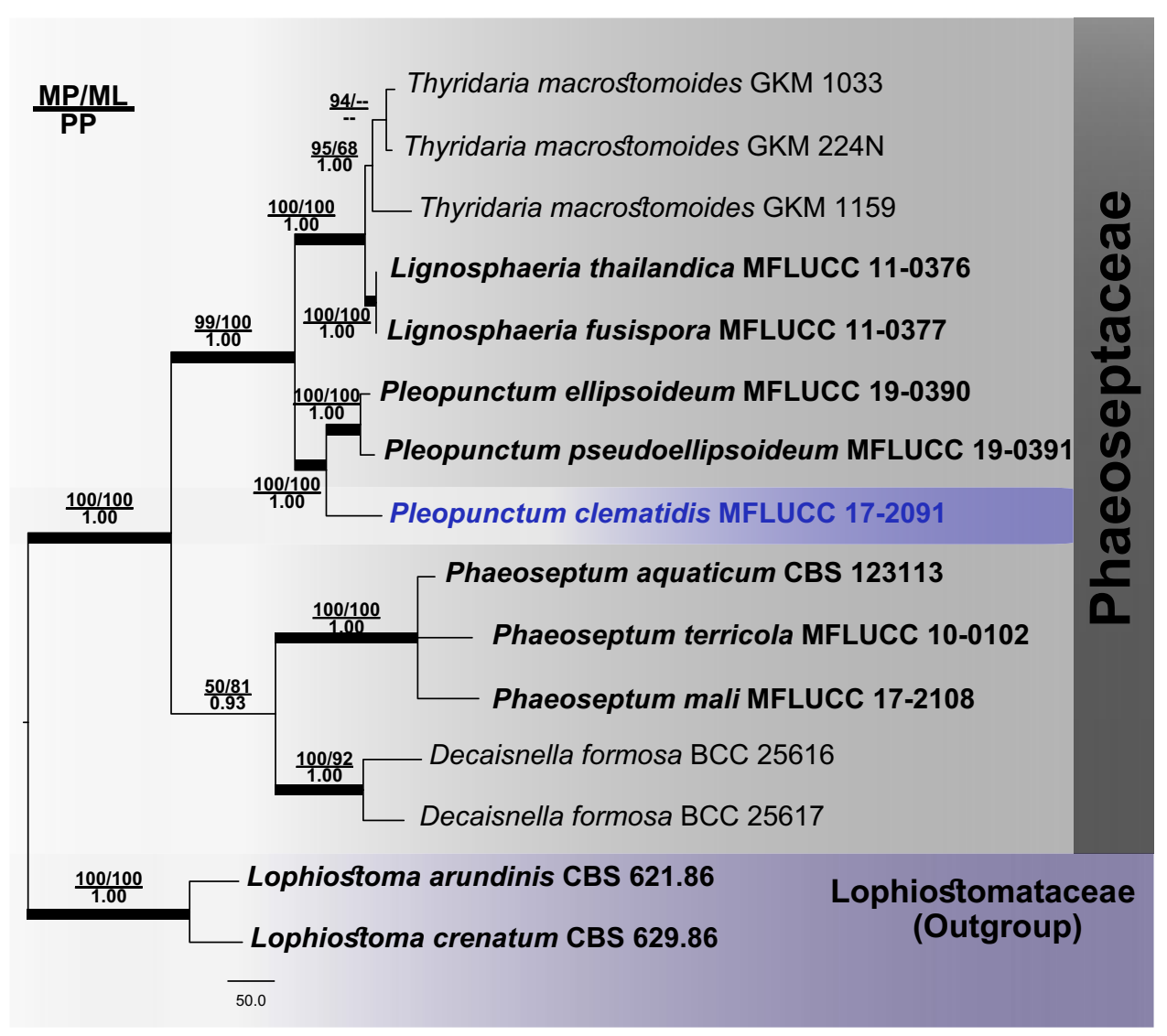

Fig. 46 Phylogram generated from maximum parsimony analysis of Phaeoseptaceae based on combined LSU, SSU, ITS, tef1 and rpb2 sequence data. Related sequences are taken from Liu et al. (2019) and retrieved from GenBank. Fifteen strains were included in the analysis of the combined loci and comprised 4077 characters (810 characters for LSU, 1017 characters for SSU, 480 characters for ITS, 895 characters for $t e f 1,875$ characters for $r p b 2$, including gaps). The tree is rooted with Lophiostoma arundinis (CBS 621.86) and L. crenatum (CBS 629.86) in Lophiostomataceae. Maximum parsimony analysis of 717 parsimony informative characters resulted in a most parsimonious tree $(\mathrm{CI}=0.797, \mathrm{RI}=0.757, \mathrm{RC}=0.603, \mathrm{HI}=0.203)$. The best scoring RAxML tree received a final likelihood value of - 12889.704989. The matrix had 769 distinct alignment pat-

discussed that the type species of Wojnowicia, W. hirta is compatible with the generic concept of Septoriella. Thus, Wojnowicia was synonymised as a member of Septoriella. Our collection associated with Clematis viticella revealed a novel species W. clematidis from Belgium (Fig. 57).

Wojnowiciella clematidis Phukhams., Ertz, Gerstmans \& K.D. Hyde, sp. nov.

Index Fungorum number: IF557200; Facesoffungi number: FoF 07307, Fig. 58.

Etymology: The epithet refers to the host plant, Clematis.

Holotype: MFLU 17-1517.

Saprobic on dried stems of Clematis viticella. Sexual morph: Ascomata $228-240 \times 223-250 \mu \mathrm{m}$, terns, with $37.49 \%$ undetermined characters and gaps. Estimated base frequencies were: $\mathrm{A}=0.241361, \mathrm{C}=0.260527, \mathrm{G}=0.275500$, $\mathrm{T}=0.222613$; substitution rates $\mathrm{AC}=1.309734, \mathrm{AG}=3.237095$, $\mathrm{AT}=1.407451, \quad \mathrm{CG}=1.436805, \quad \mathrm{CT}=9.313126, \quad \mathrm{GT}=1.000000$; gamma distribution shape parameter $\alpha=0.742589$. In our analysis, GTR + I + G model was used for each partition in Bayesian posterior analysis. Bootstrap values (BS) from maximum parsimony (MP, left), maximum likelihood (ML, right) higher than 50\% BS and Bayesian posterior probabilities (BYPP, below) greater than 0.90 are given at the nodes. Hyphens (-) represent support values less than $50 \%$ BS/0.90 BYPP. Thick branches represent significant support values from all analyses $(\mathrm{BS} \geq 70 \% / \mathrm{BYPP} \geq 0.95)$. The ex-type strains are in bold and black. The newly generated sequence is in bold and blue

$(\bar{x}=236 \times 240 \mu \mathrm{m}, \mathrm{n}=5)$, solitary, gregarious, scattered, immersed to erumpent through host epidermis, black shiny dots are visible on the host surface, uniloculate, subglobose, compressed, dark brown to black, coriaceous, apapillate, ostiolate. Ostioles central, pseudoclypeate, dark brown. Peridium 15-45 $\mu \mathrm{m}$ wide, composed of 7(-9) layers of cells arranged in textura angularis, brown to dark brown, inner layer lined with sub-hyaline cells of textura angularis. Hamathecium composed of numerous, 2-4 $\mu \mathrm{m}$ wide, filamentous, cellular pseudoparaphyses, with distinct septa, embedded in a mucilaginous matrix, anastomosing at the apex. Asci $97-136 \times 12-17 \mu \mathrm{m}(\bar{x}=116 \times 15 \mu \mathrm{m}, \mathrm{n}=30)$, 8 -spored, bitunicate, broadly cylindrical to cylindricalclavate, with short, furcate pedicel, apically rounded, with 


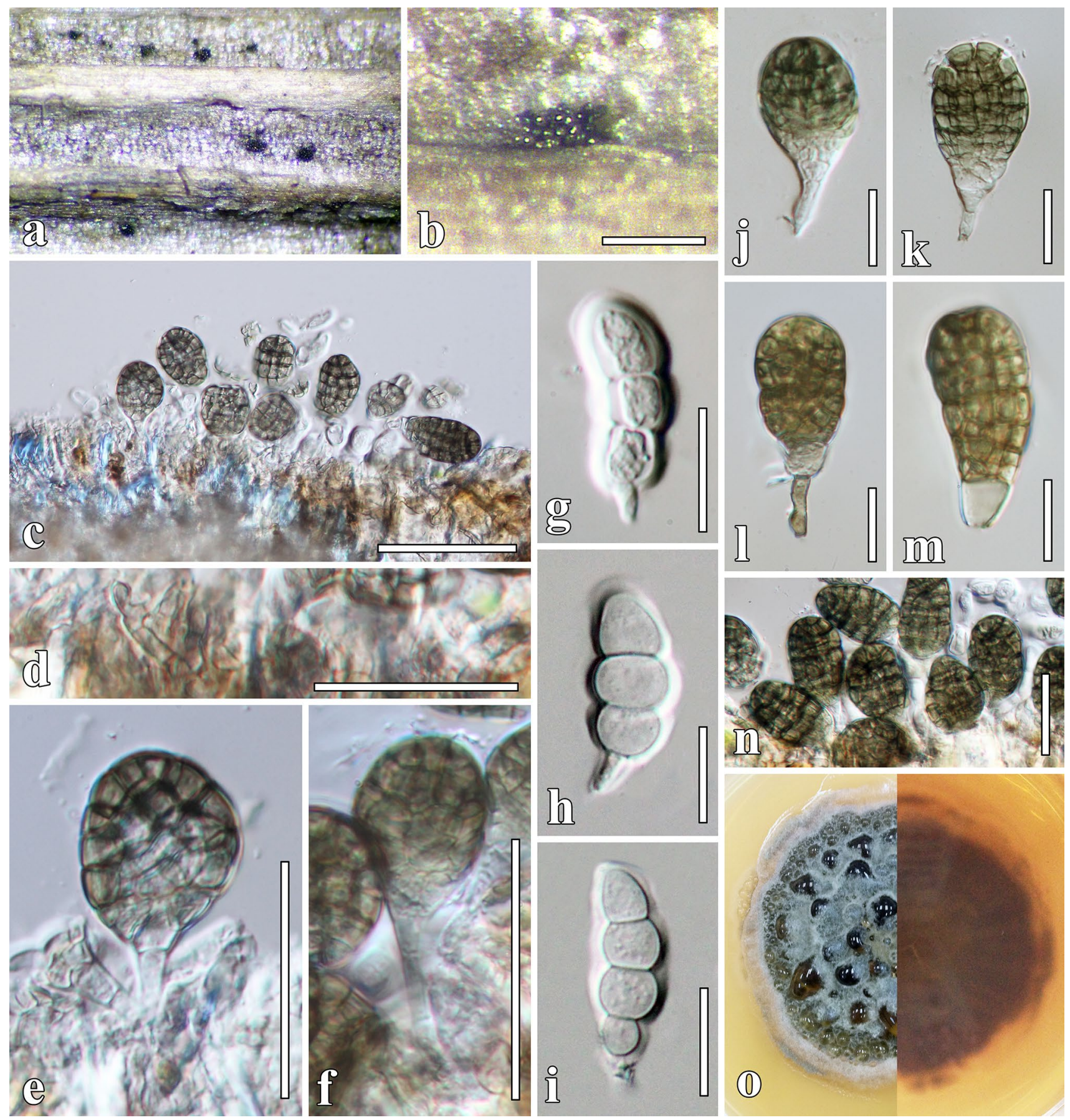

Fig. 47 Pleopunctum clematidis (MFLU 17-1499, holotype). a, b Sporodochia on natural substrate. c Vertical section of sporodochia. d Subicular hyphae. e-f Cylindrical conidia and lenticular conidia

on host substrate. g-i Cylindrical conidia. $\mathbf{j}-\mathbf{n}$ Mature lenticular conidia. o Culture characteristics on MEA. Scale bars $=\mathbf{b}=500 \mu \mathrm{m}$, $\mathbf{c}=100 \mu \mathrm{m}, \mathbf{d}-\mathbf{n}=20 \mu \mathrm{m}$

well-developed ocular chamber. Ascospores 24-38×4-9 $\mu \mathrm{m}$ $(\bar{x}=29 \times 7 \mu \mathrm{m}, \mathrm{n}=30)$, biseriate, partially overlapping, obovoid to sub-fusiform, rounded at apex, acute at the ends, hyaline to yellowish brown, 4-6-septate, with an oblique or longitudinal septum in the central $2-3$ cells, above median septum slightly enlarged, constricted at the cell above median septum, smooth-walled, with minute guttule in each cell, without a mucilaginous sheath. Asexual morph: Undetermined.

Culture characters: Colonies on MEA reaching $30 \mathrm{~mm}$ diam. after 4 weeks at $25{ }^{\circ} \mathrm{C}$. Culture from above sparse, circular, flattened, surface smooth, with fimbriae at the edge, 


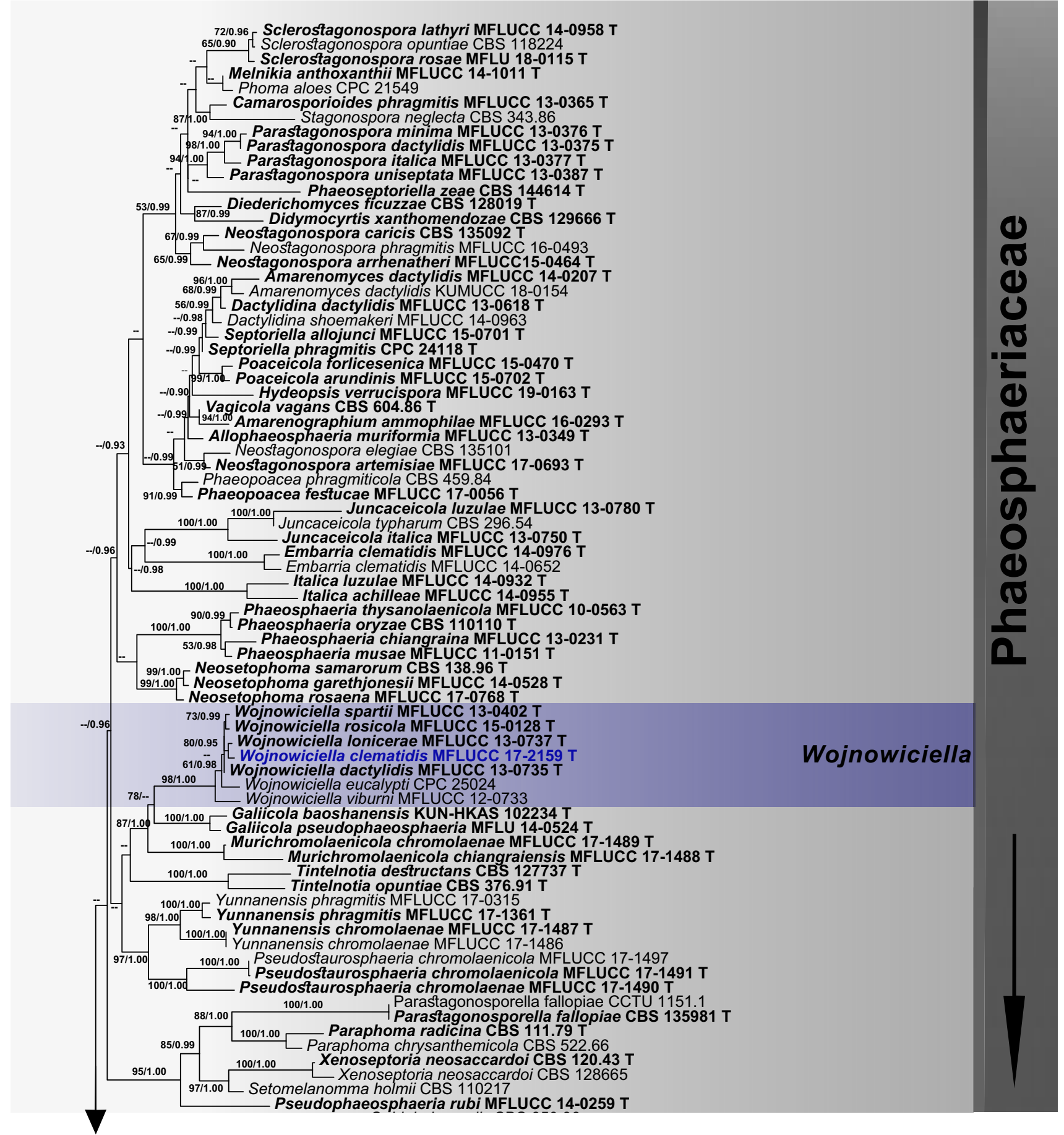

Fig. 48 The best scoring RAxML tree with a final likelihood value of - 34209.688899 based on a combined LSU, SSU, ITS and tef1 dataset for Phaeosphaeriaceae. One hundred and fifty-seven strains were included in the combined genes sequence analyses which comprised 3290 characters (822 characters for LSU, 603 characters for ITS, 991 characters for SSU and 874 characters for tefl, including gap regions). The tree is rooted with Staurosphaeria. The topology and clade stability of the combined gene analyses was compared to the single gene analyses. The tree from the maximum likelihood analysis had similar topology to the Bayesian 50\% majority-rule consensus phylogram. The matrix had 1355 distinct alignment patterns, with $23.28 \%$ of undeter- mined characters and gaps. Estimated base frequencies were as follows; $\mathrm{A}=0.241166, \mathrm{C}=0.264679, \mathrm{G}=0.235933, \mathrm{~T}=0.258221$; substitution rates $\mathrm{AC}=1.039932, \mathrm{AG}=3.142919, \mathrm{AT}=2.044232, \mathrm{CG}=0.762621$, $\mathrm{CT}=4.795230, \mathrm{GT}=1.000000$; gamma distribution shape parameter $\alpha=0.455752$. In our analysis, GTR $+\mathrm{I}+\mathrm{G}$ model was used for each partition in Bayesian posterior analysis. The species determined in this study are indicated in blue. Bootstrap values (BS) greater than 50\% BS (ML, left) and Bayesian posterior probabilities (BYPP, right) greater than 0.90 are given at the nodes. Hyphens (-) represent support values less than $50 \%$ BS/0.90 BYPP. The significant support values from all analyses are $\mathrm{BS} \geq 70 \% / \mathrm{BYPP} \geq 0.95$ 


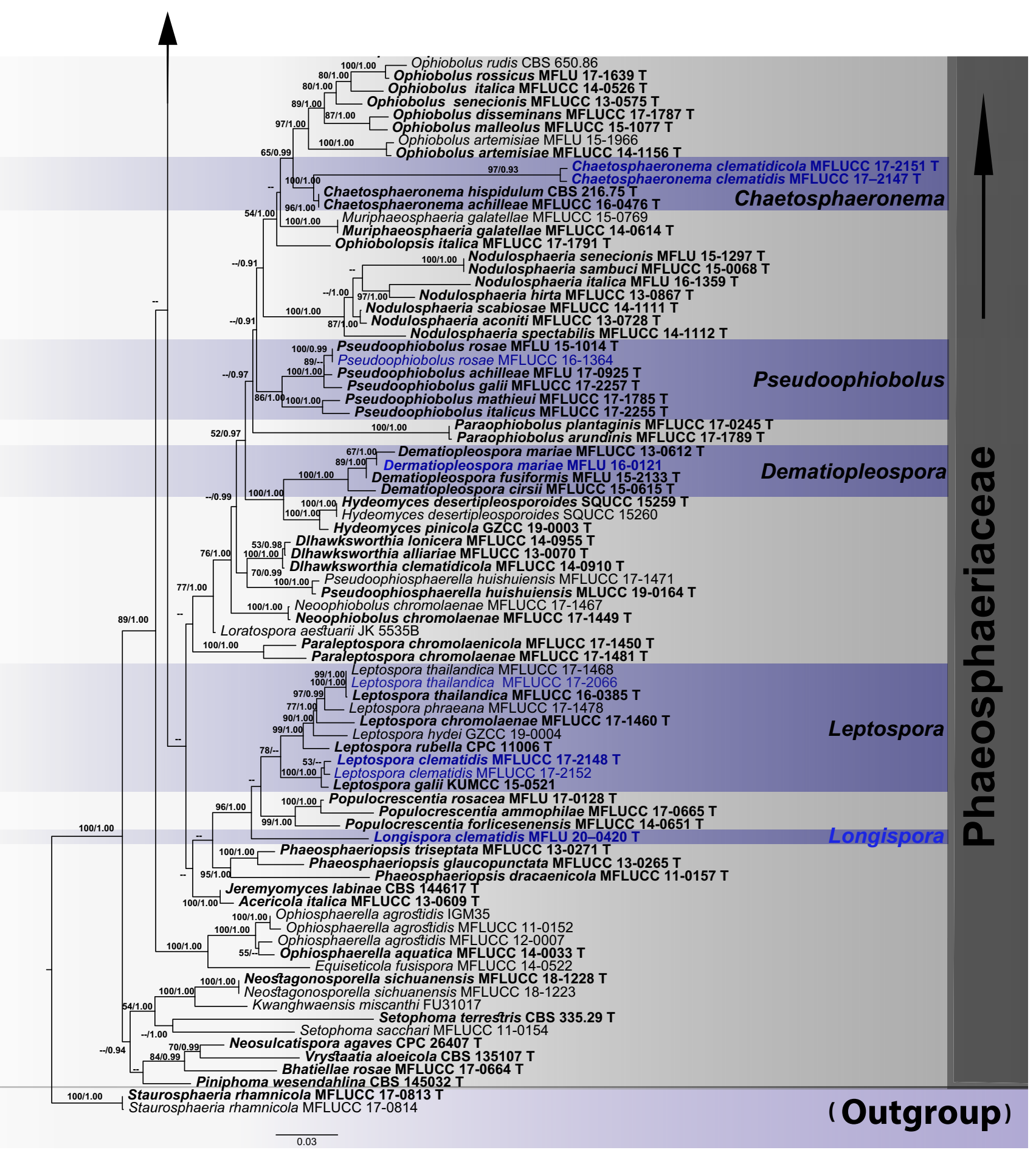

Fig. 48 (continued)

cream at the margin, white at the centre, colony from below brown.

Material examined: Belgium, Flemish Brabant, Meise Botanic Garden, Bouchout Domain, dead stems of Clematis viticella, 13 June 2017, D. Ertz \& C. Gerstmans,
BRCV5 (MFLU 17-1517, holotype); ex-type living culture, MFLUCC 17-2159.

Host: Clematis viticella-(This study).

Distribution: Belgium-(This study). 

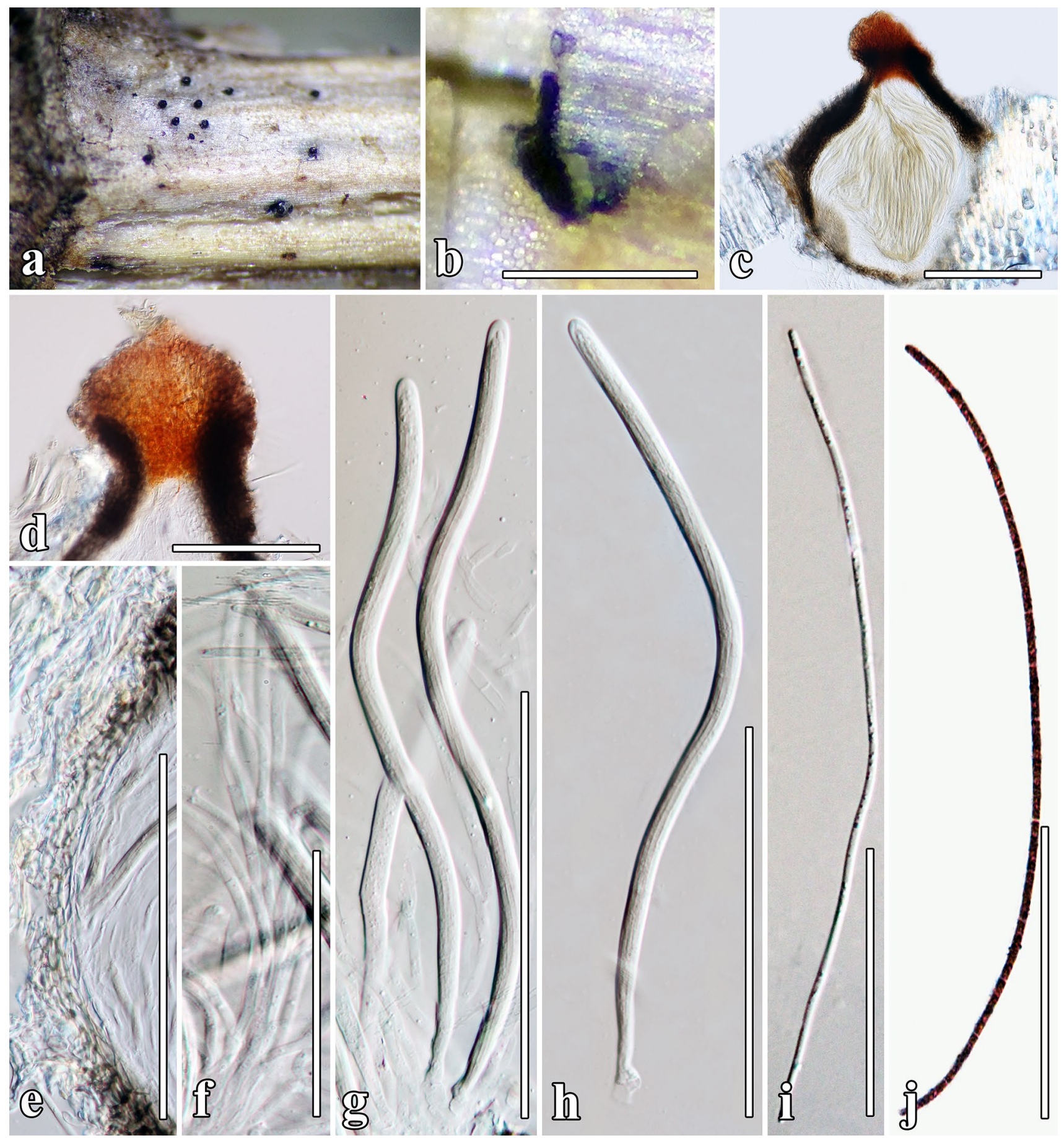

Fig. 49 Chaetosphaeronema clematidicola (MFLU 17-1508, holotype). a Appearance of ascomata on Clematis patens. b Close up of ascoma on host substrate. c Vertical section through ascoma. d Osti-

olar canal. e Section of peridium. f Pseudoparaphyses. $\mathbf{g}-\mathbf{h}$ Asci. $\mathbf{i}-\mathbf{j}$ Ascospores (j Ascospore in $10 \%$ India ink). Scale bars: $\mathbf{b}=500 \mu \mathrm{m}$, $\mathbf{c}=200 \mu \mathrm{m}, \mathbf{d}-\mathbf{h}=100 \mu \mathrm{m}, \mathbf{i}-\mathbf{j}=50 \mu \mathrm{m}$

GenBank accession numbers: LSU: MT214582; SSU: MT226695; ITS: MT310627; tef1: MT394641; rpb2: MT394698.

Notes: Wojnowiciella clematidis (strain MFLUCC 17-2159) is introduced as a novel species based on its

distinctive morphology and phylogeny (Figs. 57, 58). The species is similar to other Wojnowiciella species in having immersed to erumpent, dark brown to black, coriaceous, ostiolate, apapillate ascomata, and hyaline to yellowish brown ascospores (Crous et al. 2015a). Wojnowiciella 

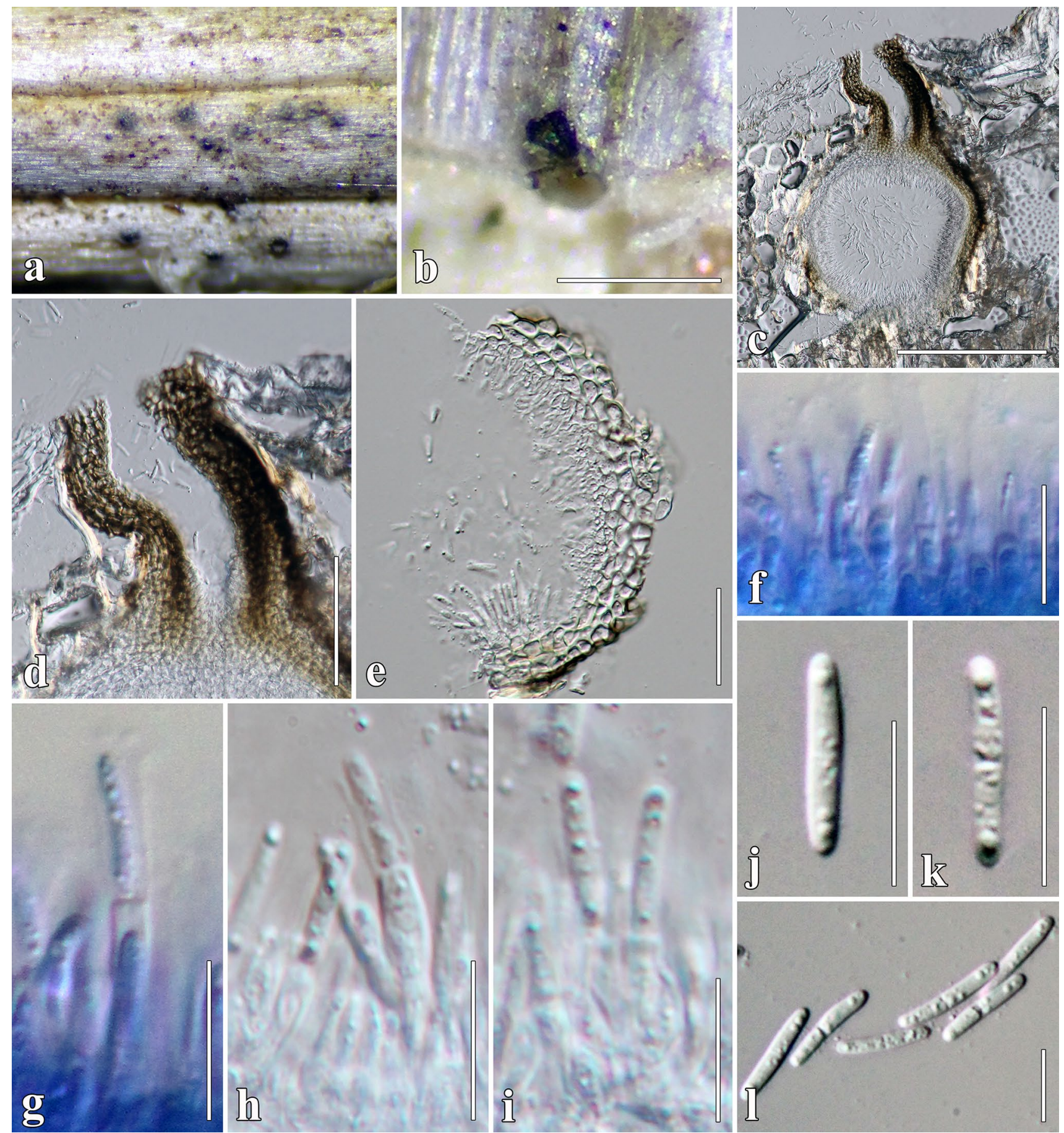

Fig. 50 Chaetosphaeronema clematidis (MFLU 17-1504, holotype). a Appearance of conidiomata on Clematis orientalis. b Close up of conidioma on host substrate. c Vertical section through conidioma. d Ostiolar canal. e Section of conidiomatal wall. $\mathbf{f}-\mathbf{i}$ Conidiog-

enous cells and conidia (f, $\mathbf{g}$ conidiogenous cells in cotton blue). $\mathbf{j}-\mathbf{l}$ Conidia. Scale bars: $\mathbf{b}=500 \mu \mathrm{m}, \mathbf{c}=200 \mu \mathrm{m}, \mathbf{d}=50 \mu \mathrm{m}, \mathbf{e}=20 \mu \mathrm{m}$, $\mathbf{f}-\mathbf{l}=10 \mu \mathrm{m}$

clematidis has similar characters to W. italica (MFLUCC 13-0447), but differs in having cylindrical to cylindricalclavate asci and obovoid to sub-fusiform ascospore (Hyde et al. 2016). Phylogeny (Fig. 57) revealed that W. clematidis (MFLUCC 17-2159) formed a close relationship

with $W$. dactylidis (CBS 145077) with good support (77\% MP/84\% ML/1.00 BYPP). Wojnowiciella dactylidis strain CBS 145077 formed a separate clade from the type species (W. dactylidis MFLUCC 13-0735), however the strain CBS 145077, which was isolated from Dypsis sp. only forms 


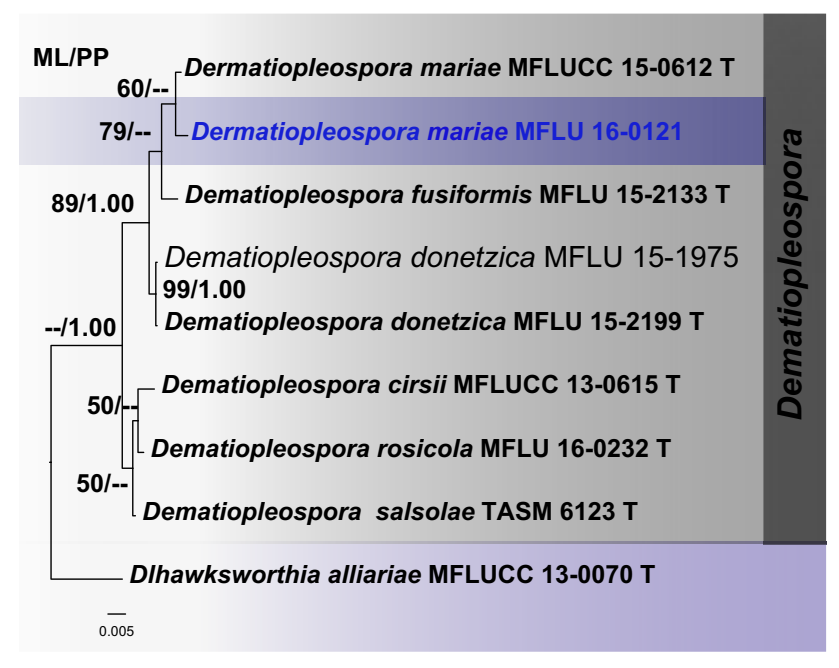

Fig. 51 The Bayesian 50\% majority-rule consensus phylogram based on combined LSU, SSU, ITS and tef1 sequence data for Dermatiopleospora species. Nine strains were included in the combined analyses which comprised 3407 characters (884 characters for LSU, 1033 characters for SSU, 617 characters for ITS and 873 characters for tefl, including gap regions). The tree is rooted with Dlhawksworthia alliariae (MFLUCC 13-0070). Single gene analyses were also performed to compare the topology and clade stability with combined gene analyses. Tree topology generated under the maximum likelihood analysis was similar to Bayesian analyses. The best scoring RAxML tree was obtained with a final likelihood value of -5814.019143 . The matrix had 162 distinct alignment patterns, with $24.34 \%$ of undetermined characters and gaps. Estimated base frequencies were as follows; $\mathrm{A}=0.252414, \mathrm{C}=0.229288, \mathrm{G}=0.264353, \mathrm{~T}=0.253945$; substitution rates $\mathrm{AC}=0.248381, \mathrm{AG}=2.072002, \mathrm{AT}=1.746797$, $\mathrm{CG}=1.084349, \mathrm{CT}=5.244757, \mathrm{GT}=1.000000$; gamma distribution shape parameter $\alpha=0.904425$. In our analysis, GTR $+\mathrm{I}+\mathrm{G}$ model was used for each partition in the Bayesian posterior analysis. The species determined in this study is indicated in blue. Bootstrap values (BS) from maximum likelihood (ML, left) of more than $50 \%$ BS and Bayesian posterior probabilities (BYPP, right) greater than 0.90 are given at the nodes. Hyphens (-) represent support values less than $50 \%$ BS/0.90 BYPP. The significantly supported values from all analyses are $\mathrm{BS} \geq 70 \% / \mathrm{BYPP} \geq 0.95$

microconidia in culture (Crous et al. 2019). A comparison of nucleotides between W. clematidis (MFLUCC 17-2159) and $W$. dactylidis (CBS 145077) showed that the ITS region (including the 5.8S region) has a single nucleotide difference (550/561-98\%, including gaps). The comparison of the tefl region revealed three base pair differences (869/440, no gaps). Based on current evidence and the lack of asexual morph character from this study, these species are considered as distinct.

\section{Pleosporaceae Nitschke}

The family was revisited by Ariyawansa et al. (2015c), with additional taxa and resegregation in Wanasinghe et al. (2017). We introduce a new species and new host records of Stemphylium from Clematis vitalba, based on a morphology and concatenated phylogenetic analysis of LSU, ITS, SSU and gadph sequence data (Fig. 59).

\section{Stemphylium Wallr.}

Stemphylium is a dematiaceous hyphomycete genus and the asexual morph has been recorded in Pleospora allies (Ariyawansa et al. 2015c; Woudenberg et al. 2017). Based on morphological studies, multi-gene phylogeny analyses, and ecological evidence, the use of Stemphylium over Pleospora has been recommended (Köhl et al. 2009; McNeill et al. 2012; Rossman et al. 2015; Woudenberg et al. 2017; Wijayawardene et al. 2018). Stemphylium is typified with $S$. botryosum. Phylogenetic placement of $S$. botryosum is verified by Woudenberg et al. (2017). Based on the phylogenetic analysis of the combined LSU, ITS and gapdh dataset (Fig. 59), we report a new host record for S. vesicarium and describe a new species $S$. clematidis from Clematis vitalba (Figs. 60, 61).

Stemphylium clematidis Wanas., Camporesi \& K.D. Hyde, sp. nov.

Index Fungorum number: IF557305; Facesoffungi number: FoF 07327, Fig. 60.

Etymology: Refers to the name of the host.

Holotype: MFLU 16-0176.

Saprobic on dead stem of Clematis vitalba. Sexual morph: Ascomata 190-230 $\times 290-320 \mu \mathrm{m}$ $(\bar{x}=220 \times 303 \mu \mathrm{m}, \mathrm{n}=20)$, solitary, scattered, uniloculate, under epidermal layer of host to superficial, compressed globose to subglobose, coriaceous, black, ostiolate. Ostioles central, papillate, with variable walls, opening by a pore, filled with hyaline periphyses. Peridium $30-43 \mu \mathrm{m}$ wide $(\bar{x}=36 \mu \mathrm{m}, \mathrm{n}=20)$, uniform, composed of 7 layers of textura angularis, black, heavy pigment at outer layer, cells towards the inside lighter, inner layer thin, hyaline gelatinous. Hamathecium composed of numerous, dense, 3-4 $\mu \mathrm{m}$ wide, filamentous, branched, septate, cellular pseudoparaphyses, situated between and above the asci embedded in a gelatinous matrix. Asci $127-172 \times 29-38 \mu \mathrm{m}$ $(\bar{x}=150 \times 35 \mu \mathrm{m}, \mathrm{n}=30), 8$-spored, bitunicate, fissitunicate, clavate to broad cylindrical-clavate, with short, with furcate pedicel, apically rounded, with an ocular chamber. Ascospores $24-37 \times 12-18 \mu \mathrm{m}(\bar{x}=32 \times 13 \mu \mathrm{m}, \mathrm{n}=50)$, biseriate or partially overlapping, broad-fusiform, tapering towards the rounded ends, dictyosporous, 1(-2)-longitudinal euseptate, 7-9-transverse euseptate, constricted at the septa, strongly constricted at the median septum, cells above median septum wider than below, yellowish, with 8-10 $\mu \mathrm{m}$ wide mucilaginous drawn out sheath. Asexual morph: Undetermined.

Culture characters: Colonies on MEA reaching $30 \mathrm{~mm}$ diam. after 4 weeks at $16{ }^{\circ} \mathrm{C}$. Culture from above cream, 

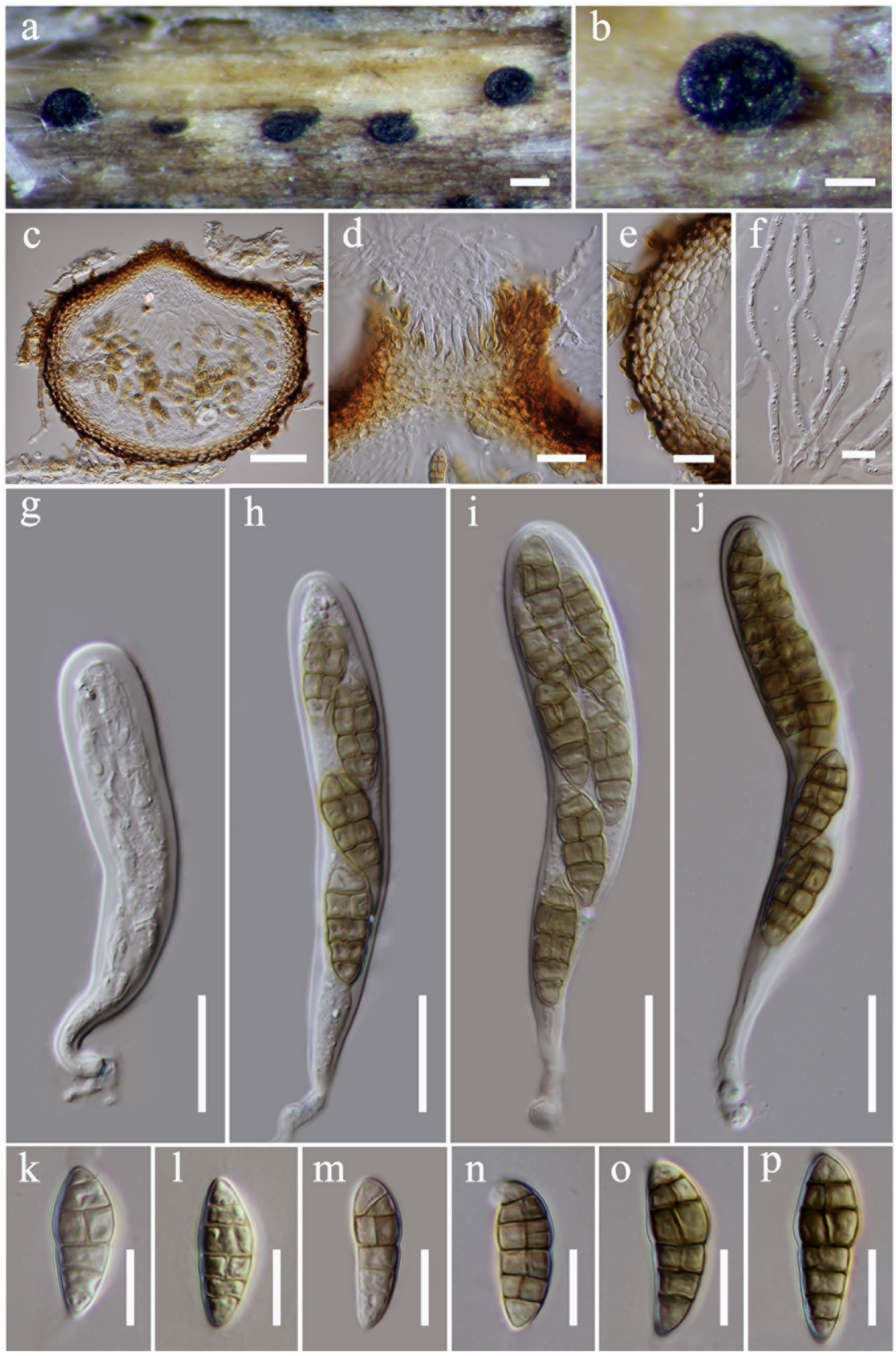
४Fig. 52 Dermatiopleospora mariae (MFLU 16-0121). a Appearance of ascomata on Clematis vitalba. b Close up of ascoma on host substrate. c Vertical section through ascoma. d Ostiolar canal. e Section of peridium. f Pseudoparaphyses. $\mathbf{g}-\mathbf{j}$ Asci. $\mathbf{k}-\mathbf{p}$ Ascospores. Scale bars: $\mathbf{a}=500 \mu \mathrm{m}, \mathbf{b}=100 \mu \mathrm{m}, \mathbf{c}-\mathbf{j}=20 \mu \mathrm{m}, \mathbf{k}-\mathbf{p}=10 \mu \mathrm{m}$

orange aerial mycelium, dense, fluffy at the edge, umbonate, rough, lobate; reverse cream radiating white outwardly.

Material examined: Italy, Forli-Cesena Province, Marsignano-Predappio, dead stems of Clematis vitalba, 31 March 2015, E. Camporesi, IT 1537 (MFLU 16-0176, holotype); ex-type living culture, MFLUCC 14-0937.

Host: Clematis vitalba-(This study).

Distribution: Italy-(This study).

GenBank accession numbers: LSU: MT214583; SSU: MT226696; ITS: MT310628; gapdh: MT394626.

Notes: Stemphylium clematidis has a pleospora-like sexual morph. The isolate formed a sister clade with $S$. majusculum, however the species is distinguishable by somewhat larger ascospores (Ramsey 1934; Simmons 1969, Fig. 60). The asexual morph was not obtained from culture. A pairwise comparison of the ITS sequence showed six nucleotide differences out of 555 nucleotides in the ITS regions (including gaps), while gapdh showed five nucleotide differences out of 595 nucleotides. The new strain is introduced as a new species of Stemphylium based on guidelines proposed by Jeewon and Hyde (2016).

Stemphylium rosae (Wanas. et al.) Phukhams. \& K.D. Hyde, comb. nov.

Index Fungorum number: IF557603; Facesoffungi number: FoF 0404

Basionym: Pleospora rosae Wanas., Camporesi, E.B.G. Jones \& K.D. Hyde, in Wanasinghe et al., Fungal Diversity [153] (2018).

Notes: Based on analyses of combined LSU, ITS and gadph sequence data for Stemphylium (Fig. 60), two isolates of Pleospora rosae and P. rosae-caninae clustered with Stemphylium sensu stricto. These two strains are compatible with the Stemphylium concept. Thus, we synonymize Pleospora rosae under Stemphylium rosae and Pleospora rosaecaninae under Stemphylium rosae-caninae. The nomenclature change is based on one fungus $=$ one name protocol.

Host: Rosa canina-(Wanasinghe et al. 2018).

Distribution: Italy_(Wanasinghe et al. 2018).

Stemphylium rosae-caninae (Wanas. et al.) Phukhams. \& K.D. Hyde, comb. nov.

Index Fungorum number: IF557604; Facesoffungi number: FoF 04047

Basionym: Pleospora rosae-caninae Wanas., Camporesi, E.B.G. Jones \& K.D. Hyde, in Wanasinghe et al., Fungal Diversity [157] (2018).
Notes: See notes under Stemphylium rosae-caninae.

Host: Rosa canina-(Wanasinghe et al. 2018).

Distribution: Italy-(Wanasinghe et al. 2018).

Stemphylium vesicarium (Wallr.) E.G. Simmons, Mycologia 61(1): 9 (1969), new host record

Index Fungorum number: IF339660; Facesoffungi number: FoF 04472, Figs. 61, 62.

Saprobic on dead stem of Clematis vitalba. Sexual morph: Ascomata 170-257 $\times 148-250 \mu \mathrm{m}$ $(\bar{x}=220 \times 205 \mu \mathrm{m}, \mathrm{n}=10)$, solitary, scattered, uniloculate, under epidermal layer of host, to superficial, globose to compressed, coriaceous, black, ostiolate. Ostioles central, papillate, with variable walls, opening by a pore, filled with hyaline periphyses. Peridium $25-49 \mu \mathrm{m}$ wide $(\bar{x}=40 \mu \mathrm{m}$, $\mathrm{n}=20$ ), thick, uniform, composed of 7-12 layers of textura angularis, black, heavy pigmented at the outer layer, cells toward the inside cells of lighter, inner layer composed of thin hyaline gelatinous layer. Hamathecium composed of numerous, dense, 1.6-2.25 $\mu \mathrm{m}$ wide $(\bar{x}=1.8 \mu \mathrm{m}, \mathrm{n}=20)$, filamentous, branched, septate, cellular pseudoparaphyses, situated between and above the asci embedded in a gelatinous matrix. Asci $103-138 \times 16-26 \mu \mathrm{m}(\bar{x}=118 \times 23 \mu \mathrm{m}$, $\mathrm{n}=30$ ), 8-spored, bitunicate, fissitunicate, oblong to cylindrical-clavate with short, furcate pedicel, apically rounded, with an ocular chamber. Ascospores 20-30 ×6-12 $\mu \mathrm{m}$ ( $\bar{x}=26 \times 10 \mu \mathrm{m}, \mathrm{n}=50$ ), biseriate or partially overlapping, muriform, tapering towards the ends, ends rounded, dictyosporous, 1(-2)-longitudinal euseptate, 4-10-transversely euseptate, constricted at the septa, strongly constricted at the median septum, yellowish, with 5-12 $\mu$ m wide drawn out mucilaginous sheath. Asexual morph: Colonies effuse on the surface of culture, scattered, hairy, and fluffy. Mycelium white, with 2-5 $\mu \mathrm{m}$ wide, effuse, hyaline, septate. Conidiophores $10-57 \times 3-5 \mu \mathrm{m}(\bar{x}=35 \times 4 \mu \mathrm{m}, \mathrm{n}=20)$, macronematous, mononematous, simple, branched, stipes straight or flexuous, cylindrical, erect, septate, smooth, dark brown to brown, 3(-6)-septate, with 1-2 primary branches, irregularly branched at the upper parts, brown, smooth. Conidiogenous cells 5-12×4-10 $\mu \mathrm{m}(\bar{x}=9 \times 7 \mu \mathrm{m}, \mathrm{n}=20)$, monotretic, integrated or terminal, on conidiophores, doliiform to oblong, pale brown. Conidia 14-31 ×13-32 $\mu \mathrm{m}$ $(\bar{x}=21 \times 21 \mu \mathrm{m}, \mathrm{n}=30)$, in branched chains, acrogenous, folded, muriform, dictyosporous, 1(-2)-transversely euseptate, 1-3-horizontal euseptate, constricted at septa, dark brown to brown, bud scars or disjunctors present at the site of attachment, easily separated.

Culture characters: Colonies on MEA reaching $30 \mathrm{~mm}$ diam. after 4 weeks at $16{ }^{\circ} \mathrm{C}$. Cultures from above, dark green, fluffy, with dark green aerial mycelium, dense, fluffy at the edge, umbonate, rough, lobate, faintly zonate; reverse: dark green, radiating. 

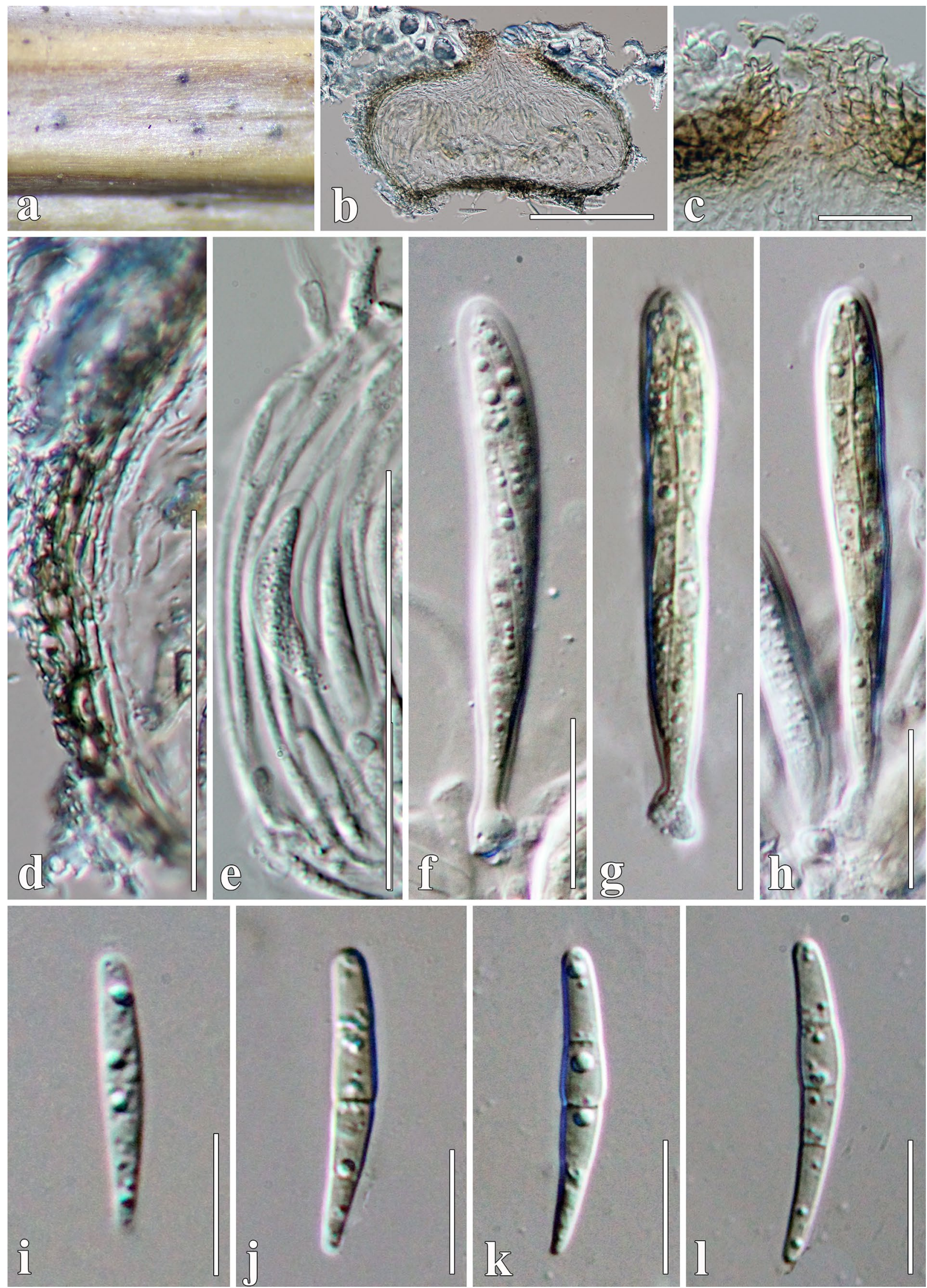
४Fig. 53 Leptospora clematidis (MFLU 17-1505, holotype). a Appearance of ascomata on Clematis patens. b Vertical section through ascoma. c Ostiolar canal. d Section of peridium. e Pseudoparaphyses. f-h Asci. i-l Ascospores. Scale bars: $\mathbf{b}=100 \mu \mathrm{m}, \mathbf{c}, \mathbf{f}-$ $\mathbf{h}=20 \mu \mathrm{m}, \mathbf{d}, \mathbf{e}=50 \mu \mathrm{m}, \mathbf{i}-\mathbf{l}=10 \mu \mathrm{m}$

Material examined: Italy, Forli-Cesena Province, Viale Salinatore-Forlì, dead stems of Clematis vitalba, 23 February 2015, E. Camporesi, IT 2983M (MFLU 16-1109); living culture, MFLUCC 16-0998.

Hosts: Abies sp., Allium cepa, A. sativum, Asparagus officinalis, Brassica nigra, Brassica pekinensis, Cirsium sp., Citrus sp., Clematis vitalba, Cremanthodium discoideum, Cremanthodium discoideum, Dahlia pinnata, Dianthus caryophyllus, Lathyrus odoratus, Leucadendron sp., Linum usitatissimum, Lunaria annua, Lunaria rediviva, Malus domestica, Malus sieversii, Mangifera indica, Medicago sativa, Phaseolus vulgaris, Pisum sativum, Populus tomentosa, Pyrus sinkiangensis, Sedum spectabile, Solanum lycopersicum, Tamaric sp., Trigonella foenum-graecum-(Simmons 1969; Simonyan 1981; Câmara et al. 2002; Köhl et al. 2009; Arzanlou et al. 2012; Ariyawansa et al. 2015c; Woudenberg et al. 2017; Farr and Rossman 2020; this study).

Distribution: Australia, Canada, China, Denmark, Germany, India, Italy, Netherlands, New Zealand, Portugal, South Africa, Tunisia, UK (England), USA (California)(Simmons 1969; Simonyan 1981; Câmara et al. 2002; Köhl et al. 2009; Arzanlou et al. 2012; Ariyawansa et al. 2015c; Woudenberg et al. 2017; Farr and Rossman 2020; this study).

GenBank accession numbers: LSU: MT214584; SSU: MT226697; ITS: MT310629; tef1: MT394642.

Notes: Stemphylium vesicarium (=Pleospora herbarum) is a plant pathogen distributed on a range of wild and cultivated hosts (Köhl et al. 2009; Arzanlou et al. 2012; Woudenberg et al. 2017). Phylogenetic analysis of combined LSU, ITS and gapdh regions show that our isolate clusters with S. vesicarium (Fig. 59). The morphological comparison of our isolate (MFLUCC 16-0998) with S. vesicarium (CPC 29939) which was reported in Woudenberg et al. (2017) showed that our collection has 4-10-transverse eusepta ascospores (Figs. 61, 62). Our collection is similar to the type strian of $S$. vesicarium (STR) which was described by Simmons (1969). A pairwise comparison of the ITS regions show that our isolate is $100 \%$ identical to the type strain of $S$. vesicarium (CBS 192.86). This is the first report of $S$. vesicarium on Clematis.

Pseudoberkleasmiaceae Phukhams. \& K.D. Hyde

Pseudoberkleasmiaceae was introduced to accommodate a berkleasmium-like species that has phylogenetic stability in Pleosporales (Hyde et al. 2019a). The family comprises Pseudoberkleasmium acacia, Pseudoberkleasmium chiangmaiense and $P$. pandanicola (the generic type). We describe the first record of $P$. chiangmaiense on Clematis from Thailand (Figs. 2, 63).

Pseudoberkleasmium Tibpromma \& K.D. Hyde

The monotypic genus Pseudoberkleasmium was introduced with $P$. pandanicola Tibpromma \& K.D. Hyde as the type species. Pseudoberkleasmium is characterized by hyaline, subglobose conidiogenous cells and acrogenous, broadly ellipsoidal to obovoid, muriform, brown or olivaceous green, and guttulate conidia. There is no sexual morph report in this family. A collection on Clematis sikkimensis reveals an additional strain of Pseudoberkleasmium chiangmaiense according to phylogenetic and morphological evidence (Figs. 2, 63).

Pseudoberkleasmium chiangmaiense Y.Z. Lu \& K.D. Hyde, in Hyde et al., Fungal Diver (2019), new host record

Index Fungorum number: IF555595; Facesoffungi number: FoF 05310, Fig. 63.

Saprobic on dead stems of Clematis sikkimensis. Sexual morph: Undetermined. Asexual morph: Hyphomycetous, colonies on natural substrate forming sporodochial conidiomata, 109-460 $\mu \mathrm{m}$ wide, superficial, scattered, gregarious, oval, brown, velvety, glistening, orbicular, conidia readily liberated when agitated. Mycelium immersed in the substrate, composed of septate, branched, smooth, hyaline to pale brown, $2.5 \mu \mathrm{m}$ wide hyphae. Conidiophores 10-25 $\times 2-5 \mu \mathrm{m}$, micronematous, mononematous, cylindrical or truncate, erect, hyaline, smooth-walled. Conidiogenous cells $9-15 \times 6-15 \mu \mathrm{m}(\bar{x}=12 \times 11 \mu \mathrm{m}, \mathrm{n}=20)$, holoblastic, monoblastic, integrated, terminal, determinate, subglobose, cylindrical or slightly truncate, guttulate, hyaline. Conidia $24-32 \times 13-18 \mu \mathrm{m}(\bar{x}=27 \times 16 \mu \mathrm{m}, \mathrm{n}=50)$, acrogenous, solitary, broadly ellipsoidal to obovoid, flattened, dictyosporous, muriform, apex rounded, basal cells globose or subglobose, in side view composed of one column of 4-6 cells, guttulate, smooth-walled, brown, usually with conidiogenous cell attached, bud scars or disjunctors present at the site of attachment.

Culture characters: Colonies on MEA reaching $30 \mathrm{~mm}$ diam. after 4 weeks at $25^{\circ} \mathrm{C}$. Cultures from above black, dense, circular, umbonate, papillate, fluffy, slightly radiating, wrinkled folded; reverse black, lifting media up in the centre, wrinkled.

Material examined: Thailand, Chiang Rai Province, Doi Tung, on dried stem of Clematis sikkimensis, 2 May 2017, C. Phukhamsakda \& M.V. de Bult, CMTHDT05 (MFLU 17-1496); living culture, MFLUCC 17-2088.

Hosts: Clematis fulvicoma, Undetermined decaying wood-(Hyde et al. 2019a; this study).

Distribution: Thailand-(Hyde et al. 2019a; this study). 


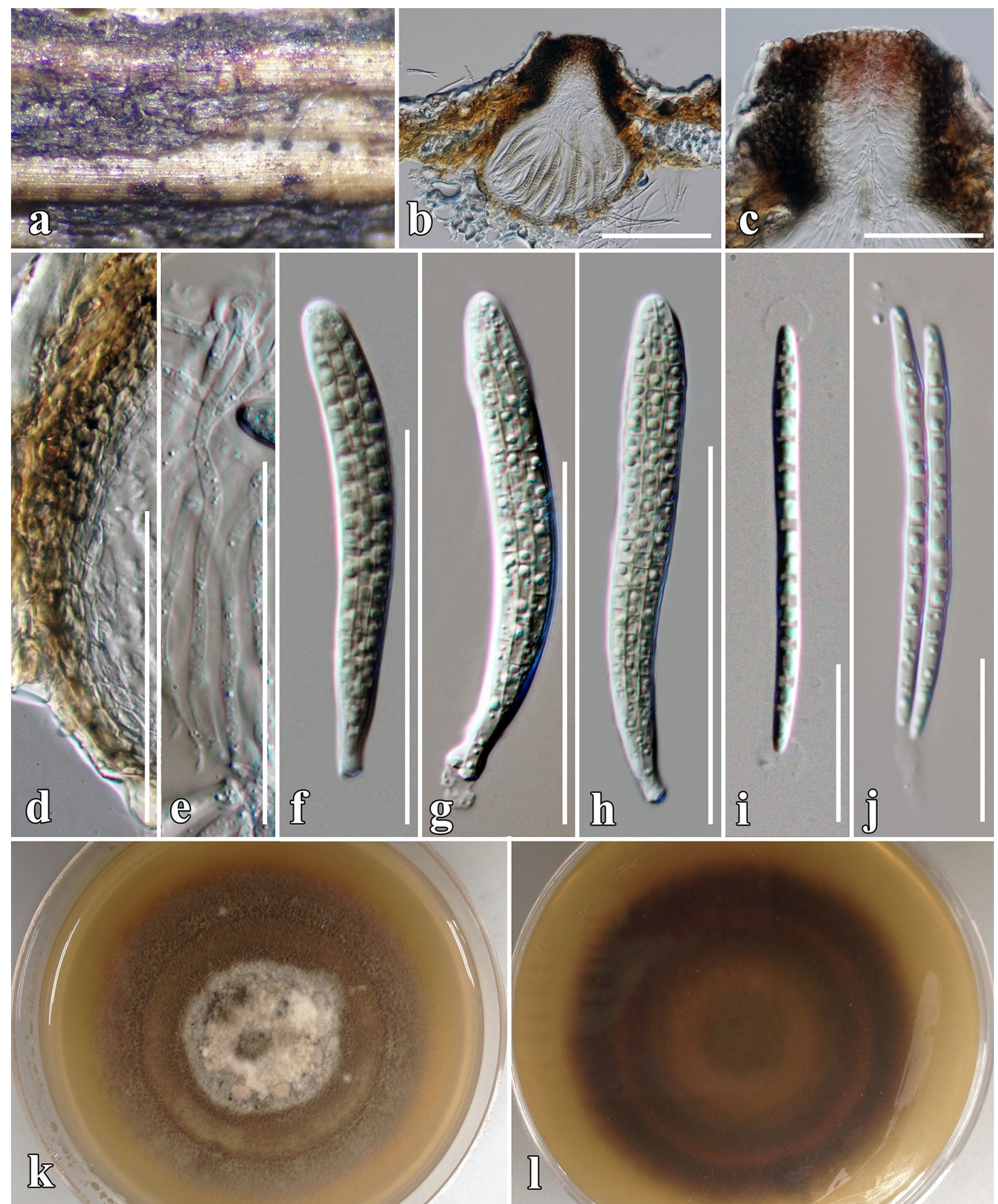

Fig. 54 Leptospora thailandica (MFLU 17-1474). a Appearance of ascomata on Clematis subumbellata. b Vertical section through ascoma. c Ostiolar canal. d Section of peridium. e Pseudoparaphyses. $\mathbf{f}-\mathbf{h}$ Asci. $\mathbf{i}, \mathbf{j}$ Ascospores. $\mathbf{k}, \mathbf{l}$ Culture characteristics on MEA. Scale bars: $\mathbf{b}=100 \mu \mathrm{m}, \mathbf{c}-\mathbf{h}=50 \mu \mathrm{m}, \mathbf{i}, \mathbf{j}=20 \mu \mathrm{m}$ 

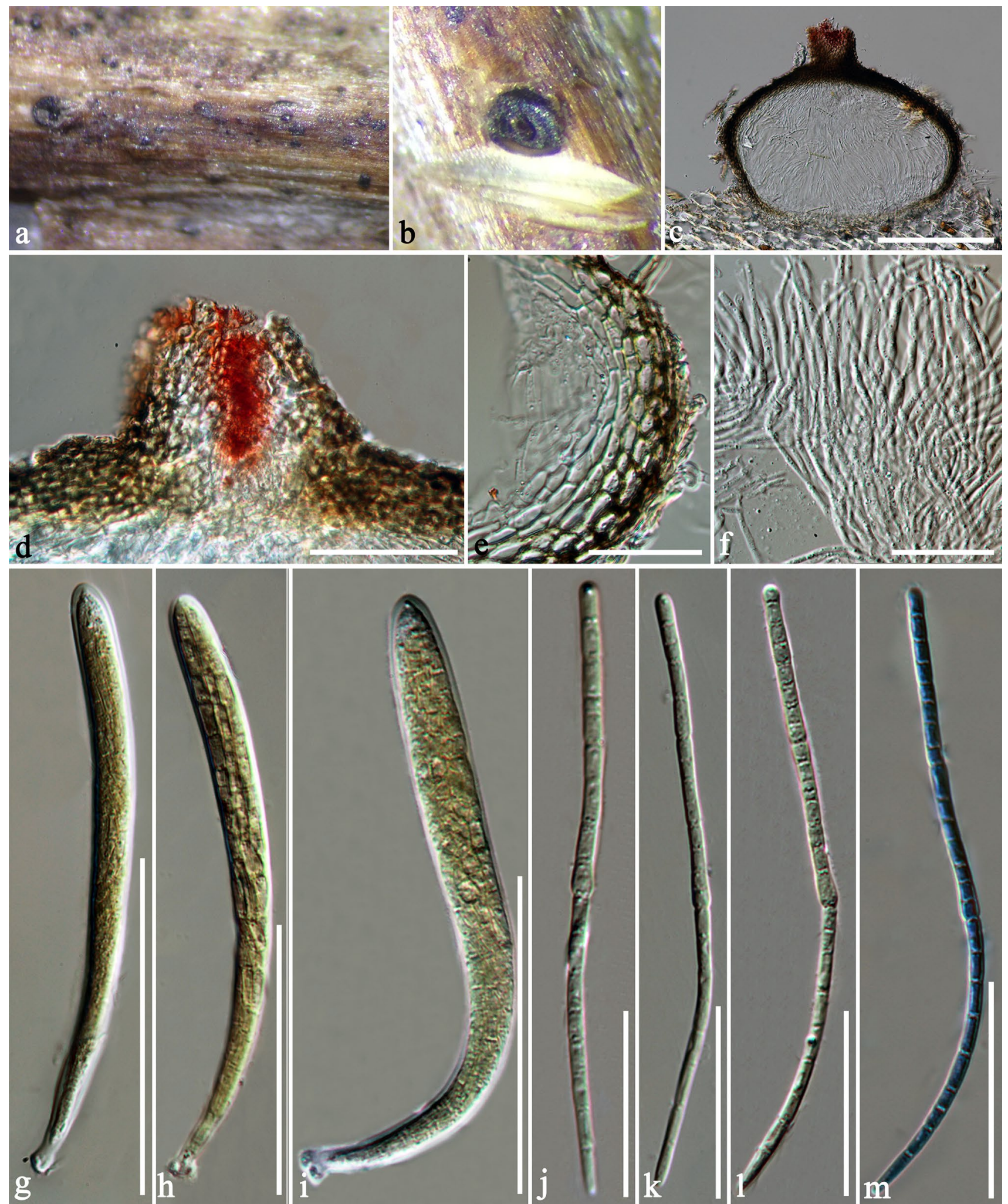

Fig. 55 Longispora clematidis (MFLU 20-0420, holotype), a, b Appearance of ascomata on Clematis vitalba. c Vertical section through ascoma. d Ostiolar canal. e Section of peridium. f Pseudo-

paraphyses. $\mathbf{g}-\mathbf{i}$ Asci. $\mathbf{j}-\mathbf{m}$ Ascospores (m Ascospore in cotton blue). Scale bars: $\mathbf{c}=100 \mu \mathrm{m}, \mathbf{d}-\mathbf{f}, \mathbf{j}-\mathbf{m}=20 \mu \mathrm{m}, \mathbf{g}-\mathbf{i}=50 \mu \mathrm{m}$ 


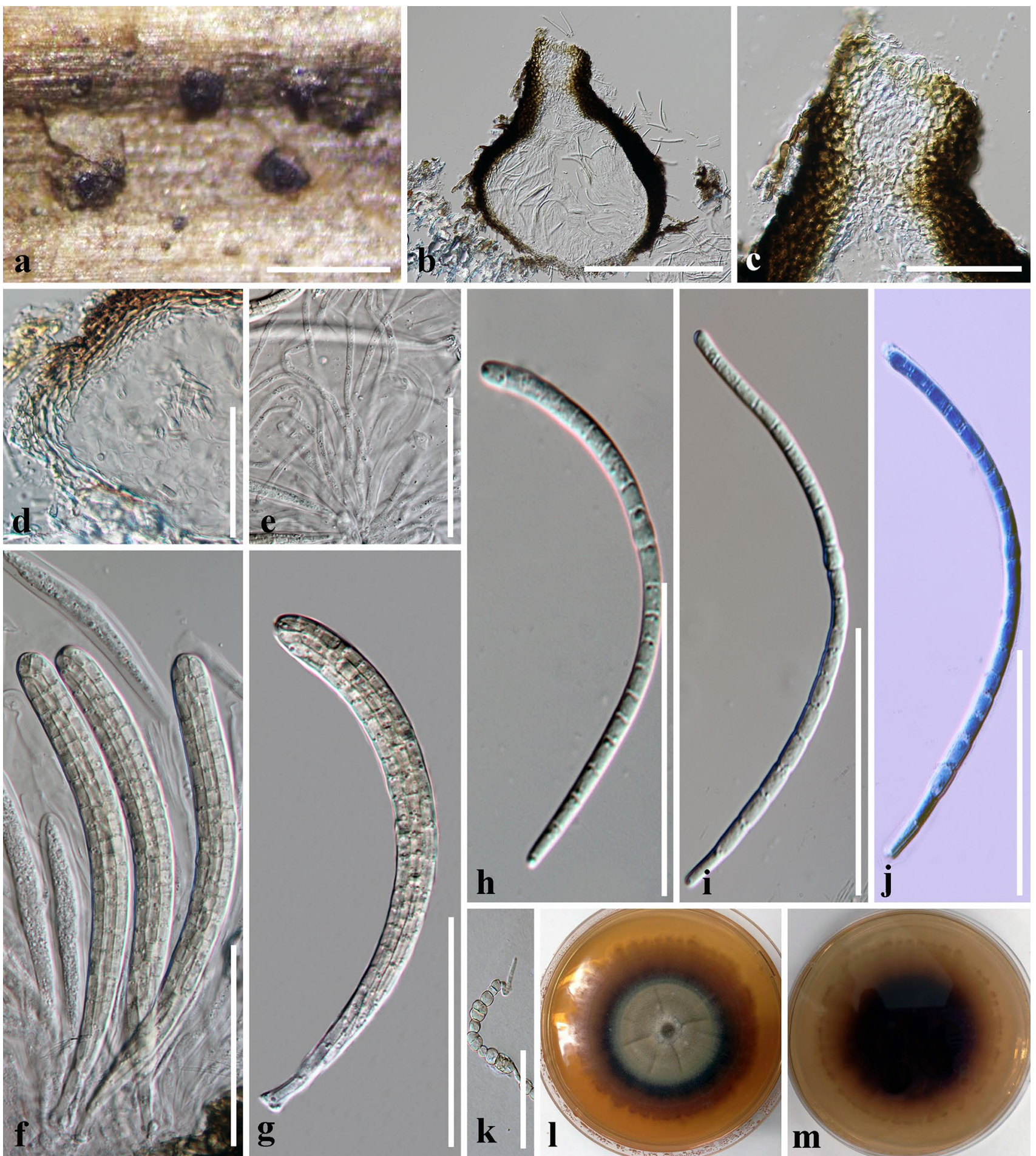

Fig. 56 Pseudoophiobolus rosae (MFLU 15-1014). a Appearance of ascomata on Clematis vitalba. b Vertical section through ascoma. c Ostiolar canal. d Section of peridium. e Pseudoparaphyses. f-g Asci.

$\mathbf{h}-\mathbf{j}$ Ascospores (j in cotton blue). $\mathbf{k}$ Germinated ascospore. $\mathbf{1}, \mathbf{m}$ Culture characteristics on MEA. Scale bars: $\mathbf{a}=500 \mu \mathrm{m}, \mathbf{b}=200 \mu \mathrm{m}$, $\mathbf{c}-\mathbf{k}=50 \mu \mathrm{m}$ 


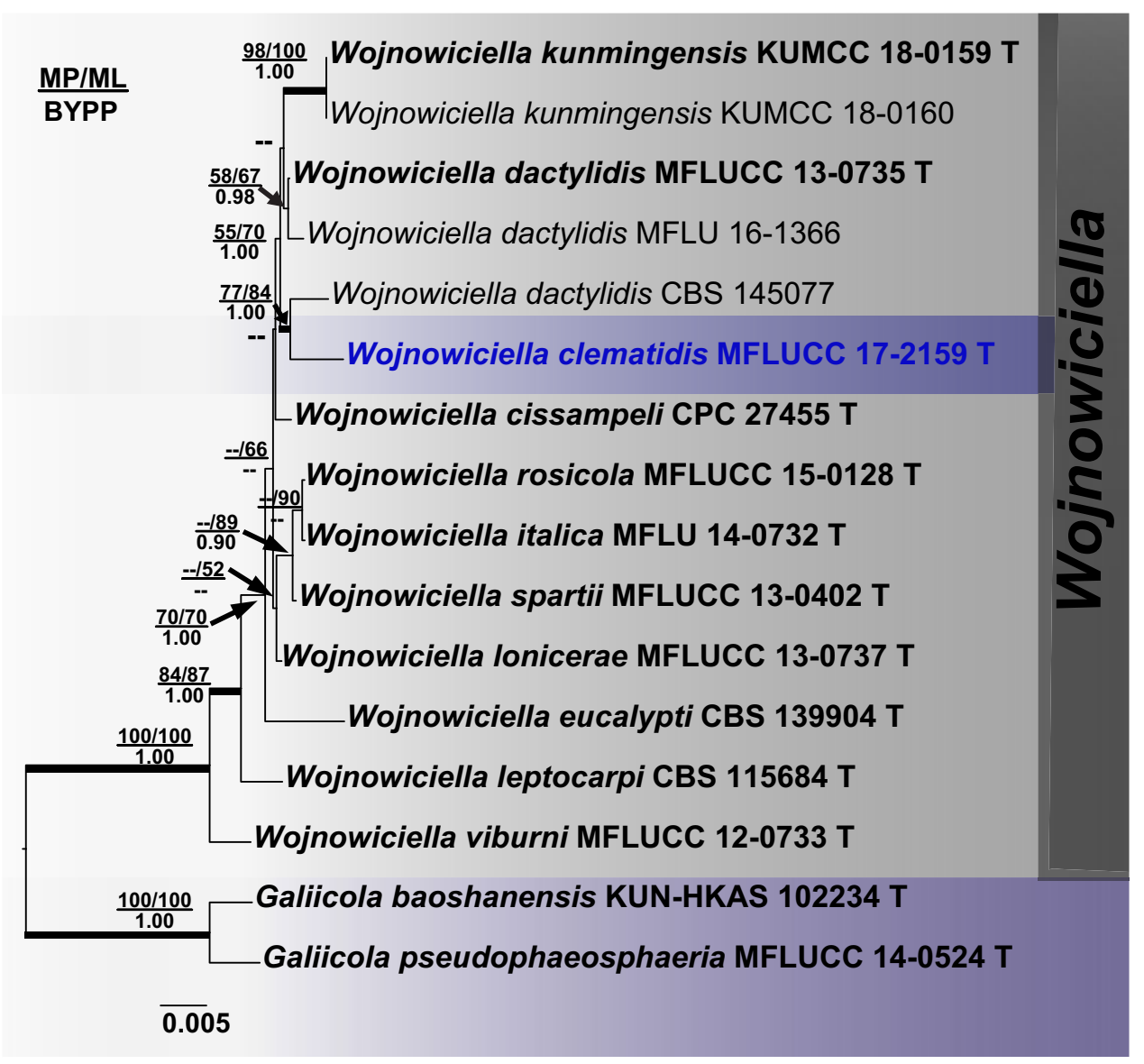

Fig. 57 Phylogram obtained from maximum likelihood based on combined LSU, SSU, ITS, tef1 and $r p b 2$ sequence data. The tree is rooted with Galiicola baoshanensis (KUN-HKAS 102234) and Galiicola pseudophaeosphaeria (MFLUCC 14-0524). Related sequences are retrieved from GenBank with 16 strains included in the analysis of the combined loci and comprises 4177 characters (820 characters for LSU, 1012 characters for SSU, 561 characters for ITS, 905 characters for $t e f 1,879$ characters for $r p b 2$, including gaps). The best scoring RAxML tree had a final likelihood value of - 7456.746869. The matrix had 277 distinct alignment patterns with $31.92 \%$ undetermined characters and gaps. Estimated base frequencies were: $\mathrm{A}=0.244763, \mathrm{C}=0.241642, \mathrm{G}=0.263061, \mathrm{~T}=0.250533$; substitution rates $\mathrm{AC}=1.095229, \mathrm{AG}=1.632728, \mathrm{AT}=1.392298$,

GenBank accession numbers: LSU: MT214585; SSU: MT226698; ITS: MT310630; tef1: MT394643; rpb2: MT394699.

Notes: Pseudoberkleasmium chiangmaiense (MFLUCC 17-2088) is similar to the type except for culture characters (Hyde et al. 2019a, Fig. 63), however, our collection was grown on MEA while the type was cultured on PDA. Phylogenetically, $P$. chiangmaiense (strain MFLUCC 17-2088) formed a clade with the type strain (MFLUCC 17-1809) with strong support (100\% ML/1.00 BYPP, Fig. 2). The type strain was isolated from decaying wood collected in Chiang Mai, therefore, we present a new host record of $P$. chiangmaiense on Clematis sikkimensis (Fig. 63).
$\mathrm{CG}=0.793970, \mathrm{CT}=6.972828, \mathrm{GT}=1.000000 ;$ gamma distribution shape parameter $\alpha=6.674062$. Maximum parsimony analysis of 111 parsimony informative characters resulted in a most parsimonious tree $(\mathrm{CI}=0.916, \mathrm{RI}=0.858, \mathrm{RC}=0.786, \mathrm{HI}=0.084)$. In our analysis, GTR + I + G model was used for each partition in Bayesian posterior analysis. Bootstrap values (BS) from maximum parsimony (MP, left), maximum likelihood (ML, right) higher than 50\% BS and Bayesian posterior probabilities (BYPP, below) greater than 0.90 are given at the nodes. Hyphens (-) represent support values less than $50 \%$ ML/0.90 BYPP. Thick branches represent significant support values from all analyses (ML $\geq 70 \% / B Y P P \geq 0.95)$. The ex-type strains are in bold and black. The newly generated sequence is in bold and blue

Pseudomassarinaceae Phukhams. \& K.D. Hyde, fam. nov. Index Fungorum number: IF557104; Facesoffungi number: FoF 07212, Fig. 64.

Saprobic on dried herbaceous plants. Sexual morph: Ascomata immersed, only ostioles visible, uniloculate, obpyriform to subglobose, light brown to brown, coriaceous. Ostioles central, brown to dark brown, carbonaceous, papillate. Peridium thin, multilayered, comprising thin-walled, light brown to brown cells of textura angularis, inner layers comprising hyaline cells. Hamathecium of dense, filiform, branched, pseudoparaphyses. Asci 8-spored, bitunicate, fissitunicate, thick-walled, oblong, apically rounded, with furcate pedicel. Ascospores biseriate, overlapping, hyaline, broad 


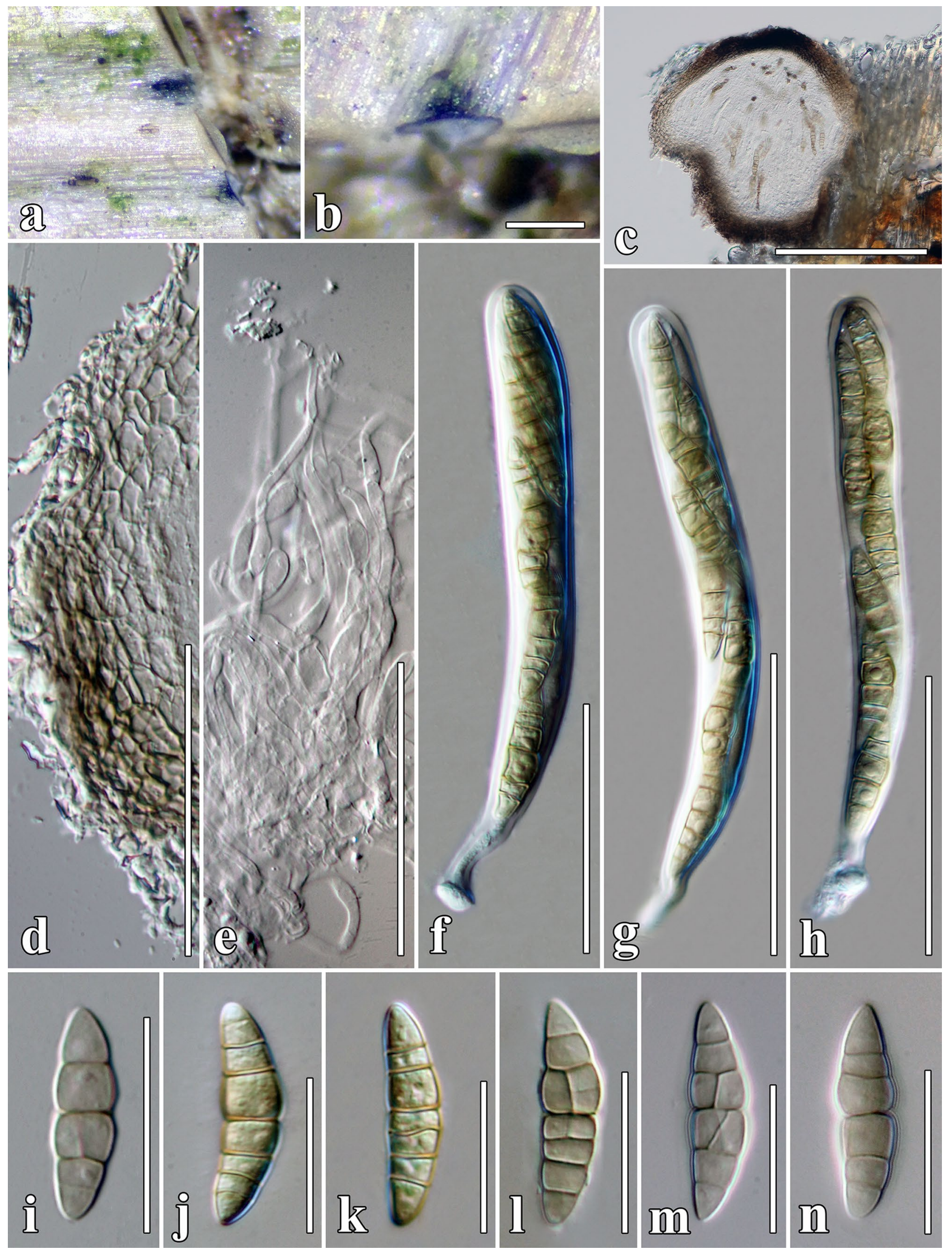


४Fig. 58 Wojnowiciella clematidis (MFLU 17-1517, holotype). a, b Appearance of ascomata on host surface. c Vertical section through ascoma. d Section of peridium. e Pseudoparaphyses. f-h Asci. i-n Ascospores. Scale bars: b, $\mathbf{c}=200 \mu \mathrm{m}, \mathbf{d}-\mathbf{h}=50 \mu \mathrm{m}, \mathbf{i}-\mathbf{n}=20 \mu \mathrm{m}$

fusiform, tapering towards the ends, acute at both ends, with transverse septa, with mucilaginous sheath. Asexual morph: Undetermined.

Type genus: Pseudomassarina Phukhams. \& K.D. Hyde

Notes: The new family Pseudomassarinaceae is introduced to accommodate a monotypic genus, Pseudomassarina (Fig. 64). Phylogenetic analysis which included related families in Pleosporales, showed that Pseudomassarinaceae formed a distinct lineage related to Amorosiaceae, Halotthiaceae, Lophiostomataceae, Neomassarinaceae, Phaeoseptaceae and Sporormiaceae (Fig. 2). The family is morphologically similar to Lophiostomataceae, Neomassariaceae and Neomassarinaceae in having hyaline, ellipsoid to fusiform, septate ascospores (Thambugala et al. 2015; Ariyawansa et al. 2018; Mapook et al. 2020). Pseudomassarinaceae is distinguished by its immersed, coriaceous ascomata with crest-like, carbonaceous ostioles, oblong and short pedicellate asci and wide mucilaginous sheath surrounding the ascospores.

Pseudomassarina Phukhams. \& K.D. Hyde, gen. nov.

Index Fungorum number: IF557097; Facesoffungi number: FoF 07213, Fig. 64.

Etymology: The genus epithet reflects its morphological similarity to Massarina species.

Saprobic on decaying plants in terrestrial habitats. Sexual morph: Ascomata on surface of the host, visible as black spots, immersed, solitary, uniloculate, obpyriform, brown, rough-walled, coriaceous, with apical ostioles. Ostioles central, brown to dark brown, partially carbonaceous, papillate, filled with periphyses. Peridium multilayered, comprising thin-walled, light brown to brown cells of textura angularis, inner layers comprising hyaline cells. Hamathecium of dense, filiform, branched, transverse septa, pseudoparaphyses. Asci 8-spored, bitunicate, fissitunicate, thick-walled, oblong, apically rounded, short pedicellate, with an ocular chamber. Ascospores biseriate, overlapping, hyaline, broad fusiform, tapering towards the ends, with transverse septum, guttulate, smooth-walled, with mucilaginous sheath. Asexual morph: Undetermined.

Type species: Pseudomassarina clematidis Phukhams, Camporesi \& K.D. Hyde

Notes: Pseudomassarina, is typified by P. clematidis and formed a distinct lineage in Pleosporales (Fig. 2). The morphological comparison showed that our collection has unique characters among related taxa in Pleosporales (Zhang et al. 2012; Hyde et al. 2013; Thambugala et al. 2015; Ariyawansa et al. 2018; Mapook et al. 2020). In a BLASTn search of GenBank, the closest match of the LSU sequence of MFLU 16-0493 is Preussia terricola (strain CBS 317.65) with $97.43 \%$ similarity. The closest match with the ITS sequence is Preussia polymorpha (strain CBS 117679) with $84.49 \%$ similarity.

Pseudomassarina clematidis Phukhams, Camporesi \& K.D. Hyde sp. nov.

Index Fungorum number: IF557098; Facesoffungi number: FoF 07214, Fig. 64.

Etymology: The epithet reflects Clematis.

Holotype: MFLU 16-0493.

Saprobic on dead stems of Clematis vitalba. Sexual morph: Ascomata $150-220 \times 80-130 \mu \mathrm{m}(\bar{x}=190 \times 110 \mu \mathrm{m}$, $\mathrm{n}=5$ ), on surface of the host, visible as black spots, immersed, only ostioles visible, solitary, scattered, uniloculate, obpyriform to subglobose, light brown to brown, roughwalled, coriaceous, with apical ostioles. Ostioles central, 65-70 $\times 50-55 \mu \mathrm{m}$, brown to dark brown, papillate, opening by a pore, filled with periphyses. Peridium 10-20 $\mu \mathrm{m}$ wide, multilayered, comprising of 4-5 layers of thin-walled light brown to brown cells of textura angularis, inner layers comprising hyaline cells. Hamathecium of dense, 1.3-1.5 $\mu \mathrm{m}$ wide $(\bar{x}=1.3 \mu \mathrm{m}, \mathrm{n}=50)$, filiform, branched, septate, pseudoparaphyses. Asci 55-80 $\times 9-15 \mu \mathrm{m}(\bar{x}=60 \times 10 \mu \mathrm{m}$, $\mathrm{n}=30$ ), 8-spored, bitunicate, fissitunicate, thick-walled, oblong, apically rounded, with short, furcate pedicel, ocular chamber clearly visible. Ascospores 16-25 $\times 3-7 \mu \mathrm{m}$ ( $\bar{x}=20 \times 5 \mu \mathrm{m}, \mathrm{n}=50$ ), biseriate, overlapping, hyaline, broad fusiform, tapering towards the ends, acute at both ends, with 1 transverse septum, with large guttules in each cell, deeply constricted at the septum, cell above septum longer and wider than below cell, smooth-walled, with 4-6 $\mu \mathrm{m}$ wide mucilaginous sheath. Asexual morph: Undetermined.

Material examined: Italy, Forlì-Cesena Province, Fiumicello-Premilcuore, on dead aerial branch of Clematis vitalba, 20 March 2016, E. Camporesi, IT 2335 (MFLU 16-0493, holotype).

Host: Clematis vitalba-(This study).

Distribution: Italy-(This study).

GenBank accession numbers: LSU: MT214586; SSU: MT226699, MT310631; ITS: MT415397; tef1: MT394644; rpb2: MT394700.

Notes: See note under Pseudomassarina.

Pseudolophiotremataceae K.D. Hyde \& S. Hongsanan

Pseudolophiotremataceae was introduced by Hongsanan et al. (2018) with Pseudolophiotrema elymicola as the generic type. The multi-locus analysis (Fig. 2) showed that Clematidis italica (MFLUCC 15-0084) clustered with $P$. elymicola. Thus, we place Clematidis italica (Fig. 65) in Pseudolophiotremataceae. 


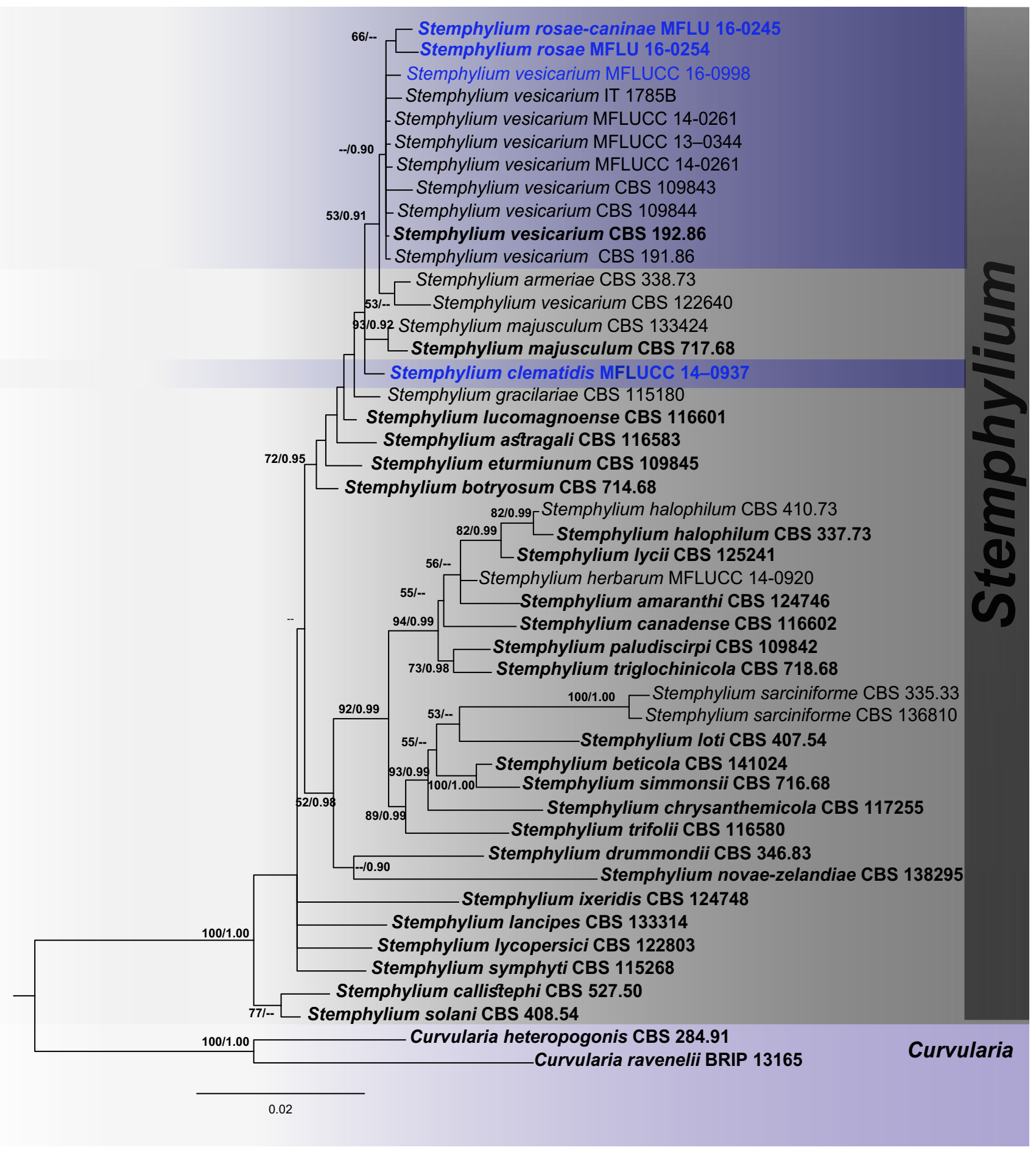

Fig. 59 The Bayesian 50\% majority-rule consensus phylogram based on combined LSU, ITS and gadph data for Stemphylium. The topology and clade stability of the combined gene analyses was compared to the single gene analyses. The tree is rooted with Curvularia species. Forty-six strains were included in the combined gene sequence analyses which comprised 2052 characters (902 characters for LSU, 555 characters for ITS, 595 characters for gadph, including gap regions). The best scoring RAxML tree had a likelihood value of - 6557.926637. The matrix had 441 distinct alignment patterns with $29.84 \%$ undetermined characters and gaps. Estimated base frequencies were as follows; $\mathrm{A}=0.245289, \mathrm{C}=0.253669, \mathrm{G}=0.255798$,
$\mathrm{T}=0.245244 ;$ substitution rates $\mathrm{AC}=1.484723, \mathrm{AG}=3.274866$, $\mathrm{AT}=0.996508, \quad \mathrm{CG}=1.050822, \quad \mathrm{CT}=5.664441, \quad \mathrm{GT}=1.000000$; gamma distribution shape parameter $\alpha=0.781417$. In our analysis, GTR + I + G model was used for each partition in Bayesian posterior analysis. The species determined in this study are indicated in blue. Bootstrap values (BS) greater than 50\% BS (ML, left) and Bayesian posterior probabilities (BYPP, right) greater than 0.90 are given at the nodes. Hyphens (-) represent support values less than 50\% BS/0.90 BYPP. Thick branches represent significant support values from all analyses (BS $\geq 70 \% / B Y P P \geq 0.95)$ 

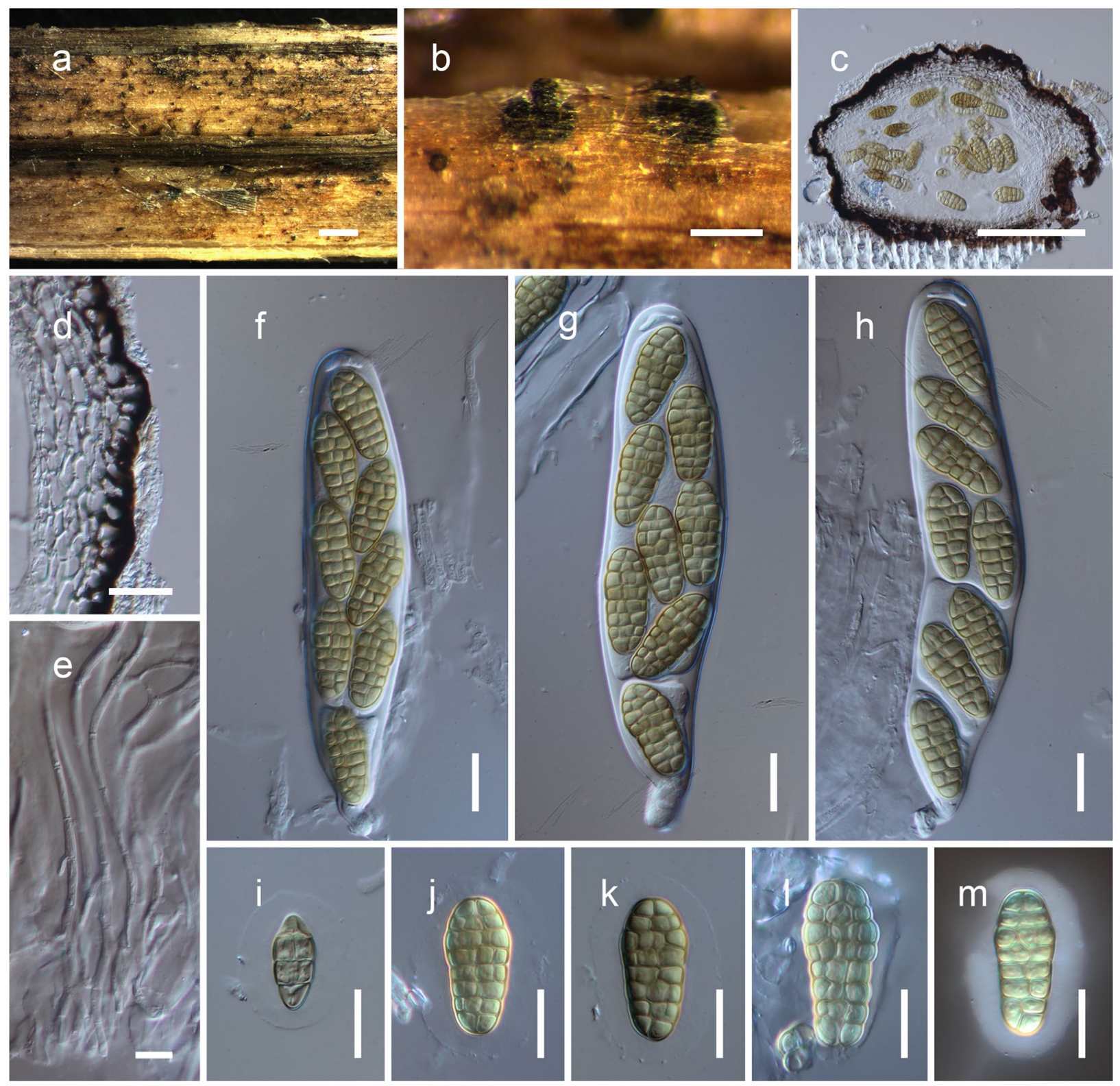

Fig. 60 Stemphylium clematidis (MFLU 16-0176, holotype). a Appearance of ascomata on host surface. b Close up of ascomata. c Vertical section though ascoma. d Peridium. e Pseudoparaphyses. f-h

Clematidis italica Tibpromma, Camporesi \& K.D. Hyde, in Li et al., Fungal Diversity 78: 60 (2016)

Index Fungorum number: IF 551867, Facesoffungi number: FoF 01813, Fig. 65.

Notes: Li et al. (2016) introduced Clematidis italica (strain MFLUCC 15-0084) based on analyses of combined LSU and SSU sequence data. Subsequently, Hashimoto et al. (2017) introduced Pseudolophiotrema elymicola (MAFF 239600) based on analyses of a SSU, ITS, LSU, tefl and
Asci. i-m Ascospores (m Ascospore stained in $10 \%$ India ink). Scale bars: $\mathbf{a}=500 \mu \mathrm{m}, \mathbf{b}=200 \mu \mathrm{m}, \mathbf{c}=100 \mu \mathrm{m}, \mathbf{d}-\mathbf{h}=20 \mu \mathrm{m}, \mathbf{i}-\mathbf{m}=10 \mu \mathrm{m}$

rpb2 dataset (Jaklitsch et al. 2018). In our LSU phylogenetic tree for Pleosporales, Clematidis and Pseudolophiotrema formed a closely related clade with strong support ( $94 \%$ ML/0.98 BYPP, data not shown). Consequently, in a combined dataset of LSU, SSU, ITS, tef1 and rpb2, Clematidis italica (MFLUCC 15-0084) and Pseudolophiotrema elymicola (JCM 13090) formed a well-supported clade (100\% ML/1.00 BYPP) basal to Anteagloniaceae (Fig. 2). A similar topology is shown in Hashimoto et al. (2017) wherein $P$. 

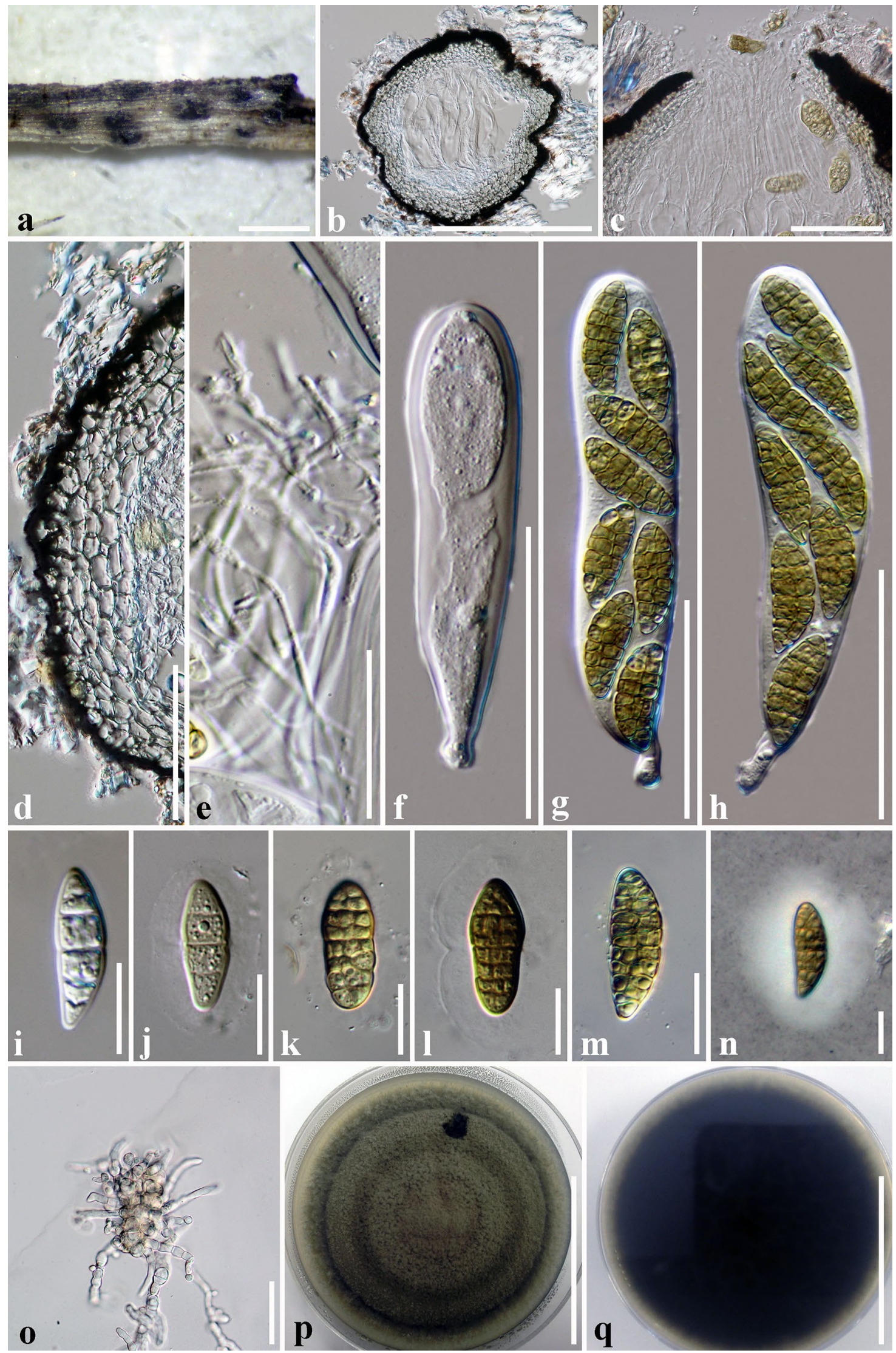
४Fig. 61 Stemphylium vesicarium (MFLU 16-1109). a Appearance of ascomata on host surface. b Vertical section of ascoma. c Ostiolar canal. d Section of peridium. e Pseudoparaphyses. f-h Asci. i-n Ascospores (n Ascospore in 10\% Indian ink). o Germinated ascospore. $\mathbf{p}$, q Culture characteristics on MEA. Scale bars: $\mathbf{a}=500 \mu \mathrm{m}, \mathbf{b}=200 \mu \mathrm{m}, \mathbf{c}-\mathbf{h}=50 \mu \mathrm{m}, \mathbf{i}-\mathbf{n}=10 \mu \mathrm{m}, \mathbf{o}=20 \mu \mathrm{m}, \mathbf{p}$, $\mathbf{q}=50 \mathrm{~mm}$

elymicola formed a distinct clade from Lophiotremataceae. As the epithet "clematidis" is similar to the plant family Clematidaceae/Clemataceae, it is difficult to introduce a generic epithet. Therefore, Pseudolophiotrema elymicola is selected as a generic type for Pseudolophiotremataceae (Hongsanan et al. 2020).

\section{Roussoellaceae Liu, Phookamsak, Dai \& K.D. Hyde}

Roussoellaceae was introduced by Liu et al. (2014) and family members have steadily increased (Jaklitsch and Voglmayr 2016; Tibpromma et al. 2017, 2018; Wanasinghe et al. 2018; Jiang et al. 2019; Karunarathna et al. 2019; Phookamsak et al. 2019; Mapook et al. 2020). We provide an updated phylogenetic analysis for Roussoellaceae based on a concatenated LSU, ITS, tef1, rpb2, and SSU sequence dataset. New host records and new species occurring on Clematis species in Thailand are described based on morphological characteristics coupled with multigene phylogenetic analyses (Fig. 66).

\section{Neoroussoella Liu et al.}

Neoroussoella was introduced with the single species, $N$. bambusae Phookamsak, J.K. Liu \& K.D. Hyde. Phylogenetic placement of the species in Roussoellaceae was demonstrated by Karunarathna et al. (2019) and Mapook et al. (2020). A multigene phylogenetic analysis (Fig. 66) reveals two novel species $N$. clematidis and $N$. fulvicomae, and the first record of $N$. heveae from a Clematis species.

Neoroussoella clematidis Phukhams. \& K.D. Hyde, sp. nov. Index Fungorum number: IF557113; Facesoffungi number: FoF 07328, Fig. 67.

Etymology: Name refers to the host genus, Clematis.

Holotype: MFLU 17-1467

Saprobic on dried stems of Clematis subumbellata. Sexual morph: Ascomata 230-250 $\times 155-160 \mu \mathrm{m}$ $(\bar{x}=235 \times 158 \mu \mathrm{m}, \mathrm{n}=5)$, only ostioles present on the surface of host, solitary, gregarious, erumpent, semi-immersed, globose to subglobose, black to rust brown, coriaceous, rough-walled, ostiolate. Ostioles central, 84-90×67-70 $\mu \mathrm{m}$, dark brown to black, papillate, ostiolar canal lined with periphyses. Peridium 12-29 $\mu \mathrm{m}$ wide, outer layer composed of 5-7 layers of brown to chestnut brown cells of textura angularis, with thin, hyaline inner layer. Hamathecium of dense, 0.8-1.5 $\mu \mathrm{m}$ wide $(\bar{x}=1.3 \mu \mathrm{m}, \mathrm{n}=40)$, filiform, branched, septate, trabeculate pseudoparaphyses. Asci $62-82 \times 4-7 \mu \mathrm{m}$
( $\bar{x}=71 \times 5 \mu \mathrm{m}, \mathrm{n}=30),(2-) 8$-spored, bitunicate, fissitunicate, cylindrical, apically rounded, with bulbose pedicel, ocular chamber visible when young. Ascospores 9-11 $\times 3-5 \mu \mathrm{m}(\bar{x}=10 \times 4 \mu \mathrm{m}, \mathrm{n}=50)$, uniseriate, partially overlapping, ellipsoid with rounded ends, olive to yellowish brown, 1-septate, constricted at septum, guttulate in each cell, rough-walled, at maturity, slightly longitudinally ribbed, without a mucilaginous sheath. Asexual morph: Undetermined.

Culture characters: Colonies on MEA reaching $20 \mathrm{~mm}$ diam. after 4 weeks at $25{ }^{\circ} \mathrm{C}$. Culture from above, brown, radiating outwards, dense, irregular in shape, umbonate, dull, edge erose, downy, covered with fairly white mycelium; reverse brown at the middle dark brown at the edge, with domes on the media.

Material examined: Thailand, Chiang Rai Province, on dead branches of Clematis subumbellata, 20 March 2017, C. Phukhamsakda, CMTH03 (MFLU 17-1467, holotype); ex-type living culture, MFLUCC 17-2061.

Host: Clematis subumbellata-(This study).

Distribution: Thailand-(This study).

GenBank accession numbers: LSU: MT214587; SSU: MT226700; ITS: MT310632; tef1: MT394645; rpb2: MT394701.

Notes: Neoroussoella clematidis shares common characters with Neoroussoella in having uniloculate ascomata without a clypeus, cylindrical to broad filiform asci with bulbose pedicel and 1-septate ascospores (Liu et al. 2014). Our collection is distinguishable by having immersed and globose ascomata with papillate ostioles (Fig. 67). In the phylogenetic analysis, N. clematidis (MFLUCC 17-2061) formed a strongly supported clade (100\% ML/1.00 BYPP, Fig. 66) with N. fulvicoma (MFLUCC 17-2073) which was an asexual morph (Fig. 68). A comparison of the ITS region (including $5.8 \mathrm{~S}$ region) showed $7.7 \%$ base pair differences (with gaps) and $3.4 \%$ base pair differences (with gaps) in the tefl region, which is evidence for new species rank.

The isolate MFLUCC 17-2061 was evaluated for the potential of secondary metabolites against Bacillus subtillis, Escherichia coli, Mucor plumbeus and Schizosaccharomyces pombe. The strain demonstrated moderate inhibitory activities against Bacillus subtillis and against conidia development in Mucor plumbeus. This isolate is suitable for further evaluation of secondary metabolites.

Neoroussoella fulvicomae Phukhams. \& K.D. Hyde, sp. nov.

Index Fungorum number: IF557114; Facesoffungi number: FoF 07329, Fig. 68.

Etymology: Name refers to Clematis fulvicoma.

Holotype: MFLU 17-1481.

Saprobic on dried stems of Clematis fulvicoma. Sexual morph: Undetermined. Asexual morph: Conidiomata 


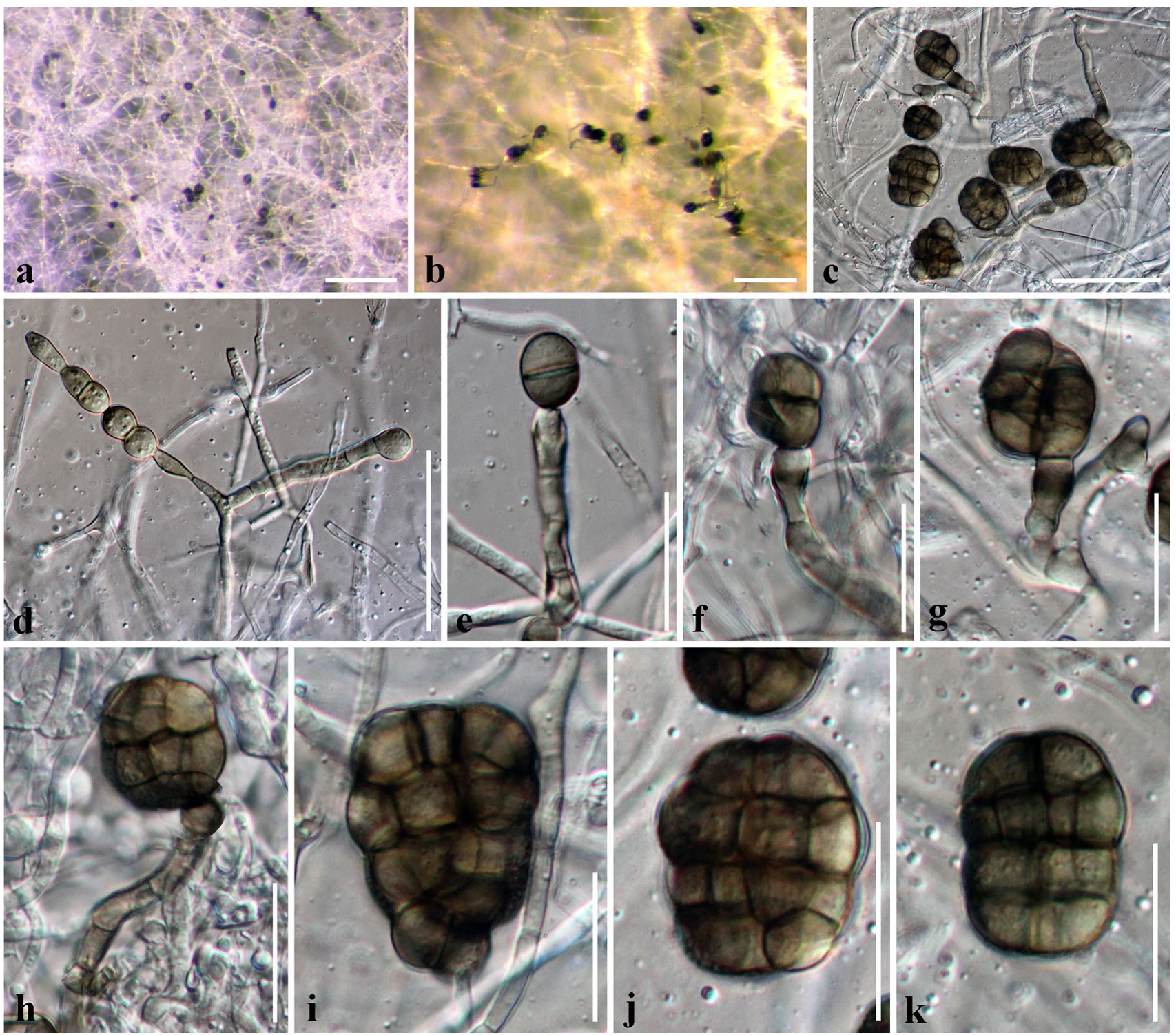

Fig. 62 Stemphylium vesicarium (MFLUCC 16-0998). a Appearance of asexual morph on the surface of MEA. b, c Close up of conidiophore. $\mathbf{d - k}$ Conidia. Scale bars: $\mathbf{a}=200 \mu \mathrm{m}, \mathbf{b}=100 \mu \mathrm{m}, \mathbf{c}, \mathbf{d}=50 \mu \mathrm{m}, \mathbf{e}-\mathrm{k}=20 \mu \mathrm{m}$

140-241×137-155 $\mu \mathrm{m}(\bar{x}=207 \times 146 \mu \mathrm{m}, \mathrm{n}=5)$, pycnidial, solitary, sometimes aggregated, uniloculate, immersed, visible as minute, black, shiny ostioles, subglobose, coriaceous, thick-walled, dark brown to brown, with papilla, ostiolate. Ostioles 51-60 $\times 49-55 \mu \mathrm{m}$, central, oblong, papillate. Conidiomatal wall $12-18 \mu \mathrm{m}$ wide $(\bar{x}=15 \mu \mathrm{m}, \mathrm{n}=20)$, thick, outer layer composed of 5-7 layers of brown to light brown cells of textura angularis, lined with a hyaline layer bearing conidiogenous cells. Conidiophores reduced to conidiogenous cells. Conidiogenous cells $2.5-5 \times 1.5-2 \mu \mathrm{m}$ $(\bar{x}=4 \times 1.7 \mu \mathrm{m}, \mathrm{n}=20)$, enteroblastic, phialidic, annellidic, determinate, discrete, truncate, smooth-walled, hyaline, arising from the inner layers of conidiomata. Conidia $3-6 \times 2-3 \mu \mathrm{m}(\bar{x}=4.5 \times 2.5 \mu \mathrm{m}, \mathrm{n}=100)$, oval, slightly curved, hyaline when immature, brown at maturity, with $1(-2)$ guttules in each cell, aseptate, smooth-walled.

Culture characters: Colonies on MEA reaching $50 \mathrm{~mm}$ diam. after 4 weeks at $25{ }^{\circ} \mathrm{C}$. Cultures from above, black, dense, circular, margin undulate, umbonate, fluffy, wrinkled, folded, covered with brown aerial mycelium; reverse black at the centre radiating outwardly.

Material examined: Thailand, Chiang Rai Province, on dead branches of Clematis fulvicoma, 20 March 2017, C. Phukhamsakda, CMTH17 (MFLU 17-1481, holotype); extype living culture, MFLUCC 17-2073.

Host: Clematis fulvicoma-(This study).

Distribution: Thailand—(This study). 

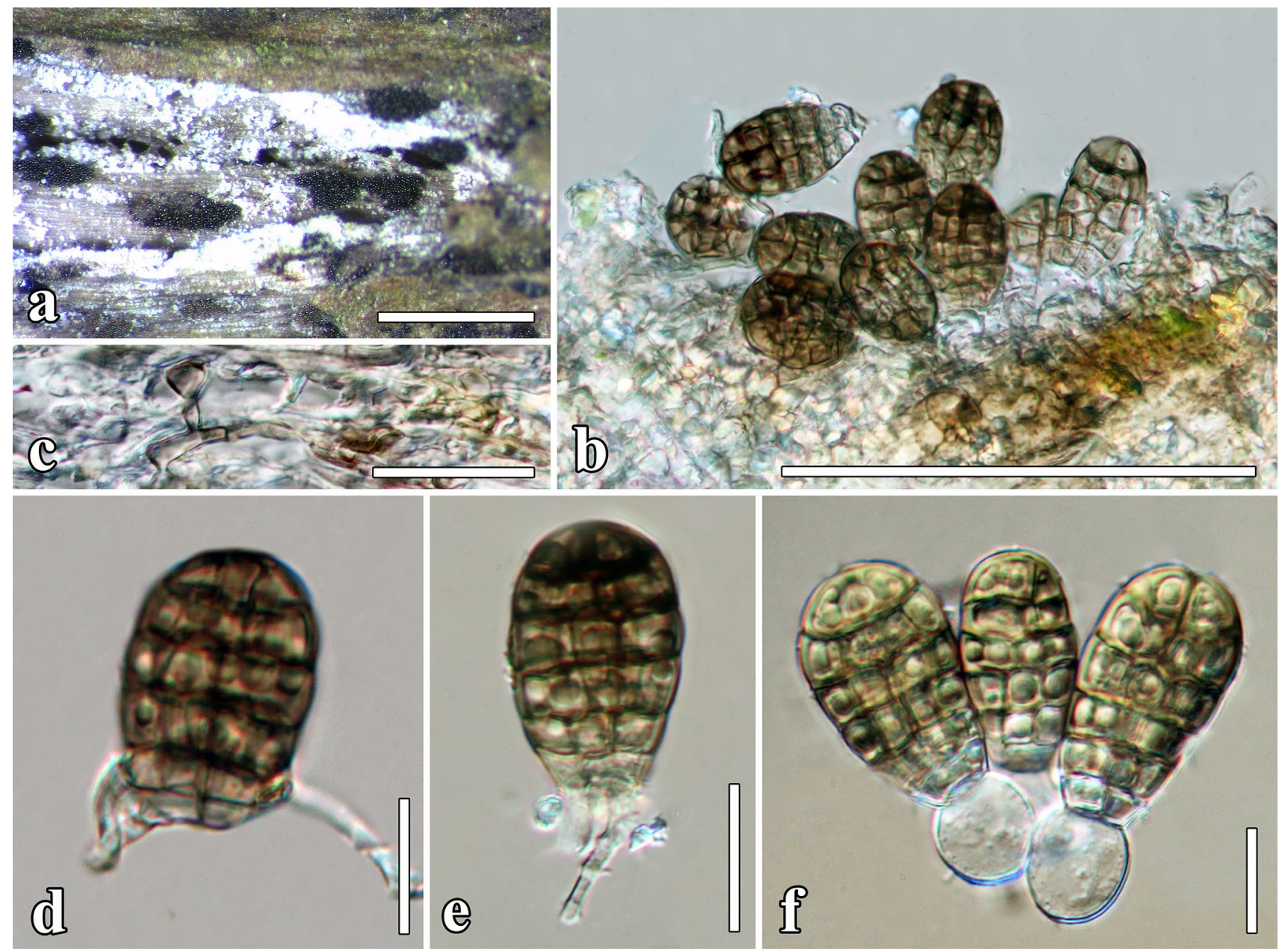

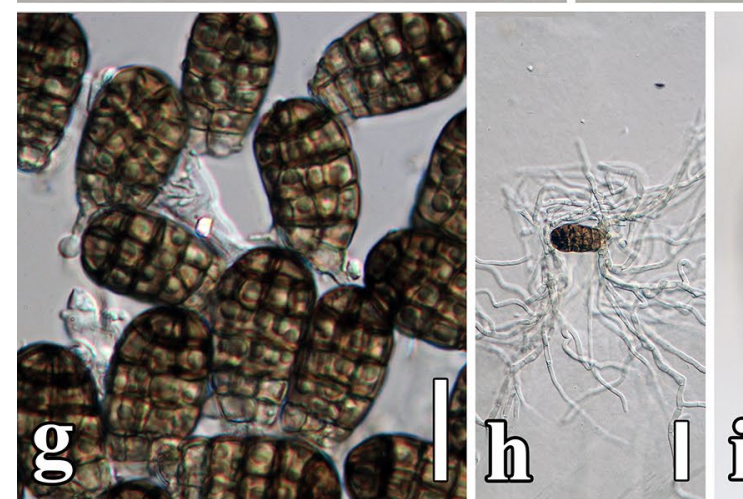

Fig. 63 Pseudoberkleasmium chiangmaiense (MFLU 17-1496). a Sporodochia on natural substrate. b Vertical section through sporodochia. c Hyphae. d-g Mature lenticular conidia. h Germinated

GenBank accession numbers: LSU: MT214588; SSU: MT226701; ITS: MT310633; tef1: MT394646; rpb2: MT394702.

Notes: In the phylogenetic analysis of combined sequence data Neoroussoella fulvicomae clustered in a separate clade with N. clematidis (100\% ML/1.00 BYPP, Fig. 66). Neoroussoella fulvicomae is similar to Neoroussoella in having conidia. $\mathbf{i}, \mathbf{j}$ Culture characteristics on MEA. Scale bars $=\mathbf{a}=1 \mathrm{~cm}$, $\mathbf{b}=100 \mu \mathrm{m}, \mathbf{c}, \mathbf{g}-\mathbf{h}=20 \mu \mathrm{m}, \mathbf{d}-\mathbf{f}=10 \mu \mathrm{m}$

immersed, uniloculate, globose to subglobose pycnidia, annellidic conidiogenesis cells, and aseptate, 2-guttulate conidia (Liu et al. 2014). Neoroussoella fulvicomae is distinguishable by having papillate ostioles and short conidiogenesis cells and brown conidia with 1-2 guttules in each cell (Fig. 68). Neoroussoella fulvicomae was evaluated for potential of secondary metabolites in the same manner as $N$. 

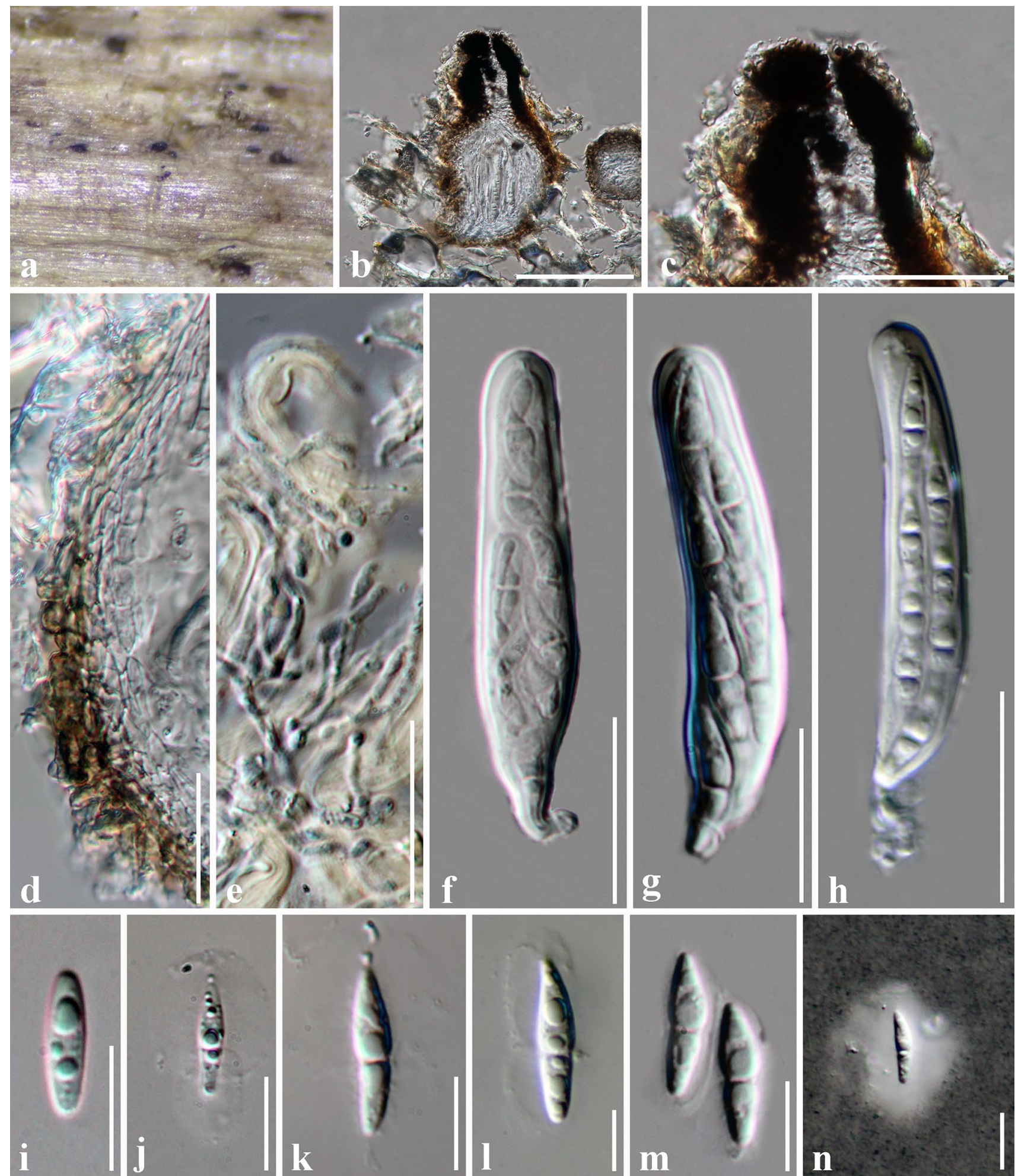

Fig. 64 Pseudomassarina clematidis (MFLU 16-0493, holotype). a Appearance of ascomata on host surface. b Vertical section of ascoma. c Ostiolar canal. d Section of peridium. e Pseudoparaphy-

ses. f-h Asci. i-m Ascospores. $\mathbf{n}$ Ascospore in $10 \%$ Indian ink. Scale bars: $\mathbf{b}=100 \mu \mathrm{m}, \mathbf{c}=50 \mu \mathrm{m}, \mathbf{d}-\mathbf{h}=20 \mu \mathrm{m}, \mathbf{i}-\mathbf{n}=10 \mu \mathrm{m}$ 

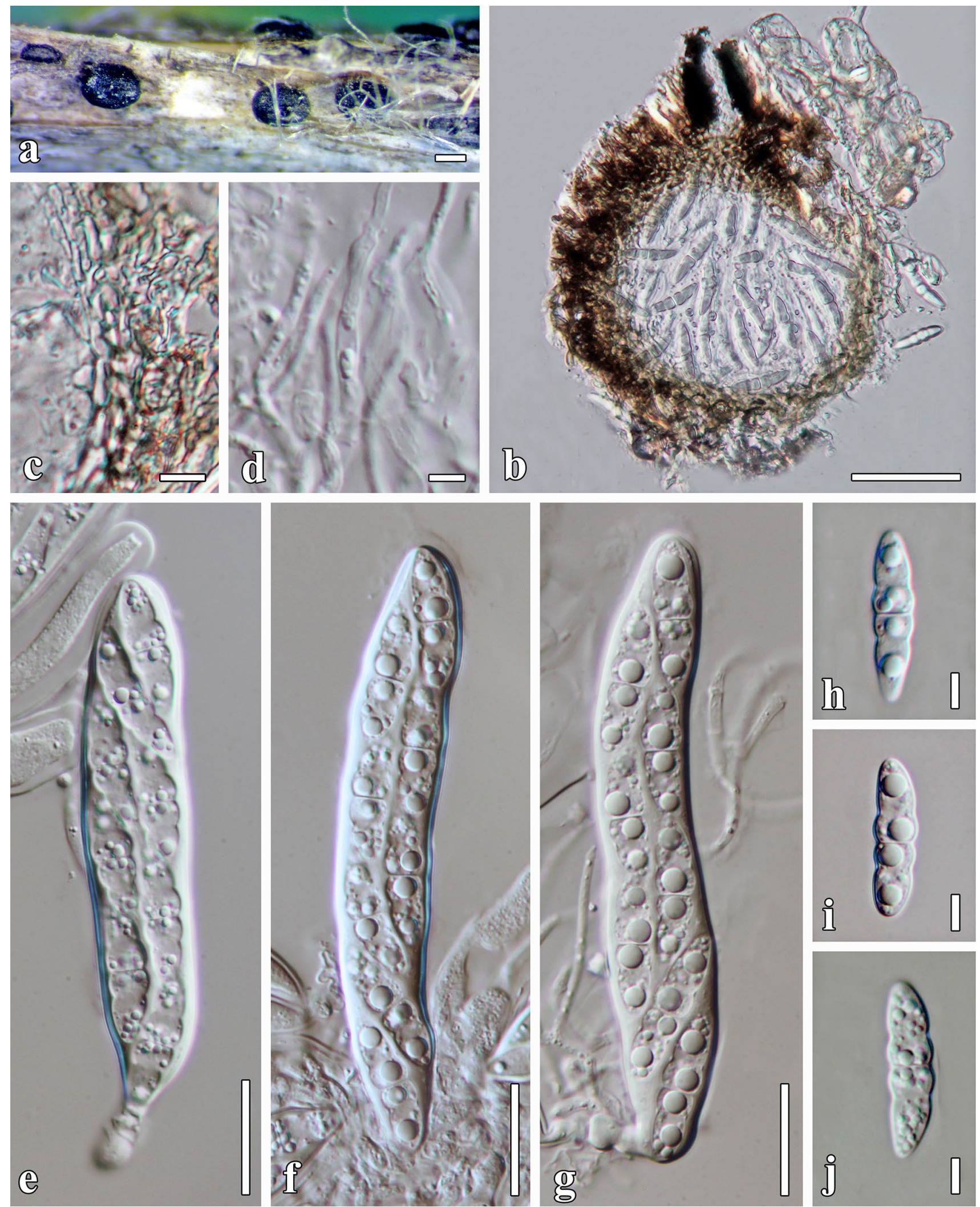

Fig. 65 Clematidis italica (MFLU 14-0669, holotype). a Appearance of ascomata on host substrate. b Vertical section of ascoma. c Section of peridium. d Pseudoparaphyses. e-g Asci. $\mathbf{h}-\mathbf{j}$ Ascospores. Scale bars: $\mathbf{a}=200 \mu \mathrm{m}, \mathbf{b}=50 \mu \mathrm{m}, \mathbf{c}=10 \mu \mathrm{m}, \mathbf{d}, \mathbf{h}-\mathbf{j}=5 \mu \mathrm{m}, \mathbf{e}-\mathbf{g}=20 \mu \mathrm{m}$ 


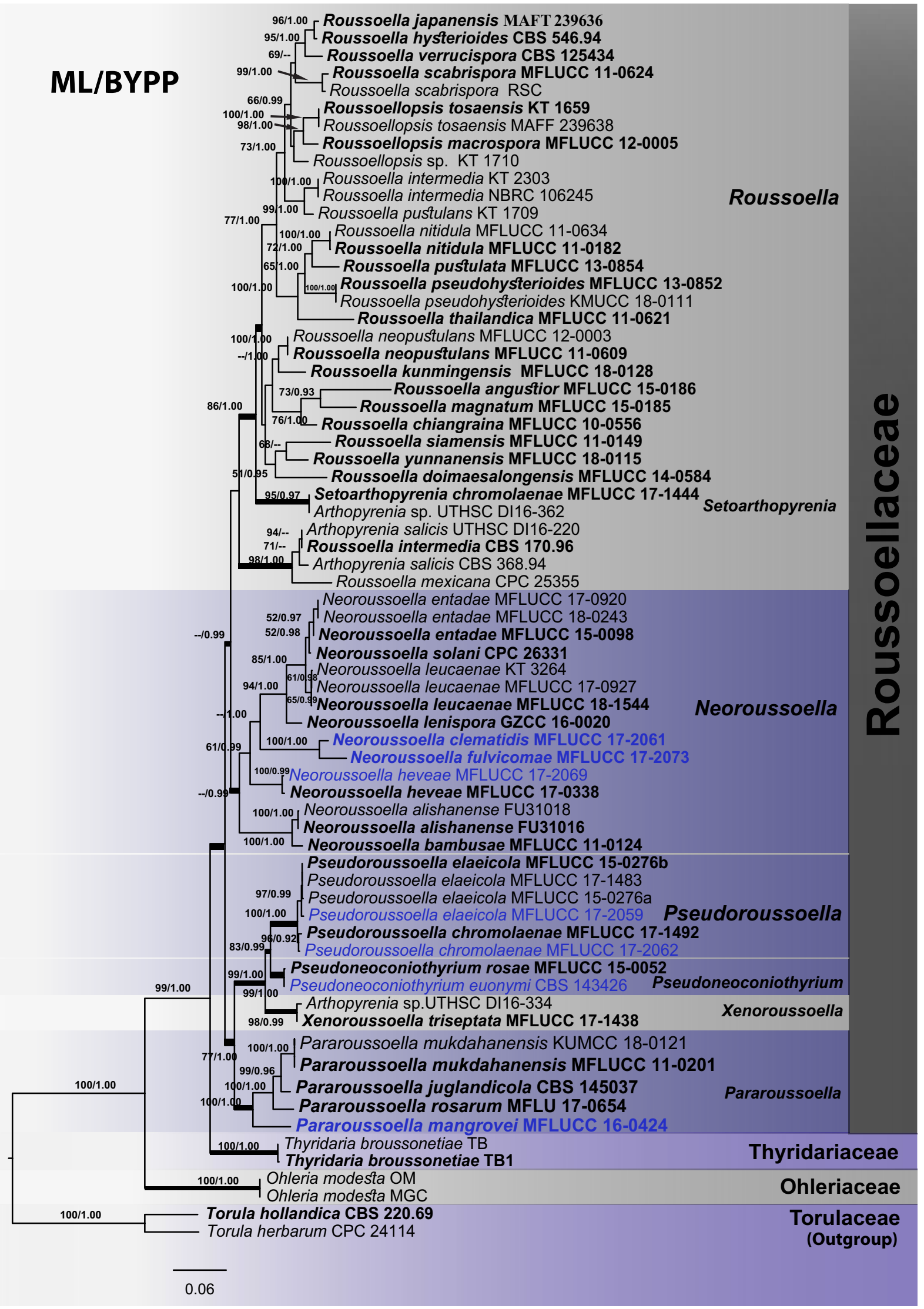


4Fig. 66 Best scoring RAxML tree with a final likelihood value of - 27212.762040 based on combined LSU, ITS, tef1, rpb2, and SSU sequence data for Roussoellaceae. The tree is rooted with members of Torulaceae. Sixty-nine strains were included in the combined analyses which comprised 4382 characters (819 characters for LSU, 567 characters for ITS, 906 characters for tefl, 1052 characters for $r p b 2$, 1038 characters for SSU, including gaps). The topology and clade stability of the combined gene analyses was compared to the single gene analyses. The tree from the maximum likelihood analysis had similar topology to the Bayesian 50\% majority-rule consensus phylogram. The matrix had 1501 distinct alignment patterns with $38.60 \%$ of undetermined characters and gaps. Estimated base frequencies were as follows: $\mathrm{A}=0.245133, \mathrm{C}=0.255324, \mathrm{G}=0.268618, \mathrm{~T}=0.230925$; substitution rates $\mathrm{AC}=1.766964, \mathrm{AG}=5.243182$, $\mathrm{AT}=2.353818$, $\mathrm{CG}=1.339749, \mathrm{CT}=11.449776, \mathrm{GT}=1.000000$; gamma distribution shape parameter $\alpha=0.473912$. In our analysis, GTR $+\mathrm{I}+\mathrm{G}$ model was used for each partition in Bayesian posterior analysis. The isolates of this study are in blue. Bootstrap values (BS) greater than $50 \%$ BS (ML, left) and Bayesian posterior probabilities (BYPP, right) greater than 0.90 are given at the nodes. Hyphens (-) represent support values less than $50 \% \mathrm{BS} / 0.90 \mathrm{BYPP}$. Thick branches represent significant support values from all analyses (BS $\geq 70 \% / B Y P P \geq 0.95$ ) at the genus and family levels

clematidis. Interestingly, isolate MFLUCC 17-2073 does not produce growth inhibitory activity against Bacillus subtillis and Mucor plumbeus.

Neoroussoella heveae Senwanna, Phookamsak \& K.D. Hyde, in Phookamsak et al., Fungal Divers [66] (2019), new host record

Index Fungorum number: IF555287; Facesoffungi number: FoF 07330, Fig. 69.

Saprobic on dried stems of Clematis subumbellata. Sexual morph: Undetermined. Asexual morph: Conidiomata $128-263 \times 142-304 \mu \mathrm{m}(\bar{x}=177 \times 200 \mu \mathrm{m}, \mathrm{n}=5)$, pycnidial, solitary, gregarious, uniloculate, immersed, visible only as minute ostioles, globose, coriaceous, thick-walled, dark brown to brown, ostiolate. Ostioles $40 \times 77 \mu \mathrm{m}$, central, papillate, oblong, opening by a pore. Conidiomatal wall $24-31 \mu \mathrm{m}$ wide $(\bar{x}=26 \mu \mathrm{m}, \mathrm{n}=20)$, thick, $7-8$ layers, outer layer composed of brown cells of textura angularis, lined with a hyaline layer bearing conidiogenous cells. Conidiophores reduced to conidiogenous cells. Conidiogenous cells $2-4 \times 1.5-2 \mu \mathrm{m}(\bar{x}=3 \times 2 \mu \mathrm{m}, \mathrm{n}=50)$, enteroblastic, phialidic, determinate, discrete, truncate, smooth-walled, hyaline, arising from the inner layers of the conidiomata. Conidia 3.5-4.5 $\times 2.3-3 \mu \mathrm{m}(\bar{x}=4 \times 2.5 \mu \mathrm{m}, \mathrm{n}=100)$, oval, hyaline when immature, olive brown at maturity, slightly curved at the ends, with 1(-2) guttules in each cell, aseptate, smooth-walled.

Culture characters: Colonies on MEA reaching $50 \mathrm{~mm}$ diam. after 4 weeks at $25{ }^{\circ} \mathrm{C}$. Cultures from above, dark brown to brown, dense, irregular, margin lobate, umbonate, wrinkled folded, thinly hairy, covered with brown aerial mycelium; reverse black at the centre, radiating outwardly.
Material examined: Thailand, Chiang Rai Province, on dead stems of Clematis subumbellata, 20 March 2017, C. Phukhamsakda, CMTH13 (MFLU 17-1477); living culture, MFLUCC 17-2069.

Hosts: Clematis subumbellata, Hevea brasiliensis(Phookamsak et al. 2019; this study).

Distribution: Thailand-(Phookamsak et al. 2019; this study).

GenBank accession numbers: LSU: MT214589; SSU: MT226702; ITS: MT310634; tef1: MT394647; rpb2: MT394703.

Notes: Neoroussoella heveae was described from a twig of Hevea brasiliensis from northern Thailand (Phookamsak et al. 2019). Isolate MFLUCC 17-2069, recorded on Clematis formed a close relationship (100\% ML/1.00 BYPP) with the type strain of $N$. heveae (MFLUCC 17-0338). Our collection (MFLU 17-1477, Fig. 69) had larger conidia than the type (128-263×142-304 vs 90-130×115-180 $\mu \mathrm{m})$. Comparison of ITS sequence data revealed only 1 base pair difference between our isolate and the type. Unfortunately, the tefl region of the type strain is not available for comparison.

Neoroussoella heveae was evaluated for potential secondary metabolite production in the same manner as N. clematidis. Isolate MFLUCC 17-2069 demonstrated weak inhibitory activities against Bacillus subtillis.

Pararoussoella Wanas., E.B.G. Jones \& K.D. Hyde

Pararoussoella (type species $P$. rosarum) was introduced for species that are distantly related to the type species of Roussoella (R. nitidula Sacc. \& Paol.). The genus is characterized by having immersed and globose ascomata with minute black dots of ostioles, cellular pseudoparaphyses, central, papillate, black ostioles, cylindrical to oblong asci, and uniseriate, brown to dark brown ascospores, with irregular, longitudinal striations (Wanasinghe et al. 2018). Multigene phylogenetic analysis (Fig. 66) showed that Roussoella mangrovei is related to Pararoussoella, thus a new combination is proposed.

Pararoussoella mangrovei (Phukhams. \& K.D. Hyde) Phukhams. \& K.D. Hyde, comb. nov.

$\equiv$ Roussoella mangrovei Phukhams. \& K.D. Hyde, in Hyde et al., Mycosphere 9(2): 339 (2018)

Index Fungorum number: IF557372; Facesoffungi number: FoF 03923

Notes: Pararoussoella mangrovei formed a related lineage with other Roussoella species. Karunarathna et al. (2019) showed that the strain is related to Pararoussoella (Fig. 66). Therefore, Roussoella mangrovei is transferred to Pararoussoella.

Pseudoneoconiothyrium Wanas., Phukhams., Camporesi \& K.D. Hyde 


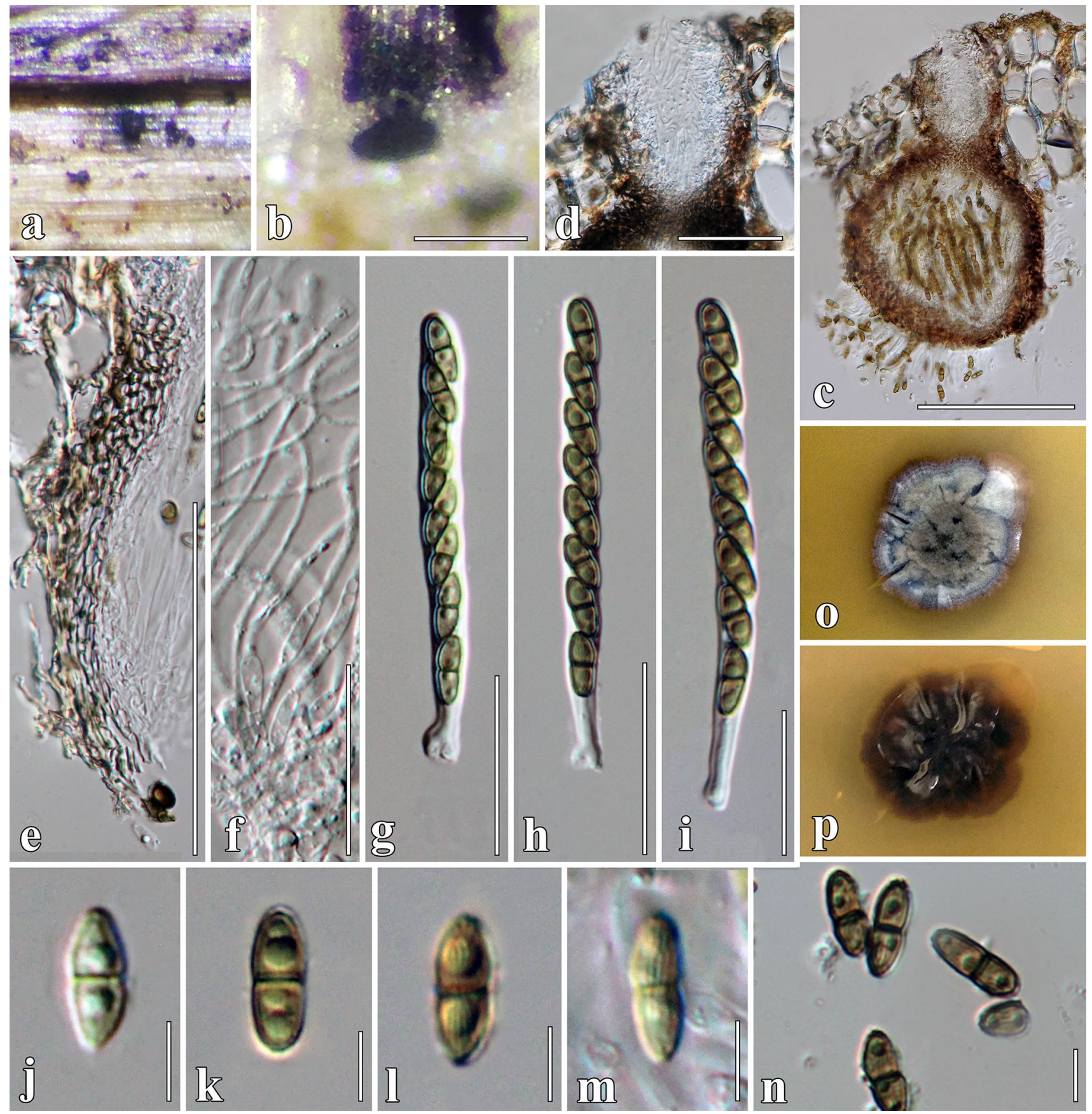

Fig. 67 Neoroussoella clematidis (MFLU 17-1467, holotype). a, b Appearance of ascomata on Clematis subumbellata. c Vertical section through ascoma. d Ostiolar canal. e Vertical section through

Pseudoneoconiothyrium was described as Neoconiothyrium for fungi associated with Rosaceae plants (Wanasinghe et al. 2018). Neoconiothyrium has been assigned for the fungal strains in Coniothyriaceae (Crous et al. 2017; Hawksworth et al. 2018). Thus, Pseudoneoconiothyrium was proposed for Neoconiothyrium species in Roussoellaceae peridium. f Trabeculate pseudoparaphyses. g-i Asci. j-n Ascospores. $\mathbf{o}, \mathbf{p}$ Culture characters on MEA. Scale bars: $\mathbf{b}=200 \mu \mathrm{m}, \mathbf{c}=100 \mu \mathrm{m}$, $\mathbf{d}-\mathbf{e}=50 \mu \mathrm{m}, \mathbf{f}-\mathbf{i}=20 \mu \mathrm{m}, \mathbf{j}-\mathbf{n}=5 \mu \mathrm{m}$

and is typified by P. rosae (Phukhams., et al.) Phukhams., Camporesi \& K.D. Hyde (Fig. 66).

Pseudoneoconiothyrium euonymi (Crous \& Akulov) Phukhams. \& K.D. Hyde, comb. nov.

$\equiv$ Roussoella euonymi Crous \& Akulov, in Crous et al., Fungal Systematics and Evolution 1: 204 (2018) 

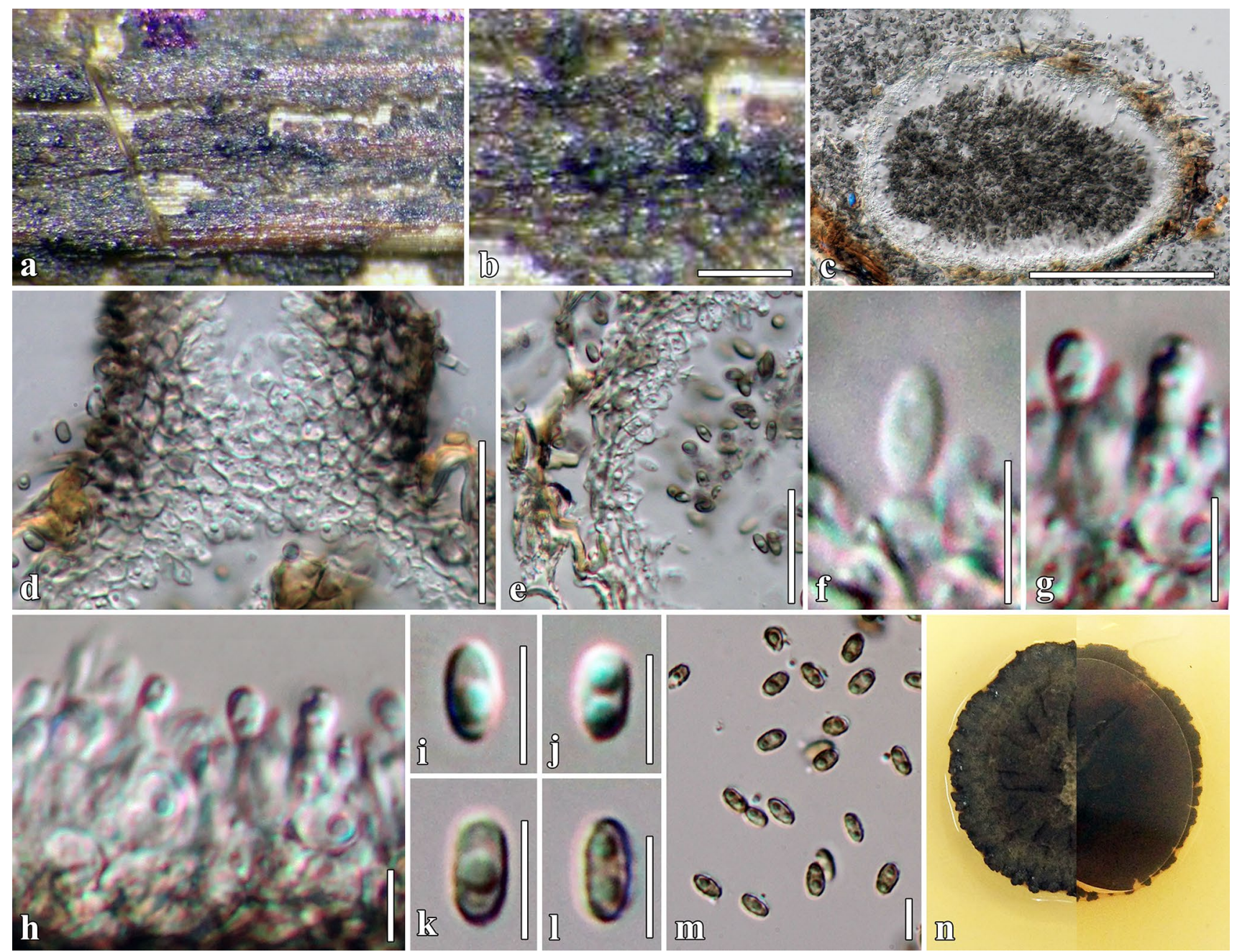

Fig. 68 Neoroussoella fulvicomae (MFLU 17-1481, holotype). a Appearance of conidiomata on Clematis fulvicoma. b Close up of conidioma on host substrate. $\mathbf{c}$ Vertical section through conidioma. d
Ostiolar canal. e Section of conidioma wall. $\mathbf{f}-\mathbf{h}$ Conidiogenous cells and conidia. $\mathbf{i}-\mathbf{m}$ Conidia. $\mathbf{n}$ Culture characteristics on MEA. Scale bars: $\mathbf{b}=200 \mu \mathrm{m}, \mathbf{c}=100 \mu \mathrm{m}, \mathbf{d}, \mathbf{e}=20 \mu \mathrm{m}, \mathbf{f}-\mathbf{m}=5 \mu \mathrm{m}$
Index Fungorum number: IF557605; Facesoffungi number: FoF 07331

Notes: Pseudoneoconiothyrium euonymi originally clustered with Pararoussoella mukdahanensis (三Roussoella mukdahanensis). Based on the phylogenetic analysis (Fig. 66), Pseudoneoconiothyrium euonymi is transferred as a second species of Pseudoneoconiothyrium.

\section{Pseudoroussoella Mapook \& K.D. Hyde}

Mapook et al. (2020) introduced Pseudoroussoella as a separate lineage for P. euonymi and P. chromolaenae. Phylogenetic analyses (Fig. 66) coupled with morphological characters of collections on Clematis species revealed a first record of $P$. chromolaenae and $P$. euonymi on Clematis species (Figs. 70, 71).
Pseudoroussoella chromolaenae Mapook \& K.D. Hyde, Mapook et al., Fungal Divers (2020), new host record Index Fungorum number: IF557116; Facesoffungi number: FoF 07332, Fig. 70.

Saprobic on dead stems of Clematis subumbellata. Sexual morph: Undetermined. Asexual morph: Conidiomata 86-100 $\times 107-112 \mu \mathrm{m}(\bar{x}=90 \times 110 \mu \mathrm{m}, \mathrm{n}=5)$, pycnidial, solitary, sometimes aggregated, uniloculate, immersed, with black shiny ostioles visible, globose to subglobose, dark brown to brown, coriaceous, thick-walled, ostiolate. Ostioles 55-70 $\times 50-67 \mu \mathrm{m}$, central, papillate, ovoid. Conidiomatal wall 6-14(-27) $\mu \mathrm{m}$ wide, outer layer composed of 8-10 layers of brown to light brown cells of textura angularis, lined with a hyaline layer bearing conidiogenous cells. Conidiophores reduced to conidiogenous cells. Conidiogenous cells $3-7 \times 1.5-3 \mu \mathrm{m}(\bar{x}=4.5 \times 2 \mu \mathrm{m}, \mathrm{n}=30)$, enteroblastic, phialidic, determinate, discrete, cylindrical 

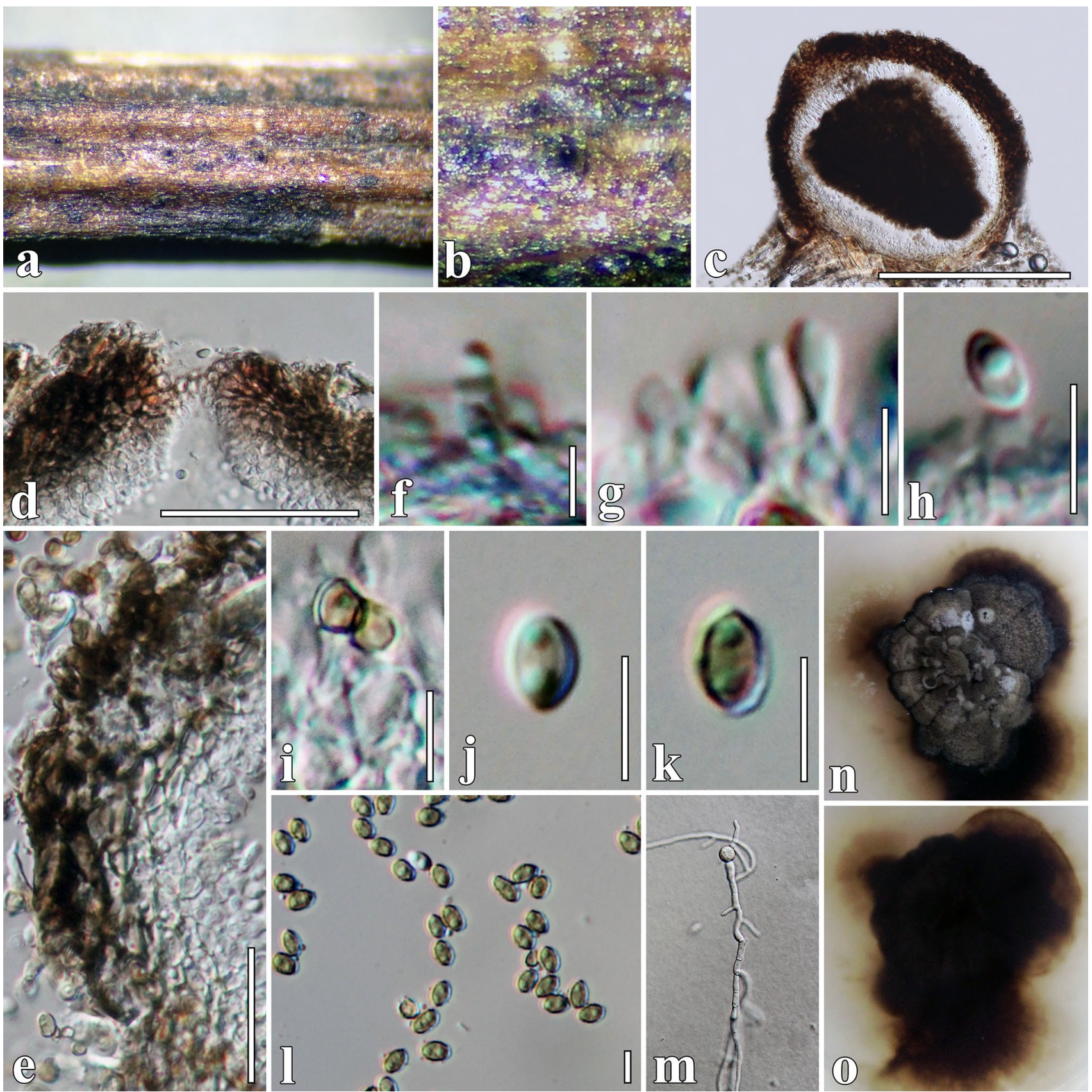

Fig. 69 Neoroussoella heveae (MFLU 17-1477). a Appearance of conidiomata on Clematis subumbellata specimen. b Close up of conidioma on host substrate. c Vertical section of conidioma. d Ostiolar canal. e Section of conidioma wall. $\mathbf{f}-\mathbf{i}$ Conidiogenous cells

to sub-cylindrical, smooth-walled, hyaline. Conidia $4.5-8 \times 3-5 \mu \mathrm{m}(\bar{x}=6 \times 4 \mu \mathrm{m}, \mathrm{n}=50)$, oval, hyaline when immature, yellowish brown at maturity, slightly curved, with $1(-2)$ guttules in each cell, aseptate, smooth-walled.

Culture characters: Colonies on MEA reaching $20 \mathrm{~mm}$ diam. after 2 weeks at $25{ }^{\circ} \mathrm{C}$. Cultures from above, greyish brown, dense, circular, umbonate, fluffy, covered with and conidia. j-l Conidia. m Germinated conidium. n, o Cultures characters on MEA. Scale bars: $\mathbf{c}=200 \mu \mathrm{m}, \mathbf{d}=100 \mu \mathrm{m}, \mathbf{e}=20 \mu \mathrm{m}$, $\mathbf{f}-\mathbf{l}=5 \mu \mathrm{m}$

white aerial mycelium; reverse dark brown at the central, mycelium cream radiating outwardly.

Material examined: Thailand, Chiang Rai Province, on dead branches of Clematis subumbellata, 20 March 2017, C. Phukhamsakda, CMTH04 (MFLU 17-1468); living culture, MFLUCC 17-2062.

Hosts: Chromolaena odorata, Clematis subumbellata(Mapook et al. 2020; this study). 


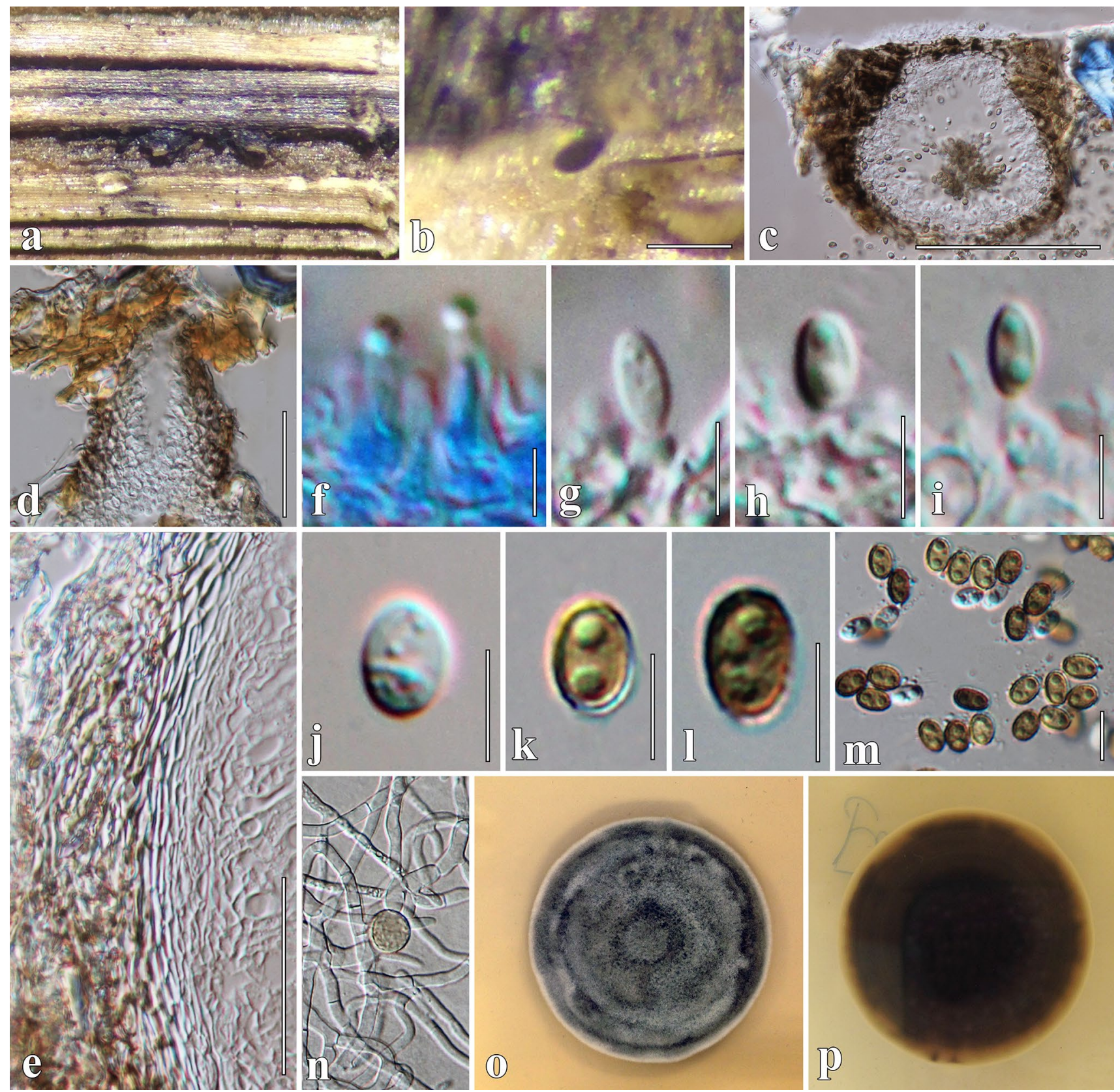

Fig. 70 Pseudoroussoella chromolaenae (MFLU 17-1468). a Appearance of conidiomata on Clematis subumbellata. b Close up of conidioma on host substrate. $\mathbf{c}$ Vertical section through conidioma. d Ostiolar canal. e Section of conidioma wall. $\mathbf{f}-\mathbf{i}$ Conidiogenous cells and conidia ( $\mathbf{f}$ conidiogenous cells in cotton blue). $\mathbf{j}-\mathbf{m}$ Conidia $\mathbf{n}$ Geminated conidium. o, $\mathbf{p}$ Cultures characters on MEA. Scale bars: $\mathbf{b}=500 \mu \mathrm{m}, \mathbf{c}=200 \mu \mathrm{m}, \mathbf{d}=100 \mu \mathrm{m}, \mathbf{e}=20 \mu \mathrm{m}, \mathbf{f}-\mathbf{m}=5 \mu \mathrm{m}$

conidiomata of our collection (Fig. 70) are slightly smaller than the ex-type strain $(90 \times 110$ vs $165 \times 195 \mu \mathrm{m})$. Pairwise comparison of the ITS region (including $5.8 \mathrm{~S}$ region) showed $100 \%$ similarity, while the tefl region had two base pair differences; these findings are not significantly distinct for the introduction of the strain as a new species (Jeewon and Hyde 2016). Pseudoroussoella chromolaenae strain MFLUCC 17-2062 was evaluated for secondary metabolite with strong support (100\% ML/1.00 BYPP, Fig. 66). The 


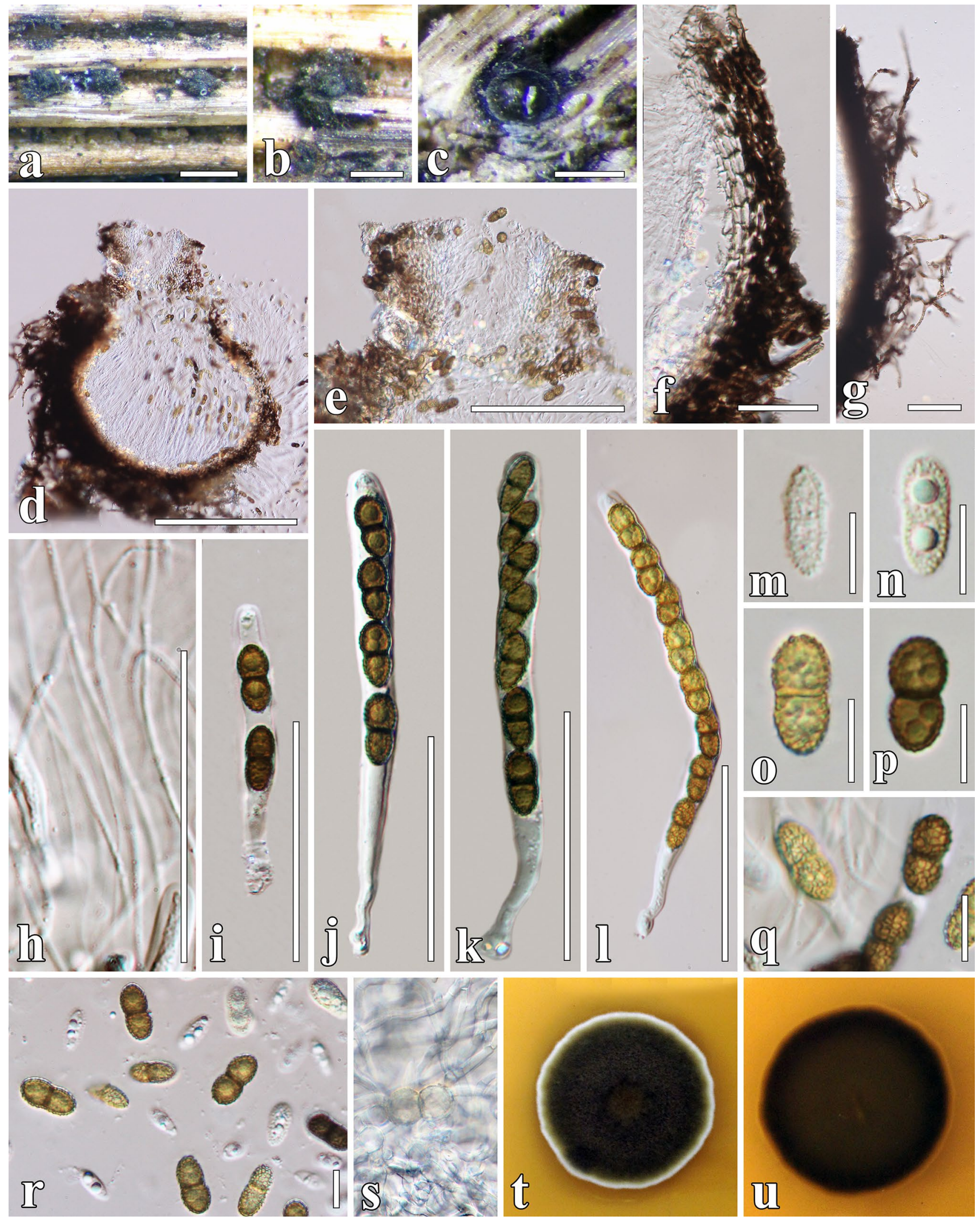

Fig. 71 Pseudoroussoella elaeicola (MFLU 17-1465). a-c Appearance of ascomata on Clematis subumbellata. d Vertical section through ascoma. e Ostiolar canal. f, $\mathbf{g}$ Section of peridium. h Pseudoparaphyses. i-l Asci. $\mathbf{m}-\mathbf{r}$ Ascospores (q verruculose surface). $\mathbf{s}$
Germinated ascospore. t, u Culture characters on MEA. Scale bars: $\mathbf{a}=500 \mu \mathrm{m}, \mathbf{b}-\mathbf{d}=200 \mu \mathrm{m}, \mathbf{e}=100 \mu \mathrm{m}, \mathbf{f}, \mathbf{g}=20 \mu \mathrm{m}, \mathbf{h}-\mathbf{l}=50 \mu \mathrm{m}$, $\mathbf{m}-\mathbf{r}=10 \mu \mathrm{m}$ 
production. The collection showed weak inhibitory activities against the growth of Bacillus subtillis.

Pseudoroussoella elaeicola (Konta \& K.D. Hyde) Mapook \& K.D. Hyde, new host record

Index Fungorum number: IF555291; Facesoffungi number: FoF 07333, Fig. 71.

Saprobic on dead stems of Clematis subumbellata. Sexual morph: Ascomata $375-554 \times 375-462 \mu \mathrm{m}(\bar{x}$ $=453 \times 430 \mu \mathrm{m}, \mathrm{n}=10$ ), on the surface of the host, solitary, gregarious, erumpent, semi-immersed, dark brown hyphae radiating outwards from the peridium wall, globose to depressed-globose, black to dark brown, coriaceous, rough-walled, ostiolar. Ostioles $149-157 \times 123-140 \mu \mathrm{m}$, central, dark brown to black, papillate, opening by a pore, ostiolate with periphyses. Peridium $17-54(-83 \mu \mathrm{m}$ at apex $)$ wide, outer layer composed of 8-10 layers of dark brown to light brown cells of textura angularis, the inner layer comprising thin, hyaline layers. Hamathecium of dense, $0.8-1.5 \mu \mathrm{m}$ wide $(\bar{x}=1.3 \mu \mathrm{m}, \mathrm{n}=50)$, filiform, branches, anastomosing above asci, septate, pseudoparaphyses. Asci 60-132 ×7-10 $\mu \mathrm{m}(\bar{x}=103 \times 8 \mu \mathrm{m}, \mathrm{n}=20),(2-) 8$-spored, bitunicate, fissitunicate, cylindrical to cylindrical-clavate, apically rounded with ocular chamber. Ascospores $10-18 \times 5-10 \mu \mathrm{m}(\bar{x}=13 \times 7 \mu \mathrm{m}, \mathrm{n}=50)$, uniseriate, sometimes partially overlapping, oval with round ends, brown to yellowish brown, uni-septate, constricted at septum, with guttules in each cell, verruculose, with mucilaginous sheath. Asexual morph: Undetermined.

Culture characters: Colonies on MEA reaching $30 \mathrm{~mm}$ diam. after 4 weeks at $25^{\circ} \mathrm{C}$. Culture above dark green radiating, edge white, dense, circular, flattened, umbonate, edge entire, fluffy; reverse light brown at the middle, dark brown at the edge.

Material examined: Thailand, Chiang Rai Province, on dead branches of Clematis subumbellata, 20 March 2017, C. Phukhamsakda, CMTH01 (MFLU 17-1465); living culture, MFLUCC 17-2059.

Hosts: Chromolaena odorata, Clematis subumbellata, Elaeis guineensis-(Phookamsak et al. 2019; Mapook et al. 2020; this study).

Distribution: Thailand-(Phookamsak et al. 2019; Mapook et al. 2020; this study).

GenBank accession numbers: LSU: MT214591; SSU: MT226704; ITS: MH744730; tef1: MH750239; rpb2: MT394705.

Notes: Pseudoroussoella elaeicola ( $\equiv$ Roussoella elaeicola) was collected from Elaeis guineensis (Phookamsak et al. 2019). Mapook et al. (2020) recorded this fungus on Chromolaena odorata. In the phylogenetic analysis, $R$. elaeicola formed a separate clade from the type species of Roussoella ( $R$. nitidula Sacc. \& Paol.), thus Mapook et al. (2020) synonymized $R$. elaeicola under Pseudoroussoella elaeicola. Our new isolate (MFLUCC 17-2059) grouped with another collections reported from Chromolaena odorata and Elaeis guineensis (97\% ML/0.99 BYPP, Fig. 70). Our collection is identical to the other collections of this species (Fig. 71). Comparison of the ITS region revealed only one base pair difference between our isolate and the ex-type strain (MFLUCC 15-0276). The pairwise comparison of the available tef1 region with MFLUCC 17-1483 also showed one base pair difference. Therefore, we introduce our collection as a new host record.

Pseudoroussoella elaeicola (MFLUCC 17-2059) was evaluated for the potential of secondary metabolite production. The isolate showed inhibitory activity on biofilm formation by Staphylococcus aureus and showed weak cytotoxicity on L929 murine fibroblasts and human KB3-1 cancer cells (Phukhamsakda et al. 2018).

\section{Sulcatisporaceae Tanaka \& K. Hirayama}

Sulcatisporaceae was erected for a well-separated clade which included Magnicamarosporium, Neobambusicola and Sulcatispora in Pleosporales (Tanaka et al. 2015). Rupcic et al. (2018) added Pseudobambusicola to Sulcatisporaceae which was collected from a twig of an unidentified plant in Thailand based on the morphology and phylogeny analyses. Sulcatisporaceae is characterized by immersed to erumpent, subglobose to hemisphaerical ascomata, short ostiolar neck, trabecular pseudoparaphyses (Liew et al. 2000), clavate, short pedicellate asci, and broadly fusiform, hyaline, septate ascospores with mucilaginous appendages (Tanaka et al. 2015). Asexual morph is pycnidial conidiomata with various conidia characters (Tanaka et al. 2015; Phukhamsakda et al. 2017a; Rupcic et al. 2018). We provide an updated tree of Sulcatisporaceae based on the combined dataset of LSU, ITS, SSU and tefl sequence data and propose two new genera from Clematis species collected in Thailand. Additionally, the biological activity of their secondary metabolites is preliminarily reported (Fig. 72).

Anthosulcatispora Phukhams. \& K.D. Hyde, gen. nov.

Index Fungorum number: IF557201; Facesoffungi number: FoF 07340, Fig. 73.

Etymology: Anthos-meaning flower, Anthosulcatispora referring to the occurrence on flowering plants.

Saprobic on dead stems of herbaceous plants. Sexual morph: Ascomata semi-immersed, blackish, irregular, scattered, uniloculate, glabrous, ostiolate, apapillate. Ostioles dark, circular and sunken. Peridium two-layered, outer layer irregular, comprising dark brown cells of textura angularis and inner layer irregular comprising light brown cells. Hamathecium composed of numerous, filamentous, branched or simple, septate, cellular pseudoparaphyses, embedded in a hyaline gelatinous matrix. Asci 4- or 8-spored, bitunicate, cylindrical to cylindrical-clavate, short pedicellate, apically 


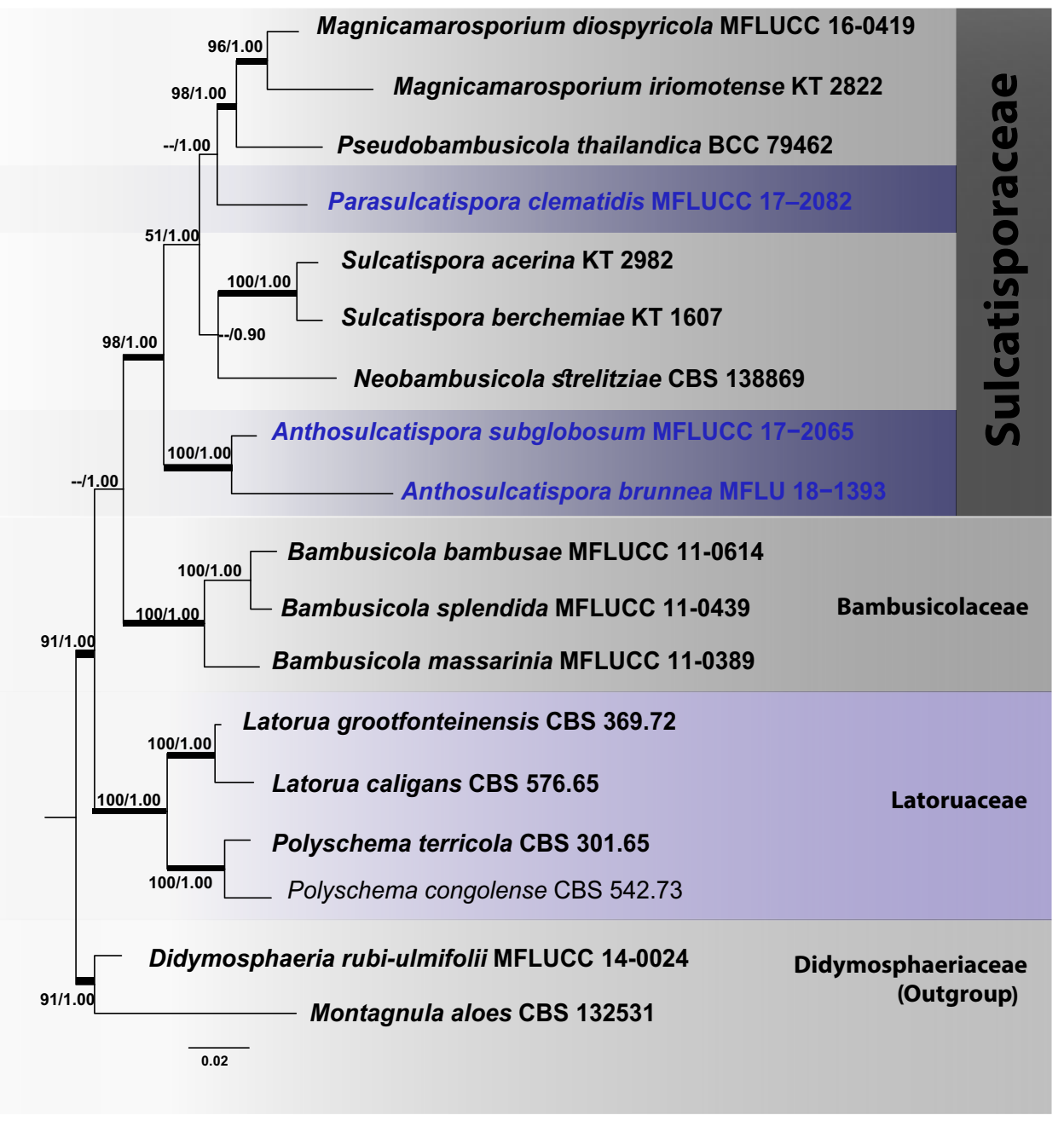

Fig. 72 Bayesian 50\% majority-rule consensus phylogram based on combined LSU, ITS, SSU and tefl sequence data for Sulcatisporaceae. The topology and clade stability of the combined gene analyses was compared to the single gene analyses. The tree is rooted with members of the Didymosphaeriaceae. Eighteen strains were included in the combined analyses which comprised 3390 characters (843 characters for LSU, 1025 characters for SSU, 585 characters for ITS, 937 characters for tefl, including gap regions). The best scoring RAxML tree had a final likelihood value of -11220.180237 . The matrix had 709 distinct alignment patterns, with $31.84 \%$ of undetermined characters and gaps. Estimated base frequencies were as fol-

rounded, with an ocular chamber. Ascospores 1-seriate, brown to dark brown, oblong to ellipsoidal, with rounded ends, 1-septate, slightly constricted at the septum, smoothwalled (Phookamsak et al. 2019). Asexual morph: Conidiomata pycnidial, solitary or gregarious, unilocular, scattered, immersed or erumpent, base flattened, subglobose to compressed, coriaceous, dark brown to reddish brown, with or without ostioles. Pycnidial wall multilayered with cells textura angularis, inner layer bearing conidiogenous cells. Conidiophores reduced to conidiogenous cells. Conidiogenous cells enteroblastic, phialidic, determinate, elongated lows; $\mathrm{A}=0.238159, \mathrm{C}=0.264197, \mathrm{G}=0.261408, \mathrm{~T}=0.236236$; substitution rates $\mathrm{AC}=0.958607, \mathrm{AG}=2.023708, \mathrm{AT}=1.033715$, $\mathrm{CG}=0.741292, \mathrm{CT}=5.717037, \mathrm{GT}=1.000000$; gamma distribution shape parameter $\alpha=0.485427$. In our analysis, GTR $+\mathrm{I}+\mathrm{G}$ model was used for each partition in Bayesian posterior analysis. The species determined in this study are indicated in blue. Bootstrap values (BS) greater than 50\% BS (ML, left) and Bayesian posterior probabilities (BYPP, right) greater than 0.90 are given at the nodes. Hyphens (-) represent support values less than 50\% BS/0.90 BYPP. Thick branches represent significant support values from all analyses (BS $\geq 70 \% / B Y P P \geq 0.95$ )

cylindrical or truncate, smooth-walled, hyaline. Conidia oblong, ends rounded, hyaline, aseptate, guttulate, smoothwalled, with mucilaginous sheath.

Type species: Anthosulcatispora subglobosa Phukhams. \& K.D. Hyde

Notes: Anthosulcatispora is introduced for a collection occurring on stems of herbaceous plants (Phookamsak et al. 2019; this study). The genus formed a basal lineage in Sulcatisporaceae with strong support (98\% ML/1.00 BYPP, Fig. 72). The sexual morph of Anthosulcatispora was described as Neobambusicola brunnea (Phookamsak et al. 
2019). Asexual morphs in Sulcatisporaceae comprised Magnicamarosporium, Neobambusicola, Pseudobambusicola and Sulcatispora (Tanaka et al. 2015; Phukhamsakda et al. 2017a; Rupcic et al. 2018). Anthosulcatispora is distinct within Sulcatisporaceae in having brown ascospores, while the sexual morph in Sulcatispora has hyaline, broadly fusiform ascospores with an entire sheath (Tanaka et al. 2015). The asexual morph of Anthosulcatispora shares similar characters with Neobambusicola and Pseudobambusicola. They all have solitary, unilocular pycnidial, phialidic conidiogenesis and hyaline conidia. Anthosulcatispora is distinct from Neobambusicola and Pseudobambusicola in its subglobose conidiomata, elongated cylindrical or truncate conidiogenous cells and oblong and aseptate conidia, while Neobambusicola and Pseudobambusicola have globose conidiomata with two types of conidia (Crous et al. 2014b; Rupcic et al. 2018).

Anthosulcatispora brunnea (Chen \& C. Norphanphoun) Phukhams. \& K.D. Hyde, comb. nov.

Index Fungorum number: IF557202; Facesoffungi number: FoF 05708

Basionym: Neobambusicola brunnea Chen \& Norphanphoun, in Phookamsak et al., Fungal diversity 95:1-273 (2019)

Notes: Neobambusicola brunnea (MFLU 18-1393) was described based on phylogenetic analysis of a combined LSU and ITS dataset (Phookamsak et al. 2019). The strain formed a clade with the type species of Neobambusicola strelitziae (CBS 138869) with moderate support (87\% ML). In our study, the phylogenetic analysis based on the combined LSU, SSU ITS, and tefl sequence data showed different topology. The strain formed a separate clade from $N$. strelitziae (CBS 138869) and clustered with our new species Anthosulcatispora subglobosa with strong support (100\% ML/1.00 BYPP, Fig. 72). Therefore, Neobambusicola brunnea is transferred to a new genus.

Hosts: Dead stem of herbage-(Phookamsak et al. 2019).

Distribution: China-(Phookamsak et al. 2019).

Anthosulcatispora subglobosa Phukhams. \& K.D. Hyde, sp. nov.

Index Fungorum number: IF557203; Facesoffungi number: FoF 07341, Fig. 73.

Etymology: Refers to the subglobose conidiomata.

Holotype: MFLU 17-1473.

Saprobic on dried stems of Clematis subumbellata. Sexual morph: Undetermined. Asexual morph: Conidiomata $160-210 \times 265-345 \mu \mathrm{m}(\bar{x}=178 \times 291 \mu \mathrm{m}, \mathrm{n}=5)$, pycnidial, solitary, unilocular, scattered, shiny, immersed or erumpent, flattened base, subglobose to compressed, coriaceous, dark brown to reddish brown, lacking ostioles. Pycnidial wall 18-32 $\mu \mathrm{m}$ wide, thick, multilayered, composed of 10-14 brown layers of textura angularis, inner layer subhyaline, lining bearing conidiogenous cells. Conidiophores reduced to conidiogenous cells. Conidiogenous cells $5-17(-30) \times 2-3.5 \mu \mathrm{m}(\bar{x}=13 \times 2.5 \mu \mathrm{m}, \mathrm{n}=30)$, enteroblastic, phialidic, determinate, elongated cylindrical or truncate, smooth-walled, hyaline. Conidia 7-10 $\times 3-4 \mu \mathrm{m}$ $(\bar{x}=8 \times 4 \mu \mathrm{m}, \mathrm{n}=50)$, oblong, rounded ends, hyaline, aseptate, with 1-3 guttules in each cell, smooth-walled, with mucilaginous sheath.

Cultural characters: Colonies on MEA reaching $30 \mathrm{~mm}$ diam. after 4 weeks at $25^{\circ} \mathrm{C}$. Cultures from above, cream at the centre, radiating, dense, circular, edge lobate, umbonate, papillate, fairly fluffy, covered with white aerial mycelium, black oil drops produced on the surface of cultures; reverse dark brown at the centre, faintly zonate, white at the edge.

Material examination: Thailand, Phayao Province, Phu Sang District, dead stems of Clematis subumbellata, 20 March 2017, C. Phukhamsakda, CMTH09 (MFLU 17-1473, holotype); ex-type living culture, MFLUCC 17-2065.

Host: Clematis subumbellata-(This study).

Distribution: Thailand-(This study).

GenBank accession numbers: LSU: MT214592; SSU: MT226705; ITS: MT310636; tef1: MT394649; rpb2: MT394706.

Notes: In a BLASTn search of GenBank, the closest match for LSU sequence of Anthosulcatispora subglobosa MFLUCC 17-2065 was Neobambusicola strelitziae (strain CBS 138869), (NG_058125) with 97\% similarity, while the closest match for the ITS sequence of MFLUCC 17-2065 was Magnicamarosporium iriomotense (strain HHUF 30125), (NR_153445) with $89 \%$ similarity. Pairwise comparison of the ITS region showed that $A$. subglobosa differs from A. brunnea with $12 \%$ differences (76 base pairs difference of 585 base pairs, with gaps). The collection has oblong, hyaline, guttulate, and aseptate, with rounded ends conidia but microconidia were not observed in culture (Crous et al. 2014b; Rupcic et al. 2018). We also noted the formation of oil droplets in culture as a notable character for A. subglobosa (Fig. 73).

Strain MFLUCC 17-2065 was evaluated for potential secondary metabolite production with Bacillus subtillis, Escherichia coli, Mucor plumbeus and Schizosaccharomyces pombe astest organisms. The isolate showed moderate growth inhibitory activities against Bacillus subtillis and Mucor plumbeus, and is thus a suitable candidate for further evaluation.

Parasulcatispora Phukhams. \& K.D. Hyde, gen. nov.

Index Fungorum number: IF557204; Facesoffungi number: FoF 01686, Fig. 74.

Etymology: Refers to the characteristic features similar to Sulcatispora. 


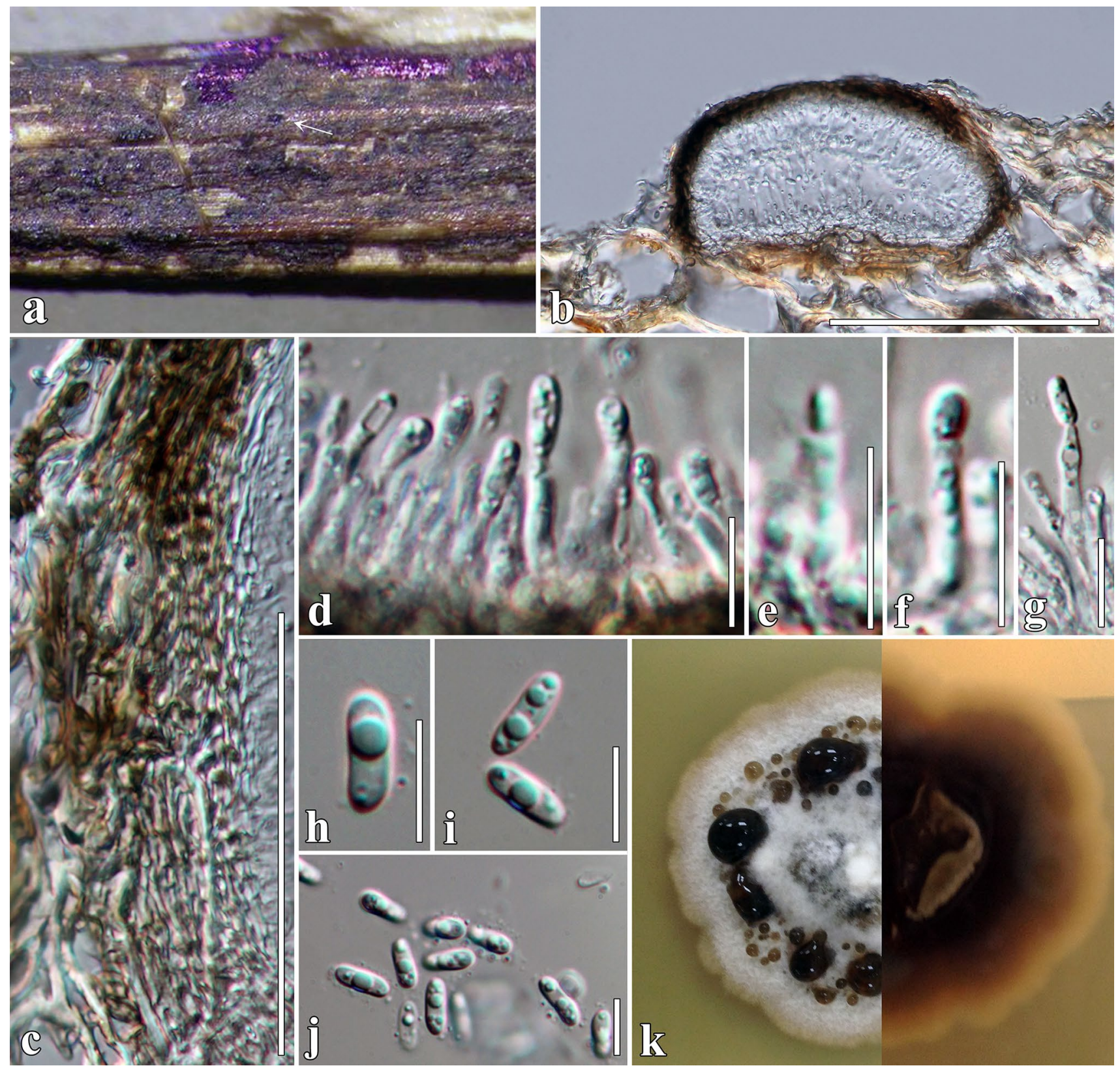

Fig. 73 Anthosulcatispora subglobosa (MFLU 17-1473, holotype). a Appearance of conidiomata on Clematis subumbellata. b Vertical section through conidioma. c Section of conidioma wall. $\mathbf{d}-\mathbf{g}$ Conid-

Saprobic on dried stem of herbaceous plants. Sexual morph: Ascomata solitary, gregarious, semi-immersed to erumpent, subglobose to compressed, coriaceous, dark brown to black, ostiolate. Ostioles central, filled with hyaline periphyses. Peridium thin, uniform of flattened cells of textura angularis, thin-walled, cells towards the inside lighter, inner layer composed of thin, hyaline, gelatinous layer. Hamathecium composed of numerous, filamentous, branched, septate, anastomosing, trabeculate pseudoparaphyses. Asci 8-spored, bitunicate, fissitunicate, iogenous cells and conidia. $\mathbf{h}-\mathbf{j}$ Conidia. $\mathbf{k}$ Culture characteristics on MEA. Scale bars: $\mathbf{b}=100 \mu \mathrm{m}, \mathbf{c}=50 \mu \mathrm{m}, \mathbf{d}-\mathbf{j}=10 \mu \mathrm{m}$

cylindrical-clavate to clavate, asymmetric, with furcate pedicel, apically rounded, with an ocular chamber. Ascospores biseriate or partially overlapping, broad fusiform, hyaline, tapering towards the ends, 1-euseptate, constricted at the septum, smooth-walled, with guttules in each cell, with mucilaginous sheath. Asexual morph: Undetermined.

Type species: Parasulcatispora clematidis Phukhams. \& K.D. Hyde

Notes: Parasulcatispora is established as a monotypic genus. In a BLASTn search of GenBank, the closest match 

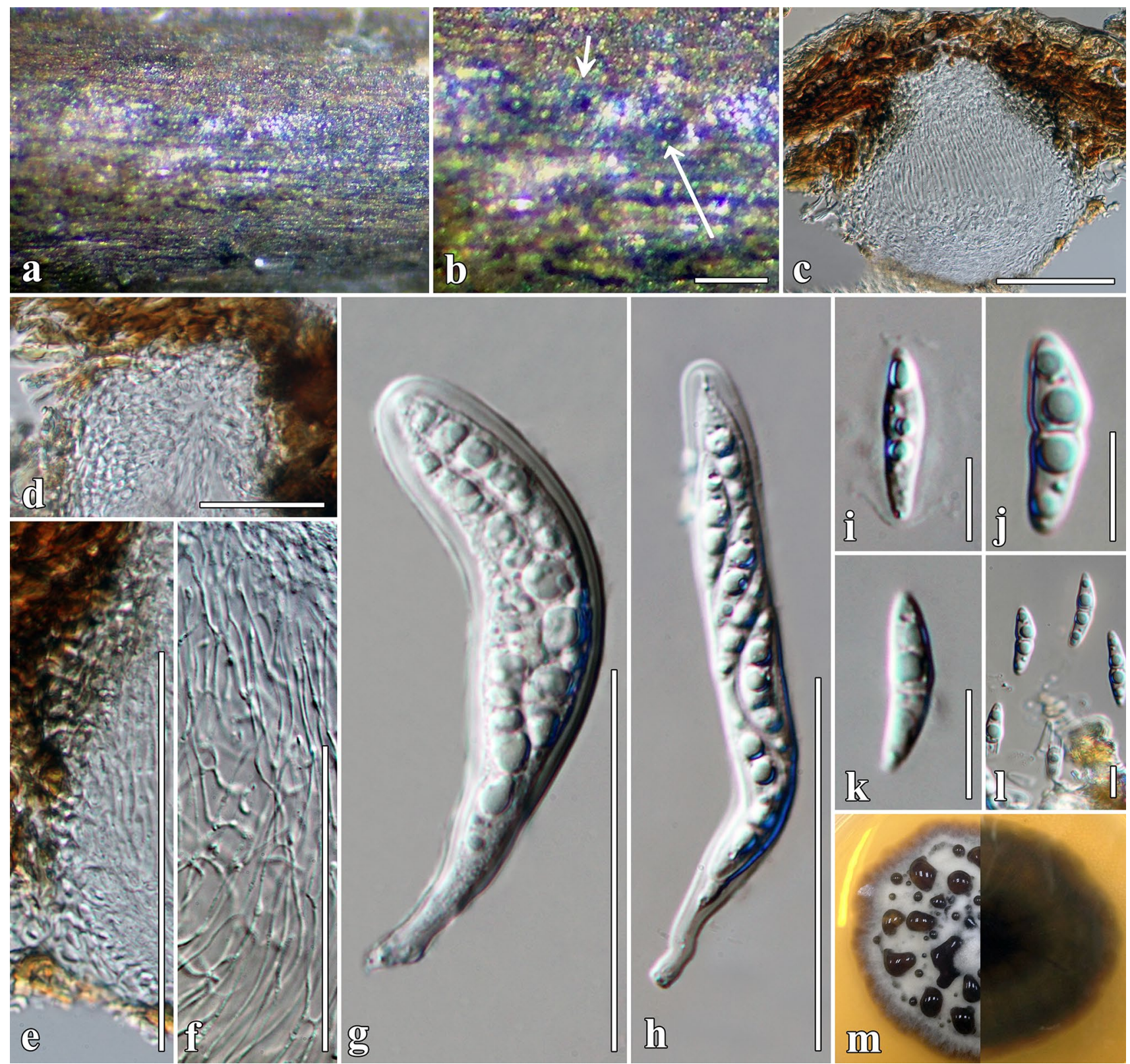

Fig. 74 Parasulcatispora clematidis (MFLU 17-1490, holotype). a Appearance of ascomata on host surface. b Close up of ascoma on host substrate. c Vertical section through ascoma. d Ostiolar canal. e Section of peridium. f Trabeculate pseudoparaphyses. g-h Asci. i-l Ascospores. m Culture characteristics on MEA. Scale bars: $\mathbf{b}=200 \mu \mathrm{m}, \mathbf{c}=100 \mu \mathrm{m}, \mathbf{d}=20 \mu \mathrm{m}, \mathbf{e}-\mathbf{h}=50 \mu \mathrm{m}, \mathbf{i}-\mathbf{l}=10 \mu \mathrm{m}$ for LSU and ITS sequences of MFLUCC 17-2082 is Sulcatispora berchemiae (HHUF 29097, NG_059390) with 98\% similarity, while the ITS sequence had $88 \%$ similarity to NR_153444. Based on the multi-gene (LSU, SSU, ITS and tef1 regions) analyses, MFLUCC 17-2082 formed a separate lineage within Sulcatisporaceae (Fig. 72). The genus matches Sulcatisporaceae species in having immersed, subglobose to hemisphaerical ascomata, short ostioles, trabeculate pseudoparaphyses (Liew et al. 2000), and fusiform, hyaline, septate ascospores with mucilaginous appendages
(Tanaka et al. 2015). Parasulcatispora is similar to Sulcatispora but lacks a pseudoclypeus and has small flattened ascomata with narrower asci and ascospores. The asexual morph failed to develop in culture. We introduce the new genus based on morphology and phylogenetic evidence.

Parasulcatispora clematidis Phukhams. \& K.D. Hyde, sp. nov.

Index Fungorum number: IF557205; Facesoffungi number: FoF 07342, Fig. 74. 
Etymology: The specific name "clematidis" refers to the host substrate.

Holotype: MFLU 17-1490.

Saprobic on dead stems of Clematis fulvicoma. Sexual morph: Ascomata $160-230 \times 230-320 \mu \mathrm{m}$ $(\bar{x}=190 \times 305 \mu \mathrm{m}, \mathrm{n}=5)$, solitary, gregarious, semiimmersed to erumpent, subglobose to compressed, coriaceous, dark brown to black, only ostiole visible, ostiolate. Ostioles $84-115 \times 116-133 \mu \mathrm{m}(\bar{x}=100 \times 124 \mu \mathrm{m}, \mathrm{n}=5)$, shiny, central, smooth-walled, filled with hyaline periphyses. Peridium 22-37 $\mu \mathrm{m}$ wide $(\bar{x}=19 \mu \mathrm{m}, \mathrm{n}=20)$, uniform, wider at the apex, composed of 3-4 layers of somewhat flattened cells of textura angularis, thin-walled, cells towards the inside lighter, inner layer composed of thin hyaline gelatinous layer. Hamathecium composed of numerous, dense, 2-3 $\mu \mathrm{m}$ wide, filamentous, branched, septate, anastomosing, trabecular pseudoparaphyses, embedded in a gelatinous matrix. Asci 53-88 $\times 8-17 \mu \mathrm{m}(\bar{x}=72 \times 13 \mu \mathrm{m}, \mathrm{n}=30)$, 8 -spored, bitunicate, fissitunicate, cylindrical-clavate to clavate, asymmetric, with furcate pedicel, apically rounded, with an ocular chamber. Ascospores 16-21 $\times 4-6 \mu \mathrm{m}$ ( $\bar{x}=17 \times 5 \mu \mathrm{m}, \mathrm{n}=40$ ), biseriate or partially overlapping, broad fusiform with acute ends, tapering towards the ends, 1-euseptate, constricted at the septum, upper cell broader than lower cell, smooth-walled, with two guttules in each cell, hyaline, with 4-7 $\mu \mathrm{m}$ wide mucilaginous appendages. Asexual morph: Undetermined.

Culture characters: Colonies on MEA reaching $30 \mathrm{~mm}$ diam. after 4 weeks at $25^{\circ} \mathrm{C}$. Culture from above, greyish brown, covered with grey fluffy mycelia, dense, circular, umbonate, dull, undulate, radially furrowed, yellow oil droplets formed in the middle of cultures; reverse grey, radiating outwardly.

Material examined: Thailand, Chiang Rai Province, Mae Sai District, dried stems of Clematis fulvicoma, 20 March 2017, C. Phukhamsakda, CMTH28 (MFLU 17-1490, holotype); ex-type living culture, MFLUCC 17-2082.

Host: Clematis fulvicoma-(This study).

Distribution: Thailand-(This study).

GenBank accession numbers: LSU: MT214593; ITS: MT310637; tef1: MT394650.

Notes: Parasulcatispora clematidis can be distinguished morphologically (Fig. 74) and is supported by the phylogenetic analyses of combined LSU, SSU, ITS and tefl data (Tanaka et al. 2015, Fig. 72). The isolate MFLUCC 17-2082 also produces oil droplets in culture, and was further evaluated for the possibility of bioactive secondary metabolite production. The isolate MFLUCC 17-2082 inhibited the growth of Bacillus subtillis and partially inhibited conidial production of Mucor plumbeus, but did not reach significant values (data not shown).

\section{Teichosporaceae Barr}

Teichosporaceae is characterized by erumpent to superficial ascomata, that are obpyriform, obovoid, or globose, with blunt ostioles filled with pseudoparaphyses or periphyses, and a multilayered peridium (Barr 2002; Jaklitsch et al. 2016). The family was treated under Floricolaceae (Thambugala et al. 2015; Wijayawardene et al. 2016), but Jaklitsch et al. (2016) synonymized Floricolaceae under Teichosporaceae. Wijayawardene et al. (2018) accepted twelve genera in Teichosporaceae. Based on molecular analyses and morphological comparisons, four of our collections from Clematis clustered in Teichosporaceae (Fig. 75).

Floricola Kohlm. \& Volkm.-Kohlm.

Floricola was introduced with $F$. striata as the type species. This genus is characterized by immersed, ostiolate, pycnidial conidiomata with a peridium of thick-walled cells with 5-6 cell layers, phialidic conidiogenesis cells, and septate, brown conidia (Ariyawansa et al. 2015a; Thambugala et al. 2015). The genus occurs on old inflorescences (Kohlmeyer and Volkmann-Kohlmeyer 2000; Ariyawansa et al. 2015a). We introduce $F$. clematidis on Clematis vitalba from Italy (Fig. 76).

Floricola clematidis Phukhams., Camporesi \& K.D. Hyde, sp. nov.

Index Fungorum number: IF557180; Facesoffungi number: FoF 07343, Fig. 76.

Etymology: The specific name "clematidis" refers to the host.

Holotype: MFLU 17-1535.

Saprobic on dead stems of Clematis vitalba. Sexual morph: Undetermined. Asexual morph: Conidiomata

Fig. 75 Best scoring RAxML tree with a final likelihood value of - 21485.053484 based on combined LSU, ITS, tef1 and rpb2 sequence data for Teichosporaceae. The topology and clade stability of the combined gene analyses was compared to the single gene analyses. The tree is rooted with members of the Sporormiaceae. Sixty-one strains were included in the combined gene sequence analyses which comprised 3719 characters (1084 characters for LSU, 626 characters for ITS, 924 characters for tefl and 1085 characters for $r p b 2$, including gap regions). The tree from the maximum likelihood analysis had similar topology to the Bayesian 50\% majority-rule consensus phylogram. The matrix had 1574 distinct alignment patterns with $42.64 \%$ undetermined characters and gaps. Estimated base frequencies were as follows; $\mathrm{A}=0.240047, \mathrm{C}=0.261812, \mathrm{G}=0.279530$, $\mathrm{T}=0.218610 ;$ substitution rates $\mathrm{AC}=1.269781, \mathrm{AG}=3.374707$, $\mathrm{AT}=1.851379, \quad \mathrm{CG}=1.247283, \quad \mathrm{CT}=9.170687, \quad \mathrm{GT}=1.000000 ;$ gamma distribution shape parameter $\alpha=0.475238$. In our analysis, $\mathrm{GTR}+\mathrm{I}+\mathrm{G}$ model was used for each partition in Bayesian posterior analysis. The species determined in this study are indicated in blue. Bootstrap values (BS) greater than 50\% BS (ML, left) and Bayesian posterior probabilities (BYPP, right) greater than 0.90 are given at the nodes. Hyphens (-) represent support values less than 50\% BS/0.90 BYPP. Thick branches represent significant support values from all analyses (BS $\geq 70 \% / \mathrm{BYPP} \geq 0.95$ ) 


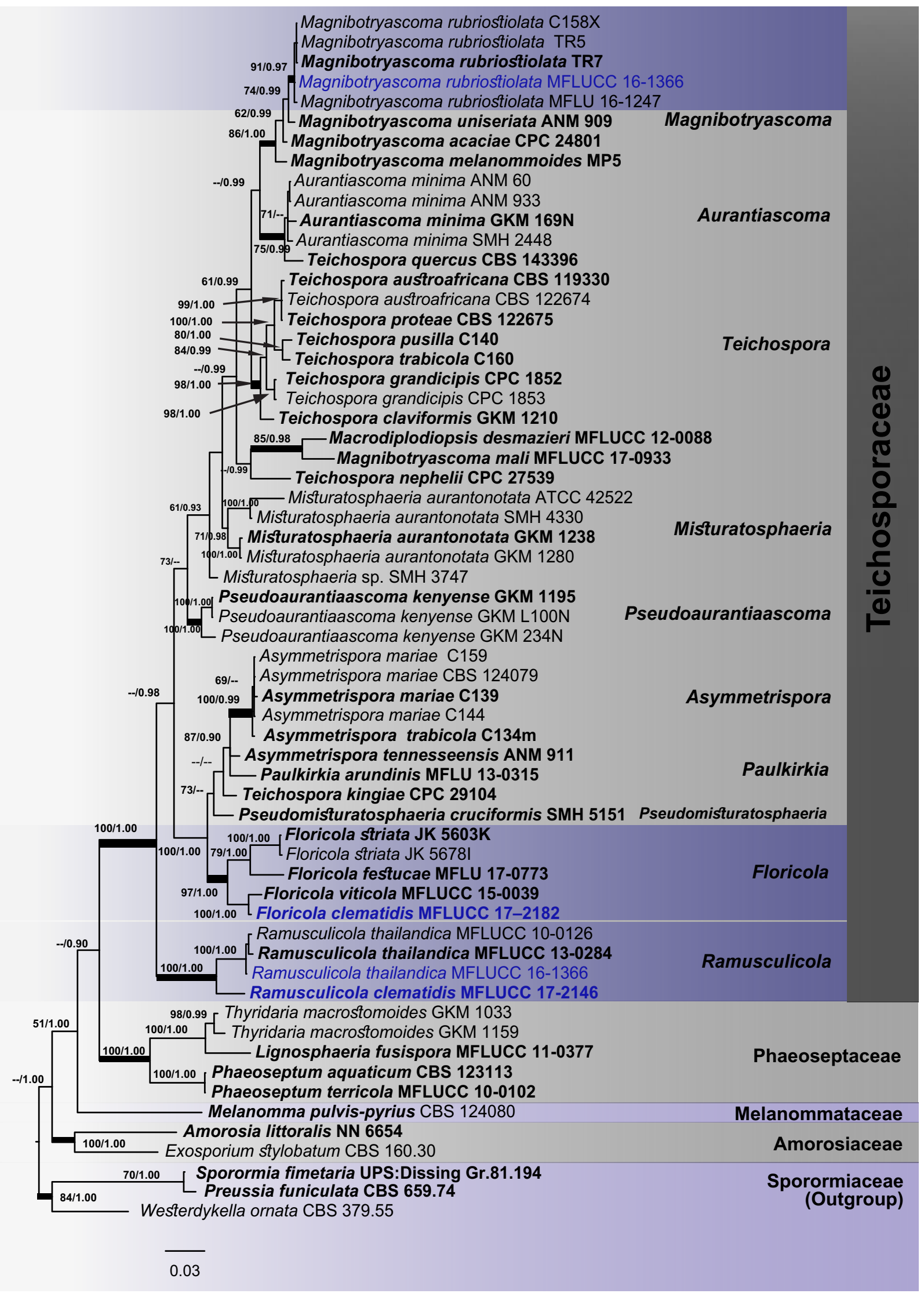



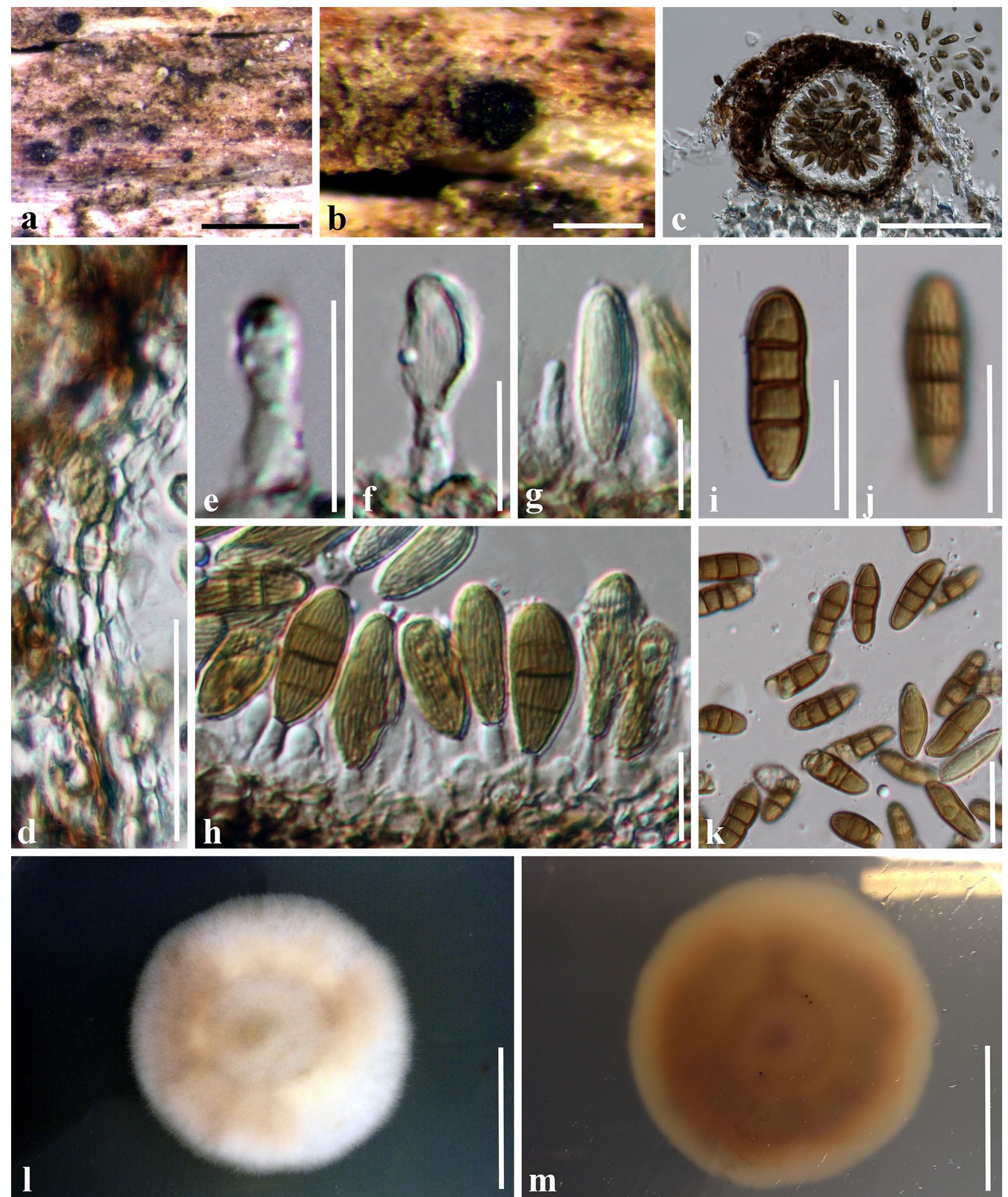

Fig. 76 Floricola clematidis (MFLU 17-1535, holotype), a, b Appearance of conidiomata on Clematis vitalba. c Vertical section through conidioma. d Section of conidioma wall. e-h Conidiog- enous cells and conidia. $\mathbf{i}-\mathbf{k}$ Conidia. $\mathbf{l}, \mathbf{m}$ Culture characteristic on MEA. Scale bars: $\mathbf{a}=500 \mu \mathrm{m}, \mathbf{b}=200 \mu \mathrm{m}, \mathbf{c}=100 \mu \mathrm{m}, \mathbf{d}, \mathbf{k}=20 \mu \mathrm{m}$, $\mathbf{e}-\mathbf{j}=5 \mu \mathrm{m}, \mathbf{l}, \mathbf{m}=25 \mathrm{~mm}$ 
119-135×133-166 $\mu \mathrm{m}(\bar{x}=127 \times 146 \mu \mathrm{m}, \mathrm{n}=10)$, pycnidial, solitary, aggregated, uniloculate, flat, semi-immersed, covered by a pseudoclypeus, globose, coriaceous, thickwalled, dark brown to reddish brown, without ostioles. Conidiomatal wall 11-24 $\mu \mathrm{m}$ wide, uniform, outer layer composed 4-5 layers of reddish brown cells of textura angularis, lined with a thin, hyaline layer bearing conidiogenous cells. Conidiophores reduced to conidiogenous cells. Conidiogenous cells $4-12 \times 2-4 \mu \mathrm{m}(\bar{x}=7 \times 3 \mu \mathrm{m}, \mathrm{n}=30)$, enteroblastic, phialidic, determinate, discrete, truncate or doliiform, hyaline. Conidia 13-21 $\times 5-7 \mu \mathrm{m}(\bar{x}=17 \times 6 \mu \mathrm{m}, \mathrm{n}=50)$, broad oblong or ellipsoid, slightly curved towards the ends, ends rounded, bud scars or disjunctors present at the site of attachment, hyaline when immature, reddish brown at maturity, with longitudinal striations visible even while attached to conidiogenous cells, 3-euseptate, with prominent longitudinal striations, smooth-walled.

Culture characters: Colonies on MEA reaching $20 \mathrm{~mm}$ diam. after 2 weeks at $25^{\circ} \mathrm{C}$. Cultures from above, cream to orangish-white, dense, circular, umbonate, papillate, fluffy, slightly radiating in the lower part; reverse orange at the centre, light brown, radiating outwardly.

Material examined: Italy, Forlì-Cesena Province, CabelliSanta Sofia, dead aerial branch of Clematis vitalba, 23 January 2014, E. Camporesi, IT 1668 (MFLU 17-1535, holotype); ex-type living culture, MFLUCC 17-2182.

Host: Clematis vitalba-(This study).

Distribution: Italy-(This study).

GenBank accession numbers: LSU: MT214594; SSU: MT226706; ITS: MT310638; tef1: MT394651.

Notes: Floricola clematidis constitutes a strongly supported clade (100\% ML/1.00 BYPP) with F. viticola (MFLUCC 15-0039) (Fig. 75). Floricola clematidis is similar to $F$. viticola. Both species are similar in having semi-immersed conidiomata, but $F$. clematidis has smaller conidiomata $(127 \times 146$ vs $237 \times 177 \mu \mathrm{m})$ and larger, broad oblong or ellipsoid conidia $(17 \times 6$ vs $9 \times 4 \mu \mathrm{m})$. Floricola clematidis also has prominent, longitudinal striations on the conidia (Ariyawansa et al. 2015a, Fig. 76). A BLASTn search of GenBank showed ITS sequence had $99.26 \%$ similarity to $F$. viticola (7 nucleotide difference in 626 nucleotides).

\section{Magnibotryascoma Thambug. \& K.D. Hyde}

Magnabotrioscoma, typified by $M$. uniseriatum was introduced to accommodate a separate lineage of Misturatosphaeria uniseriata in Teichosporaceae. Magnibotryascoma is characterized by erumpent to superficial ascomata with short ostioles, and fusiform to elliptical, septate, guttulate ascospores. The asexual morph is pycnidial with aseptate and brown conidia (Crous et al. 2015b; Jaklitsch et al. 2016). We redefine the Teichosporaceae, based on multigene phylogenetic analyses, as four species formed a strongly supported clade with Magnibotryascoma sensu stricto (Fig. 75). We introduce the first report of Magnibotryascoma rubriostiolata on Clematis vitalba and document the characters of the asexual morph (Fig. 77).

Magnibotryascoma rubriostiolata (Jaklitsch \& Voglmayr) Phukhams., E.B.G. Jones \& K.D. Hyde, comb. nov. and new host record

Index Fungorum number: IF557181; Facesoffungi number: FoF 07344, Fig. 77

Basionym: Teichospora rubriostiolata Jaklitsch \& Voglmayr, Mycological Progress 15(31):13 (2016)

Saprobic on dead stems of Clematis vitalba. Sexual morph: Described in Jaklitsch et al. 2016. Asexual morph: Conidiomata 110-188 ×93-164 $\mu \mathrm{m}(\bar{x}=160 \times 131 \mu \mathrm{m}$, $\mathrm{n}=5$ ), pycnidial, solitary, aggregated, uniloculate, immersed, globose to subglobose, coriaceous, dark brown to brown, with papilla ostiolate. Ostioles $25 \times 19 \mu \mathrm{m}$, central, papillate. Conidiomatal wall 15-29 $\mu \mathrm{m}$ wide, thick, multilayered, outer layer composed of 6-7 layers of light brown to brown cells of textura angularis, lined with a hyaline layer bearing conidiogenous cells. Conidiophores reduced to conidiogenous cells. Conidiogenous cells $4-11 \times 2-3 \mu \mathrm{m}(\bar{x}=7 \times 2 \mu \mathrm{m}$, $\mathrm{n}=30$ ), enteroblastic, discrete, integrated, oblong, cylindrical, hyaline, arising from the inner layer of pycnidium wall. Conidia $3-5 \times 1.8-3 \mu \mathrm{m}(\bar{x}=3.7 \times 2.5 \mu \mathrm{m}, \mathrm{n}=50)$, subglobose, oval, with guttule in each cell, hyaline when immature, pale brown at maturity, aseptate, smooth-walled.

Culture characters: Colonies on MEA reaching $30 \mathrm{~mm}$ diam. after 2 weeks at $25{ }^{\circ} \mathrm{C}$. Cultures from above, greenish-brown, dense, circular, umbonate, papillate, fluffy, covered with white aerial mycelium, droplets formed at room temperature; reverse orange at the centre, brown radiating outwardly.

Material examined: UK, Carmarthenshire, Laugharne, on dead stems of Clematis vitalba, 29 July 2016, E. B. G. Jones, GJ 311 (MFLU 17-1539); living culture, MFLUCC 16-1366.

Hosts: Clematis vitalba, Ribes sanguineum, Robinia pseudoacacia, Vaccinium myrtillus-(Jaklitsch et al. 2016; this study).

Distribution: Belgium, Germany, Norway, UK (England)_(Jaklitsch et al. 2016; this study).

GenBank accession numbers: LSU: MT214595; ITS: MT310639.

Notes: Isolate MFLUCC 16-1366 formed a strongly supported clade (91\% ML/0.97 BYPP) with four isolates of Magnibotryascoma rubriostiolata (Fig. 75). Magnibotryascoma rubriostiolata was introduced as Teichospora rubriostiolata by Jaklitsch et al. (2016) on bark and wood of trees, shrubs, and vineyard poles distributed in Europe. A collection on twigs of Ribes sanguinea was recorded as coniothyrium-like, but without a full description, although 

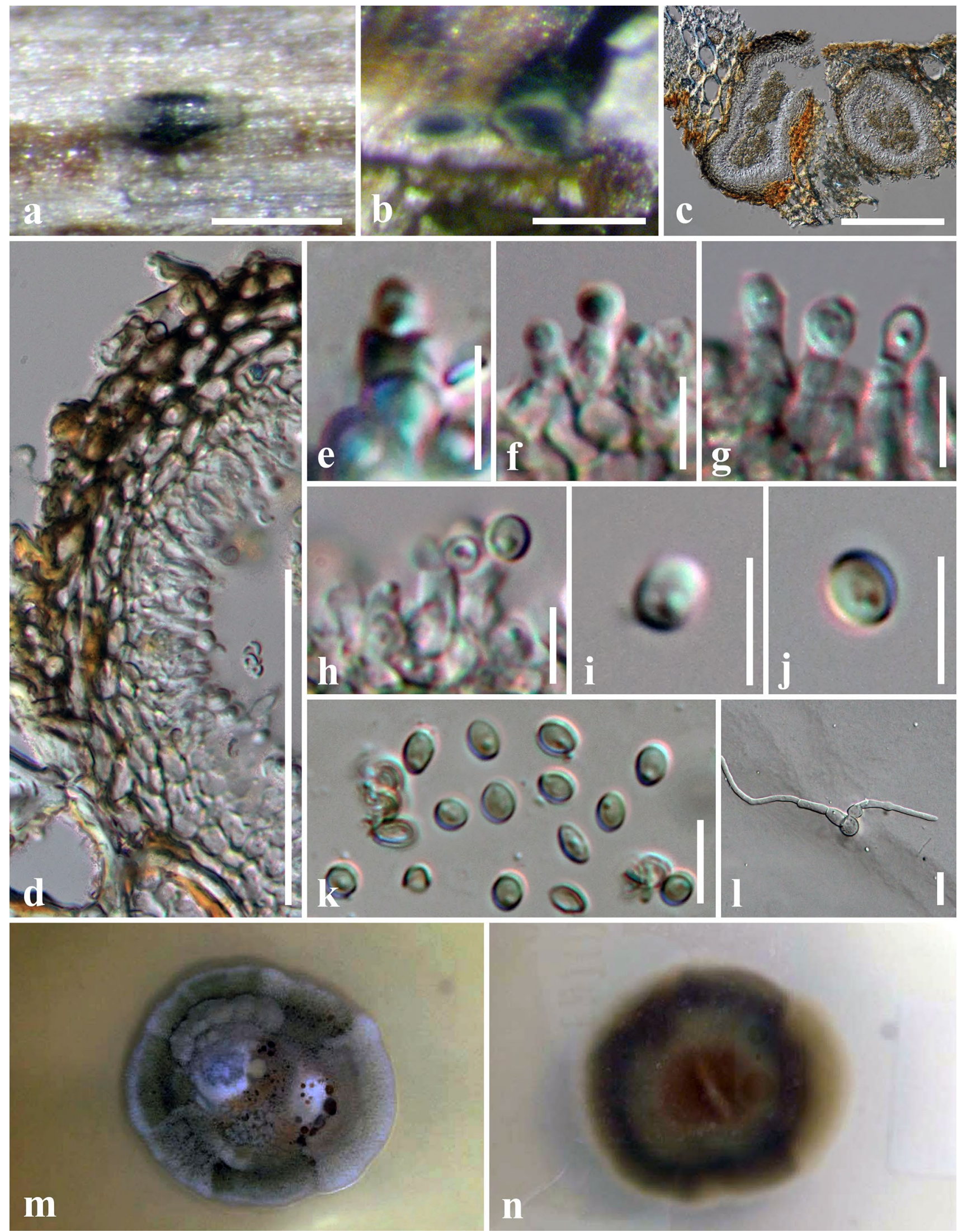

n 
४Fig. 77 Magnibotryascoma rubriostiolata (MFLU 17-1539). a, b Appearance of conidiomata on Clematis vitalba. c Vertical section through conidiomata. d Section of conidioma wall. $\mathbf{e}-\mathbf{h}$ Conidiogenous cells and conidia. $\mathbf{i}-\mathbf{k}$ Conidia. $\mathbf{l}$ Germinating conidium. $\mathbf{m}, \mathbf{n}$ Culture characteristics on MEA. Scale bars: $\mathbf{a}, \mathbf{b}=200 \mu \mathrm{m}$, $\mathbf{c}=100 \mu \mathrm{m}, \mathbf{d}=50 \mu \mathrm{m}, \mathbf{e}-\mathbf{l}=5 \mu \mathrm{m}$

Jaklitsch et al. (2016) illustrated the sexual morph. A comparison of the ITS and tefl DNA sequences of our isolate (MFLUCC 16-1366) with four isolates showed 100\% similarity. This is the first record of M. rubriostiolata on Clematis with illustration of their asexual morph (Fig. 77). We also provide sequence data and phylogenetic analyses (Fig. 75).

\section{Ramusculicola Thambug. \& K.D. Hyde}

Ramusculicola is typified by $R$. thailandica Thambug. \& K.D. Hyde. The genus is characterized by semi-immersed to partially erumpent, coriaceous ascomata, short pedicellate asci, and fusiform to cylindrical, hyaline ascospores with polar appendages with blunt ends, and a lateral pad-like structure of sheath that surrounds the ascospores (Thambugala et al. 2015). Based on phylogenetic analyses our collection isolated from Clematis species from Thailand revealed a new species, Ramusculicola clematidis (Fig. 75).

Ramusculicola clematidis Phukhams. \& K.D. Hyde, sp. nov.

Index Fungorum number: IF557183; Facesoffungi number: FoF 07345, Fig. 78.

Etymology: The specific name "clematidis" refers to the host.

Holotype: MFLU 17-1503

Saprobic on dead stem of Clematis sikkimensis. Sexual morph: Ascomata 155-205 $\times 135-200 \mu \mathrm{m}$ $(\bar{x}=175 \times 160 \mu \mathrm{m}, \mathrm{n}=5)$, solitary or scattered, uniloculate, semi-immersed to erumpent, ampulliform to compressed subglobose, coriaceous, black to dark brown, ostiolate. Ostioles 75-95×110-130 $\mu \mathrm{m}$, central, composed of 6-10 layers of textura prismatica, papillate, with variable walls, with pore-like opening, filled with hyaline periphyses. Peridium $15-30 \mu \mathrm{m}$ wide $(\bar{x}=20 \mu \mathrm{m}, \mathrm{n}=20)$, uniform, multilayered, composed of 7(-9) layers of textura prismatica, cells towards the inside lighter, somewhat flattened, inner layer composed of thin hyaline gelatinous layer. Hamathecium composed of numerous, dense, 1.5-3.5 $\mu \mathrm{m}(\bar{x}=2 \mu \mathrm{m}, \mathrm{n}=30)$, wide, filamentous, branched, septate, anastomosing, cellular pseudoparaphyses, situated between and above the asci, embedded in a gelatinous matrix. Asci $55-100 \times 8-13 \mu \mathrm{m}$ $(\bar{x}=80 \times 10 \mu \mathrm{m}, \mathrm{n}=30), 8$-spored, bitunicate, fissitunicate, oblong to cylindrical-clavate, short pedicellate, apically rounded, with an ocular chamber, arising from the basal ascoma. Ascospores $20-30 \times 4-8 \mu \mathrm{m}(\bar{x}=25 \times 6 \mu \mathrm{m}, \mathrm{n}=50)$, biseriate or partially overlapping, broad-fusiform, tapering towards the ends, rounded at upper end, acute towards the lower end, (1-)2(-3)-transversely euseptate, strongly constricted at the septa, with (1-)2 guttules in each cell, hyaline, swollen near median septum, with 3-8 $\mu$ m of sheath drawn out at both ends, forming polar appendages with blunt ends, with a lateral pad-like structure, up to $2 \mu \mathrm{m}$ wide at the sides. Asexual morph: Undetermined.

Culture characters: Colonies on MEA reaching $20 \mathrm{~mm}$ diam. after 2 weeks at $25{ }^{\circ} \mathrm{C}$. Culture from above, brownish grey, dark green in the middle, forming cream, fluffy mycelium at the edge, dense, umbonate, raised with concave edge, rough, dull, lobate, radially furrowed, slight brown pigment diffused into the agar, oil droplets formed in the middle of cultures; reverse dark brown radiating light brown with white margin.

Material examined: Thailand, Chiang Rai Province, Mae Sai District, dead stems of Clematis sikkimensis, 24 June 2017, C. Phukhamsakda \& M. van de Bult, CMTHDT16 (MFLU 17-1503, holotype); ex-type living culture, MFLUCC 17-2146.

Host: Clematis sikkimensis—(This study).

Distribution: Thailand-(This study).

GenBank accession numbers: LSU: MT214596; SSU: MT226707; ITS: MT310640; tef1: MT394652; rpb2: MT394707.

Notes: Based on phylogenetic analysis, Ramusculicola clematidis (MFLUCC 17-2146) clustered with $R$. thailandica with strong support (100\% ML/1.00 BYPP, Fig. 77). Ramusculicola clematidis can be distinguished by its broad-fusiform ascospores, tapering towards the ends, rounded at the upper end and acute towards the lower end, while $R$. thailandica has ascospores that are acute at both ends (Thambugala et al. 2015; this study). Comparison of 551 nucleotides (without gaps) in the ITS region revealed 23 bp (4.1\%) differences, while the tefl showed $27 / 920 \mathrm{bp}(3 \%)$ differences from $R$. thailandica, respectively. Therefore, $R$. clematidis is introduced as a new species (Fig. 78).

Ramusculicola thailandica Thambug. \& K.D. Hyde, in Fungal Diversity 74: 251 (2015), new host record

Index Fungorum number: IF551265; Facesoffungi number: FoF 01092, Fig. 79.

Saprobic on dead stem of Clematis sikkimensis. Sexual morph: Ascomata $174-180 \times 170-215 \mu \mathrm{m}$, solitary or scattered, uniloculate, semi-immersed to erumpent, ampulliform to compressed globose, coriaceous, dark brown to black, ostiolate. Ostioles $43-62 \times 79-120 \mu \mathrm{m}$, central, thick, composed of 20 layers of textura prismatica, papillate, with variable walls, with pore-like opening, filled with hyaline periphyses. Peridium $15-48 \mu \mathrm{m}$ wide $(\bar{x}=26 \mu \mathrm{m}$, $\mathrm{n}=20$ ), uniform, multilayered, composed of $13(-15)$ layers of textura angularis, thick-walled cells lighter towards 

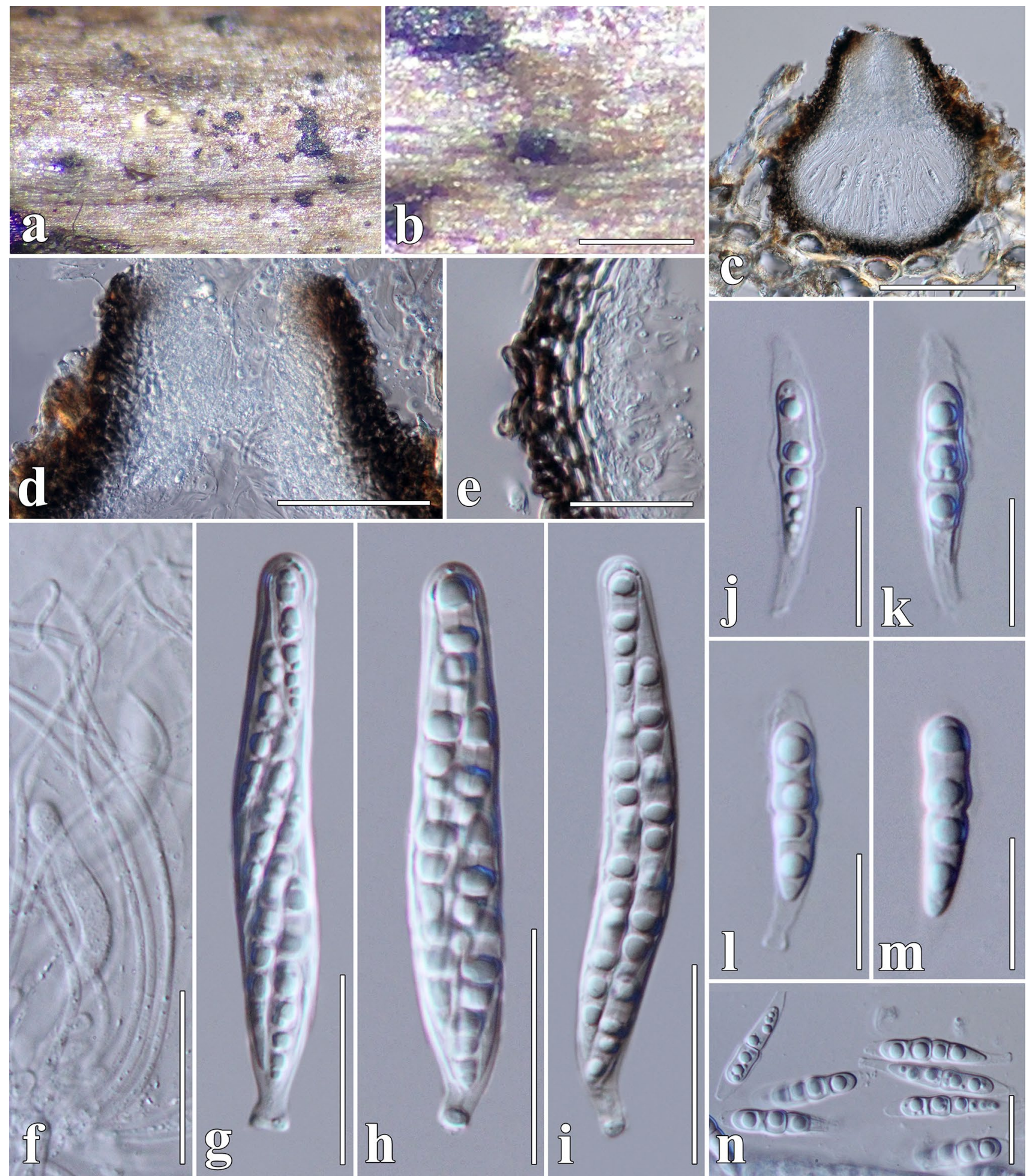

Fig. 78 Ramusculicola clematidis (MFLU 17-1503, holotype). a Appearance of ascomata on host surface. b Close up of ascoma on host substrate. c Vertical section of ascoma. d Ostiolar canal. e Sec-

tion of peridium. f Pseudoparaphyses. g-i Asci. j-n Ascospores. Scale bars: $\mathbf{b}=200 \mu \mathrm{m}, \mathbf{c}=100 \mu \mathrm{m}, \mathbf{d}=50 \mu \mathrm{m}, \mathbf{e}-\mathbf{i}=20 \mu \mathrm{m}, \mathbf{j}-$ $\mathbf{n}=10 \mu \mathrm{m}$ 
the inside, somewhat flattened, inner layer composed of thin hyaline gelatinous layer. Hamathecium composed of numerous, dense, 1.6-3 $\mu \mathrm{m}$ wide, filamentous, branched, septate, cellular pseudoparaphyses, situated between and above the asci, embedded in a gelatinous matrix. Asci 60-91 $\times 8-13 \mu \mathrm{m}(\bar{x}=74 \times 10 \mu \mathrm{m}, \mathrm{n}=30), 8$-spored, bitunicate, fissitunicate, oblong to cylindrical-clavate, short pedicellate, apically rounded, with an ocular chamber. Ascospores $18-30 \times 4-7 \mu \mathrm{m}(\bar{x}=24 \times 6 \mu \mathrm{m}, \mathrm{n}=50)$, biseriate or partially overlapping, broad-fusiform, tapering towards the ends, ends acute, 1-transversely euseptate, strongly constricted at the septum, with 2-3(-4) guttules in each cells, hyaline, swollen near median septum, with 3-6 $\mu \mathrm{m}$ of sheath drawn out at both ends forming polar appendages, with a lateral pad-like structure, up to $2 \mu \mathrm{m}$ wide at the sides. Asexual morph: Undetermined.

Culture characters: Colonies on MEA reaching $40 \mathrm{~mm}$ diam. after 4 weeks at $25^{\circ} \mathrm{C}$. Culture from above, brownish grey, forming zonate greyish orange, fluffy mycelium at the edge, dense, umbonate, raised with concave edge, rough, dull, lobate, radially furrowed, brown pigment slightly diffused in the agar, oil droplets formed in the middle of culture; reverse dark brown, radiating, light orange outwardly.

Material examined: Thailand, Chiang Rai Province, Mae Sai District, dead stems of Clematis sikkimensis, 24 June 2017, C. Phukhamsakda \& M. van de Bult, CMTHDT13 (MFLU 17-1502); living culture, MFLUCC 17-2093.

Hosts: Fallen twig of deciduous tree, Clematis sikkimensis-(Thambugala et al. 2015; this study).

Distribution: Thailand—(Thambugala et al. 2015; this study).

GenBank accession numbers: LSU: MT214597; SSU: MT226708; ITS: MT310641; tef1: MT394653; rpb2: MT394708.

Notes: Ramusculicola thailandica was first recorded by Thambugala et al. (2015). The comparison of morphological characters and pairwise comparisons in the ITS and tefl regions confirm the similarity of MFLUCC 17-2093 with collections reported in Thambugala et al. (2015). This is the first record of $R$. thailandica on Clematis species (Fig. 79). We also provide sequence data and phylogenetic analyses (Fig. 75).

\section{Thyridariaceae Tian \& K.D. Hyde}

We follow Hyde et al. (2013) and Tibpromma et al. (2017) to treat Thyridariaceae as a separate family in Pleosporales. Seven genera are listed in Thyridariaceae (Hyde et al. 2013; Tibpromma et al. 2017; Devadatha et al. 2018; Wanasinghe et al. 2018; Mapook et al. 2020). The phylogenetic tree, based on combined LSU, ITS, tefl and $r p b 2$ sequence data is presented in Fig. 80.
Parathyridaria Jaklitsch \& H. Voglmayr

Parathyridaria is typified with $P$. ramulicola. Parathyridaria is characterized by immersed and globose ascomata, a pseudoparenchymatous peridium, papilla with or without orange colouration and fusoid, septate, hyaline to greyish brown ascospores, with a pycnidial asexual morph (Jaklitsch and Voglmayr 2016; Wanasinghe et al. 2018). The concatenated LSU, ITS, tefl, and $r p b 2$ dataset showed that fungal collections from Clematis species grouped with the type strain of Parathyridaria with moderate support (51\% ML/1.00 BYPP, Fig. 80). The new species Parathyridaria clematidis, $P$. serratifoliae and $P$. virginiana are introduced from Clematis collections from the European continent.

Parathyridaria clematidis Phukhams., Camporesi \& K.D. Hyde, sp. nov.

Index Fungorum number: IF557206; Facesoffungi number: FoF 07347, Fig. 81.

Etymology: The epithet refers to the host plant, Clematis. Holotype: MFLU 16-0061

Saprobic on dead stems of Clematis. Sexual morph: Ascomata $180-310 \times 205-330 \mu \mathrm{m}(\bar{x}=253 \times 263 \mu \mathrm{m}, \mathrm{n}=15)$, on the surface of the host, solitary, gregarious, immersed, only orange ostioles are visible, globose to depressed-globose, coriaceous, black to dark brown, rough-walled, papillate, ostiolate. Ostioles $67-107 \times 122-183 \mu \mathrm{m}$, central, black to reddish brown, papillate, opening by a pore, filled with periphyses, orange around pore. Peridium $17-33(-50 \mu \mathrm{m}$ at apex) wide, multilayered, outer layer composed of 7-10 layers of dark brown to light brown cells of textura angularis, heavily pigmented at outer layer with thin, hyaline inner layer. Hamathecium composed of numerous, dense, $0.5-1.3 \mu \mathrm{m}$ wide $(\bar{x}=1 \mu \mathrm{m}, \mathrm{n}=60)$, filiform, branched, septate, trabeculate pseudoparaphyses. Asci $77-112 \times 12-15 \mu \mathrm{m}(\bar{x}=93 \times 14 \mu \mathrm{m}$, $\mathrm{n}=20$ ), (4-)8-spored, bitunicate, fissitunicate, broad fusiform, clavate, apically rounded with an ocular chamber. Ascospores $16-24 \times 5-8 \mu \mathrm{m}(\bar{x}=20 \times 6 \mu \mathrm{m}, \mathrm{n}=50)$, biseriate, partial overlapping, oval to broad fusiform, sometimes inequilateral, with rounded ends, hyaline, 1(-2)-septate, constricted at septa, cell above median septum enlarged, granulate in each cell, rough-walled, with mucilaginous sheath. Asexual morph: Coelomycetous, pycnidia produced on mycelium in MEA. Conidiomata 135-170×102-195 $\mu \mathrm{m}$ diam., pycnidial, dark brown to black, covered by dense vegetative hyphae, superficial, uniloculate, solitary to scattered, globose. Conidiomatal wall 15-17 $\mu \mathrm{m}$ wide, thin, black to brown, with cells of textura angularis. Conidiophores reduced to conidiogenous cells. Conidiogenous cells $4-8(-18) \times 2-6 \mu \mathrm{m}(\bar{x}=7 \times 3 \mu \mathrm{m}$, $\mathrm{n}=30$ ), enteroblastic, annellidic, sometimes a sympodial. Conidia 5-7 $\times 3-5 \mu \mathrm{m}(\bar{x}=6 \times 4 \mu \mathrm{m}, \mathrm{n}=100)$, ellipsoid, pale brown, aseptate, guttulate, smooth-walled.

Culture characters: Colonies on MEA reaching $30 \mathrm{~mm}$ diam. after 4 weeks at $25{ }^{\circ} \mathrm{C}$. Culture from above, cream 

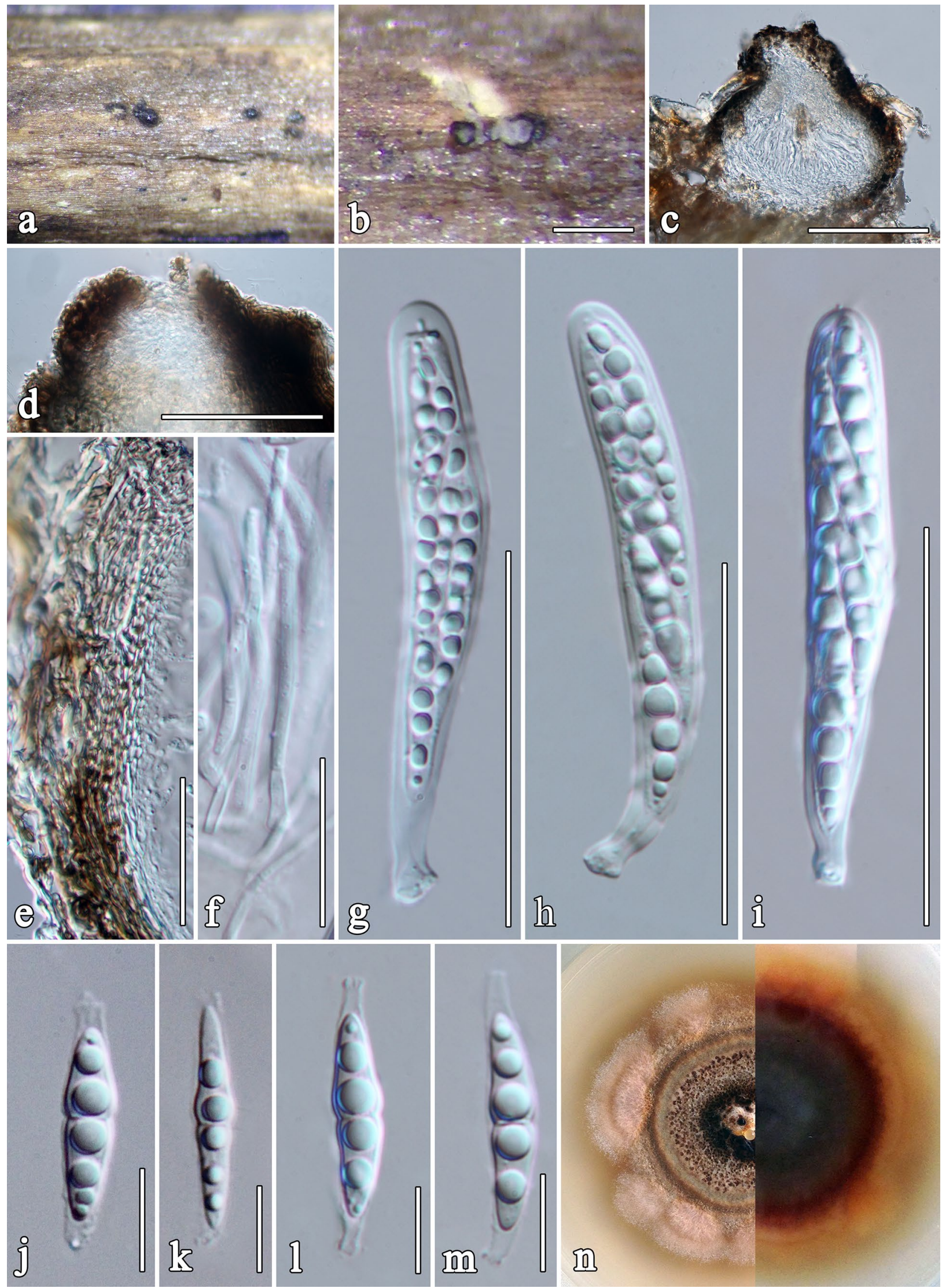
4Fig. 79 Ramusculicola thailandica (MFLU 17-1502). a Appearance of ascomata on host surface. b Close up of ascoma on host substrate. c Vertical section of ascoma. d Ostiolar canal. e Section of peridium. f Pseudoparaphyses. g-i Asci. j-m Ascospores. n Culture characters on MEA. Scale bars: $\mathbf{b}=200 \mu \mathrm{m}, \mathbf{c}=100 \mu \mathrm{m}, \mathbf{d}, \mathbf{g}-\mathbf{i}=50 \mu \mathrm{m}$, $\mathbf{e}-\mathbf{f}=20 \mu \mathrm{m}, \mathbf{j}-\mathbf{m}=10 \mu \mathrm{m}$

with lilac in the middle, white edge, dense, radially striated with lobate edge, flattened, umbonate, fluffy; reverse cream. Asexual morph formed in culture similar to those occurring on the host substrate.

Material examined: Italy, Forlì-Cesena Province, near Meldola, on dead aerial stems of Clematis vitalba, 27 December 2015, E. Camporesi, IT 2759 (MFLU 16-0061, holotype); ex-type living culture, MFLUCC 17-2185; Belgium, Flemish Brabant, Meise Botanic Garden, Bouchout Domain, on dead stems of $C$. viticella, 13 June 2017, D. Ertz \& C. Gerstmans, BRCV6 (MFLU 17-1518, paratype); ex-paratype culture, MFLUCC 17-2160; ibid., BRCV3 (MFLU 17-1515, paratype); ex-paratype culture, MFLUCC 17-2157; on dead stems of C. serratifolia, 13 June 2017, D. Ertz \& C. Gerstmans, BRCS3 (MFLU 17-1511, paratype); ex-paratype culture, MFLUCC 17-2154.

Hosts: Clematis serratifolia, C. vitalba, C. viticella(This study).

Distribution: Belgium, Italy-(This study).

GenBank accession numbers: MFLUCC 17-2185: LSU: MT214598; SSU: MT226709; ITS: MT310642; tef1: MT394654; rpb2: MT394709. MFLUCC 17-2160: LSU: MT214599; SSU: MT226710; ITS: MT310643; tef1: MT394655; rpb2: MT394710. MFLUCC 17-2157: LSU: MT214600; SSU: MT226711; ITS: MT310644; tef1: MT394656; rpb2: MT394711. MFLUCC 17-2154: LSU: MT214601; SSU: MT226712; ITS: MT310645; tefl: MT394657; rpb2: MT394712.

Notes: Four isolates of Parathyridaria clematidis were recovered from Clematis species collected from Europe. Morphological characters such as immersed ascomata, an orange ostiolar canal, trabeculate pseudoparaphyses and fusoid ascospores matches the concept of Parathyridaria (Jaklitsch and Voglmayr 2016). Parathyridaria clematidis is similar to $P$. robiniae in having hyaline ascospores, however, $P$. robiniae has larger ascomata $(450-470 \times 255-270$ vs $182-310 \times 205-329 \mu \mathrm{m}$, Table 4$)$ with one septate ascospores (Tibpromma et al. 2017). Our four isolates of $P$. clematidis grouped together with strong statistical support (96\% ML/1.00 BYPP, Fig. 80). A comparison of the tef1 region of $P$. robiniae (MFLUCC 14-1119) with our new strains revealed seven base pair differences, therefore, we identify our isolates as a new species, Parathyridaria clematidis (Fig. 81).
Parathyridaria serratifoliae Phukhams., Ertz, Gerstmans \& K.D. Hyde, sp. nov.

Index Fungorum number: IF557208, Facesoffungi number: FoF 07348, Fig. 82.

Etymology: The species epithet refers to a species of the host species Clematis serratifolia.

Holotype: MFLU 17-1512

Saprobic on dead stems of Clematis serratifolia. Sexual morph: Ascomata 288-342 $\times 235-301 \mu \mathrm{m}$ $(\bar{x}=322 \times 265 \mu \mathrm{m}, \mathrm{n}=10)$, on the surface of the host, solitary, gregarious, immersed, orange ostioles visible, globose to depressed-globose, coriaceous, dark brown to brown, rough-walled, papillate, ostioles central. Ostioles $72-103 \times 106-142 \mu \mathrm{m}(\bar{x}=83 \times 124 \mu \mathrm{m}, \mathrm{n}=5)$, central, black to reddish brown, papillate, opening by a pore, filled with periphyses. Peridium $17-30(-50 \mu \mathrm{m}$ at apex) wide, outer layer composed of 5-7 layers of reddish brown cells of textura angularis, heavily pigmented at outer layer, the inner layer composed of 7 layers of hyaline and thin-walled cells. Hamathecium of dense, $0.9-1.5 \mu \mathrm{m}$ wide $(\bar{x}=1.3 \mu \mathrm{m}$, $\mathrm{n}=50$ ), filiform, branched, septate, trabeculate pseudoparaphyses. Asci $97-145 \times 12-19 \mu \mathrm{m}(\bar{x}=110 \times 17 \mu \mathrm{m}$, $\mathrm{n}=20$ ), 8 -spored, bitunicate, fissitunicate, broad fusiform, cylindrical-clavate, apically rounded with ocular chamber. Ascospores $20-38 \times 5-9 \mu \mathrm{m}(\bar{x}=24 \times 7 \mu \mathrm{m}, \mathrm{n}=50)$, biseriate, partially overlapping, ellipsoid to broad fusiform, sometimes inequilateral, with rounded ends, hyaline, (1-)3-septate, constricted at the septa, cell above median septum enlarged, granulate in each cell, rough-walled, with mucilaginous sheath. Asexual morph: Undetermined.

Culture characters: Colonies on MEA reaching $30 \mathrm{~mm}$ diam. after 4 weeks at $25^{\circ} \mathrm{C}$. Culture from above, cream, brown in the middle, edge white, dense, flattened, umbonate, floccose; reverse cream, thin, with flat parchment-like sheets.

Material examined: Belgium, Flemish Brabant, Meise Botanic Garden, Bouchout Domain, on dead stems of Clematis serratifolia, 13 June 2017, D. Ertz \& C. Gerstmans, BRCS4 (MFLU 17-1512, holotype); ex-type living culture, MFLUCC 17-2210.

Host: Clematis serratifolia-(This study).

Distribution: Belgium-(This study).

GenBank accession numbers: LSU: MT214602; SSU: MT226713; ITS: MT310646; tef1: MT394658; rpb2: MT394713.

Notes: In our phylogenetic analysis from LSU, ITS, tefl, and rpb2 sequence data, Parathyridaria serratifoliae formed a basal clade with $P$. clematidis and $P$. robiniae with strong support (94\% ML/1.00 BYPP, Fig. 80). Parathyridaria serratifoliae can be distinguished from $P$. clematidis and $P$. robiniae based on spore dimensions and having 3-septate ascospores (Table 4). To further support the establishment of the new taxon as per the guidelines of Jeewon and Hyde (2016), we checked the nucleotide differences. Within the 


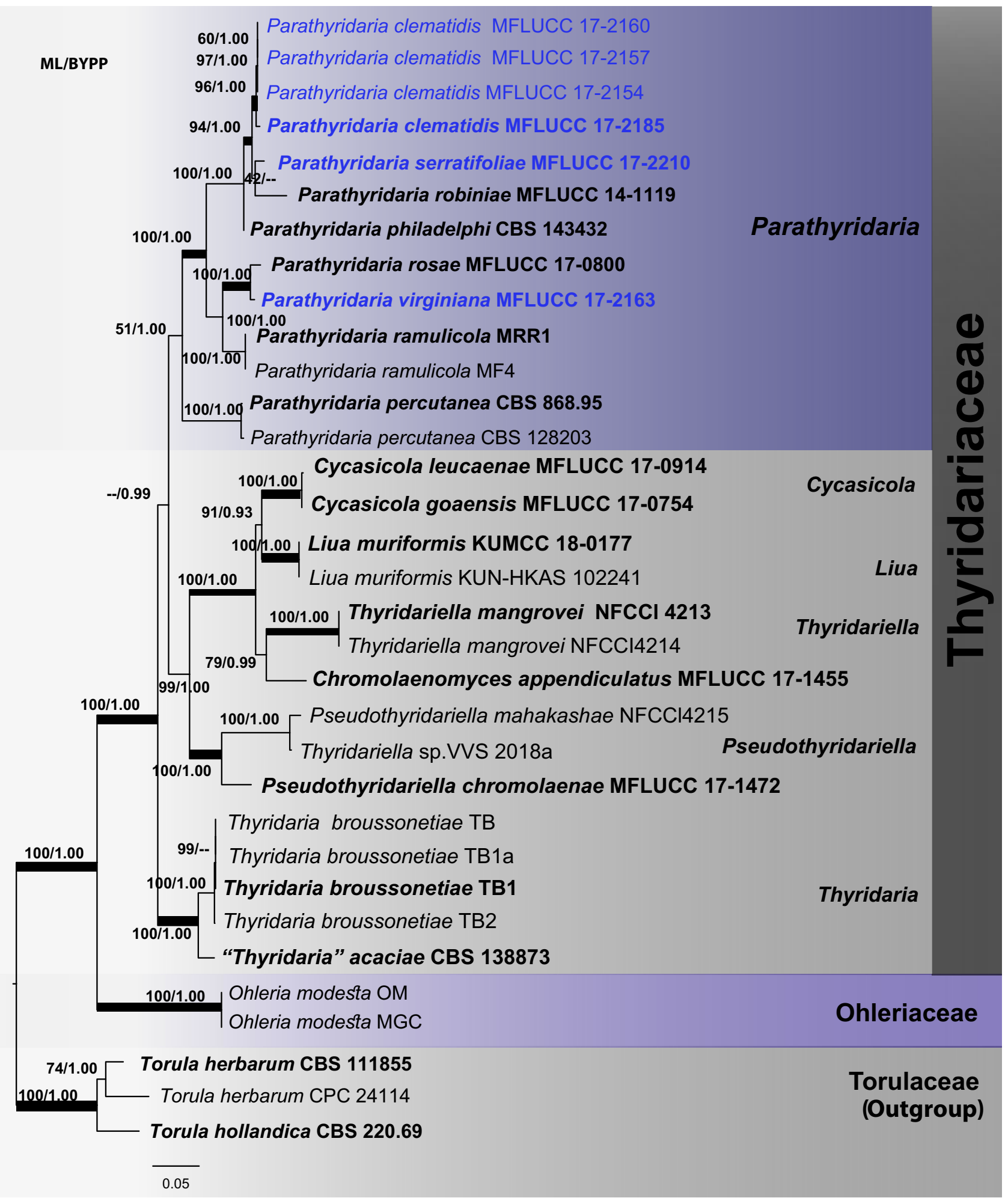

tef1 regions there were 10 base pair differences from $P$. robiniae. Therefore, $P$. serratifoliae on Clematis serratifolia is introduced as a new species (Fig. 82).
Parathyridaria virginianae Phukhams., Ertz, Gerstmans \& K.D. Hyde, sp. nov.

Index Fungorum number: IF557209; Facesoffungi number: FoF 07349, Fig. 83. 
4Fig. 80 The best scoring RAxML tree with a final likelihood value of - 16490.277529 based on combined LSU, ITS, tef1 and rpb2 sequence data for Thyridariaceae. The tree is rooted with members of the Torulaceae. Thirty-three strains were included in the combined genes sequence analyses which comprised 3466 characters (890 characters for LSU, 534 characters for ITS, 964 characters for tefl and 1078 characters for $r p b 2$, including gap regions). The topology and clade stability of the combined gene analyses was compared to the single gene analyses. The tree from the maximum likelihood analysis had similar topology to the Bayesian $50 \%$ majority-rule consensus phylogram. The matrix had 1267 distinct alignment patterns, with $27.03 \%$ of undetermined characters and gaps. Estimated base frequencies were as follows; $\mathrm{A}=0.243395, \mathrm{C}=0.269803, \mathrm{G}=0.270965$, $\mathrm{T}=0.215837$; substitution rates $\mathrm{AC}=1.430051, \mathrm{AG}=3.703624$, $\mathrm{AT}=1.723186, \quad \mathrm{CG}=1.129553, \quad \mathrm{CT}=9.368763, \quad \mathrm{GT}=1.000000$; gamma distribution shape parameter $\alpha=0.456291$. In our analysis, GTR + I + G model was used for each partition in Bayesian posterior analysis. The species determined in this study are indicated in blue. Bootstrap values (BS) greater than 50\% BS (ML, left) and Bayesian posterior probabilities (BYPP, right) greater than 0.90 are given at the nodes. Hyphens (-) represent support values less than 50\% BS/0.90 BYPP. Thick branches represent significant support values from all analyses (BS $\geq 70 \% / \mathrm{BYPP} \geq 0.95$ )

Etymology: The epithet refers to Clematis virginiana.

\section{Holotype: MFLU 17-1521}

Saprobic on dead branches of Clematis virginiana. Sexual morph: Undetermined. Asexual morph: Conidiomata 145-207×204-259 $\mu \mathrm{m}(\bar{x}=175 \times 230 \mu \mathrm{m}, \mathrm{n}=5)$, pycnidial, solitary, aggregated, uniloculate, immersed, covered by a pseudoclypeus, globose to subglobose, coriaceous, thickwalled, dark brown to brown, papillate, ostiolate. Ostioles $31 \times 50 \mu \mathrm{m}$, central. Conidiomatal wall 13-24 $\mu \mathrm{m}$ wide, outer layer composed of 5-7 layers of brown to light brown cells of textura angularis, lined with a hyaline layer bearing conidiogenous cells. Conidiophores single, short, densely aggregated, straight or flexuous, cylindrical, hyaline, erect, septate, 1-3-septate, smooth. Conidiogenous cells 4-21 $\times 2-4 \mu \mathrm{m}(\bar{x}=7 \times 3 \mu \mathrm{m}, \mathrm{n}=30)$, enteroblastic, phialidic, annellidic, hyaline, discrete, arising from the inner layer of pycnidium wall. Conidia $3-5 \times 1.8-3 \mu \mathrm{m}(\bar{x}=4 \times 2.5 \mu \mathrm{m}$, $\mathrm{n}=50$ ), oval or subglobose, slightly curved, with $1(-2)$ guttules in each cell, hyaline when immature, pale brown at maturity, aseptate, smooth-walled.

Culture characters: Colonies on MEA reaching $20 \mathrm{~mm}$ diam. after 2 weeks at $25{ }^{\circ} \mathrm{C}$. Cultures from above, white, dense, circular, umbonate, covered with white aerial mycelium; reverse yellow at the central, cream.

Material examined: Belgium, Flemish Brabant, Meise Botanic Garden, Bouchout Domain, on dead stems of Clematis virginiana L., 13 June 2017, D. Ertz \& C. Gerstmans, BRVir3 (MFLU 17-1521, holotype); ex-type living culture, MFLUCC 17-2163.

Hosts: Clematis virginiana-(This study).

Distribution: Belgium-(This study).
GenBank accession numbers: LSU: MT214603; SSU: MT226714; ITS: MT310647; tef1: MT394659; rpb2: MT394714.

Notes: According to morphology and phylogenetic analysis (Fig. 83), Parathyridaria virginianae (MFLUCC 17-2163) is closely related to P. rosae (MFLUCC 17-0800) which was collected from Rosa sp. in the USA (Wanasinghe et al. 2018). The asexual morph in Parathyridaria has pycnidia, with phialidic conidiogenous cells and ellipsoid, unicellular, hyaline to pale brown conidia (Crous et al. 2018), which resembles our collection. Parathyridaria rosae was reported as a sexual morph whilst our collection showed only the asexual morph, thus the morphology could not be compared. Pairwise comparison of ITS (including 5.8S region) region showed five base pair differences (of 534 base pairs), however, the tefl and $r p b 2$ regions are not available for comparison. Phylogenetic analyses show strong support for the two species (100\% ML/1.00 BYPP, Fig. 80), thus, we introduce a new species, $P$. virginianae.

\section{Torulaceae Corda}

Torulaceae, typified by Torula was introduced by Sturm (1829) for an asexual morph with mononematous conidiophores (Seifert et al. 2011). Placement of Torulaceae was verified in Crous et al. (2015a) with two accepted genera, Dendryphion and Torula. Subsequently, Sporidesmioides, Neotorula and Rostriconidium were introduced to the family based on modern taxonomic classification. Torulaceae currently contains five genera which are asexual morphs (Crous et al. 2015a; Hyde et al. 2016; Su et al. 2016; Tibpromma et al. 2018). In this study, a combined dataset of LSU, ITS, tef1, and $r p b 2$ sequence data was used to follow the recent treatment in Su et al. (2016), with first report of Dendryphion europaeum and Torula chromolaenae on Clematis (Fig. 84).

\section{Dendryphion Wallr.}

Dendryphion (typified with D. comosum) is commonly associated with dead stems of herbaceous plants and decaying wood, but also recorded from freshwater (Ellis 1971; Su et al. 2016). The genus is distinguishable from other members in Torulaceae in having apically branched, polytretic or enteroblastic conidiophores with dark pores, septate, brown conidia in chains with bud scars (Seifert et al. 2011; Crous et al. 2014a; Su et al. 2016). Based on morphological characters and phylogenetic results, we report the first record of Dendryphion europaeum on Clematis species (Fig. 85).

Dendryphion europaeum Crous \& R.K. Schumacher, in Persoonia 32: 243 (2014), new host records

Index Fungorum number: IF808927; Facesoffungi number: FoF 07346, Fig. 85. 

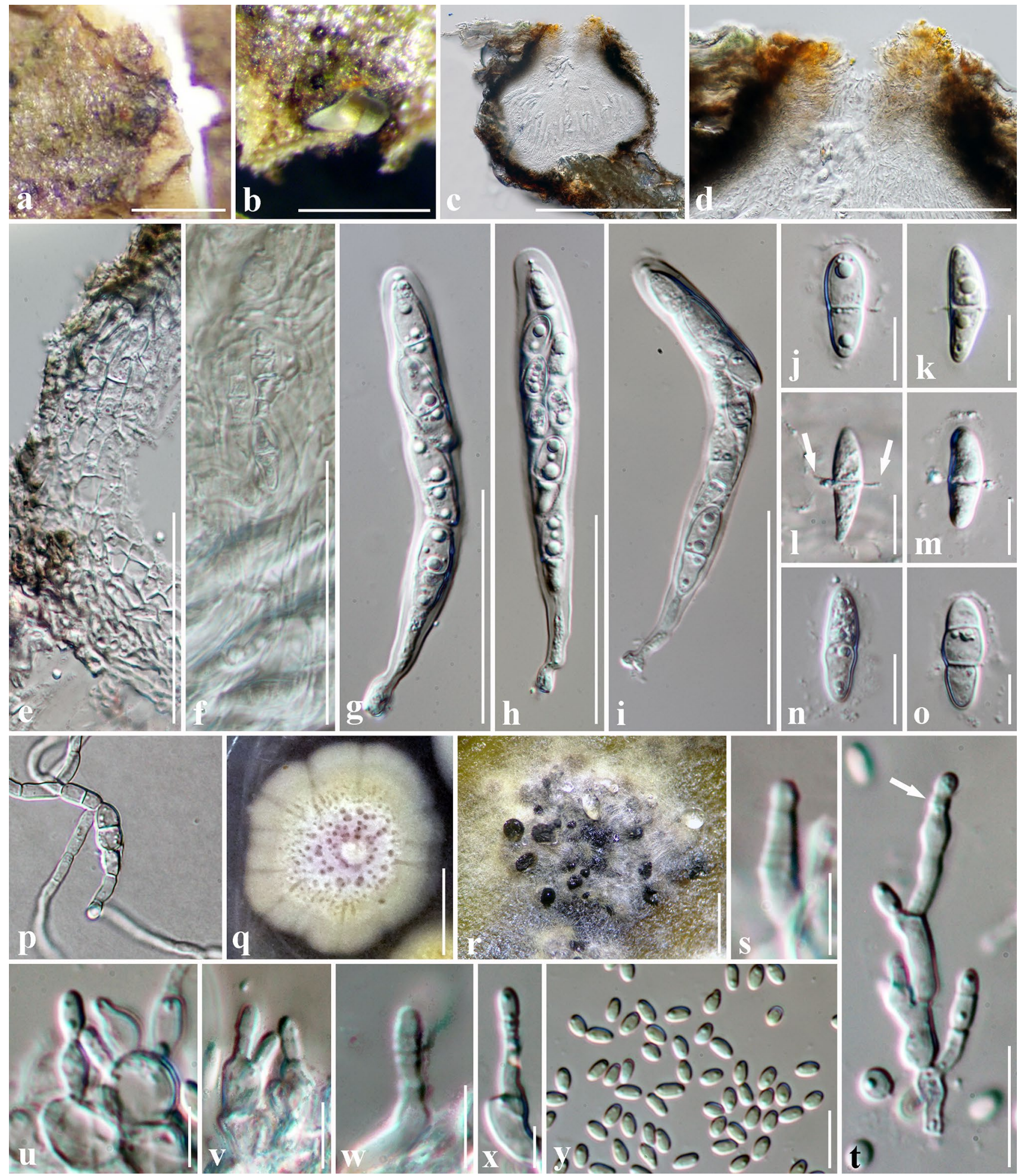

Fig. 81 Parathyridaria clematidis (MFLU 16-0061, holotype). a, b Appearance of ascomata on Clematis vitalba. c Vertical section through ascoma. d Ostiolar canal. e Section of peridium. f Trabeculate pseudoparaphyses. g-i Asci. j-o Ascospores (i Arrow indicated mucilaginous sheath). p Germinated ascospore. q Culture character- istics on MEA. $\mathbf{r}$ Conidiomata forming on agar on rice straw media after 8 weeks. $\mathbf{s}-\mathbf{x}$ Conidiogenous cells and developing conidia (t Conidiogenous cells). y Conidia. Scale bars: $\mathbf{a}, \mathbf{b}, \mathbf{r}=500 \mu \mathrm{m}$, $\mathbf{c}=200 \mu \mathrm{m}, \mathbf{d}=100 \mu \mathrm{m}, \mathbf{e}-\mathbf{i}=50 \mu \mathrm{m}, \mathbf{j}-\mathbf{o}, \mathbf{t}=10 \mu \mathrm{m}, \mathbf{s}, \mathbf{u}-\mathbf{y}=5 \mu \mathrm{m}$, $\mathbf{q}=10 \mathrm{~cm}$ 
Table 4 Synopsis of sexual morph of Parathyridaria species

\begin{tabular}{|c|c|c|c|c|c|c|c|}
\hline \multirow[t]{2}{*}{ Species } & \multirow[t]{2}{*}{ Ascomata $(\mu \mathrm{m})$} & \multirow[t]{2}{*}{ Asci $(\mu \mathrm{m})$} & \multicolumn{3}{|l|}{ Ascospores } & \multirow[t]{2}{*}{ Host } & \multirow[t]{2}{*}{ References } \\
\hline & & & Size $(\mu \mathrm{m})$ & Septa & Colour & & \\
\hline $\begin{array}{l}\text { Parathyridaria } \\
\text { clematidis } \\
\text { MFLUCC } \\
17-2185\end{array}$ & $\begin{array}{l}182-310 \times 205- \\
329\end{array}$ & $77-112 \times 12-15$ & $16-24 \times 5-8$ & $1(-2)$ & Hyaline & Clematis sp. & This study \\
\hline $\begin{array}{l}\text { P. serratifoliae } \\
\text { MFLUCC } \\
17-2210\end{array}$ & $\begin{array}{l}288-342 \times 235- \\
\quad 301\end{array}$ & $97-145 \times 12-19$ & $20-38 \times 5-9$ & $(1-) 3$ & Hyaline & $\begin{array}{l}\text { Clematis ser- } \\
\text { ratifolia }\end{array}$ & This study \\
\hline $\begin{array}{l}P . \text { ramulicola } \\
\text { MRR1 }\end{array}$ & $\begin{array}{l}(200-) 260-400(- \\
460) \times(200- \\
) 210-335(- \\
375)\end{array}$ & $\begin{array}{l}(67-) 75-89(- \\
96) \times 10.0-11.7\end{array}$ & $\begin{array}{l}14.0-16.2(- \\
19.5) \times 4.8- \\
5.6\end{array}$ & $\begin{array}{l}3(-4) \text { trans- } \\
\text { verse, some- } \\
\text { times 1-vertical }\end{array}$ & Brown & $\begin{array}{l}\text { Ribes rubrum } \\
\text { and Sambucus } \\
\text { nigra }\end{array}$ & $\begin{array}{l}\text { Jaklitsch and } \\
\text { Voglmayer } \\
(2016)\end{array}$ \\
\hline $\begin{array}{l}\text { P. robiniae } \\
\text { MFLUCC } \\
14-1119\end{array}$ & $\begin{array}{l}450-470 \times 255- \\
270\end{array}$ & $105-115 \times 10-15$ & $15-20 \times 4-7$ & 1 & Hyaline & $\begin{array}{l}\text { Robinia pseu- } \\
\text { dacacia }\end{array}$ & $\begin{array}{l}\text { Tibpromma et al. } \\
\text { (2017) }\end{array}$ \\
\hline $\begin{array}{l}\text { P. rosae } \\
\text { MFLUCC } \\
17-0800\end{array}$ & $\begin{array}{l}300-400 \times 150- \\
200\end{array}$ & $80-100 \times 12.5-16$ & $18-24 \times 6-8$ & 1 & Pale brown & Rosa sp. & $\begin{array}{l}\text { Wanasinghe et al. } \\
\text { (2018) }\end{array}$ \\
\hline
\end{tabular}

Saprobic on dead stems of Clematis species. Sexual morph: Undetermined. Asexual morph: Colonies on the natural substrate effused, scattered, hairy, dark brown. Mycelium semi-immersed to superficial, composed of pale brown, septate hyphae. Conidiophores 198-310×9-19.6 $\mu \mathrm{m}$ $(\bar{x}=240 \times 13 \mu \mathrm{m}, \mathrm{n}=20)$, macronematous, mononematous, single or in groups of $2-4$, branched at the apex, stipes straight or flexuous, subcylindrical to cylindrical, erect, septate, smooth, dark brown to reddish brown, 10-19-septate, with 3-5 primary branches, irregularly branched at the upper parts, brown, smooth or verruculose. Conidiogenous cells $10-16 \times 6-7 \mu \mathrm{m}(\bar{x}=15 \times 6 \mu \mathrm{m}, \mathrm{n}=20)$, monotretic or polytretic, integrated, terminal on conidiophores, doliiform to oblong, pale brown. Conidia $14-26(-28) \times 2.5-8 \mu \mathrm{m}(\bar{x}$ $=26 \times 7 \mu \mathrm{m}, \mathrm{n}=20$ ), phragmosporous, in branched chains, acrogenous, cylindrical to oblong, 2-5 septa, deeply constricted at septa, dark brown to reddish brown, verrucose, rounded ends, bud scars or disjunctors present at the site of attachment, easily separating.

Culture characters: Colonies on MEA reaching $30 \mathrm{~mm}$ diam. after 2 weeks at $25^{\circ} \mathrm{C}$. Cultures from above, cream to orangish-white, medium, circular, umbonate, fluffy, slightly radiating outwardly, reverse dark brown at the centre, cream, radiating outwardly.

Material examined: Belgium, Flemish Brabant, Meise Botanic Garden, Bouchout Domain, on dead stems of Clematis virginiana, 13 June 2017, D. Ertz \& C. Gerstmans, BRCVir2 (MFLU 17-1520); living culture, MFLUCC 17-2162; UK, Botley wood, Hampshire, on dead stems of C. vitalba, 16 April 2016, E.B.G. Jones, GJ 265 (MFLU 17-1462); living culture, MFLUCC 16-1003.
Hosts: Clematis virginiana, C. vitalba, Hedera helix, Heracleum sphondylium -(Crous et al. 2014a; this study).

Distribution: Belgium Germany, Netherlands, UK (England)—(Crous et al. 2014a; this study).

GenBank accession numbers: MFLUCC 17-2162: LSU: MT214604; SSU: MT226715; ITS: MT310648; tef1: MT394660; rpb2: MT394715. MFLUCC 16-1003: LSU: MT214605; SSU: MT226716; ITS: MT310649; tefl: MT394661.

Notes: Dendryphion europaeum was described by Crous et al. (2014a) from Hedera helix (Araliaceae) and Heracleum sphondylium (Apiaceae). A phylogram generated from multi-locus phylogeny analysis of our collections on Clematis is shown in Fig. 84. Isolates MFLUCC 16-1003 and MFLUCC 17-2162 formed a strongly supported clade with the ex-type strain of D. europaeum (92\% ML/1.00 BYPP). Based on morphological and geological comparisons, our isolates are identical to those reported by Crous et al. (2014a). A pairwise comparison of the ITS region of MFLUCC 16-1003 showed two nucleotide difference from the other isolates that clustered in the same clade (2/497 base pairs, $0.4 \%$ ). According to the recommendation for new taxon establishment proposed by Jeewon and Hyde (2016), this is regarded as not statistically significant. Therefore, we name our new isolates as new host records (Fig. 85).

\section{Torula Pers.}

Torula is typified by $T$. herbarum ( $=$ T. monilis) ( $\mathrm{Scott}$ et al. 2007). Torula species are characterized by asexual morph characters having monoblastic or polyblastic, intact or cupulate conidiogenous cells, and acropetal chains of dark phragmoconidia (Persoon 1795; Scott et al. 2007). More 


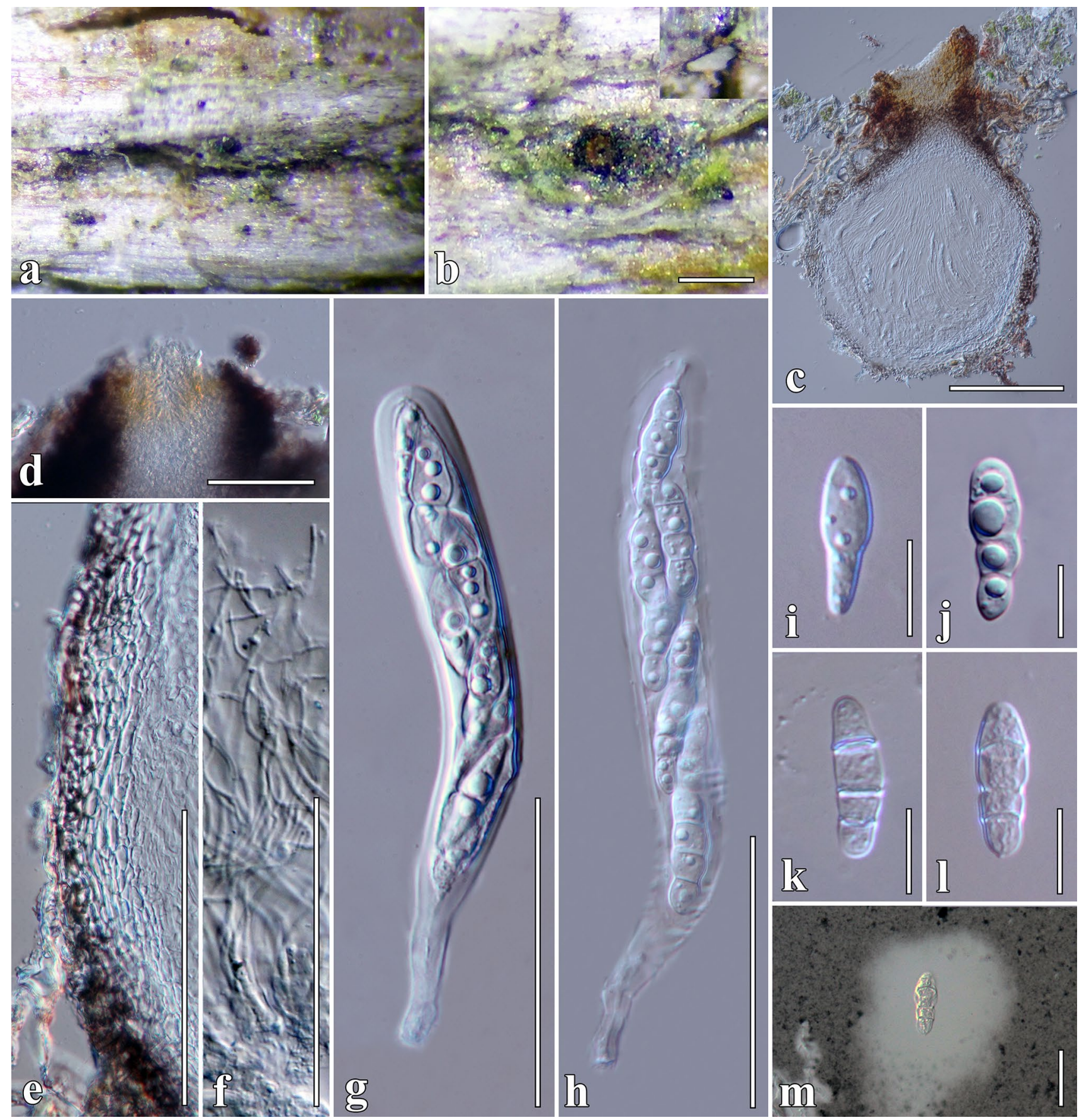

Fig. 82 Parathyridaria serratifoliae (MFLU 17-1512, holotype). a, b Appearance of ascomata on Clematis serratifolia. c Vertical section through ascoma. d Ostiolar canal. e Section of peridium. f Trabec-

than 500 epithets are listed in Index Fungorum (2020). We report $T$. chromolaenae from Clematis fulvicoma in Thailand (Fig. 86).

Torula chromolaenae Li, Phookamsak, Mapook \& K.D. Hyde, in Mycological Progress 16 (4): 454 (2017), new host record ulate pseudoparaphyses. g, h Asci. i-l Ascospores. m Ascospore in $10 \%$ Indian ink. Scale bars: $\mathbf{b}, \mathbf{c}=100 \mu \mathrm{m}, \mathbf{d}-\mathbf{h}=50 \mu \mathrm{m}, \mathbf{i}-\mathbf{l}=10 \mu \mathrm{m}$, $\mathbf{m}=20 \mu \mathrm{m}$

Index Fungorum number: IF819536; Facesoffungi number: FOF 02713, Fig. 86.

Saprobic on dried stems of Clematis fulvicoma. Sexual morph: Undetermined. Asexual morph: Colonies on the natural substrate effuse, scattered, hairy, powdery, dark brown to black. Mycelium $1.7 \mu \mathrm{m}$ wide, immersed to superficial, initially hyaline, later pale brown, septate, branched 

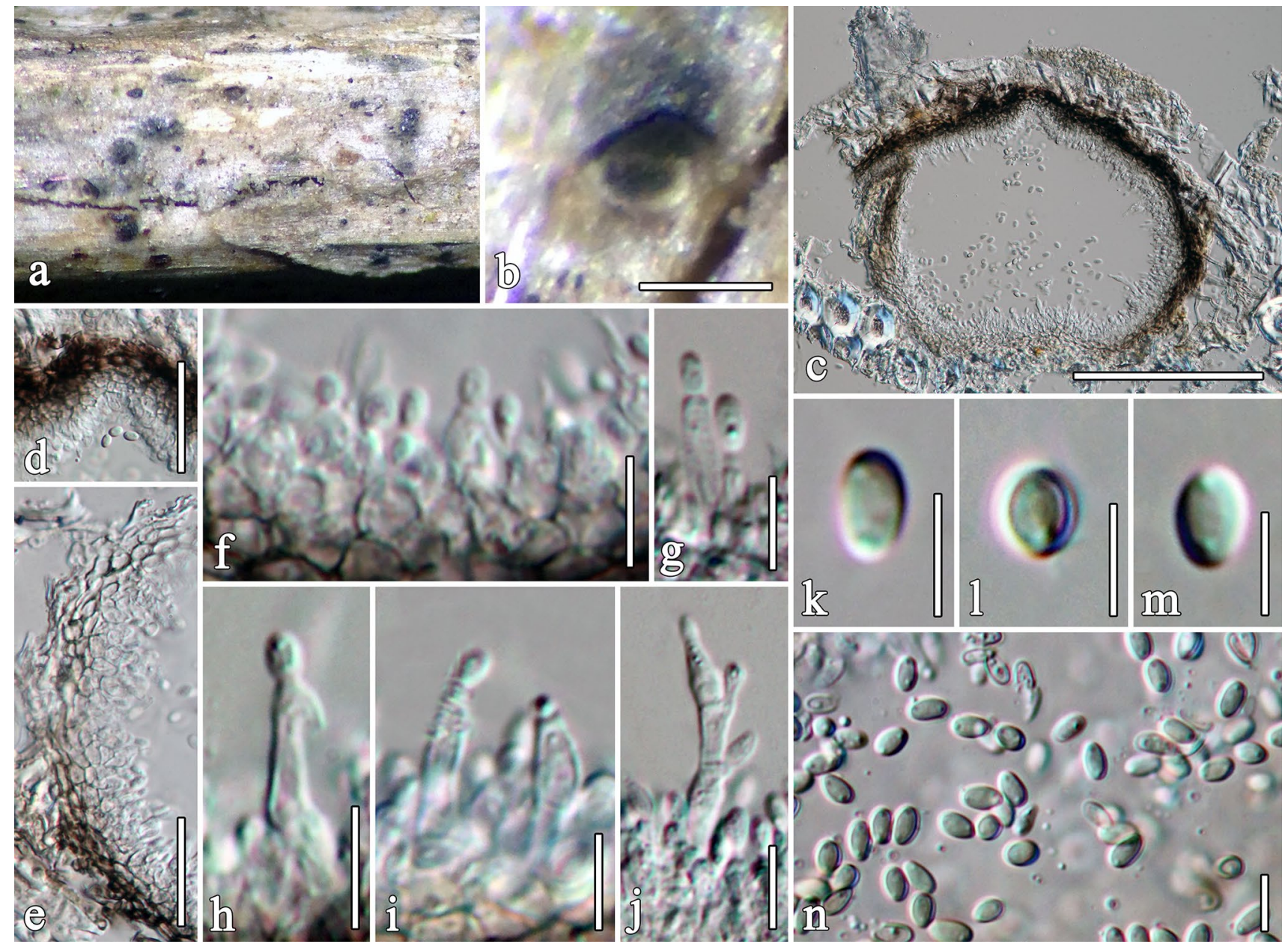

Fig. 83 Parathyridaria virginianae (MFLU 17-1521, holotype). a Appearance of conidiomata on Clematis virginiana. b Close up of conidioma on host substrate. $\mathbf{c}$ Vertical section through conidioma. d

hyphae. Conidiophores up to $5 \mu \mathrm{m}$ long, micronematous, reduced to conidiogenous cells, with hyaline to pale brown ampulliform supporting cell. Conidiogenous cells $1.15-4 \times 1.5-2 \mu \mathrm{m}(\bar{x}=2.5 \times 2.3 \mu \mathrm{m}, \mathrm{n}=20)$ diam., mono to polyblastic, solitary, cylindrical, integrated, terminal on conidiophores, hyaline to pale brown. Conidia 9.5-14×4-6.5 $\mu \mathrm{m}(\bar{x}=11 \times 5 \mu \mathrm{m}, \mathrm{n}=50)$, phragmosporous, in short branched chains, acrogenous, dry, cylindrical, 2-3-septate, deeply constricted at septa, brown to reddish brown, verrucose, rounded at both ends, bud scars or disjunctors present at the site of attachment, easily separating into segments.

Culture characters: Colonies on MEA reaching $30 \mathrm{~mm}$ diam. after 4 weeks at $25{ }^{\circ} \mathrm{C}$. Cultures from above, olive brown at the centre, faintly zonate edge, fluffy, grey, dense, lobate, raised with concave edge, convex surface, downy, brown radiating to the media; reverse dark brown at the centre, burnt umber radiating outwardly.
Ostiolar canal. e Section of conidioma wall. $\mathbf{f}-\mathbf{j}$ Conidiogenous cells and conidia. $\mathbf{k}-\mathbf{n}$ Conidia. Scale bars: $\mathbf{b}=200 \mu \mathrm{m}, \mathbf{c}=100 \mu \mathrm{m}, \mathbf{d}$, $\mathbf{e}=20 \mu \mathrm{m}, \mathbf{f}-\mathbf{n}=5 \mu \mathrm{m}$

Material examined: Thailand, Nan Province, on dead stems of Clematis fulvicoma, 20 March 2017, C. Phukhamsakda, CMTH23 (MFLU 17-1486); living culture, MFLUCC 17-2078.

Hosts: Chromolaena odorata, Clematis fulvicoma, Pandanus tectorius-(Li et al. 2017; Tibpromma et al. 2018; this study).

Distribution: China, Thailand-(Li et al. 2017; Tibpromma et al. 2018; this study).

GenBank accession numbers: LSU: MT214606; SSU: MT226717; ITS: MT310650; tef1: MT394662; rpb2: MT394716.

Notes: Torula chromolaenae was described from Chromolaena odorata collected from Thailand ( $\mathrm{Li}$ et al. 2017). Subsequently, Tibpromma et al. (2018) recorded the species from Pandanus tectorius in China. Based on the phylogenetic analyses (Fig. 84), isolate MFLUCC 17-2078 formed a strongly supported clade with $T$. chromolaenae KUMCC 16-0036 and KMUCC 17-0174. Our collection is similar 


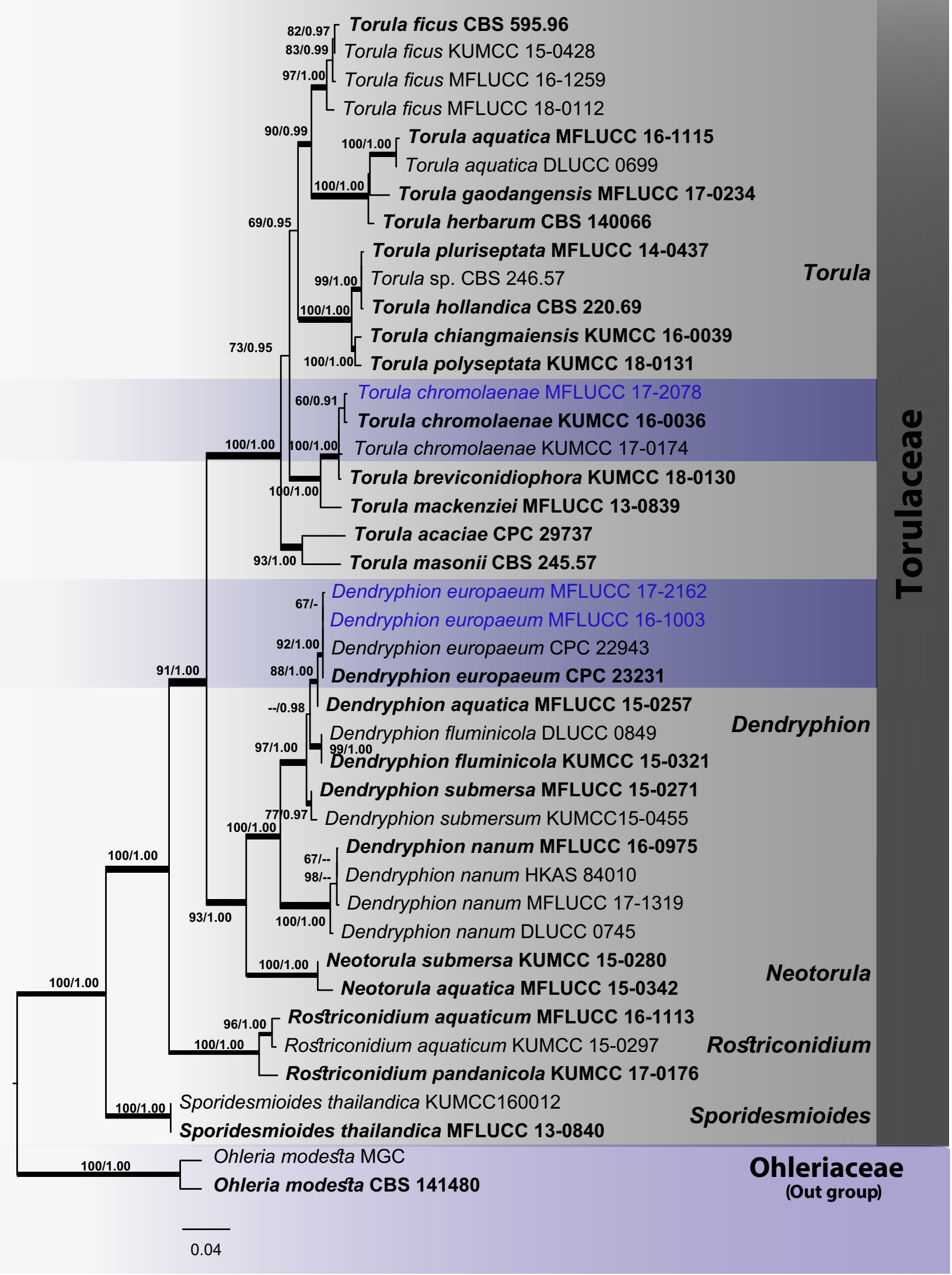


4Fig. 84 The best scoring RAxML tree with a final likelihood value of - 12765.550785 based on combined LSU, ITS, tef1 and rpb2 sequence data for Torulaceae. The topology and clade stability of the combined gene analyses was compared with the single gene analyses. The tree is rooted with members of the Ohleriaceae. Fourty-two strains were included in the combined genes sequence analyses which comprised 3000 characters (808 characters for LSU, 497 characters for ITS, 854 characters for tefl and 841 characters for $r p b 2$, including gap regions). The tree from the maximum likelihood analysis had similar topology to the Bayesian 50\% majority-rule consensus phylogram. The matrix had 907 distinct alignment patterns, with $29.34 \%$ of undetermined characters and gaps. Estimated base frequencies were as follows; $\mathrm{A}=0.240459, \mathrm{C}=0.270154, \mathrm{G}=0.275197, \mathrm{~T}=0.214190$; substitution rates $\mathrm{AC}=2.096044, \mathrm{AG}=4.720144, \mathrm{AT}=2.201665$, $\mathrm{CG}=1.169889, \mathrm{CT}=12.100709, \mathrm{GT}=1.000000$; gamma distribution shape parameter $\alpha=0.542434$. In our analysis, GTR $+\mathrm{I}+\mathrm{G}$ model was used for each partition in Bayesian posterior analysis. The species determined in this study are indicated in blue. Bootstrap values (BS) greater than 50\% BS (ML, left) and Bayesian posterior probabilities (BYPP, right) greater than 0.90 are given at the nodes. Hyphens (-) represent support values less than 50\% BS/0.90 BYPP. Thick branches represent significant support values from all analyses $(\mathrm{BS} \geq 70 \% / \mathrm{BYPP} \geq 0.95)$

to the type species of $T$. chromolaenae (KUMCC 16-0036) but differ in size of the conidia $(23 \times 8$ vs $11 \times 5 \mu \mathrm{m})(\mathrm{Tib}-$ promma et al. 2018). A pairwise comparison of DNA sequences of ITS and tefl regions of our isolate (MFLUCC 17-2078) with T. chromolaenae strains (KUMCC 16-0036 and KMUCC 17-0174) do not show significant differences. Therefore, we name our collection as a new host record.

Isolate MFLUCC 17-2078 was further evaluated for bioactive secondary metabolite production. The strain inhibited Bacillus subtillis and partially inhibited conidia production of Mucor plumbeus, but did not reach significant values (data not shown).

Dothideomycetes, family incertae sedis

Dyfrolomycetales Pang, Hyde \& E.B.G. Jones

We follow the treatment by Hyde et al. (2013) and Wijayawardene et al. (2017).

\section{Pleurotremataceae Watson}

Pleurotremataceae was introduced for Pleurotrema polysemum, a species lacking fissitunicate dehiscence asci in Sordariomycetes (Watson 1929; Barr 1994). The isotype specimens of $P$. polysemum were re-examined by Maharachchikumbura et al. (2016). Based on morphological evidence, $P$. polysemum has similar characters with species of Saccardoella and Dyfrolomyces in Dyfrolomycetaceae (Dothideomycetes). Subsequently, $P$. polysemum was excluded from Sordariomycetes and transferred to Dyfrolomycetaceae (Dothideomycetes). Dyfrolomycetaceae is currently synonymized under Pleurotremataceae (Maharachchikumbura et al. 2016). Three genera accepted in Pleurotremataceae are Dyfrolomyces, Melomastia and Pleurotrema (Wijayawardene et al. 2017).
Melomastia Nitschke ex Sacc.

Norphanphoun et al. (2017) verified the phylogenetic placement of Melomastia. Melomastia is accommodated in Pleurotremataceae with more than 30 epithets recorded in Index Fungorum (2020). Based on combined LSU, SSU and tefl sequence data (Fig. 87), we introduce two novel species, M. clematidis and M. fulvicoma, from Clematis species in Thailand.

Melomastia clematidis Phukhams., \& K.D. Hyde, sp. nov. Index Fungorum number: IF557210; Facesoffungi number: FoF 07334, Fig. 88.

Etymology: Refers to the host genus, Clematis.

Holotype: MFLU 17-1500

Saprobic on dead stems of Clematis sikkimensis. Sexual morph: Ascomata 300-510 $\times 260-445 \mu \mathrm{m}$ $(\bar{x}=420 \times 400 \mu \mathrm{m}, \mathrm{n}=10)$, only ostioles visible at the surface of host, solitary, gregarious, semi-immersed to immersed, globose to compressed globose, carbonaceous, dark brown to black, rough-walled, ostiolate. Ostioles 80-160×90-116 $\mu \mathrm{m}$, central, oblong, carbonaceous, dark brown to black, papillate, periphyses filling the ostiolar canal. Peridium 24-50(-90 at apex) $\mu \mathrm{m}$ wide, outer layer carbonaceous, composed of 10-15 layers of dark brown cells of textura prismatica mixed with cells of textura angularis, inner layer comprising thin hyaline layers. Hamathecium composed of numerous, dense, $1.9-3 \mu \mathrm{m}(\bar{x}=2.5 \mu \mathrm{m}$, $\mathrm{n}=40$ ), filiform, unbranched, septate, cellular pseudoparaphyses. Asci $115-160 \times 4-7 \mu \mathrm{m}(\bar{x}=140 \times 6 \mu \mathrm{m}, \mathrm{n}=20)$, 8 -spored, bitunicate, broad filiform, apically rounded with simple and short pedicel, ocular chamber visible. Ascospores $13-20 \times 3.8-5 \mu \mathrm{m}(\bar{x}=15 \times 4.7 \mu \mathrm{m}, \mathrm{n}=50)$, uniseriate, partially overlapping, broad fusiform with acute ends, hyaline, 3-septate,constricted at septa, guttulate, smooth-walled, with thin mucilaginous sheath. Asexual morph: Undetermined.

Culture characters: Colonies on MEA reaching $30 \mathrm{~mm}$ diam. after 4 weeks at $25^{\circ} \mathrm{C}$. Culture from above, white, radiating outwardly, with yellow ring in the middle, oil droplets produced in the cultures, medium dense, circular, umbonate, dull, edge erose, downy, covered with fluffy cream mycelium; reverse brown in the middle with orange ring, dark yellow, radiating outwardly.

Material examined: Thailand, Chiang Rai Province, on dead branches of Clematis sikkimensis, 24 June 2017, C. Phukhamsakda \& M. van de Bult, CMTHDT09 (MFLU 17-1500, holotype); ex-type living culture, MFLUCC 17-2092.

Host: Clematis sikkimensis-(This study).

Distribution: Thailand-(This study).

GenBank accession numbers: LSU: MT214607; SSU: MT226718; ITS: MT310651; tef1: MT394663.

Notes: In the phylogenetic analysis (Fig. 87), Melomastia clematidis formed a close relationship with $M$. fulvicoma 

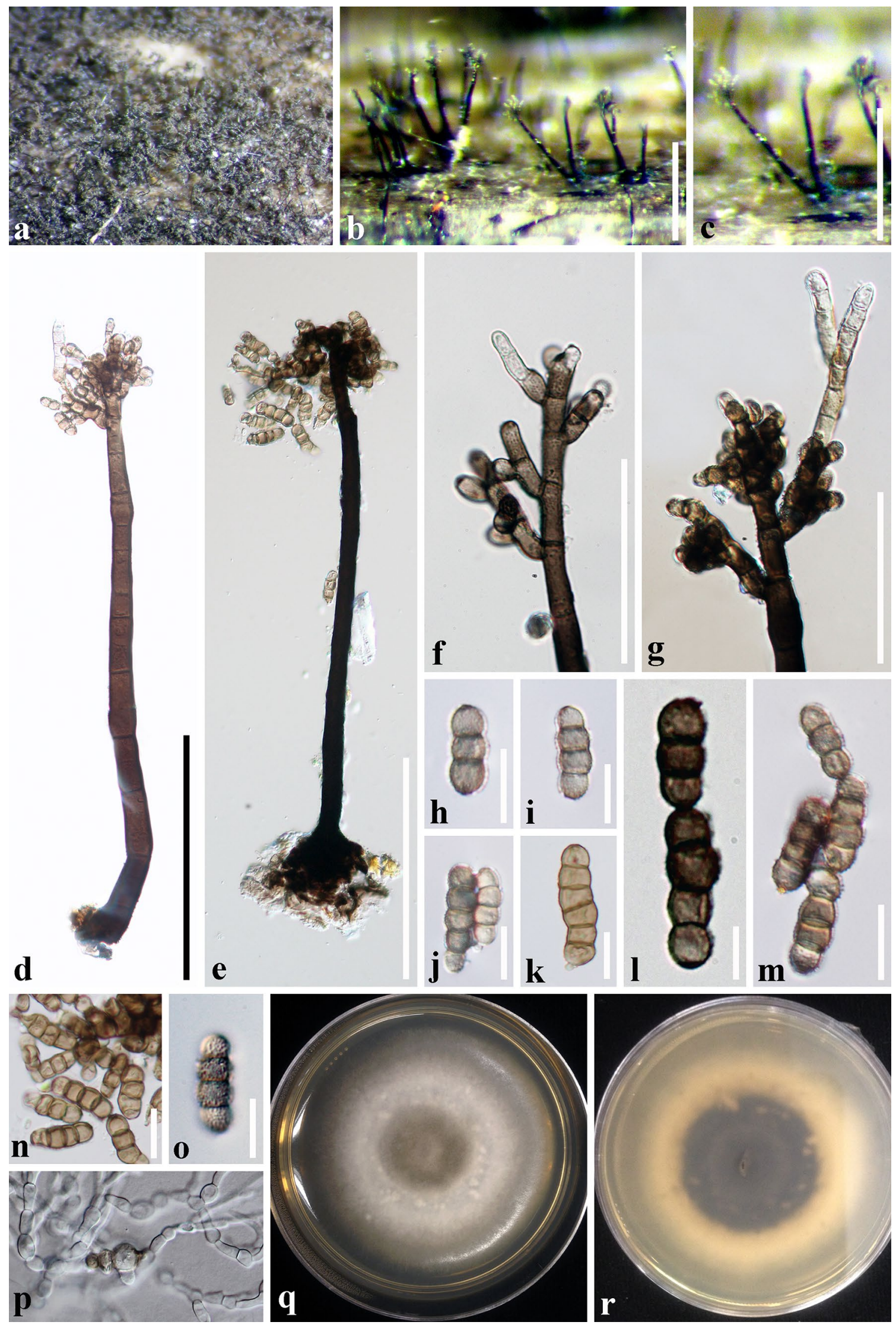
४Fig. 85 Dendryphion europaeum (MFLU 17-1520). a-c Appearance of conidiophores on Clematis. d, e Mononematous conidiophore. f, g Conidiogenous cells and conidia. h-o Conidia. p Germinated conidia. q, $\mathbf{r}$ Culture characters on MEA. Scale bars: b, $\mathbf{c}=200 \mu \mathrm{m}, \mathbf{d}, \mathbf{e}=100 \mu \mathrm{m}, \mathbf{f}, \mathbf{g}=50 \mu \mathrm{m}, \mathbf{h}-\mathbf{o}=10 \mu \mathrm{m}$

(MFLUCC 17-2083), M. italica (MFLUCC 15-0160) and M. maolanensis (GZCC 16-0102). Morphologically, our collection matched with the generic concept of Melomastia in having large ascomata with cylindrical, bitunicate asci and hyaline, symmetrical and septate ascospores (Pang et al. 2013). Our collection is distinct in having large ascomata with 3-septate ascospores. In a BLASTn search of GenBank, the closest match for the LSU region of strain MFLUCC 17-2092 is D. thailandica (MFLUCC 15-0945) with $96.79 \%$ similarity (NG_059714). The closest match for the tefl region is M. maolanensis strain GZCC 16-0102 with $93.74 \%$ similarity (KY814762). Therefore, we introduce $M$. clematidis as a new species.

Melomastia clematidis strain MFLUCC 17-2083 was evaluated for secondary metabolite production. However, the isolate did not show inhibitory activity against the tested strains.

Melomastia fulvicomae Phukhams., \& K.D. Hyde, sp. nov.

Index Fungorum number: IF557211; Facesoffungi number: FoF 07335, Fig. 89.Etymology: The epithet refers to the species of the host substrate, Clematis fulvicoma.

Holotype: MFLU 17-1491

Saprobic on dead stems of Clematis fulvicoma. Sexual morph: Ascomata $275-375 \times 130-250 \mu \mathrm{m}$ diam. $(\bar{x}=310 \times 185 \mu \mathrm{m}, \mathrm{n}=5)$, only ostioles visible on the surface of host, solitary, gregarious, semi-immersed, globose, subcarbonaceous, black to rust brown, rough-walled, ostiolate. Ostioles $140-180 \times 90-110 \mu \mathrm{m}$, central, oblong, carbonaceous, dark brown to black, papillate, periphyses filling ostiole. Peridium $15-30(-40 \mu \mathrm{m}$ at apex $)$ wide, outer layer composed of 5-7 layers of black cells of textura prismatica, the inner layer comprised of hyaline cells and thin. Hamathecium composed of numerous, $1.5-2.5 \mu \mathrm{m}(\bar{x}=2 \mu \mathrm{m}, \mathrm{n}=40)$, dense, filiform, unbranched, septate, cellular pseudoparaphyses. Asci 70-90 $\times 4-6 \mu \mathrm{m}(\bar{x}=85 \times 5 \mu \mathrm{m}, \mathrm{n}=30), 8$-spored, bitunicate, cylindrical, apically rounded, with simple and short pedicel, ocular chamber visible when young. Ascospores 9-15 $\times 3.5-5.5 \mu \mathrm{m}(\bar{x}=13 \times 4 \mu \mathrm{m}, \mathrm{n}=50)$, uniseriate, partial overlapping, broad fusiform with rounded ends, ends acute, hyaline, 2-3-septate, constricted at the septa, with guttules in each cell, smooth-walled with mucilaginous sheath. Asexual morph: Undetermined.

Culture characters: Colonies on MEA reaching $30 \mathrm{~mm}$ diam. after 4 weeks at $25^{\circ} \mathrm{C}$. Culture from above, yellowish radiating outwardly, with yellow ring in the middle, medium dense, circular in shape, umbonate, dull, edge erose, downy, covered with fairly cream mycelium; reverse: brown in the middle with orange ring, dark yellow radiating outwardly.

Material examined: Thailand, Chiang Rai Province, on dead branches of Clematis fulvicoma, 20 March 2017, C. Phukhamsakda, CMTH29 (MFLU 17-1491, holotype); extype living culture, MFLUCC 17-2083.

Hosts: Clematis fulvicoma-(This study).

Distribution: Thailand-(This study).

GenBank accession numbers: LSU: MT214608; SSU: MT226719; ITS: MT310652; tef1: MT394664.

Notes: Melomastia fulvicomae (MFLUCC 17-2146) was associated with Clematis fulvicoma in Thailand. Melomastia fulvicomae can be distinguished from $M$. clematidis by its smaller ascomata $(310 \times 185$ vs $420 \times 400 \mu \mathrm{m})$ and asci $(85 \times 5$ vs $140 \times 6 \mu \mathrm{m})$. The ascospores of $M$. fulvicomae are 2-septate, while those of $M$. clematidis are 3-septate (Fig. 89). Multi-gene analysis showed that M. fulvicoma (MFLUCC 17-2083) clustered with other Melomastia species with moderate statistical support (67\% ML/1.00 BYPP, Fig. 87).

The new strain was evaluated for secondary metabolite production with Bacillus subtillis, Escherichia coli, Mucor plumbeus and Schizosaccharomyces pombe. Isolate MFLUCC 17-2083 had moderate growth inhibitory activity against Bacillus subtillis and partial development inhibition against Mucor plumbeus. This strain is a suitable candidate for further evaluation.

Class Lecanoromycetes Erikss. \& K. Winka

Subclass Ostropomycetidae Reeb, Lutzoni \& Cl. Roux Ostropales Nannf.

Taxa of Ostropales are highly diverse and contain lichenized, lichenicolous and non-lichenized clades of fungi. Ascomata are apothecial or perithecial (Nannfeldt 1932; Lumbsch et al. 2007).

\section{Stictidaceae Fr. [as 'Stictei']}

Taxa of Stictidaceae are parasitic, lichenized or lichenicolous and characterized by crustose thalli with chlorococcoid photobionts, apothecial ascomata or perithecia, filiform unbranched paraphyses, J-, cylindrical asci and ellipsoid to filiform ascospores and, sometimes formed by fragmentation (Crous et al. 2017).

\section{Fitzroyomyces Crous}

Fitzroyomyces is a monotypic genus (Fig. 90). To date, sexual morphs have not been recorded, however, we found the sexual morph on Clematis. Asexual morphs are characterised by pycnidial conidiomata (Crous et al. 2017).

Fitzroyomyces cyperacearum Crous, Persoonia 39:389 (2017), new host record 

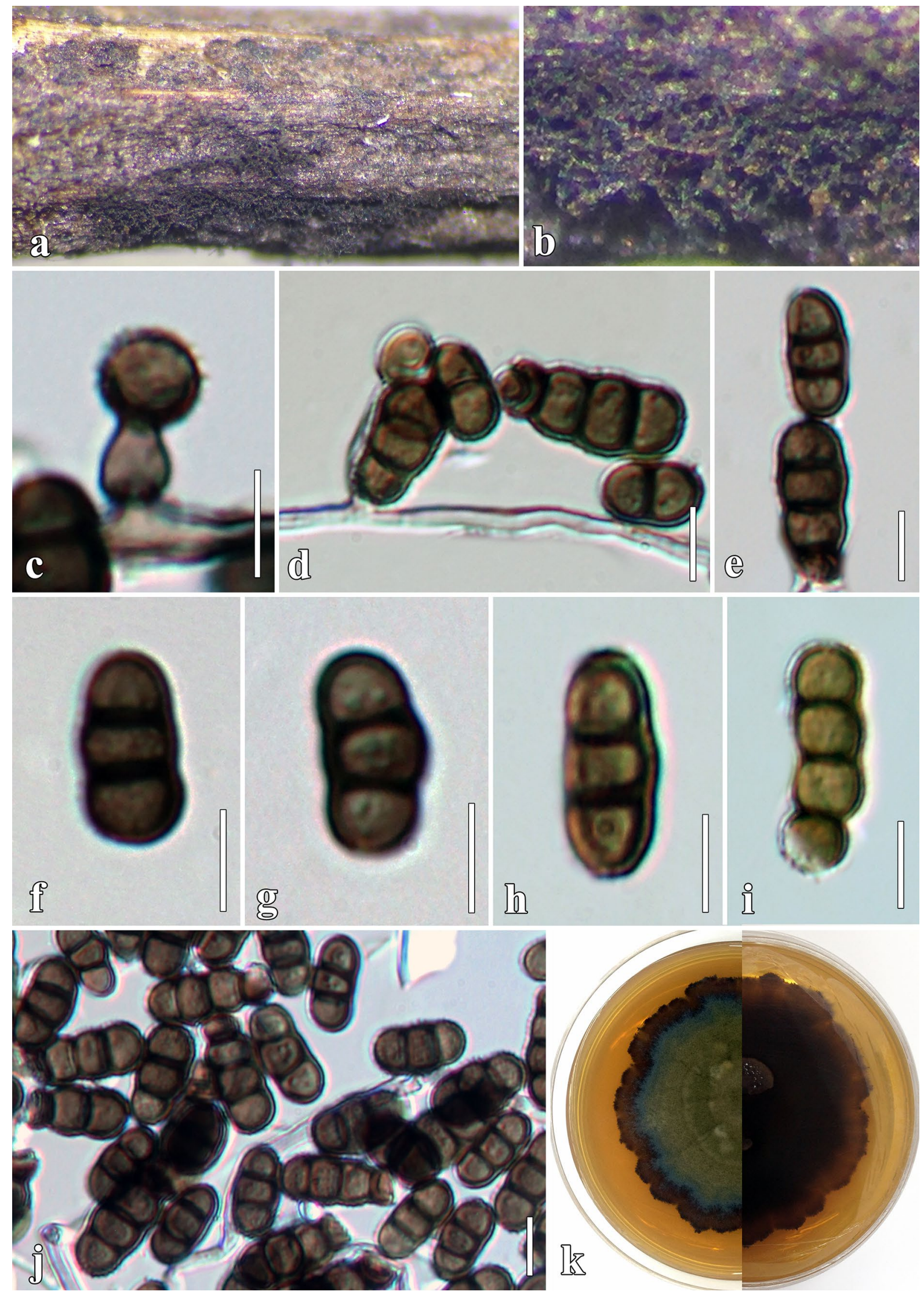
4Fig. 86 Torula chromolaenae (MFLU 17-1486). a, b Appearance of conidiophores on Clematis fulvicoma. c, d Conidiophores and conidia attached to conidiogenous cells. $\mathbf{e}-\mathbf{j}$ Conidia. $\mathbf{k}$ Culture characters on MEA. Scale bars: $\mathbf{c}-\mathbf{j}=5 \mu \mathrm{m}$

Index Fungorum number: IF 823923; Facesoffungi number: FoF 05807, Fig. 91.

Saprobic on dead stem of Clematis subumbellata. Sexual morph: Apothecia 201-260 ×210-310 $\mu \mathrm{m}$ $(\bar{x}=230 \times 260 \mu \mathrm{m}, \mathrm{n}=10)$, arising singly or in small groups, sessile, immersed in substrate, under the clypeus, cupulate. Hypothecium convex. Disc $270-370 \mu \mathrm{m}$ wide $(\bar{x}=320 \mu \mathrm{m}$, $\mathrm{n}=10$ ), whitish to cream. Margins white. Hymenium hyaline, enclosed in a thick gelatinous matrix. Epithecium absent. Excipulum 17-70 $\mu \mathrm{m}$ wide, composed of cells of textura intricata. Paraphyses $1.3-3 \mu \mathrm{m}$ wide $(\bar{x}=2 \mu \mathrm{m}, \mathrm{n}=50)$ at the apex, numerous, filiform, aseptate, unbranched. Asci 110-150×10-20 $\mu \mathrm{m}(\bar{x}=130 \times 12 \mu \mathrm{m}, \mathrm{n}=10), 8$-spored, long, broad cylindrical, rounded at the apex, short sessile. Ascospores 100-145 ×2.5-3.5 $\mu \mathrm{m}$, fasciculate, spiraled in ascus, thread-like, filiform, ends rounded, 17-21 transversely euseptate, slightly constricted at the septa, hyaline. Asexual morph: Undetermined.

Culture characters: Colonies on MEA reaching $20 \mathrm{~mm}$ diam. after 4 weeks at $25^{\circ} \mathrm{C}$. Culture from above, brown, radiating, yellowish towards the edge, erumpent, spreading, surface folded, margins lobate, dense, circular, flat, dull, fimbriate, radially furrowed, and slightly covered with white aerial mycelia; reverse pale orange, with radiating cream mycelia.

Material examined: Thailand, Chiang Rai Province, on dead stems of Clematis subumbellata, 20 March 2017, C. Phukhamsakda, CMTH16 (MFLU 17-1480); living culture, MFLUCC 17-2072.

Hosts: woody stem, Epilobium (=Chamaenerion) angustifolium, Clematis subumbellata-(Crous et al. 2017; this study).

Distribution: Australia, Thailand-(Crous et al. 2017; this study).

GenBank accession numbers: LSU: MT214609; SSU: MT226720; ITS: MT310653; tefl: MT394665.

Notes: Fitzroyomyces cyperacearum (MFLUCC 17-2072) was found on the stem of Clematis subumbellata in Thailand. The strain formed a clade with $F$. cyperacearum from Australia and the UK (Fig. 90). Isolate MFLUCC 17-2072 clustered with three Fitzroyomyces strains with strong support and the ITS data of our strain was $99 \%$ similar to the ITS data of the type species of F. cyperacearum (CBS 143170). Fitzroyomyces was introduced based on its pycnidial characters (Crous et al. 2017). However, the asexual morph was not observed in our collection, therefore it could not be compared to the asexual morph of the type strain. Taking into consideration the genetic similarity and phylogenetic results, we name our collection as the sexual morph of $F$. cyperacearum. This is the first record of $F$. cyperacearum from Thailand and on Clematis (Fig. 91).

Fitzroyomyces cyperacearum (MFLUCC 17-2072) was evaluated for secondary metabolite production with Bacillus subtillis, Escherichia coli, Aspergillus niger and Schizosaccharomyces pombe. It showed weak inhibitory activities against Bacillus subtillis and completely inhibited the development of Aspergillus niger with an inhibition zone diameter of $17 \mathrm{~mm}$. This strain is a suitable candidate for further evaluation.

Neostictis Ekanayaka, Camporesi \& K.D. Hyde, gen. nov. Index Fungorum number: IF557307; Facesoffungi number: FoF 07338, Fig. 92.

Etymology: Name refers to the similarity to Stictis.

Saprobic on decaying wood material or herbaceous plant in terrestrial habitats. Sexual morph: Apothecia arising singly or in small groups, sessile, immersed in substrate, under the clypeus, cupulate. Hypothecium convex. Disc blackish. Margins brownish. Hymenium hyaline, enclosed in a thick gelatinous matrix. Excipulum composed of multi-layer of cells of textura intricata. Paraphyses numerous, filiform, aseptate. Asci 8-spored, short sessile, broad cylindrical to oblong, rounded at the apex. Ascospores fasciculate, threadlike, spiraled, filiform, rounded ends, multi-septate, transversely eusepta, hyaline, sometimes breaking into small fragments. Asexual morph: Undetermined.

Type species: Neostictis nigricans Ekanayaka, Phukhams., Camporesi \& K.D. Hyde

Notes: Our collection MFLU 17-1540, from Italy, formed a well-supported clade close to Phacidiella podocarpi. Our new species is morphologically similar to Fitzroyomyces cyperacearum by having immersed apothecia, long cylindrical asci and filiform ascospores (Crous et al. 2017). However, our new species differs by having blackish margins, smaller disc and asci and ascospores (Fig. 92). The ascospores of our collection failed to germinate and therefore, we were unable to compare the asexual morph characters of our collection with Fitzroyomyces cyperi and Phacidiella podocarpi.

Neostictis nigricans Ekanayaka, Phukhams., Camporesi \& K.D. Hyde, sp. nov.

Index Fungorum number: IF557308; Facesoffungi number: FoF 07339, Fig. 92.

Etymology: The epithet refers to the apothecial morphology. The disc and the margins of the apothecium is black.

Holotype: MFLU 17-1540

Saprobic on dead stem of Clematis vitalba. Sexual morph: Apothecia $0.4-1 \mathrm{~mm}$ wide, arising singly or in small groups, sessile, immersed in substrate, under the clypeus, cupulate. Hypothecium convex. Disc blackish. Margins blackish. Hymenium hyaline, enclosed in a thick 


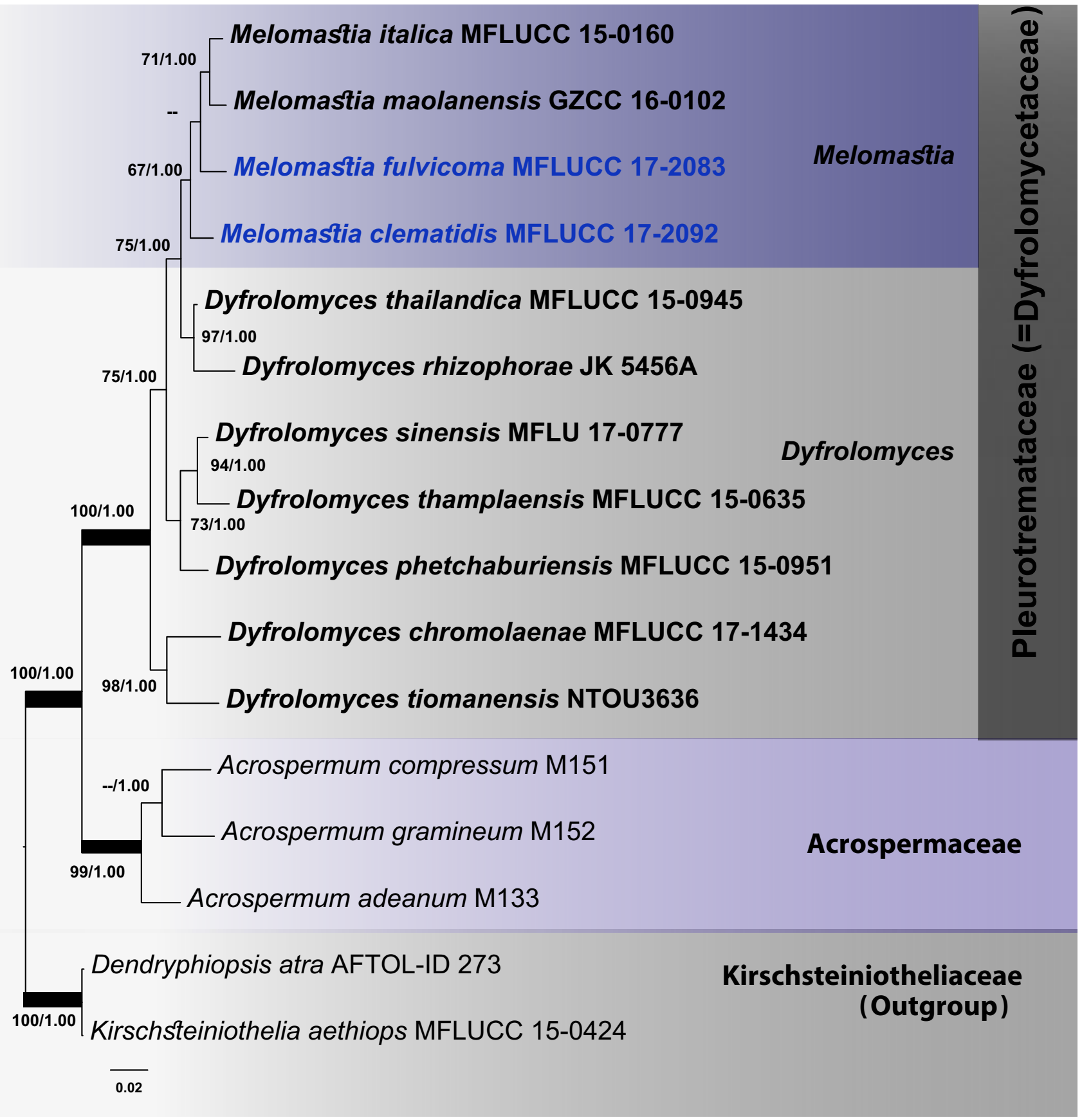

Fig. 87 The Bayesian 50\% majority-rule consensus phylogram based on combined LSU, SSU and tefl sequence data for Pleurotremataceae and related taxa. The topology and clade stability of the combined gene analyses was compared to the single gene analyses. The tree is rooted with members of the Kirschsteiniotheliaceae. Sixteen strains were included in the combined genes sequence analyses which comprised 3269 characters (1297 characters for LSU, 1049 characters for SSU, 923 characters for $t e f 1$, including gap regions). The tree from the maximum likelihood analysis had similar topology to the Bayesian analyses. The best scoring RAxML tree had a final likelihood value of -8012.999545 . The matrix had 707 distinct alignment patterns, with $31.71 \%$ of undetermined characters and gaps. Estimated base frequencies were as follows; $\mathrm{A}=0.236800, \mathrm{C}=0.268407$, $\mathrm{G}=0.273839, \mathrm{~T}=0.220954 ;$ substitution rates $\mathrm{AC}=0.626404$, $\mathrm{AG}=2.767488, \quad \mathrm{AT}=0.626269, \quad \mathrm{CG}=1.143373, \quad \mathrm{CT}=7.006679$, $\mathrm{GT}=1.000000$; gamma distribution shape parameter $\alpha=0.740235$. In our analysis, GTR + I + G model was used for each partition in Bayesian posterior analysis. The species determined in this study are indicated in blue. Bootstrap values (BS) greater than 50\% BS (ML, left) and Bayesian posterior probabilities (BYPP, right) greater than 0.90 are given at the nodes. Hyphens (-) represent support values less than 50\% BS/0.90 BYPP. Thick branches represent significant support values from all analyses at family level (BS $\geq 70 \% / B Y P P \geq 0.95)$ 

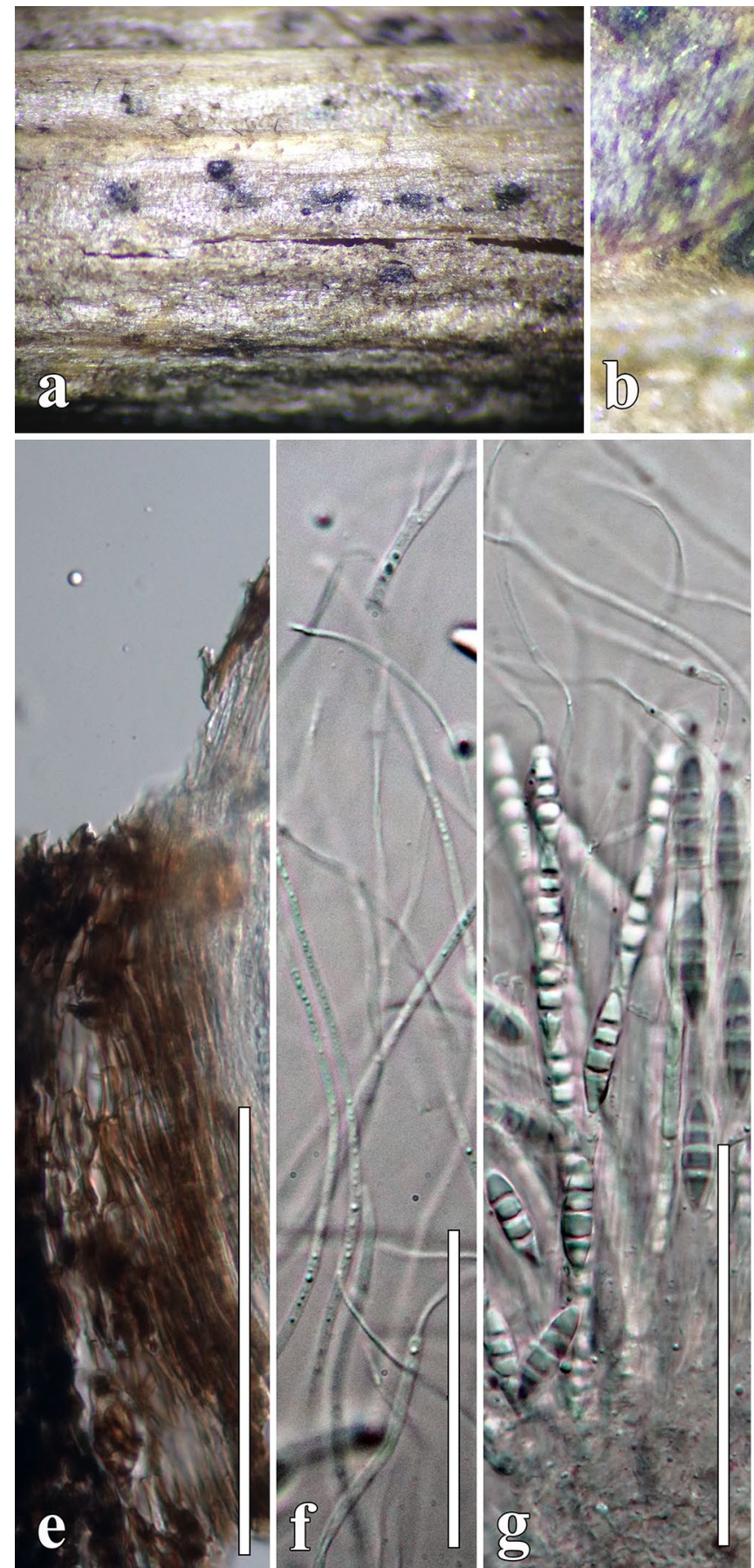

Fig. 88 Melomastia clematidis (MFLU 17-1500, holotype). a, b Appearance of ascomata on Clematis sikkimensis. c Vertical section through ascoma. d Ostiolar canal. e Section of peridium. f Pseudo-

gelatinous matrix. Excipulum 25-35 $\mu \mathrm{m}$ wide, composed of multi-layer cells of textura intricata. Paraphyses 1.3-2 $\mu \mathrm{m}$ wide at the apex, numerous, filiform, aseptate, unbranched. Asci $80-100 \times 8-12 \mu \mathrm{m}, 8$-spored, short sessile, broad cylindrical to oblong, rounded at the apex. Ascospores $35-50 \times 2.5-3.5 \mu \mathrm{m}$, fasciculate, weakly spiral, thread-like,
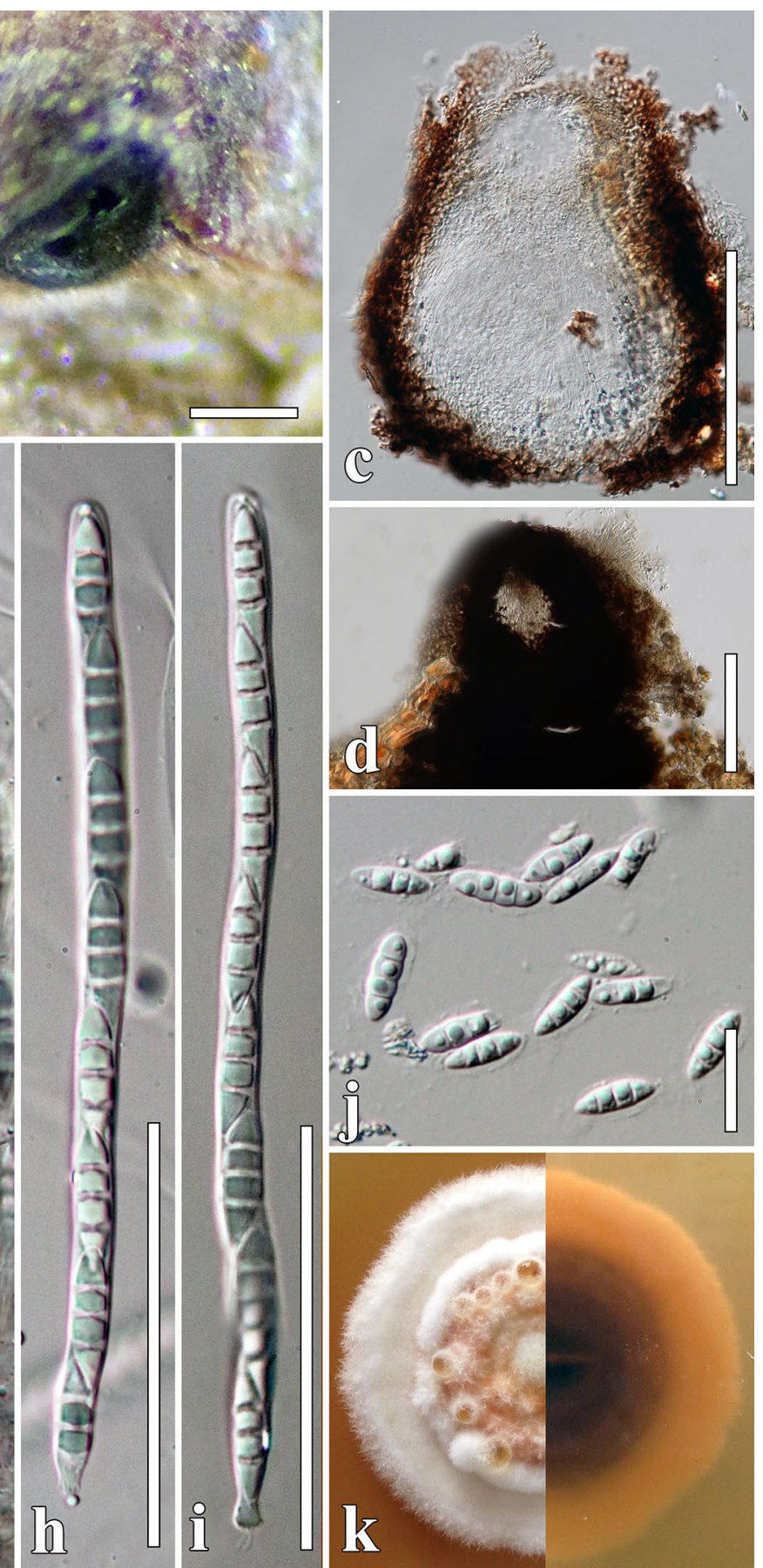

paraphyses. g-i Asci. j Ascospores. $\mathbf{k}$ Culture characteristics on MEA. Scale bars: $\mathbf{b}, \mathbf{c}=200 \mu \mathrm{m}, \mathbf{d}-\mathbf{i}=50 \mu \mathrm{m}, \mathbf{j}=10 \mu \mathrm{m}$

filiform, ends rounded, multi-septate, approximately 32-transversely euseptate, hyaline, sometimes breaking into small fragments. Asexual morph: Undetermined.

Material examined: Italy, Forlì-Cesena Province, Fiumicello di Premilcuore, Bouchout Domain, dead aerial branch of Clematis vitalba, 18 January 2014, E. Camporesi, IT1655 

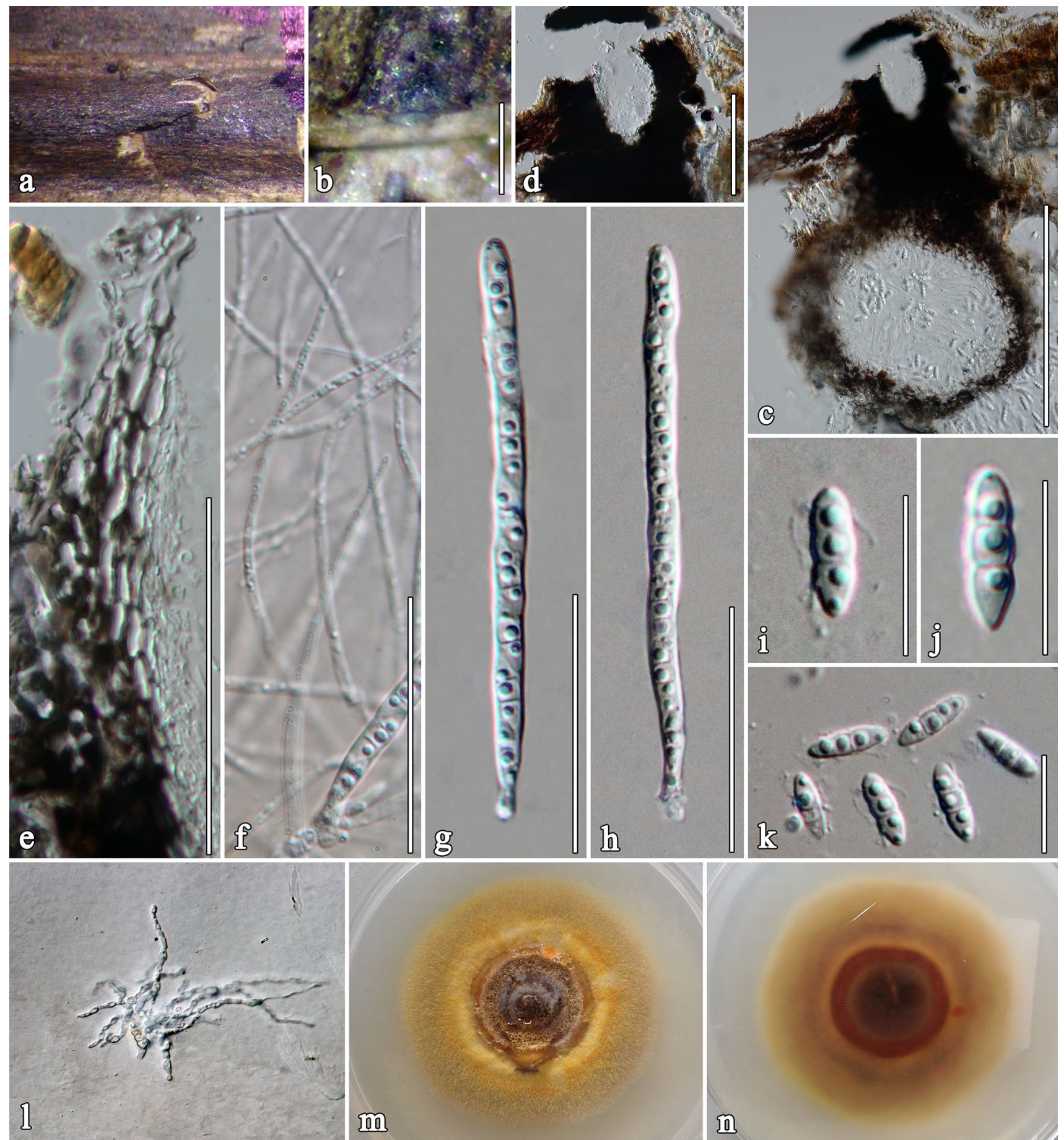

Fig. 89 Melomastia fulvicomae (MFLU 17-1491, holotype). a, b Appearance of ascomata on Clematis fulvicoma. c Vertical section through ascoma. d Ostiolar canal. e Section of peridium. f Pseudo-

(MFLU 17-1540, holotype); ibid., 10 October 2013 (MFLU 16-0483 = MFLU 16-0595).

Host: Clematis vitalba-(This study).

Distribution: Italy_(This study). paraphyses. $\mathbf{g}$, h Asci. i-k Ascospores. $\mathbf{l}$ Germinated ascospore. $\mathbf{m}, \mathbf{n}$ Culture characteristics on MEA. Scale bars: $\mathbf{b}=500 \mu \mathrm{m}, \mathbf{c}=200 \mu \mathrm{m}$, $\mathbf{d}, \mathbf{e}=50 \mu \mathrm{m}, \mathbf{f}-\mathbf{h}=20 \mu \mathrm{m}, \mathbf{i}-\mathbf{k}=10 \mu \mathrm{m}$

GenBank accession numbers: LSU: MT214610; SSU: MT226721; ITS: MT310654; tefl: MT394666.

Notes: See note under Neostictis. 


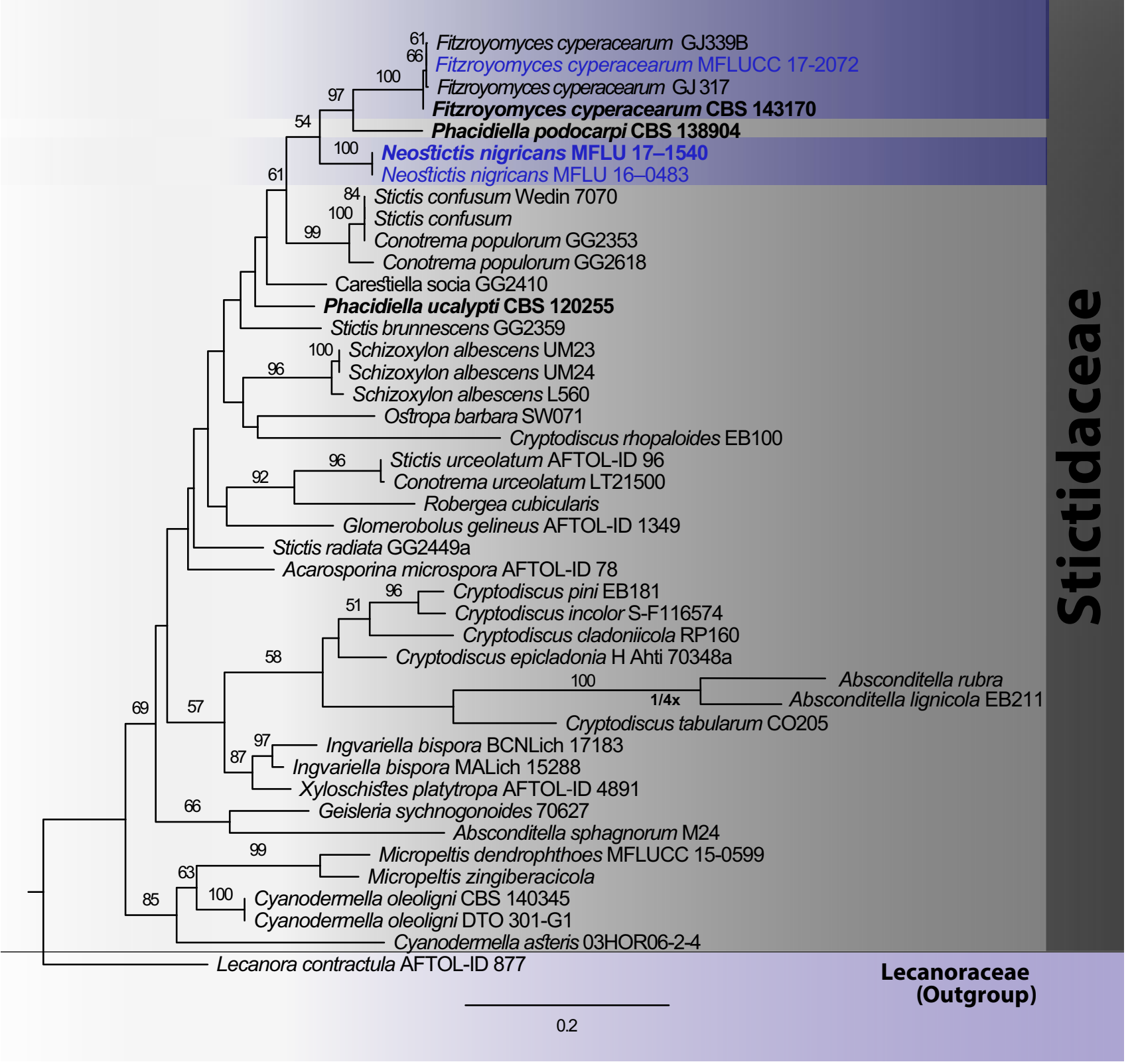

Fig. 90 The best scoring RAxML tree with a final likelihood value of - 13518.083608 for ITS and LSU sequence data. The topology and clade stability of the combined gene analyses was compared to the single gene analyses. The tree is rooted with Lecanora contractula (AFTOL-ID 877). The matrix had 958 distinct alignment patterns with $48.65 \%$ undetermined characters and gaps. Estimated base frequencies were as follows; $\mathrm{A}=0.252, \mathrm{C}=0.244, \mathrm{G}=0.276, \mathrm{~T}=0.228$;

\section{Class Sordariomycetes Erikss. \& K. Winka}

We follow Hyde et al. (2020b) which is the latest treatment of this class.

Subclass: Sordariomycetidae Erikss. \& K. Winka

Chaetosphaeriales Huhndorf, Mill. \& F.A. Fernández Chaetosphaeriales, genera incertae sedis substitution rates $\mathrm{AC}=1.173341, \mathrm{AG}=1.808670, \mathrm{AT}=1.760640$, $\mathrm{CG}=0.888202, \mathrm{CT}=5.267472, \mathrm{GT}=1.000000$; gamma distribution shape parameter $\alpha=0.339348$. Ex-type strains are in bold black and the species determined in this study are indicated in blue. Bootstrap values (BT) (over 50\% BT) from maximum likelihood are given at the nodes

We follow the treatment of the order of Hyde et al. (2020b).

Neoleptosporella Phukhams. \& K.D. Hyde, gen. nov.

Index Fungorum number: IF557081; Facesoffungi number: FoF 07246, Fig. 94.

Etymology: The generic epithet refers to its similarity with Leptosporella. 


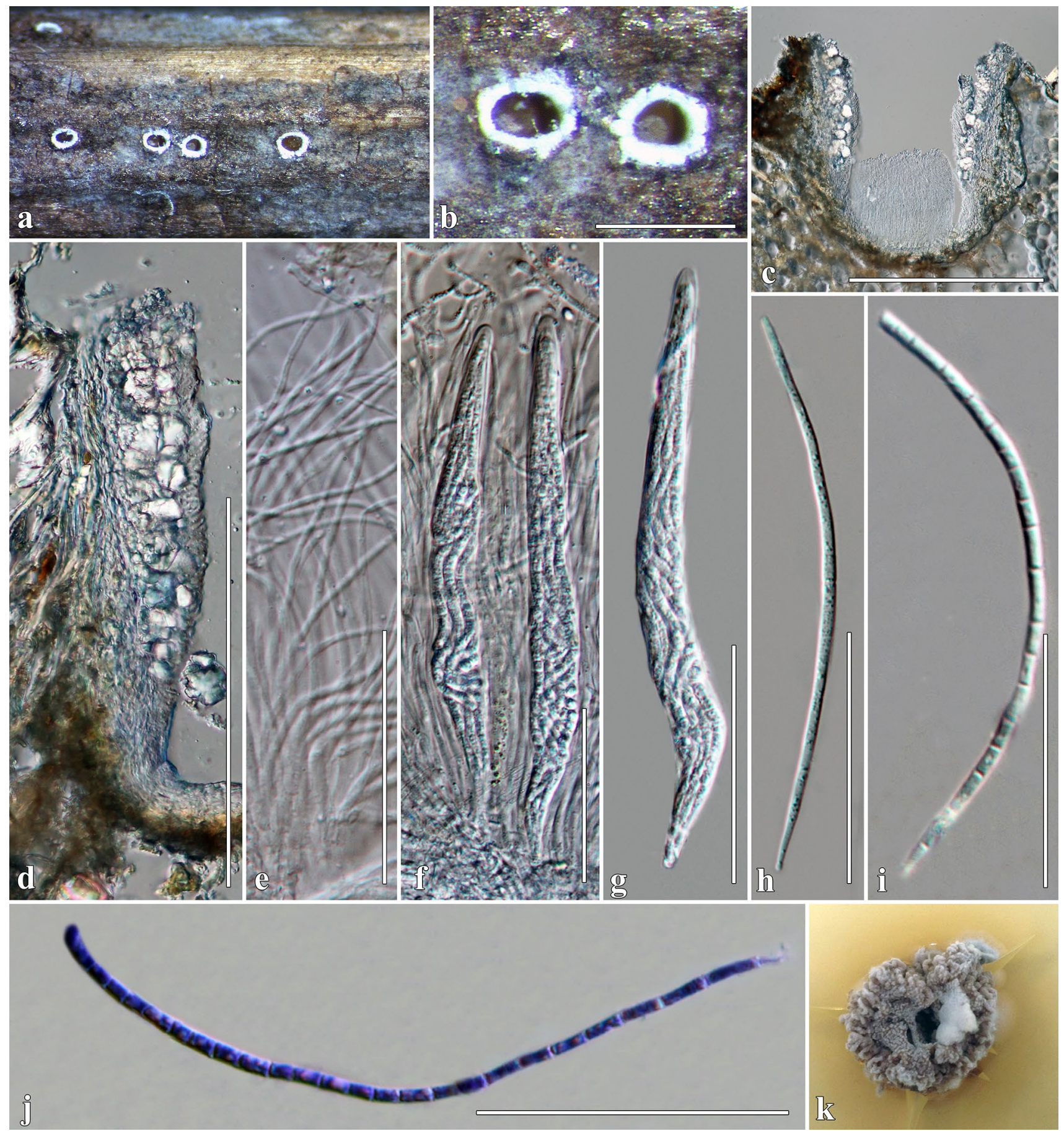

Fig. 91 Fitzroyomyces cyperacearum (MFLU 17-1480). a Appearance of apothecia on Clematis subumbellata. b Close up of apothecia on host substrate. c Vertical section through an apothecium. d Excipulum layers. e Aseptate paraphyses. f, g Cylindrical asci. h-j
Fusiform ascospores (j Ascospore in cotton blue). k Culture characteristics on MEA. Scale bars: $\mathbf{b}=500 \mu \mathrm{m}, \mathbf{c}=250 \mu \mathrm{m}, \mathbf{d}=100 \mu \mathrm{m}$, $\mathbf{e}-\mathbf{j}=50 \mu \mathrm{m}$ 

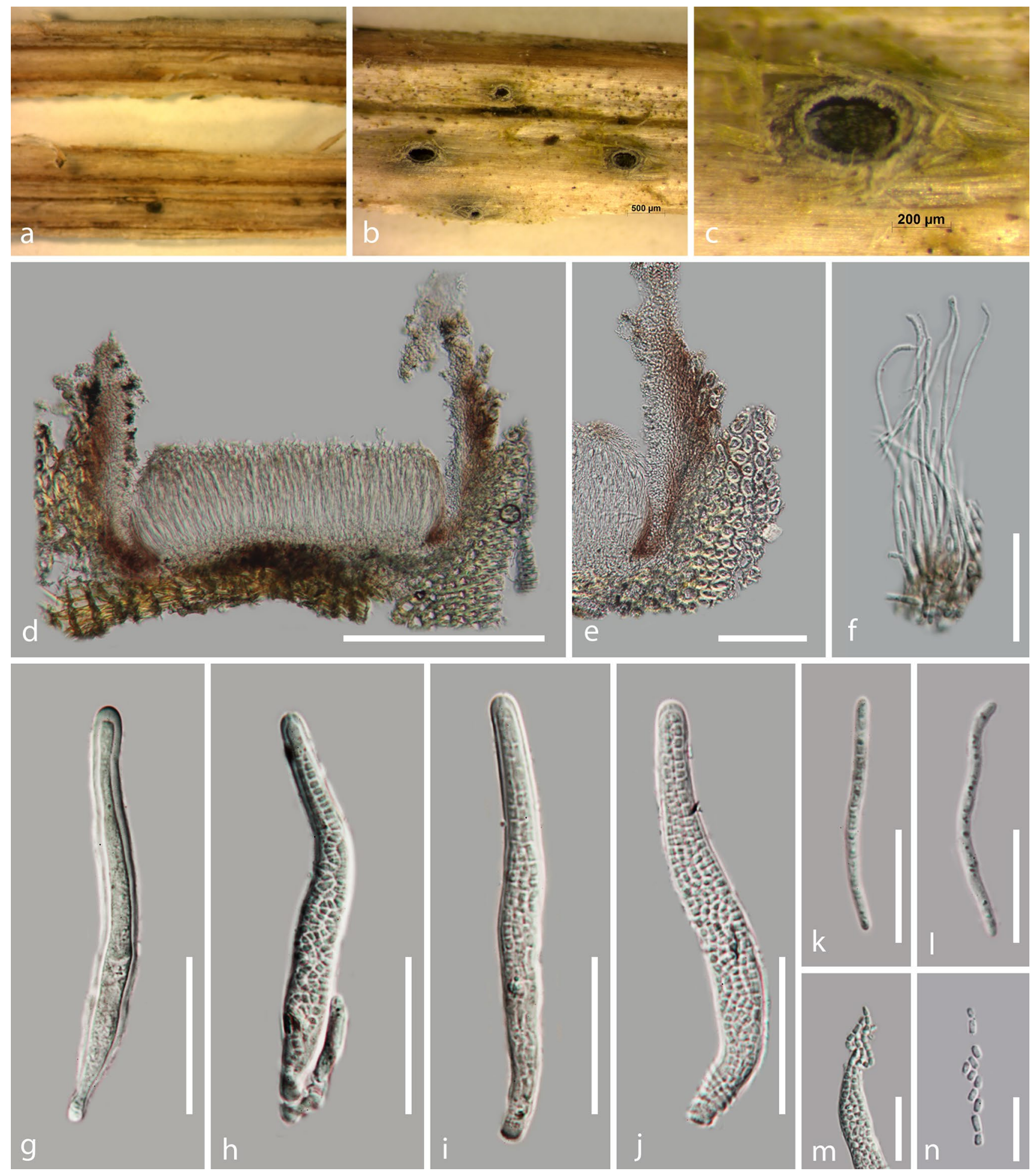

Fig. 92 Neostictis nigricans (MFLU 17-1540, holotype). a Appearance of apothecia on Clematis vitalba. b, c Close up of apothecia on substrate. d Vertical section of an apothecia. e Vertical section of the peridium. $\mathbf{f}$ Aseptate paraphyses. $\mathbf{g}-\mathbf{j}$ Asci. $\mathbf{k}$, l Needle- like ascospores. m Ascospores released from an ascus. n Secondary ascospores. Scale bars: $\mathbf{b}=500 \mu \mathrm{m}, \mathbf{c}=200 \mu \mathrm{m}, \mathbf{d}=300 \mu \mathrm{m}$, $\mathbf{e}=100 \mu \mathrm{m}, \mathbf{f}-\mathbf{j}=30 \mu \mathrm{m}, \mathbf{k}-\mathbf{n}=20 \mu \mathrm{m}$ 


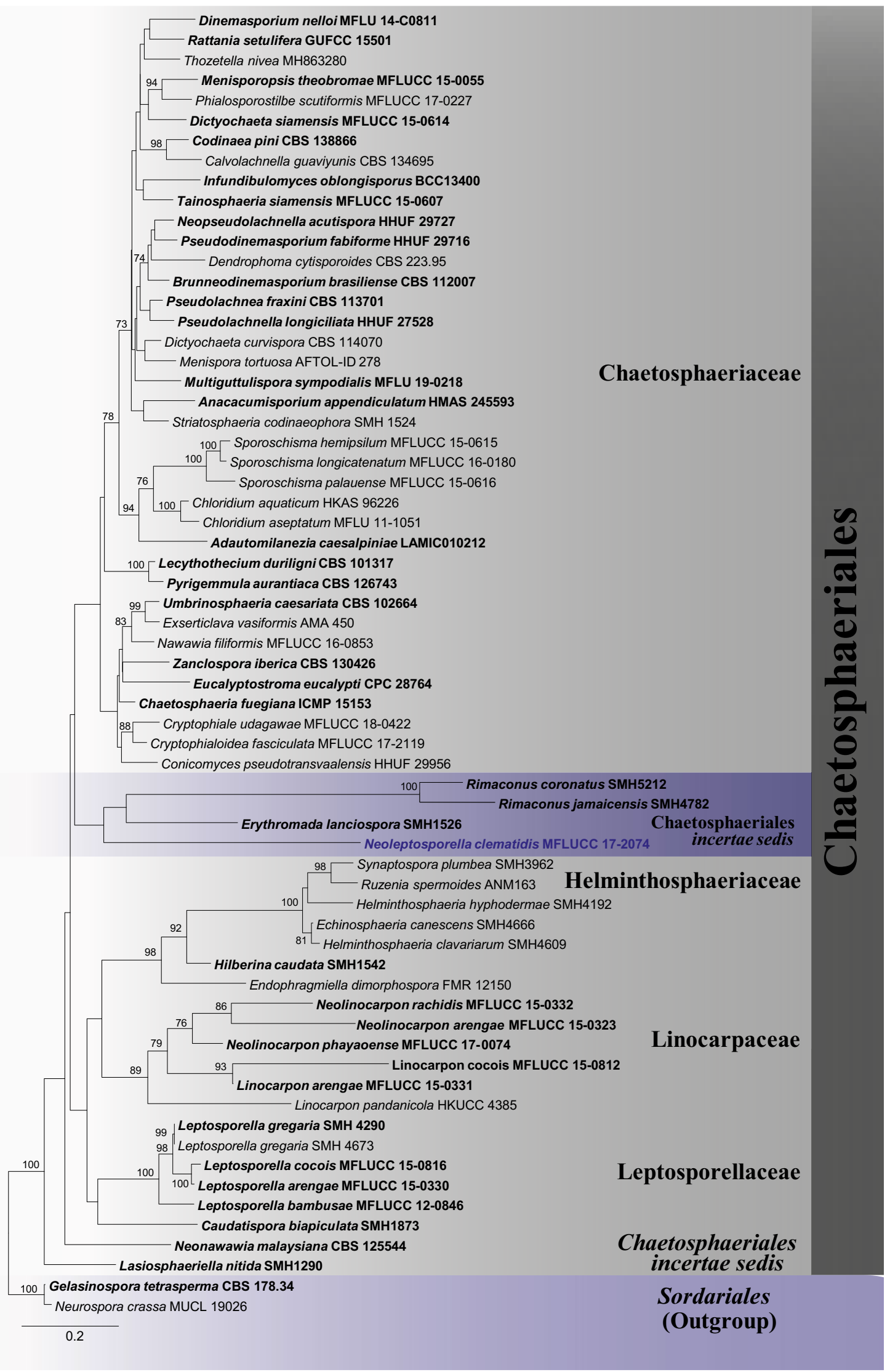


4Fig. 93 The best scoring RAxML tree with a final likelihood value of - 19621.398134 of LSU and ITS sequence data. The topology and clade stability of the combined gene analyses was compared to the single gene analyses. Sixty-five strains were included in the combined genes sequence analyses which comprised 1655 characters (1060 characters for LSU and 595 characters for ITS, including gap regions). Thistree includes selected taxa of Chaetosphaeriales and rooted with Gelasinospora tetrasperma (CBS 178.34) and $\mathrm{Neu}$ rospora crassa (MUCL 19026) in Sordariales. The matrix had 990 distinct alignment patterns, with $30.05 \%$ of undetermined characters and gaps. Estimated base frequencies were as follows; $\mathrm{A}=0.230333$, $\mathrm{C}=0.267483, \quad \mathrm{G}=0.312066, \mathrm{~T}=0.190118 ;$ substitution rates $\mathrm{AC}=1.241984, \quad \mathrm{AG}=1.768569, \quad \mathrm{AT}=1.330285, \quad \mathrm{CG}=1.057213$, $\mathrm{CT}=5.757832, \mathrm{GT}=1.000000$; gamma distribution shape parameter $\alpha=0.462145$. Ex-type strains are in bold black and the species determined in this study is indicated in blue. Bootstrap values (over 70\% BT) from maximum likelihood are given at the nodes

Saprobic on stem of terrestrial herbaceous plants. Sexual morph: Ascomata solitary, immersed, only black shiny ostioles visible, immersed beneath small clypeus, appear as disc around the neck, coriaceous, subglobose to depressed globose, as raised blister-like areas, ostiolate. Ostioles central, carbonaceous, black, filled with periphyses. Peridium outer cells merging with the host epidermal cells, dark brown to black cells of textura angularis. Paraphyses comprising numerous, hyaline, branched, septate. Asci 8-spored, unitunicate, broad cylindrical, long-pedicellate, with a J-, wedge-shaped, subapical ring. Ascospores fasciculate, fusiform, straight or curved, C-shaped or sigmoid, aseptate, ends acute, without polar appendages, smooth-walled, with guttules in each cell. Asexual morph: Undetermined.

Type species: Neoleptosporella clematidis Phukhams., Konta \& K.D. Hyde

Notes: Neoleptosporella is introduced for a taxon on Clematis subumbellata and is distinguishable from Leptosporella in having immersed ascomata which are partial carbonaceous at the apex, the lower part is coriaceous, subglobose to depressed globose, not flattened at the base and without the cover of a pseudoclypeus. The apical part of the asci is wedge-shaped, and J-, with fusiform, aseptate ascospore with acute ends (Huhndorf and Miller 2011; Dai et al. 2017; Konta et al. 2017; Hyde et al. 2020a). The strain forms a lineage with three strains that have uncertain placement in Chaetosphaeriales, but received low statistical support (less than 75\% ML, Fig. 93).

Neoleptosporella clematidis Phukhams., Konta \& K.D. Hyde, sp. nov.

Index Fungorum number: IF557060; Facesoffungi number: FoF 07246, Fig. 94.

Etymology: named after the host genus, Clematis.

Holotype: MFLU 17-1482.

Saprobic on dead branches of Clematis subumbellata. Sexual morph: Ascomata (including neck) $150-200 \times 100-120 \mu \mathrm{m}(\bar{x}=170 \times 115 \mu \mathrm{m}, \mathrm{n}=10)$, solitary, immersed, only black shiny ostioles visible, immersed beneath small clypeus, appearing as a disc around the neck, coriaceous, subglobose to depressed globose, as raised blister-like areas, ostiolate. Ostioles central, $60 \times 55 \mu \mathrm{m}$, carbonaceous, black, filled with periphyses. Peridium 5-10(-22) $\mu \mathrm{m}$ wide, outer cells merging with the host epidermal cells, composed of 3-4(-8 at apex) layers of dark brown to black cells of textura angularis. Paraphyses of numerous, $6-16 \mu \mathrm{m}$ wide $(\bar{x}=4 \mu \mathrm{m}, \mathrm{n}=10)$, hyaline, branched, septate, longer than asci. Asci $60-86 \times 6-10 \mu \mathrm{m}(\bar{x} \bar{x}=75 \times 8 \mu \mathrm{m}, \mathrm{n}=30)$, 8 -spored, unitunicate, broad cylindrical, long-pedicellate, with a J-, wedge-shaped, subapical ring. Ascospores $32-50 \times 2-4 \mu \mathrm{m}(\bar{x}=38 \times 3 \mu \mathrm{m}, \mathrm{n}=50)$, filiform, straight or curved, C-shaped or sigmoid, aseptate, acute ends, without polar appendages, smooth-walled, with minute guttules in each cell. Asexual morph: Undetermined.

Culture characters: Colonies on MEA reaching $30 \mathrm{~mm}$ diam. after 4 weeks at $25^{\circ} \mathrm{C}$, Culture from above, cream, radiating, wrinkled, folded in the middle, dense, lobate, flattened, umbonate, edge irregular, fluffy; reverse black in the middle and cream at the edge, radially striate with lobate edge.

Material examined: Thailand, Chiang Rai Province, on dead stems of Clematis subumbellata, 20 March 2017, C. Phukhamsakda, CMTH18 (MFLU 17-1482, holotype); extype living culture, MFLUCC 17-2074.

Host: Clematis subumbellata-(This study).

Distribution: Thailand-(This study).

GenBank accession numbers: LSU: MN628626; tef1: MN629286; rpb2: MN628628.

Notes: In the phylogenetic analysis, Neoleptosporella clematidis (strain MFLUCC 17-2074) formed a distinct clade from other Leptosporella species (Fig. 93). The asexual morph of our taxon was not obtained from culture. In a BLASTn search of GenBank, the closest match of the LSU sequence of MFLUCC 17-2074 is Leptosporella bambusae with $85 \%$ similarity to strain MFLUCC 12-0846 (NG_059674). This is the first record of Leptosporellaceae on Clematis (Fig. 94).

Isolate MFLUCC 17-2074 was evaluated for bioactive secondary metabolite production. The strain inhibits the growth of Bacillus subtillis but not at significant values (data not shown).

Sordariales Chadef. ex Hawksw. \& O.E. Erikss.

This order comprises three families Chaetomiaceae, Sordariaceae and Lasiosphaeriaceae sensu lato (Zhang et al. 2006; Maharachchikumbura et al. 2016).

\section{Chaetomiaceae Winter}

Chaetomiaceae is a highly diverse family that can be found in several environments as fungicolous, saprobes, or parasites in plant or animals (Mukerji and Manoharachary 

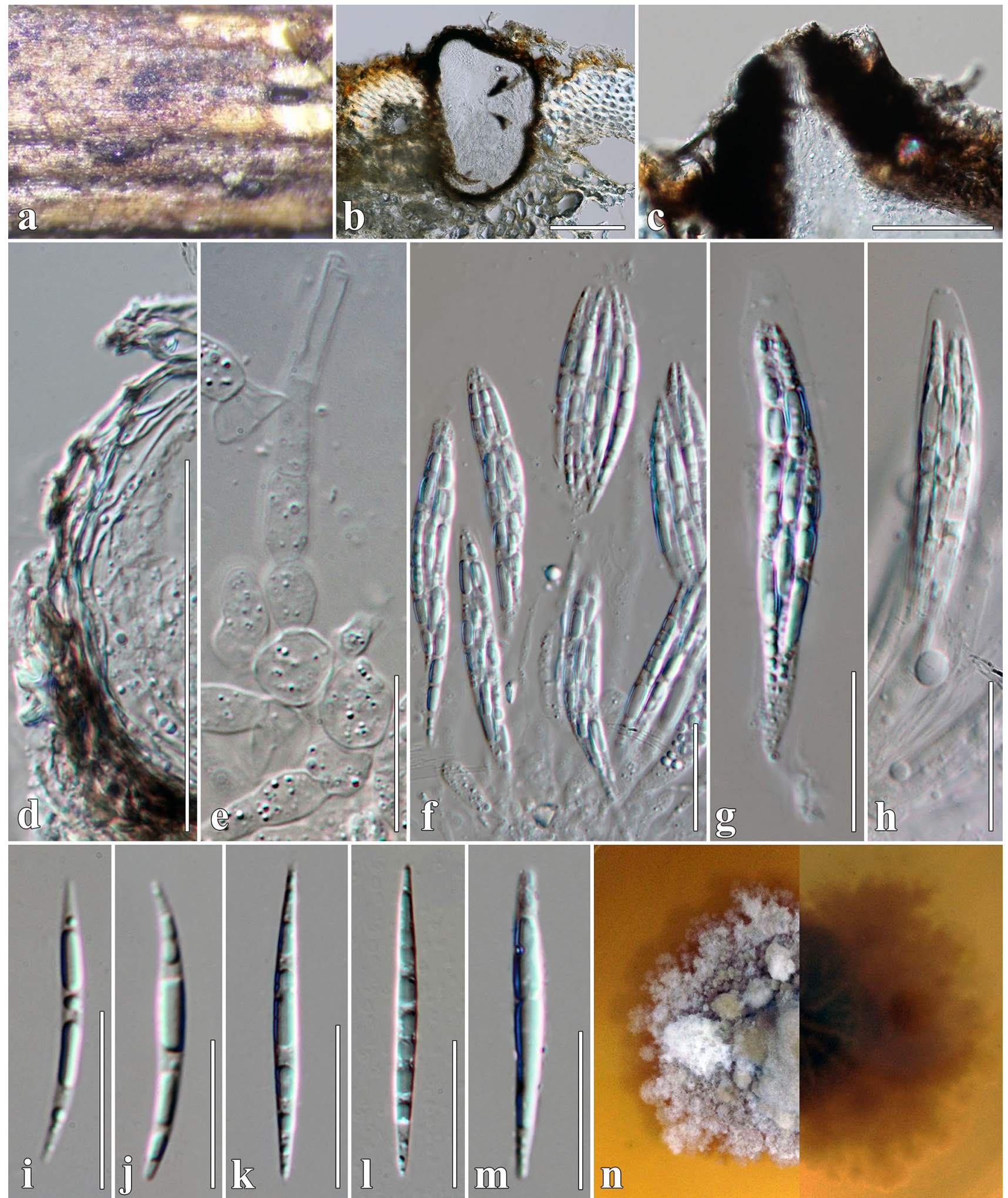

Fig. 94 Neoleptosporella clematidis (MFLU 17-1482, holotype). a Appearance of ascomata on Clematis subumbellata. b Vertical sec(h asci in $5 \% \mathrm{KOH}$ presenting a J-reaction of apical ring, wedgeshaped). $\mathbf{i}-\mathbf{m}$ Ascospores. $\mathbf{n}$ Culture characteristics on MEA. Scale bars: $\mathbf{b}=100 \mu \mathrm{m}, \mathbf{c}, \mathbf{d}=50 \mu \mathrm{m}, \mathbf{e}-\mathbf{h}=20 \mu \mathrm{m}, \mathbf{i}-\mathbf{m}=10 \mu \mathrm{m}$ 
2010; Ahmed et al. 2016). Wang et al. (2019) made a major revision for Chaetomiaceae, accepting 37 genera.

\section{Dichotomopilus Wang, Samson \& Crous}

Dichotomopilus was erected by Wang et al. (2016) for a group characterised by dichotomously branched terminal ascomatal hairs. Dichotomopilus is typified by $D$. indicus, with 12 species listed in Index Fungorum (2020). Based on both morphological and phylogenetic analysis of combined ITS, LSU, tefl and $r p b 2$ sequence data (Fig. 95), we introduce the first record of Dichotomopilus ramosissimum on Clematis (Fig. 96).

Dichotomopilus ramosissimum (X. Wei Wang \& L. Cai) Wei Wang \& Samson, Studies in Mycology 84: 217 (2016) new host record

Basionym: Chaetomium ramosissimum X. Wei Wang \& L. Cai, Mycol. Prog. 13: 725. (2014).

Index Fungorum number: IF 801734; Facesoffungi number: FoF 07245, Fig. 96.

Saprobic on dead branches of Clematis vitalba. Sexual morph: Ascomata $70-225 \times 80-220 \mu \mathrm{m}(\bar{x}=150 \times 140 \mu \mathrm{m}$, $\mathrm{n}=5$ ), erumpent to superficial, with thick aerial hyphae or exposed ostiolate, covered with black ascomatal hairs, sphaerical or ovate, without papilla. Peridium reddish brown to brown, composed of hypha-like cells, textura intricata mixed with textura epidermoidea in surface view. Terminal hairs erect, $120-290 \times 3-6 \mu \mathrm{m}(\bar{x}=170 \times 5 \mu \mathrm{m}, \mathrm{n}=20)$, rigid, dark brown, copiously dichotomously branched more than four times at the side, straight angles, starting from the lower half, punctulate or verrucose. Lateral hairs 50-100 $\times 3-4 \mu \mathrm{m}(\bar{x}=70 \times 4 \mu \mathrm{m}, \mathrm{n}=20)$, unbranched, setae-like, tapering towards the end. Asci 30-40 $\times 8-15 \mu \mathrm{m}$ $(\bar{x}=35 \times 10 \mu \mathrm{m}, \mathrm{n}=10), 8$-spored, spathulate, long pedicellate, apically rounded. Ascospores $5-8 \times 2.5-5 \mu \mathrm{m}(\bar{x}$ $=7 \times 4 \mu \mathrm{m}, \mathrm{n}=50$ ), overlapping, ovate to subglobose, ends acute, hyaline, becoming brown with age, aseptate, verruculose, with slit-like germ pores at maturity. Asexual morph: Undetermined.

Material examined: UK, Hampshire, Botley wood, Hampshire, on dead stems of Clematis vitalba, 16 April 2016, E.B.G. Jones, GJ264 (MFLU 16-2137).

Hosts: The rhizosphere of Panax notoginseng, soil sample, Clematis vitalba-(Wang et al. 2014; this study).

Distribution: China, UK-(Wang et al. 2014; this study).

GenBank accession numbers: LSU: MT214611; SSU: MT226722; ITS: MT310655; tefl: MT394667.

Notes: Dichotomopilus ramosissimum was described as Chaetomium ramosissimum. Later, with more taxon sampling of Chaetomiaceae, the species formed a separate lineage and was synonymized under Dichotomopilus. Our collection formed a close relationship with the type strain of $D$. ramosissimum (CGMCC 3.14183, 100\% ML/1.00 BYPP).
The morphological characters of our collection are similar to those reported by Wang et al. (2014). In a BLASTn search of GenBank, the closest match of the ITS sequence of strain MFLU 16-2137 was D. erectus strain CBS 140.56 with $98.5 \%$ similarity (MH857548), while the closest match of the tefl sequence was D. ramosissimum strain CGMCC 3.14183 (KC485021) with $100 \%$ similarity.

\section{Sordariaceae Winter}

Sordariaceae is typified by Sordaria, and species in this family mainly occur as coprophilous or saprobes (Cai et al. 2006; Zhang et al. 2006; Arif and Saleem 2017). Sordariaceae is characterized by coriaceous ascomata and hyaline or brown ascospores with sheaths (Maharachchikumbura et al. 2016). Eight genera are accepted in this family (Maharachchikumbura et al. 2016; Wijayawardene et al. 2017).

\section{Sordaria Ces. \& De Not}

Sordaria is typified with Sordaria fimicola. There are more than 50 epithets listed in Index Fungorum (2020), but only 15 strains have sequence data (Cai et al. 2006). Most species are reported from dung, soil, and seed pods (Furtado 1969; Watanabe 1989; Mungai et al. 2012). Sordaria is characterized by perithecioid, semi-immersed to superficial, coriaceous ascomata, paraphyses, cylindrical asci, with a lobate pedicel, and a prominent apical ring, and uniseriate ascospores that are ellipsoidal to ovoid, surrounded by a gelatinous sheath. Based on both morphological and phylogenetic analysis of combined LSU, ITS and $t u b$ sequence data (Fig. 97), we introduce the first record of Sordaria, $S$. clematidis on Clematis species (Fig. 98).

\section{Sordaria clematidis Phukhams. \& K.D. Hyde, sp. nov.}

Index Fungorum number: IF557306; Facesoffungi number: FoF 07337, Fig. 98.

Etymology: Refers to the host genus, Clematis.

Holotype: MFLU 16-2138

Saprobic on dead stems of Clematis vitalba. Sexual morph: Ascomata $220-315 \times 200-350 \mu \mathrm{m}$ $(\bar{x}=270 \times 300 \mu \mathrm{m}, \mathrm{n}=5)$, perithecial, single, superficial, solitary, scattered, ampulliform or pyriform, globose, with a sphaerical body, coriaceous, smooth or nearly, often glossy and black, ostiolate. Ostioles central, oblong, dark brown to black, papillate, periphyses filling ostioles. Peridium 20-30 $\mu \mathrm{m}$ wide, composed of 6-7 layers of textura angularis of thin-walled, brown cells, inner layer lined with thin hyaline layers. Paraphyses of numerous, $10-17 \mu \mathrm{m}(\bar{x}=14 \mu \mathrm{m}$, $\mathrm{n}=40$ ), catenophyses, branched, transversely septate, hyaline. Asci $115-160 \times 4-7 \mu \mathrm{m}(\bar{x}=180 \times 20 \mu \mathrm{m}, \mathrm{n}=20)$, unitunicate, oblong, 8 -spored, with a thin but rather persistent wall, with a disc and J-ring at the truncate apex, simple pedicel. Ascospores $21-26 \times 11-15 \mu \mathrm{m}(\bar{x}=25 \times 13 \mu \mathrm{m}, \mathrm{n}=20)$, uniseriate, ovate, aseptate, smooth-walled, hyaline or pale 


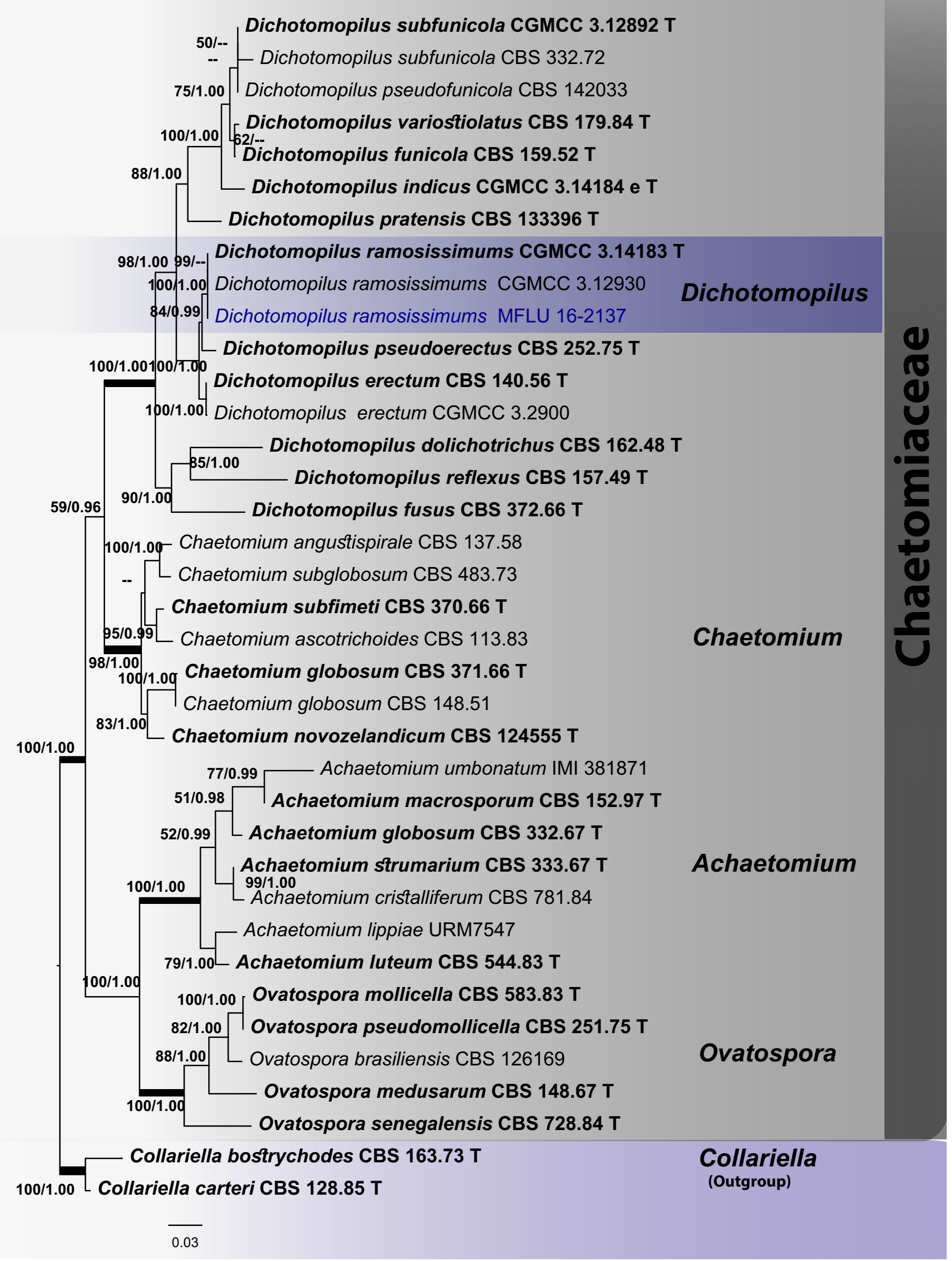


4Fig. 95 Phylogram generated from maximum likelihood analysis based on combined ITS, LSU, tef1 and $r p b 2$ sequence data representing related taxa in Chaetomiaceae. Related sequences were taken from to Wang et al. (2019) and 33 strains were included in the combined analyses which comprised 2972 characters (581 characters for ITS, 855 characters for LSU, 936 characters for tef1, 600 characters for $r p b 2$, including gap regions). Collariella bostrychodes (CBS 163.73) and Collariella carteri (CBS 128.85) are used as the outgroup taxa. The tree from the maximum likelihood analysis had similar topology to the Bayesian analyses. The best sorting RaxML tree had a final likelihood value of -12501.711733 is presented. The matrix had 710 distinct alignment patterns with $6.40 \%$ undetermined characters or gaps. Estimated base frequencies were as follows: $\mathrm{A}=0.235341, \mathrm{C}=0.273490, \mathrm{G}=0.285063, \mathrm{~T}=0.206106$; substitution rates $\mathrm{AC}=1.347902, \mathrm{AG}=3.116716, \mathrm{AT}=1.526141$, $\mathrm{CG}=1.846122, \mathrm{CT}=7.547565, \mathrm{GT}=1.000000$; gamma distribution shape parameter $\alpha=1.039485$. In our analysis, GTR $+\mathrm{I}+\mathrm{G}$ model was used for each partition in Bayesian posterior analysis. The species determined in this study is indicated in blue. Bootstrap values (BS) greater than 50\% BS (ML, left) and Bayesian posterior probabilities (BYPP, right) greater than 0.90 are given at the nodes. Hyphens (-) represent support values less than 50\% BS/0.90 BYPP. Thick branches represent significant support values from all analyses at the genus level (BS $\geq 70 \% / B Y P P \geq 0.95$ )

brown, guttulate, with 3-7 $\mu \mathrm{m}$ thick mucilaginous sheath with upper pore. Asexual morph: Undetermined.

Material examined: UK, Hampshire, Botley Wood, on dead branches of Clematis vitalba, 25 May 2016, E.B.G. Jones, GJ289 (MFLU 16-2138, holotype).

Hosts: Clematis vitalba-(This study).

Distribution: UK-(This study).

GenBank accession numbers: LSU: MT214612; SSU: MT226723; ITS: MT310656; tef1: MT394668; rpb2: MT394717.

Notes: Sordaria clematidis (Fig. 98) has characters typical of Sordaria in having single perithecial, superficial, coriaceous ascomata with papillate ostioles, unitunicate, oblong asci with uniseriate, ovate, aseptate ascospores with a mucilaginous sheath. In the phylogenetic analysis (Fig. 97), S. clematidis formed a close relationship with the generic type $S$. fimicola (CBS 508.50), but received relatively low statistical support. Sordaria species are similar in their morphological characters, however, $S$. clematidis is unique in having pale yellow ascospores with upper pore in mucilaginous sheath and a germ-slit is absent (Maharachchikumbura et al. 2016). In a BLASTn search of GenBank, the closest match of the LSU sequence of strain MFLU 16-2138 is S. fimicola (strain CBS 485.64) with $98.00 \%$ similarity (MH870123). The closest match with the ITS sequence was Sordaria fimicola strain CBS 485.64 with $99.06 \%$ similarity (MH858489). Therefore, we introduce $S$. clematidis as a new species.
Subclass Diaporthomycetidae Senan., Maharachch. \& K.D. Hyde

\section{Diaporthales Nannf.}

Diaporthales is one of the most diverse orders within Diaporthomycetidae and comprises 24 families (Senanayake et al. 2017; Guterres et al. 2019). The order includes plantassociated fungi, some of which are economically important pathogens, parasites, others are endophytes or saprobes on various substrates (Alvarez et al. 2016). Diaporthales taxa are characterized by having pseudo- or ascostromata, brown to black perithecial fruiting bodies, asci with J-, refractive apical ring and hyaline to brown ascospores. The asexual states are usually coelomycetous with conidiophores arising from the inner side of the peridium layer, enteroblastic, holoblastic, phialidic or annellidic conidiogenous cells, and hyaline to brown conidia (Sogonov et al. 2008; Senanayake et al. 2017).

\section{Diaporthaceae Höhn. ex Wehm.}

Diaporthaceae taxa have a cosmopolitan distribution occurring as pathogens, saprobes or endophytes of terrestrial plants (Udayanga et al. 2014; Rossman et al. 2017; Thambugala and Hyde 2018). The sexual morphs of this family are characterized by perithecial, immersed to erumpent, papillate ascomata, 8-spored, asci with J-, refractive apical ring, and 1 septum, hyaline or dark to blackish brown ascospores with or without polar appendages. Asexual morphs are characterized by acervular or pycnidial conidiomata, ampulliform, cylindrical, septate conidiophores, enteroblastic, phialidic, determinate conidiogenous cells and 0-2-septate, hyaline or brown conidia sometimes with short appendages (Voglmayr and Jaklitsch 2014; Dissanayake et al. 2017; Senanayake et al. 2017, 2018). The family comprises 14 genera accepted by Wijayawardene et al. (2018).

\section{Diaporthe Nitschke}

Diaporthe (= Phomopsis) is an economically important plant pathogen that also includes endophytes or saprobes on a broad range of plant hosts (Udayanga et al. 2014; Hyde et al. 2016). Over 1000 epithets are listed under Diaporthe and most were introduced based on morphological characters and host association (Aa et al. 1990). In view of the genetic diversity and complexity of the known species, identifications of Diaporthe species currently relies on multilocus phylogenetic analyses (Senanayake et al. 2018; Manawasinghe et al. 2019). Phylogenetic analysis resulting from combined ITS, tef1, cal and tub2 sequence data of selected Diaporthe species are presented in Figs. 99 and 101. The ambiguous species that are related to the newly described species were analysed separately using Genealogical Concordance Phylogenetic Species Recognition (GCPSR) (Taylor et al. 2000) by performing a pairwise homoplasy index (Фw) test and the results are shown in Figs. 100 and 103. 


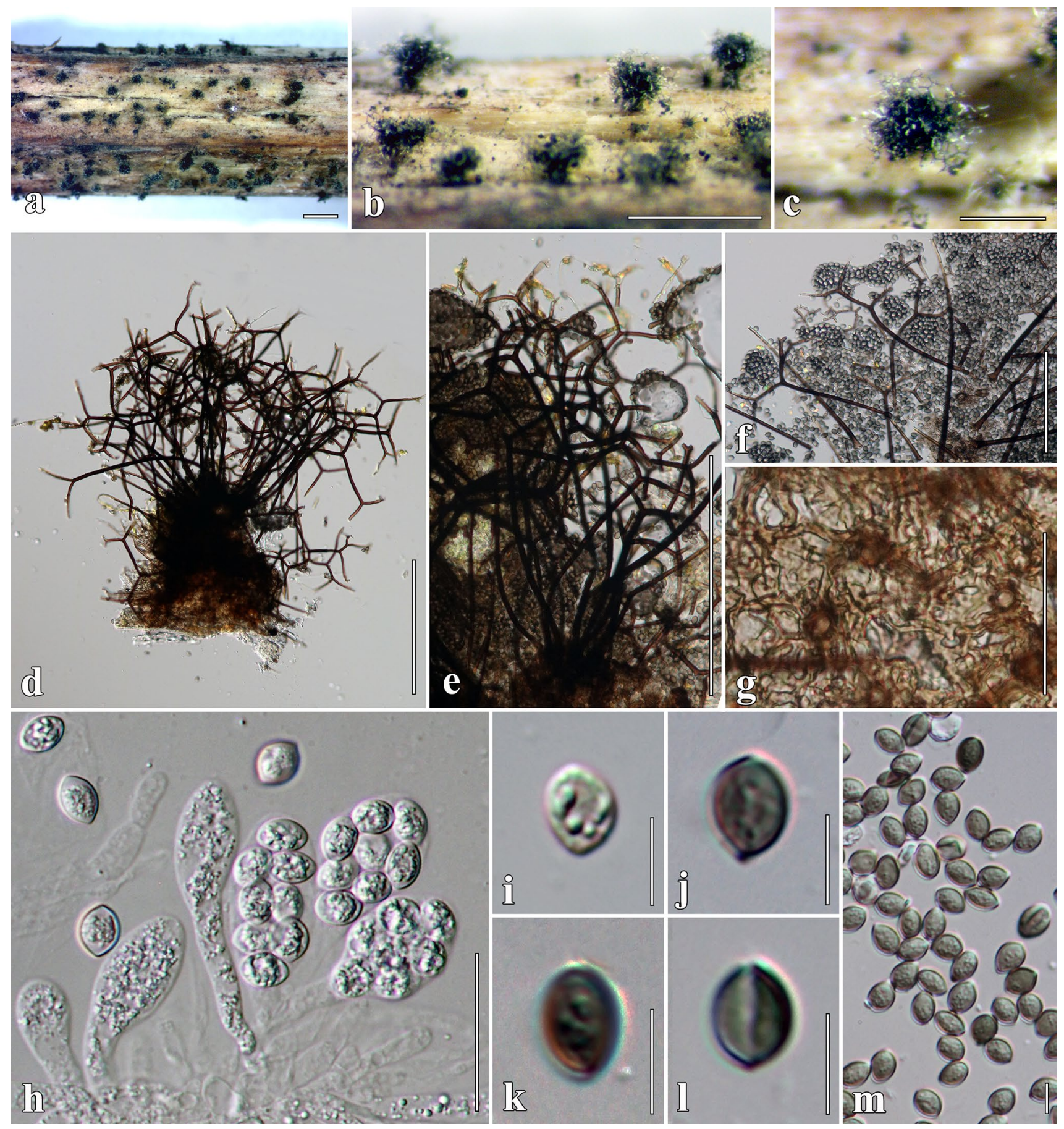

Fig. 96 Dichotomopilus ramosissimum (MFLU 16-2137). a Appearance of perithecia on Clematis vitalba. $\mathbf{b}, \mathbf{c}$ Close up of ascomata on host surface. d Ascoma. e, f Dichotomously branched terminal hairs and setae-like lateral hairs. $\mathbf{g}$ Structure of peridium in surface view. h Asci. i-m Ascospores. Scale bars: $\mathbf{b}=200 \mu \mathrm{m}, \mathbf{c}, \mathbf{d}=100 \mu \mathrm{m}$, e, $\mathbf{f}=50 \mu \mathrm{m}, \mathbf{g}, \mathbf{h}=20 \mu \mathrm{m}, \mathbf{i}-\mathbf{m}=5 \mu \mathrm{m}$ 


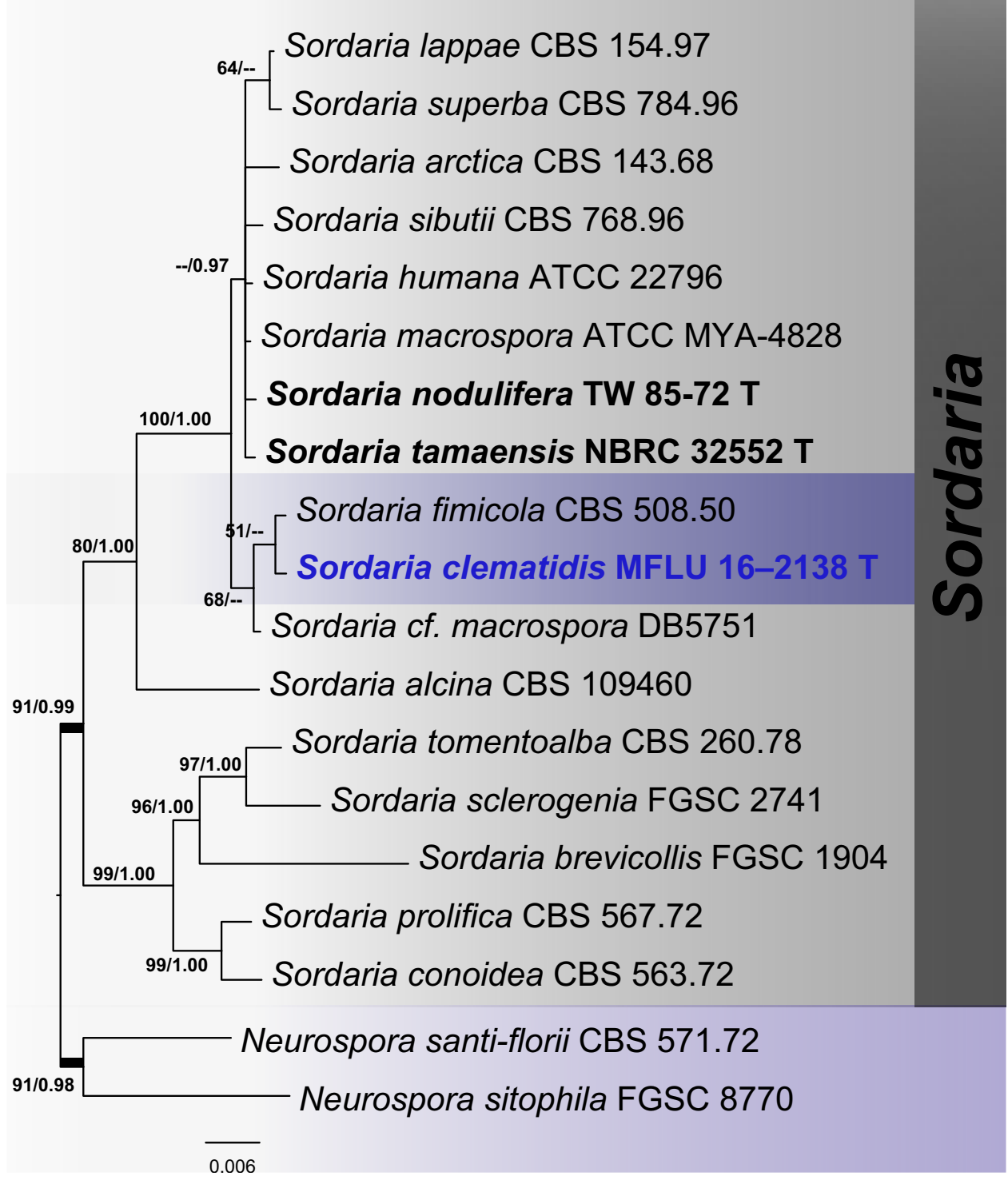

Fig. 97 The Bayesian 50\% majority-rule consensus phylogram for Sordaria members based on combined LSU, ITS and tub sequence data. The topology and clade stability of the combined gene analyses was compared to the single gene analyses. The tree is rooted with Neurospora santi-florii (CBS 571.72) and Neurospora sitophila (FGSC 8770). Nineteen strains were included in the combined analyses which comprised 2436 characters (833 characters for LSU, 601 characters for ITS, 1002 characters for $t u b$, including gap regions). The tree from the maximum likelihood analysis had similar topology to the Bayesian analyses. The best scoring RAxML tree had a final likelihood value of -5155.259712 . The matrix had 275 distinct alignment patterns with $36.05 \%$ undetermined characters and gaps. Estimated base frequencies were as follows; $\mathrm{A}=0.239918$, $\mathrm{C}=0.256198, \quad \mathrm{G}=0.278423, \mathrm{~T}=0.225461 ; \quad$ substitution rates $\mathrm{AC}=1.231551, \quad \mathrm{AG}=4.410425, \quad \mathrm{AT}=1.886486, \quad \mathrm{CG}=1.711684$, $\mathrm{CT}=9.592785, \mathrm{GT}=1.000000$; gamma distribution shape parameter $\alpha=1.270759$. In our analysis, GTR $+\mathrm{I}+\mathrm{G}$ model was used for each partition in Bayesian posterior analysis. The species determined in this study is indicated in blue. Bootstrap values (BS) greater than 50\% BS (ML, left) and Bayesian posterior probabilities (BYPP, right) greater than 0.90 are given at the nodes. Hyphens (-) represent support values less than $50 \%$ BS/0.90 BYPP. Thick branches represent significant support values from all analyses (BS $\geq 70 \% / B Y P P \geq 0.95$ ) at the genus level 


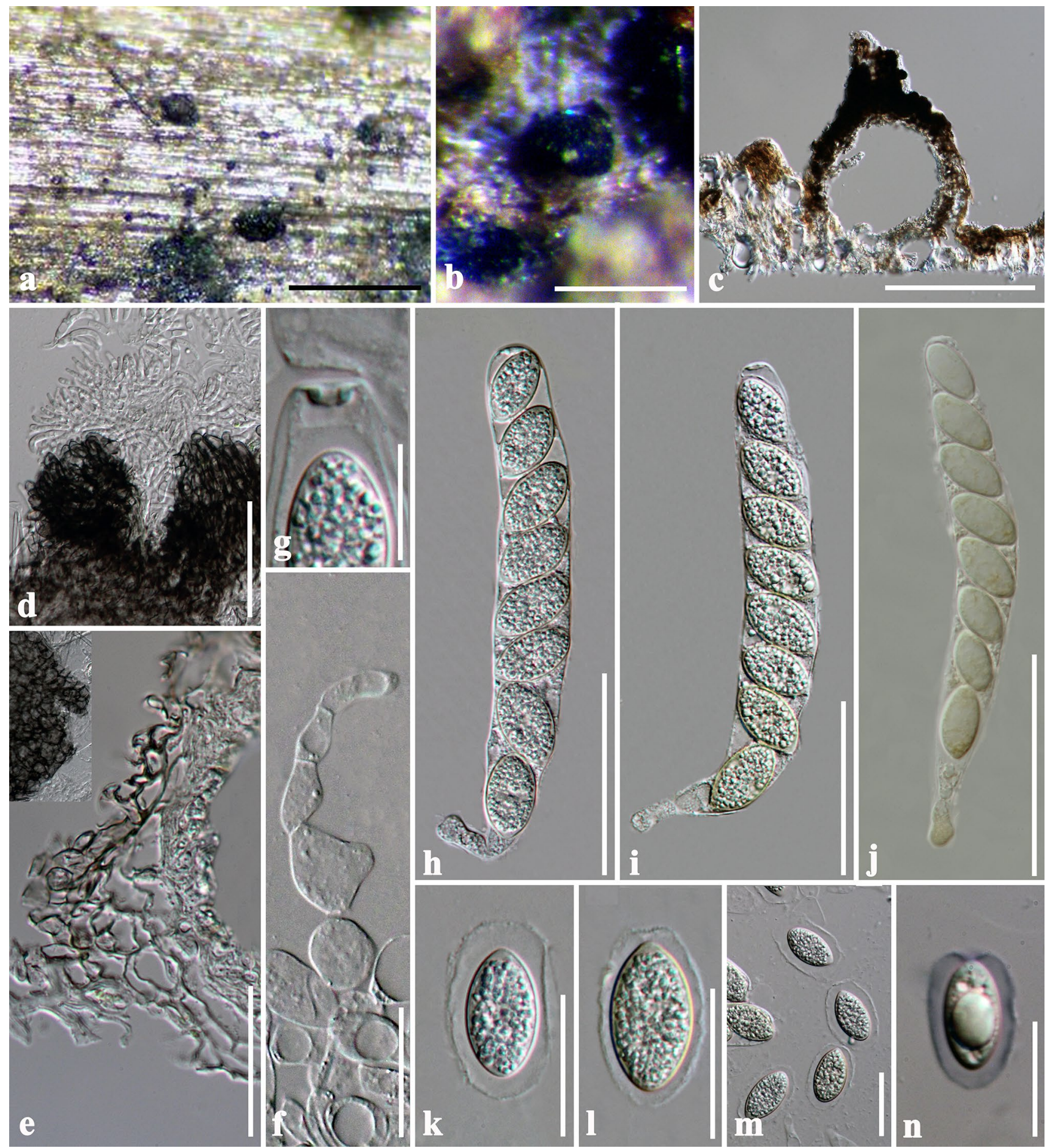

Fig. 98 Sordaria clematidis (MFLU 16-2138, holotype). a, b Appearance of ascomata on Clematis vitalba. c Vertical section through ascoma. d Ostioles. e Partial peridium part. f Paraphyses. g Presenting of apical ring. $\mathbf{h}-\mathbf{j}$ Asci (j Ascus in 5\% KOH with J-reac- tion of wedge-shaped apical ring. $\mathbf{k}-\mathbf{n}$ Ascospores (n Ascospore in $10 \%$ Indian ink). Scale bars: $\mathbf{a}=500 \mu \mathrm{m}, \mathbf{b}=200 \mu \mathrm{m}, \mathbf{c}=100 \mu \mathrm{m}$, $\mathbf{d}-\mathbf{f}, \mathbf{k}-\mathbf{n}=20 \mu \mathrm{m}, \mathbf{g}=10 \mu \mathrm{m}, \mathbf{h}-\mathbf{j}=50 \mu \mathrm{m}$ 
Fig. 99 Phylogram generated from maximum parsimony analysis based on combined ITS, tef1, cal and tub2 sequence data for selected members of Diaporthe. Related sequences are taken from Hyde et al. (2019) and retrieved from GenBank. The species tree included all members of Diaporthe and was performed for placement determination. Forty-two strains were included in the analysis of the combined loci and comprised 2359 characters (598 characters for ITS, 393 characters for tef1, 541 characters for $\mathrm{cal}, 827$ characters for $t u b 2$, including alignment gaps). The tree was rooted with Diaporthe crataegi (CBS 114435). Maximum parsimony analysis of 590 parsimony informative characters resulted in a single most parsimonious tree $(\mathrm{CI}=0.585$, $\mathrm{RI}=0.681, \mathrm{RC}=0.398$,

$\mathrm{HI}=0.415)$. The best scoring RAxML tree had a final likelihood value of -14560.846477 . GTRGAMMA bootstrapping model was applied to the matrix which had 1152 distinct alignment patterns, with $27.96 \%$ of undetermined characters and gaps. Estimated base frequencies were: $\mathrm{A}=0.218108$, $\mathrm{C}=0.320856, \mathrm{G}=0.237387$, $\mathrm{T}=0.223649$; substitution rates $\mathrm{AC}=1.282937, \mathrm{AG}=3.695471$, $\mathrm{AT}=1.225056, \mathrm{CG}=1.103739$, $\mathrm{CT}=4.789247, \mathrm{GT}=1.000000$; gamma distribution shape parameter $\alpha=0.888152$. In our analysis, GTR + I + G model was used for each partition in Bayesian posterior analysis. Bootstrap values (BS) from maximum parsimony (MP, left), maximum likelihood (ML, right) higher than 50\% BS and Bayesian posterior probabilities (BYPP, below) greater than 0.90 are given at the nodes. Hyphens (-) represent support values less than 50\% BS/0.90 BYPP. The ex-type strains are in bold and black. The newly generated sequence is in bold and blue

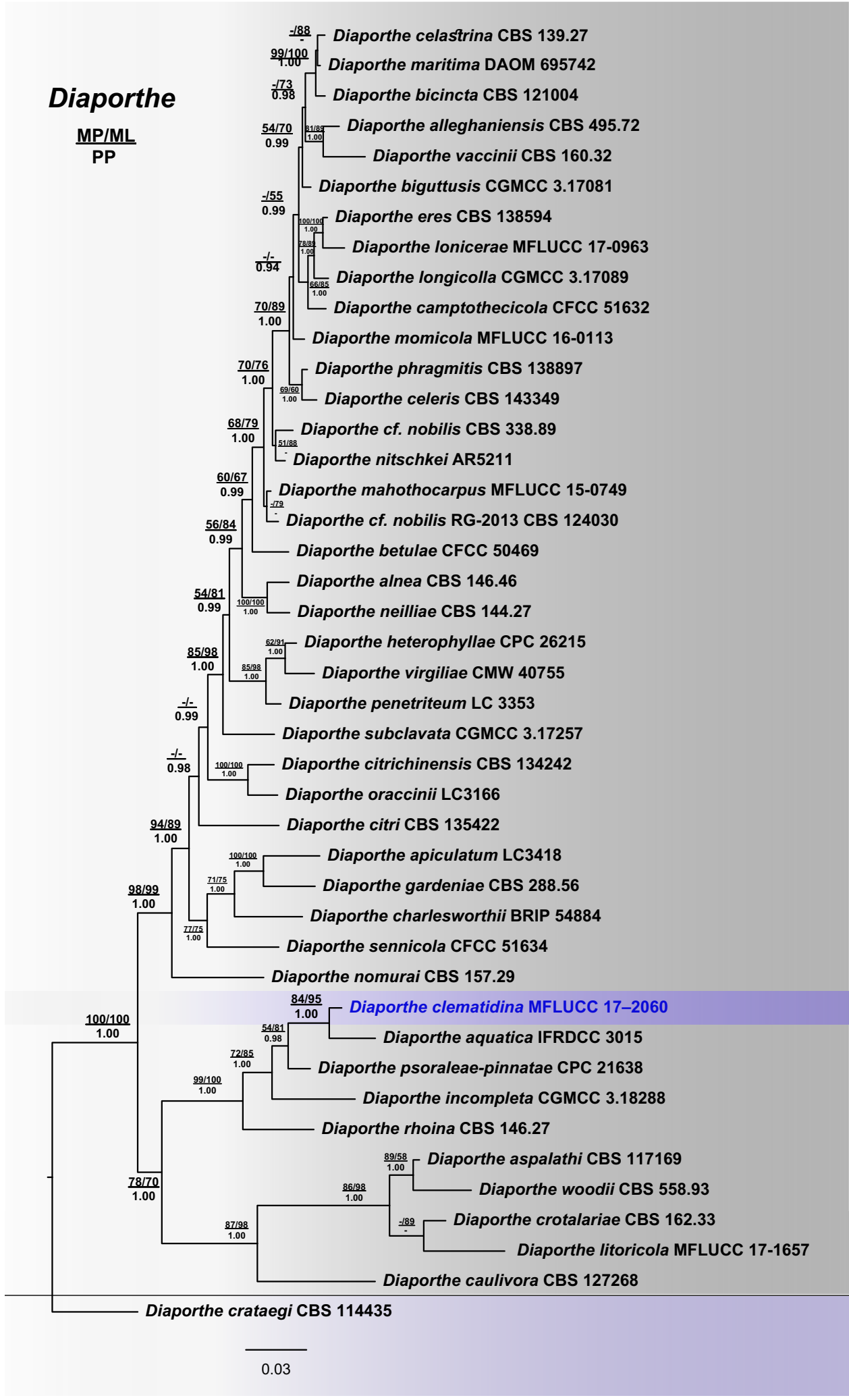


Fig. 100 The splits graph from the pairwise homoplasy index (PHI) test generated from the concatenated gene set of ITS, tef $1, c a l$ and $t u b 2$ sequence data of closely related species using both LogDet transformation and splits decomposition. In the PHI test results $(\Phi \mathrm{w})<0.05$ indicates significant recombination within the dataset. The strain determined in this study is in bold and blue

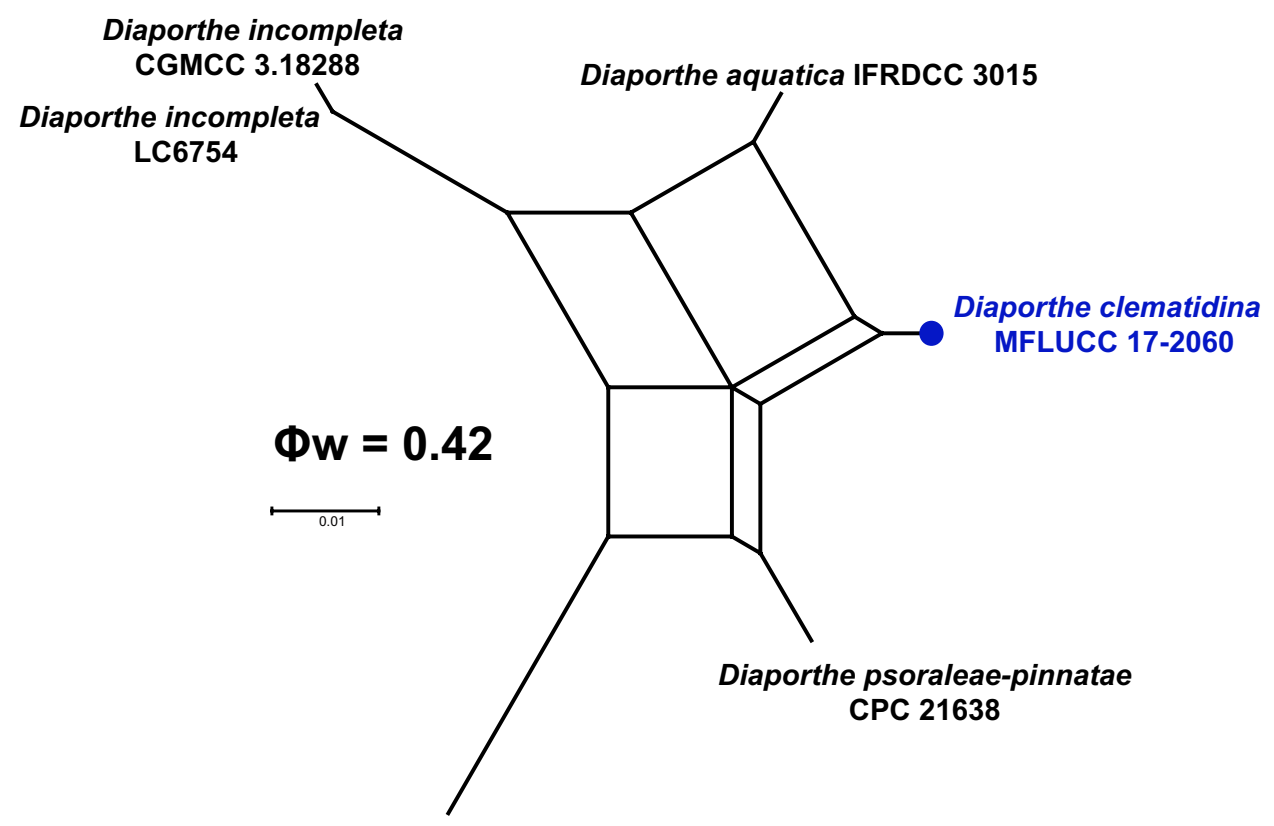

Diaporthe rhoina CBS 146.27
Diaporthe clematidina Phukhams., M.V. de Bult \& K.D. Hyde, sp. nov.

Index Fungorum number: IF557300; Facesoffungi number: FoF 07262, Fig. 101.

Etymology: Named after the host genus, Clematis.

Holotype: MFLU 17-1466.

Saprobic on Clematis subumbellata. Sexual morph: Ascomata $280-367 \times 167-296 \mu \mathrm{m}(\bar{x}=325 \times 250 \mu \mathrm{m}, \mathrm{n}=5)$, perithecial, solitary to aggregated, immersed, papillate only visible on the host substrate, obpyriform to globose, coriaceous, brown to dark brown, heavily pigmented at apex, papillate. Ostioles $125-221 \times 47-50 \mu \mathrm{m}(\bar{x}=180 \times 50 \mu \mathrm{m}$, $\mathrm{n}=5$ ), papillate, central or eccentric, broad oblong, filled with periphyses. Peridium $12-31 \mu \mathrm{m}$ wide $(\bar{x}=21 \mu \mathrm{m}$, $\mathrm{n}=20$ ), composed of 2-3 layers of thin-walled cells of textura globosa mixed with textura angularis, brown to reddish brown, thin at inner layer, hyaline. Paraphyses dense, 2-3 $\mu \mathrm{m}(\bar{x}=2.5 \mu \mathrm{m}, \mathrm{n}=30)$, septate, constricted at septa, broad filiform, tapering above asci. Asci $32-54 \times 7-10 \mu \mathrm{m}$ $(\bar{x}=46.5 \times 9 \mu \mathrm{m}, \mathrm{n}=20), 8$-spored, unitunicate, oblong to broad oblong, thin-walled, short or apedicellate, with a refractive, J-, apical ring. Ascospores $12-15 \times 3-5 \mu \mathrm{m}$ $(\bar{x}=14 \times 4 \mu \mathrm{m}, \mathrm{n}=40)$, partially overlapping, oblongellipsoidal, hyaline, uniseptate, with two guttules in each cell. Asexual morph: Pycnidial on PDA media. Conidiomata $140-350 \times 100-220 \mu \mathrm{m}(\bar{x}=225 \times 155 \mu \mathrm{m}, \mathrm{n}=5)$, globose, eustromatic, multilocular, gregarious, erumpent or superficial, covered by dense vegetative hyphae, occasionally with ostiolate necks. Pycnidial wall parenchymatous, consisting of brown, thick-walled cells of textura angularis. Conidiophores short, hyaline, smooth, densely aggregated, cylindrical, straight. Conidiogenous cells $8-14 \times 8-12 \mu \mathrm{m}$, phialidic, cylindrical, terminal, with slight tapering towards apex, hyaline, formed from the inner layer of pycnidial wall. Alpha conidia 5-8 $\times 2-3 \mu \mathrm{m}(\bar{x}=6 \times 2.5 \mu \mathrm{m}, \mathrm{n}=20)$, aseptate, hyaline, smooth, ovate to ellipsoidal, biguttulate. Beta conidia $17.5-30 \times 1-2 \mu \mathrm{m}(\bar{x}=25 \times 1.7 \mu \mathrm{m}, \mathrm{n}=5)$, aseptate, hyaline, smooth, fusiform, tapering towards both ends, apex conical, base subtruncate. Gamma conidia not observed.

Culture characters: Colonies growing on PDA reaching $20 \mathrm{~mm}$ within 4 weeks at $25^{\circ} \mathrm{C}$. Culture from above, white, radiating, to the edge, faintly zonate, margin undulate, dense, flat or umbonate; reverse light brown, white radiating outwardly.

Material examined: Thailand, Chiang Rai Province, on dead stems of Clematis subumbellata, 20 March 2017, C. Phukhamsakda, CMTH2 (MFLU 17-1466, holotype); extype living culture, MFLUCC 17-2060.

Host: Clematis subumbellata-(This study).

Distribution: Thailand-(This study).

GenBank accession numbers: LSU: MT214613; SSU: MT226724; ITS: MT310657; tef1: MT394669, MT394625; rpb2: MT394718; cal: MT394624; tub2: MT394623.

Notes: Phylogenetic analysis of Diaporthe clematidina based on the combined ITS, tefl, cal and tub2 sequence data, shows that the strain clusters in a well-supported clade (84\% MP, 95\% ML support and 1.00 BYPP) sister to $D$. aquatica (IFRDCC 3015) as shown in Fig. 99. Diaporthe clematidina differs from $D$. aquatica in its shorter neck (1100-2250×80-120 vs $125-221 \times 47-50 \mu \mathrm{m})$, and broad oblong ascospores with conical ends. Diaporthe clematidina was found in a terrestrial habitat, while $D$. aquatica was 


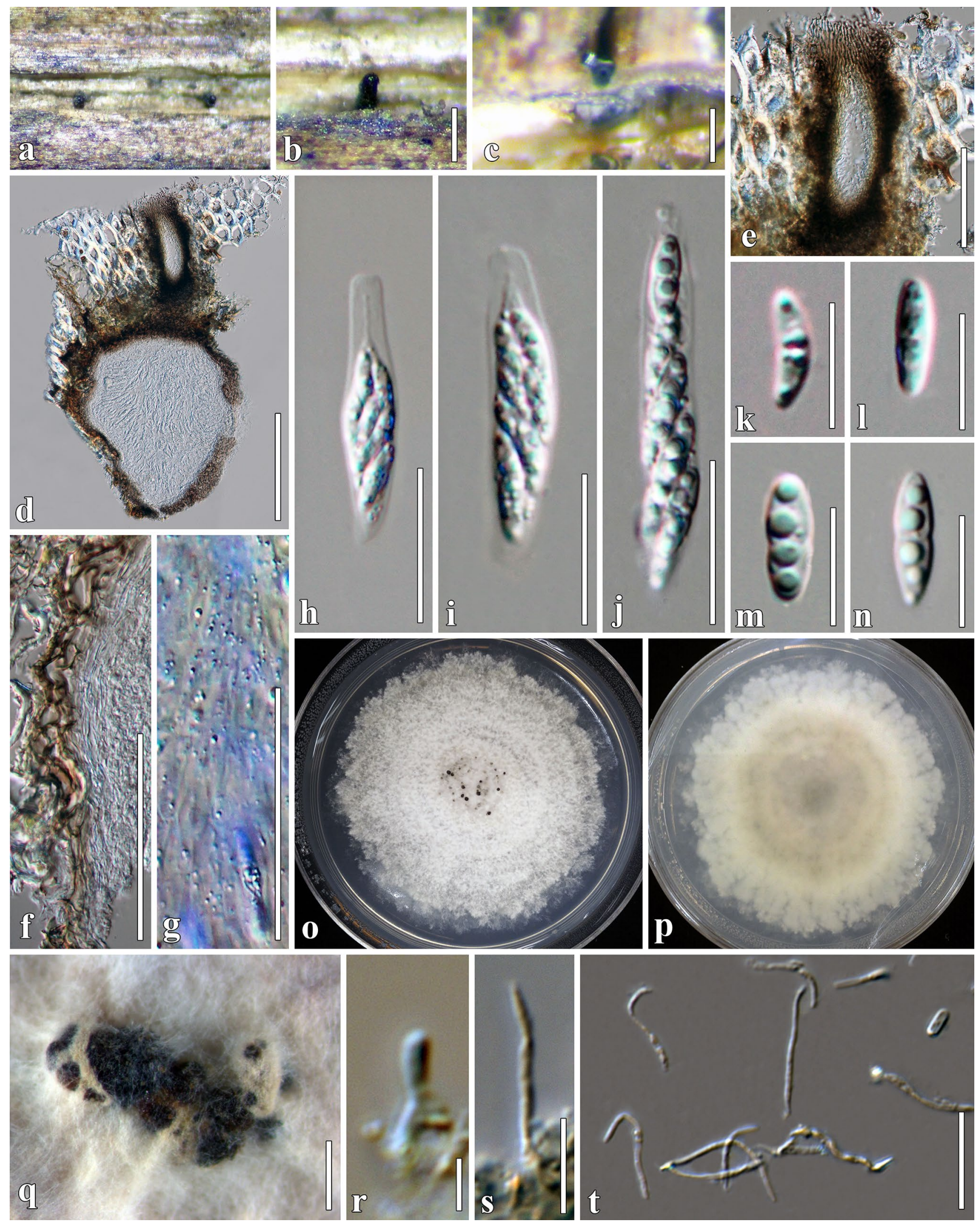

Fig. 101 Diaporthe clematidina (MFLU 17-1466, holotype). a, b Appearance of ascomata on Clematis subumbellata. c Close up of ascoma on the host. d Vertical section through ascoma. e Ostiolar canal. f Peridium. g Paraphyses. h-j Asci. k-n Ascospores. o, p Culture characteristics on PDA. q Pycnidia produced in culture. $\mathbf{r}$ Conidiogenous cell with an alpha conidium. s Conidiogenous cell with a beta conidium. $\mathbf{t}$ Alpha and beta conidia. Scale bars: $\mathbf{b}-\mathbf{d}$, $\mathbf{q}=200 \mu \mathrm{m}, \mathbf{e}=100 \mu \mathrm{m}, \mathbf{f}, \mathbf{g}=50 \mu \mathrm{m}, \mathbf{h}-\mathbf{j}=20 \mu \mathrm{m}, \mathbf{k}-\mathbf{n}, \mathbf{r}-\mathbf{t}=10 \mu \mathrm{m}$ 
Fig. 102 Phylogram generated from maximum parsimony analysis based on combined ITS, tef1, cal and tub2 sequence data for selected Diaporthe species. Related sequences were selected from Hyde et al. (2019) and retrieved from GenBank. The species tree was performed for placement determination. Sixty-four strains were included in the combined analyses, which comprised 2380 characters $(603$ characters for ITS, 409 characters for tef1, 542 characters for $c a l, 826$ characters for $t u b 2$, including alignment gaps). The tree was rooted with Diaporthe toxica (CBS 534.93). Maximum parsimony analysis of 736 parsimony informative characters resulted in a single most parsimonious tree $(\mathrm{CI}=0.555$, $\mathrm{RI}=0.815, \mathrm{RC}=0.453$, $\mathrm{HI}=0.445)$. The best scoring RAxML tree had a final likelihood value of -18803.562906 . The matrix had 1329 distinct alignment patterns, with $32.77 \%$ of undetermined characters and gaps. Estimated base frequencies were: $\mathrm{A}=0.224328$, $\mathrm{C}=0.306223, \mathrm{G}=0.237767$, $\mathrm{T}=0.231682$; substitution rates $\mathrm{AC}=1.005463, \mathrm{AG}=2.446938$, $\mathrm{AT}=0.976921, \mathrm{CG}=0.744774$, $\mathrm{CT}=3.4857627$,

$\mathrm{GT}=1.000000$; gamma distribution shape parameter $\alpha=0.765064$. In our analysis, GTR + I + G model was used for each partition in Bayesian posterior analysis. The species determined in this study are indicated in blue. Bootstrap values (BS) from maximum parsimony (MP, left), maximum likelihood (ML, right) higher than 50\% BS and Bayesian posterior probabilities (BYPP, below) greater than 0.90 are given at the nodes. Hyphens (-) represent support values less than 50\% BS/0.90 BYPP. The ex-type strains are in bold and black

\section{Diaporthe \\ MP/ML PP}

$\frac{100}{0.98}$

Diaporthe rudis CPC 28268, Vitis vinifera

Diaporthe rudis STE.U 5683, Vitis vinifera

Diaporthe rudis CBS 266.85, Rosa rugosa

Diaporthe rudis CPC 28425, Vitis vinifera

Diaporthe rudis CPC 29658, Vitis vinifera

Diaporthe rudis CBS 109292, Brugmansia sp.

Diaporthe rudis AR3654, Rosa canina

Diaporthe rudis AR3422, Laburnum anagyroides

Diaporthe rudis CPC 29320, Vitis vinifera

Diaporthe rudis CBS 114436, Sambucus cf. racemosa

Diaporthe rudis CBS 113201, Vitis vinifera

0.98
$\frac{6899}{0.99}$
Diaporthe rudis MFLUCC 17-2153, Clematis serratifolia
Diaporthe rudis MFLUCC 17-2500, Anthoxanthum odoratum

Diaporthe rudis ICMP 16419, Castanea sativa

Diaporthe asheicola CBS 136967

$\frac{66 / 99}{1.00}$

Diaporthe australafricana CBS 111886

$\frac{57168}{0.91}$

$\frac{91 / 99}{1.00}$

Diaporthe salicicola BRIP 54825

Diaporthe pseudotsugae MFLU 15-3228

12793 - Diaporthe cassines CBS 136440

Diaporthe nothofagi BRIP 54801

$\frac{9899}{1.00}$ Diaporthe cf. heveae CBS 852.97

65163 Diaporthe ocoteae CPC 26217

${ }_{-163}^{.938}$. Diaporthe ternstroemia CGMCC 3.15183

Diaporthe fusicola CGMCC 3.17087

$\frac{5903}{0.99}$ Diaporthe sterilis CBS 136969

$1001100^{0.99}$ Diaporthe ovoicicola CGMCC 3.17092

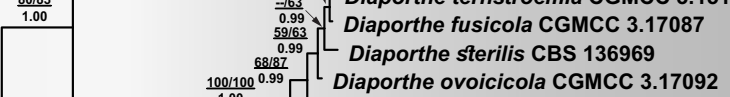

$\frac{8397}{1.00}$
1.00 $\begin{aligned} & \text { Diaporthe garethjonesii MFLUCC 12-0542 } \\ & \text { Diaporthe amygdali CBS } 126679\end{aligned}$

Diaporthe obtusifoliae CPC 32336

Diaporthe pustulata CBS 109742

[Diaporthe ravennica MFLUCC 15-0479, Tamarix sp.

-165 Diaporthe ravennica MFLUCC 17-1029, Salvia sp.

0.99 Diaporthe ravennica MFLUCC 15-0480, Tamarix sp.

681-- Diaporthe ravennica MFLUCC 16-0997, Clematis vitalba

1.00 Diaporthe baccae CBS 136972

年87

$\frac{6471}{0.95}$ Diaporthe chamaeropis CBS 454.81

Diaporthe cytosporella FAU 461

$1.00 \quad \frac{1.00}{1.0}$ Diaporthe dorycnii MFLUCC 17-1015

Diaporthe cinerascens CBS 719.96

100/100 Diaporthe macintoshii BRIP 55064

53174 Diaporthe vangueriae CPC 22703

-I.-- Diaporthe maytenicola CPC 21896

0.93 Diaporthe parapterocarpi CPC 22729

56 Diaporthe cissampeli CPC 27302

67161 Diaporthe hickoriae CBS 145.26

Diaporthe saccarata CBS 116311

Diaporthe oncostoma CBS 589.78

_57.60 Diaporthe canthii CBS 132533

$\frac{9998}{1.00}$ Diaporthe anacardii CBS 720.97

Diaporthe velutina CGMCC 3.18286

$\frac{1001100}{100}$ - Diaporthe inconspicua CBS 133813

oberliniae CPC 22549

Diaporthe elaeagni CBS 50472

Diaporthe

-151 Diaporthe stictica CBS 370.54

Diaporthe elaeagni-glabrae CGMCC 3.18287

-157 - Diaporthe diospyricola CPC 21169

Diaporthe psoraleae CPC 21634

Diaporthe crataegi CBS 114435

Diaporthe toxica CBS 534.93 


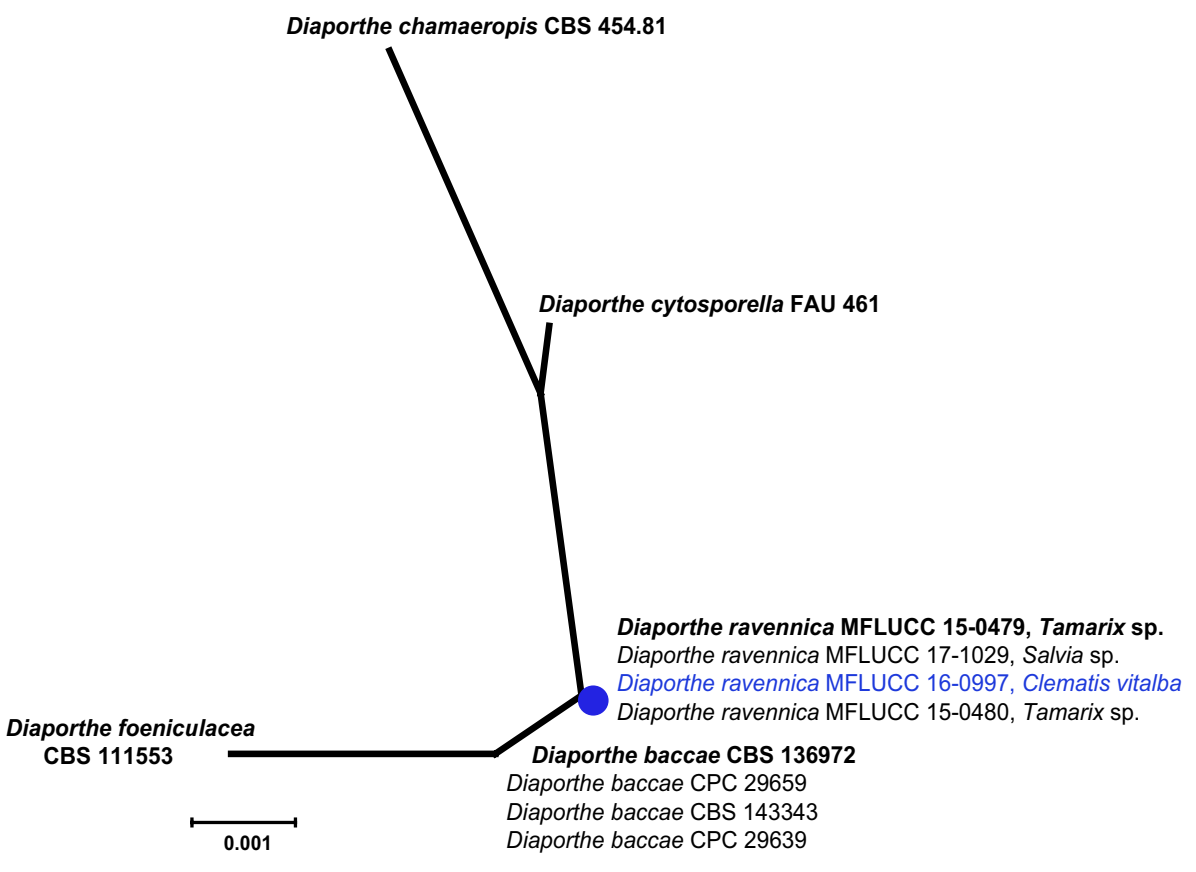

a $\Phi w=0.15$

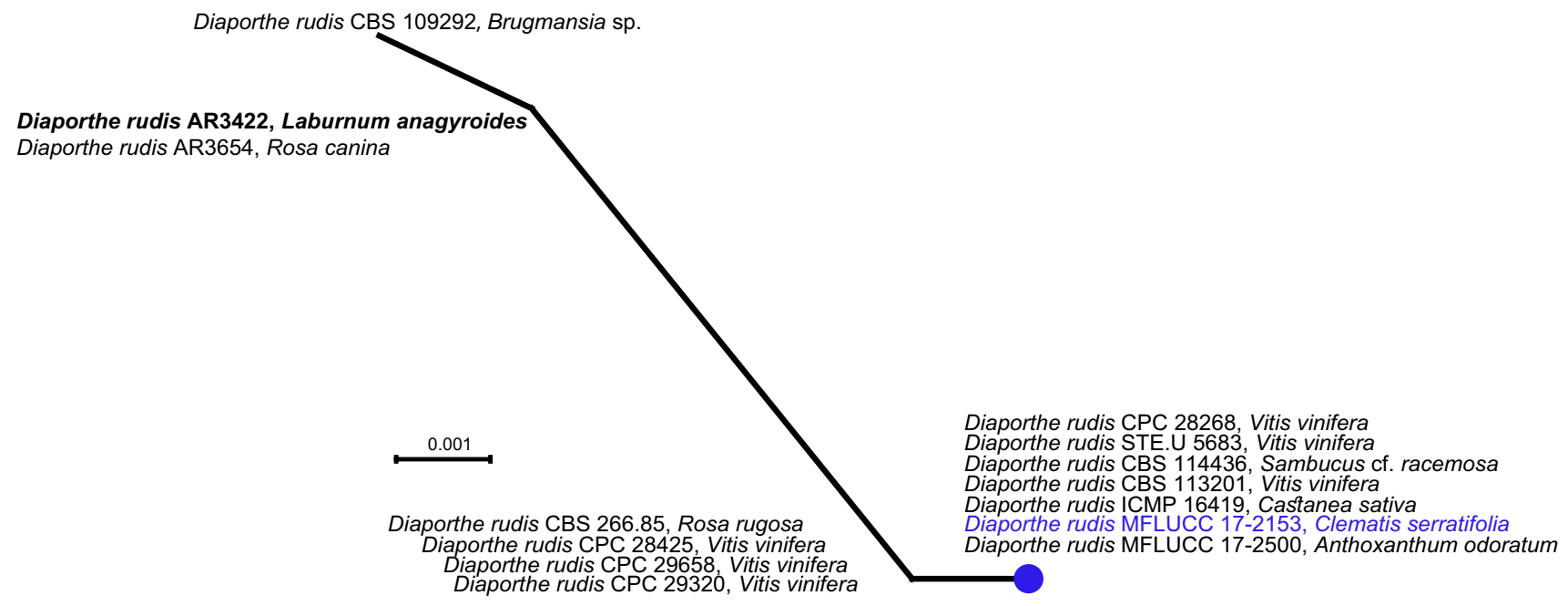

b $\Phi w=0.05$

Fig. 103 The splits graph from the pairwise homoplasy index (PHI) test generated from the concatenated gene set of closely related Diaporthe species a $D$. ravennica, b $D$. rudis using both LogDet transfor- mation and splits decomposition. The PHI test $\left(\Phi_{\mathrm{w}}\right)<0.05$ indicates significant recombination within the dataset. The strains determined in this study are in blue 

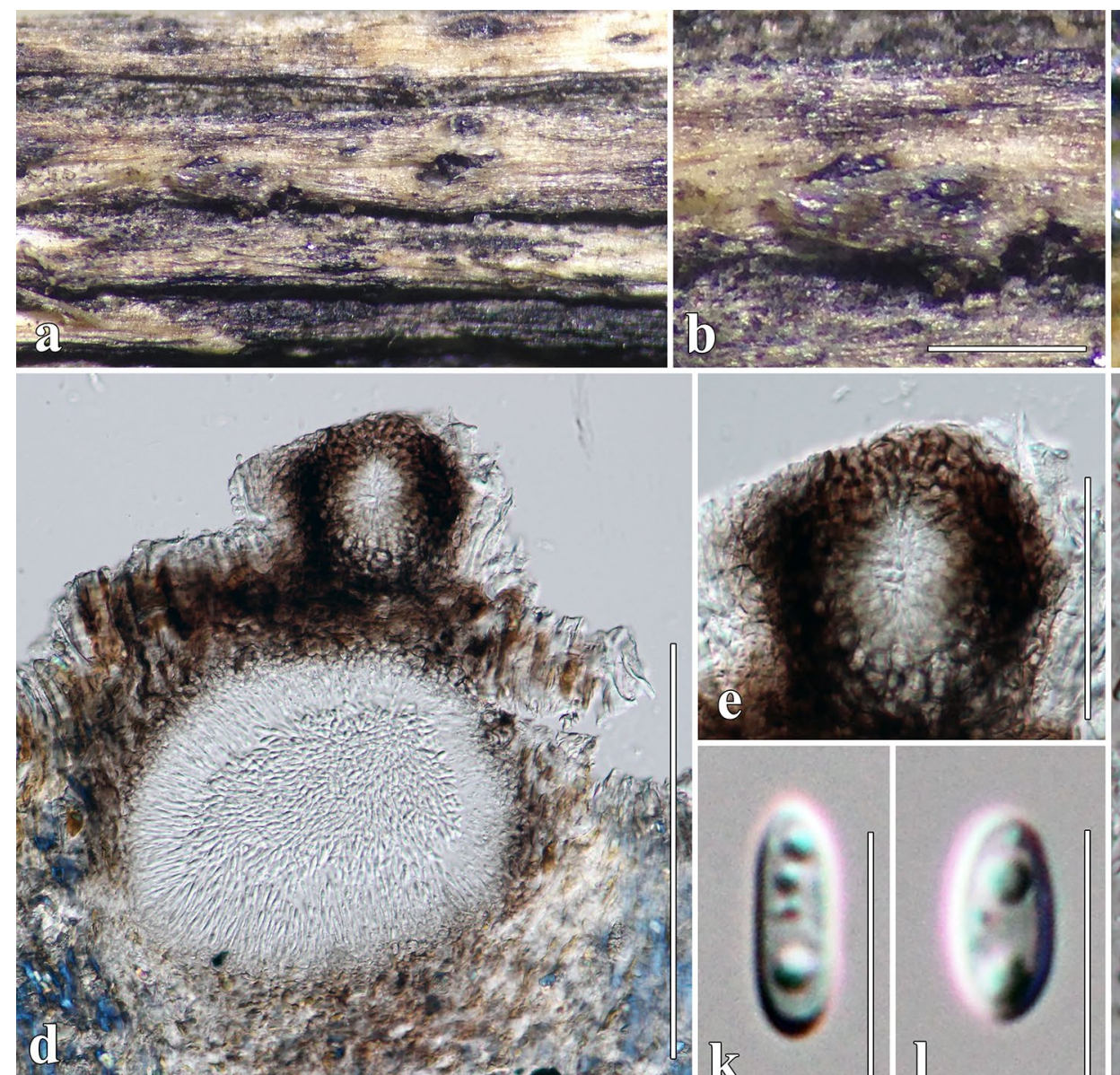

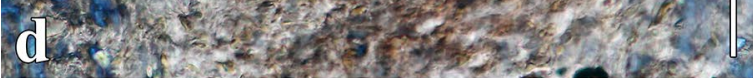

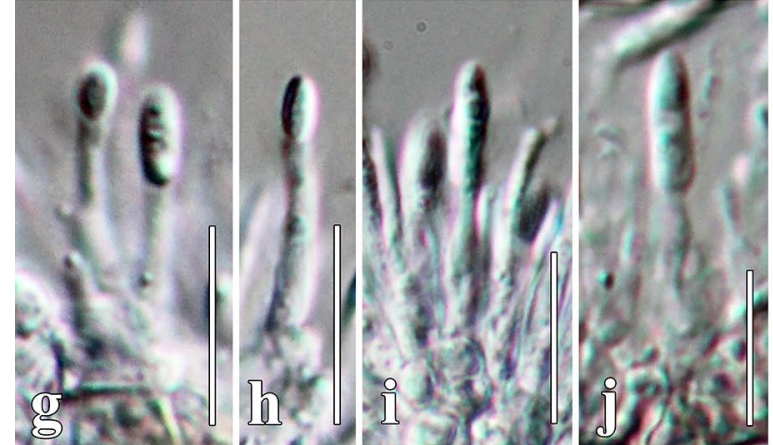

3.
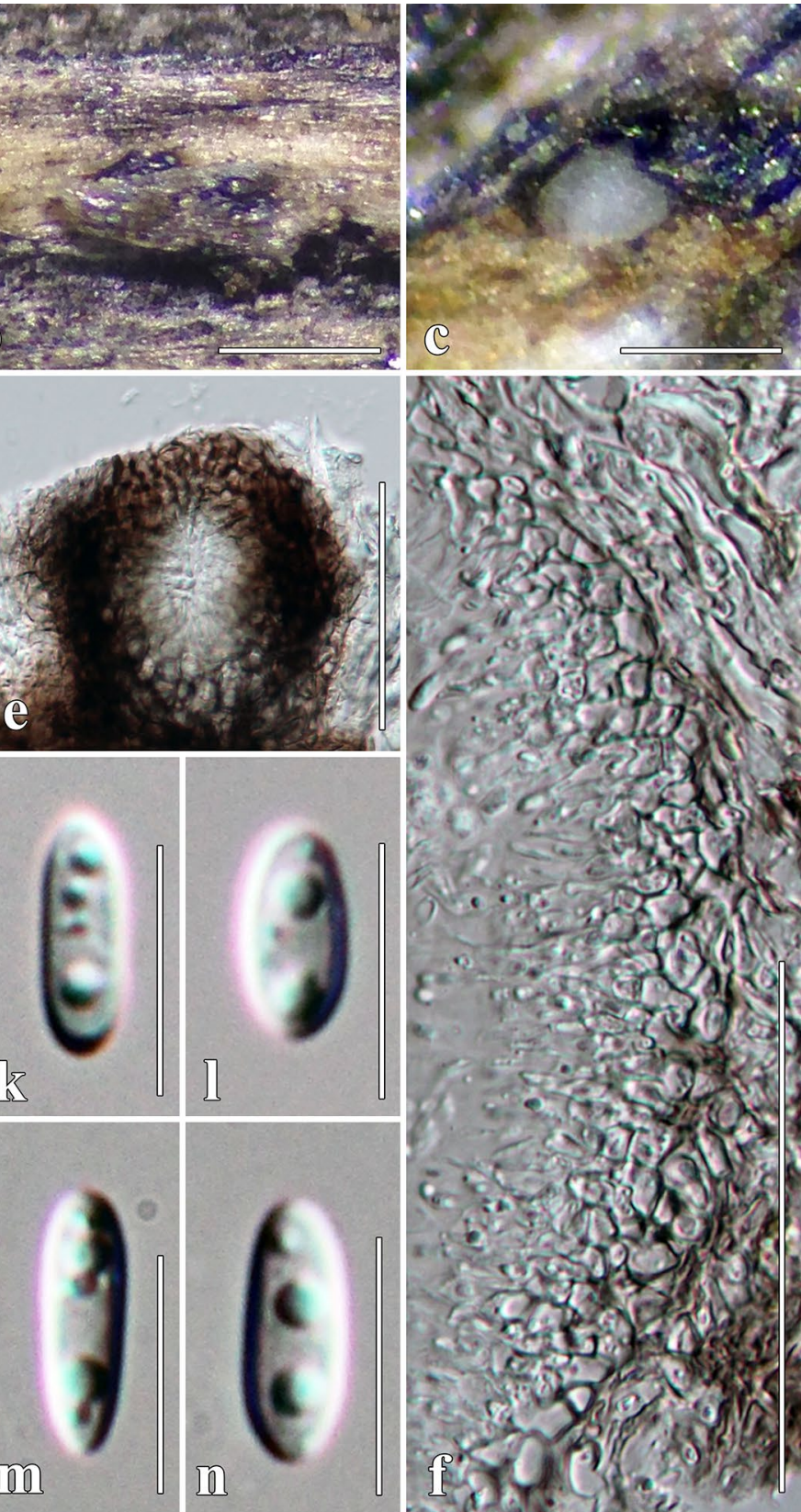

$8{ }^{2} 3{ }^{2}$.

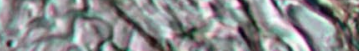

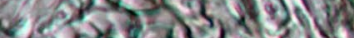

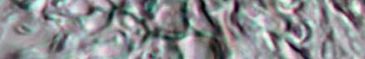

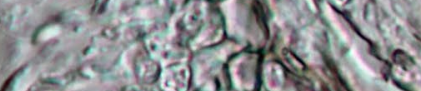

cosisgrats
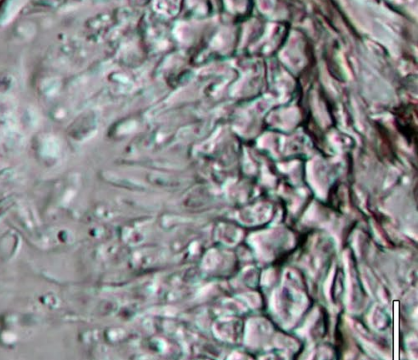

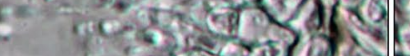
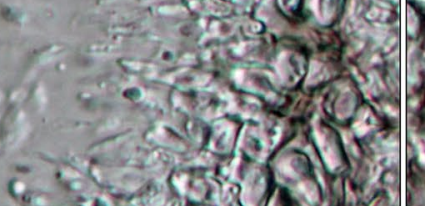

C. chersis 10
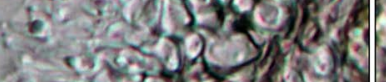

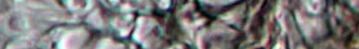

colsterant

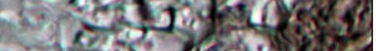

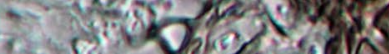

ste

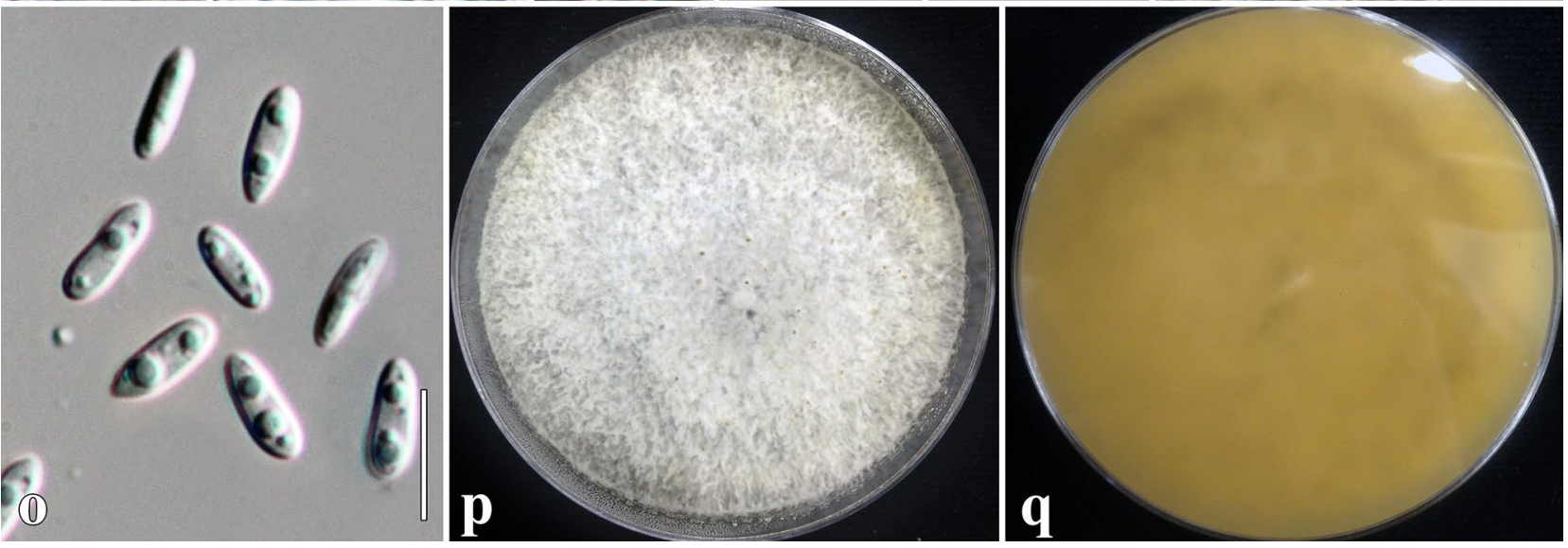


associated with submerged wood in a small ditch (Hu et al. 2012). Diaporthe clematidina is phylogenetically related, but differentiated from $D$. aquatica by 49 nucleotides in ITS. However, the other gene regions for D. aquatica are not available for nucleotide comparisons. When applying the GCPSR concept to fulfil the genetic differentially independence of the combined dataset within the closely related taxa (Fig. 99), we detected no significant recombination between these isolates ( $\Phi \mathrm{w}=0.42$, Fig. 100). Thus, D. aquatica and D. clematidina represents two distinct species.

Diaporthe ravennica Thambug., Camporesi \& K.D. Hyde, Fungal Diversity 82: 296 (2016), new host record

Index Fungorum number: IF552100; Facesoffungi number: FoF02171, Fig. 104.

Saprobic on Clematis vitalba. Sexual morph: Undetermined. Asexual morph: Conidiomata $250-450 \times 220-300 \mu \mathrm{m}(\bar{x}=330 \times 250 \mu \mathrm{m}, \mathrm{n}=5)$, scattered, uniloculate or multi-loculate, immersed to slightly erumpent, gregarious, globose, occasionally with ostiolate necks. Ostioles $75-190 \times 52-170 \mu \mathrm{m}(\bar{x}=121 \times 124 \mu \mathrm{m}, \mathrm{n}=5)$, papillate, central or eccentric, broad oblong, lined with periphyses. Pycnidial wall $12-20 \mu \mathrm{m}(\bar{x}=14.6 \mu \mathrm{m}, \mathrm{n}=20)$, parenchymatous, walls consisting of dark brown, thick, walled cells of textura angularis. Paraphyses not observed. Conidiophores $5-14 \times 1.5-2.5 \mu \mathrm{m}(\bar{x}=8.5 \times 2.0 \mu \mathrm{m}, \mathrm{n}=30)$, long, hyaline, smooth, densely aggregated, unbranched, cylindrical, straight. Conidiogenous cells $1.8-2 \times 2-3 \mu \mathrm{m}$, phialidic, cylindrical, terminal, slightly tapering towards apex, hyaline, formed from the inner layer of pycnidium wall. Alpha conidia $8-11.5 \times 2-4 \mu \mathrm{m}(\bar{x}=9.5 \times 2.8 \mu \mathrm{m}$, $\mathrm{n}=40$ ), aseptate, hyaline, smooth, ovate to ellipsoidal, biguttulate or multi-guttulate. Beta and gamma conidia not observed on Clematis vitalba or in culture.

Culture characters: Colonies growing on PDA reaching $40 \mathrm{~mm}$ within 4 weeks at $16{ }^{\circ} \mathrm{C}$. Culture from above, white, radiating to the edge, margin undulate, medium dense, flat or umbonate; reverse, cream, radiating white outwardly.

Material examined: Italy, Forlì-Cesena Province, San Lorenzo in Noceto-Forlì, on dead aerial branch Clematis vitalba, 20 March 2016, E. Camporesi, IT2893C (MFLU 20-0422); living culture, MFLUCC 16-0997.

Hosts: Clematis vitalba, Tamarix sp., Salvia sp.-(Thambugala et al. 2017; Dissanayake et al. 2017; this study).

4 Fig. 104 Diaporthe ravennica (MFLU 20-0422). a, b Appearance of conidiomata on Clematis vitalba. c Close up of conidioma on host substrate. d Vertical section through conidioma. e Ostiolar canal. f Peridium. g-j Conidiogenous cells and developing states of conidia. k-o Alpha conidia. p, q Culture characteristics on PDA. Scale bars: $\mathbf{b}=500 \mu \mathrm{m}, \mathbf{c}, \mathbf{d}=200 \mu \mathrm{m}, \mathbf{e}, \mathbf{f}=50 \mu \mathrm{m}, \mathbf{g}-\mathbf{o}=10 \mu \mathrm{m}$
Distribution: Italy—(Thambugala et al. 2017; Dissanayake et al. 2017; this study).

GenBank accession numbers: LSU: MT214614; SSU: MT226725; ITS: MT310658; tef1: MT394670.

Notes: Diaporthe ravennica (MFLUCC 16-0997) clusters with other $D$. ravennica isolates from Tamarix sp. and Salvia sp. (Thambugala et al. 2017; Dissanayake et al. 2017). The description of $D$. ravennica by Thambugala et al. (2017) stated that the strain produced beta conidia in natural substrates, but beta conidia were not observed in the strain associated with Clematis vitalba branches or in culture. A phylogenetic tree derived from an alignment of combined ITS, tefl, $c a l$ and $t u b 2$ sequence data showed that the $D$. ravennica clade received $65 \%$ support from ML and 0.99 BYPP (Fig. 102). The GCPSR concept was applied to the concatenated gene set of the closely related taxa $(D . b a c$ cae, $D$. chamaeropis, D. foeniculacea, D. ravennica) are presented (Fig. 103). A phi-test of the four loci detected nonsignificant recombination between these isolates $(\Phi w=0.15$, Fig. 103a). Thus, the four isolates of $D$. ravennica including our collection are clearly demarcated and delimited from the other taxa (Fig. 104).

Diaporthe rudis (Fr.) Nitschke, in Pyrenomycetes Germanici 2: 282 (1870), new host record

Index Fungorum number: IF552100; Facesoffungi number: FoF02171, Fig. 105.

Saprobic on Clematis serratifolia. Sexual morph: Ascomata 320-420 × 190-275 $\mu \mathrm{m}(\bar{x}=376 \times 246 \mu \mathrm{m}, \mathrm{n}=5)$, perithecial, solitary to aggregated, immersed, only papilla visible on the host substrate, obpyriform to globose, coriaceous, dark brown to black, lighter pigment at apex, papillate. Ostioles $130-255 \times 120-135 \mu \mathrm{m}(\bar{x}=205 \times 125 \mu \mathrm{m}$, $\mathrm{n}=5$ ), papillate, central or eccentric, broad oblong, lined with periphyses. Peridium $18-30(-45 \mu \mathrm{m}$ at apex) wide, composed of 2-3 layers of thin-walled cells of textura angularis, brown to reddish brown, thin at inner layer, hyaline. Paraphyses sparse, 5-8 $\mu \mathrm{m}(\bar{x}=6 \mu \mathrm{m}, \mathrm{n}=30)$, septate, constricted at septa, broad filiform, tapering above asci. Asci $50-72 \times 9-13 \mu \mathrm{m}(\bar{x}=60 \times 10 \mu \mathrm{m}, \mathrm{n}=20), 8$-spored, unitunicate, oblong to broad oblong, thin-walled, short or apedicellate, with a refractive, J-, apical ring. Ascospores $7.5-13 \times 2-5 \mu \mathrm{m}(\bar{x}=7 \times 3 \mu \mathrm{m}, \mathrm{n}=40)$, partially overlapping, biseriate, oblong-ellipsoidal, hyaline, uniseptate, with two guttules in each cell, with approximately $2.5 \mu \mathrm{m}$ long polar appendages. Asexual morph: See Udayanga et al. (2014).

Culture characters: Colonies growing on PDA reaching $20 \mathrm{~mm}$ within 4 weeks at $25^{\circ} \mathrm{C}$. Culture from above, white, radiating outwardly to the edge, circular, dense, flat or umbonate; reverse cream, white, radiating outwardly.

Material examined: Belgium, Flemish Brabant; Meise Botanic Garden, Bouchout domain, on dead branch of 


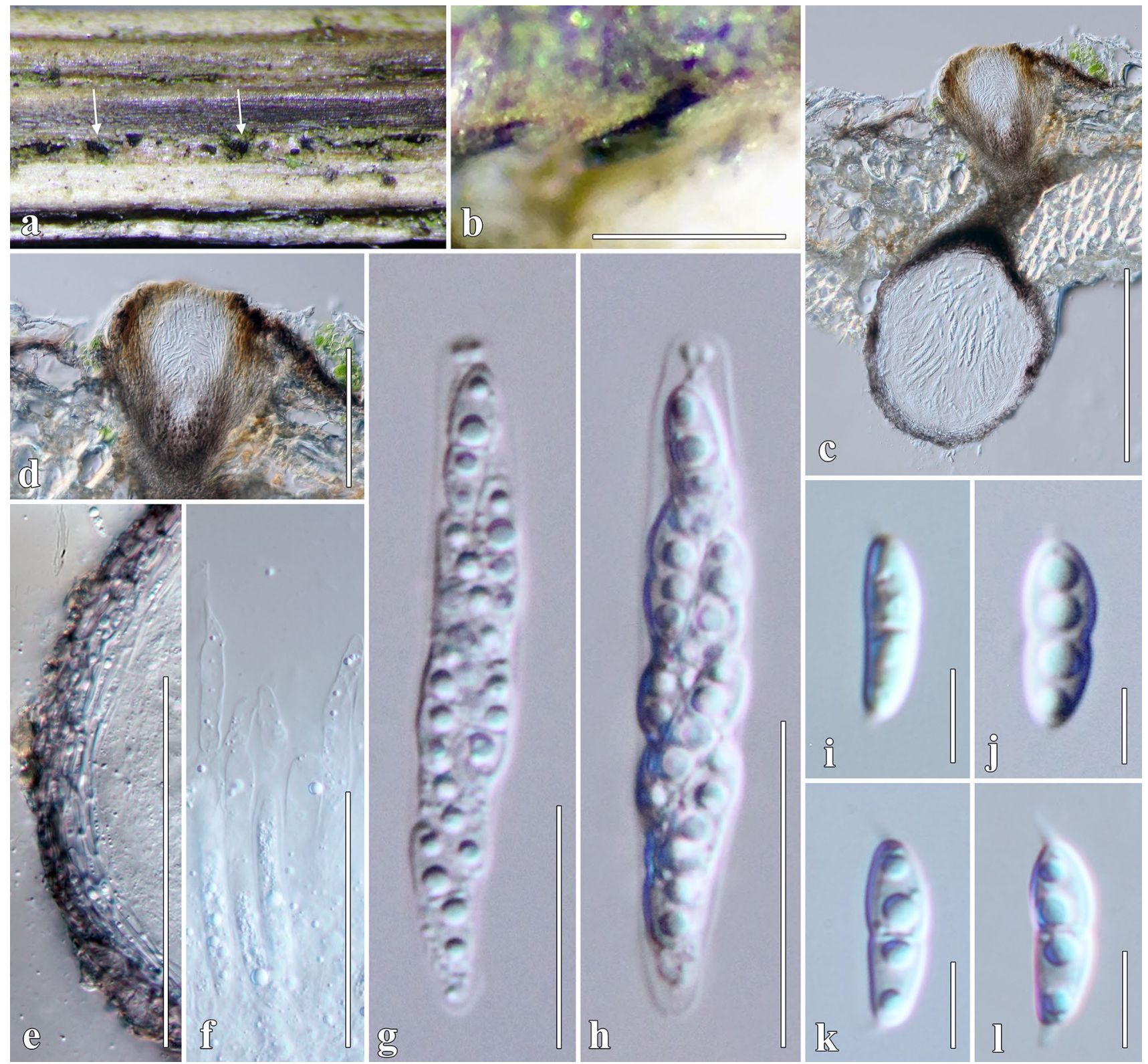

Fig. 105 Diaporthe rudis (MFLU 17-1510). a Appearance of ascomata on Clematis serratifolia. b Close up of ascoma on host substrate. c Vertical section through ascoma. d Ostiolar canal. e Perid-

Clematis serratifolia, 13 June 2017, D. Ertz \& C. Gerstmans, BRCS1 (MFLU 17-1510); living culture, MFLUCC 17-2153.

Hosts: Acer sp., Anthoxanthum odoratum, Asphodelus albus, Aucuba japonica, Brugmansia, Carlina vulgaris, Caragana arborescens, Castanea sp., Clematis serratifolia, Cornus sp., Corylus sp., Dioscorea communis, Dipsacus fullonum, Epilobium sp., Eucalyptus sp., Fagus sp., Fraxinus sp., Genista sp., Holcus sp., Hydrangea sp., Ileostylis sp., Laburnum sp., Lupinus, Malus sp., Protea sp., Pyrus sp., Rosa sp., Sambucus cf. racemosa, Salix sp., Vaccinium sp., ium. f Paraphyses. g-h Asci. i-l Ascospores. Scale bars: $\mathbf{b}=500 \mu \mathrm{m}$, $\mathbf{c}=200 \mu \mathrm{m}, \mathbf{d}, \mathbf{e}=100 \mu \mathrm{m}, \mathbf{f}=50 \mu \mathrm{m}, \mathbf{g}, \mathbf{h}=20 \mu \mathrm{m}, \mathbf{i}-\mathbf{l}=5 \mu \mathrm{m}$

Vitis vinifera-(Dissanayake et al. 2017; Guarnaccia and Crous 2017; Rossman et al. 2017; Guterres et al. 2019; Farr and Rossman 2020; this study).

Distribution: Australia, Austria, Belgium, Canada, Chile, Czech Republic, France, Germany, Italy, Latvia, Japan, Poland, Portugal, Spain, Sweden, Switzerland, Netherlands, New Zealand, South Africa, UK, Ukraine, USA-(Dissanayake et al. 2017; Guarnaccia and Crous 2017; Rossman et al. 2017; Guterres et al. 2019; Farr and Rossman 2020; this study). 
GenBank accession numbers: LSU: MT214615; SSU: MT226726; ITS: MT310659; tef1: MT394671; rpb2: MT394719.

Notes: Diaporthe rudis has been reported from a broad range of hosts such as cultivated crops, ornamental plants and is associated with grapevine trunk diseases worldwide (Lombard et al. 2014; Guarnaccia and Crous 2017). Phylogenetic analysis represented by 14 isolates of $D$. rudis from ten different hosts and 14 countries show species variation of host and geographic ranges (Dissanayake et al. 2017). The monophyletic clade has strong support with $66 \% \mathrm{MP}$ and $100 \%$ ML support and 1.00 BYPP (Fig. 102). Diaporthe rudis was described as Sphaeria rudis on Laburnum anagyroides collected in France (Udayanga et al. 2014; Guarnaccia and Crous 2017). Our strain (Fig. 105), which was isolated from Clematis serratifolia in Belgium, differs from the holotype by having a thinner peridium (Udayanga et al. 2014). Due to the genetic complexity especially in the ITS region of $D$. rudis, the recombination parameters among selected taxa were calculated as shown in Figs. 103b. The GCPSR result of the concatenated gene set showed borderline insignificant recombination between the isolates $(\Phi w=0.05$, Fig. 103b). Thus, we confirm the status of $D$. rudis according to pairwise homoplasy index and the phylogenetic results, which highlights the high degree of genetic variation and distribution in a wide host range (Quaedvlieg et al. 2014; Guarnaccia and Crous 2017).

\section{Phomatosporales Senan., Maharachch \& K.D. Hyde}

Senanayake et al. (2016) introduced Phomatosporales for fungal strains that formed a distinct lineage in Diaporthomycetidae. The order comprises one family and the phylogeny of Phomatosporaceae is shown in Fig. 106.

\section{Phomatosporaceae Senan. \& K.D. Hyde}

Phomatosporaceae was formally reinstated by Senanayake et al. (2016) and comprises three genera, Lanspora, Phomatospora and Tenuimurus (Fig. 106). Phomatosporaceae is typified by Phomatospora, which was placed in Sordariomycetes genera incertae sedis by Lumbsch and Huhndorf (2007). We establish a novel species of Phomatospora from Clematis in Thailand based on molecular data.

\section{Phomatospora Sacc.}

Phomatospora can be an endophyte or saprobe in both aquatic and terrestrial habitats (Fallah and Shearer 1998; Senanayake et al. 2016; Guarnaccia and Crous 2017). Phomatospora is typified by $P$. berkeleyi Sacc. and is characterized by immersed, globose or subglobose ascomata, pseudoparenchymatous cells forming a textura angularis to textura prismatica peridium cell type, a paraphyses of hypha-like, filamentous structures, cylindrical or oblong-fusiform, and short pedicellate, unitunicate asci, with $\mathrm{J}$-apical ring,

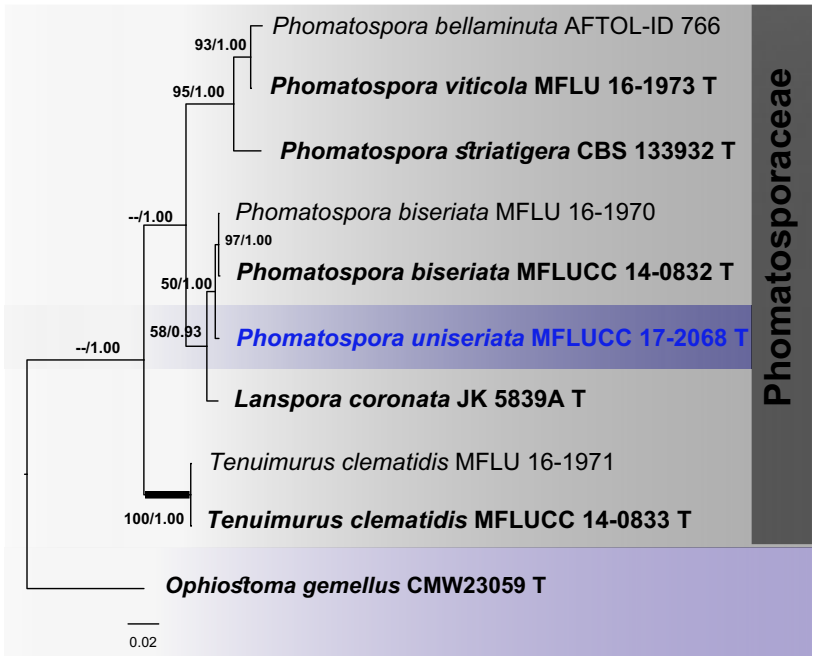

Fig. 106 The Bayesian 50\% majority-rule consensus phylogram based on combined LSU, SSU and ITS sequence data for Phomatosporaceae members. The topology and clade stability of the combined gene analyses was compared to the single gene analyses. The tree is rooted with Ophiostoma gemellus (CMW23059). Ten strains were included in the combined analyses which comprised of 2467 characters (883 characters for LSU, 1049 characters for SSU, 535 characters for ITS, including gap regions). The tree from the maximum likelihood analysis had similar topology to the Bayesian analyses. The best scoring RAxML tree had a final likelihood value of -5571.410827 . The matrix had 292 distinct alignment patterns, with $31.28 \%$ of undetermined characters and gaps. Estimated base frequencies were as follows; $\mathrm{A}=0.253538, \mathrm{C}=0.239531, \mathrm{G}=0.293422, \mathrm{~T}=0.213509$; substitution rates $\mathrm{AC}=3.147737, \mathrm{AG}=3.686222$, $\mathrm{AT}=2.035694$, $\mathrm{CG}=1.607623, \mathrm{CT}=10.739856, \mathrm{GT}=1.000000$; gamma distribution shape parameter $\alpha=0.540032$. In our analysis, GTR $+\mathrm{I}+\mathrm{G}$ model was used for each partition in Bayesian posterior analysis. The species determined in this study is indicated in blue. Bootstrap values (BS) greater than 50\% BS (ML, left) and Bayesian posterior probabilities (BYPP, right) greater than 0.90 are given at the nodes. Hyphens (-) represent support values less than 70\% BS/0.90 BYPP. Thick branches represent significant support values from all analyses (BS $\geq 70 \% / B Y P P \geq 0.95$ ) in genus level

ellipsoidal to fusiform, hyaline, aseptate to multi-septate ascospores, with a rounded bipolar gelatinous caps, and sporothrix-like asexual morphs reported from culture (Fallah and Shearer 1998; Fournier and Lechat 2010). Based on the phylogenetic results of a combined LSU, SSU and ITS dataset, the fungus collected on Clematis in Thailand clustered with other Phomatospora species (Fig. 106).

Phomatospora uniseriata Phukhams., M.V. de Bult \& K.D. Hyde, sp. nov.

Index Fungorum number: IF557302; Facesoffungi number: FoF 06577, Fig. 107.

Etymology: Based on the uniseriate arrangement of the ascospores.

Holotype: MFLU 17-1476 
Saprobic on Clematis subumbellata. Sexual morph: Ascomata $185-220 \times 115-185 \mu \mathrm{m}(\bar{x}=195 \times 175 \mu \mathrm{m}, \mathrm{n}=5)$, solitary to aggregated, immersed and becoming erumpent with age, obpyriform to subglobose, coriaceous, brown to dark brown, heavily pigmented at apex, ostiolate. Ostioles $50-60 \times 50-55 \mu \mathrm{m}(\bar{x}=57 \times 53 \mu \mathrm{m}, \mathrm{n}=5)$, papillate, central or eccentric, broadly conical, filled with periphyses. Peridium 8-12 $\mu \mathrm{m}$ wide $(\bar{x}=10 \mu \mathrm{m}, \mathrm{n}=10)$, composed of 5-6 layers of thin-walled cells of textura prismatica mixed with textura angularis, brown to reddish brown, comprising inner, hyaline, thick-walled cells. Paraphyses sparse, 1.6-3.4 $\mu \mathrm{m}(\bar{x}=2 \mu \mathrm{m}, \mathrm{n}=30)$, hypha-like, thin-walled, septate, constricted at septa, tapering above and shorter than the asci. Asci $90-135 \times 3-5 \mu \mathrm{m}(\bar{x}=103 \times 4 \mu \mathrm{m}, \mathrm{n}=20)$, 8 -spored, unitunicate, cylindrical, thin-walled, pedicellate, with a refractive, J-, apical ring. Ascospores 5.5-9 $\times 2-4 \mu \mathrm{m}$ ( $\bar{x}=7 \times 3 \mu \mathrm{m}, \mathrm{n}=40$ ), uniseriate, partially overlapping, oblong-ellipsoidal, hyaline, pale brown when mature, unicellular, bi-guttulate, guttules located at the ends of the cell, longitudinally striate. Asexual morph: Undetermined.

Culture characters: Colonies on MEA reaching $20 \mathrm{~mm}$ within 4 weeks at $25^{\circ} \mathrm{C}$. Culture from above, cream, radiating to the edge, wrinkled, folded, margin undulate, medium dense, flat or umbonate, and covered with spare grey aerial mycelium; reverse white radiating outwardly.

Material examined: Thailand, Chiang Rai Province, on dead stems of Clematis subumbellata, 20 March 2017, C. Phukhamsakda, CMTH12 (MFLU 17-1476, holotype); extype living culture, MFLUCC 17-2068.

Host: Clematis subumbellata-(This study).

Distribution: Thailand-(This study).

GenBank accession numbers: LSU: MT214616; SSU: MT226727; ITS: MT310660; tef1: MT394672; rpb2: MT394720.

Notes: Phomatospora uniseriata (MFLUCC 17-2068) formed a close relationship with $P$. biseriata which was also recorded on Clematis vitalba in Italy (Senanayake et al. 2016). Phomatospora biseriata is similar to $P$. uniseriata in having unitunicate, cylindrical, thin-walled, pedicellate asci, with J-apical ring, overlapping uniseriate as ellipsoid, hyaline, unicellular, bi-guttulate and longitudinally striate ascospores (Senanayake et al. 2016). Phomatospora uniseriata has uniseriate, oblong ascospores that become pale brown at senescence (Fig. 107). Phomatospora uniseriata is distinguished from $P$. biseriata by its smaller asci and ascospores (Table 5).

In the phylogenetic analysis, $P$. uniseriata (MFLUCC 17-2068) formed a close relationship with P. biseriata $(50 \%$ ML/1.00 BYPP, Fig. 106). A comparison of the ITS region (including of the $5.8 \mathrm{~S}$ region) showed $1.5 \%$ nucleotide (eight nucleotide difference from 535 base pairs). This justifies these two isolates as being two distinct taxa.
Diaporthomycetidae, family incertae sedis Distoseptisporaceae Hyde \& McKenzie

Distoseptisporaceae contains Distoseptispora Hyde, E. McKenzie \& S. Maharachchikumbura as the generic type (Fig. 108). We follow the latest treatment and updated accounts of Distoseptisporaceae by Maharachchikumbura et al. (2016) and Wijayawardene et al. (2017).

Distoseptispora Hyde \& E. McKenzie \& S. Maharachchikumbura

Distoseptispora is characterized by macronematous, septate, unbranched, short olivaceous to brown conidiophores, monoblastic, determinate, terminal conidiogenous cells and acrogenous, brown, euseptate or distoseptate conidia with a basal cell with cross walls and a basal scar (Yang et al. 2018b). There are 16 species listed in Distoseptispora (Hyde et al. 2016; Su et al. 2016; Tibpromma et al. 2017; Luo et al. 2018; Yang et al. 2018b). The combined gene phylogenetic analyses revealed a new species, Distoseptispora clematidis, which constitutes the first record of Distoseptispora on Clematis from Thailand (Fig. 108).

Distoseptispora clematidis Phukhams., M.V. de Bult \& K.D. Hyde, sp. nov.

Index Fungorum number: IF557301; Facesoffungi number: FoF 07261, Fig. 109.

Etymology: In reference to the host genus, Clematis.

Holotype: MFLU 17-1501

Saprobic on dried branches of Clematis sikkimensis. Colonies on the substratum superficial, effuse, scattered, hairy or velvety, black. Mycelium immersed, composed of branched, septate, smooth, dark brown hyphae. Sexual morph: Undetermined. Asexual morph: Conidiophores 22-40 $\times 4-10 \mu \mathrm{m}$ $(\bar{x}=25 \times 7 \mu \mathrm{m}, \mathrm{n}=10)$, macronematous, mononematous, septate, unbranched, single or in groups of 2 or 3, erect, straight or flexuous, 3-5-septate, smooth, dark brown to brown, cylindrical, robust at the base. Conidiogenous cells $3-10 \times 2-8 \mu \mathrm{m}(\bar{x}=6 \times 5 \mu \mathrm{m}, \mathrm{n}=20)$, monoblastic, integrated, determinate, terminal, cylindrical, light brown. Conidia $120-210 \times 12-20 \mu \mathrm{m}(\bar{x}=175 \times 17 \mu \mathrm{m}, \mathrm{n}=20)$, acrogenous, solitary, dry, oblong, obclavate, cylindrical or rostrate, elongated, straight or curved, truncate at the base, rounded at the apex, 28-35-distoseptate, smooth, brown with green tinge, lighter towards the apex, thick-walled, bud scars or disjunctors present at the site of attachment.

Culture characters: Colonies on MEA reaching $30 \mathrm{~mm}$ diam. after 4 weeks at $25^{\circ} \mathrm{C}$. Cultures from above, dark brown, medium dense, circular, umbonate, fluffy; reverse dark brown at the centre, black, radiating outwardly.

Material examined: Thailand, Chiang Rai Province, Doi Tung, on dried stem of Clematis sikkimensis, 2 May 2017, C. Phukhamsakda \& M.V. de Bult, CMTHDT12 (MFLU 


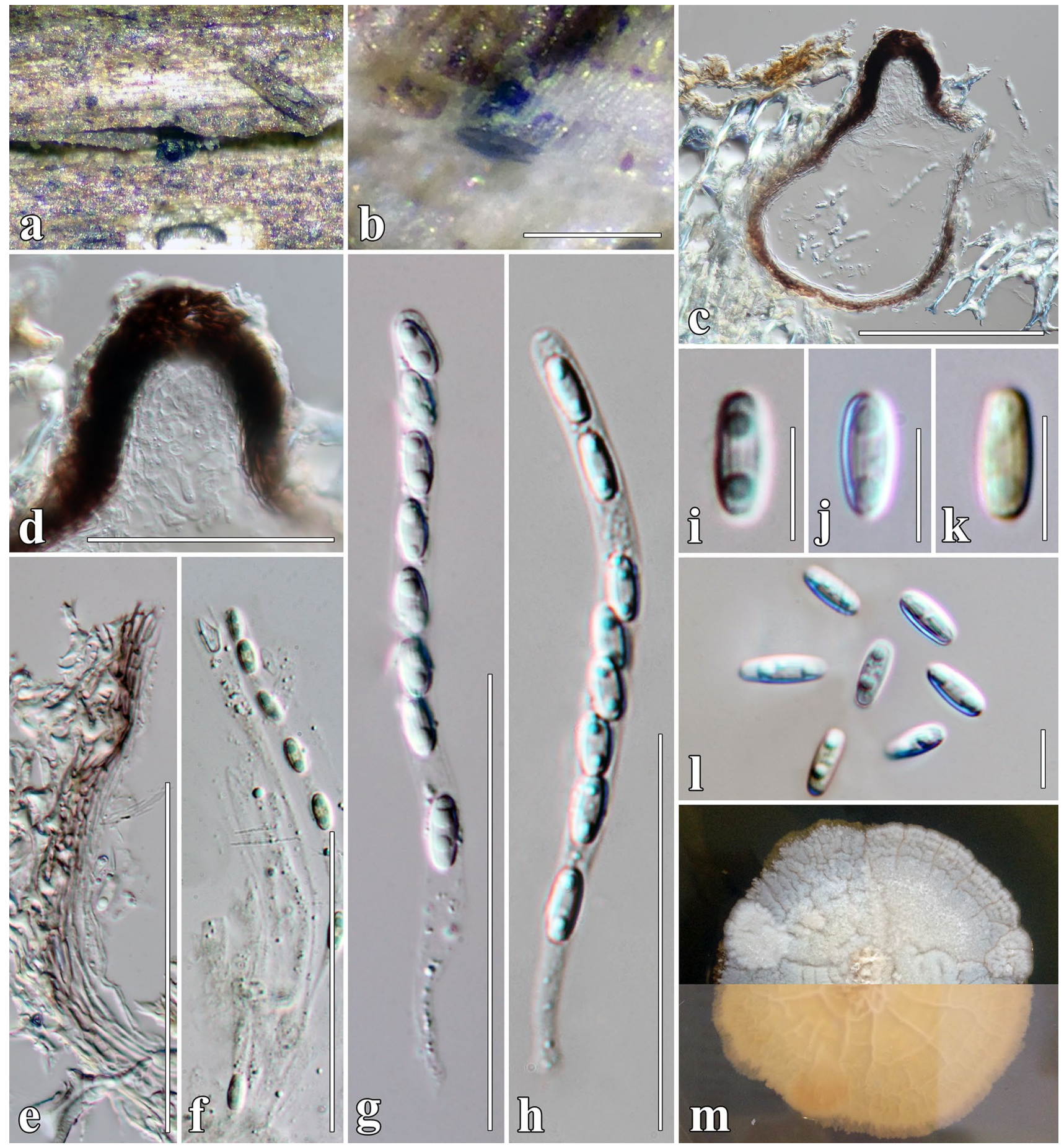

Fig. 107 Phomatospora uniseriata (MFLU 17-1476, holotype). a Appearance of ascomata on Clematis subumbellata. b Close up of ascoma on host substrate. c Vertical section through ascoma. d Osti- olar canal. e Peridium. f Paraphyses. g, h Asci i-l Ascospores. m Culture characteristics on MEA. Scale bars: $\mathbf{b}=100 \mu \mathrm{m}, \mathbf{c}-\mathbf{h}=50 \mu \mathrm{m}$, $\mathbf{i}-\mathbf{l}=5 \mu \mathrm{m}$ 


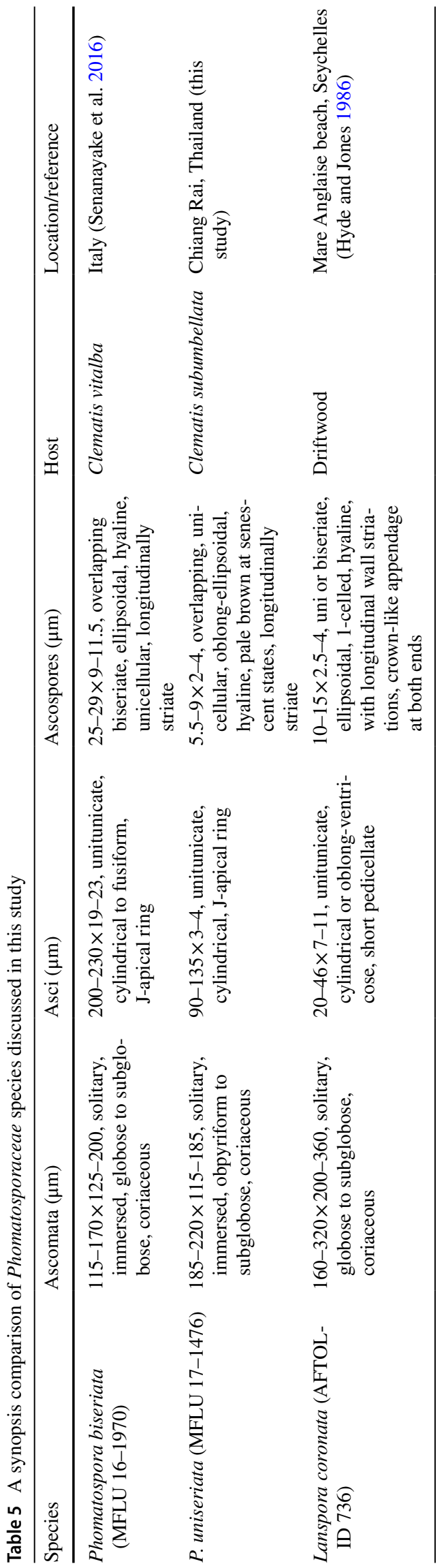

Fig. 108 Best scoring RAxML tree with a final likelihood value of - 16025.131561 based on combined LSU, SSU, ITS and $r p b 2$ sequence data for Distoseptisporaceae. The tree is rooted with Crytadelphia members. Thirty-seven strains were included in the combined analyses which comprised 3444 characters (905 characters for LSU, 1022 characters for SSU, 454 characters for ITS, 1063 characters for $r p b 2$, including gap regions). The topology and clade stability of the combined gene analyses was compared to the single gene analyses. The tree from the maximum likelihood analysis had similar topology to the Bayesian $50 \%$ majority-rule consensus phylogram. The matrix had 1081 distinct alignment patterns, with $40.90 \%$ undetermined characters and gaps. Estimated base frequencies were as follows; $\mathrm{A}=0.252755, \mathrm{C}=0.239940, \mathrm{G}=0.285179, \mathrm{~T}=0.222126$; substitution rates $\mathrm{AC}=1.420436, \mathrm{AG}=2.672673$, $\mathrm{AT}=1.211428$, $\mathrm{CG}=1.349930, \mathrm{CT}=6.537630, \mathrm{GT}=1.000000$; gamma distribution shape parameter $\alpha=0.699416$. In our analysis, GTR $+\mathrm{I}+\mathrm{G}$ model was used for each partition in Bayesian posterior analysis. The species determined in this study is indicated in blue. Bootstrap values (BS) greater than 50\% BS (ML, left) and Bayesian posterior probabilities (BYPP, right) greater than 0.90 are given at the nodes. Hyphens (-) represent support values less than 50\% BS/0.90 BYPP. Thick branches represent significant support values from all analyses (BS $\geq 70 \% / B Y P P \geq 0.95$ ) at genus and family level

17-1501, holotype); ex-type living culture, MFLUCC 17-2145.

Host: Clematis sikkimensis—(This study).

Distribution: Thailand-(This study).

GenBank accession numbers: LSU: MT214617; SSU: MT226728; ITS: MT310661; rpb2: MT394721.

Notes: Distoseptispora clematidis (MFLUCC 17-2145) is introduced based on both morphological (Fig. 109) and phylogenetic evidence (Fig. 108). The morphology of $D$. clematidis is similar to $D$. xishuangbannaensis, but distinguishable by the characters of the conidia. Distoseptispora clematidis has smaller conidia $(175 \times 17$ vs $244 \times 11.5 \mu \mathrm{m})$ and up to 35 septa, while D. xishuangbannaensis has 40 septa (Tibpromma et al. 2017). In the phylogenetic analysis, D. clematidis forms a related lineage with $D$. fluminicola, D. xishuangbannaensis and D. tectonigena with moderate support (69\% ML/0.99 BYPP). In a BLASTn search of GenBank, the closest match of the LSU sequence of MFLUCC 17-2145 was D. tectonigena (MFLUCC 12-0292) with 99.26\% similarity to NG_059144, while the closest match with the ITS sequence was $97.36 \%$ similarity to NR_154018. This is the first record of Distoseptispora on Clematis.

Subclass: Xylariomycetidae Erikss. \& W. Winka

The latest treatment of subclass Xylariomycetidae is by Senanayake et al. (2015).

Amphisphaeriales Hawksw. \& O.E. Erikss.

Several studies treated Amphisphaeriales as a synonym of Xylariales. Senanayake et al. (2015) revised the taxonomic relationship within Amphisphaeriales, and currently, 14 families are accepted by Hyde et al. (2020). 


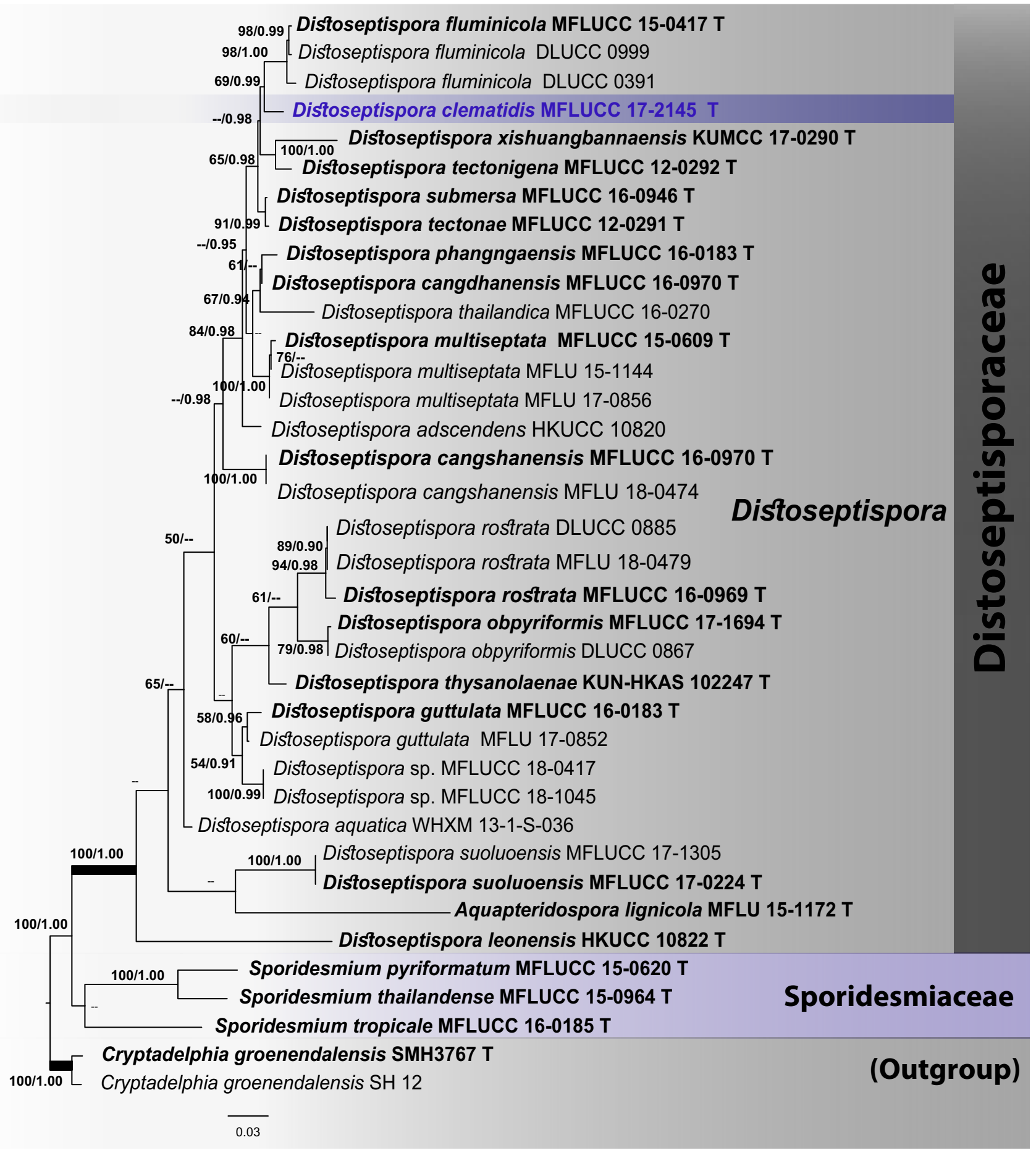



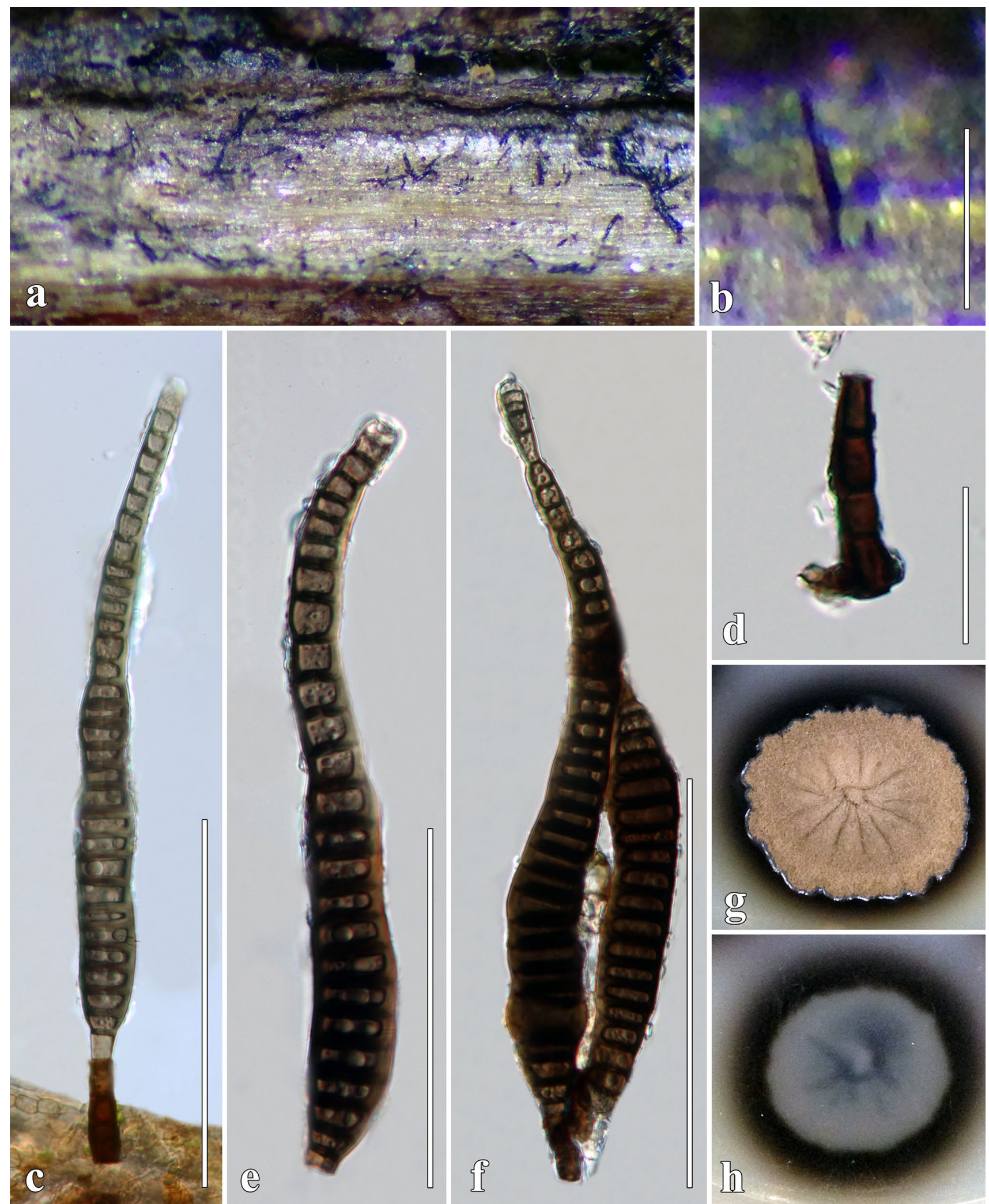

Fig. 109 Distoseptispora clematidis (MFLU 17-1501, holotype). a, b. Colonies on the substratum. c Conidiophore and conidia. d Conidiophore. e, f Conidia. $\mathbf{g}$, h Culture characteristics on MEA. Scale bars: $\mathbf{b}=200 \mu \mathrm{m}, \mathbf{c}, \mathbf{e}-\mathbf{f}=100 \mu \mathrm{m}, \mathbf{d}=20 \mu \mathrm{m}$ 
Sporocadaceae Corda [as "Sporocadeae"], Icon. Fung. (Prague) 5: 34. 1842

Sporocadaceae was resolved by Liu et al. (2019) and comprises 30 genera. Members of Sporocadaceae are saprobic or pathogenic on various plants (Senanayake et al. 2015). The family is recognised by having immersed ascomata and uniseriate, brown, ovoid to elliptic, straight or inequilateral, septate ascospores. The asexual morph characters of some Sporocadaceae are usually termed "pestaloid", referring to acervular or pycnidial conidiomata, ellipsoid to clavate, or fusiform conidia that are hyaline, pale olivaceous or brown, septate, with polar appendages (Guba 1961; Maharachchikumbura et al. 2014; Senanayake et al. 2015; Liu et al. 2019).

\section{Pestalotiopsis Stewart}

Pestalotiopsis is characterized by acervular conidioma and fusoid to oval, 4-euseptate, pigmented conidia, usually two to five apical appendages arising as tubular extensions from the apical cell, with a centric basal appendage (Maharachchikumbura et al. 2014). Pestalotiopsis occurs as an endophyte or saprobe in various plants and often causes disease symptoms on leaves and fruit in many plants (Liu et al. 2006; Maharachchikumbura et al. 2012; Chen et al. 2018). Pestalotiopsis verruculosa was associated with Clematis vitalba branches in Italy. The multigene phylogenetic analysis of ITS and $t u b$ sequence data for Pestalotiopsis is shown in Fig. 110.

Pestalotiopsis verruculosa Maharachch. \& K.D. Hyde, in Maharachchikumbura et al. Fungal Diversity 56(1): 123 (2012), new host record

Index Fungorum number: 800527; Facesoffungi number: FoF 07336, Fig. 111.

Saprobic on dead stem of Clematis vitalba. Conidiomata pycnidial in culture on PDA, globose to oval, solitary or aggregated in clusters, semi-immersed, black, $120-320 \mu \mathrm{m}$ diam., exuding globose, black, glistening, conidial masses. Conidia $21-33 \times 6-15 \mu \mathrm{m}(\bar{x}=27 \times 9 \mu \mathrm{m}, \mathrm{n}=40)$, fusiform or clavate-fusiform, straight or slightly curved, 4-septate, concolorous; basal cell conical, hyaline, thin and verruculose, $2-5 \mu \mathrm{m}$ long $(\bar{x}=3.4 \mu \mathrm{m}, \mathrm{n}=15)$, three median cells doliiform, olivaceous, concolorous, veruculose, 14-16 $\mu \mathrm{m}$ long, septa and periclinal walls darker than the rest of the cell (second cell from base 2-6 $\mu \mathrm{m}$; third cell $5-9 \mu \mathrm{m}$; fourth cell 3.4-6.9 $\mu \mathrm{m}$ long); apical cell 1.6-5.4 $\mu \mathrm{m}$ long, hyaline, cylindrical to subcylindrical with 3-6 tubular apical appendages (mostly 3 ), arising from crown of the apical cell, unbranched, filiform 11-34 $\mu \mathrm{m}(\bar{x}=20 \mu \mathrm{m}, \mathrm{n}=60)$ long; single, unbranched, filiform basal appendage present, $6-10 \mu \mathrm{m}$ long $(\bar{x}=7.5 \mu \mathrm{m}, \mathrm{n}=60)$.

Culture characters: Colonies on PDA reaching $30 \mathrm{~mm}$ diam. after 7 days at $25^{\circ} \mathrm{C}$. Culture from above,edge undulate, white to pale yellow, aerial mycelium with black fruiting bodies, concentric; reverse of culture, yellow to pale orange.

Material examined: Italy, Forlì-Cesena Province, Santa Sofia-near Corniolo, on dead and terrestrial stem of Clematis vitalba, 5 February 2013, E. Camporesi (MFLU 14-0624), living culture MFLUCC 14-1091.

Host: Clematis vitalba, Rhododendron sp.-(Maharachchikumbura et al. 2012; this study).

Distribution: China, Italy_(Maharachchikumbura et al. 2012; this study).

GenBank accession numbers: ITS: MT186199; tub2: MT199995; tef1: MT199996.

Notes: This strain of Pestalotiopsis verruculosa has somewhat smaller conidia $(21-33 \times 6-15 \mu \mathrm{m})$ when compared with the type strain of $P$. verruculosa $(28-35 \times 9-11 \mu \mathrm{m})$ and shorter apical appendages (11-34 vs 25-40 $\mu \mathrm{m}$ ) (Maharachchikumbura et al. 2012). In the phylogenetic analyses, our strain clustered with the type strain of $P$. verruculosa (Fig. 111). Pestalotiopsis verruculosa has been recorded only from Rhododendron sp. in China as an endophyte (Maharachchikumbura et al. 2012). This study provides the first report of $P$. verruculosa from Clematis vitalba.

\section{Xylariales Nannf.}

The Xylariales is a large order in Sordariomycetes, with 20 accepted families. We follow the treatments by Maharachchikumbura et al. (2016), Li et al. (2017), and Hyde et al. (2020).

\section{Diatrypaceae Nitschke}

Species of Diatrypaceae are highly diverse and widespread on woody plants in terrestrial, aquatic or marine (Trouillas and Gubler 2010; Abdel-Wahab et al. 2014; Liu et al. 2015; Dayarathne et al. 2016; Senwanna et al. 2017; Shang et al. 2017). Based on the latest treatment and updated accounts of Diatrypaceae, the family contains 20 genera (Maharachchikumbura et al. 2015, 2016; Shang et al. 2017; Phookamsak et al. 2019). Diatrypaceae is characterized by perithecial ascomata, with poorly or well-developed ascostromata, immersed to erumpent in the host substrates, with papillate ascomata (Fuckel 1870). Based on phylogenetic analysis of a combined ITS and $t u b$ dataset (Fig. 112), we 


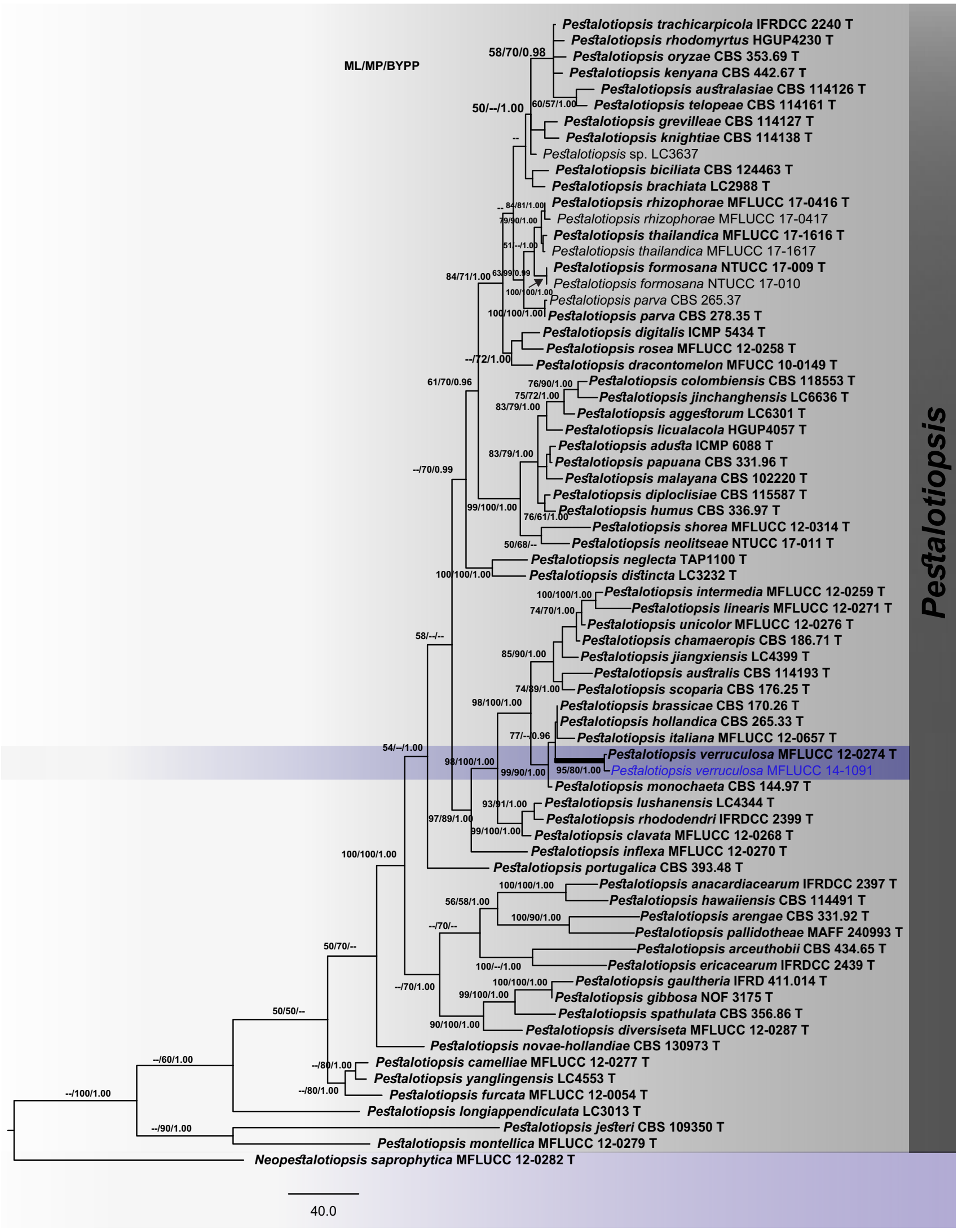


४Fig. 110 One of the 1000 most parsimonious trees obtained from a heuristic search of combined ITS and tub sequence data for Pestalotiopsis. The tree is rooted at Neopestalotiopsis saprophytica (MFLUCC 12-0282). Maximum parsimony and maximum likelihood support $\geq 50 \%$, Bayesian posterior probabilities $\geq 0.90$ (ML/MP/BYPP) are given at the nodes. The species obtained in this study is in blue. Ex-type (T) taxa from other studies are in bold black

report a new record of $N$. baoshanensis on Clematis vitalba from Europe.

Neoeutypella Raza, Shang, Phookamsak \& L. Cai

Neoeutypella was introduced as a monotypic genus for eutypella-like strains that clustered among Diatrypella species but are distantly related to Eutypella sensu stricto (Dayarathne et al. 2016). Neoeutypella is characterized by entostromatic, carbonaceous ascostromata, perithecial, black, immersed to semi-immersed, papilla filled with periphyses, thick peridium, 8-spored spindle-shaped, and long pedicellate. Asexual morph of Neoeutypella produce hyphae-like, branched, filiform, hyaline or pale brown conidia in culture conditions (Crous et al. 2016; Phookamsak et al. 2019). Phylograms generated from maximum likelihood and Bayesian probability analyses based on combined ITS and $t u b$ sequence data (Fig. 112) showed that our collection from Clematis vitalba clustered with the type species of Neoeutypella. Thus, the new host record of $N$. baoshanensis is reported (Fig. 113).

Neoeutypella baoshanensis Raza, Shang, Phookamsak \& L. Cai, new host record

Synonym: Eutypella caricae (De Not.) Berl.: [1] (1902)

Index Fungorum number: IF555372; Facesoffungi number: FoF 04928, Fig. 113.

Saprobic on dead stem of Clematis vitalba. Sexual morph: Stromata poorly developed, flask-shaped, multiloculate, with 8-12 locules forming groups in stromata, black, erumpent or semi-immersed in the surface layers of the host tissue. Ascomata partially or deeply immersed in wide-spread stroma, 550-620×350-600 $\mu \mathrm{m}$ $(\bar{x}=585 \times 500 \mu \mathrm{m}, \mathrm{n}=10)$, globose, reddish brown to black, single or gregarious and sometimes confluent, ostiolate. Ostioles $110-140 \times 90-125 \mu \mathrm{m}(\bar{x}=130 \times 110 \mu \mathrm{m}, \mathrm{n}=10)$, oblong-conical, with papillate, immersed in a wide-spread entostroma which protrudes above the substrate surface, periphyses. Peridium 13-40(-80 $\mu \mathrm{m}$ at apex) wide, comprising an outer, brown, thick-walled layer of polygonal melanized cells, interspersed with cells of the substrate and several inner, hyaline, thick-walled cell layers of textura angularis. Paraphyses composed of numerous, 1.8-3.5 $\mu \mathrm{m}$ wide, aseptate, paraphyses, narrowing and tapering towards the apex. Asci $75-120 \times 7-12 \mu \mathrm{m}(\bar{x}=100 \times 8 \mu \mathrm{m}, \mathrm{n}=20)$, multi-spored, unitunicate, with narrow, thin-walled pedicel, 40-70 $\mu \mathrm{m}$ long, with cylindrical, swollen upper portion, apex flat, with J-, cylindrical, conspicuous ring. Ascospores $10-15 \times 2-4 \mu \mathrm{m}(\bar{x}=13 \times 3 \mu \mathrm{m}, \mathrm{n}=50)$, hyaline or pale reddish brown to brown, allantoid, straight or slightly curved, unicellular, thin-walled with 2 small globules in each cell, smooth-walled. Asexual morph: Undetermined.

Culture characters: Colonies on MEA reaching $30 \mathrm{~mm}$ diam. after 4 weeks at $25^{\circ} \mathrm{C}$. Culture from above, white, yellowish towards the edge, erumpent, spreading, surface folded, margins lobate, medium dense, circular, flat, dull, fimbriate, radially furrowed and slightly covered with white aerial mycelium; reverse yellowish with radiating cream mycelium.

Material examined: UK, Hampshire, Botley Wood, on dead stems of Clematis vitalba, 16 April 2016, E.B.G. Jones, GJ 279 (MFLU 17-1461); living culture, MFLUCC 16-1002.

Hosts: Clematis vitalba, Ficus carica, Pinus armandii(Acero et al. 2004; Phookamsak et al. 2019; this study)

Distribution: China, France, UK-(Acero et al. 2004; Phookamsak et al. 2019; this study)

GenBank accession numbers: LSU: MT214618; SSU: MT226729; ITS: MT310662; tefl: MT394673.

Notes: Our new isolate MFLUCC 16-1002 clustered with the type species of Neoeutypella baoshanensis strain LC 12111 (Fig. 112) with moderate support (98\% ML/0.95 BYPP). Isolate MFLUCC 16-1002 is similar to the type species reported by Phookamsak et al. (2019), Fig. 113. In the phylogenetic analysis, Diatrype macowaniana strain CBS 214.87 clustered among Neoeutypella baoshanensis strains. Although Acero et al. (2004) mentioned that $N$. baoshanensis (=Eutypella caricae) and Diatrype macowaniana have no sequence divergence; morphological comparison of Diatrype macowaniana and N. baoshanensis were distinct in having smaller asci $(32-36 \times 6$ vs $77.5 \times 8 \mu \mathrm{m})$ and hyaline ascospores $(10.8 \times 2.4$ vs 5-7 $\times 1.5-2$ ) (Saccardo 1882). Thus, we maintain the strain as Diatrype macowaniana until the paratype specimen is re-collected. Diatrypella banksiae CPC 29054 and CPC 29118 formed a strongly supported clade with Neoeutypella. However, Diatrypella banksiae is only present as an asexual morph, thus we maintain the strain under the current name (Crous et al. 2016).

Hypocreomycetidae Erikss. \& K. Winka

Glomerellales Chadef. ex Réblová et al.

Glomerellales includes Australiascaceae, Glomerellaceae, Malaysiascaceae, Plectosphaerellaceae and Reticulascaceae (Réblová et al. 2011; Maharachchikumbura et al. 2016; Tibpromma et al. 2018).

Plectosphaerellaceae Gams, Summerb. \& R. Zare

Plectosphaerellaceae was introduced by Zare et al. (2007) to accommodate a monophyletic lineage within 

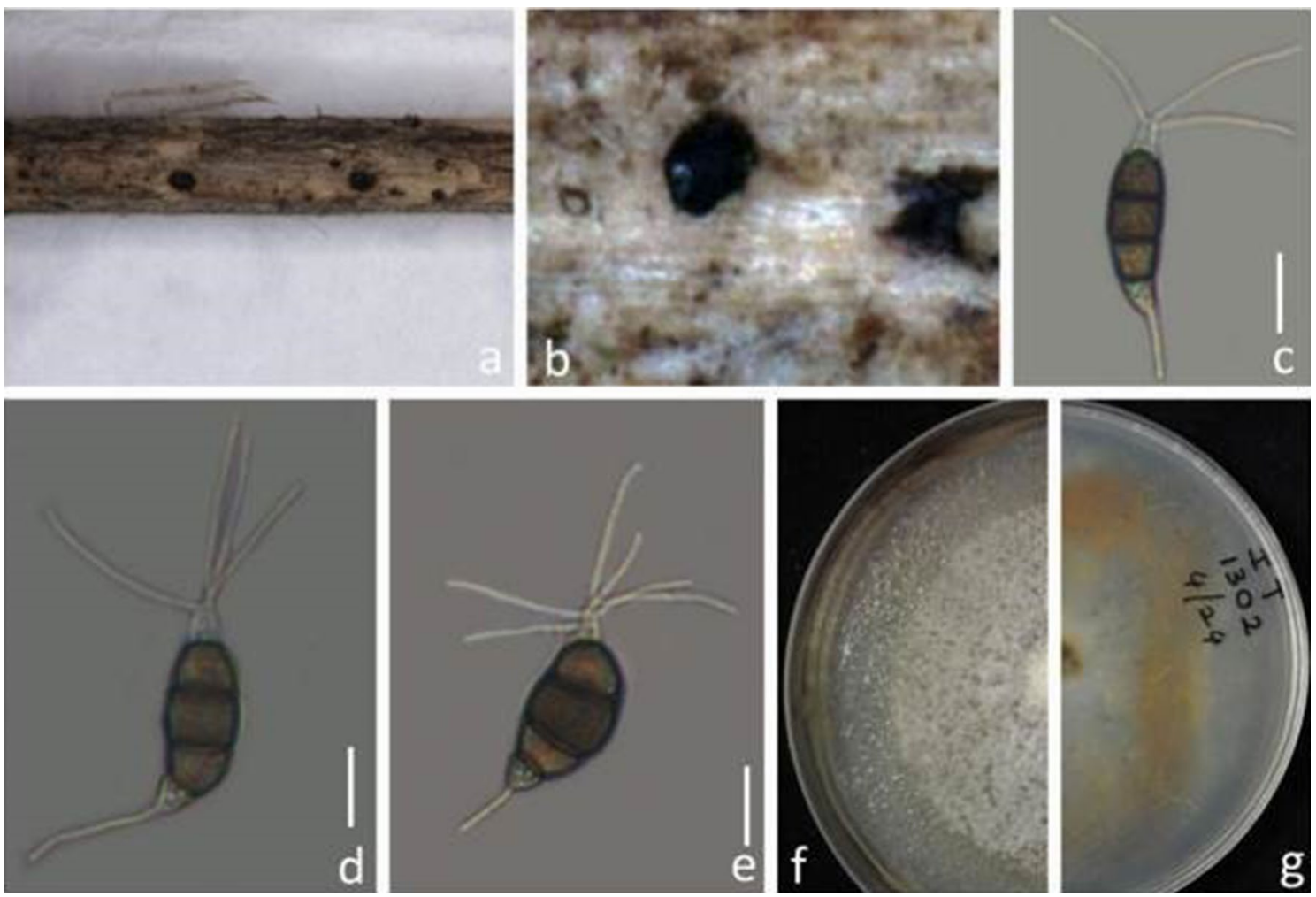

Fig. 111 Pestalotiopsis verruculosa (MFLU 14-0624) a, b Appearance of conidiomata on Clematis vitalba. c-e Conidia with concolorous median cells. f Colony on PDA (upper view) $\mathbf{g}$ Colony on PDA (reverse view). Scale bars: $\mathbf{c}-\mathbf{e}=10 \mu \mathrm{m}$

Glomerellales. Plectosphaerellaceae taxa are fungicolous, insecticolous, plant pathogens, saprobic, and cause soil-borne diseases (Cannon et al. 2012; Duc et al. 2009; Grum-Grzhimaylo et al. 2016; Giraldo et al. 2019). The family is mainly represented by asexual morphs with only a few sexual morphs described by Carlucci et al. (2012), Grum-Grzhimaylo et al. $(2013,2016)$ and Phookamsak et al. (2019). Phylogenetic relationships of the intra-members of Plectosphaerellaceae were analysed based on a LSU, ITS, tefl and rpb2 dataset (Fig. 114). Combining morphological and molecular data, one new genus Xenoplectosphaerella and one new combination Fuscohypha kunmingensis are introduced below.

\section{Fuscohypha Giraldo López \& P. Crous}

Fuscohypha is typified by F. expansa Giraldo \& Crous. The genus is characterized by branched conidiophores with ellipsoidal to cylindrical conidia, pale brown in mass, with slimy heads. Fuscohypha expansa was isolated from soil and tuber of Dioscorea. In our study, Fuscohypha formed a separate clade basal to Plectosphaerella and Brunneochlamydosporium (Fig. 114).

Fuscohypha kunmingensis (Phookamsak, J.F. Li \& K.D. Hyde) Jayaward., Phukhams., \& K.D. Hyde, comb. nov.
Index Fungorum number: IF557607; Facesoffungi number: FoF 05716

Basionym: Plectosphaerella kunmingensis Phookamsak, J.F. Li \& K.D. Hyde, in Phookamsak et al., Fungal Diversity 95:1-273(2019)

Notes: Fuscohypha kunmingensis was described as Plectosphaerella kunmingensis based on the morphological comparison and the strain formed a basal clade to Plectosphaerella species (Phookamsak et al. 2019). Phylogenetic inference in this study places the ex-type strain of Fuscohypha kunmingensis (KMUCC 18-0181) in a close relationship with the type species of Fuscohypha (F. expansa) with good support (81\% ML/100\% MP/0.99 BYPP, Fig. 114). Fuscohypha kunmingensis was a contaminant in the laboratory. The strain is similar to Fuscohypha as they both lack hyphal coils and hyaline to yellowish brown conidiophores (Giraldo et al. 2019).

Host: Air-bone fungus_-Phookamsak et al. (2019).

Distribution: China-Phookamsak et al. (2019).

Xenoplectosphaerella Jayaward., Phukhams., \& K.D. Hyde, gen. nov.

Index Fungorum number: IF557303; Facesoffungi number: FOF 01334, Fig. 115. 


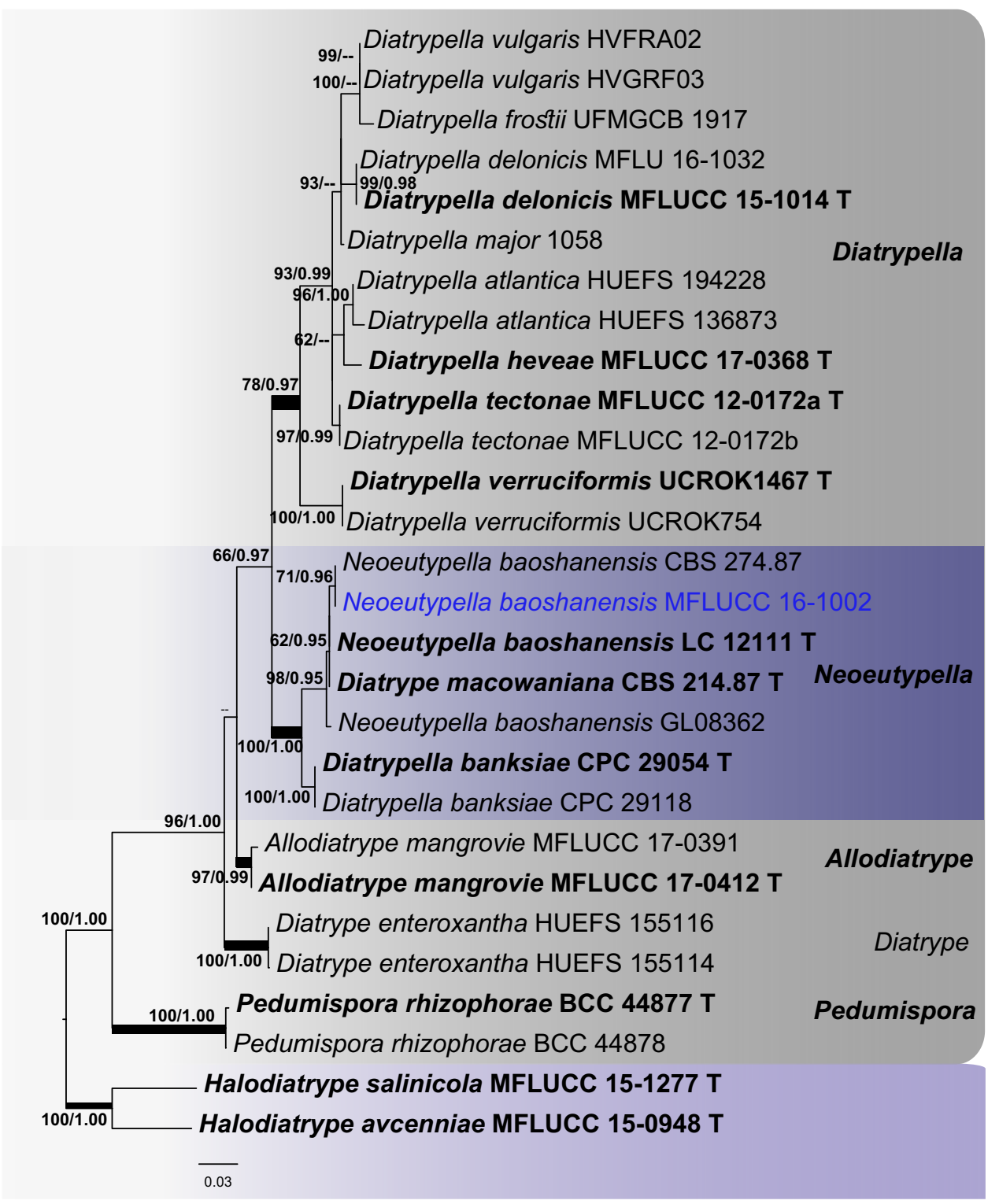

Fig. 112 Best scoring RAxML tree with a final likelihood value of -4428.491036 based on combined ITS and tub sequence data of related species. The tree is rooted with Halodiatrype avcenniae (MFLUCC 15-0948) and H. salinicola (MFLUCC 15-1277) in Diatrypaceae. Twenty-eight strains were included in the combined gene analyses which comprised 1393 characters (623 characters for ITS, 770 characters for $t u b$, including gap regions). The tree from the maximum likelihood analysis had similar topology to the Bayesian analysis. The matrix had 396 distinct alignment patterns with $40.26 \%$ undetermined characters or gaps. Estimated base frequencies were as follows: $\mathrm{A}=0.224095, \mathrm{C}=0.268057, \mathrm{G}=0.236876, \mathrm{~T}=0.270973$; substitution rates $\mathrm{AC}=1.104749, \mathrm{AG}=3.483519, \mathrm{AT}=0.878988$, $\mathrm{CG}=1.108511, \mathrm{CT}=4.234084, \mathrm{GT}=1.000000$; gamma distribution shape parameter $\alpha=0.276482$. In our analysis, GTR $+\mathrm{I}+\mathrm{G}$ model was used for each partition in Bayesian posterior analysis. The species determined in this study is indicated in bold blue. Bootstrap values (BS) greater than 50\% BS (ML, left) and Bayesian posterior probabilities (BYPP, right) greater than 0.90 are given at the nodes. Hyphens (-) represent support values less than 50\% BS/0.90 BYPP. Thick branches represent significant support values from all analyses at genus level (BS $\geq 70 \% / \mathrm{BYPP} \geq 0.95)$ 

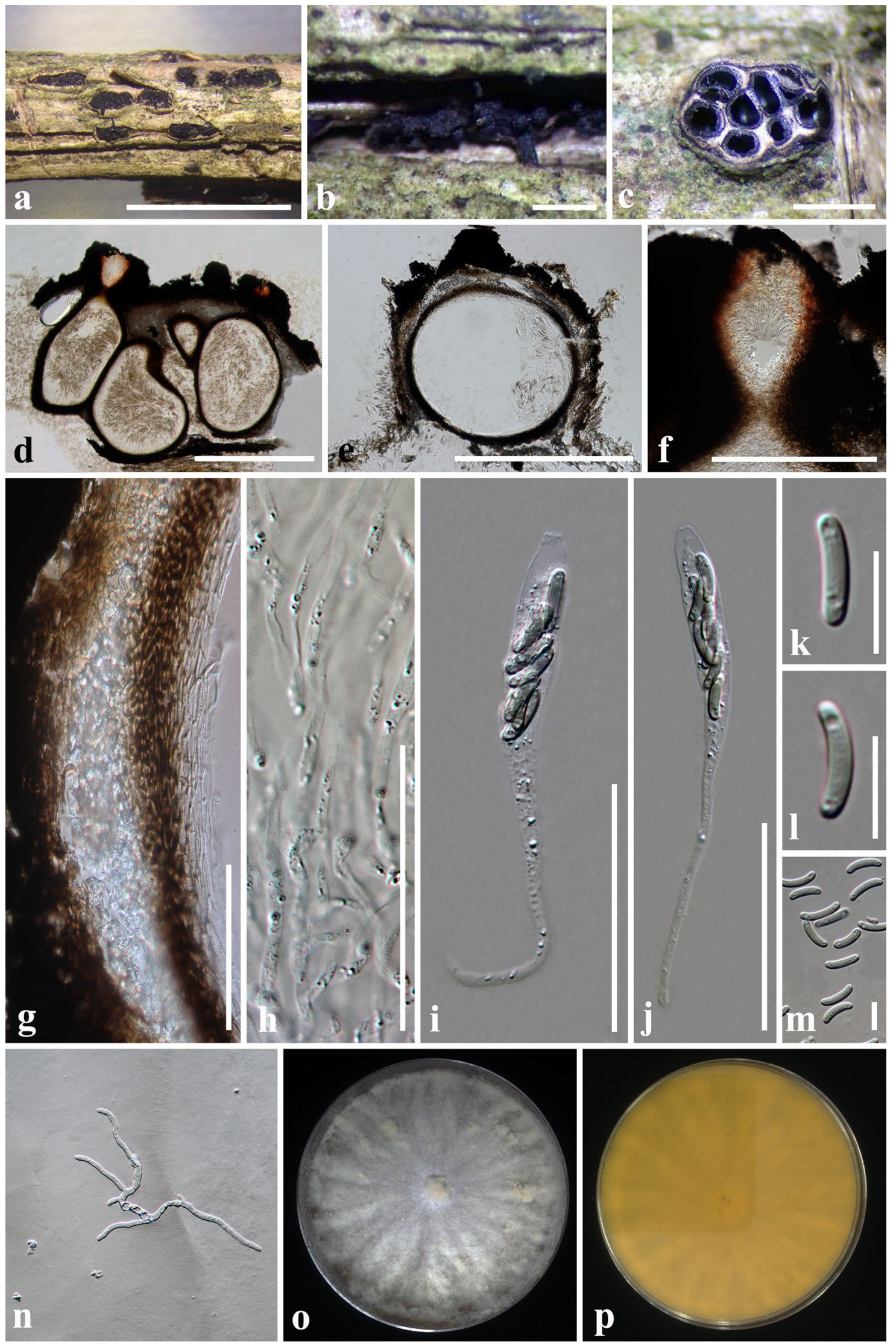
४Fig. 113 Neoeutypella baoshanensis (MFLU 17-1461). a Appearance of stromata on Clematis vitalba. b Close up of stromata on host substrate. c Horizontal section through stroma. d Vertical section through stroma. e Vertical section through ascoma. f Ostiolar canal. g Peridium. h Aseptate paraphyses. i, j Asci. k-m Ascospores. n Germinated ascospore. $\mathbf{o}, \mathbf{p}$ Culture characteristics on MEA. Scale bars: $\mathbf{a}=1 \mathrm{~mm}, \mathbf{b}-\mathbf{e}=500 \mu \mathrm{m}, \mathbf{f}=200 \mu \mathrm{m}, \mathbf{g}-\mathbf{j}=50 \mu \mathrm{m}, \mathbf{k}-\mathbf{m}=10 \mu \mathrm{m}$

Etymology: Name refers to the similarity of its morphology to Plectosphaerella.

Saprobic on herbaceous plant in terrestrial habitats. Sexual morph: Ascomata single or gregarious, erumpent or immersed under the host epidermal layer, visible as black spot on host substrate, papillate. Papilla filled with periphyses. Peridium composed of thin-walled cells of textura angularis mixed with textura globosa, multilayered, inner layers, hyaline. Paraphyses numerous, septate. Asci unitunicate, broad clavate to spathulate, with simple pedicel, conspicuous apical or subapical, J-, ring. Ascospores biseriate, overlapping, fusiform-elliptical to ellipsoid, 1 septum, hyaline, constricted at the septum, straight or slightly curved towards the apex. Asexual morph: Undetermined.

Type species: Xenoplectosphaerella clematidis Jayaward., Phukhams., \& K.D. Hyde

Notes: Xenoplectosphaerella is introduced as a monotypic genus in Plectosphaerellaceae (Fig. 115). The genus was associated with a herbaceous plant in Thailand and formed obpyriform, coriaceous ascomata with papilla, with paraphyses, and uniquely spathulate asci (Carlucci et al. 2012; Grum-Grzhimaylo et al. 2016; Giraldo et al. 2019). In the BLASTn search of GenBank, the closest match of the LSU region of the new species was Musicillium theobromae (CBS 968.72) with 97.22\% similarity (accession number LR025907). The closest match of the ITS region of MFLUCC 17-2067 was also M. theobromae (CBS 968.72) with $90.83 \%$ similarity (accession number NR_156205). However, Musicillium is phylogenetically distant from our new isolate (Fig. 114). Phylogenetic analyses of sequence data of taxa within Plectosphaerellaceae resolves Xenoplectosphaerella as basal to Musicillium and Paramusicillium, which are strains isolated from soil and monocotyledons or the mushroom genus Lactarius sp. (Giraldo et al. 2019). We name our collection as Xenoplectosphaerella clematidis MFLUCC 17-2067, a new genus which formed a distinct lineage from other genera in the family (Fig. 114).

Xenoplectosphaerella clematidis Jayaward., Phukhams., \& K.D. Hyde, sp. nov.

Index Fungorum number: IF557304; Facesoffungi number: FoF 07326, Fig. 115.

Etymology: Name refers to the host plant, Clematis.

Holotype: MFLU 17-1475
Saprobic on dead stems of Clematis subumbellata. Sexual morph: Ascomata 90-100×90-110 $\mu \mathrm{m}(\bar{x}=98 \times 105 \mu \mathrm{m}$, $\mathrm{n}=5$ ), single or gregarious, immersed under the host epidermal layer, visible as black spots on host substrate, obpyriform, coriaceous with minute papilla. Ostioles papillate, filled with periphyses. Peridium 7-12 $\mu \mathrm{m}$ wide, composed of 7-10 layers of thin-walled cells of textura angularis mixed with textura globosa, inner layers, hyaline, thickwalled. Paraphyses numerous, $1.5-3.5 \mu \mathrm{m}(\bar{x}=2.5 \mu \mathrm{m}$, $\mathrm{n}=30$ ), septate, narrowed and tapering towards the apex. Asci $31-50 \times 10-15 \mu \mathrm{m}(\bar{x}=38 \times 12 \mu \mathrm{m}, \mathrm{n}=20)$, unitunicate, broad clavate to broad fusiform, simple pedicel, apex flat, with J-, conspicuous apical or subapical ring. Ascospores $10-17 \times 4-5 \mu \mathrm{m}(\bar{x}=13 \times 4 \mu \mathrm{m}, \mathrm{n}=50)$, biseriate, overlapping, fusiform-elliptical to ellipsoid, hyaline, 1 septum, constricted at the median septum, straight or slightly curved towards the apex, thin-walled, with two guttules in each cell, smooth-walled. Asexual morph: Undetermined.

Culture characters: Colonies on MEA reaching $20 \mathrm{~mm}$ diam. after 4 weeks at $25^{\circ} \mathrm{C}$. Culture from above, black, radiating, wrinkled, folded, margin undulate, dense, flat or umbonate, and slightly covered with grey aerial mycelium; reverse black with radiating, brown mycelium.

Material examined: Thailand, Chiang Rai Province, on dead stems of Clematis subumbellata, 20 March 2017, C. Phukhamsakda, CMTH11 (MFLU 17-1475, holotype); extype living culture, MFLUCC 17-2067.

Host: Clematis subumbellata-(This study).

Distribution: Thailand-(This study).

GenBank accession numbers: LSU: MT214619; SSU: MT226730; ITS: MT310663; tef1: MT394674; rpb2: MT394722.

Notes: The novel species resembles other genera in Plectosphaerellaceae (e.g. Fuscohypha and Plectosphaerella) by its coriaceous ascomata and fusiform-elliptical to ellipsoid, 1 septum ascospores (Carlucci et al. 2012; Giraldo et al. 2019; Phookamsak et al. 2019). The species has unique characters such as paraphyses and spathulate, simple pedicel asci. Moreover, Fuscohypha and Plectosphaerella are phylogenetically not closely related (Fig. 114).

\section{Hypocreales Lindau}

We followed recent treatment by Hyde et al. (2020b).

\section{Nectriaceae Tul. \& C. Tul. [as 'Nectriei']}

Nectriaceae is a species-rich family which includes important plant and human pathogens (Lombard et al. 2015). Members of the family are distinguishable by characters such as densely gregarious, uniloculate with yellow, orangered to purple ascomata (Rossman et al. 1999; Lombard et al. 2015). Asexual morph are reported as synnematous, sporodochial or pycnidial with phialidic conidiogenesis (Rossman 


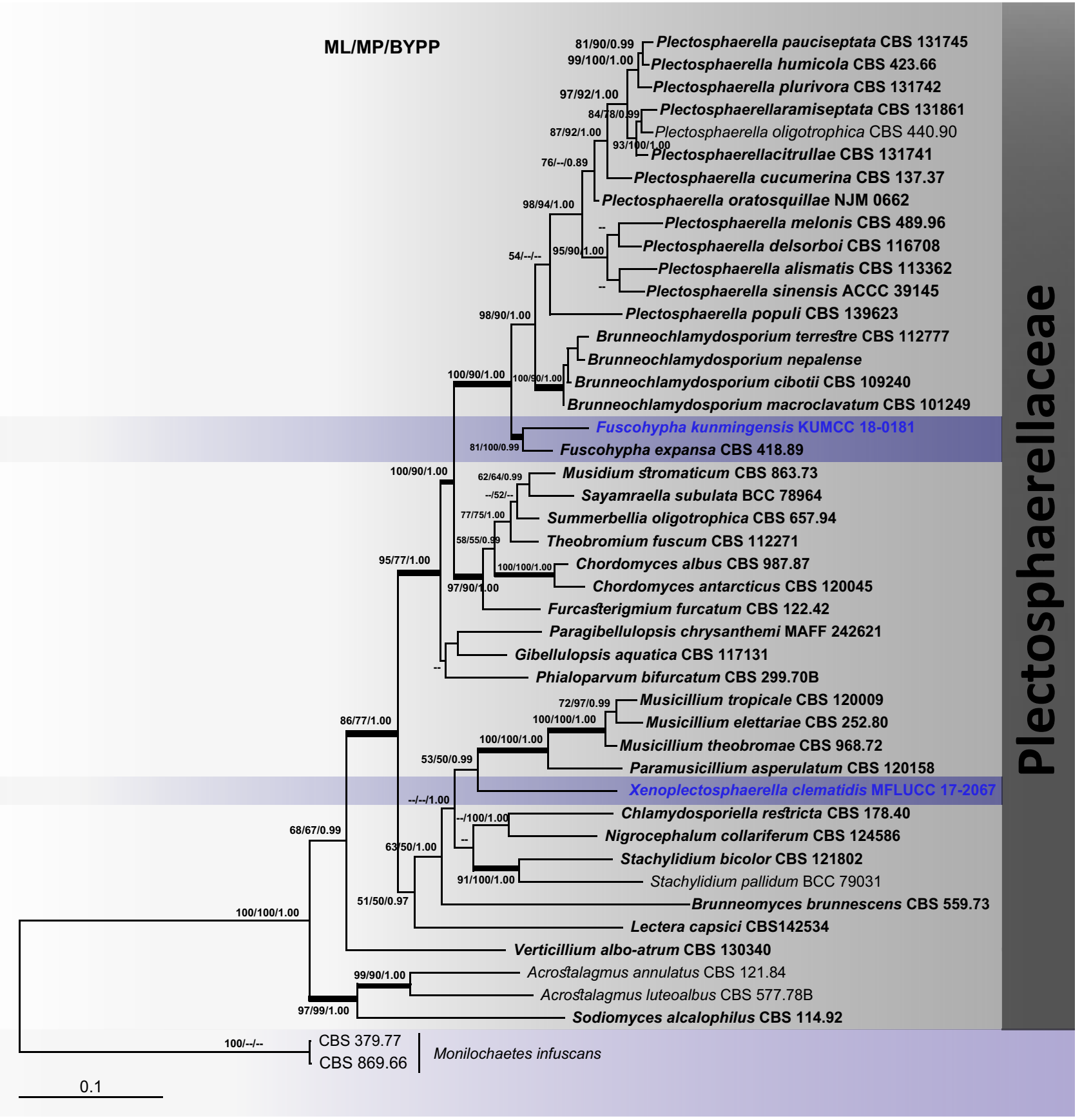

Fig. 114 The best scoring RAxML tree with a final likelihood value of - 23259.637010 of ITS, LSU, tef1 and $r p b 2$ sequence data for Plectosphaerellaceae. The topology and clade stability of the combined gene analyses was compared to the single gene analyses. The tree is rooted at Monilochaetes infuscans (CBS 379.77 and CBS 869.66). The matrix had 1093 distinct alignment patterns, with $13.22 \%$ of undetermined characters and gaps. Estimated base frequencies were as follows; $\mathrm{A}=0.224235, \mathrm{C}=0.297727, \mathrm{G}=0.281301$, $\mathrm{T}=0.196738$; substitution rates $\mathrm{AC}=0.820050, \mathrm{AG}=1.988895$,
$\mathrm{AT}=1.053617, \quad \mathrm{CG}=0.783458, \quad \mathrm{CT}=5.160854, \quad \mathrm{GT}=1.000000 ;$ gamma distribution shape parameter $\alpha=0.2928059$. The new species in this study are indicated in blue. Bootstrap values (BS) greater than 50\% BS (maximum likelihood (left); maximum parsimony (middle)) and Bayesian posterior probabilities (BYPP, right) greater than 0.90 are given at the nodes. Hyphens (-) represent support values less than $50 \%$ BS/0.90 BYPP. Thick branches represent significant support values from all analyses (BS $\geq 70 \% / B Y P P \geq 0.95)$ at the genus level 

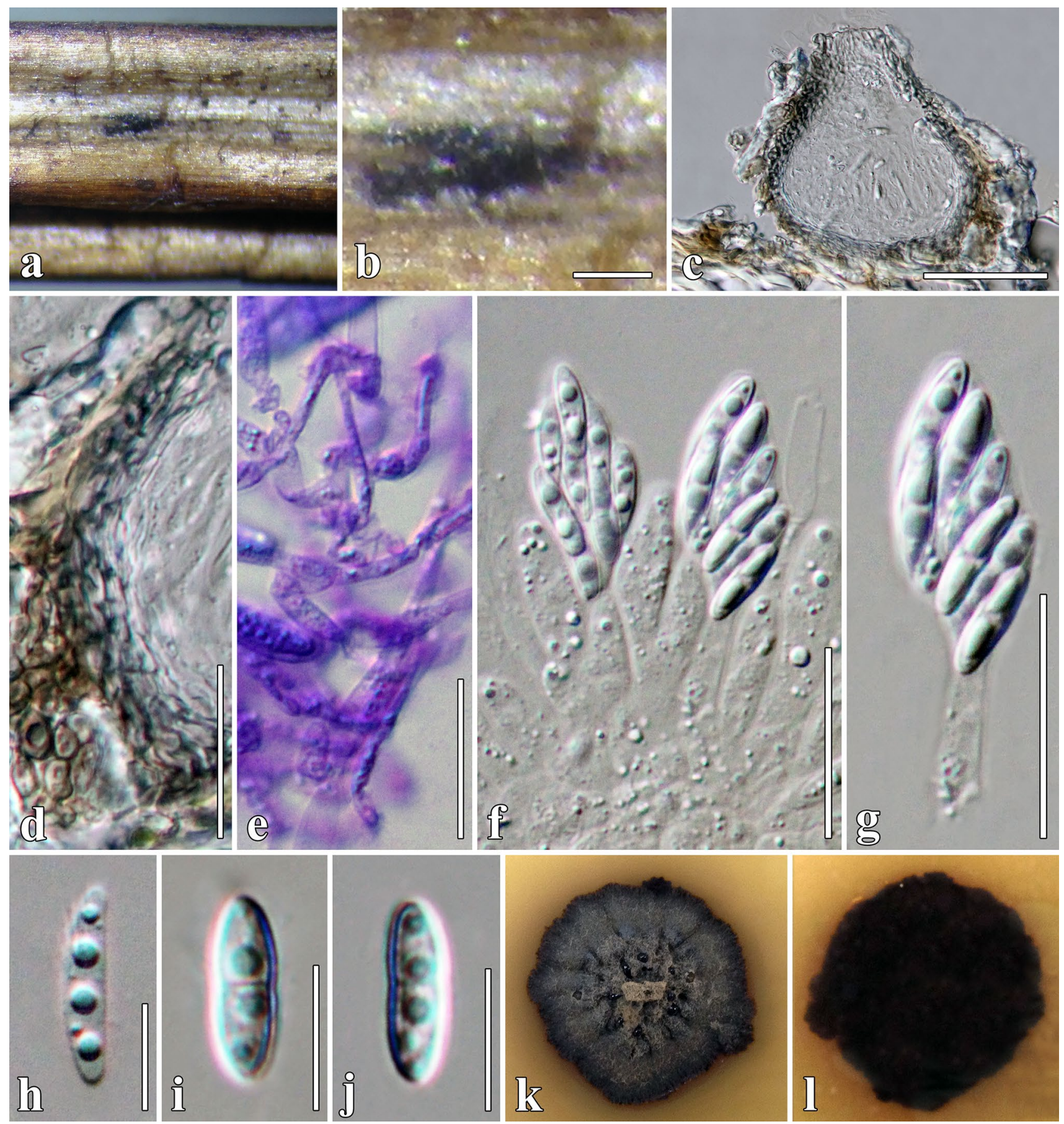

Fig. 115 Xenoplectosphaerella clematidis (MFLU 17-1475, holotype). a Appearance of ascomata on Clematis subumbellata. b Close up of ascoma on host substrate. c Vertical section through ascoma. d
Peridium. e Paraphyses (in cotton blue). f, $\mathbf{g}$ Asci. h-j Ascospores. k, I Culture characteristics on MEA. Scale bars: $\mathbf{b}=100 \mu \mathrm{m}, \mathbf{c}=50 \mu \mathrm{m}$, $\mathbf{d}-\mathbf{g}=20 \mu \mathrm{m}, \mathbf{h}-\mathbf{j}=10 \mu \mathrm{m}$ 


\section{Fusarium}

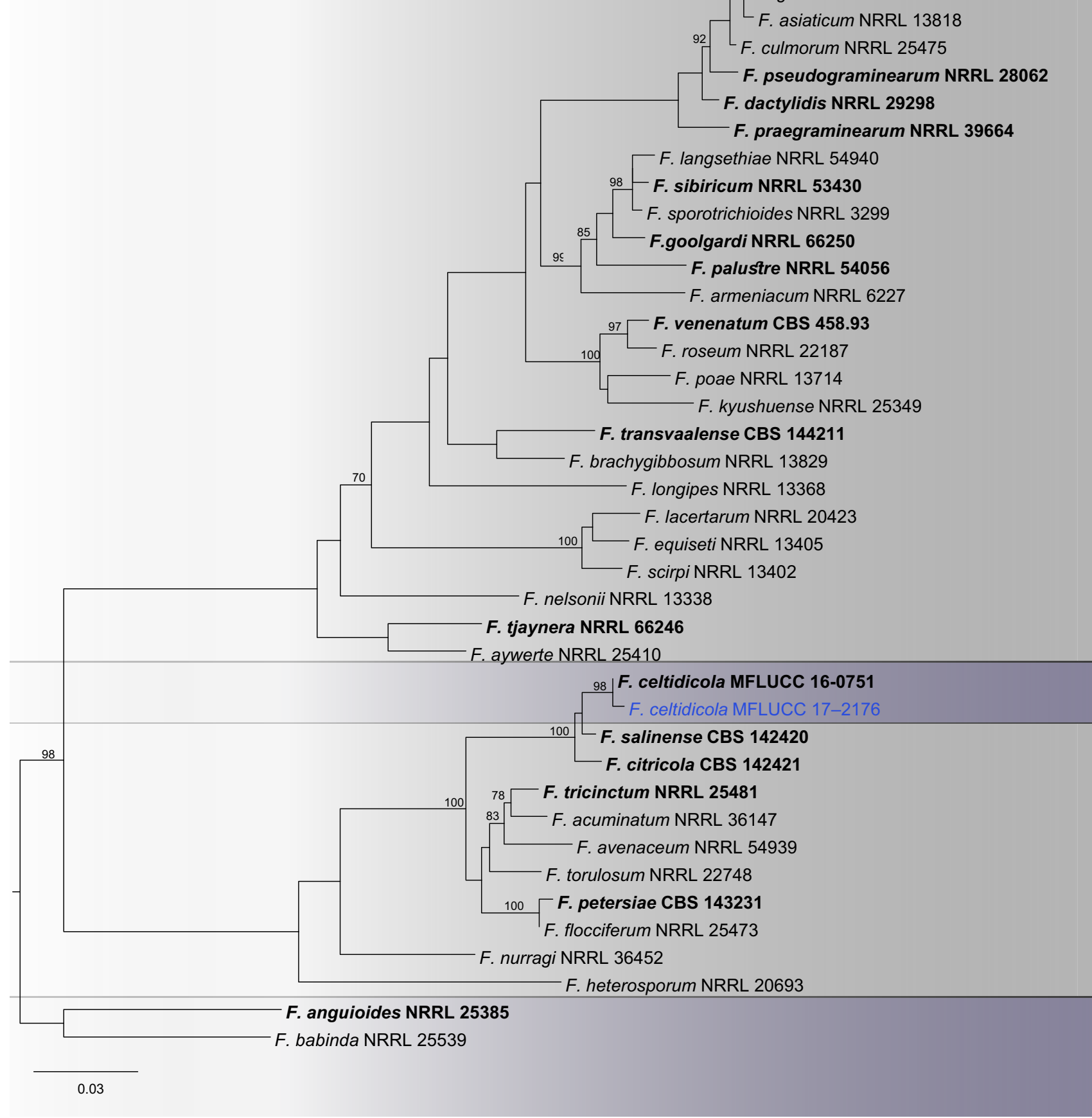

Fig. 116 The best scoring RAxML tree with a final likelihood value of -52171.145500 of $r p b 1$ and $r p b 2$ sequence data. The topology and clade stability of the combined gene analyses was compared to the single gene analyses. The tree is rooted with Fusarium anguioides (NRRL 25385) and F. babinda NRRL (25539). The matrix had 1722 distinct alignment patterns with $15.24 \%$ undetermined characters and gaps. Estimated base frequencies were as follows; $A=0.260064$,
$\mathrm{C}=0.246883, \quad \mathrm{G}=0.252626, \quad \mathrm{~T}=0.240426 ; \quad$ substitution $\quad$ rates $\mathrm{AC}=1.307580, \mathrm{AG}=5.230737, \mathrm{AT}=1.086622, \quad \mathrm{CG}=0.958821$, $\mathrm{CT}=10.666584$, GT $=1.000000$; gamma distribution shape parameter $\alpha=0.761212$. Ex-type strains are in bold black and the species determined in this study is indicated in blue. Bootstrap values (BT) (over 70\% BT) from maximum likelihood are given at the nodes 
et al. 1999; Lombard et al. 2015). The concept of the family was addressed by Lombard et al. (2015), Maharachchikumbura et al. (2016) and Hyde et al. (2020b) and include 69 genera (Wijayawardene et al. 2020).

\section{Fusarium Link}

Fusarium is a large genus in Nectriaceae, with more than 1500 epithets (Index Fungorum 2020). The genus was introduced with Fusarium roseum as the type species (Wijayawardene et al. 2018). Phylogenetic analysis based on $r p b 1$ and $r p b 2$ nucleotide sequences resulted in a wellsupported phylogenetic clade of the newly isolated strain clustering with $F$. celtidicola (Hyde et al. 2014; Shang et al. 2018). Partial sequences of DNA-directed RNA polymerase II subunit RPB1 ( $r p b 1)$ and DNA-directed RNA polymerase II subunit RPB2 ( $r p b 2$ ) gene regions were used for phylogenetic analysis (Fig. 116) and supported by morphological observations for species level characterization (Fig. 117).

Fusarium celtidicola Shang, Camporesi \& K.D. Hyde, Phytotaxa 361 (3): 255 (2018), new host record

Index Fungorum number: IF 553845; Facesoffungi number: FoF 02453, Fig. 117.

Saprobic on dead stem of Clematis vitalba. Sexual morph: Ascomata 210-255 × 180-280 $\mu \mathrm{m}$ $(\bar{x}=230 \times 225 \mu \mathrm{m}, \mathrm{n}=10)$, superficial on host substrate, single or gregarious, sometimes confluent, globose, black, ostiolate, papillate. Papilla $75 \times 95 \mu \mathrm{m}$, conical, with periphysoids, with a small pore. Peridium $25-42 \mu \mathrm{m}$ wide, comprising an outer purple layer, composed of 5-7 layers of thin-walled cells of textura angularis, inner layers, hyaline, thick-walled, several cell layers of textura angularis. Catenophyses numerous, $13-20 \mu \mathrm{m}(\bar{x}=17 \mu \mathrm{m}$, $\mathrm{n}=30$ ), septate, narrowing and tapering towards the apex. Asci $72-100 \times 7-14 \mu \mathrm{m}(\bar{x}=70 \times 10 \mu \mathrm{m}, \mathrm{n}=20)$, unitunicate, simple pedicel, broad fusiform to oblong, apex flat, with $\mathrm{J}$-, cylindrical, conspicuous apical ring. Ascospores 15-30 $\times 4-9 \mu \mathrm{m}(\bar{x}=17 \times 7 \mu \mathrm{m}, \mathrm{n}=50)$, biseriate, partialoverlapping, hyaline, oval, (1-)3-septate, constricted at the median septum, slightly constricted at the septa, straight or slightly curved towards the apex, thin-walled, with a minute guttule in each cell, smooth-walled. Asexual morph: See Shang et al. (2018).

Culture characters: Colonies on MEA reaching $30 \mathrm{~mm}$ diam. after 4 weeks at $25{ }^{\circ} \mathrm{C}$. Culture from above, purple or white radiating outwardly to the edge, undulate margin, medium dense, flat, dull, fimbriate, and slightly covered with white aerial mycelium; reverse brown with radiating cream mycelium.
Material examined: Italy, Forlì-Cesena, Casone-Dovadola, on dead aerial stems of Clematis vitalba, 9 February 2013, E. Camporesi, IT1061 (MFLU 17-1537), living culture, MFLUCC 17-2176.

Hosts: Celtis australis, Clematis vitalba-(Shang et al. 2018; this study).

Distribution: Italy_(Shang et al. 2018; this study).

GenBank accession numbers: LSU: MT214620; SSU: MT226731; ITS: MT310664; tef1: MT394675; rpb2: MT394723.

Notes: Based on the phylogenetic analysis our strain MFLUCC 17-2176 clustered with the ex-type strain of Fusarium celtidicola (MFLUCC 16-0526), which was recorded from Italy on Celtis australis (Shang et al. 2018). Our collection is morphologically identical to $F$. celtidicola (MFLUCC 16-0526) (Fig. 117).

\section{Sarocladiaceae Lombard}

Crous et al. (2018) introduced Sarocladiaceae to accommodate Parasarocladium and Sarocladium. Sarocladiaceae is characterized by its elongated phialides rising solitary on vegetative hyphae or on conidiophores that are sparsely or repeatedly branched, with elongated conidia (Giraldo et al. 2015). Phylogenetic analysis of the combined dataset of the LSU, ITS, and act sequences reveals a novel Sarocladium species (Fig. 118).

\section{Sarocladium Gams \& D. Hawksw.}

Sarocladium species have been reported as human pathogens, plant pathogens and saprobes (Gams 1975; Yeh and Kirschner 2014; Giraldo et al. 2015). The genus is typified by $S$. oryzae, a plant pathogen causing sheath-rot disease of rice (Ayyadurai et al. 2005; Seifert et al. 2011). Currently, 21 epithets are listed in Index Fungorum (2020). Sarocladium can be distinguished by its elongate phialides rising solitary on vegetative hyphae or on conidiophores that are sparsely or repeatedly branched, and cylindrical conidia. The characters of Sarocladium are mostly reported from culture, while our collection is associated with a dried stem of Clematis from Belgium (Fig. 119). The combined dataset of the LSU, ITS, and act sequences based on a multi-locus phylogenetic analysis revealed Sarocladium clematidis as a novel species (Figs. 118, 119).

Sarocladium clematidis Phukhams., Ertz, Gerstmans \& K.D. Hyde, sp. nov.

Index Fungorum number: IF556744; Facesoffungi number: FoF 06267, Fig. 119.

Etymology: Named after the host genus, Clematis.

Holotype: MFLU 17-1507 


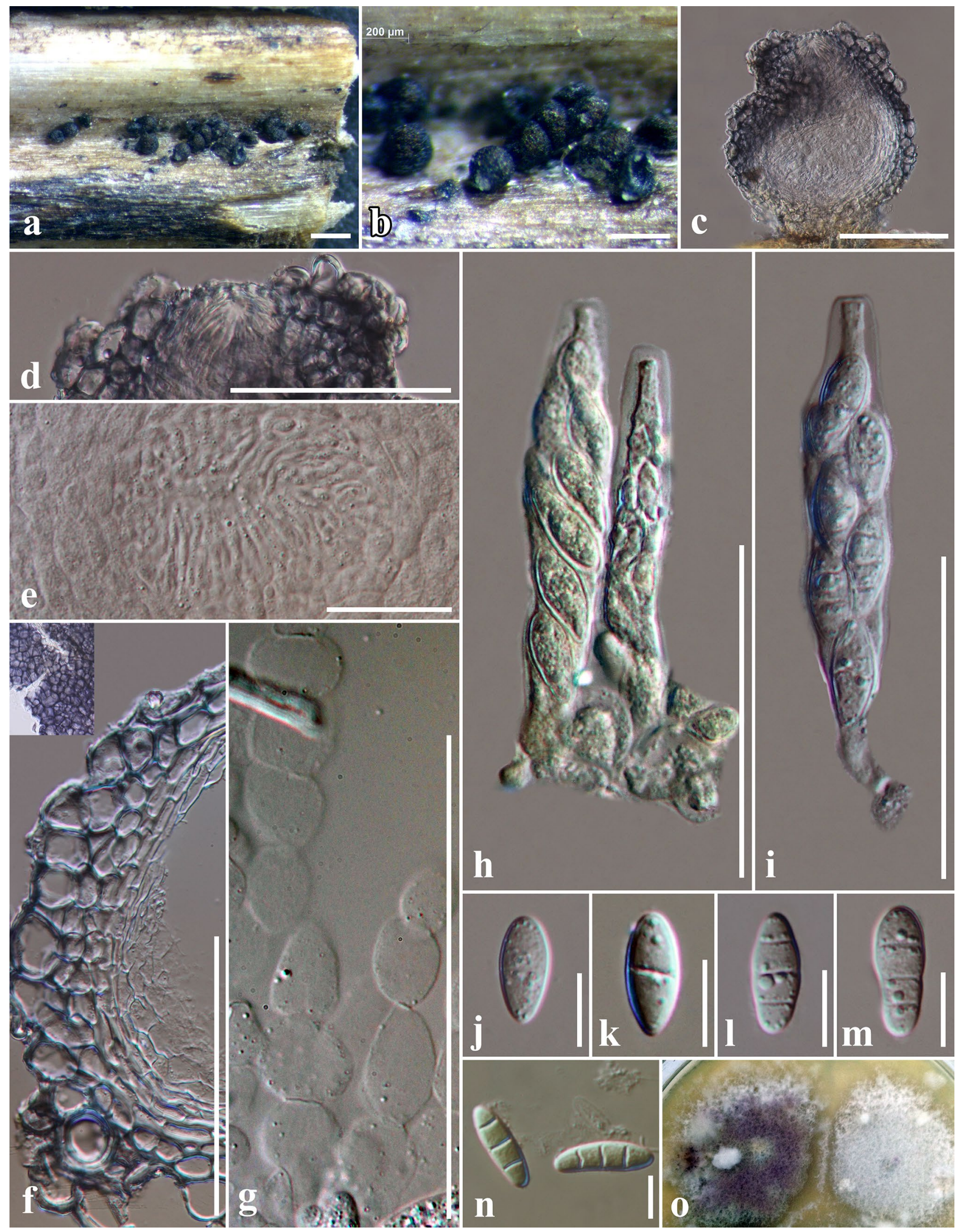


४Fig. 117 Fusarium celtidicola (MFLU 17-1461). a Appearance of ascomata on Clematis vitalba. b Close up of ascomata on host substrate. c Vertical section through an ascoma. d, e Ostiolar canal. f Peridium. g Catenophyses. $\mathbf{h}$, i Asci. $\mathbf{j}-\mathbf{n}$ Ascospores. o Culture characteristics on MEA. Scale bars: $\mathbf{a}=500 \mu \mathrm{m}, \mathbf{b}=200 \mu \mathrm{m}, \mathbf{c}, \mathbf{f}$, $\mathbf{g}=100 \mu \mathrm{m}, \mathbf{d}, \mathbf{h}-\mathbf{i}=50 \mu \mathrm{m}, \mathrm{e}=20 \mu \mathrm{m}, \mathbf{j}-\mathbf{n}=10 \mu \mathrm{m}$

Saprobic on dried stems of Clematis patens. Sexual morph: Undetermined. Asexual morph: Colonies effuse on the natural substrate, scattered, hairy, dark brown. Mycelium partly immersed, branched, composed of pale brown, septate hyphae. Conidiophores $85-320 \times 12-19 \mu \mathrm{m}$ $(\bar{x}=150 \times 15 \mu \mathrm{m}, \mathrm{n}=20)$, macronematous, synnematous, composed of 7-12 hyphae in each stipe, tree-like, parallel and unbranched in the stipe, gregarious, or scattered, erect, stripes straight or slightly flexuous, 6-17-septate, constricted at septa, 15-30 $\mu \mathrm{m}$ wide at base, tapering towards apex, 6-14 $\mu \mathrm{m}$ wide at apex, irregularly branched, cylindrical, smooth, dark brown. Conidiogenous cells $7-15 \times 2-5 \mu \mathrm{m}$ $(\bar{x}=10 \times 2.5 \mu \mathrm{m}, \mathrm{n}=20)$, polyphialidic, integrated or terminal, cylindrical, straight to slightly curved, slightly narrowing at apex, acropetally proliferating, hyaline to pale brown, verrucose. Conidia $4-9 \times 2-4 \mu \mathrm{m}(\bar{x}=6 \times 2.5 \mu \mathrm{m}, \mathrm{n}=40)$, unicellular, fusiform to broadly fusiform, aseptate, thickwalled, hyaline, verrucose, bud scars or disjunctors present at the site of attachment, 1-2-guttulate.

Culture characters: Colonies on PDA reaching $30 \mathrm{~mm}$ diam. after 4 weeks at $25^{\circ} \mathrm{C}$. Cultures from above, cream or white, medium dense, circular, umbonate, flat, at first glabrous becoming powdery at centre, wrinkled, folded, slimy in the middle, slightly radiating outwardly; reverse: cream at the centre, mycelium radiating outwardly. Asexual morph formed in culture with morphology similar to that on the natural substrates.

Material examined: Belgium, Flemish Brabant, Meise Botanic Garden, Bouchout Domain, on dead stems of Clematis patens, 13 June 2017, D. Ertz \& C. Gerstmans, BRCP3 (MFLU 17-1507, holotype); ex-type living culture, MFLUCC 17-2150.

Host: Clematis patens-(This study).

Distribution: Belgium-(This study).

GenBank accession numbers: LSU: MN629285; SSU: MN629284; ITS: MN629287; tef1: MN628625; rpb2: MN628627.

Notes: Sarocladium clematidis formed synnemata with 7-12 hypha in each stipe on the natural substrate (Fig. 119). Sarocladium clematidis (MFLUCC 17-2150) is morphologically similar to Phaeoisaria clematidis, however they are phylogenetically distant (Yeh and Kirschner 2014). Morphological characters of Sarocladium have mainly been reported from culture (Seifert et al. 2011). Sarocladium clematidis has solitary, elongate phialides, with branched conidiophores and fusiform conidia (Seifert et al. 2011). In phylogenetic analysis of combined sequence data (Fig. 118), $S$. clematidis formed a close relationship with $S$. dejongiae (CBS 144929) with strong support (100\% ML/1.00 BYPP). In a BLASTn search of GenBank, the closest match of the ITS sequence of S. clematidis is S. dejongiae with $98 \%$ similarity to the $S$. dejongiae (511/519 with five gaps). Based on its distinct characters and the phylogenetic support, we introduce a novel species herein.

\section{Stachybotryaceae Lombard \& P. Crous}

Stachybotryaceae was introduced by Crous et al. (2014a) and comprises 36 genera (Wijayawardene et al. 2018). Species are saprobes, plant and animal pathogens, or airborne (Crous et al. 2014a; Lombard et al. 2016; Rennberger 2018). Stachybotryaceae members have sporodochial to synnematous conidiomata, phialidic conidiogenous cells, and 0-1-septate conidia (Lombard et al. 2016). In this study, phylogenetic analyses of the combined LSU, ITS, tefl, rpb2 and $t u b$ dataset reveals a new record of Memnoniella from Clematis collected from Thailand (Fig. 120).

\section{Memnoniella Höhn.}

Memnoniella was synonymised under Stachybotrys (Galloway 1933). However, the distinctiveness of Memnoniella was confirmed by morphological characters and phylogenetic evidence (Lombard et al. 2016). Memnoniella is distinguished by mostly smooth, thick-walled and unbranched conidiophores giving rise to conidia in dry chains, whereas Stachybotrys has hyaline phialides, brightly coloured, or dark phialophores, producing 1-celled, dark conidia, accumulating in a slimy cluster (Wang et al. 2015). Some species of Memnoniella (e.g., M. echinata and M. longistipitata) produce dimorphic conidia ( $\mathrm{Li}$ et al. 2003). We report a new collection of $M$. oblongispora from a Clematis species from Thailand which produces dimorphic conidia, a feature not known in this species (Fig. 121).

Memnoniella oblongispora Lin, McKenzie, Wang \& K.D. Hyde, new host record and dimorphic characters report

Index Fungorum number: IF 552085; Facesoffungi number: FoF 02081, Fig. 121.

Saprobic on dried stems of Clematis subumbellata. Sexual morph: Undetermined. Asexual morph: Hyphomycetous. 1) Colonies of dry conidial chains, effuse on the natural substrate, scattered, hairy, dark brown. Mycelium semi-immersed to superficial, composed of pale brown, septate hyphae. Conidiophores 30-70(-120) $\times 3-6 \mu \mathrm{m}$ $(\bar{x}=50 \times 5 \mu \mathrm{m}, \mathrm{n}=20)$, macronematous, mononematous, erect, simple, stipes straight or flexuous, mostly unbranched, but irregularly branched at the upper parts,, sub-cylindrical to cylindrical, bearing a crown of phialides at apex, mammiform at the base cell, 3-4-septate, brown at the 
Fig. 118 Best scoring RAxML tree with a final likelihood value of -9149.858797 of LSU, ITS, and act sequence data. The tree is rooted with Kiflimonium curvulum (CBS 430.66). The matrix had 613 distinct alignment patterns with $18.90 \%$ undetermined characters and gaps. Estimated base frequencies were as follows; $\mathrm{A}=0.223643$, $\mathrm{C}=0.286812, \mathrm{G}=0.271932$, $\mathrm{T}=0.217614$; substitution rates $\mathrm{AC}=1.580411, \mathrm{AG}=2.743783$, $\mathrm{AT}=2.611458, \mathrm{CG}=0.755231$, $\mathrm{CT}=8.336114, \mathrm{GT}=1.000000$; gamma distribution shape parameter $\alpha=0.532334$. Extype strains are in bold black and the species determined in this study is indicated in blue. Bootstrap values (BS) greater than $50 \%$ BS (maximum likelihood (left)) and Bayesian posterior probabilities (PP, right) greater than 0.90 are given at the nodes. Hyphens (-) represent support values less than 50\% BS/0.90 BYPP. Thick branches represent significant support values from all analyses $(\mathrm{BS} \geq 70 \% / \mathrm{BYPP} \geq 0.95)$ at the genus and family level

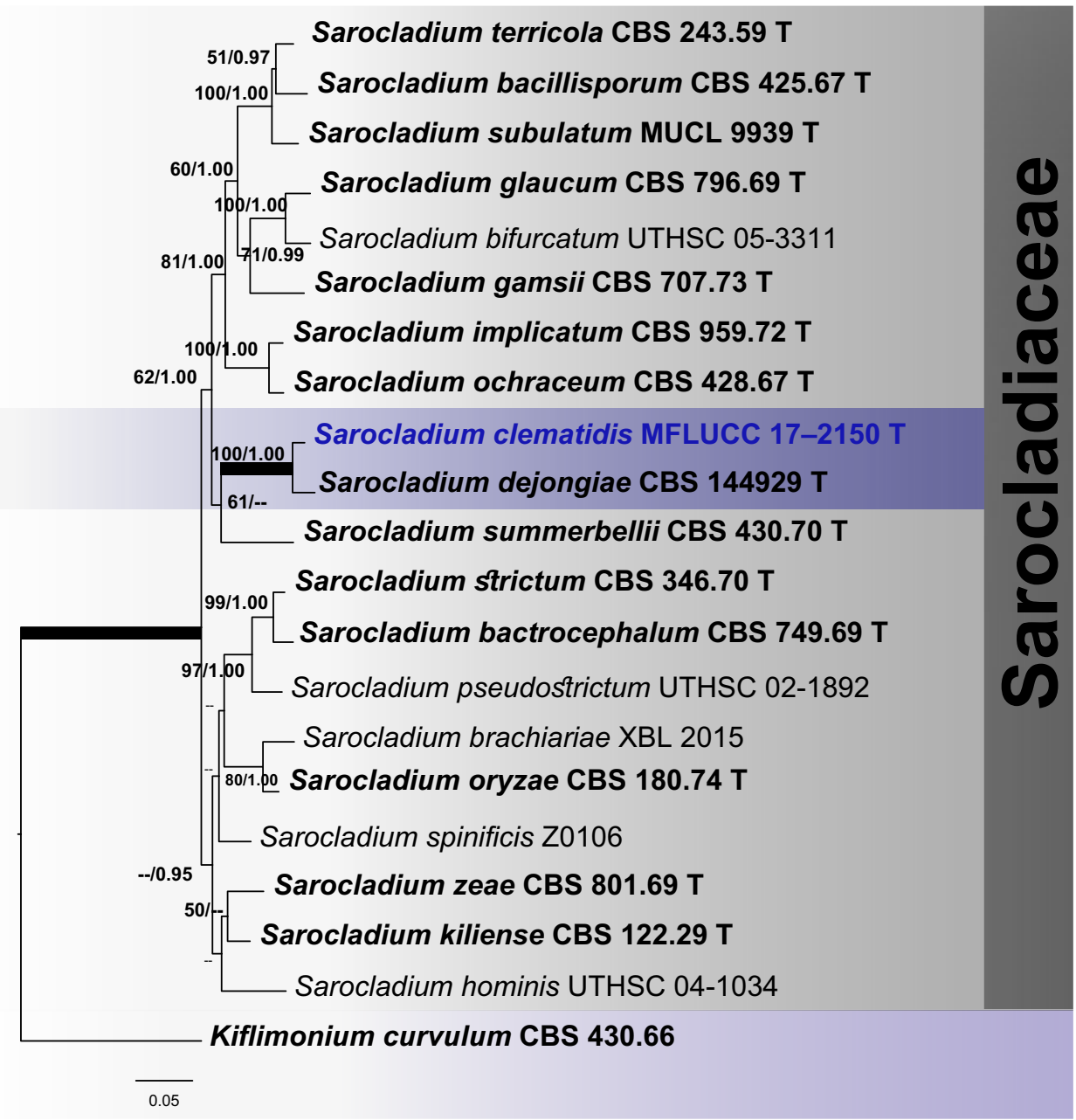

apex, hyaline at the base, smooth or verruculose. Conidiogenous cells $5-10 \times 2.5-3.5 \mu \mathrm{m}(\bar{x}=8 \times 3 \mu \mathrm{m}, \mathrm{n}=10)$, monophialidic, discrete, determinate, terminal, clustered at the apex of conidiophores, oblong, pale brown. Conidia $3-5 \times 2.5-4.5 \mu \mathrm{m}(\bar{x}=4 \times 4 \mu \mathrm{m}, \mathrm{n}=20)$, acrogenous, aseptate, globose, olivaceous, brown to dark brown, verrucose, thick-walled, dark brown to reddish brown, verrucose, formed in long chains, easily separated. 2) Colonies of slimy conidial chains produced in culture on MEA media. Conidiophores $32-125 \times 4-7 \mu \mathrm{m}(\bar{x}=70 \times 4.5 \mu \mathrm{m}, \mathrm{n}=10)$, macronematous, mononematous, erect, simple, straight or flexuous, unbranched, smooth, thick-walled, septate, subcylindrical, of elongated phialide base, apex bearing a crown of phialidic conidiogenous cells, hyaline at the base, olive grey at the apex. Conidiogenous cells $8-17 \times 4.8-5.6 \mu \mathrm{m}$ $(\bar{x}=10 \times 5 \mu \mathrm{m}, \mathrm{n}=20)$, monophialidic, discrete, determinate, terminal, clustered at the apex of conidiophores, pyriform, obovate, ellipsoidal, clavate or reniform, smooth, brown. Conidia $8-14 \times 4.5-7 \mu \mathrm{m}(\bar{x}=9 \times 5 \mu \mathrm{m}, \mathrm{n}=50)$, aggregated in large, slimy, black and glistening heads, acrogenous, simple, spherical, oblong, immature hyaline, dark brown at maturity, two guttules present when immature, unicellular, verrucose surface.

Culture characters: Colonies on MEA reaching $30 \mathrm{~mm}$ diam. after 2 weeks at $25{ }^{\circ} \mathrm{C}$. Cultures from above, cream to yellowish white, medium to sparse, circular, fimbriate, wrinkled and folded, slightly radiating outwardly; reverse orange at the centre, cream radiating, dimorphic characters produced after 3 weeks of incubation, characters of dry conidial chains similar to those on natural substrates.

Material examined: Thailand, Phayao Province, Phu Sang District, dead stems of Clematis subumbellata, 20 March 2017, C. Phukhamsakda, CMTH06 (MFLU 17-1470); living culture, MFLUCC 17-2064.

Hosts: Clematis subumbellata, decaying Quercus leaf(Lin et al. 2016; this study)

Distribution: Thailand-(Lin et al. 2016; this study)

GenBank accession numbers: LSU: MT214621; SSU: MT226732; ITS: MT310665; tef1: MT394676; rpb2: MT394724.

Notes: Memnoniella oblongispora (MFLUCC 17-2064) formed a clade with the type strain of $M$. oblongispora 
(MFLUCC 15-1074) with moderate support (75\% ML/0.92 BYPP). Memnoniella species may produce dimorphic asexual characters ( $\mathrm{Li}$ et al. 2003). Memnoniella oblongispora was described as producing slimy conidial masses in a black and glistening head, with oblong, verrucose, olive green to black conidia (Lin et al. 2016). Our collection on a natural substrate, produced dry chains of sphaerical conidia. After three weeks in culture, glistening conidial masses were observed on the surfaces of white mycelia. In culture, both dry chains and stachybotrys-type slimy conidia were formed, which correlated with the morphology reported by $\mathrm{Li}$ et al. (2003).

The analysis (Fig. 120) showed that our collection formed a clade with the ex-type strain of M. oblongispora and a strain of M. longistipitata (CBS 136197). However, the characters of M. longistipitata (CBS 136197) have not been reported (Lombard et al. 2016). Memnoniella oblongispora (MFLUCC 17-2063) and the type strain of M. longistipitata (ATCC 22699) are distinguishable by conidiophores characters. Memnoniella longistipitata has very long conidiophores in culture $(260-460 \times 3.6-4.7 \mu \mathrm{m}$; Li et al. 2003), while Memnoniella oblongispora (MFLUCC 17-2064) has shorter conidiophores based on examination of their characters on natural substrates and in culture $(32-125 \times 4-7 \mu \mathrm{m}$; Lin et al. 2016; this study).

Pairwise comparison of the ITS sequence data in Memnoniella oblongispora (strains MFLUCC 17-2064 and MFLUCC 15-1074) are identical. Therefore, we report a new record of M. oblongispora from Clematis in Thailand, with dimorphic conidial (Fig. 121).

\section{Discussion}

In this paper we provide data on collections of fungi associated with typically vigorous, woody, often invasive, climbing vines in Ranunculaceae, Clematis. The genus is distributed worldwide as a native plant and as a group that is commercially cultivated (Grey-Wilson 2000). In the present study, nine Clematis species were sampled from Asia (China, Thailand), Europe (Belgium, Italy, UK). These are Clematis fulvicoma, $C$. orientalis, $C$. patens, $C$. serratifolia, C. sikkimensis, $C$. subumbellata, $C$. virginiana, $C$. vitalba, $C$. viticella, additionally with $C$. ligusticifolia. Seventy-three taxa were added to the known fungi associated with Clematis. The classification of each species is justified by a consolidated species concept approach (Quaedvlieg et al. 2014).

\section{Applying a consolidated species concept to delineating taxa}

The implementation of a comprehensive approach for confidently introducing new fungal taxa has been strongly recommended in several studies. Quaedvlieg et al. (2014) introduced the "consolidated species concept" that distinguished fungal taxa based on the combination of the "biological species concept", "ecological species concept", "morphological species concept", "phylogenetic species concept" and the application of "genealogical concordance phylogenetic species recognition" (Taylor et al. 2000). The approach was supplemented by performing a pairwise homoplasy index, followed by the interpretation of nucleotide difference based on its importance as highlighted by Jeewon and Hyde (2016). Phylogenetic species concept is currently regarded as an effective molecular tool to differentiate a common ancestor in the fungal community. Molecular-clock age estimates have been used as additional evidence to explore the evolution of lineages and divergence dates in fungal taxa (Hongsanan et al. 2017; Liu et al. 2017; Phukhamsakda et al. 2017b; Phillips et al. 2019; Samarakoon et al. 2019; Hyde et al. 2020b). In some complex species with high similarity in the phenotype and the evolution of these sequences cannot be described by a single tree and therefore the pairwise homoplasy index was applied to distinguish the genotype group and justify the species boundaries of phylogenetically closely related taxa (Dettman et al. 2003; Quaedvlieg et al. 2014). This method has been widely used to determine the possibility of inbreeding within the population and establish the genetic differentiation in lineages from phylogenetically closely related species (Laurence et al. 2014). Although the analysis was recommended for sexual organisms, recombination sciences have also applied this method for historical recombination (Burnett 2003; Turner et al. 2013). Diaporthaceae (Diaporthales), Hermatomycetaceae, and Lophiostomataceae (Pleosporales) are used as a case-study in the present work.

Diaporthaceae (Diaporthales): Diaporthe is a complex genus that presents high genetic variation within one species and can occur on a wide range of hosts. To introduce a novel species within Diaporthe, consolidated evidence is needed. We apply genealogical concordance phylogenetic species recognition to study the nucleotide distances of the common ancestors within a targeted clade (Fig. 100). The genealogical concordance phylogenetic species recognition is relatively reliable and can be useful in the identification of species in Diaporthe. Diaporthe rudis showed the genetic complexity especially in the ITS region and the recombination parameters among selected taxa are shown in Fig. 103b. The strains probably contain high intraspecific variation in the pseudogene of the rDNA copy (Stadler et al. 2020). The GCPSR result of the concatenated gene set shows insignificant recombination between the isolates ( $\Phi \mathrm{w}=0.05$, Fig. 103b). We demonstrate that some $D$. rudis isolates have undergone recombination of species based on the evolutionary dynamics (Quaedvlieg et al. 2014; Guarnaccia and Crous 2017). 

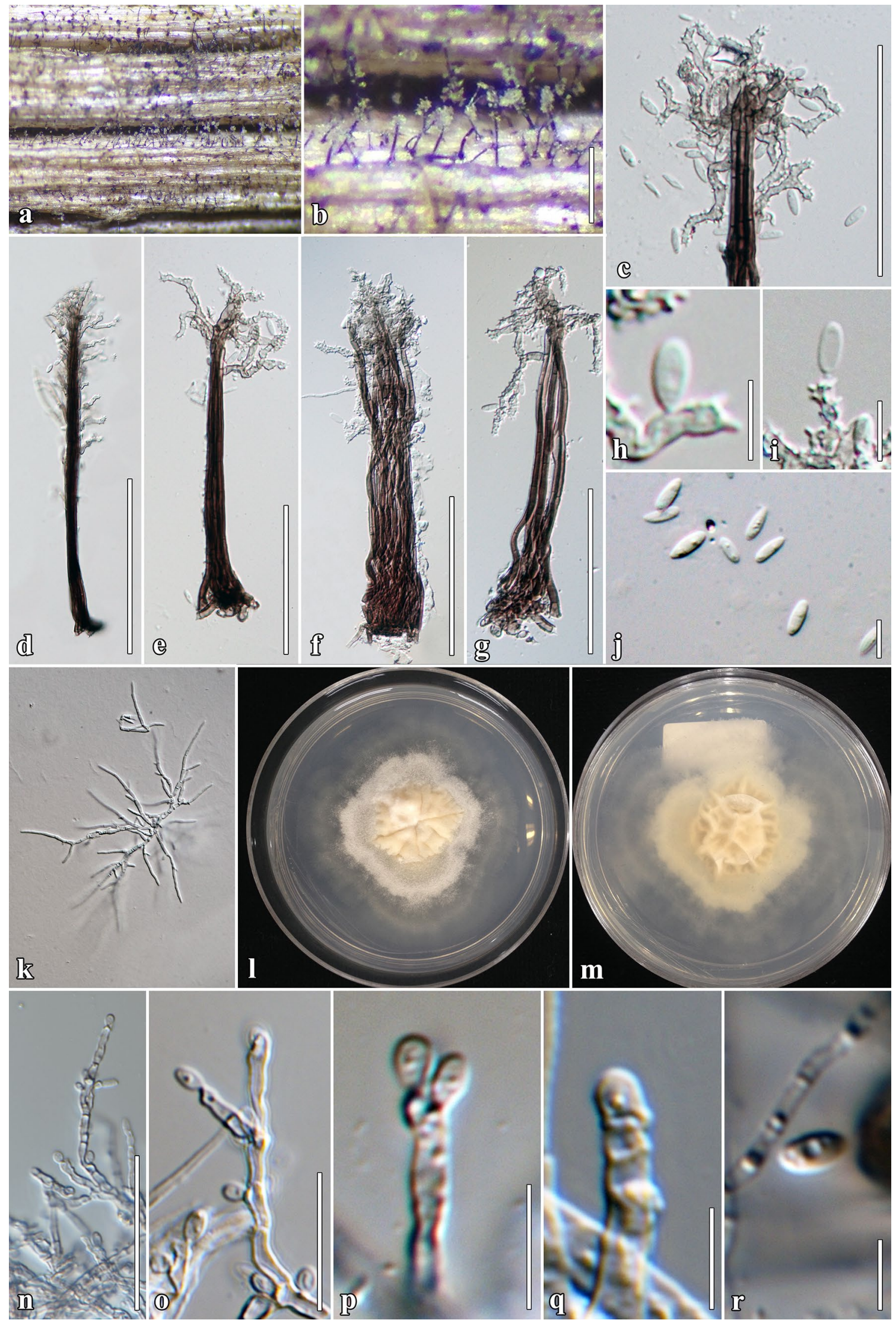
४Fig. 119 Sarocladium clematidis (MFLU 17-1507, holotype). a Appearance of synnemata on Clematis patens. b, $\mathbf{c}$ Close up of conidiophores. d-g Synnemata. h, i Conidiogenous cells and conidia. j Conidia. $\mathbf{k}$ Germinated conidia. $\mathbf{l}, \mathbf{m}$ Culture characteristics on PDA. $\mathbf{n}-\mathbf{r}$ Asexual morph produced in culture. Scale bars: $\mathbf{b}=500 \mu \mathrm{m}, \mathbf{c}$, $\mathbf{n}=50 \mu \mathrm{m}, \mathbf{d}=200 \mu \mathrm{m}, \mathbf{e}-\mathbf{g}=100 \mu \mathrm{m}, \mathbf{h}-\mathbf{j}, \mathbf{q}, \mathbf{r}=5 \mu \mathrm{m}, \mathbf{o}=20, \mathbf{p}=10$
Hermatomycetaceae (Pleosporales): This family lacks a sexual morph and the genealogical concordance phylogenetic species recognition result of Hermatomyces sphaericus (Fig. 21) contradicts the phylogeny (especially H. biconisporus and $H$. pandanicola). Phylogenies from maximum likelihood, maximum parsimony and Bayesian statistics did not give good support for the separate clade between $H$. sphaericus sensu stricto and $H$. pandanicola. This result is supported by the genealogical concordance phylogenetic species recognition value that does not significantly support

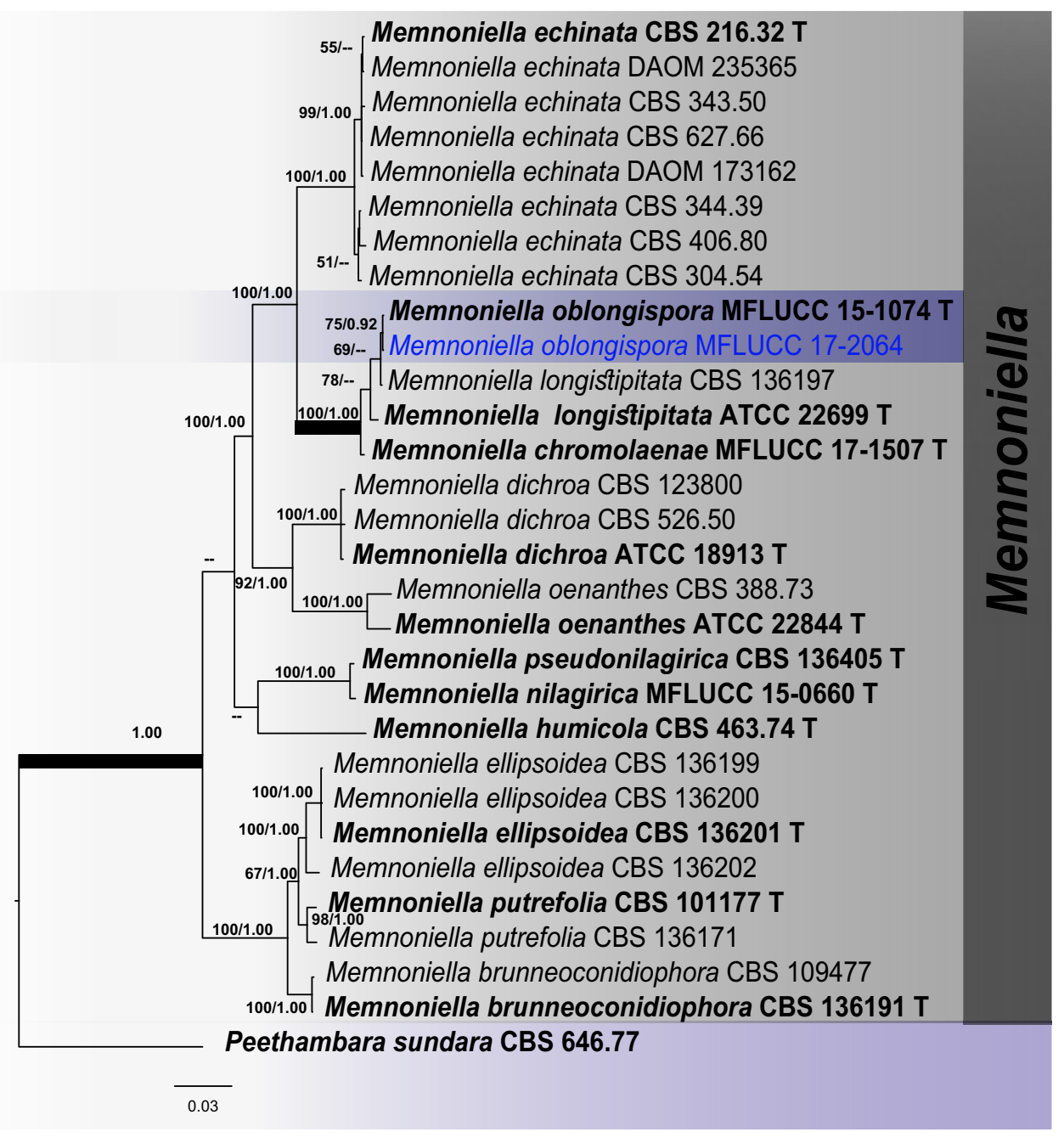

Fig. 120 Bayesian 50\% majority-rule consensus phylogram based on combined LSU, ITS, tef1, rpb2 and tub sequence data for Memnoniella species. The topology and clade stability of the combined gene analyses was compared to the single gene analyses. The tree is rooted with Peethambara sundara strain CBS 646.77. Thirty strains were included in the combined genes sequence analyses which comprised 3057 characters (798 for LSU, 618 for ITS, 554 for tefl, 721 for $r p b 2,366$ for $t u b$, including gap regions). The tree from the maximum likelihood analysis had similar topology to the Bayesian analyses. The best scoring RAxML tree had a final likelihood value of - 11438.749144. The matrix had 794 distinct alignment patterns, with $19.09 \%$ of undetermined characters and gaps. Estimated base frequencies were: $\mathrm{A}=0.236362, \mathrm{C}=0.265886, \mathrm{G}=0.272223$, $\mathrm{T}=0.225529 ;$ substitution rates $\mathrm{AC}=1.092531, \mathrm{AG}=3.397943$, $\mathrm{AT}=1.269553, \quad \mathrm{CG}=0.955550, \quad \mathrm{CT}=9.625921, \quad \mathrm{GT}=1.000000$; gamma distribution shape parameter $\alpha=0.547123$. In our analysis, $\mathrm{GTR}+\mathrm{I}+\mathrm{G}$ model was used for each partition in Bayesian posterior analysis. The species determined in this study is indicated in blue. Bootstrap values (BS) greater than 50\% BS (maximum likelihood (left)) and Bayesian posterior probabilities (PP, right) greater than 0.90 are given at the nodes. Hyphens (-) represent support values less than $50 \%$ BS/0.90 BYPP. Thick branches represent significant support values from all analyses $(B S \geq 70 \% / B Y P P \geq 0.95)$ in genus level 


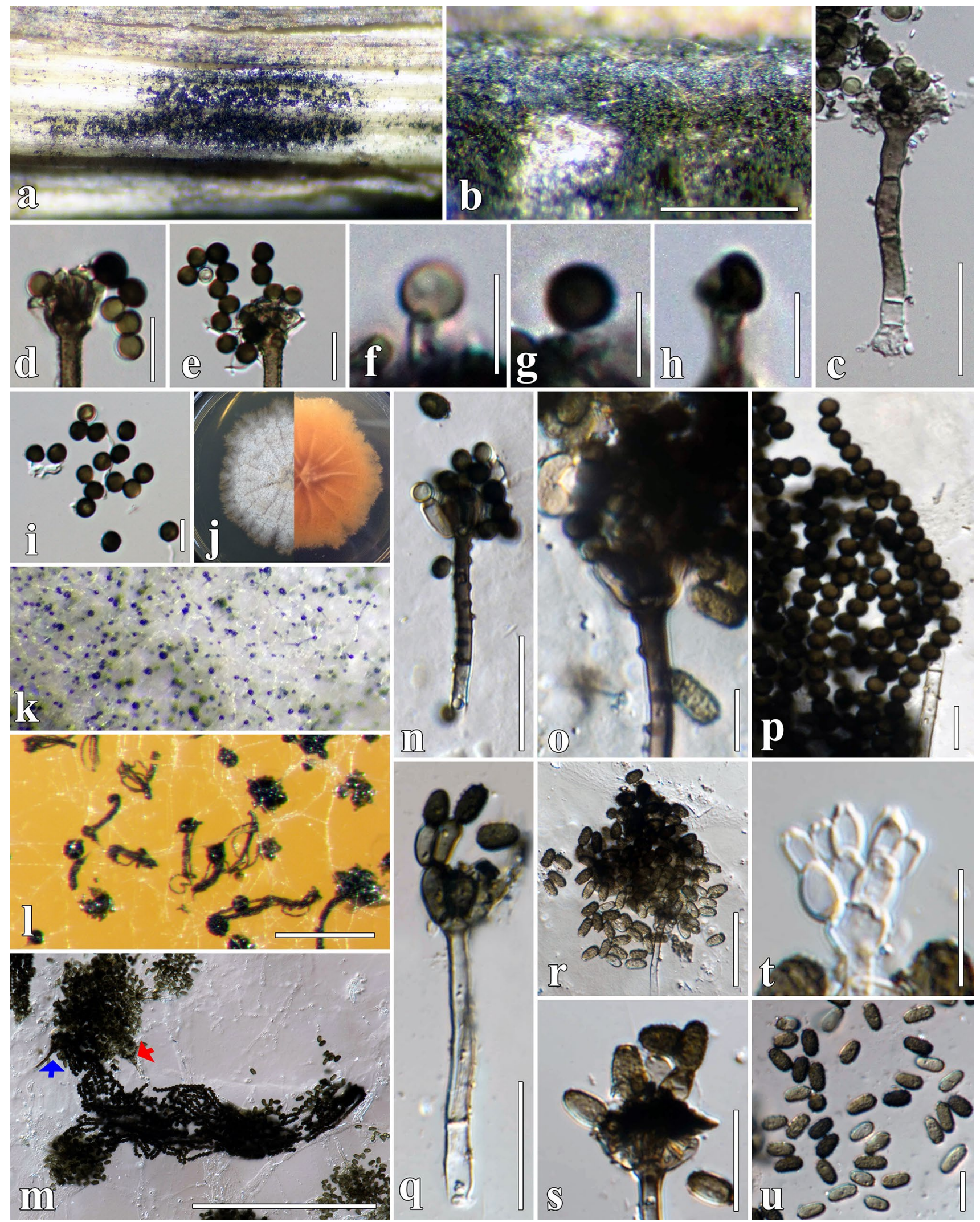


४Fig. 121 Memnoniella oblongispora (MFLU 17-1470). a, b Appearance of dry chains of conidiophores on Clematis subumbellata. c Conidiophores. $\mathbf{d}-\mathbf{h}$ Conidiogenous cells and conidia. i Conidia. $\mathbf{j}$ Culture characteristics on MEA. k Slimy chains on MEA. $\mathbf{l}-\mathbf{m}$ Dry chains and slimy chains of $M$. oblongispora (MFLUCC 17-2064) developed in the same culture on MEA media (red arrow indicates slimy chain; blue arrow indicates dry chains of conidia). n-p Dry chain of conidiophores, conidiogenous cells and conidia in culture. q-u Slimy chain with conidiophores, conidiogenous cells and conidia in culture. Scale bars: $\mathbf{b}, \mathbf{l}-\mathbf{m}=200 \mu \mathrm{m}, \mathbf{c}, \mathbf{n}, \mathbf{q}-\mathbf{s}=20 \mu \mathrm{m}, \mathbf{d}-\mathbf{e}, \mathbf{o}-\mathbf{p}$, $\mathbf{t}-\mathbf{u}=10 \mu \mathrm{m}, \mathbf{f}-\mathbf{i}=5 \mu \mathrm{m}$

its speciation. Hermatomyces sphaericus occurs in countries that lie close to the equator, such as Cuba, Panama and Thailand where the climate is mostly hot with tropical conditions. These isolates were reported as saprobes on dicotyledonous and monocotyledonous hosts. The genus lacks a known sexual morph, thus the establishment of sexual compatibility in mating-type genes such as MAT-1 and MAT-2 genes are recommended for the determination of reproductive differentiation into a sexual morph of Hermatomyces (Giraud et al. 2008; Mageswari et al. 2016).

Lophiostomataceae (Pleosporales): To support the recognition of the morphological species concept and phylogenetic species concept with numerous taxa being discovered within Lophiostomataceae, GCPSR was applied to delimit species within Lophiostomataceae using data of five gene loci (Fig. 28). There are no conflicting results in this family and we provide consolidated evidence by phylogenetic relatedness in a multi-locus dataset and the interpretation of nucleotide differences (Turner et al. 2013; Quaedvlieg et al. 2014; Jeewon and Hyde 2016). We also compared our new isolates with documented fungal taxa recorded in the database and discuss the ecological species concept.

\section{Host-fungal interactions}

It is hypothesized that modifications of the divergent plate boundaries 50 million years ago (Mya) resulting in speciation and adaptation of land plants and living organisms (Navaud et al. 2018). These caused dramatic change in continents, temperatures, peregrine, and communities of living organism and may have impacted the distribution of plant symbioses (Cawood et al. 2018). Most plants are inhabited by fungal symbionts as endophytes, mycorrhizae and saprobes. The arbuscular mycorrhizal fungi were reported to colonize the early diverging vascular plant lineages since 500 Mya (Field et al. 2012). Host-fungal interactions occurred as coevolution events with leading changes in genetic succession over generations (Naranjo-Ortiz and Gabaldón 2019). The cospeciation of the fungus with the original host consistently leads to a decrease in fitness on the original host and increased distribution of fungi species worldwide. The induction of foreign plants by global weather changes immigration of animal and anthropogenic movement resulted in the introduction of fungal strains resident in plants to adapt and expand the range of hosts (Antonovics et al. 2002). Host jumps commonly occur in fungal species with a higher rate than the host-fungus cospeciation or coevolution (Roy 2001). This event most commonly occurs in plant pathogens that occasionally change to another lifestyle (Sillo et al. 2015). Among many examples of host-fungal interactions, we demonstrate some observed in this study.

Advances in the understanding of host-pathogen specificity and co-evolutionary interactions with specific plant genera or families has been demonstrated with Didymellaceae (Aveskamp et al. 2009, 2010; Chen et al. 2015, 2017). Cospeciation is expected to have congruent phylogenies in the host and fungal species with similar divergence times (De Vienne et al. 2013). Species of Didymellaceae associated with Clematis are Calophoma clematidis-rectae (三Phoma clematidis-rectae), C. clematidina (三P. clematidina), and P. herbarum (Foister 1961; Tai 1979; Woudenberg et al. 2009; Aveskamp et al. 2010). Soleimani et al. (2018) estimated the crown age of genera within Didymellaceae by using molecular dating. The molecular evolution revealed that the species of Didymellaceae diverged in the Miocene period (35.7 Mya). These results are in congruence with the relative radiation of the crown ages of Clematis species that had also a diversification event in the Miocene (Xie et al. 2011). However, the hypotheses of coevolution and host specificity in genera of Didymellaceae needs further addressing.

The introduction of a foreign host lends a significant accidental movement of fungi into new habitats and undergo host jumps (Herrera et al. 2016). The saprobic fungus Nigrograna chromolaenae was found on Chromolaena odorata, an invasive weed in Thailand, and was also associated with Clematis fulvicoma in this country (Mapook et al. 2020). Thus, the species is associated with dicotyledons plant in tropical climates. Dictyocheirospora xishuangbannaensis which was reported from Pandanaceae (monocots) from Yunnan Province in China was also observed from Clematis sikkimensis from Thailand. It can be hypothesized that D. xishuangbannaensis generally occur in tropical climates. Stemphylium vesicarium which causes leaf blight and leaf spots on several agricultural plants worldwide was associated with Clematis vitalba in Italy as a saprobe. Based on current trends, many fungal species in this study also have relatively broad host range with the consideration of co-factors such as environments and ecological species concept. An increasing number of fungi are likely to have an ability of switch host and then speciation might occur with this host plant.

Over 560 fungal species are listed from Clematis sp. worldwide (Farr and Rossman 2020). To assess the fungal biodiversity, each individual group, host, and 
specific environmental factor could represent an alternative approaches to study fungal biodiversity (Mueller and Schmit 2007; Hyde et al. 2018b). Blackwell (2011) estimated the number of fungi to plants by more than 6 to 1 . Therefore, there are many potential fungal habitats that need to be further studied and modern molecular methods could support the discovery of species (Hawksworth 1991, 2001).

Acknowledgements Chayanard Phukhamsakda would like to thank the Royal Golden Jubilee PhD Program under Thailand Research Fund (RGJ) and the German Academic Exchange Service (DAAD) for a joint TRF-DAAD (PPP 2017-2018) academic exchange Grant to K.D. Hyde and M. Stadler and the RGJ for a personal grant to C. Phukhamsakda (The scholarship no. PHD/0020/2557 to study towards a PhD). Dr. Shaun Pennycook is thanked for checking and suggesting Latin names of the new taxa. Dr. Olivier Raspé, Dr. Rajesh Jeewon, Sirinapa Konta, Milan Samarakoon, Indunil C. Senanayake, Dr. Sinang Hongsanan, Chuan-Gen Lin, Qiu-Ju Shang and Pranami D. Abeywickrama are thanked for their valuable suggestions on the phylogenetic analysis and for sequencing. Mr. Martin van de Bult, Cyrille Gerstmans, Prof. Hong-Yan Su, Tian Qing, Dr. Zong-Long Luo are gratefully acknowledged for sample collection guidance in China and Thailand. Kevin D. Hyde thanks the future of specialist fungi in a changing climate: baseline data for generalist and specialist fungi associated with ants, Rhododendron species and Dracaena species (Grant No: DBG6080013), Impact of climate change on fungal diversity and biogeography in the Greater Mekong Subregion (Grant No: RDG6130001). Alan J. L. Phillips acknowledges the support from UID/MULTI/04046/2019 Research Unit grant from FCT, Portugal to BioISI. E. B. Gareth Jones is supported under the Distinguished Scientist Fellowship Program (DSFP), King Saud University, Kingdom of Saudi Arabia. D. N. Wanasinghe would like to thank the CAS President's International Fellowship Initiative (PIFI) for funding his postdoctoral research (Number 2019PC0008), the National Science Foundation of China and the Chinese Academy of Sciences for financial support under the following Grants: 41761144055, 41771063 and Y4ZK111B01. Wanasinghe also thanks the 64th batch of China Postdoctoral Science Foundation (Grant No.: Y913083271). Saowaluck Tibpromma would like to thanks the International Postdoctoral Exchange Fellowship Program (Number Y9180822S1), CAS President's International Fellowship Initiative (PIFI) (Number 2020PC0009), China Postdoctoral Science Foundation and the Yunnan Human Resources, and Social Security Department Foundation for funding her postdoctoral research. Mingkwan Doilom would like to thank the 5th batch of Postdoctoral Orientation Training Personnel in Yunnan Province (Grant No.: Y934283261) and the 64th batch of China Postdoctoral Science Foundation (Grant No.: Y913082271)

Open Access This article is licensed under a Creative Commons Attribution 4.0 International License, which permits use, sharing, adaptation, distribution and reproduction in any medium or format, as long as you give appropriate credit to the original author(s) and the source, provide a link to the Creative Commons licence, and indicate if changes were made. The images or other third party material in this article are included in the article's Creative Commons licence, unless indicated otherwise in a credit line to the material. If material is not included in the article's Creative Commons licence and your intended use is not permitted by statutory regulation or exceeds the permitted use, you will need to obtain permission directly from the copyright holder. To view a copy of this licence, visit http://creativecommons.org/licenses/by/4.0/.

\section{References}

Abdel-Wahab MA, Jones EBG (2003) Decaisnella formosa sp. nov. (Ascomycota, Massariaceae) from an Australian sandy beach. Can J Bot 81:598-600

Abdel-Wahab MA, Hodhod MS, Bahkali AHA, Jones EBG (2014) Marine fungi of Saudi Arabia. Bot Mar 57:323-335

Acero FJ, González V, Sánchez-Ballesteros J, Rubio V, Checa J, Bills GF, Salazar O, Platas G, Peláez F (2004) Molecular phylogenetic studies on the Diatrypaceae based on rDNA-ITS sequences. Mycologia 96:249-259

Ahmadpour SA, Farokhinejad R, Mehrabi-Koushki M (2017) Further characterization and pathogenicity of Didymella microchlamydospora causing stem necrosis of Morus nigra in Iran. Mycosphere $8: 835-852$

Ahmed SA, Khan Z, Wang X-w, Moussa TAA, Al-Zahrani HS, Almaghrabi OA, Sutton DA, Ahmad S, Groenewald JZ, Alastruey-Izquierdo A, van Diepeningen A, Menken SBJ, Najafzadeh MJ, Crous PW, Cornely O, Hamprecht A, Vehreschild MJGT, Kindo AJ, de Hoog GS (2016) Chaetomium-like fungi causing opportunistic infections in humans: a possible role for extremotolerance. Fungal Divers 76:11-26

Ahmed SA, González GM, Tirado-Sánchez A, Moreno-López LM, de Hoog S, Bonifaz A, Diekema DJ (2018) Nigrograna mackinnonii, not Trematosphaeria grisea (syn., Madurella grisea), is the main agent of black grain eumycetoma in Latin America. J Clin Microbiol 56:e01717-e01723

Ahn YM, Shearer CA (1998) Reexamination of taxa in Leptosphaeria originally described on host species in Ranunculaceae, Papaveraceae, and Magnoliaceae. Can J Bot 76:258-280

Alvarez LV, Groenewald JZ, Crous PW (2016) Revising the Schizoparmaceae: Coniella and its synonyms Pilidiella and Schizoparme. Stud Mycol 85:1-34

Antonovics J, Hood M, Partain JT (2002) The ecology and genetics of a host shift: Microbotryum as a model system. Am Nat 160:S40-S52

Aptroot A (1995) A monograph of Didymosphaeria. Stud Mycol 37:1-160

Arif R, Saleem M (2017) Isolation of coprophilous fungus Sordaria fimicola from different areas of Lahore-Pakistan, and molecular characterization by ITS and RAPD-SCAR PCR. Int J Agric Biol 19:259-265

Ariyawansa HA, Camporesi E, Thambugala KM, Mapook A, Kang JC, Alias SA, Chukeatirote E, Thines M, McKenzie EHC, Hyde KD (2014a) Confusion surrounding Didymosphaeria—phylogenetic and morphological evidence suggest Didymosphaeriaceae is not a distinct family. Phytotaxa 176:102-119

Ariyawansa HA, Tanaka K, Thambugala KM, Phookamsak R, Tian Q, Camporesi E, Hongsanan S, Monkai J, Wanasinghe DN, Mapook A, Chukeatirote E, Kang JC, Xu JC, McKenzie EHC, Jones EBG, Hyde KD (2014b) A molecular phylogenetic reappraisal of the Didymosphaeriaceae (= Montagnulaceae). Fungal Divers 68:69-104

Ariyawansa HA, Hyde KD, Jayasiri SC, Buyck B, Chethana KWT, Dai DQ, Dai YC, Daranagama DA, Jayawardena RS, Lücking R, Ghobad-Nejhad M, Niskanen T, Thambugala KM, Voigt K, Zhao RL, Li GJ, Doilom M, Boonmee S, Yang ZL, Cai Q, Cui YY, Bahkali AH, Chen J, Cui BK, Chen JJ, Dayarathne MC, Dissanayake AJ, Ekanayaka AH, Hashimoto A, Hongsanan S, Jones EBG, Larsson E, Li WJ, Li QR, Liu JK, Luo ZL, Maharachchikumbura SSN, Mapook A, McKenzie EHC, Norphanphoun C, Konta S, Pang KL, Perera RH, Phookamsak R, Phukhamsakda C, Pinruan U, Randrianjohany E, Singtripop C, Tanaka K, Tian CM, Tibpromma S, Abdel-Wahab MA, Wanasinghe DN, Wijayawardene NN, Zhang JF, Zhang H, Abdel-Aziz FA, Wedin M, 
Westberg M, Ammirati JF, Bulgakov TS, Lima DX, Callaghan TM, Callac P, Chang CH, Coca LF, Dal-Forno M, Dollhofer V, Fliegerová K, Greiner K, Griffith GW, Ho HM, Hofstetter V, Jeewon R, Kang JC, Wen TC, Kirk PM, Kytövuori I, Lawrey JD, Xing J, Li H, Liu ZY, Liu XZ, Liimatainen K, Lumbsch HT, Matsumura M, Moncada B, Nuankaew S, Parnmen S, de Azevedo Santiago ALCM, Sommai S, Song Y, de Souza CAF, de SouzaMotta CM, Su HY, Suetrong S, Wang Y, Wei SF, Wen TC, Yuan HS, Zhou LW, Réblová M, Fournier J, Camporesi E, Luangsa-ard JJ, Tasanathai K, Khonsanit A, Thanakitpipattana D, Somrithipol S, Diederich P, Millanes AM, Common RS, Stadler M, Yan JY, Li X, Lee HW, Nguyen TTT, Lee HB, Battistin E, Marsico O, Vizzini A, Vila J, Ercole E, Eberhardt U, Simonini G, Wen HA, Chen XH, Miettinen O, Spirin V, Hernawati A (2015a) Fungal diversity notes 111-252-taxonomic and phylogenetic contributions to fungal taxa. Fungal Divers 75:1-248

Ariyawansa HA, Phukhamsakda C, Thambugala KM, Bulgakov TS, Wanasinghe DN, Perera RH, Mapook A, Camporesi E, Kang JC, Jones EBG, Bahkali AH (2015b) Revision and phylogeny of Leptosphaeriaceae. Fungal Divers 74:19-51

Ariyawansa HA, Thambugala KM, Manamgoda DS, Jayawardena R, Camporesi E, Boonmee S, Wanasinghe DN, Phookamsak R, Hongsanan S, Singtripop C, Chukeatirote E (2015c) Towards a natural classification and backbone tree for Pleosporaceae. Fungal Divers 71:85-139

Ariyawansa HA, Jaklitsch WM, Voglmayr H (2018) Additions to Taiwan fungal flora 1: Neomassariaceae fam. nov. Cryptog Mycol 39:359-373

Arzanlou M, Khodaei S, Babai-Ahari A (2012) Helianthus annuus as a natural host for Stemphylium vesicarium in Iran. Austral Plant Dis Notes 7:167-170

Ashton IW, Lerdau MT (2008) Tolerance to herbivory, and not resistance, may explain differential success of invasive, naturalized, and native North American temperate vines. Divers Distrib 14:169-178

Aveskamp MM, Verkley GJM, de Gruyter J, Murace MA, Perelló A, Woudenberg JHC, Groenewald JZ, Crous PW (2009) DNA phylogeny reveals polyphyly of Phoma section Peyronellaea and multiple taxonomic novelties. Mycologia 101:363-382

Aveskamp MM, de Gruyter J, Woudenberg JHC, Verkley GJM, Crous PW (2010) Highlights of the Didymellaceae: a polyphasic approach to characterise Phoma and related pleosporalean genera. Stud Mycol 65:1-60

Ayyadurai N, Kirubakaran SI, Srisha S, Sakthivel N (2005) Biological and molecular variability of Sarocladium oryzae, the sheath rot pathogen of rice (Oryza sativa L.). Curr Microbiol 50:319-323

Barr ME (1989) The genus Chaetomastia (Dacampiaceae) in North America. Mycotaxon 34:507-515

Barr ME (1990) Melanommatales (Loculoascomycetes). N Am Flora Ser II 13:1-129

Barr ME (1994) Note on Amphisphaeriaceae and related families. Mycotaxon 51:191-224

Barr ME (2002) Teichosporaceae, another family in the Pleosporales. Mycotaxon 82:373-389

Baylis GT (1954) Rust fungi on New Zealand Clematis. Trans R Soc N Zeal 82:633-637

Blackwell M (2011) The fungi: 1, 2, 3.. 5.1 million species? Am J Bot 98:426-438

Boonmee S, D'souza MJ, Luo Z, Pinruan U, Tanaka K, Su H, Bhat JD, McKenzie EHC, Jones EBG, Taylor JE, Phillips AJL, Hirayama K, Eungwanichayapant PD, Hyde KD (2016) Dictyosporiaceae fam nov. Fungal Divers 80:457-482

Braun U (1992) Studies on Ramularia and allied genera (V). Nova Hedw 54:459-478
Bruen TC, Philippe H, Bryant D (2006) A simple and robust statistical test for detecting the presence of recombination. Genetics 172:2665-2681

Burnett JH (2003) Fungal populations and species. Oxford University Press, Oxford

Cai L, Jeewon R, Hyde KD (2006) Phylogenetic investigations of Sordariaceae based on multiple gene sequences and morphology. Mycol Res 110:137-150

Câmara MP, O'Neill NR, Van Berkum P (2002) Phylogeny of Stemphylium sp. based on ITS and glyceraldehyde-3-phosphate dehydrogenase gene sequences. Mycologia 94:660-672

Cannon P, Buddie A, Bridge P, de Neergaard E, Lübeck M, Askar M (2012) Lectera, a new genus of the Plectosphaerellaceae for the legume pathogen Volutella colletotrichoides. MycoKeys 3:23-36

Cao M, Zou X, Warren M, Zhu H (2006) Tropical forests of Xishuangbanna, China 1. Biotropica 38:306-309

Carlucci A, Raimondo ML, Santos J, Phillips AJ (2012) Plectosphaerella species associated with root and collar rots of horticultural crops in southern Italy. Persoonia 28:34-48

Cawood PA, Hawkesworth CJ, Pisarevsky SA, Dhuime B, Capitanio FA, Nebel O (2018) Geological archive of the onset of plate tectonics. Philos Trans A Math Phys Eng Sci 376(2132):20170405

Chang HS (1995) Notes on Taiwan dematiaceous hyphomycetes, some species of the genera Exserticlava, Craspedodidymum and Hermatomyces. Bot Bull Acad Sin 36:243-246

Chen Q, Jiang JR, Zhang GZ, Cai L, Crous PW (2015) Resolving the Phoma enigma. Stud Mycol 82:137-217

Chen Q, Hou LW, Duan WJ, Crous PW, Cai L (2017) Didymellaceae revisited. Stud Mycol 87:105-159

Chen Y, Zeng L, Shu N, Jiang M, Wang H, Huang Y, Tong H (2018) Pestalotiopsis-like species causing gray blight disease on Camellia sinensis in China. Plant Dis 102:98-106

Chomnunti P, Hongsanan S, Hudson BA, Tian Q, Peršoh D, Dhami MK, Alias AS, Xu J, Liu X, Stadler M, Hyde KD (2014) The sooty moulds. Fungal Divers 66:1-36

Clements FE, Shear CL (1931) The genera of fungi, 2d edn. H.W. Wilson, New York

Corlett M (1981) A taxonomic survey of some species of Didymella and Didymella-like species. Can J Bot 59:2016-2042

Crivelli PG (1983) Über die heterogene Ascomycetengattung Pleospora Rabh.: vorschlag für eine Aufteilung. PhD Dissertation ETH Nr. 7318, Zürich, Germany

Crous PW, Groenewald JZ (2017) The genera of fungi-G4: Camarosporium and Dothiora. IMA Fungus 8:131-152

Crous PW, Verkley GJ, Groenewald JZ (2006) Eucalyptus microfungi known from culture. 1. Cladoriella and Fulvoflamma genera nova, with notes on some other poorly known taxa. Stud Mycol 55:53-63

Crous PW, Shivas RG, Quaedvlieg W, van der Bank M, Zhang Y, Summerell BA, Guarro J, Wingfield MJ, Wood AR, Alfenas AC, Braun U, Cano-Lira JF, García D, Marin-Felix Y, Alvarado P, Andrade JP, Armengol J, Assefa A, den Breeÿen A, Camele I, Cheewangkoon R, De Souza JT, Duong TA, Esteve-Raventós F, Fournier J, Frisullo S, García-Jiménez J, Gardiennet A, Gené J, Hernández-Restrepo M, Hirooka Y, Hospenthal DR, King A, Lechat C, Lombard L, Mang SM, Marbach PAS, Marincowitz S, Marin-Felix Y, Montaño-Mata NJ, Moreno G, Perez CA, Pérez Sierra AM, Robertson JL, Roux J, Rubio E, Schumacher RK, Stchigel AM, Sutton DA, Tan YP, Thompson EH, van der Linde E, Walker AK, Walker DM, Wickes BL, Wong PTW, Groenewald JZ (2014a) Fungal planet description sheets: 214-280. Persoonia 32:184-306

Crous PW, Wingfield MJ, Schumacher RK, Summerell BA, Giraldo A, Gené J, Guarro J, Wanasinghe DN, Hyde KD, Camporesi E, Jones EBG, Thambugala KM, Malysheva EF, Malysheva VF, Acharya K, Álvarez J, Alvarado P, Assefa A, Barnes CW, 
Bartlett JS, Blanchette RA, Burgess TI, Carlavilla JR, Coetzee MPA, Damm U, Decock CA, Denbreeÿen A, Devries B, Dutta AK, Holdom DG, Rooney-Latham S, Manjón JL, Marincowitz S, Mirabolfathy M, Moreno G, Nakashima C, Papizadeh M, Shahzadehfazeli SA, Amoozegar MA, Romberg MK, Shivas RG, Stalpers JA, Stielow B, Stukely MJC, Swart WJ, Tan YP, Vanderbank M, Wood AR, Zhang Y, Groenewald JZ (2014b) Fungal planet description sheets: 281-319. Persoonia 33:212-289

Crous PW, Carris LM, Giraldo A, Groenewald JZ, Hawksworth DL, Hernández-Restrepo M, Wood AR (2015a) The genera of fungifixing the application of the type species of generic names- $\mathrm{G} 2$ : Allantophomopsis, Latorua, Macrodiplodiopsis, Macrohilum, Milospium, Protostegia, Pyricularia, Robillarda, Rotula, Septoriella, Torula, and Wojnowicia. IMA Fungus 6:163-198

Crous PW, Schumacher RK, Wingfield MJ, Lombard L, Giraldo A, Christensen M, Gardiennet A, Nakashima C, Pereira OL, Smith AJ, Groenewald JZ (2015b) Fungal systematics and evolution: FUSE 1. Sydowia 67:81-118

Crous PW, Wingfield MJ, Burgess TI, Hardy GESJ, Crane C, Barrett S, Cano-Lira JF, Leroux JJ, Thangavel R, Guarro J, Stchigel AM, Martín MP, Alfredo DS, Barber PA, Barreto RW, Baseia IG, Cano-Canals J, Cheewangkoon R, Ferreira RJ, Gené J, Lechat C, Moreno G, Roets F, Shivas RG, Sousa JO, Tan YP, Wiederhold NP, Abell SE, Accioly T, Albizu JL, Alves JL, Antoniolli ZI, Aplin N, Araújo J, Arzanlou M, Bezerra JDP, Bouchara JP, Carlavilla JR, Castillo A, Castroagudín VL, Ceresini PC, Claridge GF, Coelho G, Coimbra VRM, Costa LA, da Cunha KC, da Silva SS, Daniel R, de Beer ZW, Dueñas M, Edwards J, Enwistle P, Fiuza PO, Fournier J, García D, Gibertoni TB, Giraud S, Guevara-Suarez M, Gusmão LFP, Haituk S, Heykoop M, Hirooka Y, Hofmann TA, Houbraken J, Hughes DP, Kautmanová I, Koppel O, Koukol O, Larsson E, Latha KPD, Lee DH, Lisboa DO, Lisboa WS, López-Villalba Maciel JLN, Manimohan P, Manjón JL, Marincowitz S, Marney TS, Meijer M, Miller AN, Olariaga I, Paiva LM, Piepenbring M, Poveda-Molero JC, Raj KNA, Raja HA, Rougeron A, Salcedo I, Samadi R, Santos TAB, Scarlett K, Seifert KA, Shuttleworth LA, Silva GA, Silva M, Siqueira JPZ, Souza-Motta CM, Stephenson SL (2016) Fungal planet description sheets: 469-557. Persoonia 37:218-403

Crous PW, Wingfield MJ, Burgess TI, Carnegie AJ, Hardy GESJ, Smith D, Summerell BA, Cano-Lira JF, Guarro J, Houbraken J, Lombard L, Martin MP, Sandoval-Denis M, Alexandrova AV, Barnes CW, Baseia IG, Bezerra JDP, Guarnaccia V, May TW, Hernandez-Restrepo M, Stchigel AM, Miller AN, Ordonez ME, Abreu VP, Accioly T, Agnello C, Agustin Colman A, Albuquerque CC, Alfredo DS, Alvarado P, Araujo-Magalhaes GR, Arauzo S, Atkinson T, Barili A, Barreto RW, Bezerra JL, Cabral TS, Camello Rodriguez F, Cruz RHSF, Daniels PP, da Silva BDB, de Almeida DAC, de Carvalho Junior AA, Decock CA, Delgat L, Denman S, Dimitrov RA, Edwards J, Fedosova AG, Ferreira RJ, Firmino AL, Flores JA, Garcia D, Gene J, Giraldo A, Gois JS, Gomes AAM, Goncalves CM, Gouliamova DE, Groenewald M, Gueorguiev BV, Guevara-Suarez M, Gusmao LFP, Hosaka K, Hubka V, Huhndorf SM, Jadan M, Jurjevic Z, Kraak B, Kucera V, Kumar TKA, Kusan I, Lacerda SR, Lamlertthon S, Lisboa WS, Loizides M, Luangsa-ard JJ, Lyskova P, Mac Cormack WP, Macedo DM, Machado AR, Malysheva EF, Marinho P, Matocec N, Meijer M, Mesic A, Mongkolsamrit S, Moreira KA, Morozova OV, Nair KU, Nakamura N, Noisripoom W, Olariaga I, Oliveira RJV, Paiva LM, Pawar P, Pereira OL, Peterson SW, Prieto M, Rodriguez-Andrade E, Rojo De Blas C, Roy M, Santos ES, Sharma R, Silva GA, Souza-Motta CM, Takeuchi-Kaneko Y, Tanaka C, Thakur A, Smith MT, Tkalcec Z, Valenzuela-Lopez N, van der Kleij P, Verbeken A, Viana MG, Wang XW, Groenewald JZ (2017) Fungal planet description sheets: 625-715. Persoonia 39:270-467
Crous PW, Luangsa-Ard JJ, Wingfield MJ, Carnegie AJ, HernándezRestrepo M, Lombard L, Roux J, Barreto RW, Baseia IG, CanoLira JF, Martín MP, Morozova OV, Stchigel AM, Summerell BA, Brandrud TE, Dima B, García D, Giraldo A, Guarro J, Gusmão LFP, Khamsuntorn P, Noordeloos ME, Nuankaew S, Pinruan U, Rodríguez-Andrade E, Souza-Motta CM, Thangavel R, van Iperen AL, Abreu VP, Accioly T, Alves JL, Andrade JP, Bahram M, Baral HO, Barbier E, Barnes CW, Bendiksen E, Bernard E, Bezerra JDP, Bezerra JL, Bizio E, Blair JE, Bulyonkova TM, Cabral TS, Caiafa MV, Cantillo T, Colmán AA, Conceição LB, Cruz S, Cunha AOB, Darveaux BA, da Silva AL, da Silva GA, da Silva GM, da Silva RMF, de Oliveira RJV, Oliveira RL, De Souza JT, Dueñas M, Evans HC, Epifani F, Felipe MTC, Fernández-López J, Ferreira BW, Figueiredo CN, Filippova NV, Flores JA, Gené J, Ghorbani G, Gibertoni TB, Glushakova AM, Healy R, Huhndorf SM, Iturrieta-González I, Javan-Nikkhah M, Juciano RF, Jurjević Ž, Kachalkin AV, Keochanpheng K, Krisai-Greilhuber I, Li YC, Lima AA, Machado AR, Madrid H, Magalhães OMC, Marbach PAS, Melanda GCS, Miller AN, Mongkolsamrit S, Nascimento RP, Oliveira TGL, Ordoñez ME, Orzes R, Palma MA, Pearce CJ, Pereira OL, Perrone G, Peterson SW, Pham THG, Piontelli E, Pordel A, Quijada L, Raja HA, Rosas de Paz E, Ryvarden L, Saitta A, Salcedo SS, SandovalDenis M, Santos TAB, Seifert KA, Silva BDB, Smith ME, Soares AM, Sommai S, Sousa JO, Suetrong S, Susca A, Tedersoo L, Telleria MT, Thanakitpipattana D, Valenzuela-Lopez N, Visagie CM, Zapata M, Groenewald JZ (2018) Fungal Planet description sheets: 785-867. Persoonia 41:238-417

Crous PW, Schumacher RK, Akulov A, Thangavel R, HernándezRestrepo M, Carnegie AJ, Cheewangkoon R, Wingfield MJ, Summerell BA, Quaedvlieg W, Coutinho TA, Roux J, Wood AR, Giraldo A, Groenewald JZ (2019) New and interesting fungi 2. Fungal Syst Evol 3:57-134

Dai DQ, Phookamsak R, Wijayawardene NN, Li WJ, Bhat DJ, Xu JC, Taylor JE, Hyde KD, Chukeatirote E (2017) Bambusicolous fungi. Fungal Divers 82:1-105

Dayarathne M, Phookamsak R, Hyde KD, Manawasinghe I, To-Anun C, Jones EBG (2016) Halodiatrype, a novel diatrypaceous genus from mangroves with $H$. salinicola and $H$. avicenniae sp. nov. Mycosphere 7:612-627

de Gruyter J, Boerema GH, Van der Aa HA (2002) Contributions towards a monograph of Phoma (Coelomycetes). VI-2. Section Phyllostictoides: outline of its taxa. Persoonia 18:1-53

de Gruyter J, Woudenberg JHC, Aveskamp MM, Verkley GJM, Groenewald JZ, Crous PW (2013) Redisposition of phoma-like anamorphs in Pleosporales. Stud Mycol 75:1-36

De Vienne DM, Refrégier G, López-Villavicencio M, Tellier A, Hood ME, Giraud T (2013) Cospeciation vs host-shift speciation: methods for testing, evidence from natural associations and relation to coevolution. New Phytol 198:347-385

Dettman JR, Jacobson DJ, Turner E, Pringle A, Taylor JW (2003) Reproductive isolation and phylogenetic divergence in Neurospora: comparing methods of species recognition in a model eukaryote. Evolution 57:2721-2741

Devadatha B, Sarma VV, Jeewon R, Wanasinghe DN, Hyde KD, Jones EBG (2018) Thyridariella, a novel marine fungal genus from India: morphological characterization and phylogeny inferred from multigene DNA sequence analyses. Mycol Prog 17:791-804

Ding Q, Yang LX, Yang HW, Jiang C, Wang YF, Wang S (2009) Cytotoxic and antibacterial triterpenoids derivatives from Clematis ganpiniana. J Ethnopharmacol 126:382-385

Dissanayake AJ, Phillips AJ, Hyde KD, Yan JY, Li XH (2017) The current status of species in Diaporthe. Mycosphere 8:1106-1156

Doilom M, Dissanayake AJ, Wanasinghe DN, Boonmee S, Liu JK, Bhat DJ, Taylor JE, Bahkali AH, McKenzie EHC, Hyde KD 
(2017) Microfungi on Tectona grandis (teak) in Northern Thailand. Fungal Divers 82:107-182

Duc PM, Hatai K, Kurata O, Tensha K, Yoshitaka U, Yaguchi T, Udagawa SI (2009) Fungal infection of mantis shrimp (Oratosquilla oratoria) caused by two anamorphic fungi found in Japan. Mycopathologia 167:229-247

Ellis MB (1971) Dematiaceous hyphomycetes. Commonwealth, Mycological Institute Kew, Kew

Fallah PM, Shearer CA (1998) Freshwater ascomycetes: Phomatospora sp. from lakes in Wisconsin. Mycologia 90:323-329

Farr DF, Rossman AY (2020) Fungal Databases, U.S. National Fungus Collections, ARS, USDA. https://nt.ars-grin.gov/fungaldatabases /Retrieved. Accessed 31 Jan 2020

Feng LF, Weng MY, Tian FR, Chen JH (2011) Comparasion on total flavonoid content from aerial parts of 11 medicinal plants of Clematis L. Mod Chin Med 13:14-18

Field K, Cameron D, Leake J, Tille S, Bidartondo MI, Beerling DJ (2012) Contrasting arbuscular mycorrhizal responses of vascular and non-vascular plants to a simulated Palaeozoic $\mathrm{CO}_{2}$ decline. Nat Commun 3:1-8

Foister CE (1961) The economic plant diseases of Scotland. Tech Bull Dept Agric Fish Scotland 1:1-210

Fournier J, Lechat C (2010) Phomatospora luteotingens sp. nov., a new aquatic species of Phomatospora from France and Spain. Mycosphere 1:39-43

Fu Q, Zan K, Zhao M, Zhou S, Shi S, Jiang Y, Tu P (2010) Triterpene saponins from Clematis chinensis and their potential anti-inflammatory activity. J Nat Prod 73:1234-1239

Fuckel L (1870) Symbolae mycologicae. Beiträge zur Kenntniss der Rheinischen Pilze. Jahrb Nassau Ver Nat 23-24:1-459

Furtado JS (1969) Ascal cytology of Sordaria sclerogenia. Protoplasma 67:473-478

Galloway LD (1933) Note on an unusual mould fungus. Trans $\mathrm{Br}$ Mycol Soc 18:163-166

Gams W (1975) Cephalosporium-like hyphomycetes: some tropical species. Trans Br Mycol Soc 64:389-404

Gioan E, Paul C (2012) Split decomposition and graph-labelled trees: characterizations and fully dynamic algorithms for totally decomposable graphs. Discret Appl Math 160:708-733

Giraldo A, Gené J, Sutton DA, Madrid H, De Hoog GS, Cano J, Decock C, Crous PW, Guarro J (2015) Phylogeny of Sarocladium (Hypocreales). Persoonia 34:10-24

Giraldo A, Hernández-Restrepo M, Crous PW (2019) New plectosphaerellaceous species from Dutch garden soil. Mycol Prog 18:1135-1154

Giraud T, Refrégier G, Le Gac M, de Vienne DM, Hood ME (2008) Speciation in fungi. Fungal Genet Biol 45(6):791-802

Golzar H, Wang C, Willyams D (2011) First report of Phoma clematidina the cause of leaf spot-wilt disease of Clematis pubescens in Australia. Austral Plant Dis Notes 6:87-90

Gourlay AH, Wittenberg R, Hill RL, Spiers AG, Fowler SV (2000) The biological control programme against Clematis vitalba in New Zealand. In: Proceedings of the X international symposium on biological control of weeds. Montana State University Bozeman, Montana, USA, pp 799-806

Grey-Wilson C (2000) The Genus Clematis. B T Batsford Ltd, London, pp 1-224

Grum-Grzhimaylo AA, Debets AV, Van Diepeningen AD, Georgieva ML, Bilanenko EN (2013) Sodiomyces alkalinus, a new holomorphic alkaliphilic ascomycete within the Plectosphaerellaceae. Persoonia 31:147-158

Grum-Grzhimaylo AA, Georgieva ML, Bondarenko SA, Debets AJ, Bilanenko EN (2016) On the diversity of fungi from soda soils. Fungal Divers 76:27-74
Gu X, Li WH (1996a) A general additive distance with time-reversibility and rate variation among nucleotide sites. Proc Natl Acad Sci USA 93:4671-4676

Gu X, Li WH (1996b) Bias-corrected paralinear and LogDet distances and tests of molecular clocks and phylogenies under nonstationary nucleotide frequencies. Mol Biol Evol 13:1375-1383

Guarnaccia V, Crous PW (2017) Emerging citrus diseases in Europe caused by species of Diaporthe. IMA Fungus 8:317-334

Guba EF (1961) Monograph of Monochaetia and Pestalotia. Harvard University Press, Cambridge, pp 1-342

Guterres DC, Galvão-Elias S, dos Santos MD, de Souza BC, de Almeida CP, Pinho DB, Miller RN, Dianese JC (2019) Phylogenetic relationships of Phaeochorella parinarii and recognition of a new family, Phaeochorellaceae (Diaporthales). Mycologia 111:660-675

Hashimoto A, Matsumura M, Hirayama K, Tanaka K (2017) Revision of Lophiotremataceae (Pleosporales, Dothideomycetes): Aquasubmersaceae, Cryptocoryneaceae, and Hermatomycetaceae fam. nov. Persoonia 39:51-73

Hashimoto A, Hirayama K, Takahashi H, Matsumura M, Okada G, Chen CY, Huang JW, Kakishima M, Ono T, Tanaka K (2018) Resolving the Lophiostoma bipolare complex: generic delimitations within Lophiostomataceae. Stud Mycol 90:161-189

Hatakeyama S, Tanaka K, Harada Y (2008) Bambusicolous fungi in Japan (7): a new coelomycetous genus, Versicolorisporium. Mycoscience 49:211-214

Hawaze S, Deti H, Suleman S (2012) In vitro antimicrobial activity and phytochemical screening of Clematis species indigenous to Ethiopia. Indian J Pharm Sci 74:29-35

Hawksworth DL (1991) The fungal dimension of biodiversity: magnitude, significance, and conservation. Mycol Res 95:641-655

Hawksworth DL (2001) The magnitude of fungal diversity: the 1.5 million species estimate revisited. Mycol Res 105:1422-1432

Hawksworth DL, May TW, Redhead SA (2018) Fungal nomenclature evolving: changes adopted by the 19th International Botanical Congress in Shenzhen 2017, and procedures for the Fungal Nomenclature Session at the 11th International Mycological Congress in Puerto Rico 2018. IMA Fungus 8:211-218

He J, Lyu RD, Yao M, Xie L, Yang ZZ (2019) Clematis mae (Ranunculaceae), a new species of C. sect. Meclatis from Xinjiang, China. PhytoKeys 117:133-142

Hernández-Restrepo M, Gené J, Castañeda-Ruiz RF, Mena-Portales J, Crous PW, Guarro J (2017) Phylogeny of saprobic microfungi from Southern Europe. Stud Mycol 86:53-97

Herrera CS, Hirooka Y, Chaverri P (2016) Pseudocospeciation of the mycoparasite Cosmospora with their fungal hosts. Ecol Evol 6:1504-1514

Hirayama K, Tanaka K (2011) Taxonomic revision of Lophiostoma and Lophiotrema based on reevaluation of morphological characters and molecular analyses. Mycoscience 52:401-412

Hongsanan S, Maharachchikumbura SSN, Hyde KD, Samarakoon MC, Jeewon R, Zhao Q, Al-Sadi AM, Bahkali AH (2017) An updated phylogeny of Sordariomycetes based on phylogenetic and molecular clock evidence. Fungal Divers 84:25-41

Hongsanan S, Zeng Y, Hyde KD, Xie N (2018) Familial status of Lophiotremataceae and its related families in Pleosporales. Phytotaxa 383:93-102

Hongsanan S, Hyde KD, Phookamsak R, Wanasinghe DN, Mckenzie E, Sarma VV, Boonmee S, Lücking R, Pem D, Bhat DJ, Liu N, Tennakoon DS, Karunarathna A, Jiang SH, Wei JC, Jones EBG, Phillips AJL, Manawasinghe I, Tibpromma S, Jayasiri SC, Sandamali D, Jayawardena RS, Wijayawardene NN, Ekanayaka AH, Jeewon R, Lu YZ, Dissanayake AJ, Zeng XY, Luo Z, Tian Q, Phukhamsakda C, Thambugala KM, Dai D, Chethana KWT, Ertz D, Pérez-Ortega P, Suija A, Doilom M, Senwanna C, Wijesinghe NS, Konta S, Niranjan M, Zhang S, Ariyawansa HA, Jiang HB, 
Zhang JF, de Silva NI, Thiyagaraja V, Zhang H, Bezerra JDP, Miranda-Gonzáles R, Aptroot A, Kashiwadani H, Harishchandra D, Aluthmuhandiram JVS, Abeywickrama PD, Bao DF, Devadatha B, Wu HX, Moon KH, Gueidan C, Schumm F, Bundhun D, Mapook A, Monkai J, Chomnunti P, Samarakoon MC, Suetrong S, Chaiwan N, Dayarathne M, Jing Y, Achala R, Bhunjun CS, Zheng J, Liu G, Feng Y, Xie N (2020) Refined families of Dothideomycetes. Fungal Divers (in prep)

Hu DM, Cai L, Hyde KD (2012) Three new ascomycetes from freshwater in China. Mycologia 104:1478-1489

Huhndorf SM (1993) Neotropical Ascomycetes 3. Reinstatement of the genus Xenolophium and two new species from French Guiana. Mycologia 85:490-502

Huhndorf SM, Miller AN (2011) A molecular re-appraisal of taxa in the Sordariomycetidae and a new species of Rimaconus from New Zealand. Stud Mycol 68:203-210

Huson DH, Bryant D (2006) Application of phylogenetic networks in evolutionary studies. Mol Biol Evol 23(2):254-267

Hyde KD, Jones EBG (1986) Marine fungi from Seychelles. II. Lanspora coronata gen. et sp. nov. from driftwood. Can J Bot 64:1581-1585

Hyde KD, Jones EBG, Liu JK, Ariyawansa H, Boehm E, Boonmee S, Braun U, Chomnunti P, Crous PW, Dai DQ, Diederich P, Dissanayake A, Doilom M, Doveri F, Hongsanan S, Jayawardena R, Lawrey JD, Li YM, Liu YX, Lücking R, Monka J, Muggia L, Nelsen MP, Pang KL, Phookamsak R, Senanayake IC, Shearer CA, Suetrong S, Tanaka K, Thambugala KM, Wijayawardene NN, Wikee S, Wu HX, Zhang Y, Begoña AH, Alias SA, Aptroot A, Bahkali AH, Bezerra JL, Bhat DJ, Camporesi E, Chukea E, Gueidan C, Hawksworth DL, Hirayama K, Hoog SD, Kang JK, Knudsen K, Li WJ, Li XH, Liu ZY, Mapook A, Mckenzie EHC, Miller AN, Mortimer PE, Phillips AJL, Raja HA, Scheuer C, Schumm F, Taylor JE, Tian Q, Tibpromma S, Wanasinghe DN, Wang Y, Xu JC, Yacharoen S, Yan JY, Zang M (2013) Families of Dothideomycetes. Fungal Divers 63:1-313

Hyde KD, Nilsson RH, Alias SA, Ariyawansa HA, Blair JE, Cai L, de Cock AW, Dissanayake AJ, Glockling SL, Goonasekara ID, Gorczak M (2014) One stop shop: backbones trees for important phytopathogenic genera: I. Fungal Divers 67:21-125

Hyde KD, Hongsanan S, Jeewon R, Bhat DJ, McKenzie EHC, Jones EBG, Phookamsak R, Ariyawansa HA, Boonmee S, Zhao Q, Abdel-Aziz FA, Abdel-Wahab MA, Banmai S, Chomnunti P, Cui BK, Daranagama DA, Das K, Dayarathne MC, de Silva NI, Dissanayake AJ, Doilom M, Ekanayaka AH, Gibertoni TB, GóesNeto A, Huang SK, Jayasiri SC, Jayawardena RS, Konta S, Lee HB, Li WJ, Lin CG, Liu JK, Lu YZ, Luo ZL, Manawasinghe IS, Manimohan P, Mapook A, Niskanen T, Norphanphoun C, Papizadeh M, Perera RH, Phukhamsakda C, Richter C, deSantiago ALCMA, Drechsler-Santos ER, Senanayake IC, Tanaka K, Tennakoon TMDS, Thambugala KM, Tian Q, Tibpromma S, Thongbai B, Vizzini A, Wanasinghe DN, Wijayawardene NN, Wu HX, Yang J, Zeng XY, Zhang H, Zhang JF, Bulgakov TS, Camporesi E, Bahkali AH, Amoozegar AM, Araujo-Neta LS, Ammirati JF, Baghela A, Bhatt RP, Bojantchev S, Buyck B, da Silva GA, de Lima CLF, de Oliveira RJV, de Souza CAF, Dai YC, Dima B, Duong TT, Ercole E, Mafalda-Freire F, Ghosh A, Hashimoto A, Kamolhan S, Kang JC, Karunarathna SC, Kirk PM, Kytövuori I, Lantieri A, Liimatainen K, Liu ZY, Liu XZ, Lücking R, Medardi G, Mortimer PE, Nguyen TTT, Promputtha I, Raj KNA, Reck MA, Lumyong S, Shahzadeh-Fazeli SA, Stadler M, Soudi MR, Su HY, Takahashi T, Tangthirasunun N, Uniyal P, Wang Y, Wen TC, Xu JC, Zhang ZK, Zhao YC, Zhou JZ, Zhu L (2016) Fungal diversity notes 367-490: taxonomic and phylogenetic contributions to fungal taxa. Fungal Divers 80:1-270
Hyde KD, Norphanphoun C, Abreu VP, Bazzicalupo A, Chethana KWT, Clericuzio M, Dayarathne MC, Dissanayake AJ, Ekanayaka AH, He MQ, Hongsanan S, Huang SK, Jayasiri SC, Jayawardena RS, Karunarathna A, Konta S, Kušan I, Lee H, Li J, Lin CG, Liu NG, Lu YZ, Luo ZL, Manawasinghe IS, Mapook A, Perera RH, Phookamsak R, Phukhamsakda C, Siedlecki I, Soares AM, Tennakoon DS, Tian Q, Tibpromma S, Wanasinghe DN, Xiao YP, Yang J, Zeng XY, Abdel-Aziz FA, Li WJ, Senanayake IC, Shang QJ, Daranagama DA, De Silva NI, Thambugala KM, Abdel-Wahab MA, Bahkali AH, Berbee ML, Boonmee S, Bhat DJ, Bulgakov TS, Buyck B, Camporesi E, Castañeda-Ruiz RF, Chomnunti P, Doilom M, Dovana F, Gibertoni TB, Jadan M, Jeewon R, Jones EBG, Kang JC, Karunarathna SC, Lim YW, Liu JK, Liu ZY, Plautz HL Jr, Lumyong S, Maharachchikumbura SSN, Matočec N, Mckenzie EHC, Meśič A, Miller D, Pawłowska J, Pereira OL, Promputtha I, Romero AI, Ryvarden L, Su HY, Suetrong S, Tkalčec Z, Vizzini A, Wen TC, Wisitrassameewong K, Wrzosek M, Xu JC, Zhao Q, Zhao RL, Mortimer PE (2017) Fungal diversity notes 603-708: taxonomic and phylogenetic notes on genera and species. Fungal Divers 87:1-235

Hyde KD, Chaiwan N, Norphanphoun C, Boonmee S, Camporesi E, Chethana KWT, Dayarathne MC, de Silva NI, Dissanayake AJ, Ekanayaka AH, Hongsanan S, Huang SK, Jayasiri SC, Jayawardena RS, Jiang HB, Karunarathna A, Lin CG, Liu JK, Liu NG, Lu YZ, Luo ZL, Maharachchimbura SSN, Manawasinghe IS, Pem D, Perera RH, Phukhamsakda C, Samarakoon MC, Senwanna C, Shang Q, Tennakoon DS, Thambugala KM, Tibpromma S, Wanasinghe DN, Xiao YP, Yang J, Zeng XY, Zhang JF, Zhang SN, Bulgakov TS, Bhat DJ, Cheewangkoon R, Goh TK, Jones EBG, Kang JC, Jeewon R, Liu ZY, Lumyong S, Kuo CH, McKenzie EHC, Wen TC, Yan JY, Zhao Q (2018a) Mycosphere notes 169-224. Mycosphere 9:271-430

Hyde KD, Norphanphoun C, Chen J, Dissanayake AJ, Doilom M, Hongsanan S, Jayawardena RS, Jeewon R, Perera RH, Thongbai B, Wanasinghe DN, Wisitrassameewong K, Tibpromma S, Stadler M (2018b) Thailand's amazing diversity: up to $96 \%$ of fungi in northern Thailand may be novel. Fungal Divers 93:215-239

Hyde KD, Danushka S, Tennakoon DS, Jeewon R, Bhat DJ, Maharachchikumbura SSN, Rossi W, Leonardi M, Lee HB, Mun HY, Houbraken J, Nguyen TTT, Jeon SJ, Frisvad JC, Dhanushka N, Wanasinghe DN, Luücking R, Aptroot A, Cáceres MES, Karunarathna SC, Hongsanan S, Phookamsak R, de Silva NI, Thambugala KM, Jayawardena RS, Senanayake IC, Boonmee S, Chen J, Luo ZL, Phukhamsakda C, Pereira OL, Abreu VP, Rosado AWC, Bart B, Randrianjohany E, Hofstetter V, Gibertoni TB, da Silva Soares AM, Plautz HL Jr, Sotão HMP, Xavier WKS, Bezerra JDP, de Oliveira TGL, de Souza-Motta CM, Magalhães OMC, Bundhun D, Harishchandra D, Manawasinghe IS, Dong W, Zhang SN, Bao DF, Samarakoon MC, Pem D, Karunarathna A, Lin CG, Yang J, Perera RH, Kumar V, Huang SK, Dayarathne MC, Ekanayaka AH, Jayasiri SC, Xiao YP, Konta S, Niskanen T, Liimatainen K, Dai YC, Ji XH, Tian XM, Mešić A, Singh SK, Phutthacharoen K, Cai L, Sorvongxay T, Thiyagaraja V, Norphanphoun C, Chaiwan N, Lu YZ, Jiang HB, Zhang JF, Abeywickrama PD, Aluthmuhandiram JVS, Brahmanage RS, Zeng M, Chethana T, Wei DP, Réblová M, Fournier J, Nekvindová J, do Nascimento Barbosa R, dos Santos JEF, de Oliveira NT, Li GJ, Ertz D, Shang QJ, Phillips AJL, Kuo CH, Camporesi E, Bulgakov TS, Lumyong S, Jones EBG, Chomnunti P, Gentekaki E, Bungartz F, Zeng XY, Fryar S, Tkalčec Z, Liang J, Li GS, Wen TC, Singh PN, Gafforov Y, Promputtha I, Yasanthika E, Goonasekara ID, Zhao RL, Zhao Q, Kirk PM, Liu JK, Yan JY, Mortimer PE, Xu JC (2019a) Fungal diversity notes 1036-1150: taxonomic and phylogenetic contributions on genera and species of fungal taxa. Fungal Divers 96:1-242 
Hyde KD, Xu JC, Rapior S, Jeewon R, Lumyong S, Niego AGT, Abeywickrama PD, Aluthmuhandiram JVS, Brahamanage RS, Brooks S, Chaiyasen A, Chethana KWT, Chomnunti P, Chepkirui C, Chuankid B, de Silva NI, Doilom M, Faulds C, Gentekaki E, Gopalan V, Kakumyan P, Harishchandra D, Hemachandran H, Hongsanan S, Karunarathna A, Karunarathna SC, Khan S, Kumla J, Jayawardena RS, Liu JK, Liu N, Luangharn T, Macabeo APG, Marasinghe DS, Meeks D, Mortimer PE, Mueller P, Nadir S, Nataraja KN, Nontachaiyapoom S, O'Brien M, Penkhrue W, Phukhamsakda C, Ramanan US, Rathnayaka AR, Sadaba RB, Sandargo B, Samarakoon BC, Tennakoon DS, Siva R, Sriprom W, Suryanarayanan TS, Sujarit K, Suwannarach N, Suwunwong T, Thongbai B, Thongklang N, Wei DP, Wijesinghe SN, Winiski J, Yan J, Yasanthika E, Stadler M (2019b) The amazing potential of fungi: 50 ways we can exploit fungi industrially. Fungal Divers 97:1-136

Hyde KD, Dong Y, Rungtiwa Phookamsak R, Jeewon R, Bhat DJ, Jones EBG, Liu NG, Abeywickrama PD, Mapook A, Wei DP, Perera RH, Manawasinghe IS, Pem D, Bundhun D, Karunarathna A, Ekanayaka AH, Bao DF, Li JF, Samarakoon MC, Chaiwan N, Lin CG, Kunthida Phutthacharoen K, Zhang SN, Senanayake IC, Goonasekara ID, Thambugala KM, Phukhamsakda C, Tennakoon DS, Jiang HB, Yang J, Zeng M, Huanraluek N, Liu JK (Jack), Wijesinghe SN, Tian Q, Tibpromma S, Brahmanage RS, Boonmee S, Huang SK, Thiyagaraja V, Lu YZ, Jayawardena RS, Dong W, Yang EF, Singh SK, Singh SM, Rana S, Lad SS, Anand G, Devadatha B, Niranjan M, Sarma VV, Liimatainen K, Aguirre-Hudson B, Niskanen T, Overall A, Alvarenga RLM, Gibertoni TB, Pfliegler WP, Horváth E, Imre A, Alves AL, da Silva Santos AC, Tiago PV, Bulgakov TS, Wanasinghe DN, Bahkali AH, Doilom M, Elgorban AM, Maharachchikumbura SSN, Rajeshkumar KC, Haelewaters D, Mortimer PE, Zhao Q, Lumyong S, Xu JC, Sheng J (2020a) Fungal diversity notes 1151-1276: taxonomic and phylogenetic contributions on genera and species of fungal taxa. Fungal Divers 100 (proof)

Hyde KD, Norphanphoun C, Maharachchikumbura SSN, Bhat DJ, Jones EBG, Bundhun D, Chen YJ, Bao DF, Boonmee S, Calabon MS, Chaiwan N, Chethana KWT, Dai DQ, Dayarathne MC, Devadatha B, Dissanayake AJ, Dissanayake LS, Doilom M, Dong W, Fan XL, Goonasekara ID, Hongsanan S, Huang SK, Jayawardena RS, Jeewon R, Karunarathna A, Konta S, Kumar V, Lin CG, Liu JK, Liu N, Luangsa-ard J, Lumyong S, Luo ZL, Marasinghe DS, McKenzie EHC, Niego AGT, Niranjan M, Perera RH, Phukhamsakda C, Rathnayaka AR, Samarakoon MC, Samarakoon SMBC, Sarma VV, Senanayake IC, Shang QJ, Stadler M, Tibpromma S, Wei DP, Wijayawardene NN, Xiao YP, Xiang MM, Yang J, Zeng XY, Zhang SN (2020b) Refined families of Sordariomycetes. Mycosphere 11:305-1059

Index Fungorum 2020. http://www.indexfungorum.org/

Iturrieta-González I, Gené J, Guarro J, Castañeda-Ruiz RF, García D (2018) Neodendryphiella, a novel genus of the Dictyosporiaceae (Pleosporales). MycoKeys 37:19-38

Jaklitsch WM, Voglmayer H (2016) Hidden diversity in Thyridaria and a new circumscription of the Thyridariaceae. Stud Mycol 85:35-64

Jaklitsch WM, Olariaga I, Voglmayr H (2016) Teichospora and the Teichosporaceae. Mycol Prog 15:31

Jaklitsch WM, Fournier J, Voglmayr H (2018) Two unusual new species of Pleosporales: Anteaglonium rubescens and Atrocalyx asturiensis. Sydowia 70:129-140

Jayasiri SC, Hyde KD, Abd-Elsalam KA, Abdel-Wahab MA, Ariyawansa HA, Bhat J, Buyck B, Dai YC, Ertz D, Hidayat I, Jeewon R, Jones EBG, Karunarathna SC, Kirk P, Lei C, Liu JK, Maharachchikumbura SSN, McKenzie E, Ghobad-Nejhad M, Nilsson H, Pang KL, Phookamsak R, Rollins AW, Romero AI, Stephenson S, Suetrong S, Tsui CKM, Vizzini A, Wen TC,
De Silva NI, Promputtha I, Kang JC (2015) The Facesoffungi database: fungal names linked with morphology, molecular and human attributes. Fungal Divers 74:3-18

Jayasiri SC, Hyde KD, Jones EBG, McKenzie EHC, Jeewon R, Phillips AJL, Bhat DJ, Wanasinghe DN, Liu JK, Lu YZ, Kang JC, Xu J, Karunarathna SC (2019) Diversity, morphology and molecular phylogeny of Dothideomycetes on decaying wild seed pods and fruits. Mycosphere 10:1-186

Jeewon R, Hyde KD (2016) Establishing species boundaries and new taxa among fungi: recommendations to resolve taxonomic ambiguities. Mycosphere 7:1669-1677

Jiang HB, Hyde KD, Jayawardene RS, Doilom M, Xu J, Phookamsak R (2019) Taxonomic and phylogenetic characterizations reveal two new species and two new records of Roussoella (Roussoellaceae, Pleosporales) from Yunnan, China. Mycol Prog 18:577-591

Johnson M (2001) The Genus Clematis. Magnus Johnson Plantskola $\mathrm{AB}$ and Bengt Sundstrom, Sweden

Karunarathna A, Phookamsak R, Jayawardena RS, Cheewangkoon R, Hyde KD, Kuo CH (2019) The holomorph of Neoroussoella alishanense sp. nov. (Roussoellaceae, Pleosporales) on Pennisetum purpureum (Poaceae). Phytotaxa 406:218-236

Katoh K, Rozewicki J, Yamada KD (2019) MAFFT online service: multiple sequence alignment, interactive sequence choice and visualization. Brief Bioinform 20(4):1160-1166

Kirk PM, Cannon PF, Minter DW, Stalpers JA (2008) Dictionary of the fungi, 10th edn. CABI, Wallingford

Köhl J, Groenenboom-de Haas B, Goossen-van de Geijn H, Speksnijder A, Kastelein P, de Hoog S, van den Ende BG (2009) Pathogenicity of Stemphylium vesicarium from different hosts causing brown spot in pear. Eur J Plant Pathol 124:151-162

Kohlmeyer J, Volkmann-Kohlmeyer B (2000) Fungi on Juncus roemerianus 14. Three new coelomycetes, including Floricola, anam. gen. nov. Bot Mar 43:385-392

Konta S, Hongsanan S, Eungwanichayapant PD, Liu JK, Jeewon R, Hyde KD, Maharachchikumbura SS, Boonmee S (2017) Leptosporella (Leptosporellaceae fam. nov.) and Linocarpon and Neolinocarpon (Linocarpaceae fam. nov.) are accommodated in Chaetosphaeriales. Mycosphere 8:1943-1974

Koukol O, Delgado G, Hofmann TA, Piepenbring M (2018) Panama, a hot spot for Hermatomyces (Hermatomycetaceae, Pleosporales) with five new species, and a critical synopsis of the genus. IMA Fungus 9:107-141

Lamarck C (1805) A Paris: Chez H. Agasse, rue des Poitevins, № 6 (De l'imprimerie de Stoupe). Edn 3 (Paris) 2:243

Larsson A (2014) AliView: a fast and lightweight alignment viewer and editor for large datasets. Bioinformatics 30:3276-3278

Laurence MH, Summerell BA, Burgess LW, Liew EC (2014) Genealogical concordance phylogenetic species recognition in the Fusarium oxysporum species complex. Fungal Biol 118:374-384

Lehtonen S, Christenhusz MJ, Falck D (2016) Sensitive phylogenetics of Clematis and its position in Ranunculaceae. Bot J Linn Soc 182:825-867

Leuchtmann A (1984) Über Phaeosphaeria Miyake und andere bitunicate Ascomyceten mit mehrfach querseptierten Ascosporen. Sydowia 37:75-194

Leuschner C, Ellenberg H (2017) Life forms and growth types of central European plant species. Ecology of Central European Forests. Springer, Cham, pp 23-28

Li DW, Yang CS, Haugland R, Vesper S (2003) A new species of Memnoniella. Mycotaxon 85:253-258

Li GJ, Hyde KD, Zhao RL, Hongsanan S, Abdel-Aziz FA, AbdelWahab MA, Alvarado P, Alves-Silva G, Ammirati JF, Ariyawansa HA, Baghela A, Bahkali AH, Beug M, Bhat DJ, Bojantchev D, Boonpratuang T, Bulgakov TS, Camporesi E, Boro MC, Ceska O, Chakraborty D, Chen JJ, Chethana KWT, Chomnunti P, Consiglio G, Cui BK, Dai DQ, Dai YC, 
Daranagama DA, Das K, Dayarathne MC, De Crop E, De Oliveira RJV, de Souza CAF, de Souza JI, Dentinger BTM, Dissanayake AJ, Doilom M, Drechsler-Santos ER, Ghobad-Nejhad M, Gilmore SP, Góes-Neto A, Gorczak M, Haitjema CH, Hapuarachchi KK, Hashimoto A, He MQ, Henske JK, Hirayama K, Iribarren MJ, Jayasiri SC, Jayawardena RS, Jeon SJ, Jerônimo GH, Jesus AL, Jones EBG, Kang JC, Karunarathna SC, Kirk PM, Konta S, Kuhnert E, Langer E, Lee HS, Lee HB, Li WJ, Li XH, Liimatainen K, Lima DX, Lin CG, Liu JK, Liu XZ, Liu ZY, Luangsa-ard JJ, Lücking R, Lumbsch HT, Lumyong S, Leaño EM, Marano AV, Matsumura M, McKenzie EHC, Mongkolsamrit S, Mortimer PE, Nguyen TTT, Niskanen T, Norphanphoun C, O'Malley MA, Parnmen S, Pawłowska J, Perera RH, Phookamsak R, Phukhamsakda C, Pires-Zottarelli CLA, Raspé O, Reck MA, Rocha SCO, de Santiago ALCMA, Senanayake IC, Setti L, Shang QJ, Singh SK, Sir EB, Solomon KV, Song J, Srikitikulchai P, Stadler M, Suetrong S, Takahashi H, Takahashi T, Tanaka K, Tang LP, Thambugala KM, Thanakitpipattana D, Theodorou MK, Thongbai B, Thummarukcharoen T, Tian Q, Tibpromma S, Verbeken A, Vizzini A, Vlasák J, Voigt K, Wanasinghe DN, Wang Y, Weerakoon G, Wen HA, Wen TC, Wijayawardene NN, Wongkanoun S, Wrzosek M, Xiao YP, Xu JC, Yan JY, Yang J, Da Yang S, Hu Y, Zhang JF, Zhao J, Zhou LW, Peršoh D, Phillips AJL, Maharachchikumbura SSN (2016) Fungal diversity notes 253-366: taxonomic and phylogenetic contributions to fungal taxa. Fungal Divers 78:1-237

Li WL, Luo ZL, Liu JK, Bhat DJ, Bao DF, Su HY, Hyde KD (2017) Lignicolous freshwater fungi from China I: Aquadictyospora lignicola gen. et sp. nov. and new record of Pseudodictyosporium wauense from northwestern Yunnan Province. Mycosphere 8:1587-1597

Liew ECY, Aptroot A, Hyde KD (2000) Phylogenetic significance of the pseudoparaphyses in Loculoascomycete taxonomy. Mol Phyl Evol 16:392-402

Lin CG, McKenzie EH, Bhat DJ, Rann SF, Chen Y, Hyde KD, Li DW, Wang Y (2016) Stachybotrys-like taxa from karst areas and a checklist of stachybotrys-like species from Thailand. Mycosphere 7:1273-1291

Linnaeus C (1753) Species plantarum, vol 1. Impensis Laurentii Salvii, Holmiae

Liu AR, Wu X, Xu T, Guo L, Wei J (2006) Endophytic Pestalotiopsis species from Hainan, China. Mycosystema 25:389-397

Liu JK, Phookamsak R, Dai DQ, Tanaka K, Jones EBG, Xu JC, Chukeatirote E, Hyde KD (2014) Roussoellaceae, a new pleosporalean family to accommodate the genera Neoroussoella gen. nov., Roussoella and Roussoellopsis. Phytotaxa 181:1-33

Liu JK, Hyde KD, Jones EBG, Ariyawansa HA, Bhat DJ, Boonmee S, Maharachchikumbura SSN, McKenzie EHC, Phookamsak R, Phukhamsakda C, Shenoy BD, Abdel-Wahab MA, Buyck B, Chen J, Chethana KWT, Singtripop C, Dai DQ, Dai YC, Daranagama DA, Dissanayake AJ, Doilom M, D'souza MJ, Fan XL, Goonasekara ID, Hirayama K, Hongsanan S, Jayasiri SC, Jayawardena RS, Karunarathna SC, Li WJ, Mapook A, Norphanphoun C, Pang KL, Perera RH, Peršoh D, Pinruan U, Senanayake IC, Somrithipol S, Suetrong S, Tanaka K, Thambugala KM, Tian Q, Tibpromma S, Udayanga D, Wijayawardene NN, Wanasinghe D, Wisitrassameewong K, Zeng XY, Abdel-Aziz FA, Adamčík S, Bahkali AH, Boonyuen N, Bulgakov T, Callac P, Chomnunti P, Greiner K, Hashimoto A, Hofstetter V, Kang JC, Lewis D, Li XH, Liu XZ, Liu ZY, Matsumura M, Mortimer PE, Rambold G, Randrianjohany E, Sato G, Sri-Indrasutdhi V, Tian CM, Verbeken A, von Brackel W, Wang Y, Wen TC, Xu JC, Yan JY, Zhao RL, Camporesi E (2015) Fungal diversity notes 1-110: taxonomic and phylogenetic contributions to fungal species. Fungal Divers 72:1-197
Liu JK, Hyde KD, Jeewon R, Phillips AJ, Maharachchikumbura SS, Ryberg M, Liu ZY, Zhao Q (2017) Ranking higher taxa using divergence times: a case study in Dothideomycetes. Fungal Divers 84:75-99

Liu JK, Luo ZL, Liu NG, Cheewangkoon R, To-Anun C (2018) Two novel species of Paradictyoarthrinium from decaying wood. Phytotaxa 338:285-293

Liu NG, Hyde KD, Bhat DJ, Jumpathong J, Liu JK (2019) Morphological and phylogenetic studies of Pleopunctum gen. nov. (Phaeoseptaceae, Pleosporales) from China. Mycosphere 10:757-775

Lombard L, Van Leeuwen GC, Guarnaccia V, Polizzi G, Van Rijswick PC, Rosendahl KC, Gabler J, Crous PW (2014) Diaporthe species associated with Vaccinium, with specific reference to Europe. Phytopathol Mediterr 53:287-299

Lombard L, Van der Merwe NA, Groenewald JZ, Crous PW (2015) Generic concepts in Nectriaceae. Stud Mycol 80:189-245

Lombard L, Houbraken J, Decock C, Samson RA, Meijer M, Réblová M, Groenewald JZ, Crous PW (2016) Generic hyper-diversity in Stachybotriaceae. Persoonia 36:156-246

Lu B, Zhang B, Qi W, Zhu Y, Zhao Y, Zhou N, Sun R, Bao J, Wu C (2014) Conformational study reveals amino acid residues essential for hemagglutinating and anti-proliferative activities of Clematis montana lectin. Acta Biochim Biophys Sin 46:923-934

Lumbsch HT, Huhndorf SM (2007) Outline of ascomycota. Myconet 13:1-58

Luo ZL, Hyde KD, Liu JK, Bhat DJ, Bao DF, Li WL, Su HY (2018) Lignicolous freshwater fungi from China II: Novel Distoseptispora (Distoseptisporaceae) species from northwestern Yunnan Province and a suggested unified method for studying lignicolous freshwater fungi. Mycosphere 9:444-461

Macabeo AP, Pilapil LA, Garcia KY, Quimque MT, Phukhamsakda C, Cruz AJ, Hyde KD, Stadler M (2020) Alpha-Glucosidase-and Lipase-Inhibitory Phenalenones from a new species of Pseudolophiostoma originating from Thailand. Molecules 25(4):965

Mageswari A, Kim JS, Cheon KH, Kwon SW, Yamada O, Hong SB (2016) Analysis of the MAT1-1 and MAT1-2 Gene Ratio in Black Koji Molds Isolated from Meju. Mycobiology 44(4):269-276

Maharachchikumbura SSN, Guo LD, Cai L, Chukeatirote E, Wu WP, Sun X, Crous PW, Bhat DJ, McKenzie EHC, Bahkali AH, Hyde KD (2012) A multi-locus backbone tree for Pestalotiopsis, with a polyphasic characterization of 14 new species. Fungal Divers 56:95-129

Maharachchikumbura SSN, Hyde KD, Groenewald JZ, Xu J, Crous PW (2014) Pestalotiopsis revisited. Stud Mycol 79:121-186

Maharachchikumbura SSN, Hyde KD, Jones EBG, McKenzie EHC, Huang SK, Abdel-Wahab MA, Daranagama DA, Dayarathne M, D'souza MJ, Goonasekara ID, Hongsanan S, Jayawardena RS, Kirk PM, Konta S, Liu JK, Liu ZY, Norphanphoun C, Pang KL, Perera RH, Senanayake IC, Shang Q, Shenoy BD, Xiao Y, Bahkali AH, Kang J, Somrothipol S, Suetrong S, Wen T, Xu J (2015) Towards a natural classification and backbone tree for Sordariomycetes. Fungal Divers 72:199-301

Maharachchikumbura SSN, Hyde KD, Jones EBG, McKenzie EHC, Bhat JD, Dayarathne MC, Huang SK, Norphanphoun C, Senanayake IC, Perera RH, Shang QJ, Xiao Y, D'souza MJ, Hongsanan S, Jayawardena RS, Daranagama DA, Konta S, Goonasekara ID, Zhuang WY, Jeewon R, Phillips AJL, Abdel-Wahab MA, AlSadi AM, Bahkali AH, Boonmee S, Boonyuen N, Cheewangkoon R, Dissanayake AJ, Kang J, Li QR, Liu JK, Liu XZ, Liu ZY, Luangsa-ard JJ, Pang KL, Phookamsak R, Promputtha I, Suetrong S, Stadler M, Wen T, Wijayawardene NN (2016) Families of Sordariomycetes. Fungal Divers 79:1-317

Manawasinghe IS, Dissanayake A, Liu M, Wanasinghe D, Xu J, Zhao W, Wei Z, Zhou Y, Hyde KD, Brooks S, Yan J (2019) High 
genetic diversity and species complexity of Diaporthe associated with grapevine dieback in China. Front Microbiol 10:1936

Mantle PG, Hawksworth DL, Pazoutova S, Collinson LM, Rassing BR (2006) Amorosia littoralis gen. sp. nov., a new genus and species name for the scorpinone and caffeine-producing hyphomycete from the littoral zone in The Bahamas. Mycol Res 110:1371-1378

Mapook A, Hyde KD, McKenzie EHC, E. B. Gareth Jones, D. Jayarama Bhat, Jeewon R, Stadler M, Samarakoon MC, Malaithong M, Tanunchai B, Buscot F, Wubet T, Purahong W (2020). Taxonomic and phylogenetic contributions to fungi associated with the invasive weed Chromolaena odorata (Siam weed). Fungal Divers 101:1-175

Mason EW, Ellis MB (1953) British species of Periconia. Mycol Pap $56: 1-127$

Matsumura M, Kato W, Hashimoto A, Takahashi YS, Shirouzu T, Tanaka K (2018) Crassiperidium (Pleosporales, Dothideomycetes), a new ascomycetous genus parasitic on Fagus crenata in Japan. Mycosphere 9:1256-1267

Matsushima T (1996) Matsushima mycological memoirs 9. Matsushima Mycol Mem 9:1-30

McNeill J, Barrie FR, Buck WR (2012) International code of nomenclature for algae, fungi, and plants (Melbourne code). Koeltz Scientific Books, Königstein, Germany [Regnum vegetabile no. 154.]

Miller MA, Pfeiffer W, Schwartz T (2017) Creating the CIPRES Science Gateway for inference of large phylogenetic trees. In 2010 gateway computing environments workshop (GCE): 1-8

Moesz G (1915) Mykologiai közlemények. II. Közlemény. Bot Kölzlem $14: 145-158$

Mueller GM, Schmit JP (2007) Fungal biodiversity: what do we know? What can we predict? Biodivers Conserv 16:1-5

Mugambi GK, Huhndorf SM (2009) Parallel evolution of hysterothecial ascomata in ascolocularous fungi (Ascomycota, Fungi). Syst Biodivers 7:453-464

Mukerji KG, Manoharachary C (2010) Taxonomy and ecology of Indian fungi. IK International Publishing House, London

Müller E (1950) Die schweizerischen Arten der Gattung Leptosphaeria und ihrer Verwandten. Sydowia 4:185-319

Mungai PG, Chukeatirote E, Njogu JG, Hyde KD (2012) Studies of coprophilous ascomycetes in Kenya: Sordariales from wildlife dung. Mycosphere 3:437-448

Nannfeldt JA (1932) Studien über die morphologie und systematik der nichtlichenisierten inoperculaten discomyceten. Nova Acta Regiae Soc Sci Upsal 8:1-368

Naranjo-Ortiz MA, Gabaldón T (2019) Fungal evolution: major ecological adaptations and evolutionary transitions. Biol Rev 94:1443-1476

Navaud O, Barbacci A, Taylor A, Clarkson JP, Raffaele S (2018) Shifts in diversification rates and host jump frequencies shaped the diversity of host range among Sclerotiniaceae fungal plant pathogens. Mol Ecol 27:1309-1323

Nishimaki T, Sato K (2019) An extension of the Kimura two-parameter model to the natural evolutionary process. J Mol Evol 87:60-67

Norphanphoun C, Jeewon R, Mckenzie EH, Wen TC, Camporesi E, Hyde KD (2017) Taxonomic position of Melomastia italica sp. nov. and phylogenetic reappraisal of Dyfrolomycetales. Cryptog Mycol 38:507-526

Nuankaew S, Suetrong S, Wutikhun T, Pinruan U (2019) Hermatomyces trangensis $\mathrm{sp}$. nov., a new dematiaceous hyphomycete (Hermatomycetaceae, Pleosporales) on sugar palm in Thailand. Phytotaxa 391:277-288

Nylander JAA (2004) MrModeltest v2. Program distributed by the author. Evolutionary Biology Centre, Uppsala University, Uppsala
Ogle CC, la Cock GD, Arnold G, Mickleson N (2000) Impact of an exotic vine Clematis vitalba (F. Ranunculaceae) and of control measures on plant biodiversity in indigenous forest, Taihape, New Zealand. Austral Ecol 25:539-551

Pang KL, Hyde KD, Alias SA, Suetrong S, Jones EBG (2013) Dyfrolomycetaceae, a new family in the Dothideomycetes, Ascomycota. Cryptogr Mycol 34:223-232

Persoon C (1795) Observationes mycologica. Ann Bot 15:1-39

Petrak F (1944) Über die Gattungen Chaetopyrena Pass, Sclerochaeta v Höhn, Sclerochaetella v Höhn, Chaetosphaeronema Moesz, und Pseudophoma v Höhn. Ann Mycol 42:58-71

Phillips AJ, Hyde KD, Alves A, Liu JK (2019) Families in Botryosphaeriales: a phylogenetic, morphological and evolutionary perspective. Fungal Divers 94:1-22

Phookamsak R, Liu JK, McKenzie EHC, Manamgoda DS, Ariyawansa HA, Thambugala KM, Dai DQ, Camporesi E, Chukeatirote E, Wijayawardene NN, Bahkali AH, Mortimer PE, Xu JC, Hyde KD (2014) Revision of Phaeosphaeriaceae. Fungal Divers 68:159-238

Phookamsak R, Wanasinghe DN, Hongsanan S, Phukhamsakda C, Huang S-K, Tennakoon DS, Norphanphoun C, Camporesi E, Bulgakov TS, Promputtha I, Mortimer PE, Xu JC, Hyde KD (2017) Towards a natural classification of Ophiobolus and ophiobolus-like taxa; introducing three novel genera Ophiobolopsis, Paraophiobolus and Pseudoophiobolus in Phaeosphaeriaceae (Pleosporales). Fungal Divers 87:299-339

Phookamsak R, Hyde KD, Jeewon R, Bhat DJ, Jones EBG, Maharachchikumbura SSN, Raspé O, Karunarathna SC, Wanasinghe DN, Hongsanan S, Doilom M, Tennakoon DS, Machado AR, Firmino AL, Ghosh A, Karunarathna A, Mešić A, Dutta AK, Thongbai B, Devadatha B, Norphanphoun C, Senwanna C, Wei D, Pem D, Ackah FK, Wang GN, Jiang HB, Madrid H, Lee HB, Goonasekara ID, Manawasinghe IS, Kušan Cano J, Gené J, Li J, Das K, Acharya K, Raj KNA, Latha KPD, Chethana KWT, He MQ, Dueñas M, Jadan M, Martín MP, Samarakoon MC, Dayarathne MC, Raza M, Park MS, Telleria MT, Chaiwan N, Matočec N, de Silva NI, Pereira OL, Singh PN, Manimohan P, Uniyal P, Shang QJ, Bhatt RP, Perera RH, Alvarenga RLM, Nogal-Prata S, Singh SK, Vadthanarat S, Oh SY, Huang SK, Rana S, Konta S, Paloi S, Jayasiri SC, Jeon SJ, Mehmood T, Gibertoni TB, Nguyen TTT, Singh U, Thiyagaraja V, Sarma VV, Dong W, Yu XD, Lu YZ, Lim YW, Chen Y, Tkalčec Z, Zhang ZF, Luo ZL, Daranagama DA, Thambugala KM, Tibpromma S, Camporesi E, Bulgakov T, Dissanayake AJ, Senanayake IC, Dai DQ, Tang LZ, Khan S, Zhang H, Promputtha I, Cai L, Chomnunti P, Zhao RL, Lumyong S, Boonmee S, Wen TC, Mortimer PE, Xu J (2019) Fungal diversity notes 929-1036: taxonomic and phylogenetic contributions on genera and species of fungal taxa. Fungal Divers 95:1-273

Phukhamsakda C, Ariyawansa HA, Phillips AJ, Wanasinghe DN, Bhat DJ, McKenzie EH, Singtripop C, Camporesi E, Hyde KD (2016) Additions to Sporormiaceae: Introducing two novel genera, Sparticola and Forliomyces, from Spartium. Cryptogamie Mycol 37:75-97

Phukhamsakda C, Bhat DJ, Hongsanan S, Tibpromma S, Yang JB, Promputtha I (2017a) Magnicamarosporium diospyricola sp. nov. (Sulcatisporaceae) from Thailand. Mycosphere 8:512-520

Phukhamsakda C, Hongsanan S, Ryberg M, Ariyawansa HA, Chomnunti P, Bahkali AH, Hyde KD (2017b) The evolution of Massarineae with Longipedicellataceae fam. nov. Mycosphere 7:1713-1731

Phukhamsakda C, Macabeo AP, Yuyama KT, Hyde KD, Stadler M (2018) Biofilm inhibitory abscisic acid derivatives from the plant-associated Dothideomycetes Fungus, Roussoella sp. Molecules 23:2190 
Phukhamsakda C, Jeewon R, McKenzie EHC, Xu JC (2019) Morphology and phylogeny of Phaeoseptum mali sp. nov. (Phaeoseptaceae, Pleosporales) on bark of Malus halliana. AJOM 2:118-128

Quaedvlieg W, Verkley GJM, Shin HD, Barreto RW, Alfenas AC, Swart WJ, Groenewald JZ, Crous PW (2013) Sizing up Septoria. Stud Mycol 75:307-390

Quaedvlieg W, Binder M, Groenewald JZ, Summerell BA, Carnegie AJ, Burgess TI, Crous PW (2014) Introducing the consolidated species concept to resolve species in the Teratosphaeriaceae. Persoonia 33:1-40

Rabenhorst GL (1857) Erklärung der Taf. XV. Hedwigia 1:116

Rambaut A (2014) FigTree v1.4. Institute of Evolutionary Biology, University of Edinburgh, Edinburgh. http://tree.bio.ed.ac.uk/ software/figtree/

Rambaut A, Drummond AJ, Xie D, Baele G, Suchard MA (2018) Posterior summarization in Bayesian phylogenetics using Tracer 1.7. Syst Biol 67:901

Ramsey GB (1934) Pleospora lycopersici E and E March, a tomato pathogen in the United States. Science 79:294

Réblová M, Gams W, Seifert KA (2011) Monilochaetes and allied genera of the Glomerellales, and a reconsideration of families in the Microascales. Stud Mycol 68:163-191

Redmond CM, Stout JC (2018) Breeding system and pollination ecology of a potentially invasive alien Clematis vitalba $\mathrm{L}$. in Ireland. J Plant Ecol 11:56-63

Rennberger G (2018) Occurrence and pathogenicity of foliar pathogens on cucurbits in South Carolina with special emphasis on Stagonosporopsis and Stachybotriaceae on watermelon. Dissertation, Clemson University

Ronquist F, Huelsenbeck JP (2003) MrBayes 3: Bayesian phylogenetic inference under mixed models. Bioinformatics 19:1572-1574

Rossman AY, Samuels GJ, Rogerson CT, Lowen R (1999) Genera of Bionectriaceae, Hypocreaceae and Nectriaceae (Hypocreales, Ascomycetes). Stud Mycol 42:1-248

Rossman AY, Crous PW, Hyde KD, Hawksworth DL, Aptroot A, Bezerra JL, Bhat JD, Boehm E, Braun U, Boonmee S, Camporesi E, Chomnunti P, Dai DQ, D'souza MJ, Dissanayake A, Jones EBG, Groenewald JZ, Hernández-Restrepo M, Hongsanan S, Jaklitsch WM, Jayawardena R, Jing LW, Kirk PM, Lawrey JD, Mapook A, McKenzie EHC, Monkai J, Phillips AJL, Phookamsak R, Raja HA, Seifert KA, Senanayake I, Slippers B, Suetrong S, Tanaka K, Taylor JE, Thambugala KM, Tian Q, Tibpromma S, Wanasinghe DN, Wijayawardene NN, Wikee S, Woudenberg JHC, Wu HX, Yan J, Yang T, Zhang Y (2015) Recommended names for pleomorphic genera in Dothideomycetes. IMA Fungus 6:507-523

Rossman AY, Farr DF, Castlebury LA (2017) A review of the phylogeny and biology of the Diaporthales. Mycoscience 48:135-144

Roy BA (2001) Patterns of association between crucifers and their flower-mimic pathogens: host jumps are more common than coevolution or cospeciation. Evol 55:41-53

Ruibal C, Gueidan C, Selbmann L, Gorbushina AA, Crous PW, Groenewald JZ, Muggia L, Grube M, Isola D, Schoch CL, Staley JT, Lutzoni F, de Hoog GS (2009) Phylogeny of rock-inhabiting fungi related to Dothideomycetes. Stud Mycol 64:123-133

Rupcic Z, Chepkirui C, Hernández-Restrepo M, Crous PW, LuangsaArd JJ, Stadler M (2018) New nematicidal and antimicrobial secondary metabolites from a new species in the new genus, Pseudobambusicola thailandica. MycoKys 33:1-23

Saccardo PA (1882) Sylloge Fungorum I:1-196

Saccardo PA (1883) Sylloge Pyrenomycetum, Vol II Sylloge Fungorum $2: 1-813$

Saccardo PA (1892) Sylloge Fungorum X: 244

Samarakoon MC, Hyde KD, Hongsanan S, McKenzie EH, Ariyawansa HA, Promputtha I, Zeng XY, Tian Q, Liu JK (2019) Divergence time calibrations for ancient lineages of Ascomycota classification based on a modern review of estimations. Fungal Divers 96:285-346

Scott JA, Untereiner WA, Ewaze JO, Wong B, Doyle D (2007) Baudoinia, a new genus to accommodate Torula compniacensis. Mycologia 99:592-601

Seifert KA, Morgan-Jones G, Gams W, Kendrick B (2011) The genera of Hyphomycetes. CBS-KNAW Fungal Biodiversity Centre, Utrecht

Senanayake IC, Maharachchikumbura SS, Hyde KD, Bhat JD, Jones EBG, McKenzie EH, Dai DQ, Daranagama DA, Dayarathne MC, Goonasekara ID, Konta S (2015) Towards unraveling relationships in Xylariomycetidae (Sordariomycetes). Fungal Divers 73:73-144

Senanayake IC, Al-Sadi AM, Bhat JD, Camporesi E, Dissanayake AJ, Lumyong S, Maharachchikumbura SS, Hyde KD (2016) Phomatosporales ord. nov. and Phomatosporaceae fam. nov., to accommodate Lanspora, Phomatospora and Tenuimurus, gen. nov. Mycosphere 7:628-641

Senanayake IC, Crous PW, Groenewald JZ, Maharachchikumbura SSN, Jeewon R, Phillips AJL, Bhat JD, Perera RH, Li QR, Li WJ, Tangthirasunun N, Norphanphoun C, Karunarathna SC, Camporesi E, Manawasighe IS, Al-Sadi AM, Hyde KD (2017) Families of Diaporthales based on morphological and phylogenetic evidence. Stud Mycol 86:217-296

Senanayake IC, Jeewon R, Chomnunti P, Wanasinghe DN, Norphanphoun C, Karunarathna A, Pem D, Perera RH, Camporesi E, McKenzie EHC, Hyde KD, Karunarathna SC (2018) Taxonomic circumscription of Diaporthales based on multigene phylogeny and morphology. Fungal Divers 93:241-443

Senwanna C, Phookamsak R, Doilom M, Hyde KD, Cheewangkoon $\mathrm{R}$ (2017) Novel taxa of Diatrypaceae from Para rubber (Hevea brasiliensis) in northern Thailand; introducing a novel genus Allocryptovalsa. Mycosphere 8:1835-1855

Serrano JA, Pisani ID, Lopez FA (1998) Black grain minimycetoma caused by Pyrenochaeta mackinnonii. The first clinical case of eumycetoma reported in Barinas State, Venezuela: Clinicalhistological features and case treatment. J Mycol Med 8:34-39

Shang QJ, Hyde KD, Phookamsak R, Doilom M, Bhat DJ, Maharachchikumbura SS, Promputtha I (2017) Diatrypella tectonae and Peroneutypa mackenziei sp. nov. (Diatrypaceae) from northern Thailand. Mycol Prog 16:463-476

Shang QJ, Phookamsak Camporesi E, Khan S, Lumyong S, Hyde KD (2018) The holomorph of Fusarium celtidicola sp. nov. from Celtis australis. Phytotaxa 361:251-265

Shoemaker RA (1976) Canadian and some extralimital Ophiobolus species. Can J Bot 54:2365-2404

Sillo F, Garbelotto M, Friedman M, Gonthier P, Sciences Paolo L (2015) Comparative genomics of sibling fungal pathogenic taxa identifies adaptive evolution without divergence in pathogenicity genes or genomic structure. Genome Biol Evol 7:3190-3206

Simmons EG (1969) Perfect states of Stemphylium. Mycologia 61:1-26

Simonyan SA (1981) Mycoflora of Botanical gardens and arboretums of the Armenian SSR (Translated from Russian). Publ. House Acad Sci Armenian SSR, p. 234

Sivanesan A (1984) The bitunicate ascomycetes and their anamorphs. J. Cramer, Vaduz

Sogonov MV, Castlebury L, Rossman AY (2008) Leaf-inhabiting genera of the Gnomoniaceae, Diaporthales. Stud Mycol 62:1-79

Soleimani P, Soleimani MJ, Hosseini S (2018) Phylogenetic relationship and evolution of Neodidymelliopsis isolates collected from Iran. Mycosphere 9:1235-1255

Spegazzini C (1911) Mycetes Argentinenses (Series V). Anales Mus Nac Hist Nat Buenos Aires 13:329-467

Stadler M, Lambert C, Wibberg D, Kalinowski J, Cox RJ, Kolařík M, Kuhnert E (2020) Intragenomic polymorphisms in the ITS 
region of high-quality genomes of the Hypoxylaceae (Xylariales, Ascomycota). Mycol Progress 19:235-245

Stamatakis A (2014) RAxML version 8: a tool for phylogenetic analysis and post-analysis of large phylogenies. Bioinformatics 30:1312-1313

Sturm J (1829) Deutschlands Flora, Abt. III. Die Pilze Deutschlands 2:1-136

Su H, Hyde KD, Maharachchikumbura SS, Ariyawansa HA, Luo Z, Promputtha I, Chai H (2016) The families Distoseptisporaceae fam. nov. Kirschsteiniotheliaceae, Sporormiaceae and Torulaceae with new species from freshwater in Yunnan Province China. Fungal Divers 80:375-409

Sudisha J, Vasanth Kumar T, Niranjana SR, Shekar Shetty H (2004) First report of gummy stem blight caused by Didymella bryoniae on muskmelon (Cucumis melo) in India. Plant Pathol 53:533

Sutton BC (1980) The Coelomycetes fungi imperfecti with pycnidia, acervuli and stromata. CMI, Kew, pp 1-696

Tai FL (1979) Sylloge fungorum sinicorum. Sci Press, Peking

Tamura M (1956) Notes on Clematis of eastern Asia III. Acta Phytotax Geobot 16:79-83

Tamura M (1997) Synoptic flora the ranunculaceae in Thailand. Thai For Bull (Bot) 25:63-80

Tamura M (2000) A new species of Clematis (Ranunculaceae) from Thailand. Thai For Bull (Bot) 28:17-18

Tanaka K, Harada Y (2003) Pleosporales in Japan (2): the genus Lophiotrema. Mycoscience 44:115-121

Tanaka K, Harada Y (2004) Pleosporales in Japan (4). The genus Massariosphaeria. Mycoscience 45:96-105

Tanaka K, Hirayama K, Yonezawa H, Sato G, Toriyabe A, Kudo H, Hashimoto A, Matsumura M, Harada Y, Kurihara Y, Shirouzu T, Hosoya T (2015) Revision of the Massarineae (Pleosporales, Dothideomycetes). Stud Mycol 82:75-136

Taylor JW (2011) One Fungus = One Name: DNA and fungal nomenclature twenty years after PCR. IMA Fungus 2:113-120

Taylor JW, Jacobson DJ, Kroken S, Kasuga T, Geiser DM, Hibbett DS, Fisher MC (2000) Phylogenetic species recognition and species concepts in fungi. Fungal Genet Rep 31:21-32

Thambugala KM, Hyde KD (2018) Additions to the genus Massariothea in Diaporthaceae. Mycol Prog 17:1139-1147

Thambugala KM, Hyde KD, Tanaka K, Tian Q, Wanasinghe DN, Ariyawansa HA, Jayasiri SC, Boonmee S, Camporesi E, Hashimoto A, Hirayama K, Schumacher RK, Promputtha I, Liu ZY (2015) Towards a natural classification and backbone tree for Lophiostomataceae, Floricolaceae, and Amorosiaceae fam. nov. Fungal Divers 74:199-266

Thambugala KM, Daranagama DA, Phillips AJ, Bulgakov TS, Bhat DJ, Camporesi E, Bahkali AH, Eungwanichayapant PD, Liu ZY, Hyde KD (2017) Microfungi on Tamarix. Fungal Divers 82:239-306

Tian Q, Liu JK, Hyde KD, Wanasinghe DN, Boonmee S, Jayasiri SC, Luo ZL, Taylor JE, Phillips AJL, Bhat DJ, Li WJ, Ariyawansa H, Thambugala KM, Jones EBG, Chomnunti P, Bahkali AH, Xu JC, Camporesi E (2015) Phylogenetic relationships and morphological reappraisal of Melanommataceae (Pleosporales). Fungal Divers 74:267-324

Tibpromma S, Bhat J, Doilom M, Lumyong S, Nontachaiyapoom S, Yang JB, Hyde KD (2016) Three new Hermatomyces species (Lophiotremataceae) on Pandanus odorifer from Southern Thailand. Phytotaxa 275:127-139

Tibpromma S, Hyde KD, Jeewon R, Maharachchikumbura SSN, Liu JK, Bhat DJ, McKenzie EHC, Jones EBG, Camporesi E, Bulgakov TS, Doilom M, de Azevedo Santiago ALCM, Das K, Manimohan P, Gibertoni TB, Lim YW, Ekanayaka AH, Thongbai B, Lee HB, Yang JB, Kirk PM, Sysouphanthong P, Singh SK, Boonmee S, Dong W, Raj KNA, Latha KPD, Phookamsak R, Phukhamsakda C, Tennakoon DS, Li J, Dayarathne MJ, Perera
RH, Xiao Y, Wanasinghe DN, Senanayake IC, Goonasekara ID, de Silva NI, Mapook A, Jayawardena RS, Dissanayake AJ, Manawasinghe IS, Chethana KWT, Luo ZL, Hapuarachchi KK, Baghela A, Soares AM, Vizzini A, Meiras-Ottoni A, Mesic A, Dutta AK, de Souza CAF, Richter C, Lin CG, Chakrabarty D, Daranagama DA, Lima DX, Chakraborty D, Ercole E, Wu F, Simonini G, Vasquez G, da Silva GA, Plautz HLP Jr, Ariyawansa HA, Lee H, Kusan I, Song J, Sun J, Karmakar J, Hu K, Semwal KC, Thambugala KM, Voigt K, Acharya K, Rajeshkumar KC, Ryvarden L, Jadan M, Hosen MI, Miksýk M, Samarakoon MC, Wijayawardene NN, Kim NK, Matocec N, Singh PN, Tian Q, Bhatt RP, Jose R, de Oliveira V, Tulloss RE, Aamir S, Kaewchai S, Marathe SD, Khan S, Hongsanan S, Adhikari S, Mehmood T, Bandyopadhyay TK, Nguyen TTT, Antonýn V, Li WJ, Wang Y, Indoliya Y, Tkalcec Z, Elgorban AM, Bahkali AH, Tang AMC, Su HY, Zhang H, Promputtha I, Luangsaard J, Xu J, Yan J, JiChuan K, Stadler M, Mortimer PT, Chomnunti P, Zhao Q, Phillips AJL, Nontachaiyapoom S, Wen TC, Karunarathna SC (2017) Fungal diversity notes 491-602: taxonomic and phylogenetic contributions to fungal taxa. Fungal Divers 43:1-261

Tibpromma S, Hyde KD, McKenzie EHC, Bhat DJ, Phillips AJL, Wanasinghe DN, Samarakoon MC, Jayawardena RS, Dissanayake AJ, Tennakoon DS, Doilom M, Phookamsak R, Tang AMC, Xu J, Mortimer PE, Promputtha I, Maharachchikumbura SSN, Khan S, Karunarathna SC (2018) Fungal diversity notes 840928: micro-fungi associated with Pandanaceae. Fungal Divers 93:1-160

Trouillas FP, Gubler WD (2010) Host range, biological variation, and phylogenetic diversity of Eutypa lata in California. Phytopathology 100:1048-1056

Turner JW, Paranjpye RN, Landis ED, Biryukov SV, GonzálezEscalona N, Nilsson WB, Strom MS (2013) Population structure of clinical and environmental Vibrio parahaemolyticus from the Pacific Northwest coast of the United States. PLoS ONE 8:55726

Udayanga D, Castlebury LA, Rossman AY, Hyde KD (2014) Species limits in Diaporthe: molecular re-assessment of D. citri, D. cytosporella, D. foeniculina and D. rudis. Persoonia 32:83-101

Vaghefi N, Pethybridge SJ, Ford R, Nicolas ME, Crous PW, Taylor PW (2012) Stagonosporopsis sp. associated with ray blight disease of Asteraceae. Austral Plant Path 41:675-686

Vaidya G, Lohman DJ, Meier R (2011) SequenceMatrix: concatenation software for the fast assembly of multi-gene datasets with character set and codon information. Cladistics 27(2):171-180

Valenzuela-Lopez N, Cano-Lira JF, Guarro J, Sutton DA, Wiederhold N, Crous PW et al (2018) Coelomycetous Dothideomycetes with emphasis on the families Cucurbitariaceae and Didymellaceae. Stud Mycol 90:1-69

van der Aa HA, Noordeloos ME, de Gruyter J (1990) Species concepts in some larger genera of the Coelomycetes. Stud Mycol 32:3-19

Verkley GJM, da Silva M, Wicklow DT, Crous PW (2004) Paraconiothyrium, a new genus to accommodate the mycoparasite Coniothyrium minitans, anamorphs of Paraphaeosphaeria, and four new species. Stud Mycol 50:323-335

Voglmayr H, Jaklitsch WM (2014) Stilbosporaceae resurrected: generic reclassification and speciation. Persoonia 33:61-82

Voglmayr H, Jaklitsch WM (2017) Corynespora, Exosporium and Helminthosporium revisited-New species and generic reclassification. Stud Mycol 87:43-76

Wanasinghe DN, Jones EBG, Camporesi E, Boonmee S, Ariyawansa HA, Wijayawardene NN, Mortimer PE, Xu J, Yang JB, Hyde KD (2014) An exciting novel member of Lentitheciaceae in Italy from Clematis vitalba. Cryptogr Mycol 35:323-337

Wanasinghe DN, Camporesi E, Hu DM (2016a) Neoleptosphaeria jonesii sp. nov., a novel saprobic sexual species Leptosphaeriaceae. Mycosphere 7:1368-1377 
Wanasinghe DN, Jones EBG, Camporesi E, Dissanayake AJ, Kamolhan S, Mortimer PE, Xu J, Abd-Elsalam KA, Hyde KD (2016b) Taxonomy and phylogeny of Laburnicola gen. nov. and Paramassariosphaeria gen. nov. (Didymosphaeriaceae, Massarineae, Pleosporales). Fungal Biol 120:1354-1373

Wanasinghe DN, Hyde KD, Jeewon R, Crous PW, Wijayawardene NN, Jones EBG, Bhat DJ, Phillips AJ, Groenewald JZ, Dayarathne MC, Phukhamsakda C (2017) Phylogenetic revision of Camarosporium (Pleosporineae, Dothideomycetes) and allied genera. Stud Mycol 87:207-256

Wanasinghe DN, Phukhamsakda C, Hyde KD, Jeewon R, Lee HB, Jones EBG, Tibpromma S, Tennakoon DS, Dissanayake AJ, Jayasiri SC, Gafforov Y, Camporesi E, Bulgakov TS, Ekanayake AH, Perera RH, Samarakoon MC, Goonasekara ID, Mapook A, Li WJ, Senanayake IC, Li JF, Norphanphoun C, Doilom M, Bahkali AH, Xu JC, Mortimer PE, Tibell L, Tibell S, Karunarathna SC (2018) Fungal diversity notes 709-839:taxonomic and phylogenetic contributions to fungal taxa withan emphasis on fungi on Rosaceae. Fungal Divers 89:1-236

Wang XW, Wang XL, Liu FJ, Zhao XM, Li J, Cai L (2014) Phylogenetic assessment of Chaetomium indicum and allied species, with the introduction of three new species and epitypification of $C$. funicola and C. indicum. Mycol Prog 13:719-732

Wang Y, Hyde KD, McKenzie EHC, Jiang YL, Li DW, Zhao DG (2015) Overview of Stachybotrys (Memnoniella) and current species status. Fungal Divers 71:17-83

Wang XW, Houbraken J, Groenewald JZ, Meijer M, Andersen B, Nielsen KF, Crous PW, Samson RA (2016) Diversity and taxonomy of Chaetomium and chaetomium-like fungi from indoor environments. Stud Mycol 84:145-224

Wang XW, Yang FY, Meijer M, Kraak B, SunBD, Jiang YL, Wu YM,Bai FY, Seifert KA, Crous PW, Samson RA(2019a) Redefining Humicola sensu stricto andrelated genera in the Chaetomiaceae.Stud Mycol 93:65-153

Watanabe T (1989) Three species of Sordaria, and Eudarluca biconica from cherry seeds. Trans Mycol Soc 30:395-400

Watson W (1929) The classification of lichens II. New Phytol 28:85-116

Wijayawardene NN, Song Y, Bhat DJ, McKenzie EH, Chukeatirote E, Wang Y, Hyde KD (2013) Wojnowicia viburni sp. nov., from China and its phylogenetic placement. Sydowia 65:129-138

Wijayawardene NN, Hyde KD, Wanasinghe DN, Papizadeh M, Goonasekara ID, Camporesi E, Bhat DJ, McKenzie EHC, Phillips AJL, Diederich P, Tanaka K, Li WJ, Tangthirasunun N, Phookamsak R, Dai DQ, Dissanayake AJ, Weerakoon G, Maharachchikumbura SSN, Hashimoto A, Matsumura M, Bahkali AH, Wang Y (2016) Taxonomy and phylogeny of dematiaceous coelomycetes. Fungal Divers 77:1-316

Wijayawardene NN, Hyde KD, Rajeshkumar KC, Hawksworth DL, Madrid H, Kirk PM, Braun U, Singh RV, Crous PW, Kukwa M, Lücking R, Kurtzman CP, Yurkov A, Haelewaters D, Aptroot A, Lumbsch HT, Timdal E, Ertz D, Etayo J, Phillips AJL, Groenewald JZ, Papizadeh M, Selbmann L, Dayarathne MC, Weerakoon G, Jones EBG, Suetrong S, Tian Q, Castañeda-Ruiz RF, Bahkali AH, Pang KL, Tanaka K, Dai DQ, Sakayaroj J, Hujslová M, Lombard L, Shenoy BD, Suija A, Maharachchikumbura SSN, Thambugala KM, Wanasinghe DN, Sharma BO, Gaikwad S, Pandit G, Zucconi L, Onofri S, Egidi E, Raja HA, Kodsueb R, Cáceres MES, Pérez-Ortega S, Fiuza PO, Monteiro JS, Vasilyeva LN, Shivas RG, Prieto M, Wedin M, Olariaga I, Lateef AA, Agrawal Y, Fazeli SAS, Amoozegar MA, Zhao GZ, Pfliegler WP, Sharma G, Oset M, Abdel-Wahab MA, Takamatsu S, Bensch K, de Silva NI, De Kesel A, Karunarathna A, Boonmee S, Pfister DH, Lu YZ, Luo ZL, Boonyuen N, Daranagama DA, Senanayake
IC, Jayasiri SC, Samarakoon MC, Zeng XY, Doilom M, Quijada L, Rampadarath S, Heredia G, Dissanayake AJ, Jayawardana RS, Perera RH, Tang LZ, Phukhamsakda C, Hernández-Restrepo M, Ma X, Tibpromma S, Gusmao LFP, Weerahewa D, Karunarathna SC (2017) Notes for genera: Ascomycota. Fungal Divers $86: 1-594$

Wijayawardene NN, Hyde KD, Lumbsch HT, Liu JK, Maharachchikumbura SSN, Ekanayaka AH, Tian Q, Phookamsak R (2018) Outline of Ascomycota-2017. Fungal Divers 88:167-263

Wijayawardene NN, Hyde KD, Al-Ani LKT, Tedersoo L, Haelewaters D, Rajeshkumar KC, Zhao RL, Aptroot A, Leontyev DV, Saxena RK, Tokarev YS, Dai DQ, Letcher PM, Stephenson SL, Ertz D, Lumbsch HT, Kukwa M, Issi IV, Madrid H, Phillips AJL, Selbmann L, Pfliegler WP, Horváth E, Bensch K, Kirk P, Kolaříková Z, Raja HA, Radek R, Papp V, Dima B, Ma J, Malosso E, Takamatsu S, Rambold G, Gannibal PB, Triebel D, Gautam AK, Avasthi S, Suetrong S, Timdal E, Fryar SC, Delgado G, Réblová M, Doilom M, Dolatabadi S, Pawłowska J, Humber RA, Kodsueb R, Sánchez-Castrov I, Goto BT, Silva DKA, de Souza FA, Oehl F, da Silva GA, Silva IR, Błaszkowski J, Jobim K, Maia LC, Barbosa FR, Fiuza PO, Divakar PK, Shenoy BD, Castañeda-Ruiz RF, Somrithipol S, Karunarathna SC, Tibpromma S, Mortimer PE, Wanasinghe DN, Phookamsak R, Xu J, Wang Y, Fenghua T, Alvarado P, Li DW, Kušan I, Matočec N, Maharachchikumbura SSN, Papizadeh M, Heredia G, Wartchow F, Bakhshi M, Boehm E, Youssef N, Hustad VP, Lawrey JD, Santiago ALCM, Bezerra JDP, Souza-Motta CM, Firmino AL, Tian Q, Houbraken J, Hongsanan S, Tanaka K, Dissanayake AJ, Monteiro JS, Grossart HP, Suija A, Weerakoon G, Etayo J, Tsurykau A, Kuhnert E, Vázquez V, Mungai P, Damm U, Li QR, Zhang H, Boonmee S, Lu YZ, Becerra AG, Kendrick B, Brearley FQ, Motiejūnaitè J, Sharma B, Khare R, Gaikwad S, Wijesundara DSA, Tang LZ, He MQ, Flakus A, RodriguezFlakus P, Zhurbenko MP, McKenzie EHC, Stadler M, Bhat DJ, Kui-Liu J, Raza M, Jeewon R,. Nassonova ES, Prieto M, Jayalal RGU, Yurkov A, Schnittler M, Shchepin ON, Novozhilov YK, Liu Pu, Cavender JC, Kang Y, Mohammad S, Zhang LF, Xu RF, Li YM, Dayarathne MC, Ekanayaka AH, Wen TC, Deng CY, Lateef AA, Pereira OL, Navathe S, Hawksworth DL, Fan XL, Dissanayake LS, Erdoğdu M (2020) Outline of fungi and fungilike taxa. Mycosphere 11:1060-1456

Winter G (1885) Pilze-Ascomyceten. In: GL Rabenhorst's Kryptogamen-Flora von Deutschland. Oester Schw 1:193-528

Woudenberg JHC, Aveskamp MM, de Gruyter J, Spiers AG, Crous PW (2009) Multiple Didymella teleomorphs are linked to the Phoma clematidina morphotype. Persoonia 22:56-62

Woudenberg JH, Hanse B, Van Leeuwen GC, Groenewald JZ, Crous PW (2017) Stemphylium revisited. Stud Mycol 87:77-103

Xie L, Wen J, Li LQ (2011) Phylogenetic analyses of Clematis (Ranunculaceae) based on sequences of nuclear ribosomal ITS and three plastid regions. Syst Bot 36:907-921

Yang J, Liu JK, Hyde KD, Jones EBG, Liu ZY (2018a) New species in Dictyosporium, new combinations in Dictyocheirospora and an updated backbone tree for Dictyosporiaceae. MycoKeys 36:83-105

Yang J, Maharachchikumbura SSN, Liu JK, Hyde KD, Jones EBG, Al-Sadi AM, Liu ZY (2018b) Pseudostanjehughesia aquitropica gen. et. sp. nov. and Sporidesmium sensu lato species from freshwater habitats. Mycol Prog 17:591-616

Yeh YH, Kirschner R (2014) Sarocladium spinificis, a new endophytic species from the coastal grass Spinifex littoreus in Taiwan. Bot Stud 55:25

Yuan Q, Yang QE (2020) The identity of Clematis dongchuanensis (Ranunculaceae) from northeastern Yunnan, China. Phytotaxa 430:9-16 
Yuan T, Wang LY, Roh MS (2010) Confirmation of Clematis hybrids using molecular markers. Sci Hortic 125:136-145

Zare R, Gams W, Starink-Willemse M, Summerbell RC (2007) Gibellulopsis, a suitable genus for Verticillium nigrescens, and Musicillium, a new genus for $V$. theobromae. Nova Hedwig 85:463-489

Zhang N, Castlebury LA, Miller AN, Huhndorf SM, Schoch CL, Seifert KA, Rossman AY, Rogers JD, Kohlmeyer J, VolkmannKohlmeyer B, Sung GH (2006) An overview of the systematics of the Sordariomycetes based on four-gene phylogeny. Mycologia 98:1076-1087

Zhang Y, Fournier J, Crous PW, Pointing SB, Hyde KD (2009) Phylogenetic and morphological assessment of two new species of Amniculicola and their allies (Pleosporales). Persoonia 23:48-54
Zhang Y, Crous PW, Schoch CL, Hyde KD (2012) Pleosporales. Fungal Divers 53:1-221

Zhao M, Da-Wa ZM, Guo DL, Fang DM, Chen XZ, Xu HX, Gu YC, Xia B, Chen L, Ding LS, Zhou Y (2016) Cytotoxic triterpenoid saponins from Clematis tangutica. Phytochemistry 130:228-237

Zhaxybayeva O, Gogarten JP (2002) Bootstrap, Bayesian probability and maximum likelihood mapping: exploring new tools for comparative genome analyses. BMC Genom 3(1):4

Ziman SN, Keener CS (1989) A geographical analysis of the family Ranunculaceae. Ann Mo Bot Gard 76:1012-1049

\section{Affiliations}

\section{Chayanard Phukhamsakda ${ }^{1,2,3}$ - Eric H. C. McKenzie ${ }^{4}$. Alan J. L. Phillips ${ }^{5}$ - E. B. Gareth Jones ${ }^{9,10}$ • D. Jayarama Bhat ${ }^{14}$. Stadler Marc ${ }^{16}$. Chitrabhanu S. Bhunjun ${ }^{3}$. Dhanushka N. Wanasinghe ${ }^{2,3,8,15}$. Benjarong Thongbai ${ }^{16}$. Erio Camporesi ${ }^{11,12,13} \cdot$ Damien Ertz $^{17,20} \cdot$ Ruvishika S. Jayawardena $^{3} \cdot$ Rekhani Hansika Perera $^{3,18}$. Anusha H. Ekanayake ${ }^{3}$. Saowaluck Tibpromma ${ }^{2,8,19} \cdot$ Mingkwan Doilom $^{2,8,19} \cdot$ Jianchu Xu ${ }^{2,19,8} \cdot K_{\text {Kevin D. Hyde }}^{1,2,3,6,7,8}$}

Kevin D. Hyde kdhyde3@gmail.com

1 Institute of Plant Health, Zhongkai University of Agriculture and Engineering, Haizhu District, Guangzhou 510225, People's Republic of China

2 Key Laboratory for Plant Diversity and Biogeography of East Asia, Kunming Institute of Botany, Chinese Academy of Sciences, Kunming 650201, Yunnan, People's Republic of China

3 Center of Excellence in Fungal Research, Mae Fah Luang University, Chiang Rai 57100, Thailand

4 Landcare Research Manaaki Whenua, Private Bag 92170, Auckland, New Zealand

5 University of Lisbon, Faculty of Sciences, Biosystems and Integrative Sciences Institute (BioISI), Campo Grande, 1749-016 Lisbon, Portugal

6 Mushroom Research Foundation, 128 M.3 Ban Pa Deng T. Pa Pae, A. Mae Taeng, Chiang Mai 50150, Thailand

7 Department of Biology, Faculty of Science, Chiang Mai University, Chiang Mai 50200, Thailand

8 State Key Laboratory for Conservation and Utilization of East and Central Asia Regional Office, World Agroforestry Centre (ICRAF), Kunming 650201, Yunnan, People's Republic of China

933 B St. Edwards Road Southsea Hants, Hampshire PO5 3DH, UK

10 Department of Botany and Microbiology, College of Science, King Saud University, P.O Box 2455, Riyadh 11451, Kingdom of Saudi Arabia
11 A.M.B. Gruppo, Micologico Forlivese "Antonio Cicognani", Viale Roma 18, 47121 Forli, Italy

12 A.M.B, Circolo Micologico “Giovanni Carini”, C.P. 101, 25121 Brescia, Italy

13 Societá per gli Studi Naturalistici della Romagna, C.P. 143, 48012 Bagnacavallo, RA, Italy

14 No. 128/1-J, Azad Housing Society, Curca, P.O. Goa Velha, 403108, India

15 Center for Yunnan Plateau Biological Resources Protection and Utilization, College of Biological Resource and Food Engineering, Qujing Normal University, Qujing, Yunnan 655011, People's Republic of China

16 Department of Microbial Drugs, Helmholtz Centre for Infection Research and German Centre for Infection Research (DZIF), partner site Hannover/Braunschweig, Inhoffenstrasse 7, 38124 Brunswick, Germany

17 Department of Research, Meise Botanic Garden, 1860 Meise, Belgium

18 Guizhou Key Laboratory of Agricultural Biotechnology, Guizhou Academy of Agricultural Sciences, Guiyang, Guizhou Province 550006, People's Republic of China

19 Centre for Mountain Futures (CMF), Kunming Institute of Botany, Kunming 650201, Yunnan, People's Republic of China

20 Fédération Wallonie-Bruxelles, Service Général de l'Enseignement Supérieur et de la Recherche Scientifique, Rue A. Lavallée 1, 1080 Brussels, Belgium 